\section{To: (Receiving Organization)}

Distribution

\section{Proj./Prog./Dept./Div.: \\ 73500}

\section{Originator Remarks:}

Consists of the Analysis and Sumary Report of Historical Dry Well Gamma Logs for the 241-T Tank Farm - 200 West

\section{Receiver Remarks: \\ 11A. Design Baseline Document? $O$ Yes $O$ No \\ For clearance, release, and RMIS processing.}

\author{
3. From: (Originating Organization) \\ RPP Vadose Zone Characterization \\ 6. Design Authority/Design Agent/Cog. Engr.: \\ H. A. Sydnor
}

\author{
4. Related EDT No.: \\ N/A \\ 7. Purchase Order No.: \\ $\mathrm{N} / \mathrm{A}$ \\ 9. Equip./Component No: \\ $\mathrm{N} / \mathrm{A}$ \\ 10. System/Bldg./Facility: \\ $\mathrm{N} / \mathrm{A}$ \\ 12. Major Assm. Dwg. No.: \\ $\mathrm{N} / \mathrm{A}$ \\ 13. Permit/Permit Application No.: \\ $\mathrm{N} / \mathrm{A}$
}

14. Required Response Date:

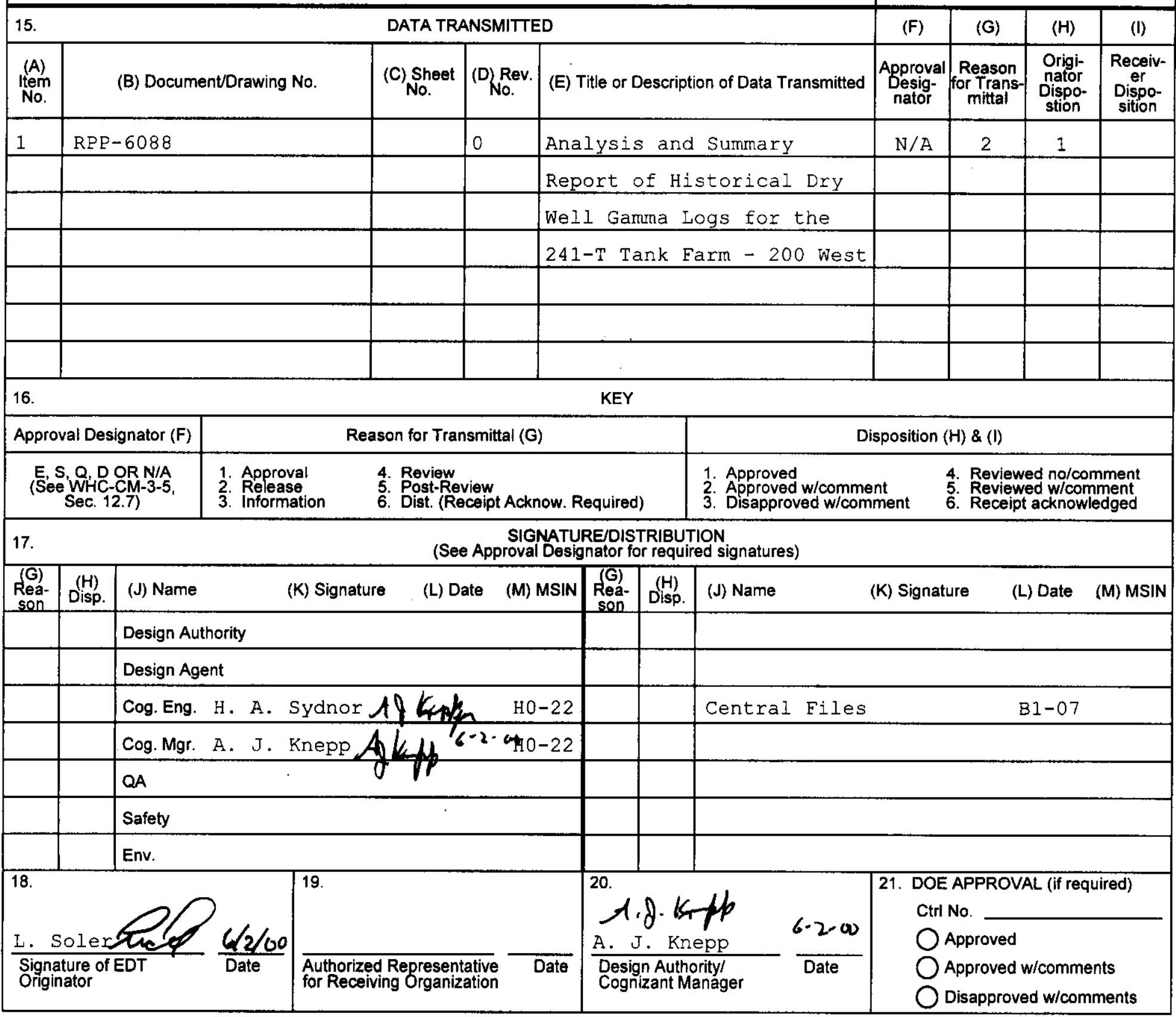




\section{ANALYSIS AND SUMMARY REPORT OF HISTORICAL DRY WELL GAMMA LOGS FOR THE 241-T TANK FARM - 200 WEST}

Harold A. Sydnor, CH2M HILL Hanford Group, Inc. Anthony J. Knepp, CH2M HILL Hanford Group, Inc. Richland, WA 99352 U.S. Department of Energy Contract DE-AC06-99RL14047
EDT/ECN: 628613
UC: 2010
Cost Center: 73500
Charge Code: $110161 \mathrm{BA} 0$
B\&R Code: EWO2J2040
Total Pages: 421

Key Words: Dry well gamma logs, gross gamma, vadose zone characterization 24.1 T Tank Farm, single-shell tank

Abstract: This report provides a summary of the gross gamma ray data for the 241-T Tank Farm and is intended to identify changes in the gamma activity of gamma-emitting radionuclide contaminants around each accessible borehole, and is not intended to provide interpretation of the data relative to vadose zone mechanics. Trends in data, as well as areas where additional information would be helpful in evaluating the unusual nature of some of the data, are discussed.

TRADEMARK DISCLAIMER. Reference herein to any specific commercial product, process, or service by trade name, trademark, manufacturer, or otherwise, does not necessarily constitute or imply its endorsement, recommendation, or favoring by the United States Government or any agency thereof or its contractors or subcontractors.

Printed in the United States of America. To obtain copies of this document, contact: Document Control Services, P.O. Box 950, Mailstop H6-08, Richland WA 99352, Phone (509) 372-2420; Fax (509) 376-4989.
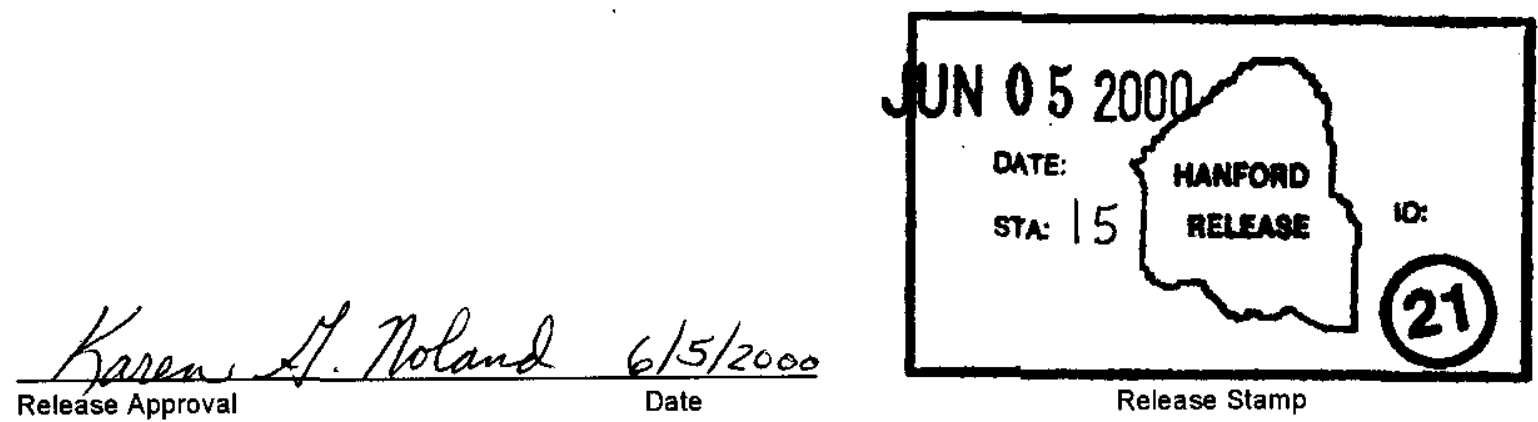

Approved For Public Release 
RPP-6088, Rev.0.

Title Page

\section{Analysis and Summary Report of Historical Dry Well Gamma Logs for 241-T Tank Farm - 200 West}

April 2000

Russel Randall, PhD

Randall Price

Joseph Caggiano, $\mathrm{PhD}$ 


\section{Table of Contents}

Topic

Title Page.

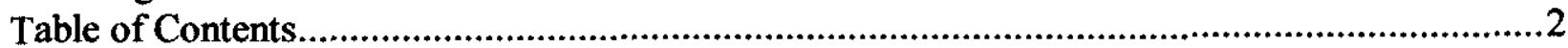

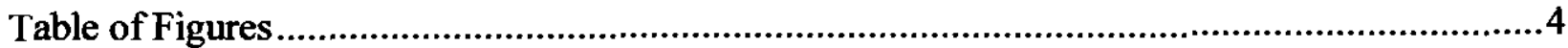

Table of Tables ...................................................................................................

Analysis and Summary Report of Historical Dry Well Gamma Logs for the 241-T Tank Farm -

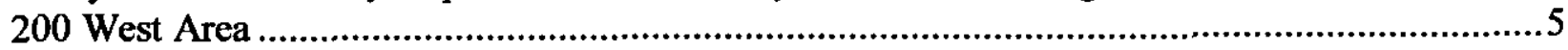

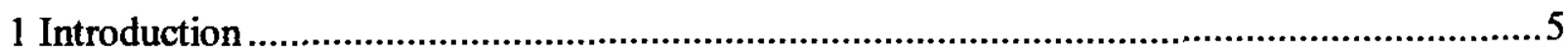

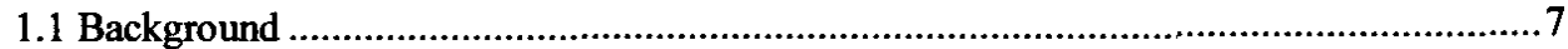

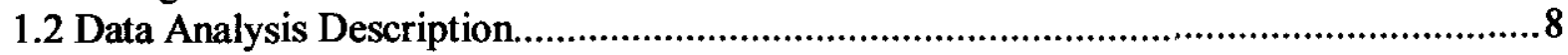

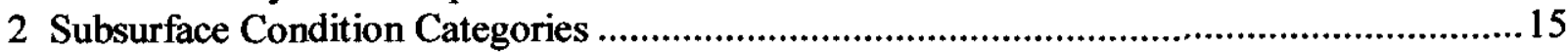

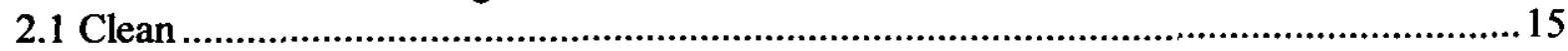

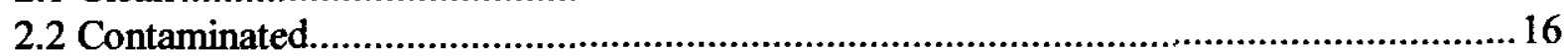

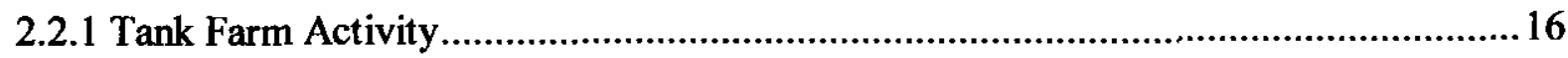

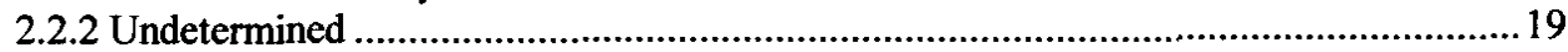

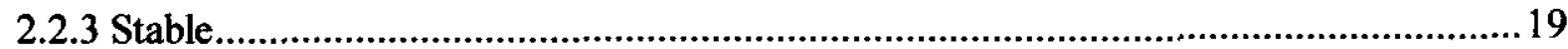

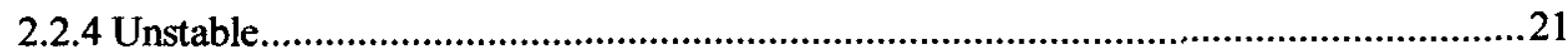

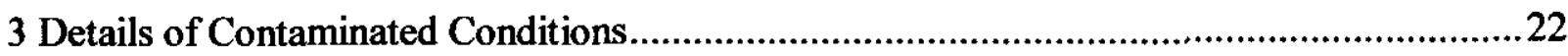

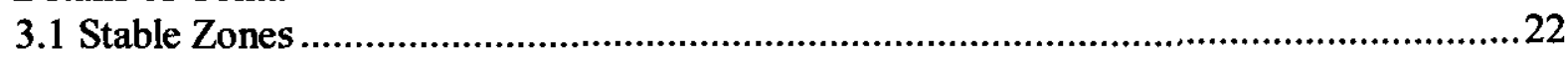

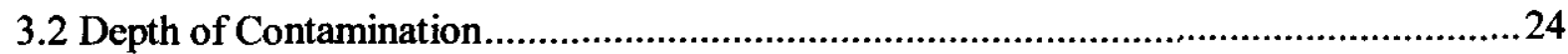

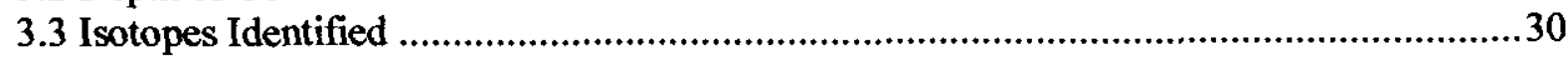

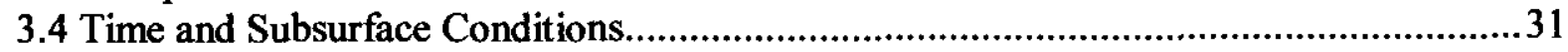

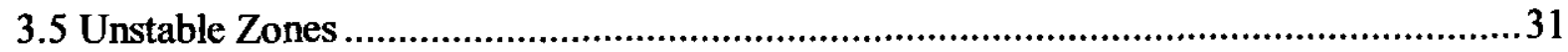

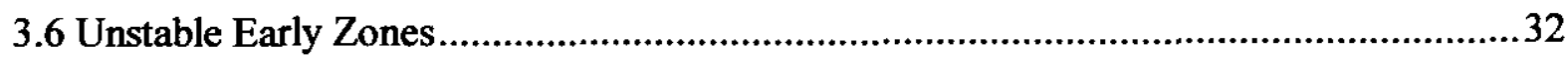

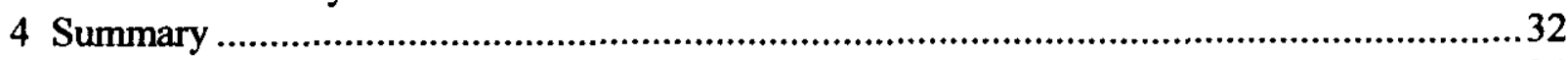

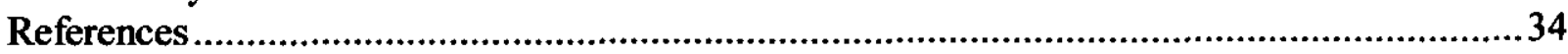

Brief Listing of General Observations and Special Data Presentation Conditions .....................35

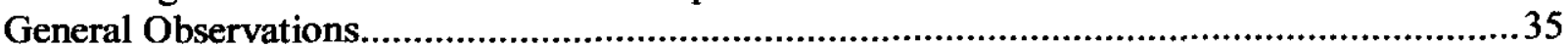

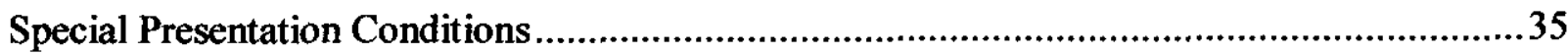

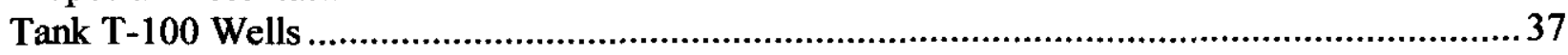

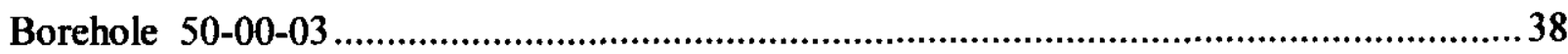

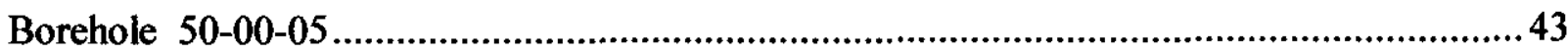

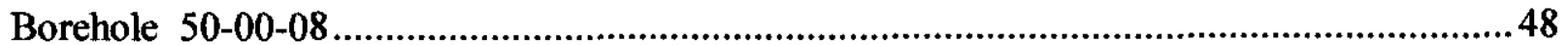

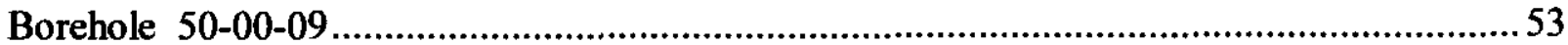

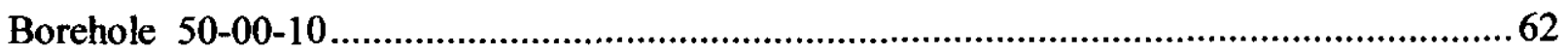

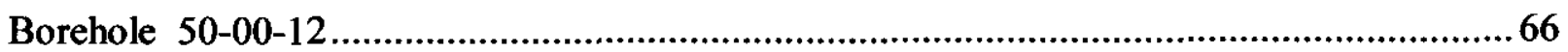

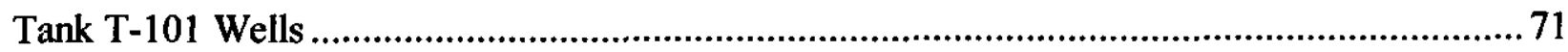

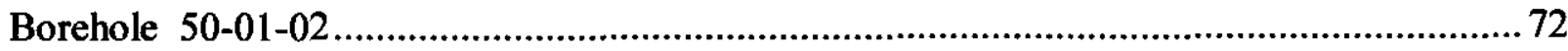

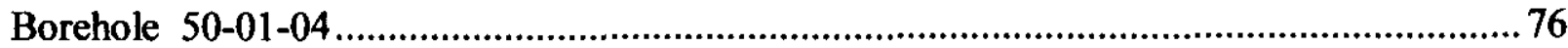

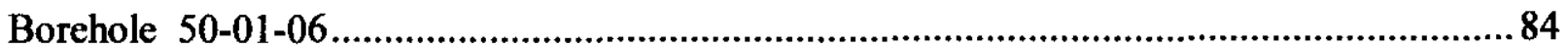

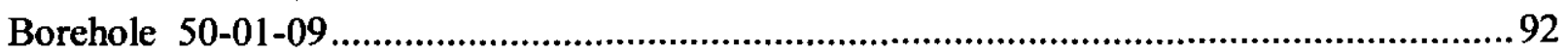

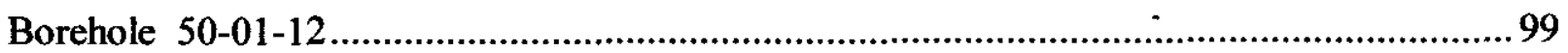

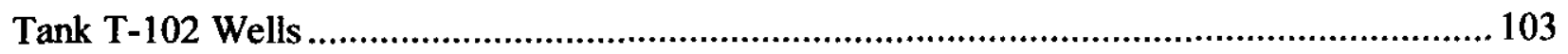




\section{RPP-6088, Rev. 0.}

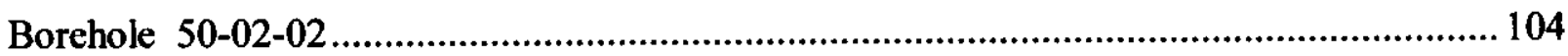

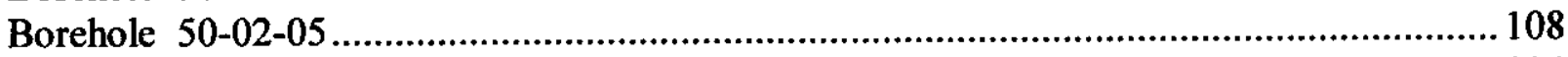

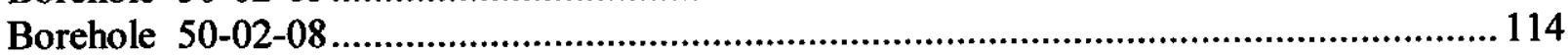

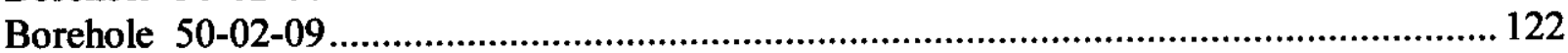

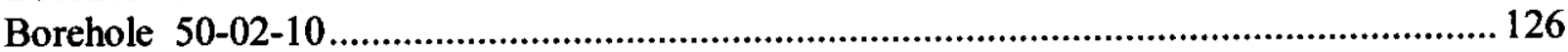

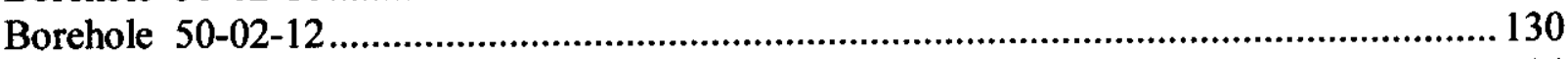

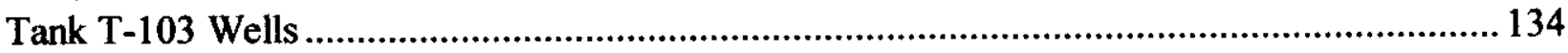

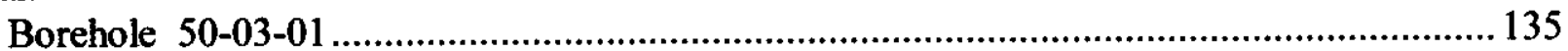

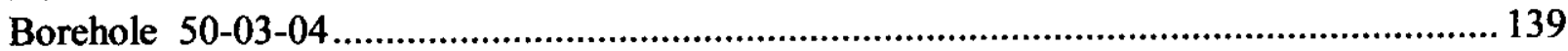

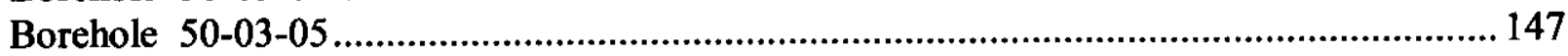

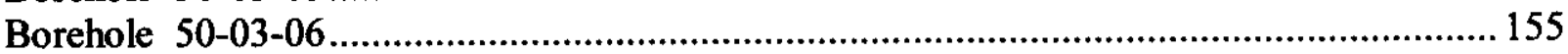

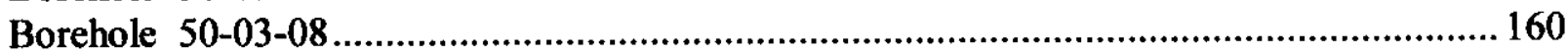

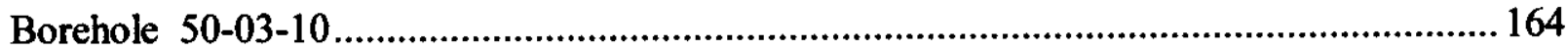

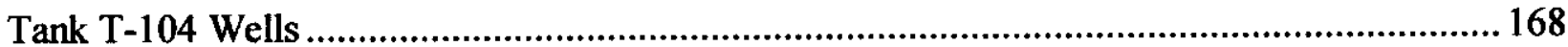

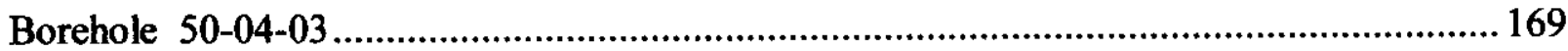

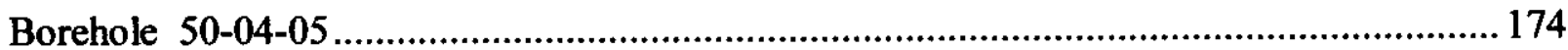

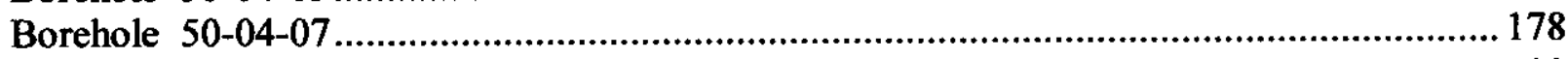

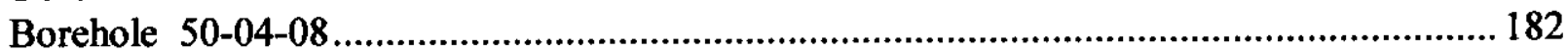

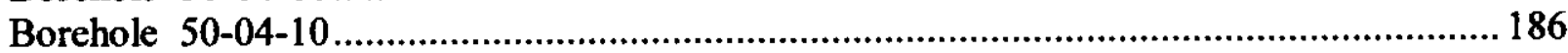

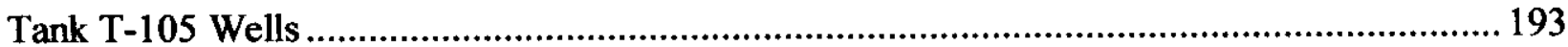

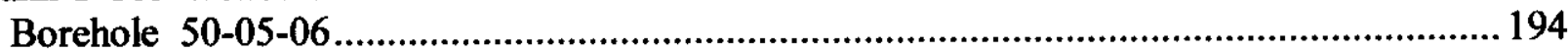

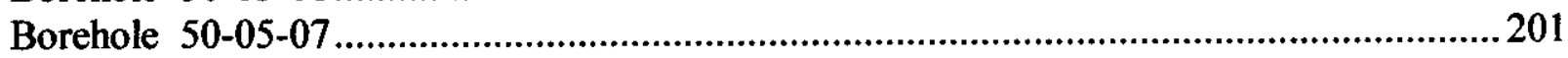

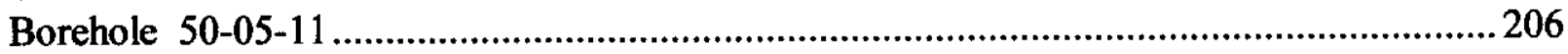

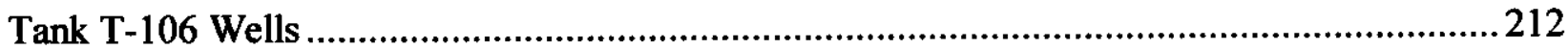

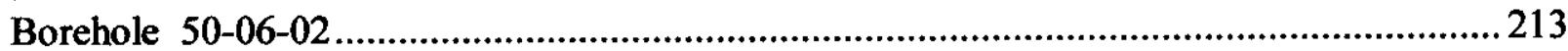

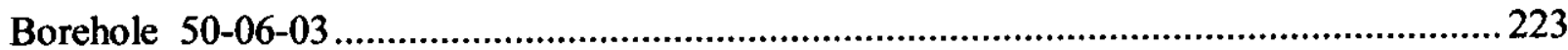

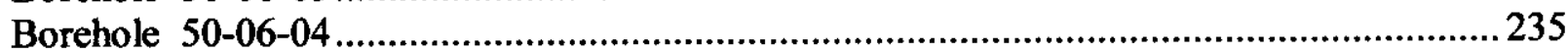

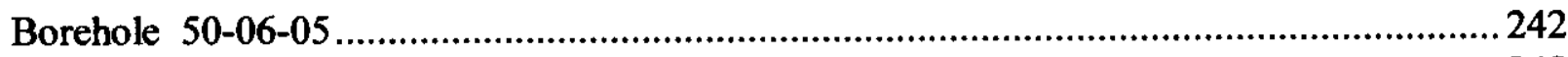

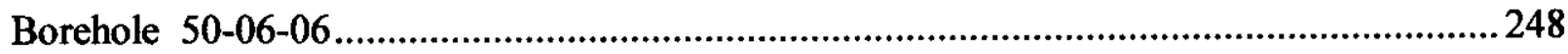

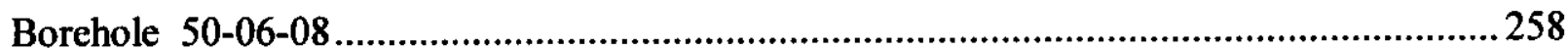

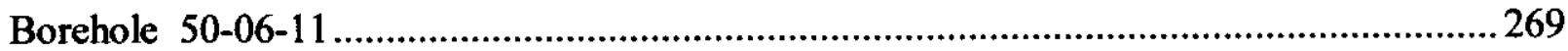

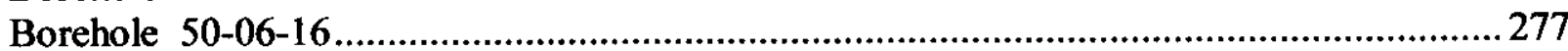

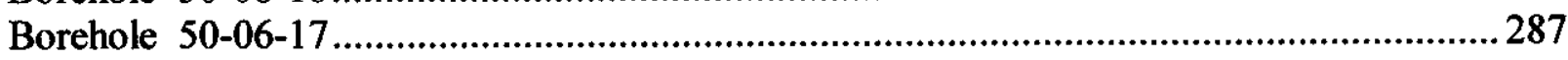

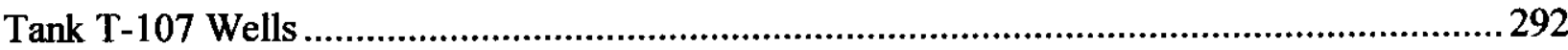

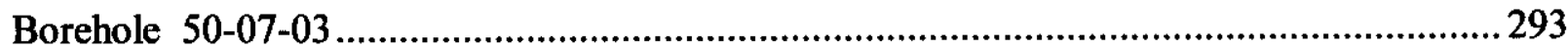

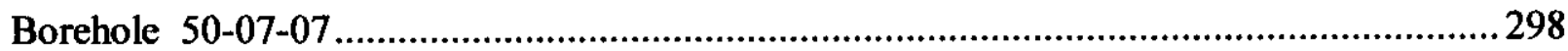

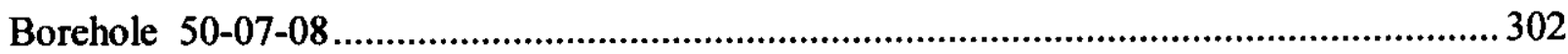

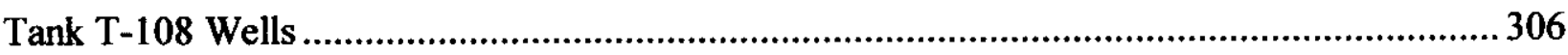

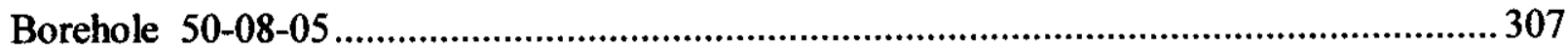

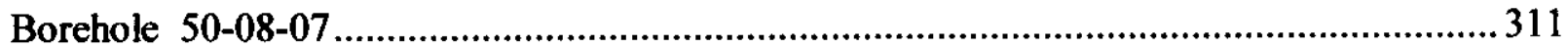

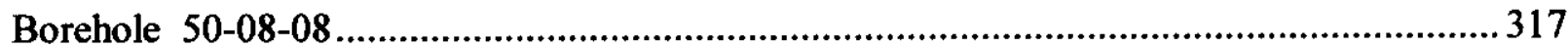

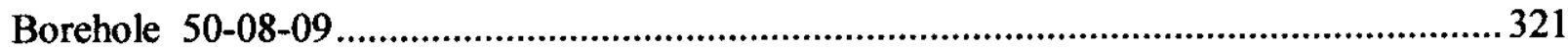

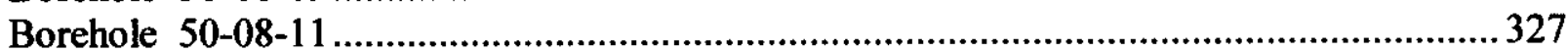

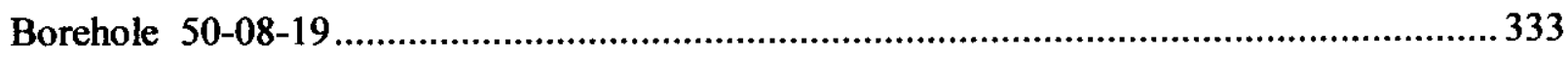

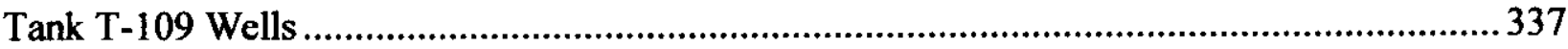

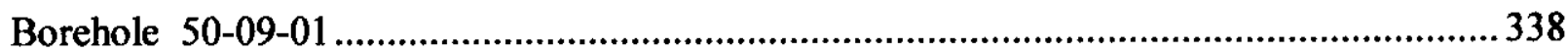




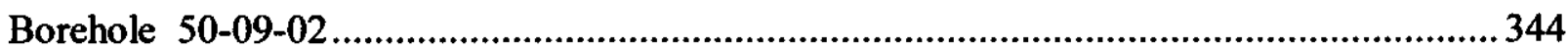

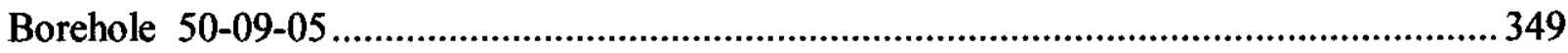

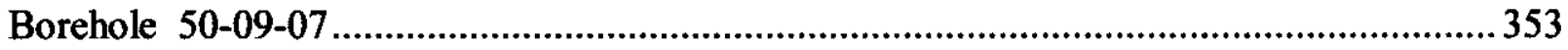

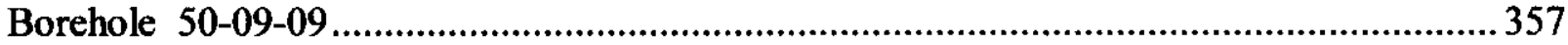

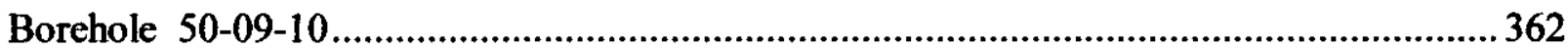

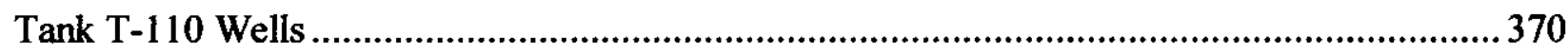

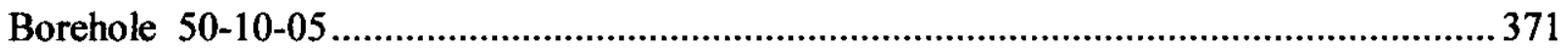

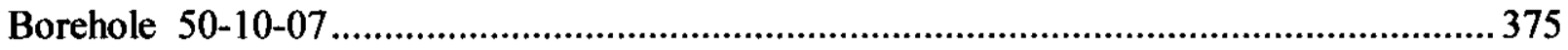

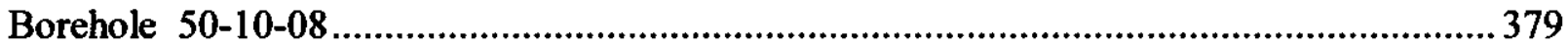

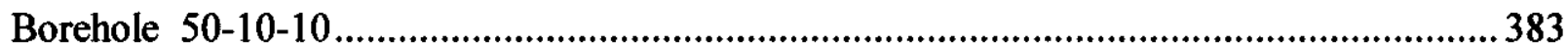

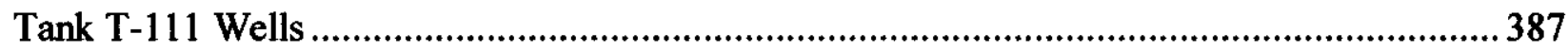

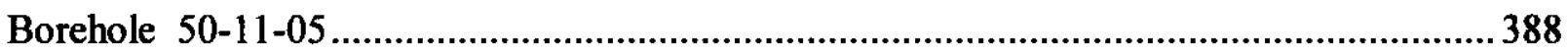

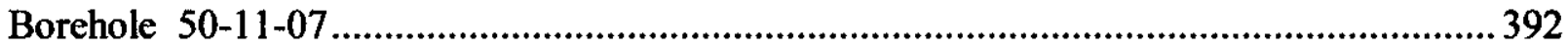

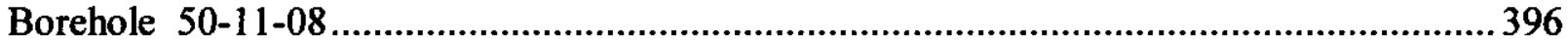

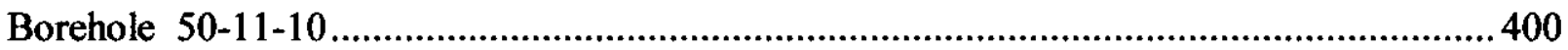

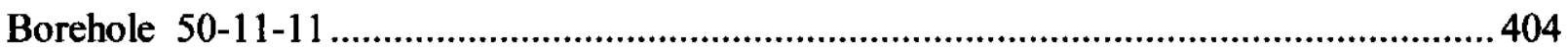

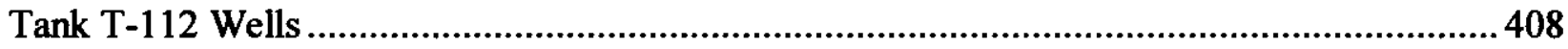

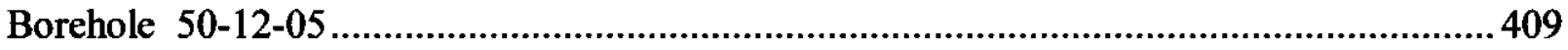

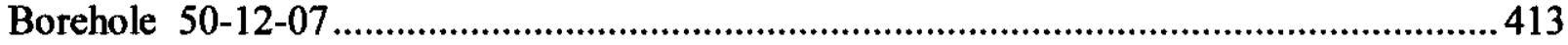

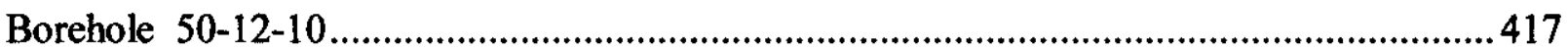

\section{Table of Figures}

Figure Page

Figure 1. T Tank Farm Borehole Locations and Total Depth .........................................................

Figure 2. T Tank Farm Radiation Zone Categories............................................................18

Figure 3. Radionuclide Half-life Decay Rates .....................................................................23

Figure 4. T Tank Farm Top of Contamination ......................................................................26

Figure 5. T Tank Farm Observable Bottom of Contamination ...............................................22

Figure 6. T Tank Farm Grade Thickness Product Greater Than $1,000 \mathrm{ft}^{*} \mathrm{c} / \mathrm{s} . \ldots \ldots \ldots \ldots \ldots \ldots \ldots \ldots \ldots . . .28$

\section{Table of Tables}

Table Page

Table 1. T Tank Farm Borehole Contaminate Zones ..........................................................12

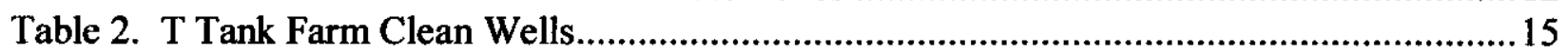

Table 3. T Tank Farm Activity Zones................................................................................

Table 4. T Tank Farm Undetermined and Unassigned Deviation Zones....................................19

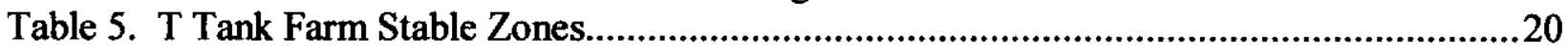

Table 6. T Tank Farm Unstable and Unstable Early Zones ......................................................21

Table 7. Half-life of Isotopes Identified in the T Tank Farm Boreholes .....................................24

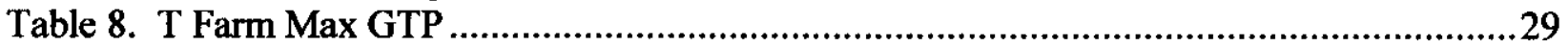


RPP-6088, Rev. 0.

\section{Analysis and Summary Report of Historical Dry Well Gamma Logs for the 241-T Tank Farm - 200 West Area}

\section{Introduction}

The single shell tank farm dry well surveillance program was established as one of several methods used to identify leaking tanks. Gross gamma logging in boreholes peripheral to and surrounding single-shell tanks was used to supplement in-tank liquid level measurements to determine the integrity of an individual tank. Until 1975, gross gamma ray data were collected in a non-digital format. In 1975, the surveillance program was upgraded to a digital logging system. Under the upgraded system, gross gamma ray logs were captured in digital form utilizing several types of logging detectors. These logs were then reviewed immediately after collection to identify significant changes in activity from previous logs or confirm leaks of gamma-emitting liquid radionuclides from suspect underground tanks. Sudden drops of in-tank liquid level measurements were used to identify suspect tanks. The system was not intended to identify the specific radionuclides contributing to the total gross gamma ray activity; the data were used to make operational decisions regarding the integrity of tanks and their ability to safely contain high-level radioactive waste. While the system targeted gamma-emitting radionuclides as indicator species, other radionuclides and hazardous chemical constituents would also have leaked from the suspect tanks when gross gamma activity significantly increased.

Digital gross gamma ray logs were acquired for the period from January 1975 through mid-year 1994 and have been re-analyzed to determine contaminant distribution in the subsurface around boreholes during this interval. Data acquired prior to 1975 require reformatting to be useful for this analysis. A detailed description of the analysis procedure is described in "Analysis Techniques and Monitoring Results, 241-SX Dry Well Surveillance Logs," (Randall and Price, 1999).

Isotopes identified during the spectral gamma logging analysis that occurred from 1995 to 1999 for all single-shell tank farms is integral to the analysis of the gross gamma ray data. Spectral gamma log data for T Tank Farm were obtained by Three Rivers Scientific from a report issued by the U.S. Dept. of Energy prepared by MACTEC-ERS of Grand Junction, Colorado under contract \#DE-AC04-94AL96907 (MACTEC-ERS, 1999). The spectral gamma logging system (SGLS) employs a high-purity germanium (HPGe) detector to obtain data leading to the identification and depth of gamma-emitting radioactive isotopes. The identity of gammaemitting radionuclides in soils surrounding a tank is required for interpretation of the tank farm gross gamma ray dry well surveillance logs. By integrating SGLS data with historical dry well surveillance data, information concerning the tank leak history along with the historical mobility and decay of man-made gamma-emitting radionuclides in the vadose zone is obtained. These analyses concern gamma-emitting contaminants and contaminant mobility (or lack of mobility) that has occurred over the time period spanned by the available data (i.e., 1975 to 1994).

This report provides a summary of the gross gamma ray data for the 241-T Tank Farm and is intended to identify changes in the gamma activity of gamma-emitting radionuclide contaminants around each accessible borehole, and is not intended to provide interpretation of 
RPP-6088, Rev. 0.

the data relative to vadose zone mechanics. Trends in the data, as well as areas where additional information would be helpful in evaluating the unusual nature of some of the data, are discussed. In general, the data analysis resulted in the identification of two types of subsurface conditions; clean dry wells and dry wells with radionuclide contamination at one or more depth intervals. Within the dry wells with contaminated intervals (discrete depth zones) five categories of contamination were identified. Following this system, a borehole and/or a zone may be classified into one of several categories:

- CLEAN: no gamma-emitting contaminants detected for the survey speeds and sensitivities of the gross gamma ray probes used; specifically no systematic trend above the naturally occurring radionuclide background in the soils is indicated by the data.

- STABLE: gamma activity follows a decay curve of an isotope identified by HPGe or a hypothesized radionuclide based on decay characteristics; specifically, the decay rate of the isotope(s) identified in the zone matches the change over time in the gross gamma log response, and no noticeable deviation from the radionuclide decay is apparent within the time period of the data.

- UNSTABLE: evidence of contaminant migration exists within the period of data collection; specifically, in logs with proper depth control, a peak migrates with passage of time, or there is a sudden increase in GTP (Grade Thickness Product) that does not correlate with any change of logging tools or procedure. Such changes are interpreted to reflect the addition of a gamma-emitting contaminant.

Some contamination zones were identified as initially unstable in older logs and as stable in more recent logs; i.e., instability in earlier data was succeeded by stability in more recent data.

Note: Nomenclature for the classification of subsurface contamination categories has evolved beyond those presented in the Analysis Techniques report (Randall and Price, 1998). The contaminate category of "changing" has been replaced by more descriptive terms of "unstable early" and "unstable"

- TANK FARM ACTIVITY: erratic log response at the bottom of dry wells or at shallow depths result from logging procedure changes, radioactive waste transfer operations, surface or near surface leaks/spills, and/or clean up of surface contamination; specifically, an irregular change is observed in gross gamma-ray log values between successive surveys at or near the surface and/or at the bottom of the dry well. These rapid and inconsistent log changes suggest that contamination may be the result of tank farm operation activities (e.g., waste transfers) or logging procedure changes, and are not related to vadose zone mechanics.

- UNDETERMINED: no specific conclusion can be reached with the available data; specifically, stability cannot be determined due to: 1) insufficient data, 2) exceeding the system design criteria (both upper and lower limits) for recording gross gamma ray data, or 3) possible effects of depth shift or surface activities. 
RPP-6088, Rev. 0.

- UNASSIGNED DEVIATION: gamma activity for a contaminant zone has the following characteristics: 1) GTP precision is good, 2) no evidence of contaminant migration on the stack plot, 3) survey data is within the linear response region of the logging system, 4) good match of GTP data with fitted decay curve is present for majority of surveillance time period, 5) an unambiguous time interval is present in which the GTP rate of decrease does not match the isotope decay curve, and 6) no time period exist in which the GTP was observed to increase.

Stable vs. unstable is an apparent condition limited by the time interval over which data were collected, the sensitivity of the tools, and the level of contamination; it is not necessarily a statement concerning the fixed or mobile nature of a given isotope in the vadose zone.

Radionuclide isotopes discussed in this report are either identified using the HPGe data or are hypothesized to exist presently or to have existed in the past. Radionuclides cannot be identified from a gross gamma ray log alone. The presence of hypothesized isotopes generally have a rapid rate of decay (e.g., Ru-106) which may not be identified by the HPGe tool if the level of radioactivity falls below detection limits at the time the SGLS data were obtained (mid 1990's). The earlier presence of such isotopes can be speculated based on the fit of a decay curve of the isotope to the change over time of the gross gamma ray data and knowing that such an isotope was initially present in the leaked waste.

It is beyond the scope of this project to identify the contaminant source, rate of movement, or migration pathway and the ultimate impact of leaked waste to the environment. It is also noted that where boreholes do not exist, gamma-emitting isotopes may be present and movement can and may have occurred without detection. This investigation is limited to the immediate area (approximately 20 inches) around each borehole from which gamma rays are readily detected, and is not rigorous enough to interpret the condition of the space between boreholes and outside of the investigated area. Contaminants which do not emit gamma rays or whose decay products do not emit gamma rays, are not detected by gross or spectral gamma logging and are therefore not discussed in this report. While such isotopes may be present, they are beyond the scope of this report.

\subsection{Background}

A series of sixteen tanks were constructed at the $T$ Tank Farm (one of four original tank farms at the Hanford Site) in 1943-44 to receive high-level, liquid, mixed waste resulting from chemical processing of spent fuel rods (Brevick, et. al., 1996). Twelve of these tanks held 550,000 gallons, were constructed on 100-foot centers and are 75 feet in diameter, leaving 25 feet between the sides of each tank. Four smaller 55,000-gallon tanks were also constructed in $T$ Farm. The large tanks are connected in a variety of ways, such as by cascade and transfer lines, the details of which can be obtained from the engineering construction diagrams for this tank farm. Each tank consists of a reinforced concrete tank with a single lining of carbon steel. No historical gross gamma surveillance logs were available for the four smaller tanks. A network of vadose monitoring wells (dry wells) was installed throughout the $T$ Tank Farm as part of a leak detection and surveillance system. Borehole locations (centered on the borehole name) and the depth of logging, (listed below borehole name) are presented in Figure 1. The boreholes range in depth from 85 to 145 feet, with 27 (of 67) being 100 or more feet deep. The 1975 to 1995 digital 
RPP-6088, Rev. 0.

gross gamma ray data were analyzed by Three Rivers Scientific (under subcontract to Waste Management Technical Services, Richland, Washington) and the results are the subject of this report.

A major leak of 115,000 gallons was reported in June 1973 from the 241-T-106 Tank. This is the largest known Hanford tank leak and this incident led to a major investigation to determine the composition and the three-dimensional extent of the leaked waste in the soil surrounding this tank (ARH 2874, 1973). Additional boreholes were constructed around this tank as part of this investigation. Some of these boreholes were extended and other boreholes were added in 1978 (Routson et al, 1978) to determine whether the waste leaked from this tank had migrated and to determine the new volume of contaminated soil. Because of these two investigations, the number of boreholes surrounding tank T-106 exceeds the 2 to 6 boreholes that were constructed as part of the original leak detection system. Boreholes that were extended typically have double casing that dampens the response of the various gross gamma tools employed in the leak detection program. An additional borehole (299-W10-196) was constructed through the plume of leaked waste in 1992-93 in response to an audit finding by the Government Account Office (GAO). This borehole was logged with the SGLS during construction, is double- (and in some cases triple-) cased, contains an annular seal and has not become part of the network of boreholes used for gross gamma logging.

\subsection{Data Analysis Description}

The dry well data analysis procedure used for the T Tank Farm gross gamma historical logs is discussed in detail in the analysis techniques report (Randall and Price, 1999; HNF-3136).

Data from the dry well logs were compiled to maximize trend identification. This process does not add or delete data, but merely compiles the data into a more useful format. This data set is used to create a depth vs. time plot (stack plot) to identify trends over time and zones of contamination. All historical log surveys for a single dry well (borehole) are analyzed as a whole for each radioactive zone above background in the well, allowing statements to be made about the apparent condition or rate of change of any given radioactive interval. For clarity, all logs are not plotted; quarterly logs are plotted to render the stack plot readable without affecting the integrity of the data. 
RPP-6088, Rev. 0.

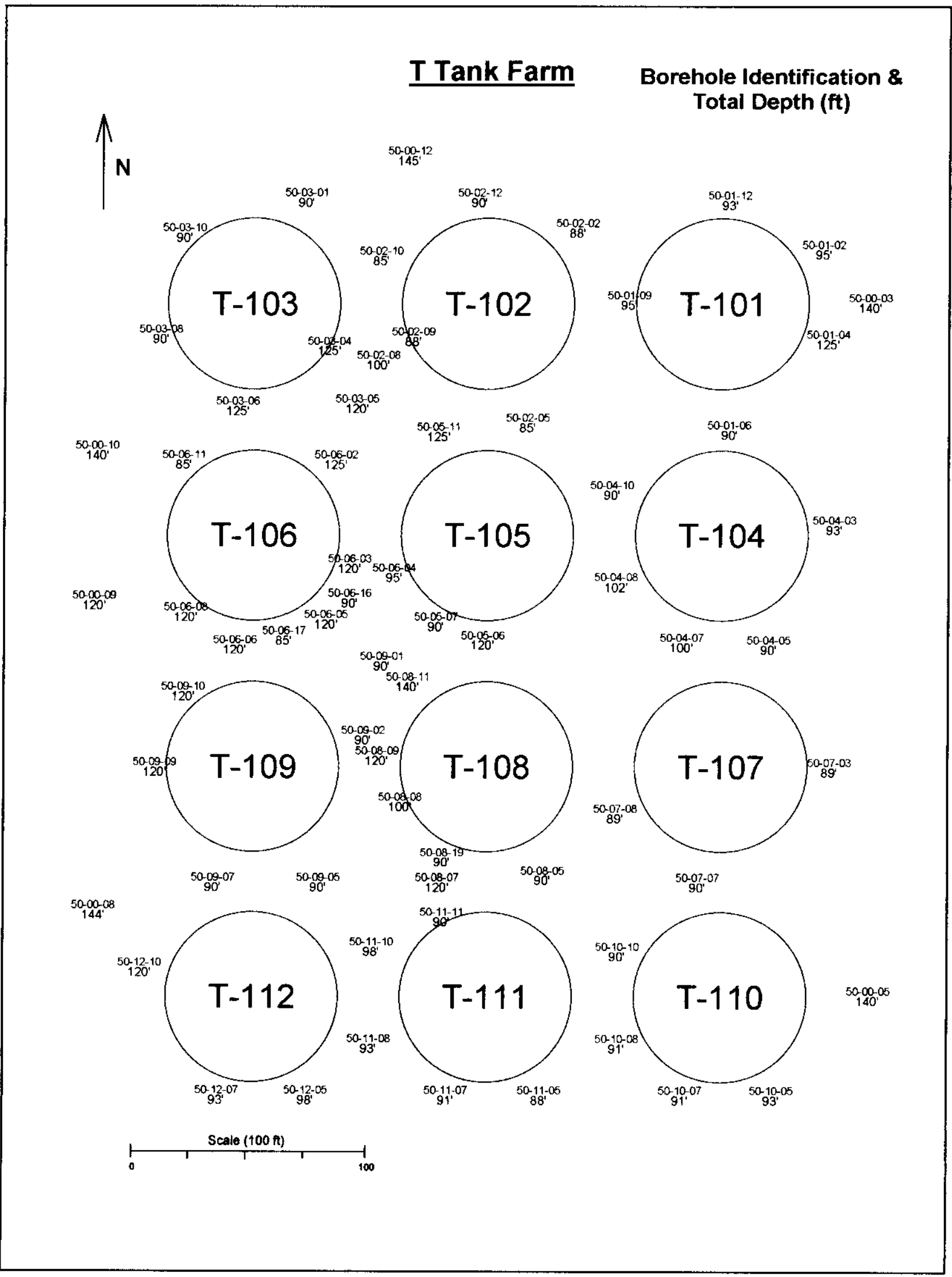

Figure 1. T Tank Farm Borehole Locations and Total Depth 
Review of the historical gross gamma ray data revealed that limits in the system design for collecting data prior to 1983 created a situation where the zero-depth reference point for the start of data collection was inconsistent. This difference in zero-depth point makes evaluating trends in the data difficult. Several methods can be employed to overcome varying zero points and to essentially create a common starting point from which to view the data, making trend identification easier. One method applies a depth shift to the data, which is simply adjusting data up or down so that certain identifiable features in the logs can be aligned and evaluated. No depth shifting was required to analyze the $T$ Tank Farm, thus maintaining maximum data integrity.

A second method to analyze changes between successive gross gamma logs utilizes a calculation called the Grade Thickness Product (GTP) which can be applied over a depth interval wide enough to include all depth variances of peaks so as not to require depth shifting. The GTP is a summation of the values of logging instrument readings over the depth interval of interest (minus background activity), multiplied by the distance between sample point depths. This calculation yields a constant that is independent of the log depth and the specifically chosen starting/ending points. When the calculation is applied over the entire contamination interval, the result is a more accurate representation of the condition of the zone over time.

Gross gamma ray log surveys were recorded over the length of the borehole at sampling intervals of one foot, starting at the maximum depth to which the logging detector was positioned (near or at the bottom of the dry well). In thin radioactive zones, different zero depths between successive surveys using the one foot sample intervals will cause variations in the apparent shape of the $\log$ for a thin contamination zone. Furthermore, changes in the apparent maximum count rate for the labeled center of the zone can vary with the depth sampling errors to one side of the true maximum. The GTP calculation is used to eliminate this apparent problem.

Note: Gross gamma ray data were collected using a variety of probe types. The count rates generated by these probe types do not directly correlate, as discussed in the Analysis Techniques report (Randall and Price, 1998). Caution must therefore be used when relating GTP values in zones recorded with different probe types (e.g. the Nal probe type 04 does not record values that relate to those recorded with the Green or Red GM probe types 01 and 02). Scaling factors between the different probe types are presented in "Dry Well Probe Calibrations" (Randall, 1999).

The average background activity for the GTP calculation and "Average Background" plots, which are provided, is the gamma radiation from naturally occurring potassium, uranium, and thorium (i.e. natural background) in the soil. The average background is computed and reviewed for each survey and provided a level of confidence that the instrumentation worked consistently and that the gross gamma ray data are valid. The average background is calculated either between a lower and upper count rate limit or for a depth range. The lower count rate limit is generally set at zero $(0) \mathrm{c} / \mathrm{s}$; a value defined as indicating a data gap. The upper count rate limit is generally set at $50 \mathrm{c} / \mathrm{s}$ for the $\mathrm{NaI}$ probe (i.e., type 04 probe), a conservative value near what is considered background activity. For comparison, the original leak detection program, considered a count rate equal to or exceeding $200 \mathrm{c} / \mathrm{s}$ a reportable occurrence for the probe type 04 (NaI). 
RPP-6088, Rev. 0.

The percentage of data values for each survey that are considered as representing the natural background (i.e. non-contaminated interval) is also calculated and presented on the summary plots as "Frequency Clean".

Zones of gamma-emitting contamination are examined for historical character using the GTP calculation. The average background activity is subtracted from peak values so that only the contaminated levels above background are included in the analysis. A graph is generated with GTP plotted against time for each depth interval analyzed. One or more decay lines are then superimposed on the graph based on isotopes identified by the SGLS data, knowledge of tank constituents, and the known presence of isotopes in other boreholes. Sometimes decay lines can be fit through the data a number of ways with none of them fitting perfectly. When two or more isotopes are identified, a least squares fit analysis for a multi-component decay is performed. A detailed discussion of how two or more curves are combined is provided in the Appendix to the "Data Analysis Results for the BX Single Shell Tank Farm Dry Well Gross Gamma Ray Surveillance Log Surveys" (Randall \& Price, 1999). Gamma-emitting isotopes that are known to exist in the inventory of the tank farm, or are identified in nearby wells, may not be identified by the SGLS because they were at or below detection levels for the HPGe when the logs were recorded. Such isotopes are hypothesized to have been present when the gross gamma logs were recorded and are therefore included in the least squares fit analysis. The decay rates for each of the components are held fixed in the fitting process and the relative intensities of the components are calculated and reported in the data analysis when appropriate. The relative contribution of gross gamma rays from one component to another depends on the nature of the isotopes and the detector design.

Comparing the GTP data and the decay line(s) reveals information about the rate of change of contamination within a zone over the period that data were collected. When appropriate, multiple plots are generated to show the results for different zones within a borehole. The details for the use of GTP data are described in the analysis techniques report (Randall and Price, 1999; HNF-3136).

\footnotetext{
Note: Spurious data were generated during normal data collecting activities. Spurious zero values are called data gaps and are considered as unrealistically low natural background activity when recorded with the sodium-iodide probes. Between 1975 and 1982 , the equipment would occasionally record a spurious data value of minus one $(-1) \propto$ zero $(0)$. A value of minus one represents an invalid count rate. Data gaps occur at various locations in the surveys, including in the background or in the middle of a high contamination zone within a borehole. Many times the zero readings near the top 3 feet are viewable in the stack plots from mid 1981 to 1984. Data gaps are not included in the calculation of average background, grade thickness product, or frequency clean values.
}

The objective of the analysis is to assure that a consistent and thorough examination of dry well surveillance logs is performed and to determine if contamination abruptly entered the region of the borehole and quickly migrated out. All digital surveys within the time interval analyzed are examined to minimize undetected problems or conditions. Table 1 contains a list of the dry wells located in the $T$ Tank Farm as well as information concerning the identity, level, and depth of contamination. Step changes (decreases) in the average background were observed in several boreholes. The date of the step change(s) in the average background is tabulated in Table 1. The drop in average background is specifically associated with an increase in the survey depths logged, indicative of well deepening and dual casing for the older section of the dry well. 
The data available for this analysis are limited. Some of the limitations are the:

- Inability to identify when down-hole contamination is a result of vadose zone transport or drag down during casing installation

- Insufficient number of gross gamma ray surveys available to establish a statistical trend or rigorous statistical analysis

- Lack of data, especially when low sensitivity probes are required to survey boreholes with a zone of high gamma activity, the maximum sensitivity detector is not used for this zone

- Insufficient time interval over which data are available

- Insufficient borehole depth

- Inability to identify isotopes that have decayed to levels below the detection limits of the SGLS HPGe detector.

Table 1. T Tank Farm Borehole Analysis Results Summary

\begin{tabular}{|c|c|c|c|c|c|c|c|c|c|}
\hline $\begin{array}{l}\text { Borehole } \\
\text { Number }\end{array}$ & $\begin{array}{l}\text { Survey } \\
\text { Depth } \\
\text { (feet) }\end{array}$ & $\begin{array}{l}\text { Number } \\
\text { Surveys }\end{array}$ & $\begin{array}{l}\text { "Probe } \\
\text { Type }\end{array}$ & Category & $\begin{array}{l}\text { Zone } \\
\text { Depth } \\
\text { (foet) }\end{array}$ & $\begin{array}{c}\text { Max } \\
\text { GTP } \\
\text { (fbxcls) }\end{array}$ & $\begin{array}{l}\text { Year } \\
\text { Max } \\
\text { GTP }\end{array}$ & $\begin{array}{l}\text { Bsotopes } \\
\text { Present }\end{array}$ & $\begin{array}{l}\text { Change in } \\
\text { Average } \\
\text { Background }\end{array}$ \\
\hline $50-00-03$ & 140 & 185 & 4 & 'Stable & $50-60$ & 300 & 1975 & ${ }^{\mathrm{R}} \mathrm{Ru}^{106}$ & $\begin{array}{l}8 / 5 / 778 \\
10 / 6 / 78\end{array}$ \\
\hline $50-00-05$ & $140^{\circ}$ & 433 & 4 & Unstable Early & $28-50$ & 1000 & 1975 & $\mathrm{Co}^{80} ;{ }^{8+} \mathrm{Ru}^{108}$ & $10 / 12 / 78$ \\
\hline $50-00-08$ & $144^{\prime}$ & 196 & 4 & ${ }^{\mathrm{b}}$ Clean & & & & & $\begin{array}{c}11 / / 4 / 778 \\
10 / 31 / 78\end{array}$ \\
\hline \multirow[t]{3}{*}{$50-00-09$} & $120^{\prime}$ & 54 & 4 & Unstable Earty & $40-59$ & $350 \mathrm{~K}$ & 1979 & $\mathrm{Eu}^{154} ; \mathrm{CO}^{80} ; \mathrm{Ru}^{106}$ & \\
\hline & & & & Unstable & $62-94$ & $24 K$ & 1981 & $\mathrm{Co}^{80} ; R^{1000}$ & \\
\hline & & & & dundetermined & $100-120$ & $6 \mathrm{~K}$ & 1979 & $\mathrm{Co}^{80} ; \mathrm{Ru}^{186}$ & \\
\hline $50-00-10$ & $140^{\circ}$ & 153 & 4 & ${ }^{\mathrm{b}}$ Clean & & & & & $9 / 16 / 77$ \\
\hline $50-00-12$ & $145^{\prime}$ & 154 & 4 & ${ }^{\mathrm{b}}$ Clean & & & & & $\begin{array}{c}7 / 15 / 77 \& \\
10 / 6 / 78\end{array}$ \\
\hline $50-01-02$ & 95 & 144 & 4 & ${ }^{b}$ Clean & & & & & $9 / 16 / 80$ \\
\hline \multirow[t]{4}{*}{ 50-01-04 } & 125 & 444 & 2 & 'Stable & $15-40$ & $150 \mathrm{~K}$ & 1977 & $\mathrm{Cs}^{\text {I3t }}$ & \\
\hline & & & & $\begin{array}{l}{ }^{e} \text { Stable } \\
\end{array}$ & 40-55 & $5.5 \mathrm{~K}$ & 1977 & $\mathrm{Cs}^{137}$ & \\
\hline & & & & ${ }^{\text {EStable }}$ & $55-70$ & $2.5 \mathrm{~K}$ & 1977 & $\mathrm{Cs}^{3+1}$ & \\
\hline & & & & 'Undetermined & $75-90$ & 150 & 1977 & $\mathrm{Cs}^{137}$ & \\
\hline \multirow[t]{4}{*}{$50-01-06$} & $90^{\prime}$ & 853 & 4 & 'TF Activity & $0-8$ & 800 & 1976 & $\mathrm{Cs}^{131}$ & $9 / 16 / 80$ \\
\hline & & & & Unstable Early & $45-69$ & $50 \mathrm{~K}$ & 1975 & $\mathrm{Co}^{60, *} \mathrm{Ru}^{108}$ & \\
\hline & & & & Undetermined & $69-78$ & 1100 & 1987 & $\mathrm{CO}^{\circ 0^{\circ}}$ & \\
\hline & & & & Jundetermined & $78-90$ & 1000 & 1990 & $\mathrm{Co}^{60}$ & \\
\hline \multirow[t]{3}{*}{$50-01-09$} & 95 & 444 & 4 & 'TF Activity & $0-12$ & $15 \mathrm{~K}$ & 1977 & $\mathrm{Cs}^{13 t}$ & $9 / 16 / 80$ \\
\hline & & & & Unstable Early & $12-28$ & $10 \mathrm{~K}$ & 1990 & $\mathrm{Cs}^{137}$ & \\
\hline & & & & Unstable & $32-45$ & 300 & 1977 & $\mathrm{Co}^{\circ 0}$ & \\
\hline $50-01-12$ & $93^{\prime}$ & 438 & 4 & EStable & $30-40$ & 500 & 1975 & $\mathrm{Co}^{0^{60 ;} ; \mathrm{Ru}} \mathrm{u}^{100}$ & $9 / 16 / 80$ \\
\hline $50-02-02$ & $88^{\prime}$ & 282 & 4 & ${ }^{6}$ Clean & & & & & \\
\hline \multirow[t]{3}{*}{$50-02-05$} & $85^{\prime}$ & 116 & 4 & Stable & $30-45$ & $40 \mathrm{~K}$ & 1980 & $\mathrm{CS}^{13 t}$ & $2 / 18 / 81$ \\
\hline & & & & Unstable & 45-54 & 100 & 1993 & $\mathrm{Co}^{\circ 0}$ & \\
\hline & & & & Unstable & 5470 & 600 & 1981 & $\mathrm{Co}^{80}$ & \\
\hline \multirow[t]{2}{*}{$50-02-08$} & $100^{\circ}$ & 284 & 4 & ${ }^{\text {estable }}$ & $32-50$ & $80 \mathrm{~K}$ & 1975 & $\mathrm{Eu}^{184} ; \mathrm{CO}^{60 ;} ; \mathrm{Ru}^{108}$ & $9 / 5 / 80$ \\
\hline & & & & 'Stable & $50-56$ & 450 & 1975 & ${ }^{8} \mathbf{R u}^{10}$ & \\
\hline
\end{tabular}


RPP-6088, Rev. 0.

\begin{tabular}{|c|c|c|c|c|c|c|c|c|c|}
\hline & & & & eStable & $60-72$ & 1100 & 1975 & ${ }^{\mathrm{R} \mathrm{Ru}^{\mathrm{10}}}$ & \\
\hline & & & & Undetermined & $78-85$ & 400 & 1975 & ${ }^{*} \mathrm{Ru}^{106}$ & \\
\hline $50-02-09$ & $88^{\prime}$ & 285 & 4 & Unstable Earty & $32-48$ & $4.4 \mathrm{~K}$ & 1975 & $E u^{137} ; S^{125} ;{ }^{12} R^{100}$ & $9 / 3 / 80$ \\
\hline $50-02-10$ & 85 & 286 & 4 & ${ }^{\mathrm{b}}$ Clean & & & & & $9 / 3 / 80$ \\
\hline $50-02-12$ & $90^{\circ}$ & 285 & 4 & ${ }^{6}$ Clean & & & & & $9 / 3 / 80$ \\
\hline $50-03-01$ & $90^{\circ}$ & 176 & 4 & ${ }^{b}$ Clean & & & & & $9 / 3 / 80$ \\
\hline \multirow[t]{4}{*}{ 50-03-04 } & $125^{\prime}$ & 175 & 4 & Estable & $12-52$ & $520 \mathrm{~K}$ & 1975 & $\mathrm{Eu}^{134} ; \mathrm{Co}^{60} ;{ }^{\circ} \mathrm{Ru}^{108}$ & 4/28/81 \\
\hline & & & & EStable & $52-60$ & 350 & 1975 & "Ru & \\
\hline & & & & "Stable & $60-75$ & 300 & 1981 & $\mathrm{Co}^{63}: \mathrm{Sb}^{125}$ & \\
\hline & & & & ${ }^{c}$ Stable & $75-90$ & 1000 & 1975 & 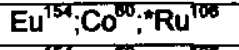 & \\
\hline \multirow[t]{4}{*}{$50-03-05$} & $120^{\circ}$ & 173 & 4 & ${ }^{\text {eStable }}$ & $32-52$ & $60 K$ & 1975 & $\mathrm{Eu}^{157} ; \mathrm{Co}^{80} ;{ }^{8 *} \mathrm{Ru}^{106}$ & $3 / 31 / 81$ \\
\hline & & & & "Undetermined & $52-65$ & $7 \mathrm{~K}$ & 1975 & $\mathrm{Eu}^{154} ; \mathrm{Ru}^{106}$ & \\
\hline & & & & DUndetermined & $65-72$ & 300 & 1975 & ${ }^{*} \mathrm{Ru}^{106}$ & \\
\hline & & & & 'Stable & $75-90$ & 600 & 1975 & $\mathrm{Eu}^{159 ;} ; \mathrm{Ru}^{\mathrm{TOS}}$ & \\
\hline $50-03-06$ & $125^{\circ}$ & 156 & 4 & dundetermined & $50-98$ & 9K & 1975 & $\mathrm{Eu}^{134} ; \mathrm{Co}^{806} ; \mathrm{Ru}^{106}$ & $9 / 15 / 78$ \\
\hline $50-03-08$ & $90^{\prime}$ & 179 & 4 & ${ }^{b}$ Clean & & & & & $9 / 3 / 80$ \\
\hline 50-03-10 & $90^{\prime}$ & 179 & 4 & ${ }^{b}$ Clean & & & & & $9 / 3 / 80$ \\
\hline \multirow[t]{2}{*}{$50-04-03$} & $93^{*}$ & 819 & 4 & ${ }^{c}$ TF Activity & $0-12$ & $3 K$ & 1985 & $\mathrm{Cs}^{137}$ & $2 / 17 / 81$ \\
\hline & & & & estable & $18-30$ & 100 & 1975 & $\mathrm{Cs}^{137}$ & \\
\hline 50-04-05 & $90^{\circ}$ & 684 & 4 & GTF Activity & $0-10$ & 250 & 1985 & $\mathrm{Cs}^{13 T}$ & $1 / 27 / 81$ \\
\hline $50-04-07$ & $100^{\prime}$ & 676 & 4 & ${ }^{{ }^{\circ} \text { TF Activity }}$ & $0-28$ & $7 \mathrm{~K}$ & 1975 & $\mathrm{Cs}^{137}$ & $2 / 10 / 81$ \\
\hline $50-04-08$ & $102^{\prime}$ & 653 & 4 & Unstable & 63-72 & 350 & 1981 & $\mathrm{CO}^{60}$ & $2 / 10 / 81$ \\
\hline \multirow{2}{*}{$50-04-10$} & $90^{\circ}$ & 502 & 4 & Unstable & 62-71 & 1000 & 1980 & $\mathrm{Co}^{\circ 0}$ & $9 / 16 / 80$ \\
\hline & & & & Unstable Early & $82-90$ & 100 & 1979 & $\mathrm{CO}^{30}$ & \\
\hline \multirow[t]{3}{*}{$50-05-06$} & $120^{\prime}$ & 402 & 4 & Undetermined & $0-20$ & 300 & 1975 & $\mathrm{Cs}^{13 t}$ & 9/14/78 \\
\hline & & & & Unstable Early & $58-74$ & $14 \mathrm{~K}$ & 1978 & ${ }^{*} \mathbf{R u}^{100}$ & \\
\hline & & & & Unstable Early & $70-82$ & $3 \mathrm{~K}$ & 1978 & $\mathrm{Co}^{\circ 0}$ & \\
\hline \multirow[t]{2}{*}{$50-05-07$} & 85 & 349 & 4 & ${ }^{\text {eStable }}$ & 4-18 & 300 & 1976 & ${ }^{2} \mathrm{Ru}^{106}$ & $10 / 31 / 75$ \\
\hline & & & & Unstable Early & $58-90$ & $190 \mathrm{~K}$ & 1976 & $\mathrm{Co}^{\circ 0}$ & \\
\hline \multirow[t]{3}{*}{$50-05-11$} & $125^{\circ}$ & 341 & 4 & Undetermined & $50-60$ & 100 & 1977 & ${ }^{\circ} \mathrm{Ru}^{100}$ & $3 / 31 / 81$ \\
\hline & & & & Unstable Earty & $68-92$ & $4.5 \mathrm{~K}$ & 1976 & ${ }^{2} \mathrm{Ru} \mathrm{u}^{100}$ & \\
\hline & & & & "Stable & $92-106$ & 200 & 1982 & $\mathrm{Co}^{\circ 0}$ & \\
\hline \multirow[t]{2}{*}{$50-06-02$} & 125 & 49 & 2 & "Stable & $38-100$ & $6 \mathrm{~K}$ & 1975 & $\mathrm{Eu}^{154} ; \mathrm{CO}^{60} ;{ }^{60} \mathrm{Ru}^{108}$ & \\
\hline & & 76 & 14 & Unstable Early & $100-124$ & $3.5 \mathrm{~K}$ & 1978 & ${ }^{*} \mathrm{Ru}^{108}$ & \\
\hline \multirow[t]{4}{*}{$50-06-03$} & $120^{\prime}$ & 49 & 4 & ${ }^{\circ}$ Stable & 16-24 & 200 & 1975 & $\mathrm{Cs}^{35 t}$ & \\
\hline & & 105 & 2 & Unstable Earty & $30-60$ & $10 \mathrm{~K}$ & 1975 & $\mathrm{Co}^{60 ;} ; \mathrm{Ru}^{100}$ & \\
\hline & & & 2 & Unstable Early & $60-98$ & $20 K$ & 1975 & $\mathrm{Co}^{0.00} ; \mathbf{R u}^{100}$ & \\
\hline & & 165 & 14 & Unstable Early & $98-120$ & $40 \mathrm{~K}$ & 1977 & $\mathrm{Eu}^{1{ }^{150}} ; \mathrm{CO}^{80 .} ;{ }^{2} \mathrm{Ru}^{106}$ & \\
\hline \multirow[t]{3}{*}{ 50-06-04 } & $95^{\prime}$ & 181 & 2 & ${ }^{\circ}$ Stable & $29-42$ & $2 K$ & 1975 & $\mathrm{Cs}^{137}$ & \\
\hline & & & & "Undetermined & $42-66$ & $15 K$ & 1975 & ${ }^{+} \mathrm{Ru}^{100}$ & \\
\hline & & & & dUndetermined & $66-90$ & $5 K$ & 1976 & ${ }^{*} \mathrm{Ru}^{108}$ & \\
\hline \multirow[t]{3}{*}{$50-06-05$} & $120^{\circ}$ & 189 & 2 & ${ }^{\text {eStable }}$ & $27-60$ & $45 \mathrm{~K}$ & 1975 & $\mathrm{Cs}^{3 / 2}$ & \\
\hline & & & & ${ }^{e}$ Stable & $60-94$ & 3K & 1975 & $\mathrm{Cs}^{13 T}$ & \\
\hline & & & & EStable & $94-120$ & 300 & 1975 & $\mathrm{Cs}^{137}$ & \\
\hline \multirow[t]{3}{*}{$50-06-06$} & $120^{\prime}$ & 128 & 2 & Unstable Early & 2968 & $35 \mathrm{~K}$ & 1975 & $\mathrm{Cs}^{137} ; \mathrm{CO}^{007}+\mathrm{Ru}^{105}$ & \\
\hline & & & & Unstable Earty & $68-110$ & $10 \mathrm{~K}$ & 1975 & $\mathrm{Cs}^{137} ;{ }^{*} \mathrm{Ru}^{100}$ & \\
\hline & & 102 & 14 & Stable & $110-120$ & 4K & 1978 & 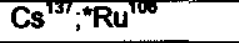 & \\
\hline \multirow[t]{3}{*}{$50-06-08$} & $120^{\prime}$ & 181 & 2 & 'Stable & 28-44 & $2 K$ & 1975 & $\mathrm{Cs}^{137}$ & \\
\hline & & & 2 & estable & $44-89$ & $15 \mathrm{~K}$ & 1975 & $\mathrm{Cs}^{137} ; \mathrm{Co}^{00} ;{ }^{60} \mathrm{Ru}^{100}$ & \\
\hline & & 62 & 14 & Undetermined & $89-120$ & $15 K$ & 1976 & $\mathrm{Cs}^{137} ; \mathrm{Ru}^{100}$ & \\
\hline \multirow[t]{2}{*}{$50-06-11$} & $85^{\prime}$ & 169 & 4 & ${ }^{e}$ Stable & $30-44$ & $140 \mathrm{~K}$ & 1976 & ${ }^{*} \mathrm{Ru}{ }^{100}$ & \\
\hline & & & & Unstable Eariy & 44-54 & $12 K$ & 1976 & ${ }^{*} \mathrm{Ru}^{106}$ & \\
\hline \multirow[t]{3}{*}{$50-06-16$} & $90^{\circ}$ & 66 & 4 & ${ }^{\text {EStable }}$ & $10-20$ & 1200 & 1976 & $\mathrm{Cs}^{13 \mathrm{~T}}$ & \\
\hline & & 81 & 2 & eStable & $30-63$ & $6 K$ & 1976 & $\mathrm{Cs}^{137} ; \mathrm{CO}^{100 ;} ; \mathrm{Ru}^{108}$ & \\
\hline & & & 2 & 'Stable & $63-90$ & $4 \mathrm{~K}$ & 1976 & $\mathrm{Eu}^{134} ; \mathrm{CO}^{\circ 00} ;{ }^{\circ} \mathrm{Ru}^{106}$ & \\
\hline 50-06-17 & $85^{\circ}$ & 276 & 2 & ${ }^{e}$ Stable & 28-52 & 10K & 1975 & $\mathrm{Cs}^{313}$ & \\
\hline
\end{tabular}


RPP-6088, Rev. 0.

\begin{tabular}{|c|c|c|c|c|c|c|c|c|c|}
\hline & & & & 'Stable & $52-70$ & $8 \mathrm{~K}$ & 1975 & $\mathrm{Cs}^{131 ;} ; \mathrm{Ru}^{\mathrm{T}}{ }^{106}$ & \\
\hline $50-07-03$ & 89 & 403 & 4 & "Undetermined & $0-20$ & 120 & 1975 & $\mathrm{Cs}^{137} ; \mathrm{Co}^{80}$ & $1 / 20 / 81$ \\
\hline & & & & Unstable Earty & $34-50$ & $3.3 \mathrm{~K}$ & 1976 & $\mathrm{Co}^{80}-{ }^{8 *} \mathrm{Ru}^{100}$ & $1 / 27 / 81$ \\
\hline $50-07-07$ & $90^{\circ}$ & 375 & 4 & Undetermined & $36-48$ & 230 & 1975 & $\mathrm{Cs}^{137}$ & \\
\hline $50-07-08$ & $89^{\prime}$ & 361 & 4 & ${ }^{6}$ Clean & & & & & $2 / 4 / 81$ \\
\hline $50-08-05$ & $90^{\circ}$ & 488 & 4 & ${ }^{b}$ Clean & & & & & $7 / 22 / 80$ \\
\hline $50-08-07$ & $120^{\prime}$ & 305 & 4 & Unstable Early & $64-76$ & $2.6 \mathrm{~K}$ & 1980 & $\mathrm{Co}^{80 * * \mathrm{Ru}^{700}}$ & $3 / 3 / 81$ \\
\hline & & & & Unstable Early & $76-95$ & $2.2 \mathrm{~K}$ & 1981 & $\mathrm{Co}^{80} ; \mathrm{Ru}^{100}$ & \\
\hline $50-08-08$ & $100^{\circ}$ & 119 & 4 & Unstable Earty & $60-72$ & 1100 & 1978 & $\mathrm{Co}^{80} ;{ }^{8 *} \mathrm{Ru}^{108}$ & \\
\hline $50-08-09$ & $120^{\prime}$ & 81 & 4 & $\begin{array}{l}\text { Unassigned } \\
\text { Deviation }\end{array}$ & $58-92$ & $55 K$ & 1980 & $\mathrm{Co}^{80} ;{ }^{\circ} \mathrm{Ru}^{100}$ & \\
\hline & & & & "Stable & $92-116$ & 1100 & 1980 & $\mathrm{Co}^{60}: \mathrm{Ru}^{108}$ & \\
\hline $50-08-11$ & $140^{\prime}$ & 95 & 14 & 'Stable & $58-88$ & 500 & 1980 & $\mathrm{Co}^{800} ;{ }^{8 *} \mathrm{Ru}^{106}$ & \\
\hline & & & & "Stable & $96-106$ & $100 \mathrm{~K}$ & 1980 & $\mathrm{Co}^{80} ; * \mathrm{Ru}^{108}$ & \\
\hline $50-08-19$ & $90^{\prime}$ & 77 & 4 & "Undetermined & $60-90$ & $45 K$ & 1979 & $\mathrm{Co}^{80} ;{ }^{8 *} \mathrm{Ru}^{808}$ & \\
\hline $50-09-01$ & $90^{\circ}$ & 78 & 14 & 'Stable & $0-8$ & 50 & 1980 & $\mathrm{Cs}^{13 T}$ & \\
\hline & & & & "Stable & $44-58$ & $3.5 K$ & 1980 & $\mathrm{Co}^{80} ;{ }^{\circ} \mathrm{Ru}{ }^{106}$ & \\
\hline & & & & 'Stable & $58-86$ & 120K & 1980 & $\mathrm{Co}^{80} ;{ }^{8 / 2 u^{108}}$ & \\
\hline $50-09-02$ & $90^{\prime}$ & 76 & 4 & Jundetermined & $0-10$ & 100 & 1985 & $\mathrm{Cs}^{137}$ & \\
\hline & & & & 'Stable & $58-86$ & $350 \mathrm{~K}$ & 1980 & $\mathrm{Co}^{60} ;{ }^{\circ} \mathrm{Ru}^{108}$ & \\
\hline 50-09-05 & $90^{\prime}$ & 333 & 4 & Unstable Early & $68-86$ & 300 & 1983 & $\mathrm{Co}^{60} ;{ }^{*} \mathrm{Ru}^{108}$ & $8 / 5 / 80$ \\
\hline $50-09-07$ & $90^{\prime}$ & 306 & 4 & Clean & & & & & $8 / 5 / 80$ \\
\hline $50-09-09$ & $120^{\circ}$ & 306 & 4 & Unstable Early & $52-65$ & 500 & 1976 & ${ }^{*} \mathrm{Ru}^{\mathrm{j03}}$ & $8 / 18 / 78$ \\
\hline $50-09-10$ & $120^{\circ}$ & 86 & 4 & Unstable Early & $33-44$ & $2.3 \mathrm{~K}$ & 1980 & $\mathrm{CO}^{\circ 0} ;{ }^{\circ 0} \mathrm{Ru}^{100}$ & \\
\hline & & & & Unstable Early & $44-74$ & $120 \mathrm{~K}$ & 1980 & $\mathrm{Co}^{60}-\mathrm{Ru}^{906}$ & \\
\hline & & & & "Stable & $74-99$ & $120 K$ & 1980 & $\mathrm{Co}^{600} ; \mathrm{Ru}^{10 \%}$ & \\
\hline & & & & Unstable & $99-115$ & $3.5 \mathrm{~K}$ & 1980 & $\mathrm{Co}^{800} ; \mathrm{Ru}^{108}$ & \\
\hline $50-10-05$ & $93^{\prime}$ & 886 & 4 & ${ }^{\mathrm{b}}$ Clean & & & & & $2 / 2 / 81$ \\
\hline $50-10-07$ & $91^{\prime}$ & 875 & 4 & ${ }^{\mathrm{b}}$ Clean & & & & & $1 / 27 / 81$ \\
\hline $50-10-08$ & $91^{\prime}$ & 676 & 4 & ${ }^{\mathrm{b}}$ Clean & & & & & $2 / 17 / 81$ \\
\hline $50-10-10$ & $90^{\circ}$ & 693 & 4 & ${ }^{\mathrm{B}}$ Clean & & & & & $2 / 2 / 81$ \\
\hline $50-11-05$ & $88^{\prime}$ & 888 & 4 & ${ }^{\mathrm{b}}$ Clean & & & & & $8 / 5 / 80$ \\
\hline $50-11-07$ & $91^{\prime}$ & 867 & 4 & ${ }^{\mathrm{b}}$ Clean & & & & & $8 / 5 / 80$ \\
\hline $50-11-08$ & $93^{\prime}$ & 651 & 4 & ${ }^{b}$ Clean & & & & & $8 / 5 / 80$ \\
\hline $50-11-10$ & $98^{\prime}$ & 643 & 4 & ${ }^{6}$ Clean & & & & & $8 / 19 / 80$ \\
\hline $50-11-11$ & $90^{\prime}$ & 685 & 4 & Unstable Early & $64-74$ & $1.8 \mathrm{~K}$ & 1980 & $\mathrm{Co}^{80} ;{ }^{*} \mathrm{Ru}^{\mathrm{ros}}$ & \\
\hline $50-12-05$ & $98^{\circ}$ & 265 & 4 & ${ }^{b}$ Clean & & & & & $7 / 22 / 80$ \\
\hline $50-12-07$ & $93^{\prime}$ & 277 & 4 & ${ }^{\mathrm{b}}$ Clean & & & & & $7 / 22 / 80$ \\
\hline $50-12-10$ & $120^{\prime}$ & 267 & 4 & ${ }^{6}$ Clean & & & & & $9 / 878$ \\
\hline
\end{tabular}

"Probe type:

$2=$ Red GM, least sensitive; reads highest level of gamma ray activity and therefore used in zone of high activity

$4=\mathrm{Nal}$, most sensitive, reads lowest level of gamma ray activity and therefore used in zones of limited activity

14 = Shielded Nal, moderate sensitivity, reads about ten times lower than the Nal probe

Caution must be used when relating GTP values in zones recorded with different probe types.

No systematic trend above the detection threshold for the gross gamma ray logs is indicated by the data.

'An irregular change in the intensity of gross gamma rays between successive surveys at or near the surface suggests that contamination may be the result of tank farm activities or logging procedure changes and not vadose zone transport.

'Stability cannot be determined due to insufficient data, exceeding the system design criteria (both upper and lower limits) for recording gross gamma ray data, or possible effects of depth shift or surface activities.

"The decay rate of the isotope(s) identified in the zone matches the change in concentration of the isotope(s) as measured over time, and no noticeable deviation from the match is apparent within the period that gross gamma ray data were collected.

'The GTP for Unassigned Deviaiton has good precision, matches the isotope decay curve for the majority of the surveillance time interval, except for an unambiguous time interval in which the GTP rate of decrease does not match the isotope decay curve, and no time period exist in which the GTP was observed to increase. 
Currently, isotopes cannot be identified from gross gamma ray data alone; therefore, if the period of instability is prior to the collection of SGLS data, isotopes with a rapid rate of decay (e.g., Ru-106), or at levels that decay below detection limits, may not be identified. Also, beta-emitting isotopes such as Sr-90 cannot be directly detected by the SGLS. The presence of such isotopes is hypothesized.

'Stable vs. unstable is an apparent condition limited by the time interval over which data were collected and the level of contamination and is not a statement concerning the fixed or mobile nature of a given isotope.

\section{Subsurface Condition Categories}

Six subsurface categories were identified during the analysis of the historical dry well data. The six categories are clean, tank farm activity, undetermined, unassigned deviation, stable, and unstable. The category of unstable is further subdivided into 1) unstable, meaning changing other than decay at the end of data collection; and 2) unstable early, meaning stability was reached before the end of data collection.

\subsection{Clean}

A clean well is one that exhibits no observable change in the character of the activity over the logging history of the well, and does not have any isotopes identified by the SGLS greater than the average background levels of naturally occurring gamma ray emitting isotopes. Non-gamma emitting radionuclides or other contaminant species might be present but are not detected by either HPGe or gross gamma logging. Although spurious surveys (those readings that do not repeat over time) may exist in the frequency clean and the average background plots, the trend of the data is clear. Twenty two of 67 wells in the $T$ Tank Farm are considered clean (Figure 2) and are listed in Table 2. The remaining 45 wells are considered contaminated and are categorized and discussed in the following sections.

Table 2. T Tank Farm Clean Wells

\begin{tabular}{|c|c|c|}
\hline $\begin{array}{c}\text { Borehole } \\
\text { Number }\end{array}$ & $\begin{array}{c}\text { Survey } \\
\text { Depth } \\
\text { (feet) }\end{array}$ & Category \\
\hline $50-00-08$ & $144^{\prime}$ & Clean \\
\hline $50-00-10$ & $140^{\prime}$ & Clean \\
\hline $50-00-12$ & $1^{\prime}$ & Clean \\
\hline $50-01-02$ & $9^{\prime}$ & Clean \\
\hline $50-02-02$ & $8^{\prime}$ & Clean \\
\hline $50-02-10$ & $8^{\prime}$ & Clean \\
\hline $50-02-12$ & $90^{\prime}$ & Clean \\
\hline $50-03-01$ & $90^{\prime}$ & Clean \\
\hline $50-03-08$ & $90^{\prime}$ & Clean \\
\hline $50-03-10$ & $90^{\prime}$ & Clean \\
\hline $50-07-08$ & $89^{\prime}$ & Clean \\
\hline $50-08-05$ & $90^{\prime}$ & Clean \\
\hline $50-09-07$ & $90^{\prime}$ & Clean \\
\hline $50-10-05$ & $93^{\prime}$ & Clean \\
\hline $50-10-07$ & $91^{\prime}$ & Clean \\
\hline $50-10-08$ & $91^{\prime}$ & Clean \\
\hline $50-10-10$ & $9^{\prime}$ & Clean \\
\hline $50-11-05$ & $88^{\prime}$ & Clean \\
\hline $50-11-07$ & $9^{\prime}$ & Clean \\
\hline & & \\
\hline
\end{tabular}


RPP-6088, Rev. 0.

\begin{tabular}{|c|c|c|}
\hline $50-11-08$ & $93^{\prime}$ & Clean \\
\hline $50-11-10$ & $98^{\prime}$ & Clean \\
\hline $50-12-05$ & $98^{\prime}$ & Clean \\
\hline $50-12-07$ & $93^{\prime}$ & Clean \\
\hline $50-12-10$ & $120^{\prime}$ & Clean \\
\hline
\end{tabular}

\subsection{Contaminated}

Specific gamma-emitting isotopes that are in the subsurface are identified from data acquired by the SGLS. Integration of the decay rate of the radionuclide species identified by the SGLS with the gross gamma ray data collected during the dry well surveillance program provides insight as to the rate of change, if any, of radionuclides in the subsurface. During the analysis of T Tank Farm data, eight gamma-emitting isotopes were identified or hypothesized to have occurred in one or more radioactive contamination zones. They are cesium-137 (Cs-137), cobalt-60 (Co-60), europium-152 (Eu-152), europium-154 (Eu-154), strontium-90 (Sr-90), niobium-94 (Nb-94), antimony-125 (Sb-125), and ruthenium-106 (Ru-106). Cesium-137 was identified in 32 boreholes, often associated with other isotopes, although it is the sole gamma-emitting isotope in 22 wells.

Ruthenium-106 is not currently present above the detection threshold in any of the wells examined by the SGLS due to the very rapid exponential decay of Ru-106 over a short half-life of 1.02 years. Ruthenium-106 is hypothesized to have been present in 49 wells in 1975 on the basis of the gross gamma ray data and the resulting GTP calculations that mimic the decay rate of $\mathrm{Ru}-106$, coupled with the inventory list of radionuclides known to be in the tanks during that time. Ruthenium-106 is the sole isotope identified in 15 wells in the mid-1970s. Ruthenium-106 is assumed to be present if the decay curve for $\mathrm{Ru}-106$ matches the GTP plot. If a decay curve does not match, then the contaminants cannot be identified without additional information.

Cobalt-60 was identified by SGLS in 49 zones in T Tank Farm boreholes, mostly in combination with other isotopes. However, it is the sole isotope identified by SGLS in 11 zones.

Europium-152, Eu-154, and to a large extent $\mathrm{Nb}-94$, and $\mathrm{Sb}-125$ are present in a few zones in combination with other isotopes.

The isotopes identified in T Tank Farm with the SGLS exist primarily under four categories of subsurface conditions: tank farm activity, undetermined, stable, and unstable. Fifteen unstable conditions and twenty-four "unstable early" conditions are also present in T Tank Farm. Dry well locations (centered beneath the borehole name on the map) are labeled with the conditions of subsurface zones and are shown in Figure 2. A different condition can be indicated for each contaminated zone within a well that exhibits multiple zones of contamination.

\subsubsection{Tank Farm Activity}

A sudden, significant change in the intensity of gross gamma rays between successive gross gamma surveys at or near the ground surface suggests that contamination may have resulted from tank farm activities or logging procedure changes. Radioactive contamination occurs near 
RPP-6088, Rev. 0.

the surface in five wells, apparently as the result of tank farm activities (i.e., logging procedure changes, transfer line operations, valve box and conduit leaks, surface spills, etc.). These wells are listed in Table 3. 
RPP-6088, Rev. 0.

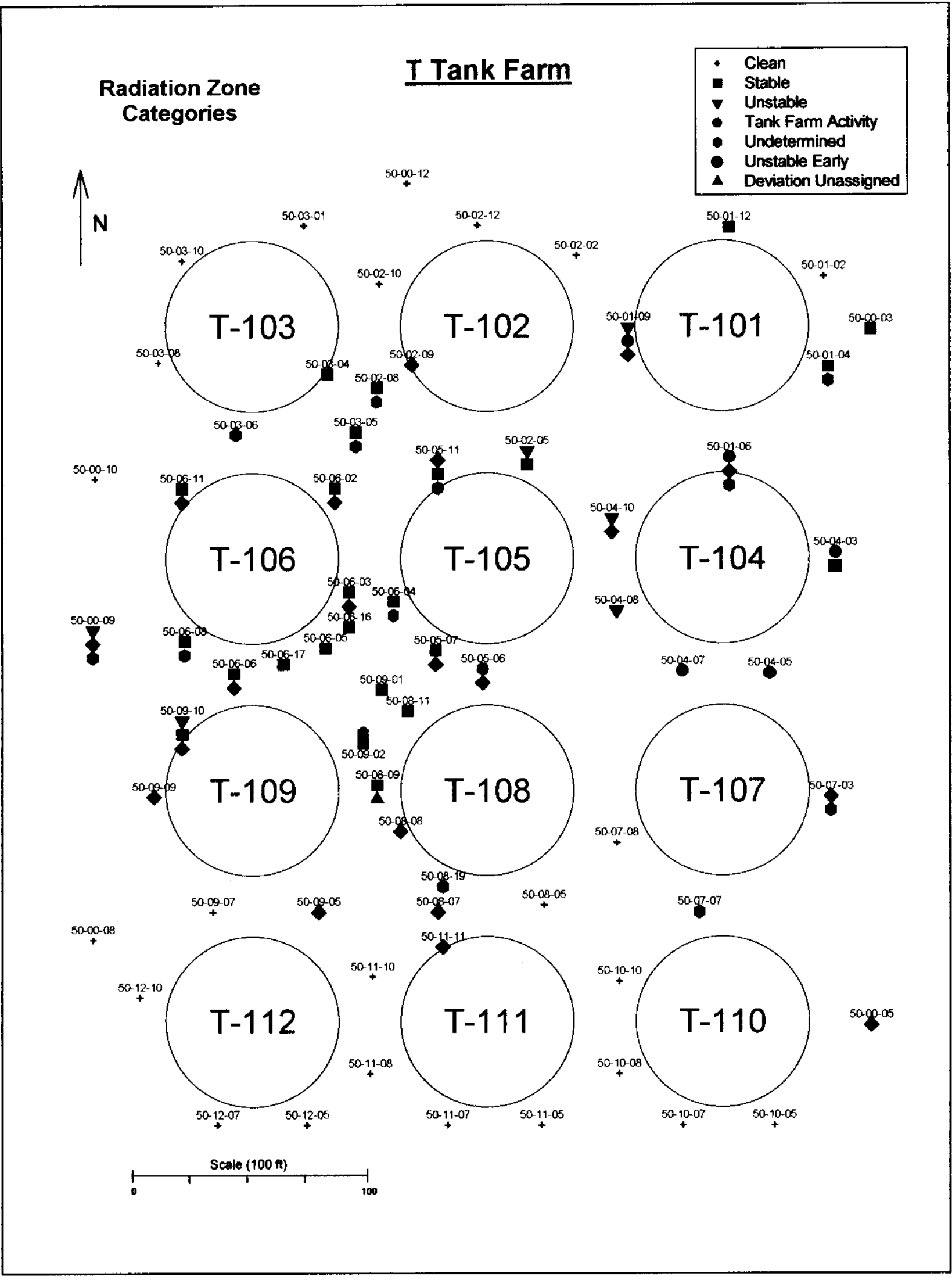

Figure 2. T Tank Farm Radiation Zone Categories 
RPP-6088, Rev. 0.

Table 3. T Tank Farm Activity Zones

\begin{tabular}{|c|c|c|c|c|c|c|}
\hline $\begin{array}{c}\text { Borehole } \\
\text { Number }\end{array}$ & $\begin{array}{c}\text { Survey } \\
\text { Depth } \\
\text { (feet) }\end{array}$ & Category & $\begin{array}{c}\text { Zone } \\
\text { Depth } \\
\text { (feet) }\end{array}$ & $\begin{array}{c}\text { Max } \\
\text { GTP } \\
\text { (ft x c/s) }\end{array}$ & $\begin{array}{c}\text { Year Max } \\
\text { GTP }\end{array}$ & $\begin{array}{c}\text { Isotope } \\
\text { Present }\end{array}$ \\
\hline $50-01-06$ & $90^{\prime}$ & TF Activity & $0-8$ & 800 & 1976 & $\mathrm{Cs}^{13 /}$ \\
\hline $50-01-09$ & $95^{\prime}$ & TF Activity & $0-12$ & $15 \mathrm{~K}$ & 1977 & $\mathrm{Cs}^{137}$ \\
\hline $50-04-03$ & $93^{\prime}$ & TF Activity & $0-12$ & $3 \mathrm{~K}$ & 1985 & $\mathrm{Cs}^{13 /}$ \\
\hline $50-04-05$ & $90^{\prime}$ & TF Activity & $0-10$ & 250 & 1985 & $\mathrm{Cs}^{13 /}$ \\
\hline $50-04-07$ & $100^{\prime}$ & TF Activity & $0-28$ & $7 \mathrm{~K}$ & 1975 & $\mathrm{Cs}^{137}$ \\
\hline
\end{tabular}

\subsubsection{Undetermined}

Infrequently, stability cannot be determined due to: gross gamma energy levels exceeding the system design criteria (both upper and lower limits), insufficient data, possible effects of depth shift, and surface activities. Seventeen zones out of the 67 wells examined are undetermined and one unassigned deviation zone: These zones are listed in Table 4.

Table 4. T Tank Farm Undetermined and Unassigned Deviation Zones

\begin{tabular}{|l|c|c|c|c|c|c|l|}
\hline $\begin{array}{c}\text { Borehole } \\
\text { Number }\end{array}$ & $\begin{array}{c}\text { Survey } \\
\text { Depth } \\
\text { (feet) }\end{array}$ & $\begin{array}{c}\text { Probe } \\
\text { Type }\end{array}$ & Category & $\begin{array}{c}\text { Zone } \\
\text { Depth } \\
\text { (feet) }\end{array}$ & $\begin{array}{c}\text { Max } \\
\text { GTP } \\
\text { (ft x c/s) }\end{array}$ & $\begin{array}{c}\text { Year Max } \\
\text { GTP }\end{array}$ & $\begin{array}{c}\text { Isotopes } \\
\text { Present }\end{array}$ \\
\hline $50-08-09$ & $120^{\prime}$ & 4 & $\begin{array}{c}\text { Unassigned } \\
\text { Deviation }\end{array}$ & $58-92$ & $55 \mathrm{~K}$ & 1980 & $\mathrm{Co}^{60} ; \mathrm{Ru}^{106}$ \\
\hline $50-00-09$ & $120^{\prime}$ & 4 & Undetermined & $100-120$ & $6 \mathrm{~K}$ & 1979 & $\mathrm{Co}^{60} ; \mathrm{Ru}^{100}$ \\
\hline $50-01-04$ & $125^{\prime}$ & 2 & Undetermined & $75-90$ & 150 & 1977 & $\mathrm{Cs}^{13 i^{\prime}}$ \\
\hline $50-01-06$ & $90^{\prime}$ & 4 & Undetermined & $69-78$ & 1100 & 1987 & $\mathrm{Co}^{60}$ \\
\hline $50-01-06$ & $90^{\prime}$ & 4 & Undetermined & $78-90$ & 1000 & 1990 & $\mathrm{Co}^{60}$ \\
\hline $50-02-08$ & $100^{\prime}$ & 4 & Undetermined & $78-85$ & 400 & 1975 & $\mathrm{Ru}^{106}$ \\
\hline $50-03-05$ & $120^{\prime}$ & 4 & Undetermined & $52-65$ & $7 \mathrm{~K}$ & 1975 & $\mathrm{Eu}^{154} ; \mathrm{Ru}^{106}$ \\
\hline $50-03-05$ & $120^{\prime}$ & 4 & Undetermined & $65-72$ & 300 & 1975 & $\mathrm{Ru}^{105}$ \\
\hline $50-03-06$ & $125^{\prime}$ & 4 & Undetermined & $50-98$ & $9 \mathrm{~K}$ & 1975 & $\mathrm{Eu}^{154} ; \mathrm{Co}^{60} ; \mathrm{Ru}^{105}$ \\
\hline $50-05-06$ & $120^{\prime}$ & 4 & Undetermined & $0-20$ & 300 & 1975 & $\mathrm{Cs}^{137}$ \\
\hline $50-05-11$ & $125^{\prime}$ & 4 & Undetermined & $50-60$ & 100 & 1977 & $\mathrm{Ru}^{106}$ \\
\hline $50-06-04$ & $95^{\prime}$ & 2 & Undetermined & $42-66$ & $15 \mathrm{~K}$ & 1975 & $\mathrm{Ru}^{106}$ \\
\hline $50-06-04$ & $95^{\prime}$ & 2 & Undetermined & $66-90$ & $5 \mathrm{~K}$ & 1976 & $\mathrm{Ru}^{106}$ \\
\hline $50-06-08$ & $120^{\prime}$ & 14 & Undetermined & $89-120$ & $15 \mathrm{~K}$ & 1976 & $\mathrm{Cs}^{137} ; \mathrm{Ru}^{106}$ \\
\hline $50-07-03$ & $89^{\prime}$ & 4 & Undetermined & $0-20$ & 120 & 1975 & $\mathrm{Cs}^{13 i} ; \mathrm{Co}^{60}$ \\
\hline $50-07-07$ & $90^{\prime}$ & 4 & Undetermined & $36-48$ & 230 & 1975 & $\mathrm{Cs}^{137}$ \\
\hline $50-08-19$ & $90^{\prime}$ & 4 & Undetermined & $60-90$ & $45 \mathrm{~K}$ & 1979 & $\mathrm{Co}^{60} ; \mathrm{Ru}^{106}$ \\
\hline $50-09-02$ & $90^{\prime}$ & 4 & Undetermined & $0-10$ & 100 & 1985 & $\mathrm{Cs}^{13 i}$ \\
\hline
\end{tabular}

\subsubsection{Stable}

The subsurface condition of a zone with radioactive contamination is considered stable when: 
- The decay rate of the isotope(s) identified with SGLS matches the trend observed in the GTP of the gross gamma ray data

- Contaminants continue to decay at a rate consistent with the hypothesized isotope(s) halflife

- No noticeable change in concentration is apparent over the short time interval that data were collected.

Forty one zones are considered stable in T Tank Farm and these zones are listed in Table 5.

Table 5. T Tank Farm Stable Zones

\begin{tabular}{|c|c|c|c|c|c|c|c|}
\hline $\begin{array}{l}\text { Borehole } \\
\text { Number }\end{array}$ & $\begin{array}{l}\text { Survey } \\
\text { Depth } \\
\text { (feet) }\end{array}$ & $\begin{array}{c}\text { Probe } \\
\text { Type }\end{array}$ & Category & $\begin{array}{l}\text { Zone } \\
\text { Depth } \\
\text { (feet) }\end{array}$ & $\begin{array}{c}\operatorname{Max} \\
\text { GTP } \\
(f \mathbb{f} \times \mathrm{C} / \mathrm{s})\end{array}$ & $\begin{array}{c}\text { Year Max } \\
\text { GTP }\end{array}$ & $\begin{array}{l}\text { Isotopes } \\
\text { Present }\end{array}$ \\
\hline $50-00-03$ & $140^{\prime}$ & 4 & Stable & $50-60$ & 300 & 1975 & $\mathrm{Ru}^{\mathrm{T}}$ \\
\hline $50-01-04$ & $125^{\prime}$ & 2 & Stable & $15-40$ & $150 \mathrm{~K}$ & 1977 & $\mathrm{Cs}^{137}$ \\
\hline $50-01-04$ & $125^{\prime}$ & 2 & Stable & $40-55$ & $5.5 \mathrm{~K}$ & 1977 & $\mathrm{Cs}^{73}$ \\
\hline $50-01-04$ & $125^{\prime}$ & 2 & Stable & $55-70$ & $2.5 K$ & 1977 & $\mathrm{Cs}^{13}$ \\
\hline $50-01-12$ & $93^{\prime}$ & 4 & Stable & $30-40$ & 500 & 1975 & $\mathrm{Co}^{80 ;} \mathrm{Ru}^{106}$ \\
\hline $50-02-05$ & $85^{\prime}$ & 4 & Stable & $30-45$ & $40 \mathrm{~K}$ & 1980 & $\mathrm{Cs}^{13 i}$ \\
\hline $50-02-08$ & $100^{\prime}$ & 4 & Stable & $32-50$ & $80 \mathrm{~K}$ & 1975 & $\mathrm{Eu}^{154} ; \mathrm{Co}^{60} ; \mathrm{Ru}^{106}$ \\
\hline $50-02-08$ & $100^{\prime}$ & 4 & Stable & $50-56$ & 450 & 1975 & $\mathrm{Ru}^{106}$ \\
\hline $50-02-08$ & $100^{\prime}$ & 4 & Stable & $60-72$ & 1100 & 1975 & $\mathrm{Ru}^{706}$ \\
\hline 50-03-04 & $125^{\prime}$ & 4 & Stable & $12-52$ & $520 \mathrm{~K}$ & 1975 & $\mathrm{Eu}^{754} ; \mathrm{Co}^{60} ; \mathrm{Ru}^{106}$ \\
\hline 50-03-04 & $125^{\prime}$ & 4 & Stable & $52-60$ & 350 & 1975 & $\mathrm{Ru}^{906}$ \\
\hline $50-03-04$ & $125^{\prime}$ & 4 & Stable & $60-75$ & 300 & 1981 & $\mathrm{Co}^{60} ; \mathrm{Sb}^{125}$ \\
\hline $50-03-04$ & $125^{\prime}$ & 4 & Stable & $75-90$ & 1000 & 1975 & $\mathrm{Eu}^{154} ; \mathrm{Co}^{60}$ \\
\hline $50-03-05$ & $120^{\prime}$ & 4 & Stable & $32-52$ & $60 \mathrm{~K}$ & 1975 & $\mathrm{Ru}^{106}$ \\
\hline 50-03-05 & $120^{\prime}$ & 4 & Stable & $75-90$ & 600 & 1975 & $\mathrm{Eu}^{154} ;^{*} \mathrm{Ru}^{106}$ \\
\hline $50-04-03$ & $93^{\prime}$ & 4 & Stable & $18-30$ & 100 & 1975 & $\mathrm{Cs}^{137}$ \\
\hline 50-05-07 & $85^{\prime}$ & 4 & Stable & 4-18 & 300 & 1976 & $\mathrm{Ru}^{106}$ \\
\hline $50-05-11$ & $125^{\prime}$ & 4 & Stable & $92-106$ & 200 & 1982 & $\mathrm{Co}^{60}$ \\
\hline 50-06-02 & $125^{\prime}$ & 2 & Stable & $38-100$ & $6 \mathrm{~K}$ & 1975 & $\mathrm{Eu}^{154} ; \mathrm{Co}^{60} ; \mathrm{Ru}^{106}$ \\
\hline $50-06-03$ & $120^{\prime}$ & 4 & Stable & $16-24$ & 200 & 1975 & $\mathrm{Cs}^{131}$ \\
\hline $50-06-04$ & $95^{\prime}$ & 2 & Stable & $29-42$ & $2 K$ & 1975 & $\mathrm{Cs}^{13}$ \\
\hline $50-06-05$ & $120^{\prime}$ & 2 & Stable & $27-60$ & $45 K$ & 1975 & $\mathrm{Cs}^{13}$ \\
\hline $50-06-05$ & $120^{\prime}$ & 2 & Stable & $60-94$ & $3 K$ & 1975 & $\mathrm{Cs}^{13}$ \\
\hline $50-06-05$ & $120^{\circ}$ & 2 & Stable & 94-120 & 300 & 1975 & $\mathrm{Cs}^{137}$ \\
\hline $50-06-06$ & $120^{\prime}$ & 14 & Stable & $110-120$ & $4 K$ & 1978 & $\mathrm{Ru}^{\mathrm{T}}$ \\
\hline $50-06-08$ & $120^{\prime}$ & 2 & Stable & $28-44$ & $2 K$ & 1975 & $\mathrm{Cs}^{137}$ \\
\hline $50-06-08$ & $120^{\prime}$ & 2 & Stable & 44-89 & $15 K$ & 1975 & $\mathrm{Cs}^{137} ; \mathrm{Co}^{60} ; \mathrm{Ru}^{100}$ \\
\hline $50-06-11$ & $85^{\prime}$ & 4 & Stable & $30-44$ & $140 \mathrm{~K}$ & 1976 & $\mathrm{Ru}^{106}$ \\
\hline $50-06-16$ & $90^{\prime}$ & 4 & Stable & $10-20$ & 1200 & 1976 & $\mathrm{Cs}^{137}$ \\
\hline $50-06-16$ & $90^{\prime}$ & 2 & Stable & $30-63$ & $6 K$ & 1976 & $\mathrm{Cs}^{13 /} ; \mathrm{Co}^{60} ; \mathrm{Ru}^{106}$ \\
\hline $50-06-16$ & $90^{\prime}$ & 2 & Stable & $63-90$ & $4 \mathrm{~K}$ & 1976 & $\mathrm{Eu}^{154} ; \mathrm{Co}^{60} ; \mathrm{Ru}^{100}$ \\
\hline $50-06-17$ & $85^{\prime}$ & 2 & Stable & $28-52$ & $10 \mathrm{~K}$ & 1975 & $\mathrm{Cs}^{137}$ \\
\hline $50-06-17$ & $85^{\prime}$ & 2 & Stable & $52-70$ & $8 K$ & 1975 & $\mathrm{Cs}^{137} ; \mathrm{Ru}^{106}$ \\
\hline 50-08-09 & $120^{\prime}$ & 4 & Stable & $92-116$ & 1100 & 1980 & $\mathrm{Co}^{60 ;} ; \mathrm{Ru}^{105}$ \\
\hline
\end{tabular}


RPP-6088, Rev. 0.

\begin{tabular}{|c|c|c|c|c|c|c|c|}
\hline $50-08-11$ & $140^{\prime}$ & 14 & Stable & $58-88$ & 500 & 1980 & $\mathrm{Co}^{60} ;{ }^{\circ} \mathrm{Ru}^{106}$ \\
\hline $50-08-11$ & $140^{\prime}$ & 14 & Stable & 96-106 & $100 \mathrm{~K}$ & 1980 & $\mathrm{Co}^{80} ; \mathrm{Ru}^{106}$ \\
\hline $50-09-01$ & $90^{\prime}$ & 14 & Stable & $0-8$ & 50 & 1980 & $\mathrm{Cs}^{13 i}$ \\
\hline 50-09-01 & $90^{\prime}$ & 14 & Stable & $44-58$ & $3.5 \mathrm{~K}$ & 1980 & $\mathrm{Co}^{80} ; \mathrm{Ru}^{\mathrm{TO6}}$ \\
\hline 50-09-01 & $90^{\prime}$ & 14 & Stable & $58-86$ & $120 \mathrm{~K}$ & 1980 & $\mathrm{Co}^{80} ; \mathrm{Ru}^{106}$ \\
\hline $50-09-02$ & $90^{\prime}$ & 4 & Stable & $58-86$ & $350 \mathrm{~K}$ & 1980 & $\mathrm{Co}^{80} ; \mathrm{Ru}^{108}$ \\
\hline $50-09-10$ & $120^{\prime}$ & 4 & Stable & 74-99 & $120 \mathrm{~K}$ & 1980 & $\mathrm{Co}^{80} ; \mathrm{Ru}^{106}$ \\
\hline
\end{tabular}

Presence of Ru-106 isotope is hypothesized. Isotope cannot be identified from gross gamma ray data alone; concentration was below detection levels when SGLS data collected due to rapid rate of decay.

The term "Stable" as determined for this analysis is defined for the apparent match of the decay to the isotopes known or hypothesized, and does not refer to the inherent condition of the contamination. The mobility of the radioactive contaminants in the subsurface soils before or after the gross gamma ray and SGLS data collection period is undetermined. If a new driver were introduced, such as the influx of a large volume of liquid, contaminants could be remobilized. Similarly, a change in geochemical conditions in the soil could also affect mobility. Given the current gross gamma and SGLS data, it cannot be determined if remobilization will or will not occur.

\subsubsection{Unstable}

The subsurface condition of a zone with radioactive contamination is considered unstable when, at some point within the time interval of data collection, contamination was not decreasing at the decay rate of the isotope(s) identified with SGLS. In this case, the decay curve does not match the trend observed in the GTP of the identified or hypothesized isotope. In the T Tank Farm, seven zones are identified which exhibited instability within the time period that gross gamma ray data were collected. In another 26 zones, instability occurs during the earlier years of data collection for certain depth intervals. A listing of unstable and "unstable early" zones is presented in Table 6.

Table 6. T Tank Farm Unstable and Unstable Early Zones

\begin{tabular}{|l|c|c|c|c|c|c|c|}
\hline $\begin{array}{c}\text { Borehole } \\
\text { Number }\end{array}$ & $\begin{array}{c}\text { Survey } \\
\text { Depth } \\
\text { (feet) }\end{array}$ & $\begin{array}{c}\text { Probe } \\
\text { Type }\end{array}$ & Category & $\begin{array}{c}\text { Zone } \\
\text { Depth } \\
\text { (feet) }\end{array}$ & $\begin{array}{c}\text { Max } \\
\text { GTP } \\
\text { (ft x c/s) }\end{array}$ & $\begin{array}{c}\text { Year Max } \\
\text { GTP }\end{array}$ & $\begin{array}{c}\text { Isotopes } \\
\text { Present }\end{array}$ \\
\hline $50-00-09$ & $120^{\prime}$ & 4 & Unstable & $62-94$ & $24 \mathrm{~K}$ & 1981 & $\mathrm{Co}^{60} ; \mathrm{Ru}^{106}$ \\
\hline $50-01-09$ & $95^{\prime}$ & 4 & Unstable & $32-45$ & 300 & 1977 & $\mathrm{Co}^{100}$ \\
\hline $50-02-05$ & $85^{\prime}$ & 4 & Unstable & $45-54$ & 100 & 1993 & $\mathrm{Co}^{60}$ \\
\hline $50-02-05$ & $85^{\prime}$ & 4 & Unstable & $54-70$ & 600 & 1981 & $\mathrm{Co}^{60}$ \\
\hline $50-04-08$ & $102^{\prime}$ & 4 & Unstable & $63-72$ & 350 & 1981 & $\mathrm{Co}^{60}$ \\
\hline $50-04-10$ & $90^{\prime}$ & 4 & Unstable & $62-71$ & 1000 & 1980 & $\mathrm{Co}^{60}$ \\
\hline $50-09-10$ & $120^{\prime}$ & 4 & Unstable & $99-115$ & $3.5 \mathrm{~K}$ & 1980 & $\mathrm{Co}^{60} ; \mathrm{Ru}^{106}$ \\
\hline $50-00-05$ & $140^{\prime}$ & 4 & Unstable Early & $28-50$ & 1000 & 1975 & $\mathrm{Co}^{60} ; \mathrm{Ru}^{106}$ \\
\hline $50-00-09$ & $120^{\prime}$ & 4 & Unstable Early & $40-59$ & $350 \mathrm{~K}$ & 1979 & $\mathrm{Eu}^{154} ; \mathrm{Co}^{60} ; \mathrm{Ru}^{106}$ \\
\hline $50-01-06$ & $90^{\prime}$ & 4 & Unstable Early & $45-69$ & $50 \mathrm{~K}$ & 1975 & $\mathrm{Co}^{60} ; \mathrm{Ru}^{105}$ \\
\hline $50-01-09$ & $95^{\prime}$ & 4 & Unstable Early & $12-28$ & $10 \mathrm{~K}$ & 1990 & $\mathrm{Cs}^{13 \prime}$ \\
\hline $50-02-09$ & $88^{\prime}$ & 4 & Unstable Early & $32-48$ & $4.4 \mathrm{~K}$ & 1975 & $\mathrm{Eu}^{154} ; \mathrm{Sb}^{120} ; \mathrm{Ru}^{106}$ \\
\hline
\end{tabular}


RPP-6088, Rev. 0.

\begin{tabular}{|c|c|c|c|c|c|c|c|}
\hline $50-04-10$ & $90^{\prime}$ & 4 & Unstable Early & $82-90$ & 100 & 1979 & $\mathrm{Co}^{80}$ \\
\hline 50-05-06 & $120^{\prime}$ & 4 & Unstable Early & $58-74$ & $14 \mathrm{~K}$ & 1978 & $\mathrm{Ru}^{106}$ \\
\hline $50-05-06$ & $120^{\prime}$ & 4 & Unstable Earty & $70-82$ & 3K & 1978 & $\mathrm{CO}^{60}$ \\
\hline 50-05-07 & $85^{\prime}$ & 4 & Unstable Early & $58-90$ & $190 \mathrm{~K}$ & 1976 & $\mathrm{Co}^{80}$ \\
\hline $50-05-11$ & $125^{\prime}$ & 4 & Unstable Early & $68-92$ & $4.5 \mathrm{~K}$ & 1976 & $\mathrm{Ru}^{1}$ \\
\hline $50-06-02$ & $125^{\prime}$ & 14 & Unstable Early & $100-124$ & $3.5 \mathrm{~K}$ & 1978 & $\mathrm{Ru}^{1}$ \\
\hline $50-06-03$ & $120^{\prime}$ & 2 & Unstable Early & $30-60$ & $10 \mathrm{~K}$ & 1975 & $\mathrm{Ru}^{106}$ \\
\hline $50-06-03$ & $120^{\prime}$ & 2 & Unstable Early & $60-98$ & $20 K$ & 1975 & $\mathrm{Ru}^{106}$ \\
\hline $50-06-03$ & $120^{\prime}$ & 14 & Unstable Earty & $98-120$ & $40 \mathrm{~K}$ & 1977 & $; \mathrm{CO}^{60} ; \mathrm{Ru}^{100}$ \\
\hline $50-06-06$ & $120^{\prime}$ & 2 & Unstable Early & $29-68$ & $35 K$ & 1975 & $\mathrm{Co}^{80} ; \mathrm{Ru}^{100}$ \\
\hline $50-06-06$ & $120^{\prime}$ & 2 & Unstable Earty & $68-110$ & $10 \mathrm{~K}$ & 1975 & $R u^{106}$ \\
\hline $50-06-11$ & $85^{\prime}$ & 4 & Unstable Early & $44-54$ & $12 \mathrm{~K}$ & 1976 & $\mathbf{R u}$ \\
\hline $50-07-03$ & $89^{\prime}$ & 4 & Unstable Early & $34-50$ & $3.3 \mathrm{~K}$ & 1976 & $\mathrm{Ru}^{106}$ \\
\hline $50-08-07$ & $120^{\prime}$ & 4 & Unstable Early & $64-76$ & $2.6 \mathrm{~K}$ & 1980 & $\mathrm{Co}^{60} ; \mathrm{Ru}^{106}$ \\
\hline $50-08-07$ & $120^{\prime}$ & 4 & Unstable Early & $76-95$ & $2.2 \mathrm{~K}$ & 1981 & $\mathrm{Co}^{60} ; \mathrm{Ru}^{106}$ \\
\hline $50-08-08$ & $100^{\prime}$ & 4 & Unstable Early & $60-72$ & 1100 & 1978 & $\mathrm{Co}^{60} ; \mathrm{Ru}^{106}$ \\
\hline $50-09-05$ & $90^{\prime}$ & 4 & Unstable Early & $68-86$ & 300 & 1983 & $\mathrm{Co}^{60} ; \mathrm{Ru}^{106}$ \\
\hline $50-09-09$ & $120^{\prime}$ & 4 & Unstable Early & $52-65$ & 500 & 1976 & $R u^{10}$ \\
\hline $50-09-10$ & $120^{\prime}$ & 4 & Unstable Early & $33-44$ & $2.3 \mathrm{~K}$ & 1980 & $\mathrm{Co}^{80} ; \mathrm{Ru}^{100}$ \\
\hline $50-09-10$ & $120^{\prime}$ & 4 & Unstable Early & 44-74 & $120 \mathrm{~K}$ & 1980 & $\mathrm{CO}^{80} ; \mathrm{Ru}^{106}$ \\
\hline $50-11-11$ & $90^{\prime}$ & 4 & Unstable Early & 64-74 & $1.8 \mathrm{~K}$ & 1980 & $\mathrm{Co}^{6}$ \\
\hline
\end{tabular}

\section{Details of Contaminated Conditions}

Characteristics of the contaminated zones are summarized in the following discussions.

\subsection{Stable Zones}

Several zones within a number of wells exhibit gross gamma ray activity above natural background. Many of these radioactive intervals are observed to be stable as verified by the change in GTP over time which coincides with the decay rate of the isotope(s) identified or hypothesized to have been present in the soil surrounding the dry well during the time interval data were collected. The isotopes present in these stable zones vary and are presented above in Table 5. In general, they occur as follows:

- Cs-137 is present in 32 (of 97) contamination zones, sometimes with other isotopes. Cs137 is present in 16 of the stable zones.

- Co-60 is present in 50 zones, mostly with other isotopes. It is the sole isotope identified in 11 of the 50 zones. Seventeen of the stable zones contain Co- 60 .

- Ru-106 is hypothesized to have existed early in the history of sixty zones, usually with other isotopes. However, it is the sole identified isotope in 16 zones. Twenty five of the stable zones are hypothesized to contain Ru-106.

- Eu-154 is present in 12 contamination zones, usually with Co-60 and Ru-106. Seven stable zones contain Eu-154. 
RPP-6088, Rev. 0.

- Eu-152 is present, but at much lower concentrations than Eu-154 for the T tank farm.

The fixed decay rate of the isotope(s) present is used to calculate the decay line (Figure 3). Table 7 lists the half-life of the isotopes encountered in the T Tank Farm.

When a contaminated interval contains multiple isotopes, the intensity of the slowest decay component is plotted to match the data over the most recent time period for which data exist. Faster decay isotopes are then clearly indicated as necessary to match the trend of the GTP values. When the decay curve fits the GTP plot, a stable condition is said to exist. When the decay curve does not fit any portion of the GTP plot, stability cannot be established. The factors responsible for this instability are beyond the scope of this report.

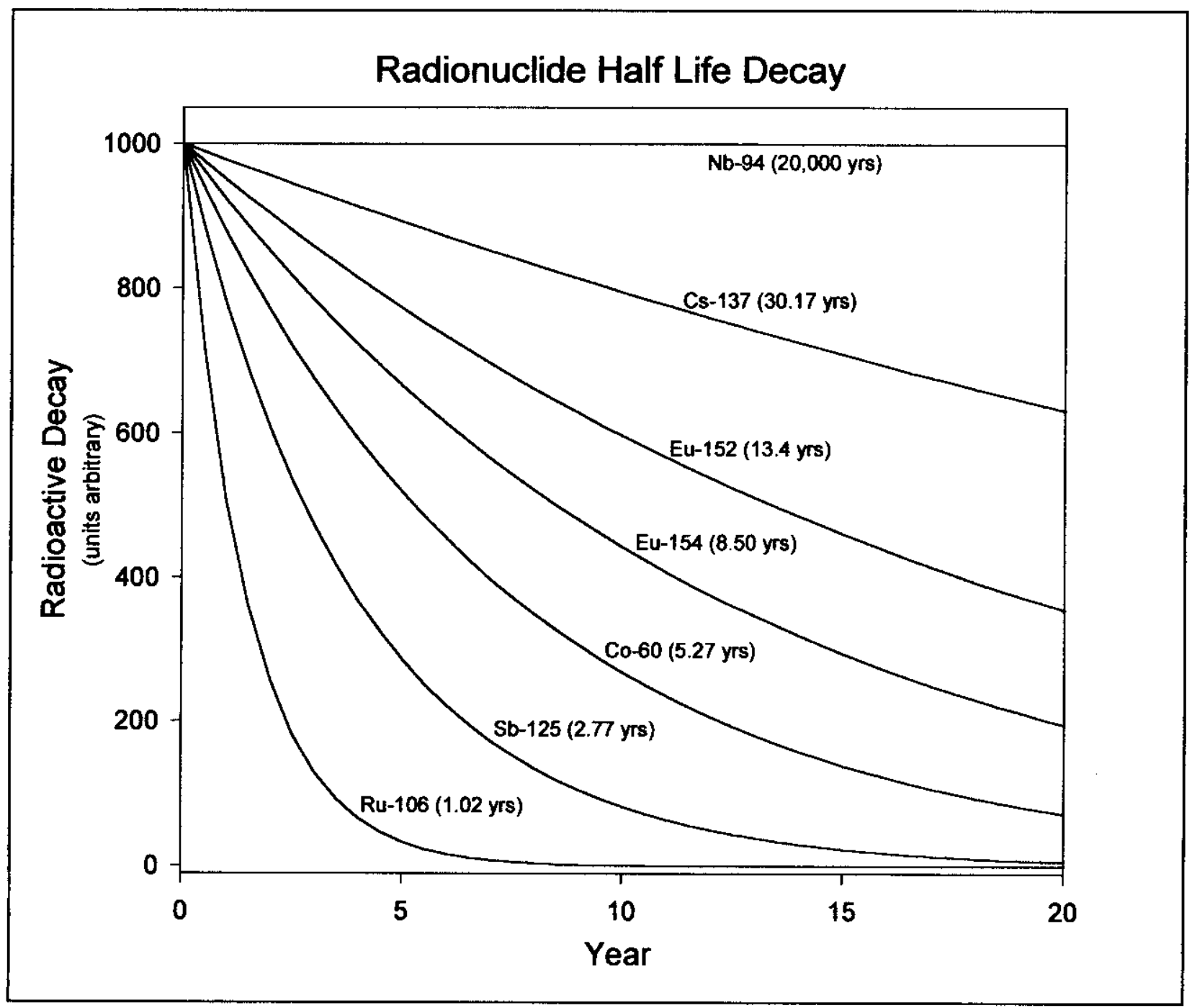

Figure 3. Radionuclide Half-life Decay Rates 
RPP-6088, Rev. 0.

Table 7. Half-life of Isotopes Identified in the T Tank Farm Boreholes

\begin{tabular}{|c|c|}
\hline Isotope & Half Life (yrs) \\
\hline Ru-106 & 1.02 \\
\hline Sb-125 & 2.77 \\
\hline Co-60 & 5.27 \\
\hline Eu-154 & 8.50 \\
\hline Eu-152 & 13.40 \\
\hline Cs-137 & 30.17 \\
\hline Nb-94 & 20,000 \\
\hline
\end{tabular}

\subsection{Depth of Contamination}

Most of the dry wells within the T Tank Farm show some contamination. Only 24 of 67 wells (35\%) are categorized as Clean. Another two wells show only surface contamination (categorized as Tank Farm Activity). Figures 4, 5, and 6 depict borehole locations (centered beneath the borehole name) and contaminant information. Figure 4 illustrates the depth to the top of contamination and the isotope(s) present at that depth. Figure 5 illustrates the depth to the bottom of contamination and the isotope(s) present at that depth. Figure 6 shows locations where GTP values are greater than $1,000 \mathrm{ft} * \mathrm{c} / \mathrm{s}$. Most contaminant zones range up to 20 feet thick, but 33 zones exceed $20 \mathrm{ft}$ thickness. The range is from $6(50-02-08$ and 50-06-05) to 62 feet (50-0602 ) in thickness. Not surprisingly, the thickest zones are common around the 241-T-106 Tank where the largest known leak from a SST occurred. Note on Figure 6 that several wells near the T-106 Tank were logged with the Red GM probe because of high levels of radiation that were too high to be adequately assessed by the NaI probe. Several boreholes (e.g., 50-01-04, 50-01-06, 50-02-08, 50-03-04, 50-03-05, 50-06-03) contain up to four distinct zones, with the same or different contaminants at different depths. Boreholes with multiple zones are common around the T-106 tank, with 25 of 97 total zones identified in boreholes surrounding this tank. Several boreholes exhibit contamination at or very close to the bottom of the borehole, with many of these surrounding the T-106 Tank.

The observable maximum depth of contamination (Figure 5) is dependent on the depth to which detectors penetrated the subsurface. Depth control issues related to logging make much of the data at the surface prior to 1983 unusable for evaluating contaminant conditions. Changes in background values in the 1970 s through the early 1980 s were common in many boreholes. Depth control issues inhibit the ability to identify any downward movement of contamination prior to 1983. However, where inconsistent depth control is not an issue, data analysis can identify movement of contamination by the changes in the gross gamma ray activity occurring at a rate that is faster than the decay rate of the isotope(s) present in the zone.

Downward migration of a peak over time in a borehole with good depth control also indicates contaminant transport. This can be seen in the stack plot for three boreholes:

- Borehole 50-00-09 shows contamination movement in the interval from 80 to 85 feet from 1981 to 1988.

- Borehole 50-04-10 shows redistribution between 70 and 75 feet from 1975 to 1987.

- Borehole 50-06-03 (probe type 14) shows contamination migration from 1980 to 1994 between 105 and 120 feet. 
RPP-6088, Rev. 0.

If contamination continues to move away from a well, whether downward or laterally, it is reasonable to assume that movement would continue in the same manner beyond the confines of the well, provided subsurface conditions have not changed. There is verifiable contamination at the bottom of several wells (e.g., 50-06-03, 50-06-05), most of which surround the T-106 Tank. In at least one well (50-08-08), the condition of Cs-137 and Ru-106 at the bottom of the dry well is undetermined, and there is not enough evidence to indicate if this contamination went deeper than the bottom of the well. During some logging operations prior to 1984 , there may have been a few to several seconds of delay between when the operator activated the detector and when the hoist was activated. Such an occurrence increases the counting time at the bottom of the hole and leads to artificially high counts that do not reflect actual conditions.

Boreholes that have high contaminant levels below the surface may indicate proximity to infiltration or a leak event. Figure 6 depicts zones where the GTP is greater than $1,000 \mathrm{ft} * \mathrm{c} / \mathrm{s}$. GTP exceeds 1,000 in 66 zones, with values ranging as high as 520,000 for the NaI detector (40,000 for the Red GM detector and 150,000 for the shielded NaI detector). Caution must be used when relating GTP values in zones recorded with different probe types (Randall 1999) since they were designed to read different intensities of contamination. GTP values for the shielded $\mathrm{NaI}$ probe and for the Red $\mathrm{Gm}$ are reported for four wells (50-06-02, 50-06-03, 50-06-06, and 50-06-08, respectively). These values are lower than those reported for the unshielded NaI probe because of different detection efficiencies. The shielded NaI and Red GM probes are used where the activity levels in the soil are high and would saturate the unshielded NaI probe. In addition, the GTP values for intervals of different thickness are not directly comparable. Since GTP incorporates both the depth interval and the intensity of gross gamma ray activity, possible differences in interval thickness must be accounted for before comparing the GTP values between intervals. The distribution of GTP values with depth range (in order of depth range) and contributing isotope(s) is shown in Table 8. 


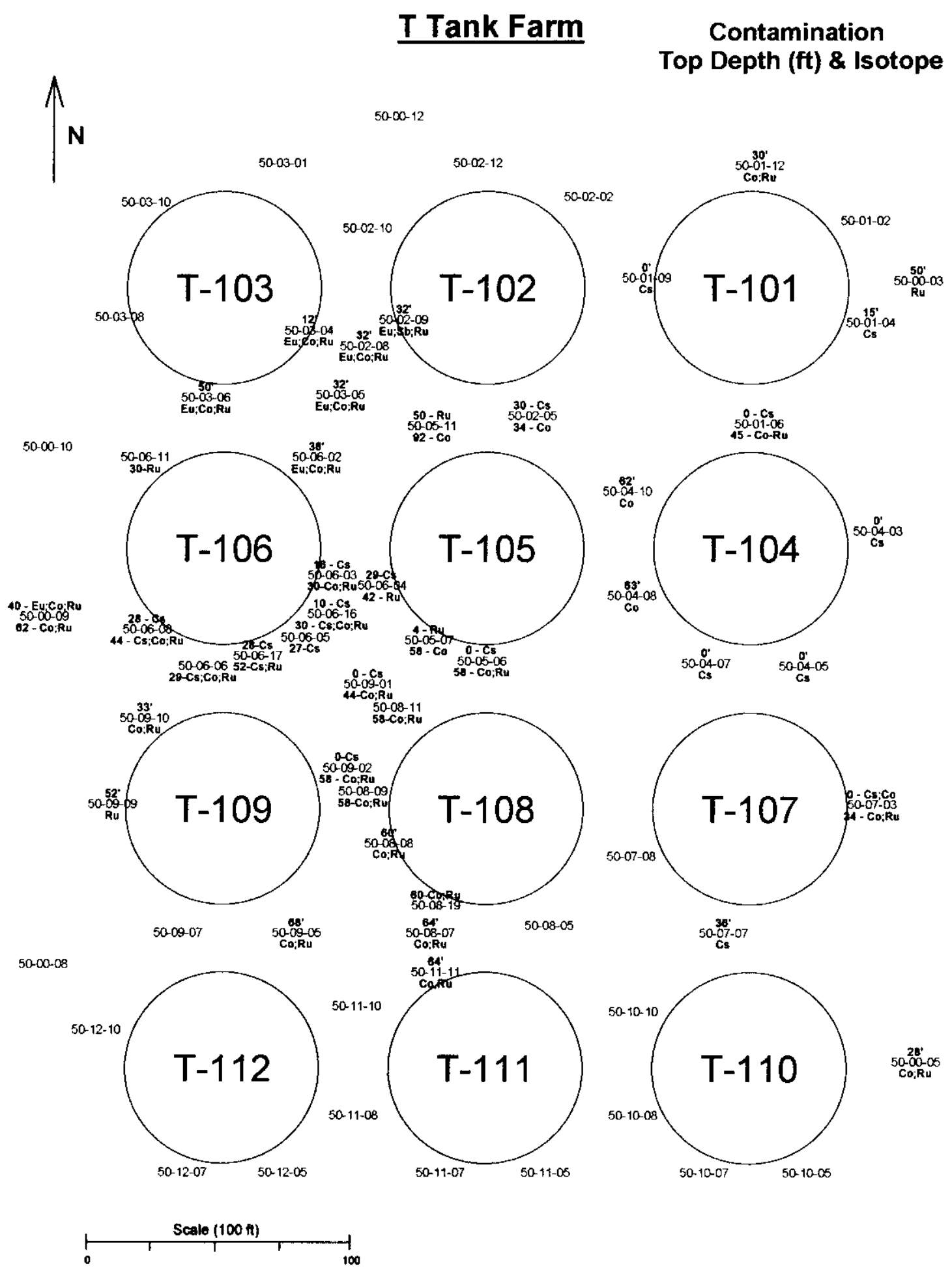

Figure 4. T Tank Farm Top of Contamination 
RPP-6088, Rev. 0.

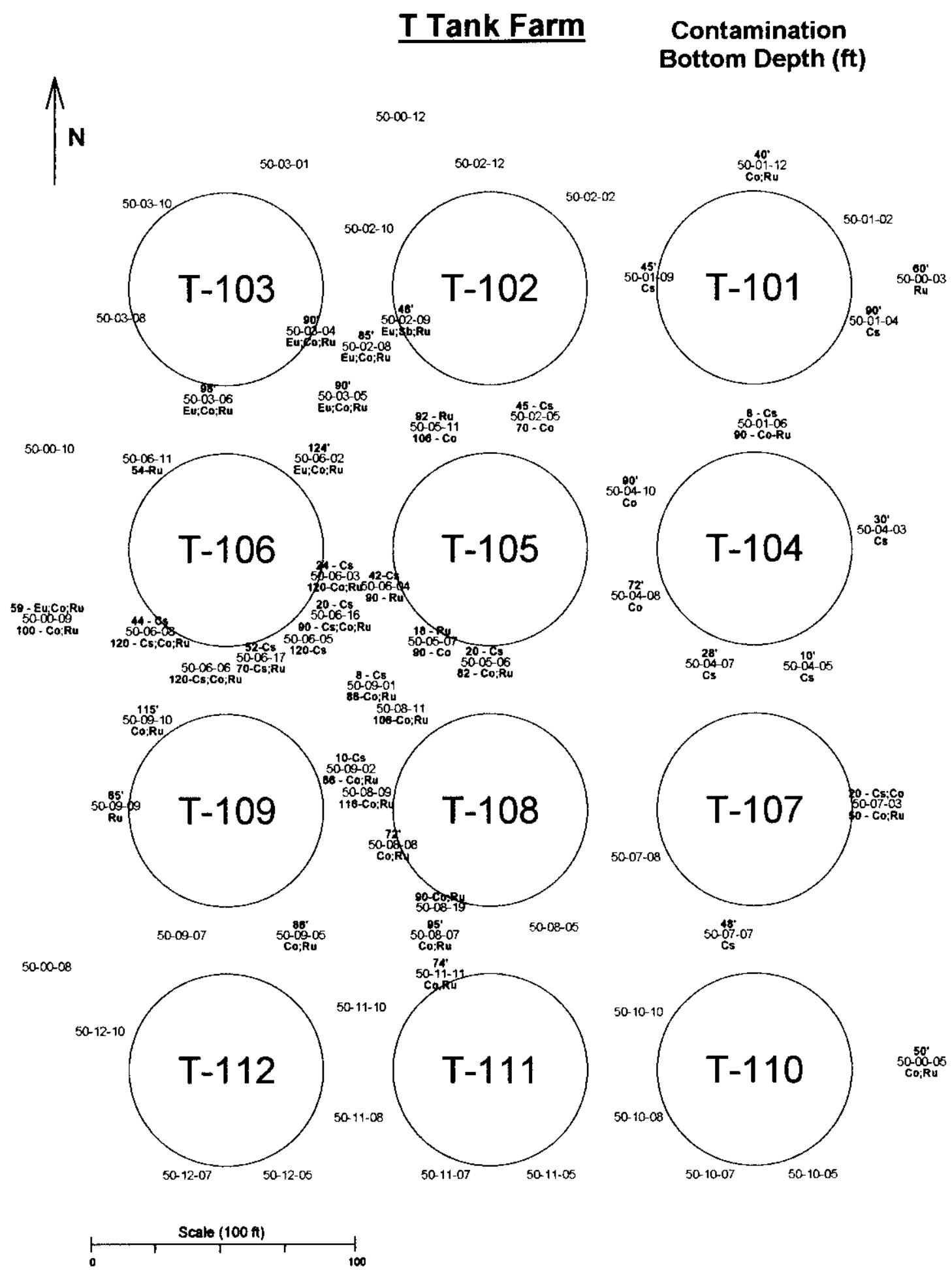

Figure 5. T Tank Farm Observable Bottom of Contamination 


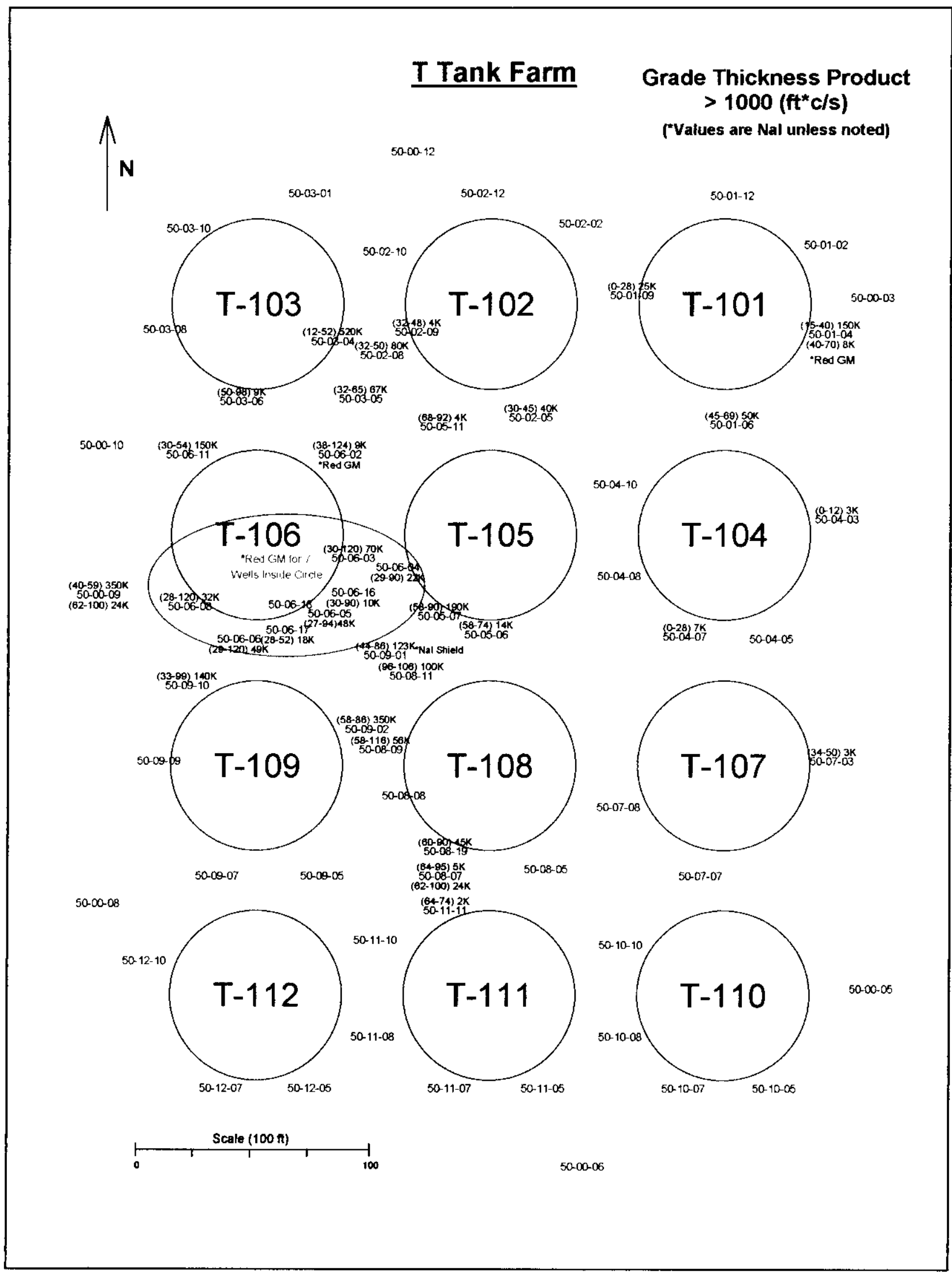

Figure 6. T Tank Farm Grade Thickness Product Greater Than $1,000 \mathrm{ft}^{\star} \mathrm{c} / \mathrm{s}$ 
RPP-6088, Rev. 0.

Table 8. T Farm Max GTP

\begin{tabular}{|c|c|c|c|c|c|c|}
\hline Borehole & $\begin{array}{l}\text { Survey } \\
\text { Depth }\end{array}$ & $\begin{array}{c}\text { Probe } \\
\text { Type }\end{array}$ & $\begin{array}{c}\text { Zone } \\
\text { Depth (ft.) }\end{array}$ & $\begin{array}{l}\text { Max. GTP } \\
(\mathrm{ft} \times \mathrm{c} / \mathrm{s})\end{array}$ & $\begin{array}{c}\text { Year } \\
\text { Max GTP }\end{array}$ & $\begin{array}{l}\text { Isotopes } \\
\text { Present }\end{array}$ \\
\hline $50-00-05$ & 140 & 4 & $28-50$ & 1,000 & 1975 & Co-60, Ru-106 \\
\hline \multirow[t]{3}{*}{$50-00-09$} & 120 & 4 & $40-59$ & 350,000 & 1979 & Eu-154, Co-60, Ru-106 \\
\hline & & & $62-94$ & 24,000 & 1981 & Co-60, Ru-106 \\
\hline & & & $100-120$ & 6,000 & 1979 & Co-60, Ru-106 \\
\hline \multirow[t]{3}{*}{$50-01-04$} & 125 & 2 & $15-40$ & 150,000 & 1977 & Cs-137 \\
\hline & & & $40-55$ & 5,000 & 1977 & Cs-137 \\
\hline & & & $55-70$ & 2,500 & 1977 & Cs-137 \\
\hline \multirow[t]{3}{*}{$50-01-06$} & 90 & 4 & $45-69$ & 50,000 & 1975 & Co-60, Ru-106 \\
\hline & & & $69-78$ & 1,100 & 1987 & Co-60 \\
\hline & & & $78-90$ & 1,000 & 1990 & Co-60, \\
\hline \multirow[t]{2}{*}{$50-01-09$} & 95 & 4 & $0-12$ & 15,000 & 1977 & Cs-137 \\
\hline & & & $12-28$ & 10,000 & 1990 & Cs-137 \\
\hline $50-02-05$ & 85 & 4 & $30-45$ & 40,000 & 1980 & Cs-137 \\
\hline \multirow[t]{2}{*}{$50-02-08$} & 100 & 4 & $32-50$ & 80,000 & 1975 & Eu-154, Co-60, Ru-106 \\
\hline & & & $60-72$ & 1,100 & 1975 & Ru-106 \\
\hline $50-02-09$ & 88 & 4 & $32-48$ & 4,400 & 1975 & Eu-154, Sb-125, Ru-106 \\
\hline \multirow[t]{2}{*}{$50-03-04$} & 125 & 4 & $12-52$ & 520,000 & 1975 & Eu-154, Co-60, Ru-106 \\
\hline & & & $75-90$ & 1,000 & 1975 & Eu-154, Co-60, Ru-106 \\
\hline \multirow[t]{2}{*}{ 50-03-05 } & 120 & 4 & $32-52$ & 60,000 & 1975 & Eu-154, Co-60, Ru-106 \\
\hline & & & $52-65$ & 7,000 & 1975 & Eu-154, Ru-106 \\
\hline 50-03-06 & 125 & 4 & $50-98$ & 9,000 & 1975 & Eu-154, Co-60, Ru-106 \\
\hline $50-04-03$ & 93 & 4 & $0-12$ & 3,000 & 1985 & Cs-137 \\
\hline $50-04-07$ & 100 & 4 & $0-28$ & 7,000 & 1975 & Cs-137 \\
\hline $50-04-10$ & 90 & 4 & $62-71$ & 1,000 & 1980 & Co-60 \\
\hline \multirow[t]{2}{*}{$50-05-06$} & 120 & 4 & $58-74$ & 14,000 & 1978 & Ru-106 \\
\hline & & & $70-82$ & 3,000 & 1978 & Co-60 \\
\hline $50-05-07$ & 85 & 4 & $58-90$ & 190,000 & 1976 & Co-60 \\
\hline $50-05-11$ & 125 & 4 & $68-92$ & 4,500 & 1976 & Ru-106 \\
\hline \multirow[t]{2}{*}{$50-06-02$} & 125 & 14 & $38-100$ & 6,000 & 1975 & Eu-154, Co-60, Ru-106 \\
\hline & & & $100-124$ & 3,500 & 1978 & $R u-106$ \\
\hline \multirow[t]{3}{*}{$50-06-03$} & 120 & 2 & $30-60$ & 10,000 & 1975 & Co-60, Ru-106 \\
\hline & & 2 & $60-98$ & 20,000 & 1975 & Co-60, Ru-106 \\
\hline & & 14 & $98-120$ & 40,000 & 1977 & Eu-154, Co-60, Ru-106 \\
\hline \multirow[t]{3}{*}{$50-06-04$} & 94 & 2 & $29-42$ & 2,000 & 1975 & Cs-137 \\
\hline & & & $42-66$ & 15,000 & 1975 & Ru-106 \\
\hline & & & $66-90$ & 5,000 & 1976 & Ru-106 \\
\hline \multirow[t]{2}{*}{ 50-06-05 } & 120 & 2 & $27-60$ & 45,000 & 1975 & Cs-137 \\
\hline & & & $60-94$ & 3,000 & 1975 & Cs-137 \\
\hline \multirow[t]{3}{*}{ 50-06-06 } & 120 & 2 & $29-68$ & 35,000 & 1975 & Cs-137, Co-60, Ru-106 \\
\hline & & & $68-110$ & 10,000 & 1975 & Cs-137, Ru-106 \\
\hline & & 14 & $110-120$ & 4,000 & 1978 & Cs-137, Ru-106 \\
\hline \multirow[t]{2}{*}{$50-06-08$} & 120 & 2 & $28-44$ & 2,000 & 1975 & Cs-137 \\
\hline & & & $44-89$ & 15,000 & 1975 & Cs-137, Co-60, Ru-106 \\
\hline
\end{tabular}




\begin{tabular}{|l|l|l|l|l|l|l|}
\hline & & 14 & $89-120$ & 15,000 & 1976 & Cs-137, Ru-106 \\
\hline $50-06-11$ & 85 & 4 & $30-44$ & 140,000 & 1976 & Ru-106 \\
\hline & & & $44-54$ & 12,000 & 1976 & Ru-106 \\
\hline $50-06-16$ & 90 & 4 & $10-20$ & 1,200 & 1976 & Cs-137 \\
\hline & & 2 & $30-63$ & 6,000 & 1976 & Cs-137, Co-60, Ru-106 \\
\hline & & & $63-90$ & 4,000 & 1976 & Eu-154, Co-60, Ru-106 \\
\hline $50-06-17$ & 85 & 2 & $28-52$ & 10,000 & 1975 & Cs-137 \\
\hline & & & $52-70$ & 8,000 & 1975 & Cs-137, Ru-106 \\
\hline $50-07-03$ & 89 & 4 & $34-50$ & 3,300 & 1976 & Co-60, Ru-106 \\
\hline $50-08-07$ & 120 & 4 & $64-76$ & 2,600 & 1980 & Co-60, Ru-106 \\
\hline & & & $76-95$ & 2,200 & 1981 & Co-60, Ru-106 \\
\hline $50-08-08$ & 100 & 4 & $60-72$ & 1,100 & 1978 & Co-60, Ru-106 \\
\hline $50-08-09$ & 120 & 4 & $58-92$ & 55,000 & 1980 & Co-60, Ru-106 \\
\hline & & & $92-116$ & 1,100 & 1980 & Co-60, Ru-106 \\
\hline $50-08-11$ & 140 & 14 & $96-106$ & 100,000 & 1980 & Co-60, Ru-106 \\
\hline $50-08-19$ & 90 & 4 & $60-90$ & 45,000 & 1979 & Co-60, Ru-106 \\
\hline $50-09-01$ & 90 & 14 & $44-58$ & 3,500 & 1980 & Co-60, Ru-106 \\
\hline & & & $58-86$ & 120,000 & 1980 & Co-60, Ru-106 \\
\hline $50-09-02$ & 90 & 4 & $58-86$ & 350,000 & 1980 & Co-60, Ru-106 \\
\hline $50-09-10$ & 86 & 4 & $33-44$ & 2,300 & 1980 & Co-60, Ru-106 \\
\hline & & & $44-74$ & 120,000 & 1980 & Co-60, Ru-106 \\
\hline & & & $74-99$ & 120,000 & 1980 & Co-60, Ru-106 \\
\hline & & & $99-115$ & 3,500 & 1980 & Co-60, Ru-106 \\
\hline $50-11-11$ & 90 & 4 & $64-74$ & 1,800 & 1980 & Co-60, Ru-106 \\
\hline & & & & & & \\
\hline
\end{tabular}

\subsection{Isotopes Identified}

Seven man-made isotopes are known to be, or hypothesized to have been present, in the T Tank Farm at or above the detection limit based on the HPGe and gross gamma ray log analysis. They are listed in Table 7 along with their half-life. Although no longer detectable, Ru-106 is the most common isotope found in the T Tank Farm and it occurred in 59 zones in the farm at varying depths and intensities. It most often is found with other isotopes, most notably Co-60 and Eu154; however, it was the sole isotope identified in 14 zones. The half-life of Ru-106 is short (1.02 years) and it is no longer detectable by the HPGe detector (HPGe surveys were performed in the mid-1990s). However, it is an isotope known to be in the tank waste inventory at the time when early logging was conducted, and the decay line calculated for Ru-106 matches well with the GTP calculations in the wells where it occurs. Cobalt-60 is the next most common isotope, having been identified in 49 zones. Although it was the sole isotope identified in 11 zones, Co60 occurs most often with other isotopes, most notably Ru-106 and Eu-154. Cesium-137 was detected in 30 zones, being the sole isotope identified in 19 zones. Europium-154 was detected in 11 zones, and always was identified with other isotopes-most notably Co-60 and Ru-106. Europium-152 was detected in a few zones by HPGe data, but is not separately identified by the gross gamma ray log in Table 1. Antimony-125 (Sb-125) and Niobium-94 (Nb-94) were also identified in spot locations (50-02-08, 50-03-04) in T Farm by the SGLS but are not used in the gross gamma log analysis. 


\subsection{Time and Subsurface Conditions}

Data evaluation in this report is limited to the period when digital data were first captured in 1975 to the last digital data collection in 1994. Six general conditions are possible concerning the life cycle of contamination events over the time interval during which digital data were acquired:

1. Subsurface conditions were unstable at the beginning of digital logging and then apparently became stable,

2. Subsurface conditions at the beginning of data collection were stable followed by a period of instability (indicated by a rate of change that is inconsistent with the decay rate of known isotopes in the well), followed by apparent stability,

3. Subsurface conditions at the beginning of data collection were stable and then became unstable (indicated by a rate of change that is inconsistent with the decay rate of known isotopes in the well). This unstable condition remains through the period of data collection,

4. Subsurface conditions are unstable because gamma-emitting isotopes entered the zone during some time interval and the GTP decay curve for that time does not match the decay curve of the hypothesized or known (causative) isotopes,

5. Subsurface conditions are undetermined because there is insufficient digitally recorded data (i.e., too few data points resulting from infrequent logging), or there is so much scatter in the GTP that no definitive conclusion can be reached,

6. Subsurface conditions were stable throughout the monitoring period.

Five of these six conditions are present in T Farm. The second condition was not encountered.

For some near surface contaminant distribution profiles, the lack of depth control prior to 1986 results in data that cannot be used to determine the stability. After 1983 the upgraded logging system has excellent depth control and even complex distributions can be analyzed for stability.

There is insufficient information available for this report to determine if contamination at depth may be the result of well installation, e.g. drag down of preexisting contaminated soil during drilling.

\subsection{Unstable Zones}

There are seven unstable zones identified in T Tank Farm. Details of these zones are given above in Table 6. In each of these zones Co-60 is present. 
RPP-6088, Rev. 0.

\subsection{Unstable Early Zones}

There are 25 zones classified as "unstable early"; i.e., zones of initial instability that were followed by stability in which the identified (hypothesized) isotope(s) followed a curve of known decay rate. These zones are listed in Table 6. In these zones, Co-60 is present in 18 zones (72\%), Cs-137 as a single isotope is present in one zone, and $\mathrm{Ru}-106$ with other isotopes is present in the remaining zones.

\section{Summary}

By integrating SGLS data with historical dry well surveillance data, information is gained concerning the behavior of gamma-emitting radionuclides in the vadose zone over time. The SGLS and gross gamma ray data allow a rigorous analysis of the identity, character, and decay trends of isotopes present in contaminated intervals that were identified during the twenty-year period that the digital dry well data were collected.

Subsurface conditions were identified during the analysis of the historical dry well data. The conditions were categories of: clean, tank farm activity, undetermined, unassigned deviation, stable, and unstable. (Note that the category of unstable is further subdivided into 1) unstable, meaning changing other than decay at end of data collection; and 2) unstable early, meaning stability was reached before the end of data collection.) This classification reflects the conditions in which contamination is present (or not present) within the period gross gamma ray data were collected electronically. It does not represent the conditions within the subsurface after 1994. However, an assumption that the trend of the data might continue unaltered past 1994 seems reasonable, barring any event that changes the hydrogeologic or geochemical conditions in the subsurface.

There are 24 wells that are classified as Clean. These wells are found principally along the northern margin and the southern row of tanks of the T Farm; i.e., the northern side of Tanks 101, 102 and 103 and around Tanks 110,111 and 112.

The contaminated boreholes cluster principally around the T-105, T-106, T-108 and T-109 Tanks. Only five of the contaminated zones are designated as having resulted from tank farm activities. Seventeen zones scattered throughout $T$ Farm are classified as Undetermined. The levels of contamination in these zones are generally near the detection threshold; improved monitoring equipment and analysis techniques might be used to establish stability. Forty (of 97) zones are designated as Stable. Twenty-six zones are designated as Unstable Early, with the majority of them surrounding the T-105, T-106 and T 108 Tanks. Seven zones are considered Unstable; most are less than 30 feet thick and none extend to the bottom of the borehole. There are two unstable zones in boreholes adjacent the T-102 and T-104 Tanks. The others are in boreholes 50-00-09, 50-01-09 and 50-09-10.

The most common gamma-emitting isotope present in the subsurface of the T Tank Farm in the 1970s is Ru-106, which was detected in 59 of 97 zones of contamination in the T Farm dry wells. 
RPP-6088, Rev. 0.

This isotope, with a half life of 1 year, was not detected during logging with the SGLS, as it has decayed to below detection thresholds of the system. Ruthenium-106 was found throughout boreholes from near surface to the bottom.

The isotope most commonly detected by the SGLS in T Farm is Co-60, which occurs in 49 zones throughout the farm. This isotope typically occurs at a depth of 30 feet or greater, but is found with Cs-137 at a depth of 0-20 ft in borehole 50-07-03. Cesium-137 is the second most common isotope identified with the SGLS, occurring in 30 zones. Cesium-137 occurs at all depths throughout boreholes, but is the most common isotope in the shallow depth range and is the usual isotope present in zones of Tank Farm Activity. Europium 154 (and some Eu-152) is present in 11 zones, and is usually accompanied by Co-60, Ru-106, Sb-125 (in one instance), or $\mathrm{Nb}-94$ (in two instances). The depth distribution for Eu-154 is from 30 feet to the bottom of a borehole. Europium-152 along with $\mathrm{Nb}-60$ and $\mathrm{Sb}-125$ were also detected in a few zones by the SGLS.

There are 67 zones of contamination with GTP greater than $1,000 \mathrm{ft} * \mathrm{c} / \mathrm{s}$, and only three of these are due to tank farm activities. These wells are scattered throughout the T Tank Farm and are primarily concentrated around the T-101, T-105, T-106, and T-108 Tanks. For many of the zones around the T-106 Tank, the probe used was the Red GM which doesn't equate with contamination levels detected by the unshielded NaI probe (i.e., probe type 4). It is not known if contamination exists beneath the bottom of any given well.

According to the current understanding of chemistry, Ru-106 is not readily sorbed and thus is very mobile in Hanford soils. Thus, a migrating slug containing $\mathrm{Ru}-106$ would be recorded on the gross gamma monitoring logs as a four-phase change.

1. Abrupt activity increase from the approaching contaminant front,

2. High activity while in the migrating contamination zone,

3. Rapid decrease, faster than the $\mathrm{Ru}-106$ decay rate, as the liquid contaminant moved away, leaving only residual concentrations in its path, and

4. Decrease in gamma $\log$ activity that matches the decay rate of $\mathrm{Ru}-106$ as the residual component in the soil decays away.

The monitoring logs hypothesized to contain $\mathrm{Ru}-106$ rarely contain these four phases. Typically the logs indicate more stability for Ru-106 in the soils. Borehole 50-07-03 is a good example, indicating Ru-106 has low mobility. The GTP plot (34-60 ft zone) shows an abrupt activity increase from the approaching front, which immediately becomes stable and decreases at a rate consistent with the decay rate of $\mathrm{Ru}-106 . \mathrm{Ru}-106$ frequently exists under stable conditions, as apparent by its identification in 25 stable zones; in some as the sole identified isotope and in others in combination with other isotopes-usually Co-60 or Eu-154. It is also present in eighteen other zones in which there is instability early, followed by stability. Ru-106 appears in zones close to ground surface as well as to the maximum depth of boreholes in T Farm (i.e., 125 ft.).

Information on how or whether geology and/or geochemistry affect the direction, rate and extent of isotope migration in the subsurface is not considered in this report. However, it is noted in several boreholes that total gamma due to natural potassium- 40 , uranium and thorium shows a marked increase at about the base of backfill (i.e., the top of the natural, in-place strata) in the $T$ 
Tank Farm. This interface between materials of apparently different sediment materials and compaction may have influenced the mobility and distribution of contaminant isotopes. The base of backfill occurs at a depth of about 35-40 feet.

\section{References}

Brevick, C. H., R. L. Newell, J. W. Funk, May 1996, "Supporting Document for the Historical Tank Content Estimate for BX Tank Farm," WHC-SD-WM-ER-311, Rev. 1, Westinghouse Hanford Company, Richland, Washington.

MACTEC-ERS, 1999, "Hanford Tank Farm Vadose Zone T Tank Farm Report," GJO-99-101TAR \& GJO-HAN-27, MACTEC-ERS, Richland, Washington, Sept 1999.

Randall, R. R., R. K. Price, 1999, "Analysis Techniques and Monitoring Results, 241-SX Dry Well Surveillance Logs," HNF-3136, Lockheed Martin Hanford Corporation, Richland, Washington.

Randall, R. R., 1999, "Dry Well Probe Calibrations," HNF-3861, Lockheed Martin Hanford Corporation, Richland, Washington.

Randall, R. R., R. K. Price, 1999, “Analysis of Historical Gross Gamma Logging Data from BX Tank Farm," HNF-3531, Lockheed Martin Corporation, Richland, Washington.

ARH, 1973, "241-T-106 Tank Leak Investigation," ARH-2874, Atlantic Richfield Handford Company, Richland, Washington

Routson, R.C., W.H. Price, D.H. Brown and K.R. Fecht, 1979, High-Level Waste Leakage from the 241-T-106 Tank and Hanford," RHO-ST-14, Rockwell Hanford Operations, Richland, Washington 


\section{Brief Listing of General Observations and Special Data Presentation Conditions}

\section{General Observations}

Several re-occurring features are listed in the following:

- Depth control after 1984 is excellent and detailed survey features can be analyzed in complex contaminant structures after this date.

- Around 1985 , the frequency clean plot often shows a drop to a value slightly less than $100 \%$. This effect is caused by the zero readings at the surface (i.e., a change in logging procedure).

- The first 2 to 5 surveys in 1975 often show an average (natural) background that is higher than the remaining surveys.

- Occasionally, different files with different dates show the exact same data indicating electronic copying errors.

- Before the onset of depth control (around 1984), the bottom reading for surveys varies between low and high count-rates for successive surveys. The pattern between surveys is apparently random.

\section{Special Presentation Conditions}

Several analysis processing and presentation methods are listed in the following:

- No data are deleted from the presentation plots; thus spurious surveys are often viewed.

- Stack plots are generated from a selected frequency (most common is quarterly). There is no selection based upon interpreted validity of the survey.

- During analysis each survey is processed and analyzed, even when some surveys are not viewed in a specific plot, such as the stack plot. A few spurious surveys can be presented on the stack plot that have valid data (generally due to tool failure). And the following survey, generally the next day is consistent with the surveys prior to the anomalous survey.

- The oldest and latest survey plots on a grade thickness plot are not necessarily the first and last in the electronic data set. The oldest and latest surveys that represent the true vadose zone condition are shown in the GTP and Clean plots. Thus the dates on the log plots may not match the dates listed in the table on the header page preceding each dry well presentation.

- The random readings at the bottom of surveys before 1984 are judged not valid unless the SGLS data indicates a measurable quantity at the bottom of a dry well.

- While other probe data exists in the set analyzed, these data are not processed in this work scope unless they affect the conclusion for the stability of the dry well. However, the presence of these data may be useful to the reader, and thus are listed in the table of the header page.

- Many of the well surveyed in this tank farm showed both a deeper survey and lower average background after a specific date. This is consistent with dry well work-over to deeper depths 
and additional casing. Selected contaminant zones required a scaling of the grade thickness product in order to assess the historical trends. The scaling was derived by forming the ratio of the average background before and after the date of change. This ratio was then applied to the grade thickness product as a first order correction.

Two methods may be used to calculate the average background for grade thickness product. One is a threshold method, where all reading between 0 and $50 \mathrm{c} / \mathrm{s}$ are averaged to obtain an average background. The second is the use of an analyst selected depth interval. If the SGLS indicates multiple zones of average background in a dry well the second method is used to select the appropriate background for the GTP zone. 


\section{Tank T-100 Wells}

Table of Contents $\quad$ Page

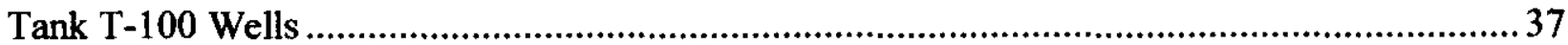

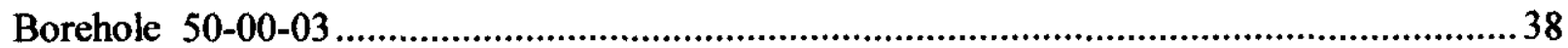

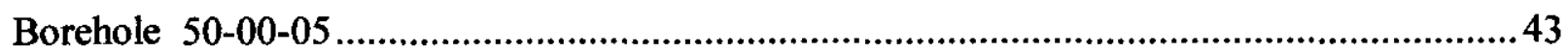

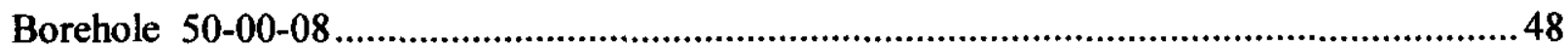

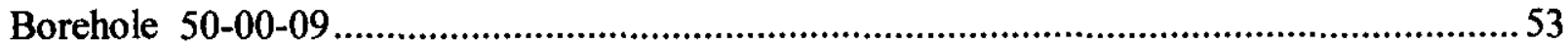

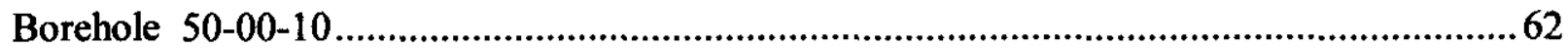

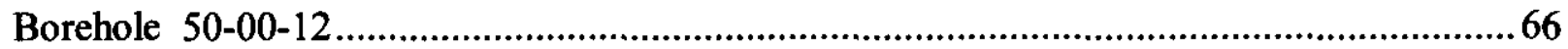

This section contains the analysis results for vadose zone boreholes (dry wells) associated with the "T" Tank Farm in general, and are not associated with a specific tank.

Special Note:

None 
RPP-6088, Rev.0.

\section{Borehole 50-00-03}

\section{Contamination (Ru-106) from 50-60 feet is Stable.}

Grade thickness product over 50 to 60 feet is decreasing consistent with Ru-106 (hypothesis) decay. The HPGe logging system detected Cs-137 at less than $1 \mathrm{pCi} / \mathrm{g}$ below 1 foot.

The average background plot shows a step decrease after 8-5-77 and a second step decrease after 10-6-78.

Gross Gamma Survey Information

\begin{tabular}{|r|l|}
\hline Probe Type Processed : & $04:$ NaI \\
\hline Other Probe Types : & $03:$ Neutron \\
\hline Survey Depth : & $140 \mathrm{ft}$ \\
\hline First Survey Date : & $6 / 30 / 1975$ \\
\hline Last Survey Date : & $11 / 1 / 1993$ \\
\hline Number Surveys Processed : & 185 \\
\hline
\end{tabular}

Analysis Notes

Method Used to Compute Background : $65-85 \mathrm{ft}$

Depth(s) where Contamination Identified $50-60$ Stable

in Gross Gamma Surveys :

\begin{tabular}{l|l} 
Analyst Name : & R.R. Randall \\
\hline
\end{tabular}

Company Name : 1 Three Rivers Scientific 
RPP-6088, Rev.0.

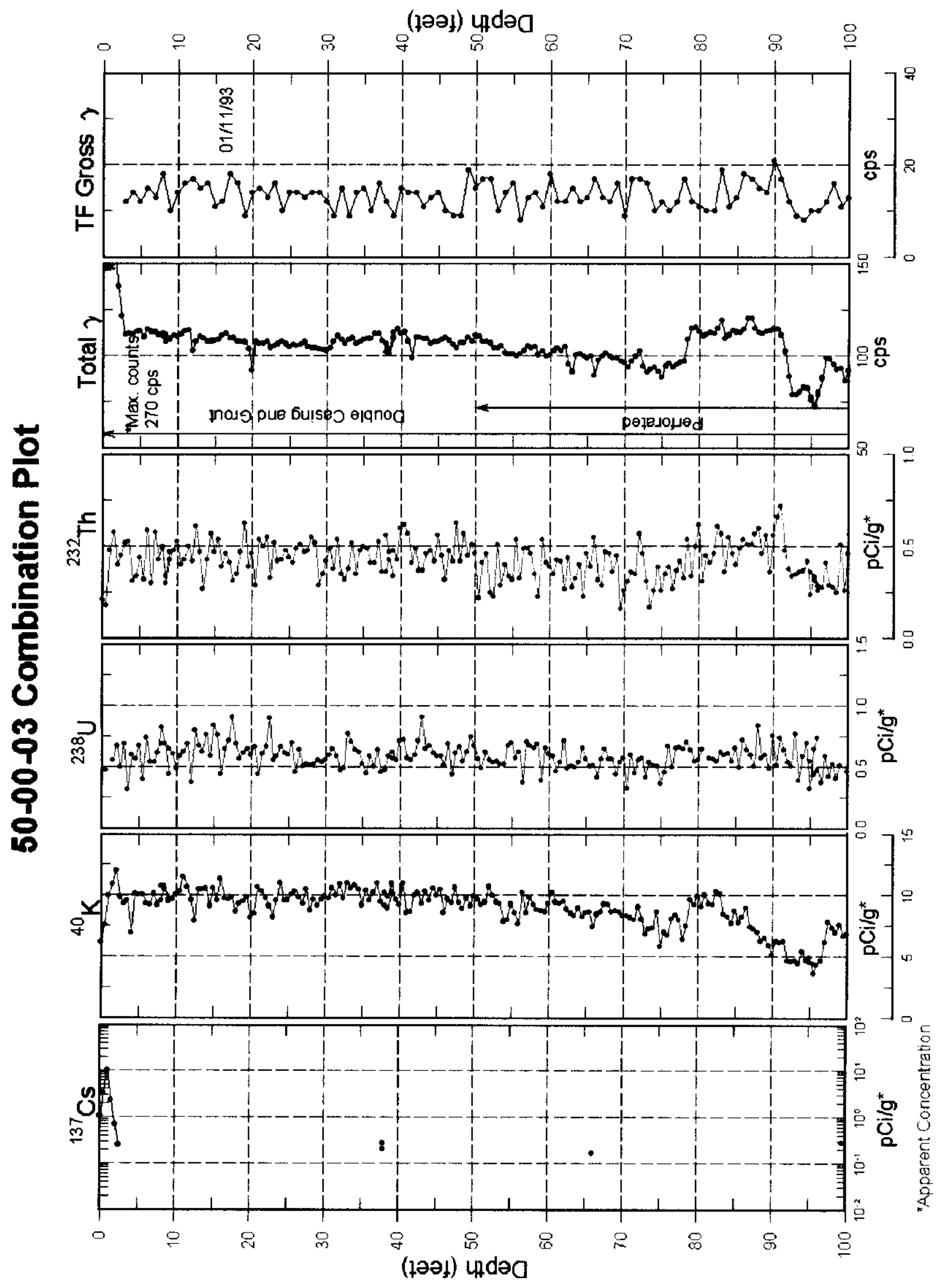

Peripheral Wells

Page 39 
RPP-6088, Rev.0.

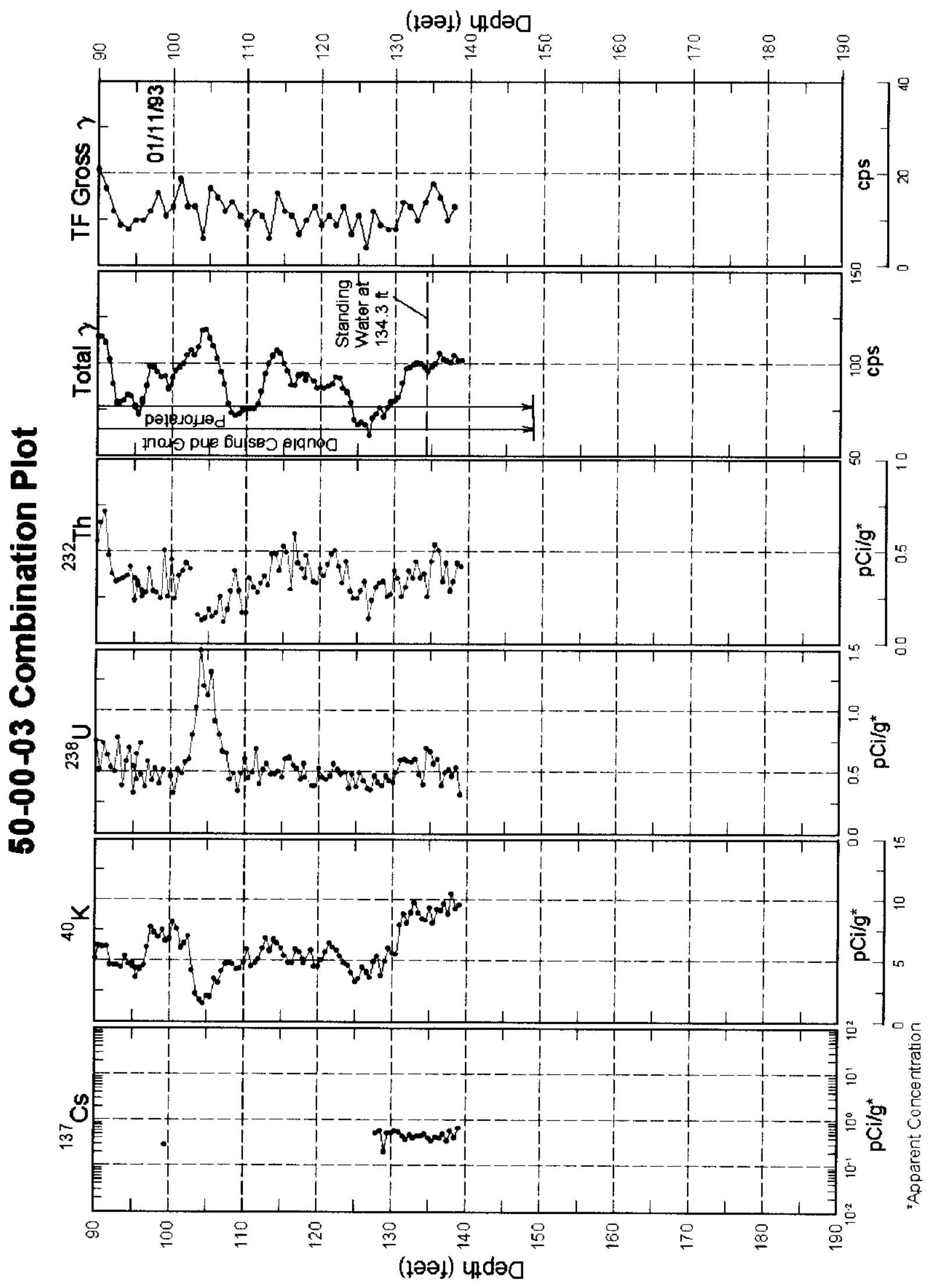

Peripheral Wells

Page 40 
RPP-6088, Rev.0.

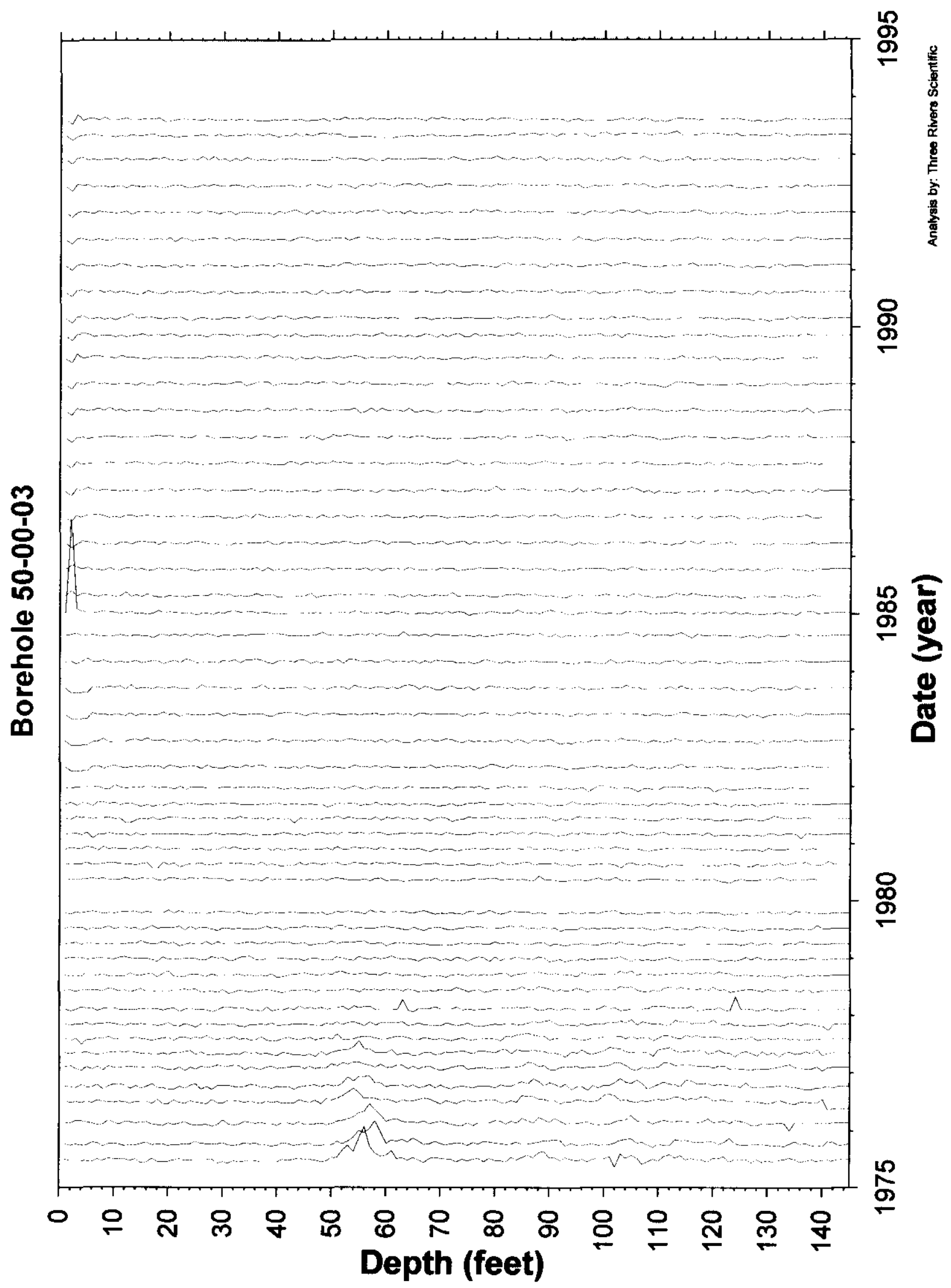

Peripheral Wells 
RPP-6088, Rev.0.
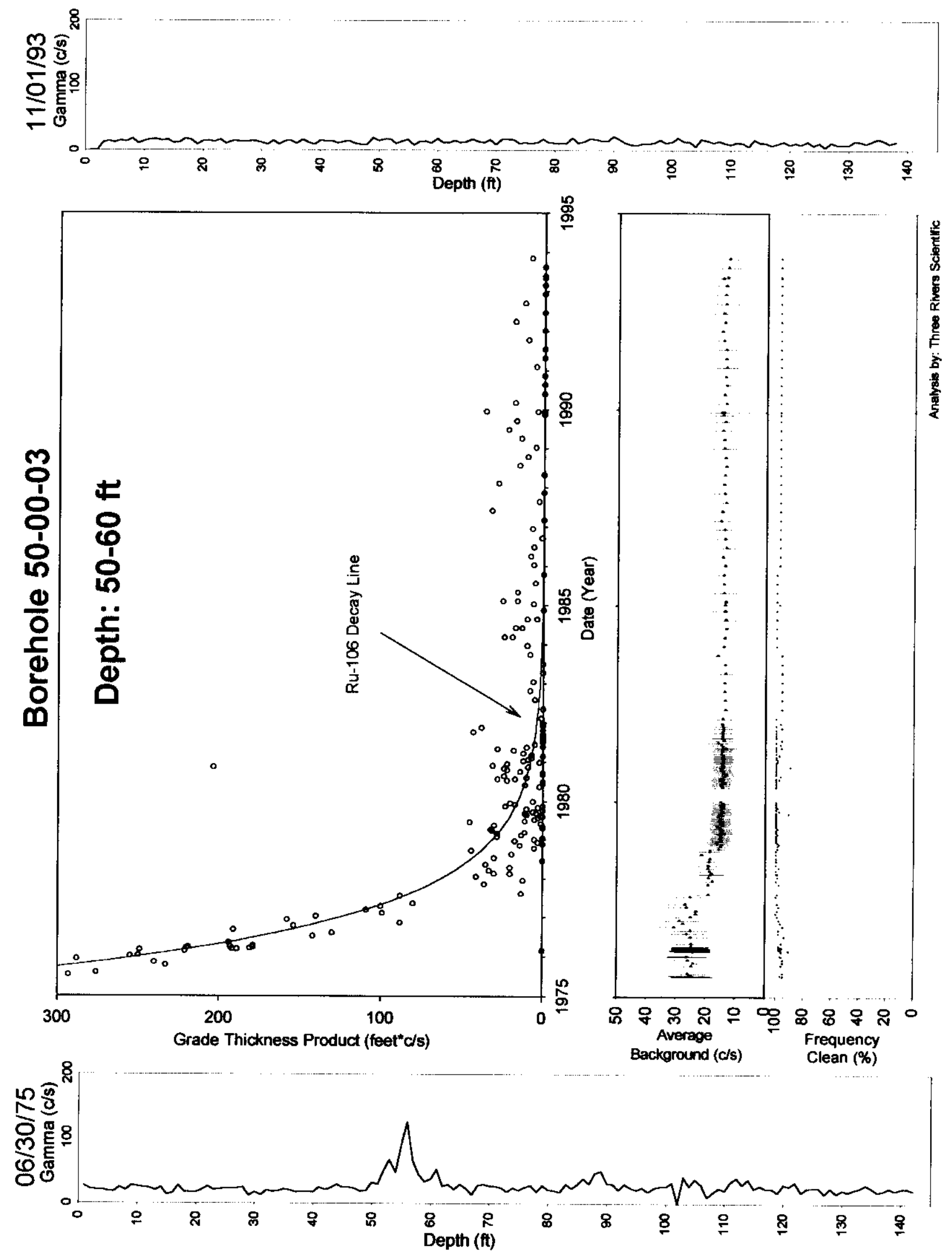
RPP-6088, Rev.0.

\section{Borehole 50-00-05}

\section{Contamination (Co-60 \& Ru-106) from 28-50 feet is Unstable Early.}

Grade thickness product over 28 to 50 feet is decreasing consistent with a least square fit to Co60 (HPGe identified) and Ru-106 (hypothesized) decay after 1976. Before 1976 there is indication of contaminant build up. The ratio of gross gamma contribution from Ru-106 to the gross gamma contribution from Co-60 is 8.1 as of 1-13-75.

The average background plot shows a step decrease after 7-28-77, and a second step decrease after 10-12-78.

Gross Gamma Survey Information

\begin{tabular}{|r|l|}
\hline Probe Type Processed : & $04: \mathrm{NaI}$ \\
\hline Other Probe Types : & $03:$ Neutron (4) $\quad$ 14: Shielded NaI (1) \\
\hline Survey Depth : & $140 \mathrm{ft}$ \\
\hline First Survey Date : & $1 / 13 / 1975$ \\
\hline Last Survey Date : & $10 / 18 / 1993$ \\
\hline Number Surveys Processed : & 433 \\
\hline
\end{tabular}

Analysis Notes

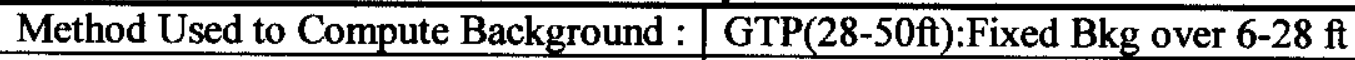

Depth(s) where Contamination Identified $28-50 \mathrm{ft}$ Unstable Early in Gross Gamma Surveys :

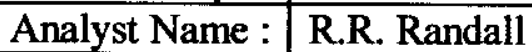

Company Name : $\quad$ Three Rivers Scientific 
RPP-6088, Rev.0.

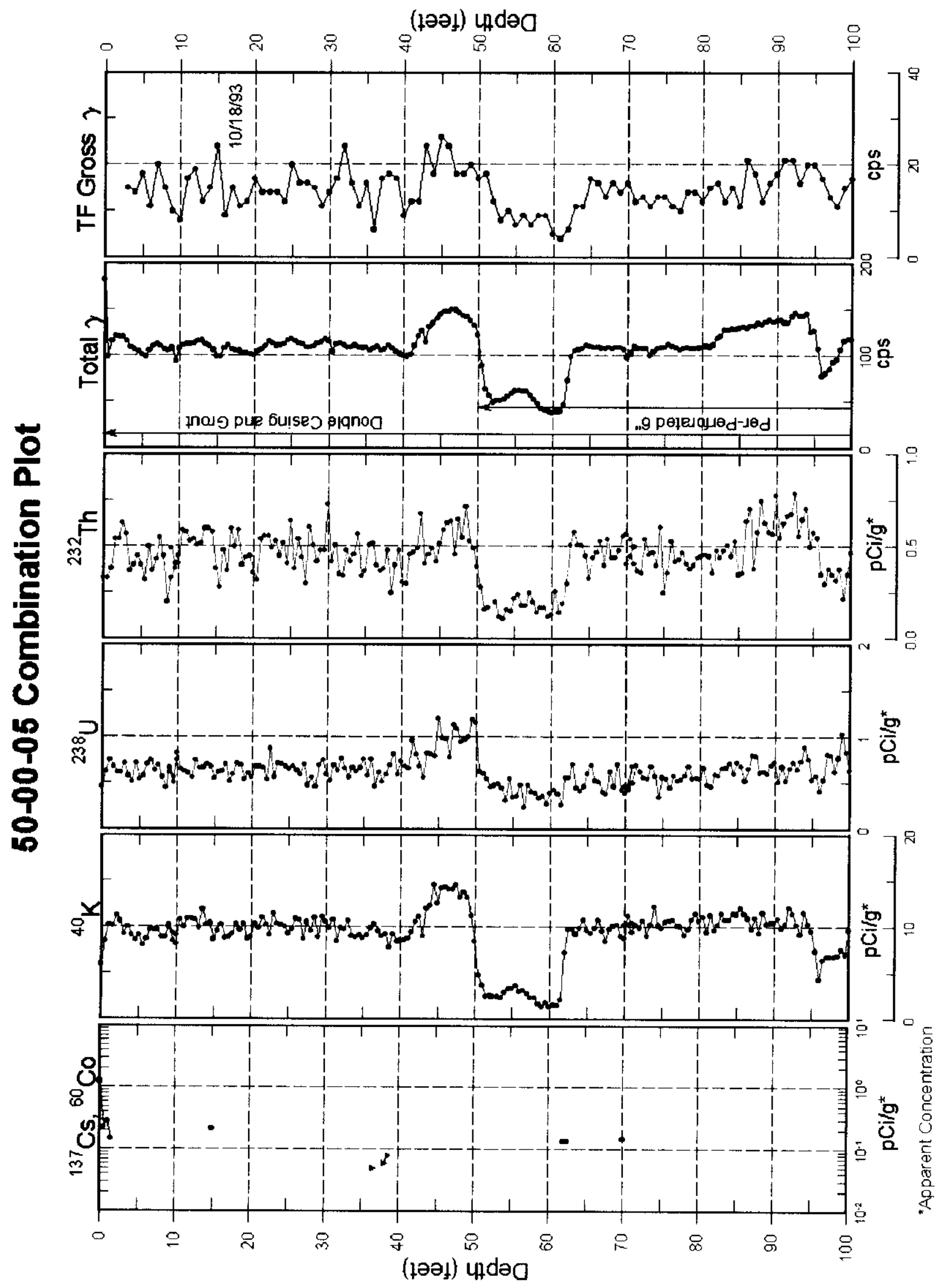

Peripheral Wells 
RPP-6088, Rev.0.

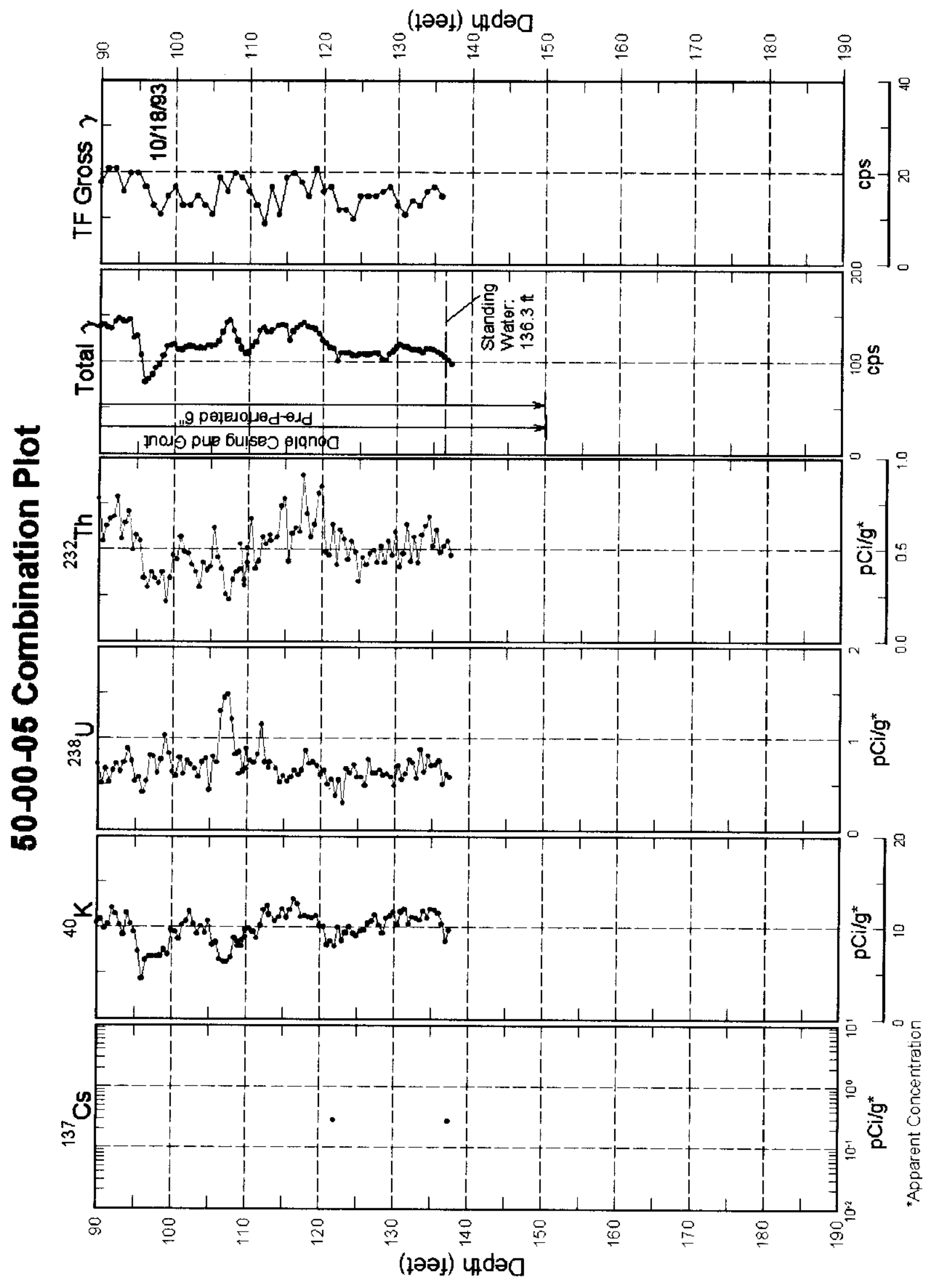

Peripheral Wells

Page 45 
RPP-6088, Rev.0.

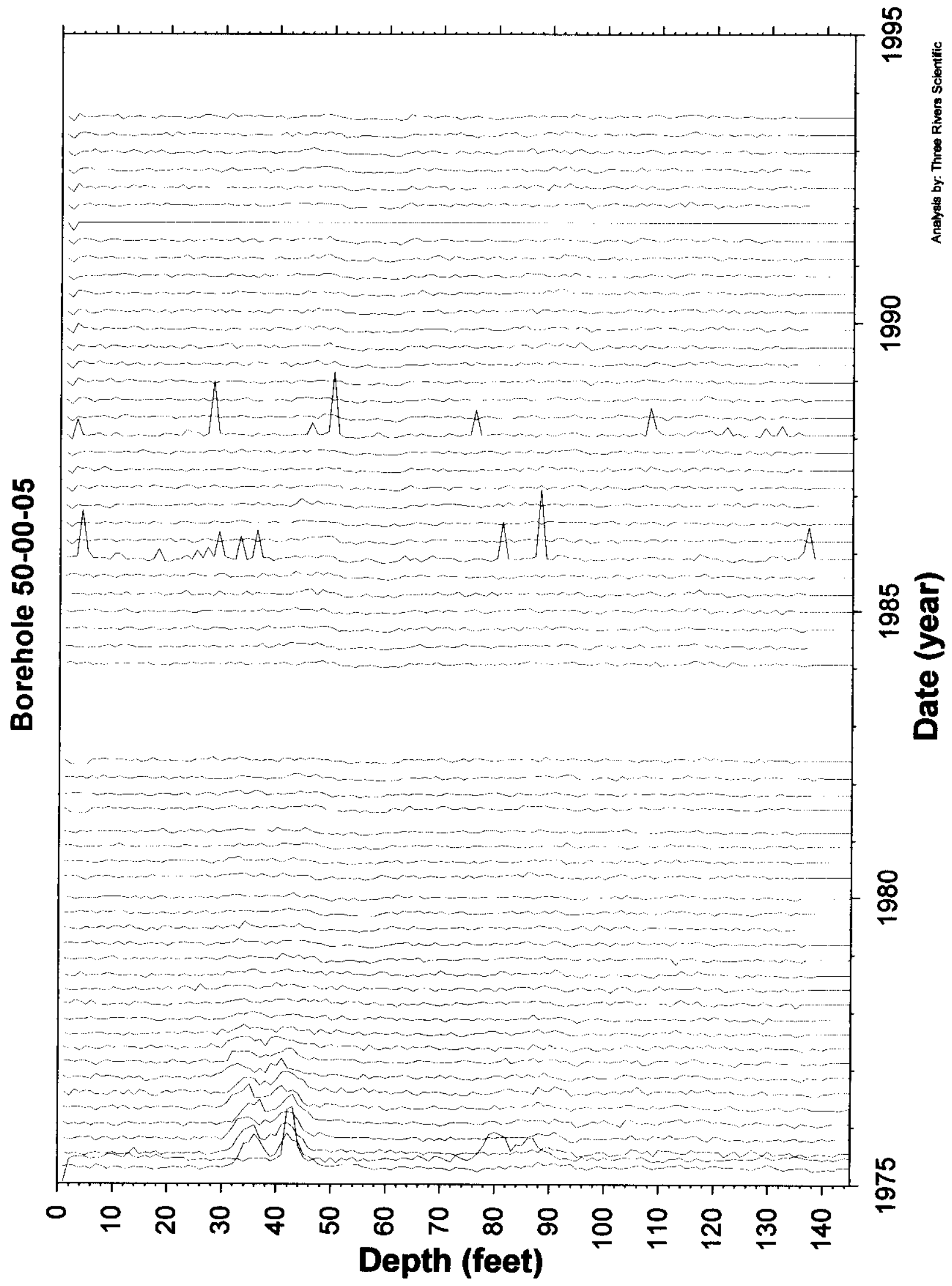

Peripheral Wells

Page 46 
RPP-6088, Rev.0.
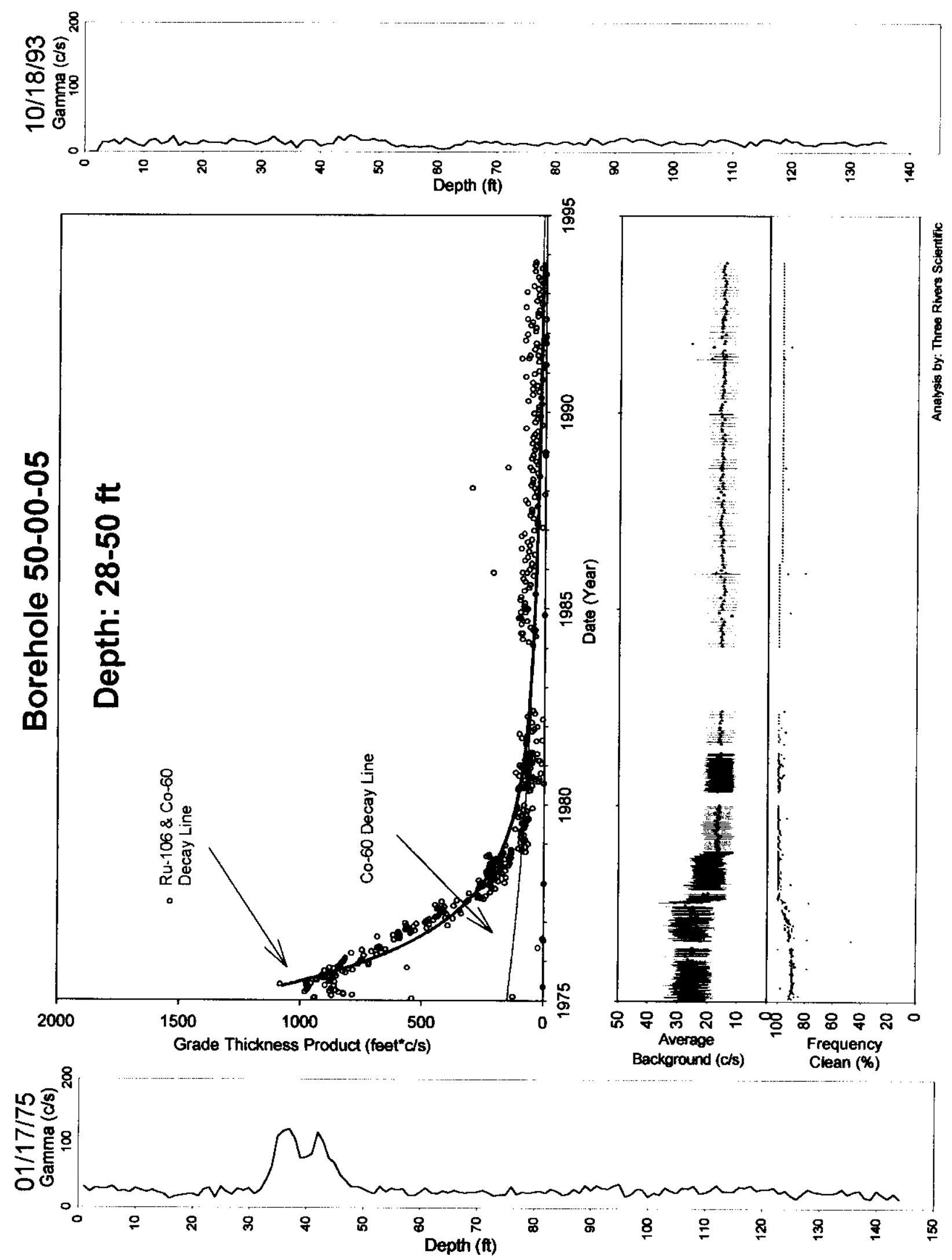
RPP-6088, Rev.0.

\section{Borehole 50-00-08}

\section{No Gamma Ray Emitting Contamination Identified.}

No significant levels of gamma ray contamination are present, based upon gross gamma data, above the survey probe detection threshold between 1975 and 1994 in the vadose zone from 2 to 142 feet. The HPGe logging system detected Cs-137 at less than $1 \mathrm{pCi} / \mathrm{g}$.

The average background plot shows a step decrease after 11-4-77 and a second step decrease after 10-31-78.

Gross Gamma Survey Information

\begin{tabular}{|r|l|}
\hline Probe Type Processed : & $04:$ NaI \\
\hline Other Probe Types : & $03:$ Neutron \\
\hline Survey Depth : & $144 \mathrm{ft}$ \\
\hline First Survey Date : & $1 / 13 / 1975$ \\
\hline Last Survey Date : & $11 / 1 / 1993$ \\
\hline Number Surveys Processed : & 196 \\
\hline
\end{tabular}

Analysis Notes

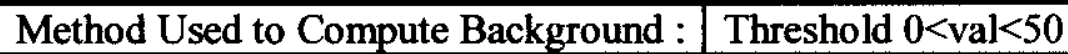

Depth(s) where Contamination Identified NONE in Gross Gamma Surveys :

Analyst Name : R.R. Randall

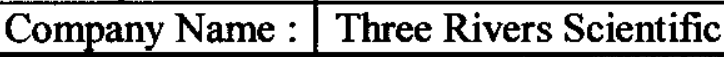


RPP-6088, Rev.0.

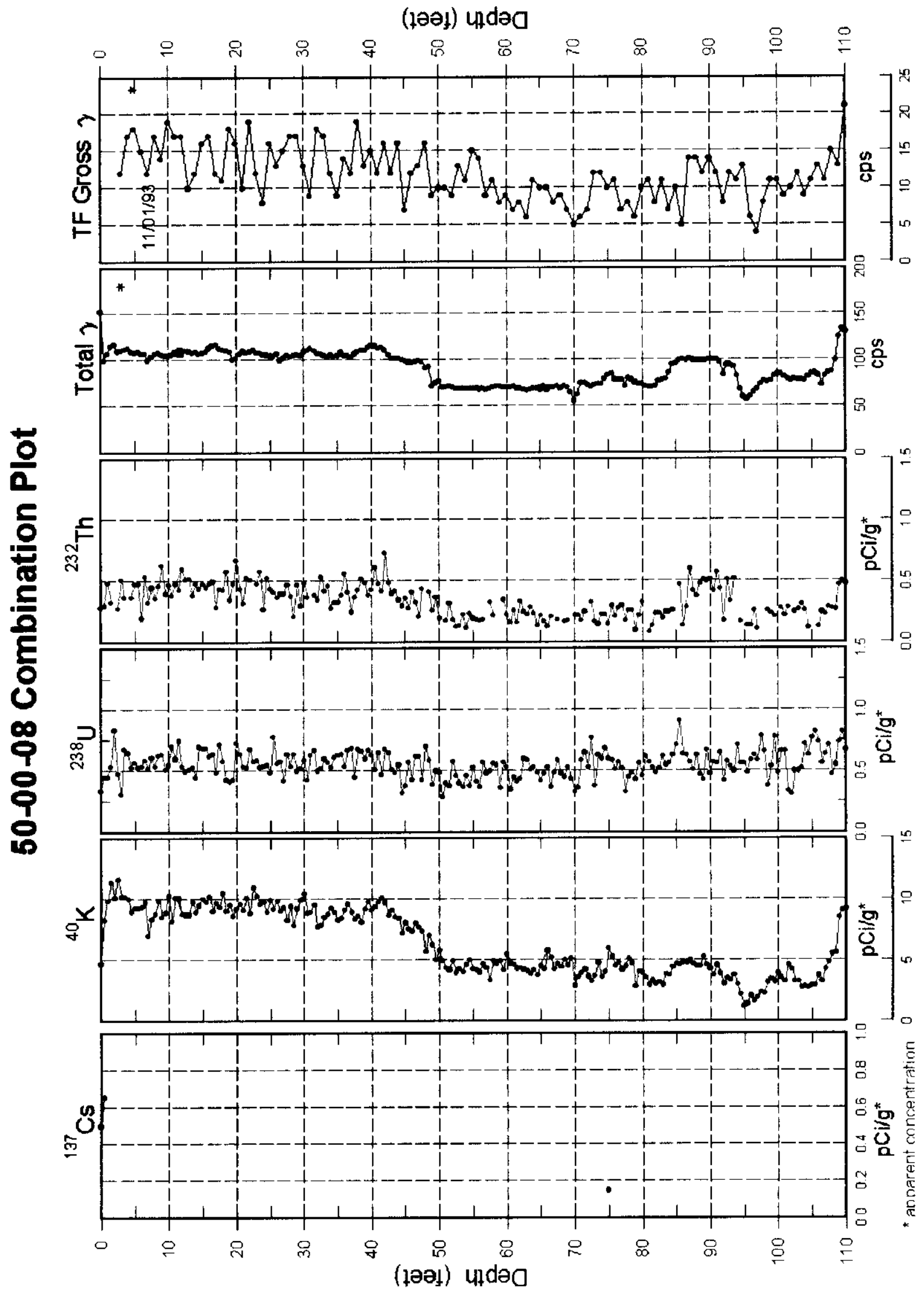

Peripheral Wells 
RPP-6088, Rev.0.

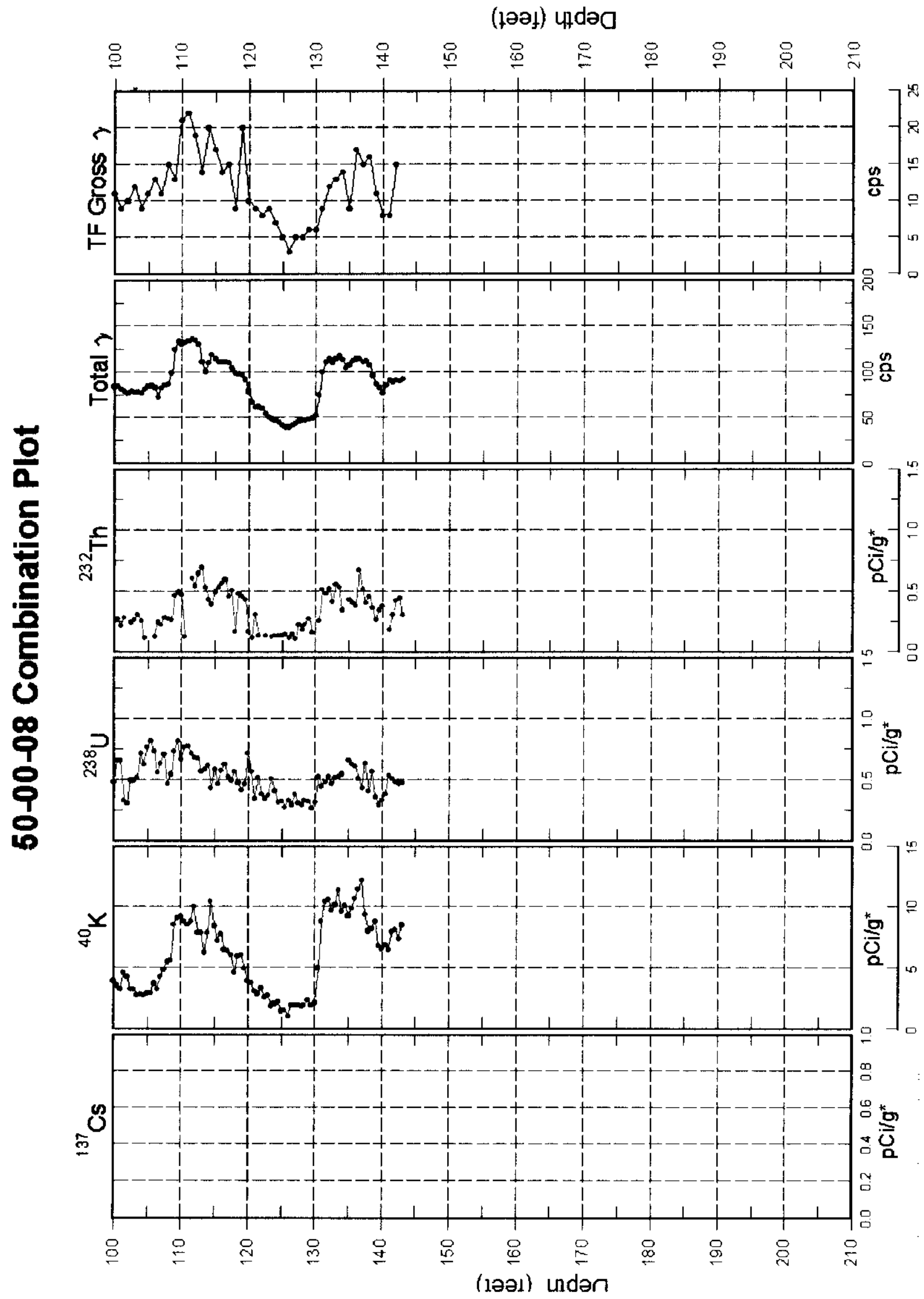

Peripheral Wells

Page 50 
RPP-6088, Rev.0.

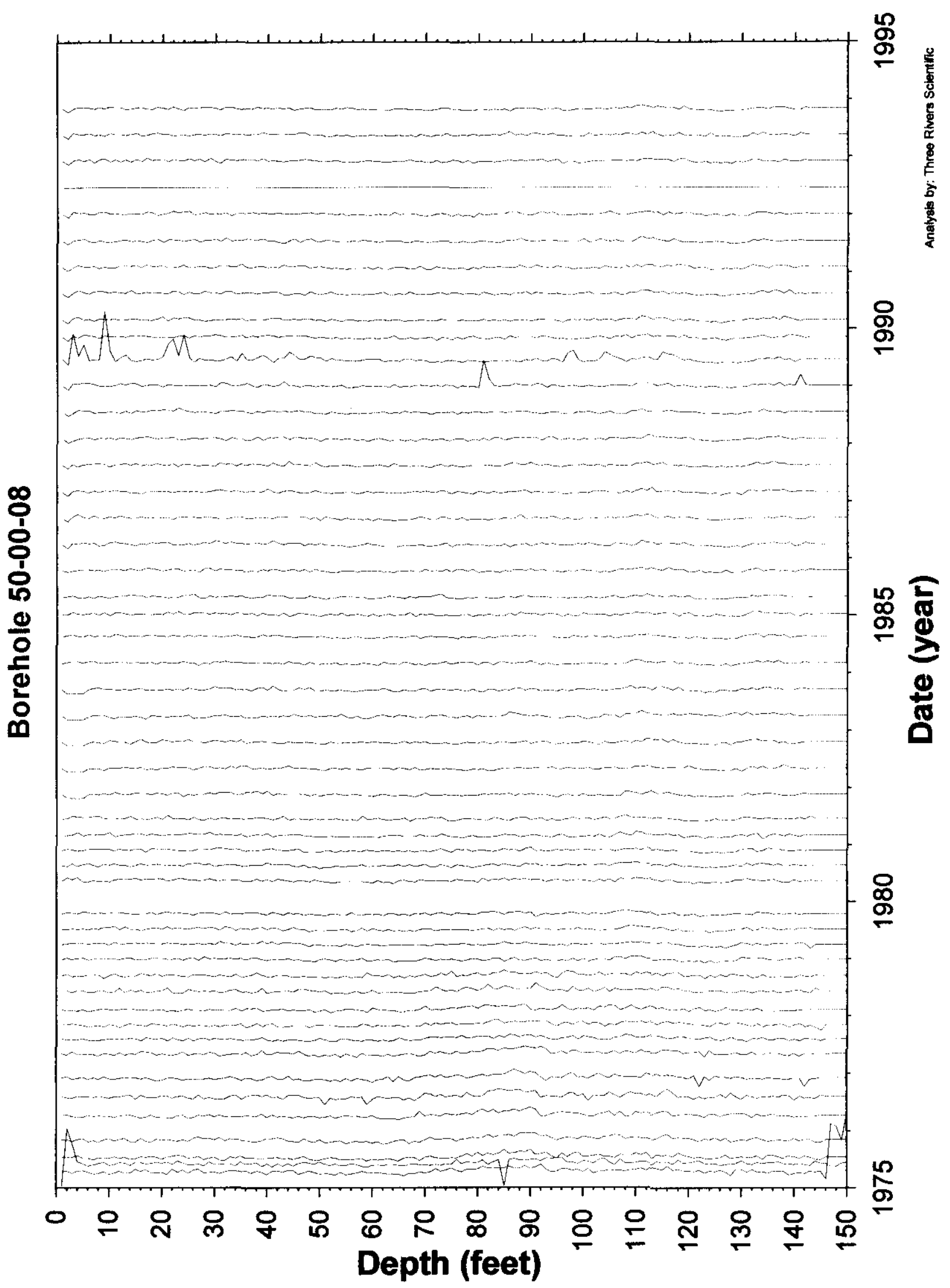

Peripheral Wells

Page 51 
RPP-6088, Rev.0.

\section{Borehole 50-00-08}

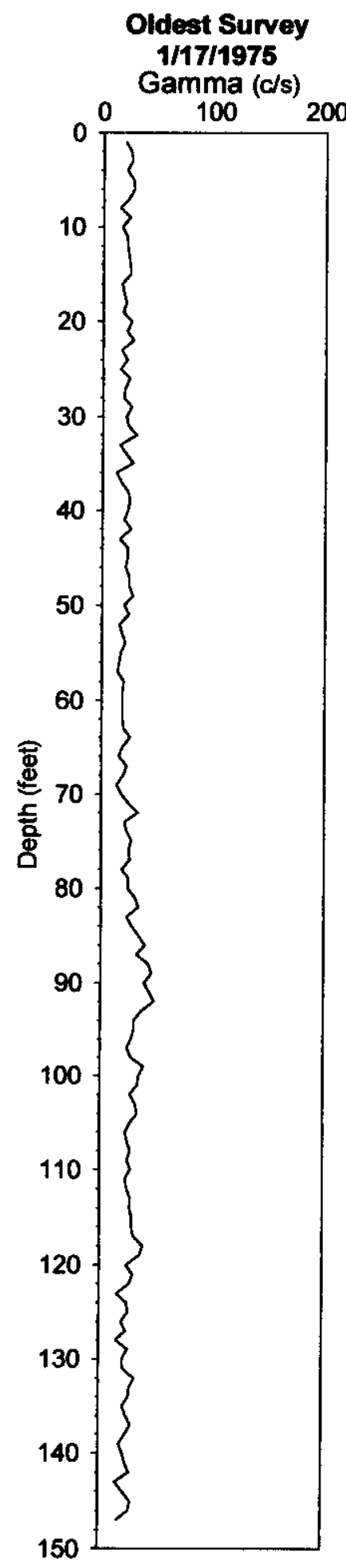

No Gamma-Ray Emitting Contamination

Above Survey Detection Threshold
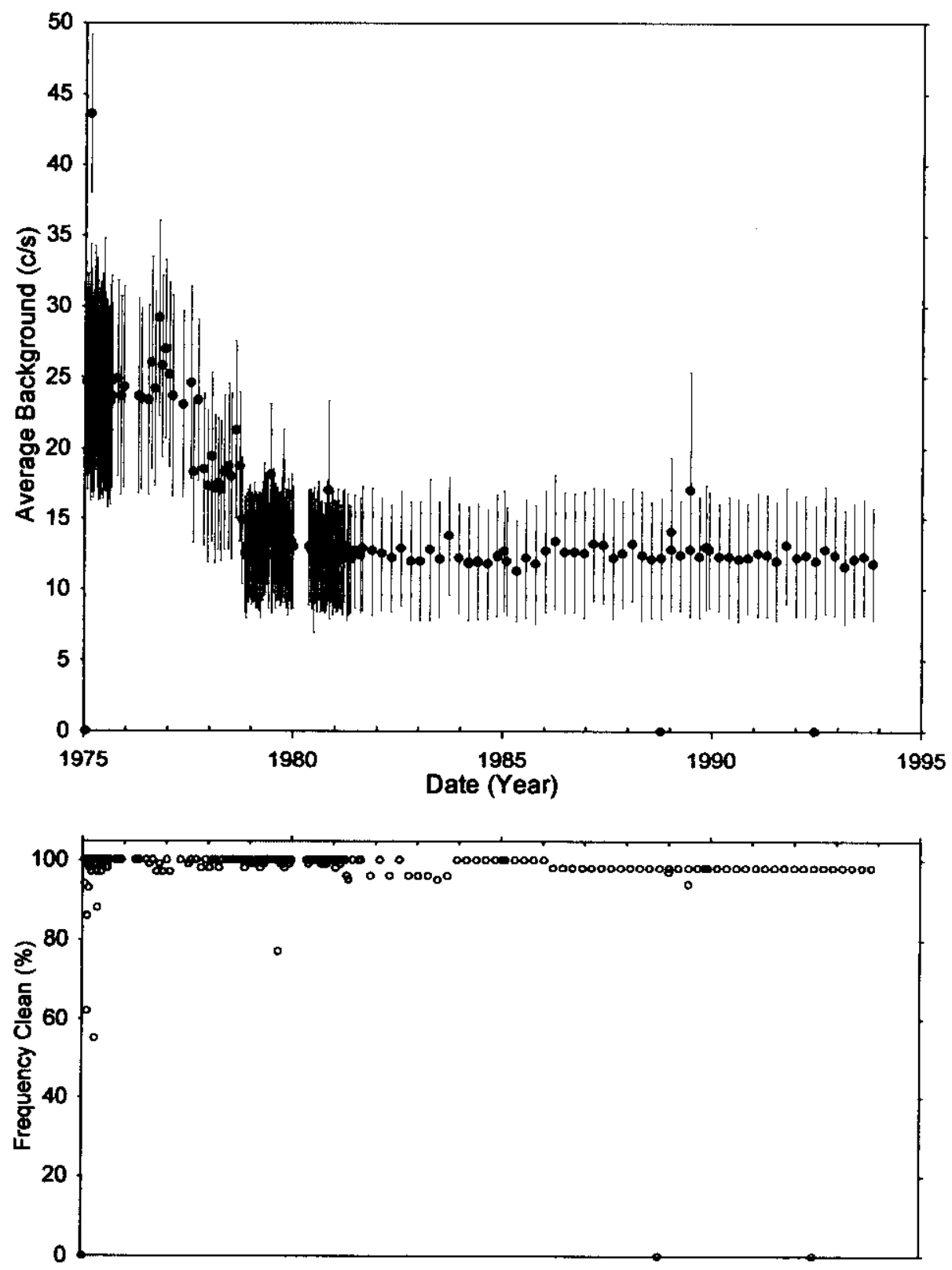

Analysis by. Three Rivers Scientific 
RPP-6088, Rev.0.

\section{Borehole 50-00-09}

\section{Contamination (Eu-154, Co-60 \& Ru-106) from 40-59 feet is Unstable Early. \\ Contamination (Co-60 \& Ru-106) from 62-94 feet is Unstable. Contamination (Co-60 \& Ru-106) from 100-120 feet is Undetermined.}

Both probe types (04 and 14) are examined to determine the historical trends for the zone from 40 to 59 feet. The early data (from 1977 to 1981 ) for probe type 14, is not affected by the highcount rate, and closely matches the Ru-106 (hypothesized) decay. The grade thickness product for the probe type 04 matches a least square fit for Eu-154, Co-60 (HPGe identified), and Ru-106 (hypothesized) decay after 1982. From late 1980 to 1982 there is a systematic deviation from the least square fit, thus the determination of unstable early. As of 7-6-93 the ratio of gross gamma (determined by least square fit) of Eu-154:Co-60:Ru-106 is 5350:182:11.

The zone from 62 to 94 feet has no high count rate limitations for the probe type 04; however, the depth control errors are abundant before 1981. The grade thickness product matches Co-60 (HPGe identified) and Ru-106 (hypothesized) least square fit from 1981 to 1993 . The match is only possible since the zone used to define the grade thickness product spans all of the downward movement. The probe type 14 stack plot shows a rapid downward movement initiation in 1979, and the probe type 04 stack plot shows downward movement of the bottom of the zone from 1981 to 1988 . After 1988 the levels of gross gamma may be too low to detect further downward movement. A classification of unstable early is possible, but since the levels of contamination are to low at the end of the data set, the classification of this interval is unstable. The gross gamma relative contribution derived from the least square results for Co-60 to $\mathrm{Ru}-106$ is 46 to 1 , as of $11 / 06 / 93$.

The zone from 100 to 120 feet also demonstrates difficulty in matching the gamma emitting radionuclides HPGe identified, (i.e. Co-60 and Eu-154). The levels of Co-60 and Eu-154 are very low and the early character of this interval is a rapid decay. The grade thickness product over 100 to 120 feet matches the Ru-106 (hypothesized) decay. The early character does not have sufficient data collection frequency to make a rigorous determination, and the later data is too close to natural background; thus the classification is undetermined. 
Gross Gamma Survey Information

Probe Type Processed : $04: \mathrm{NaI}(54)$; 14: Shielded NaI(126)

Other Probe Types : 03 : Neutron(3); 01: Green GM(1);

02: $\operatorname{Red} \mathrm{GM}(3)$;

Survey Depth : $120 \mathrm{ft}$

First Survey Date : $2 / 9 / 1977$

Last Survey Date : $11 / 6 / 1993$

Number Surveys Processed : 54

Analysis Notes

Method Used to Compute Background : $\quad$ Threshold $0<$ val $<50$

Depth(s) where Contamination Identified $40-59 \mathrm{ft}$ Unstable Early, in Gross Gamma Surveys : $62-94 \mathrm{ft}$ Unstable

100-120 ft Undetermined

Analyst Name : $\quad$ R.R. Randall

Company Name : Three Rivers Scientific 
RPP-6088, Rev.0.

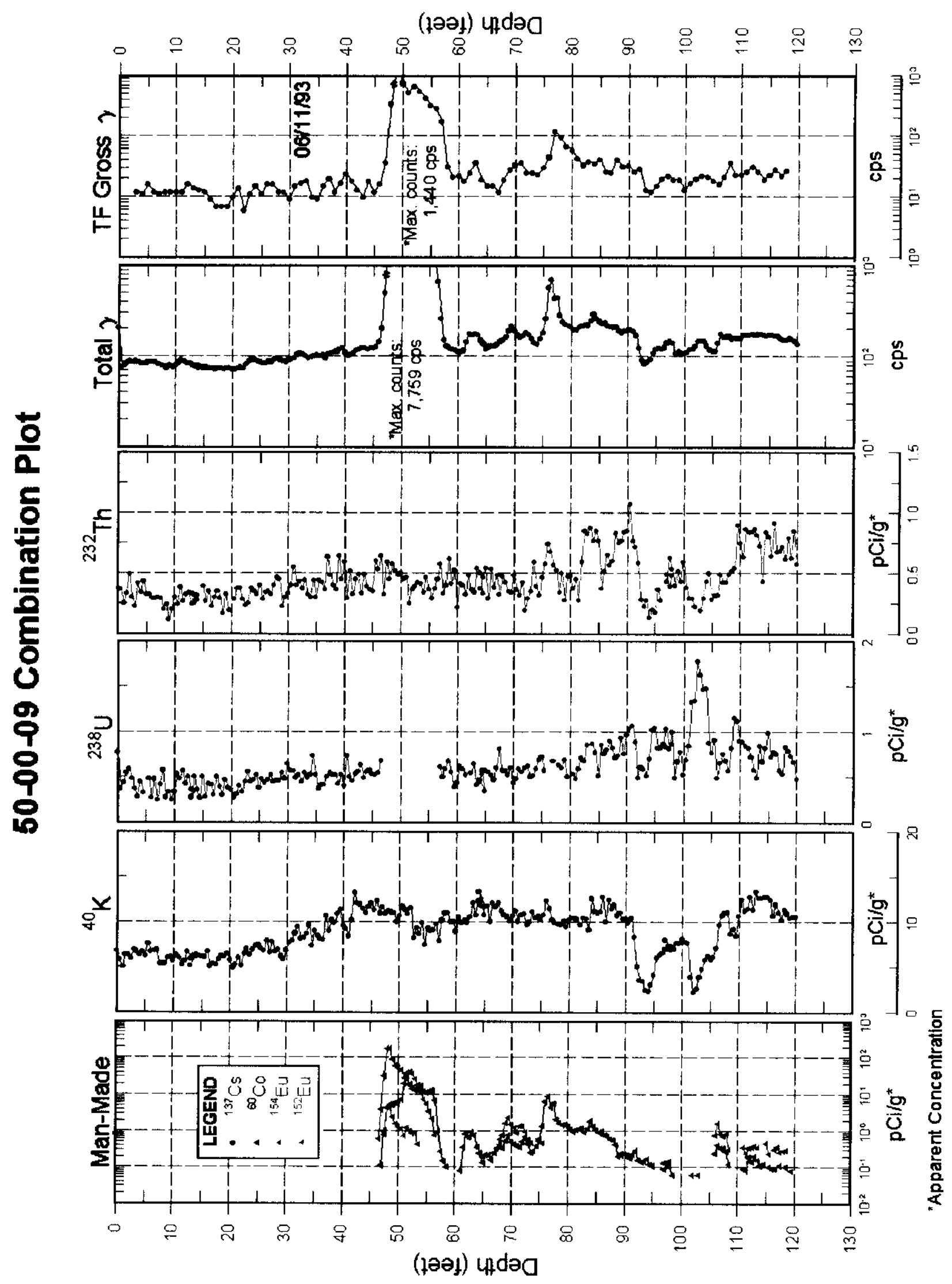

Peripheral Wells

Page 55 
RPP-6088, Rev.0.

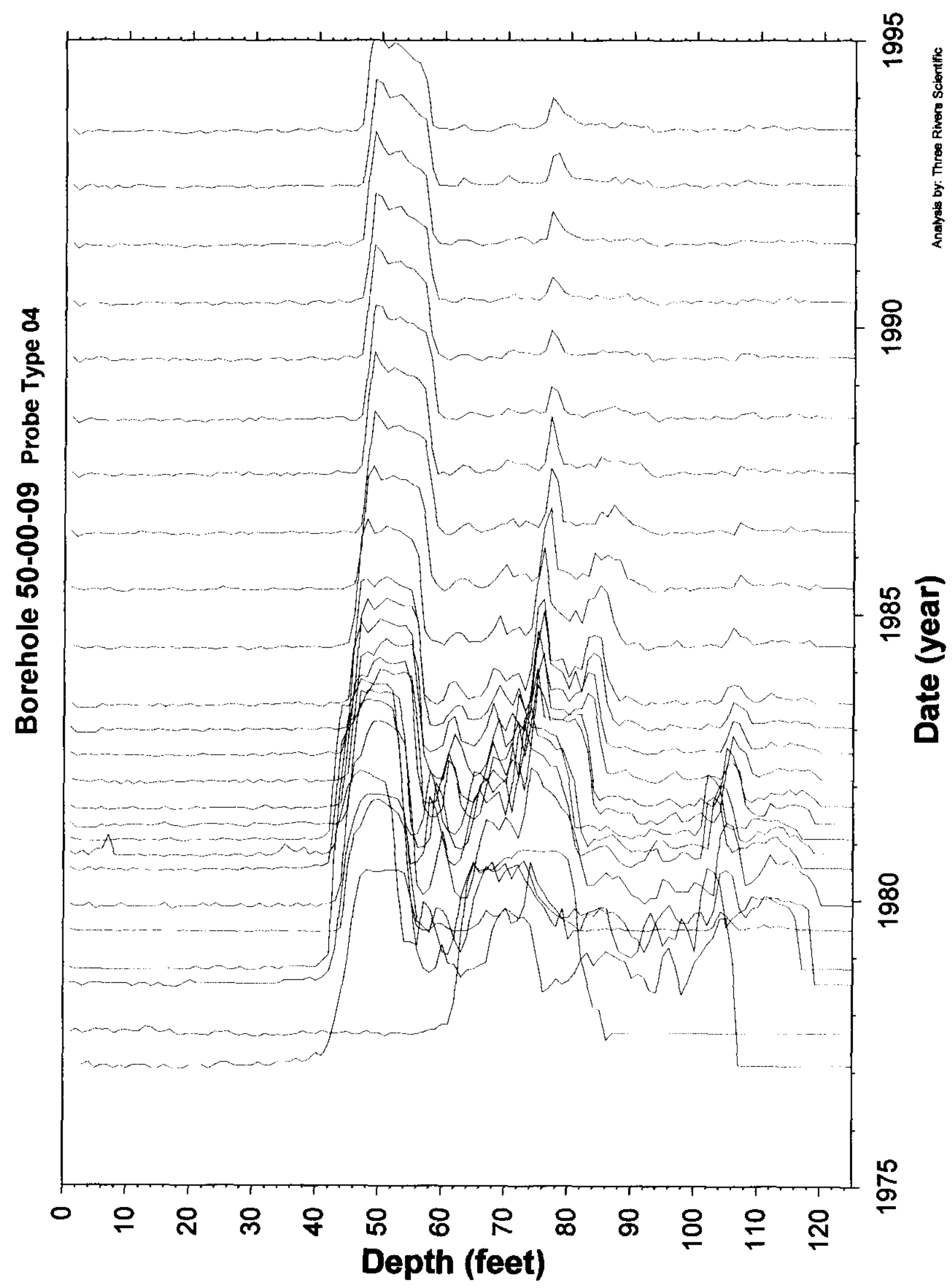

Peripheral Wells

Page 56 
RPP-6088, Rev.0.

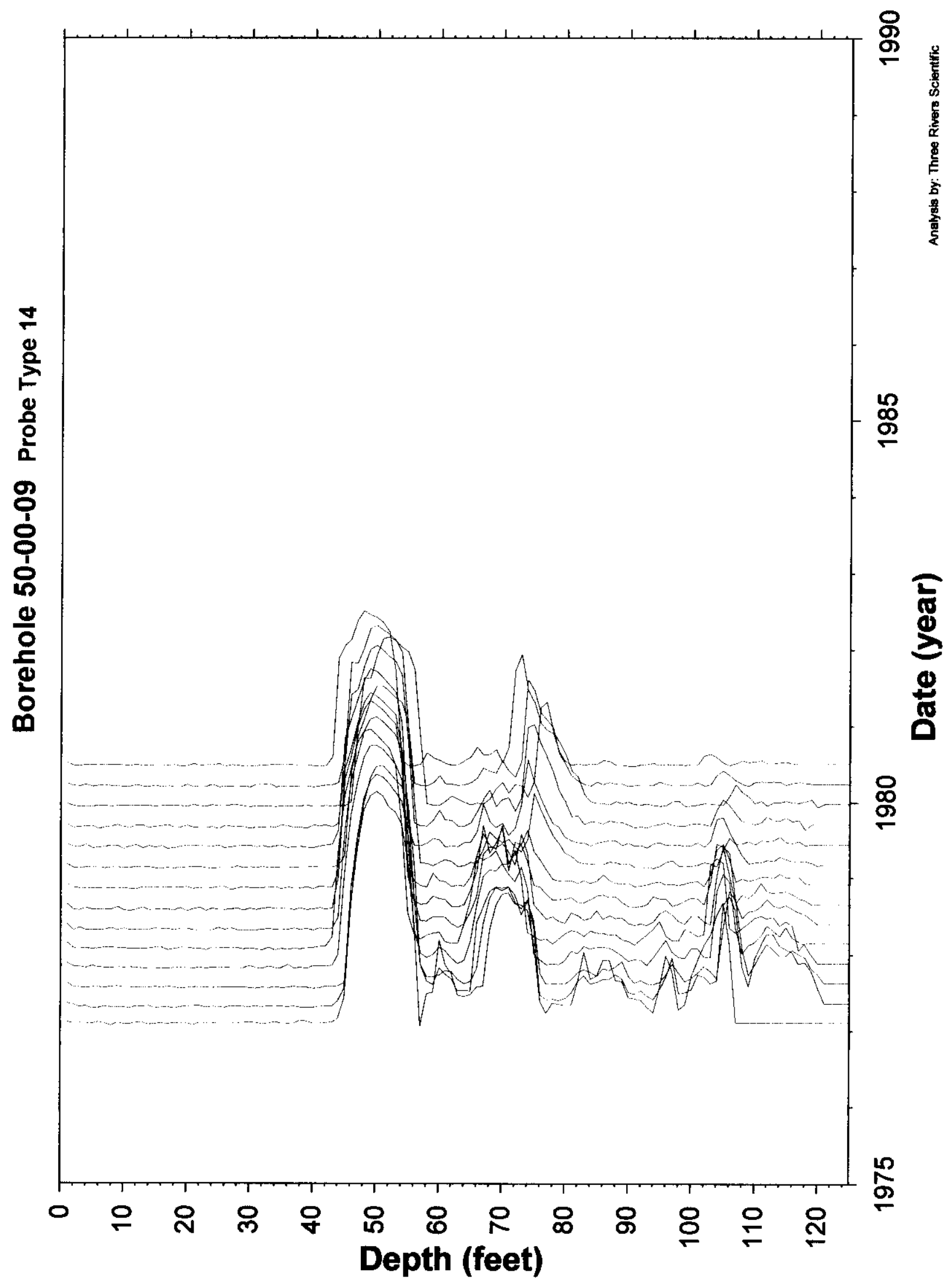

Peripheral Wells

Page 57 
RPP-6088, Rev.0.
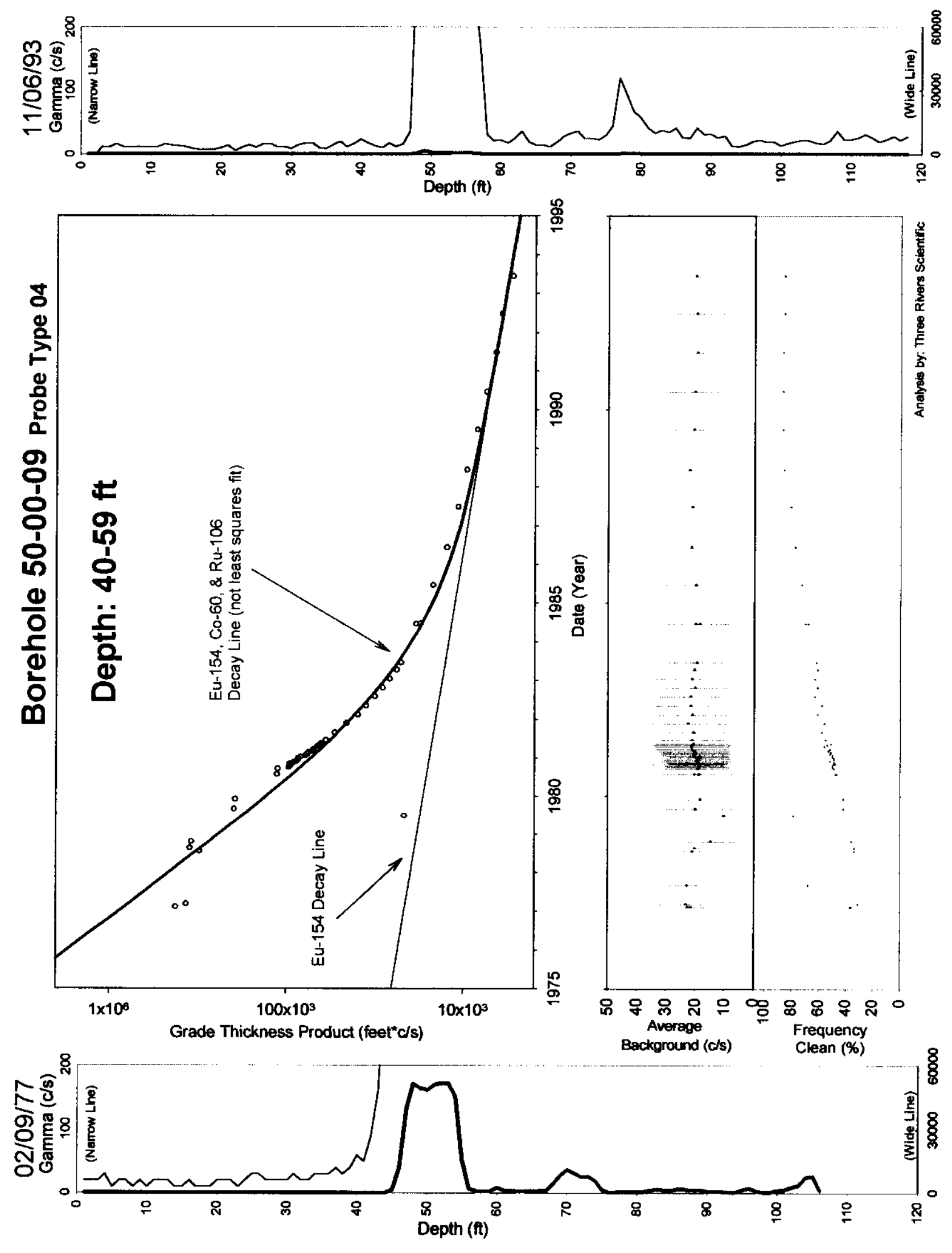

Peripheral Wells

Page 58 
RPP-6088, Rev.0.
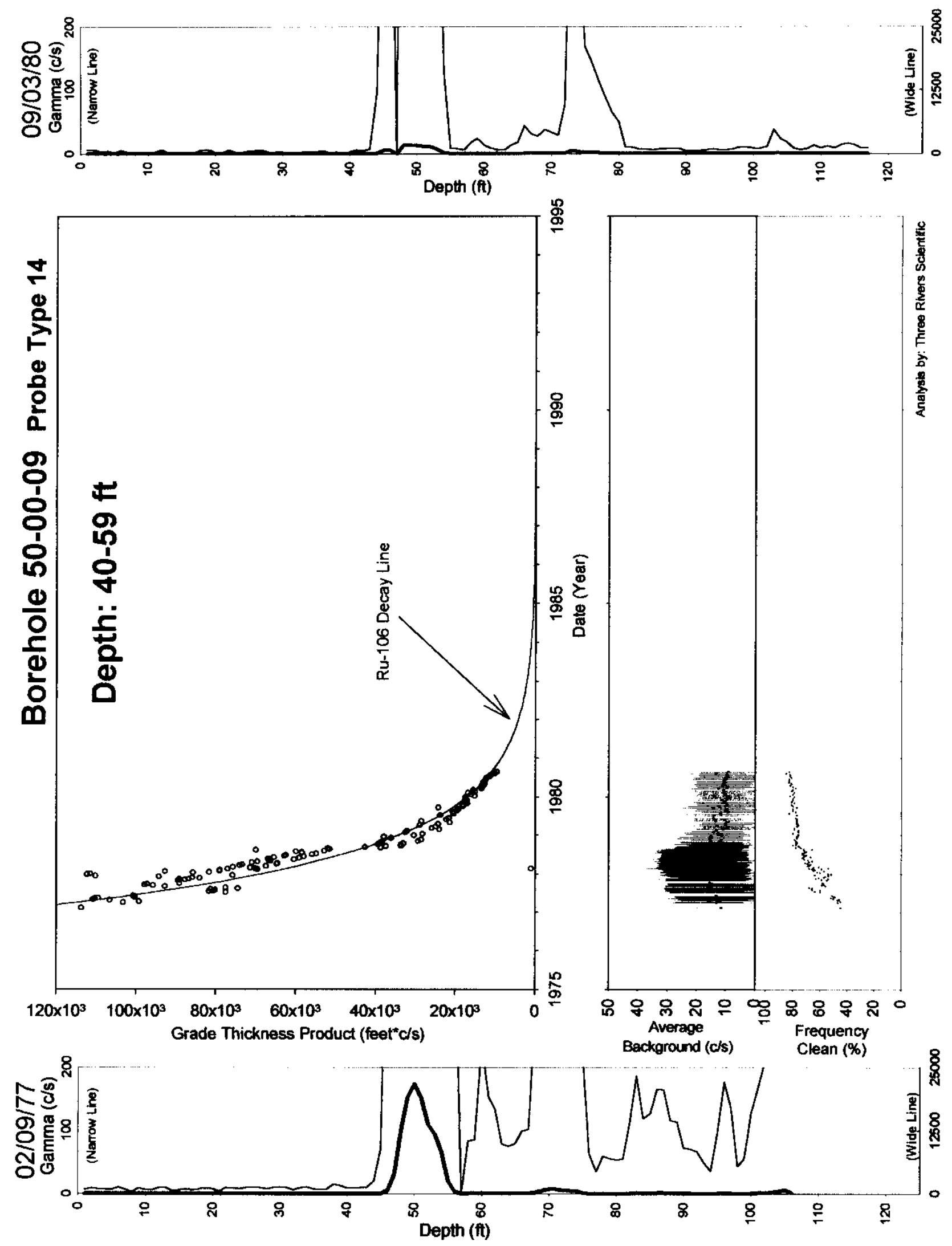

Peripheral Wells

Page 59 
RPP-6088, Rev.0.
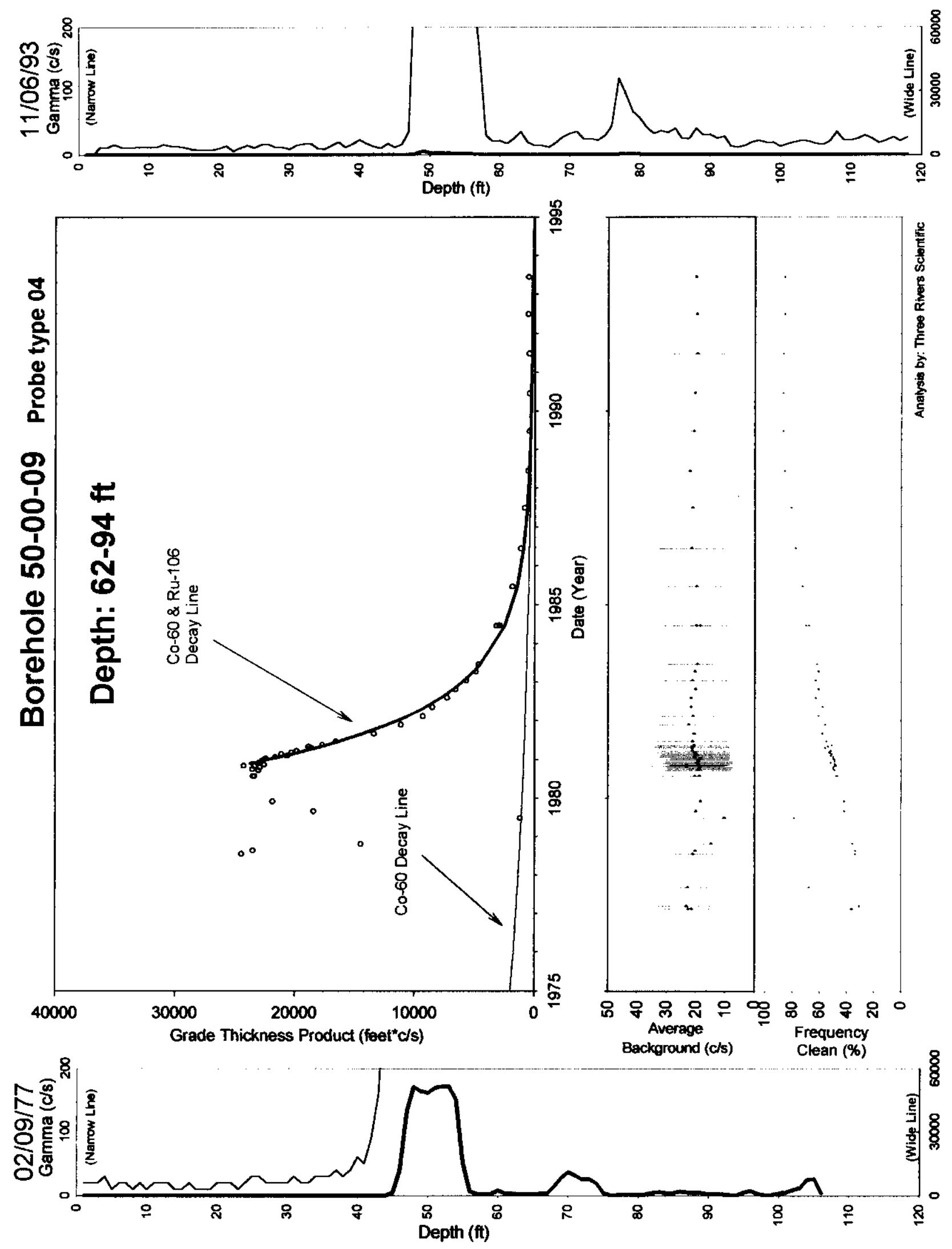

Peripheral Wells 
RPP-6088, Rev.0.
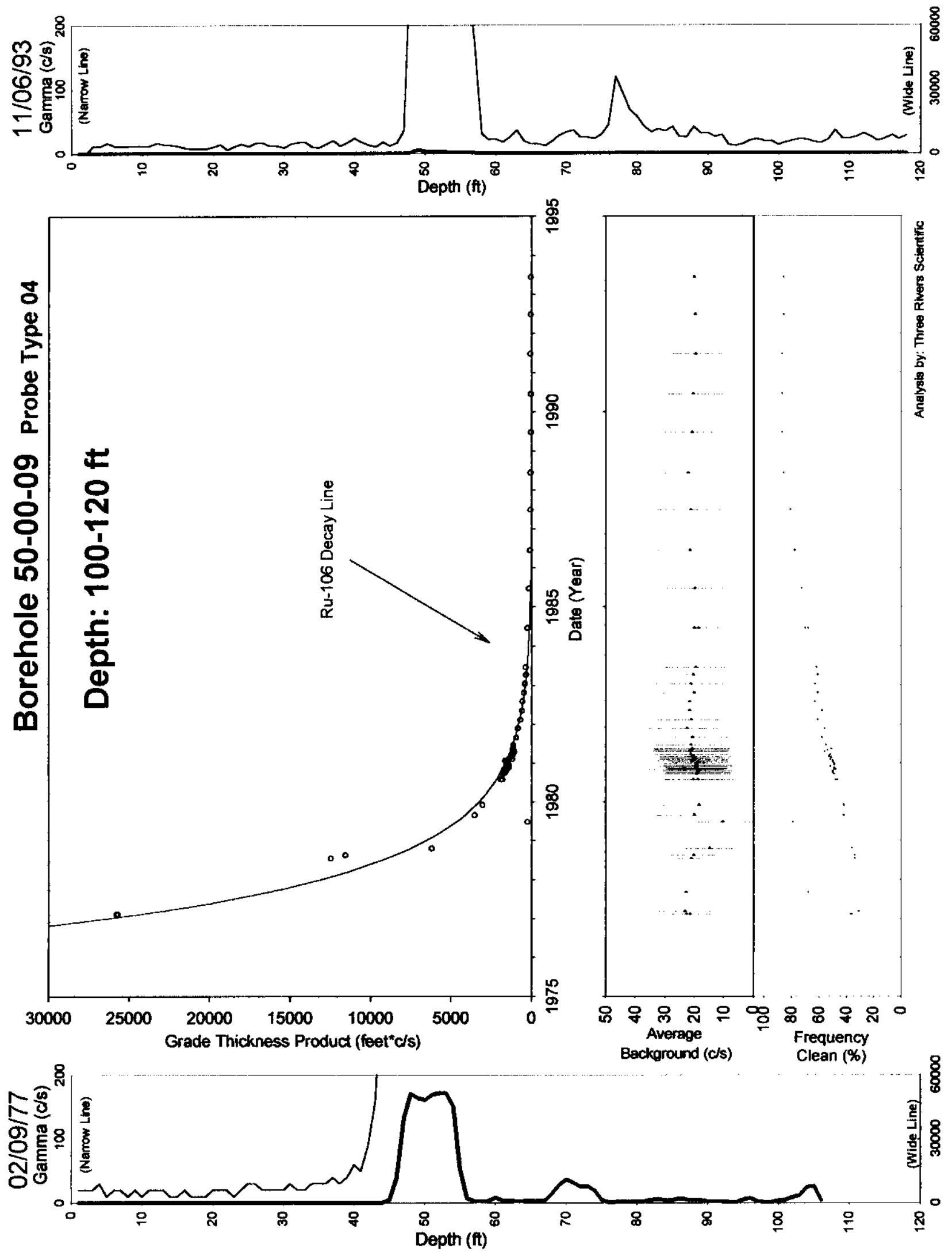

Peripheral Wells 
RPP-6088, Rev.0.

\section{Borehole 50-00-10}

\section{No Gamma Ray Emitting Contamination Identified.}

No significant levels of gamma ray contamination are present, based upon gross gamma data, above the survey probe detection threshold between 1975 and 1994 in the vadose zone from 2 to 138 feet. The HPGe logging system detected Cs-137 at less than $1 \mathrm{pCi} / \mathrm{g}$.

The average background plot shows a step decrease after 9-16-77. Likewise, the survey depth increased from 115 feet to 140 feet after this same date.

Gross Gamma Survey Information

\begin{tabular}{|r|l|}
\hline Probe Type Processed : & $04:$ NaI \\
\hline Other Probe Types : & $03:$ Neutron \\
\hline Survey Depth : & $140 \mathrm{ft}$ \\
\hline First Survey Date : & $1 / 13 / 1975$ \\
\hline Last Survey Date : & $6 / 18 / 1993$ \\
\hline Number Surveys Processed : & 153 \\
\hline
\end{tabular}

Analysis Notes

Method Used to Compute Background : $\quad$ Threshold $0<$ val $<50$

Depth(s) where Contamination Identified NONE

in Gross Gamma Surveys :

Analyst Name : $\quad$ R.R. Randall

Company Name : $\quad$ Three Rivers Scientific 
RPP-6088, Rev.0.

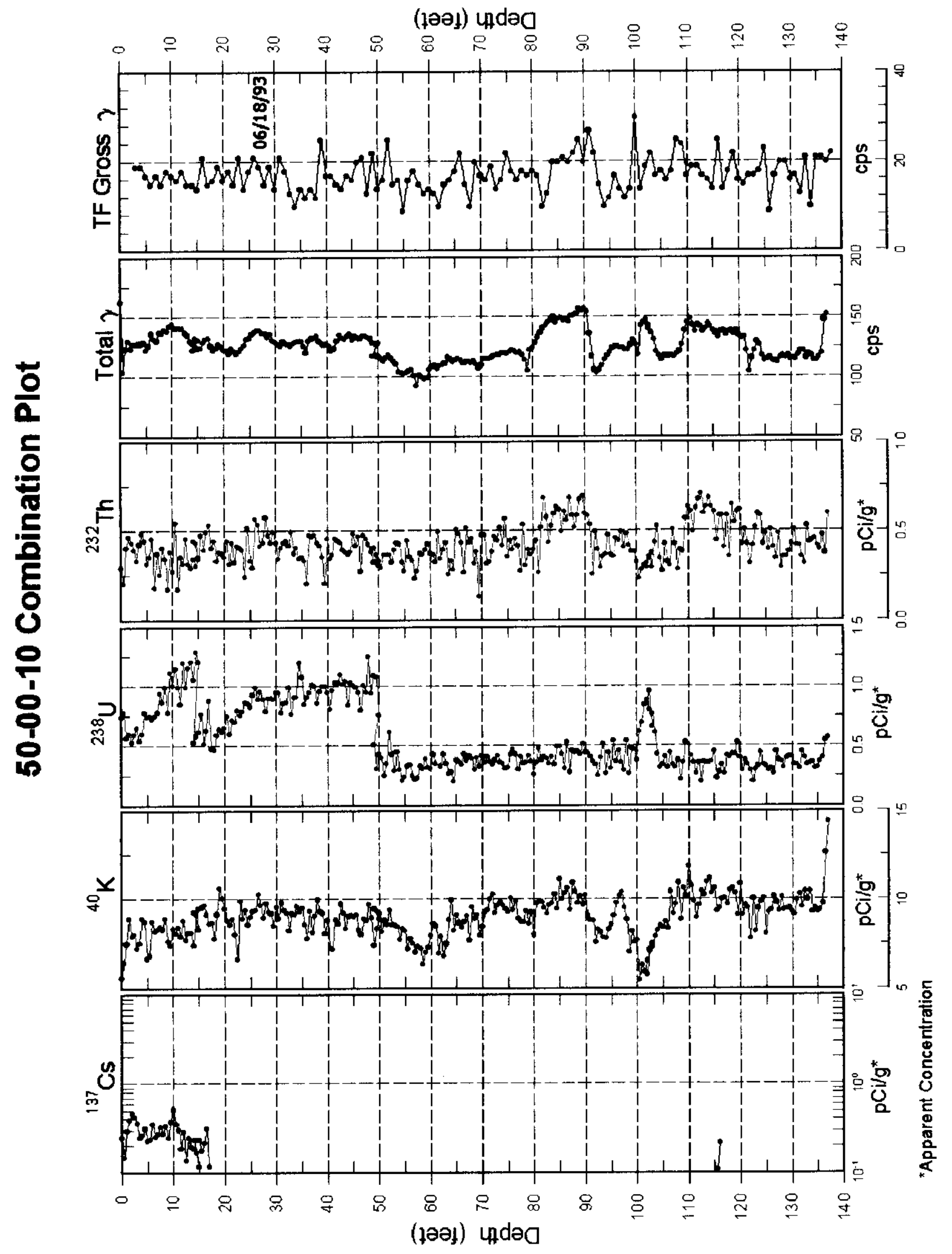

Peripheral Wells 
RPP-6088, Rev.0.

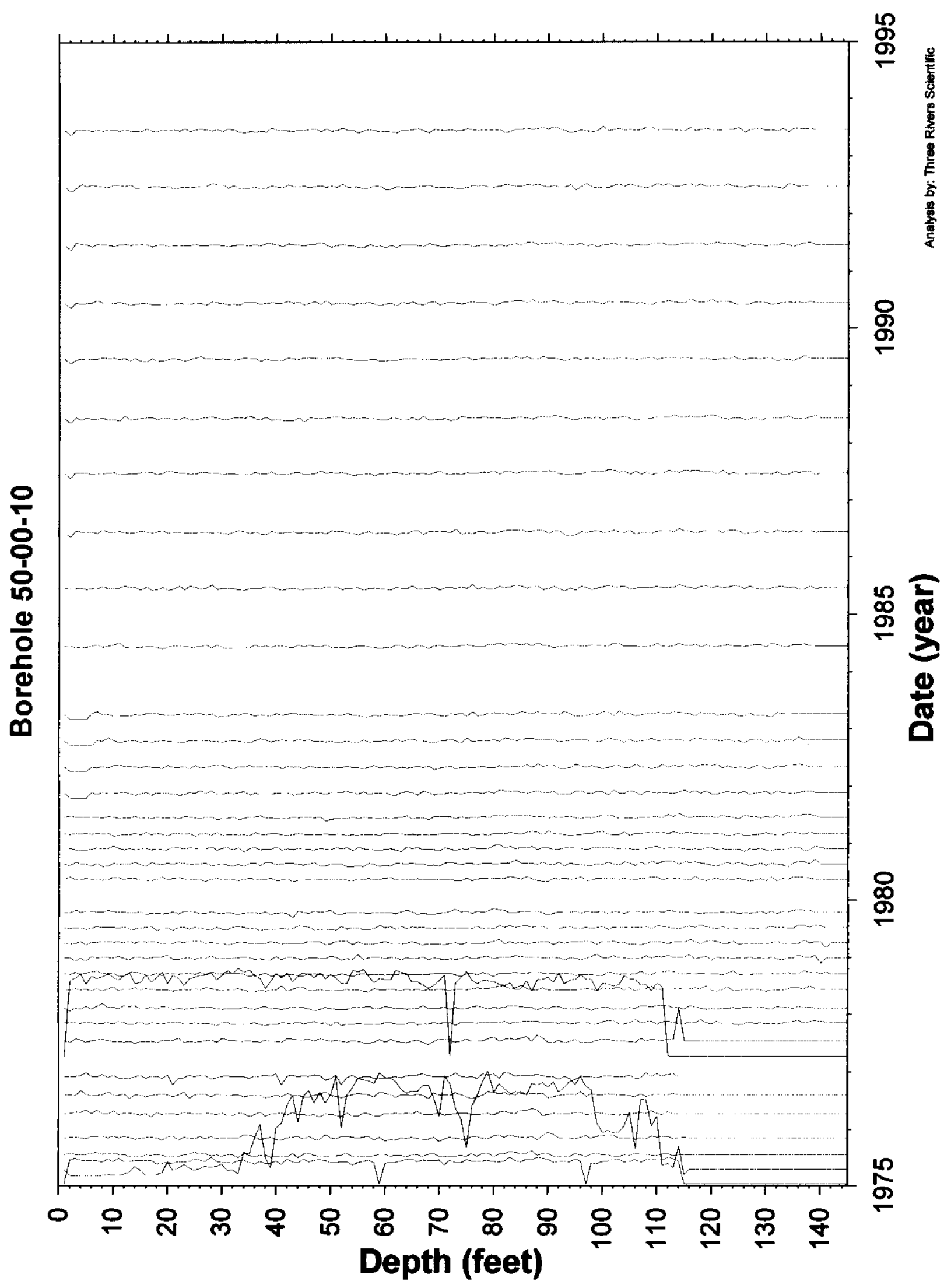

Peripheral Wells

Page 64 
RPP-6088, Rev.0.

\section{Borehole 50-00-10}

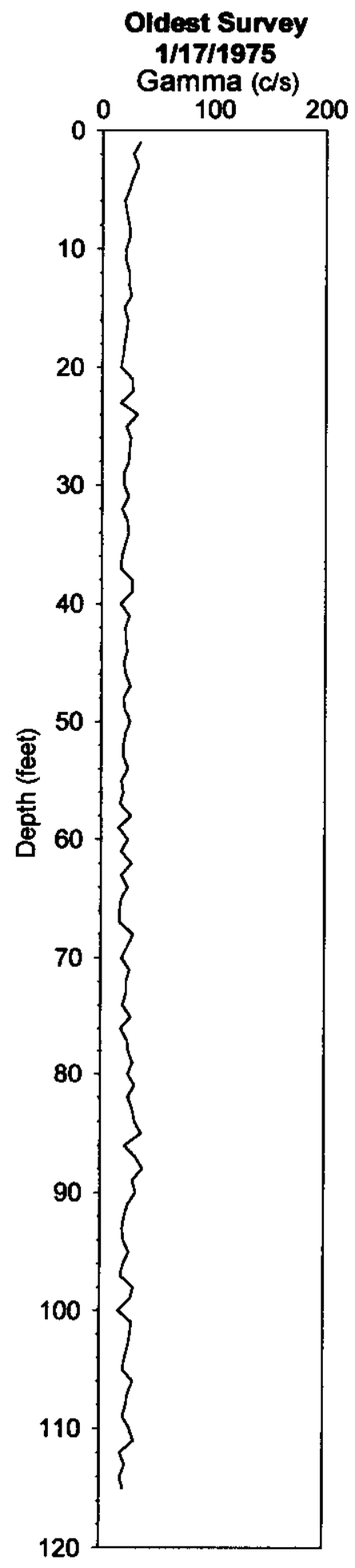

No Gamma-Ray Emitting Contamination

Above Survey Detection Threshold
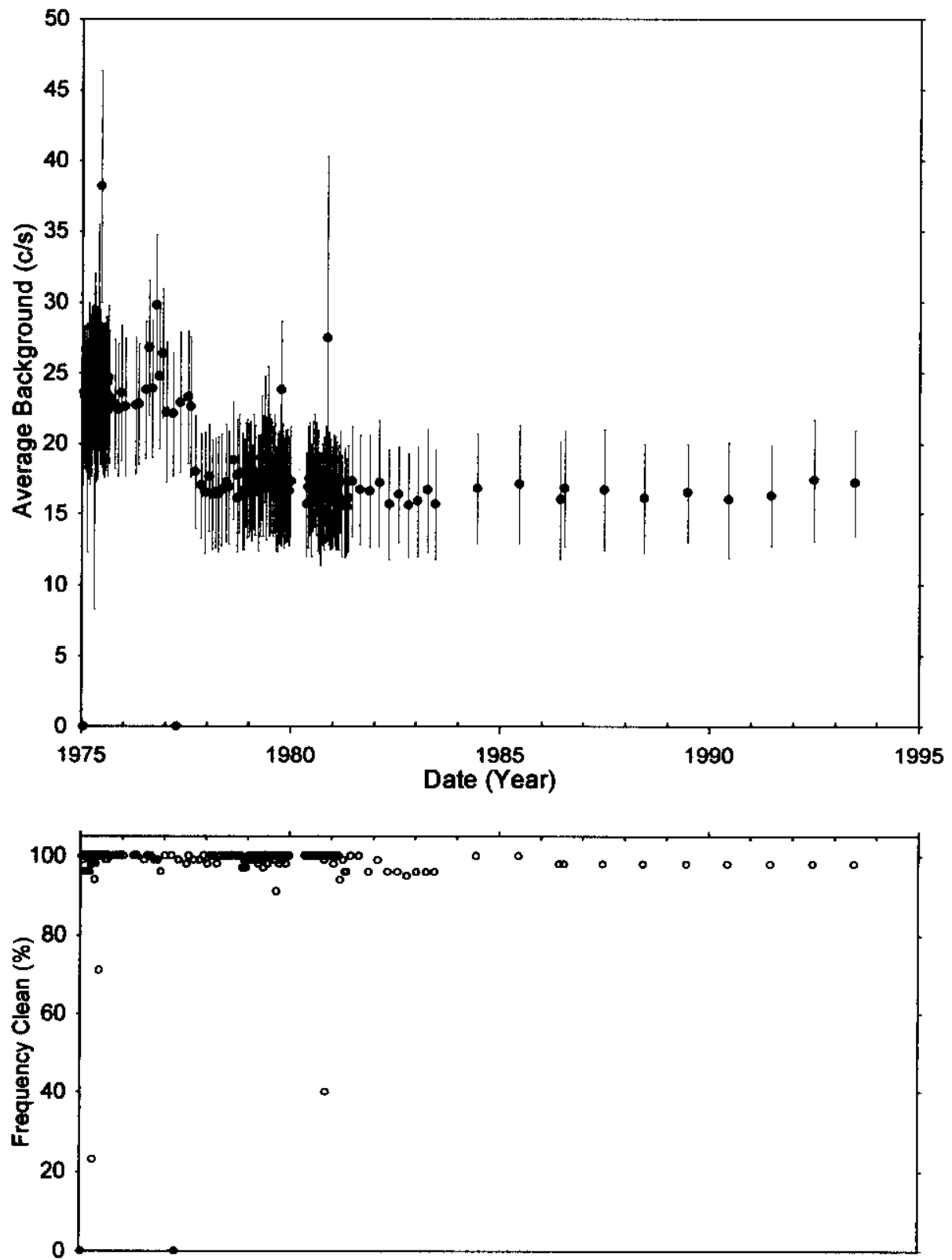

Anatysis by: Three Rivers Scientific

Peripheral Wells 
RPP-6088, Rev.0.

\section{Borehole 50-00-12}

\section{No Gamma Ray Emitting Contamination Identified.}

No significant levels of gamma ray contamination are present, based upon gross gamma data, above the survey probe detection threshold between 1975 and 1994 in the vadose zone from 2 to 143 feet. The HPGe logging system detected Cs-137 at $2 \mathrm{pCi} / \mathrm{g}$ (12 feet) and less than $1 \mathrm{pCi} / \mathrm{g}$ for the remainder of the survey.

The average background plot shows a step decrease after 7-15-77, and a second step decrease after 10-6-78.

Gross Gamma Survey Information

\begin{tabular}{|r|l|}
\hline Probe Type Processed : & $04: \mathrm{NaI}$ \\
\hline Other Probe Types : & $03:$ Neutron \\
\hline Survey Depth : & $145 \mathrm{ft}$ \\
\hline First Survey Date : & $1 / 13 / 1975$ \\
\hline Last Survey Date : & $6 / 23 / 1993$ \\
\hline Number Surveys Processed : & 154 \\
\hline
\end{tabular}

Analysis Notes

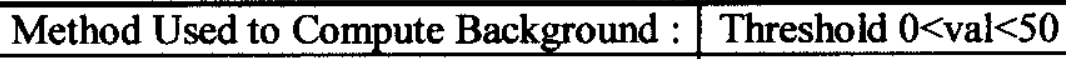

Depth(s) where Contamination Identified NONE in Gross Gamma Surveys :

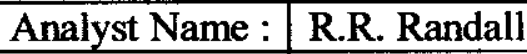

Company Name : Three Rivers Scientific 
RPP-6088, Rev.0.

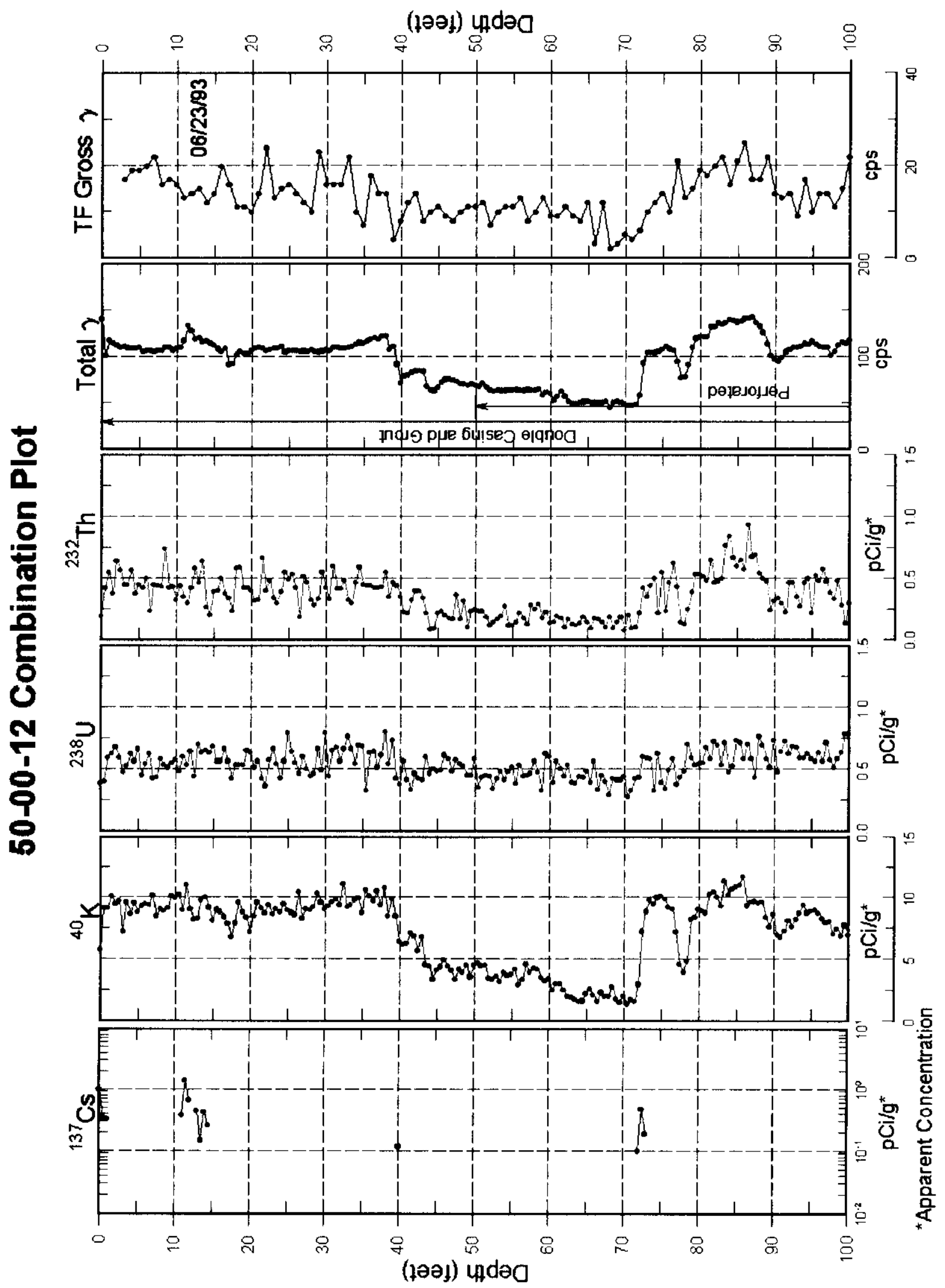

Peripheral Wells 
RPP-6088, Rev.0.

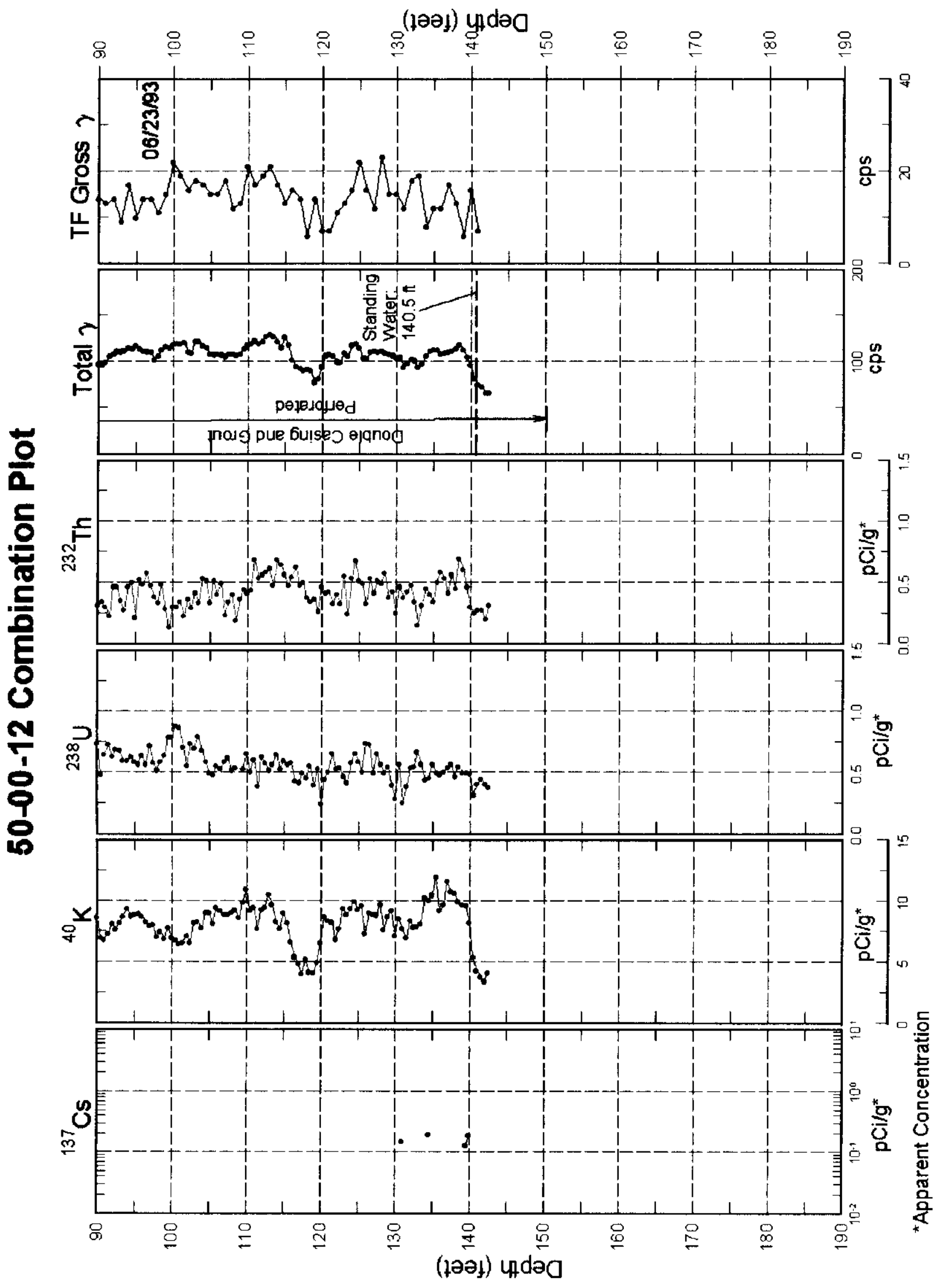

Peripheral Wells

Page 68 
RPP-6088, Rev.0.

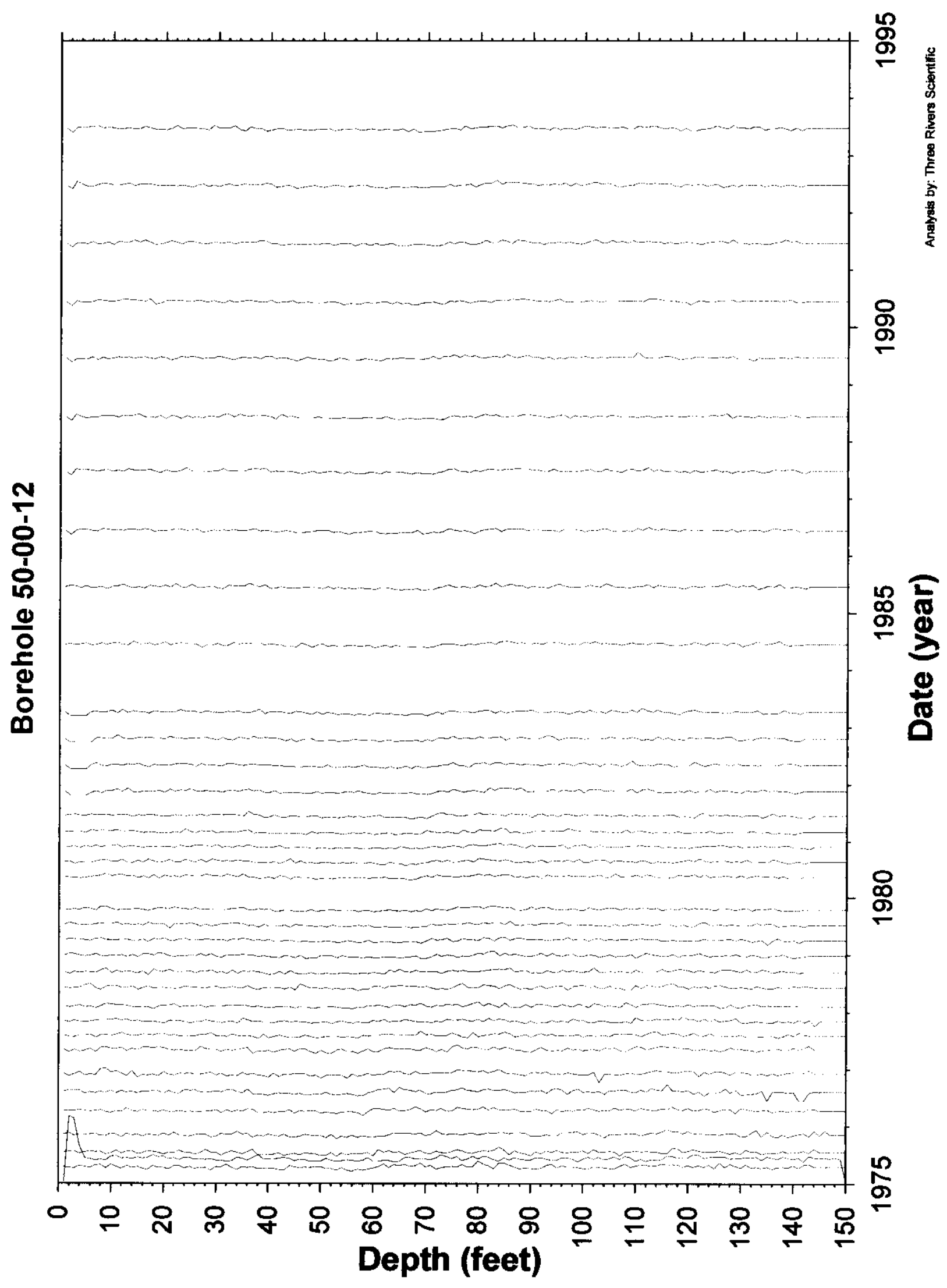

Peripheral Wells 
RPP-6088, Rev.0.

\section{Borehole 50-00-12}

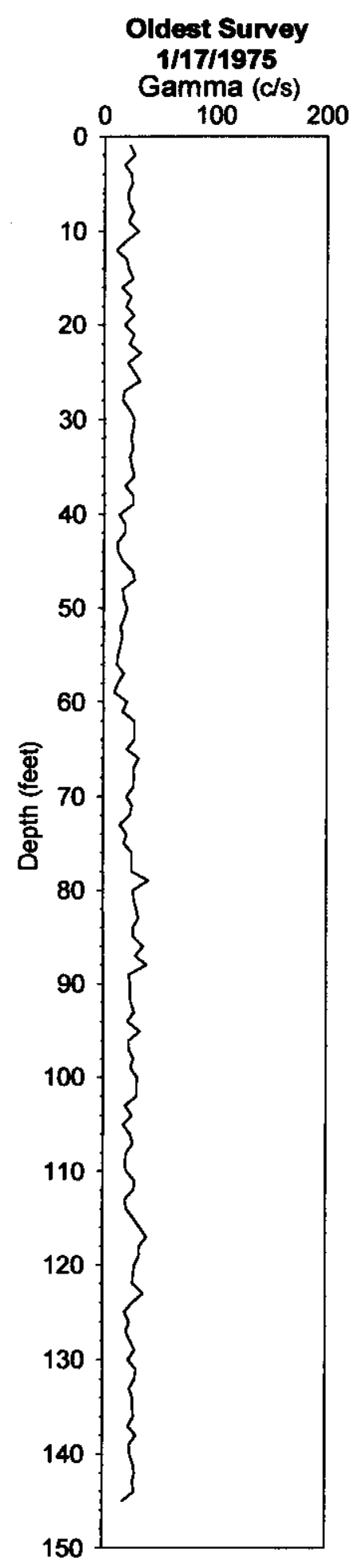

No Gamma-Ray Emitting Contamination
Above Survey Detection Threshold
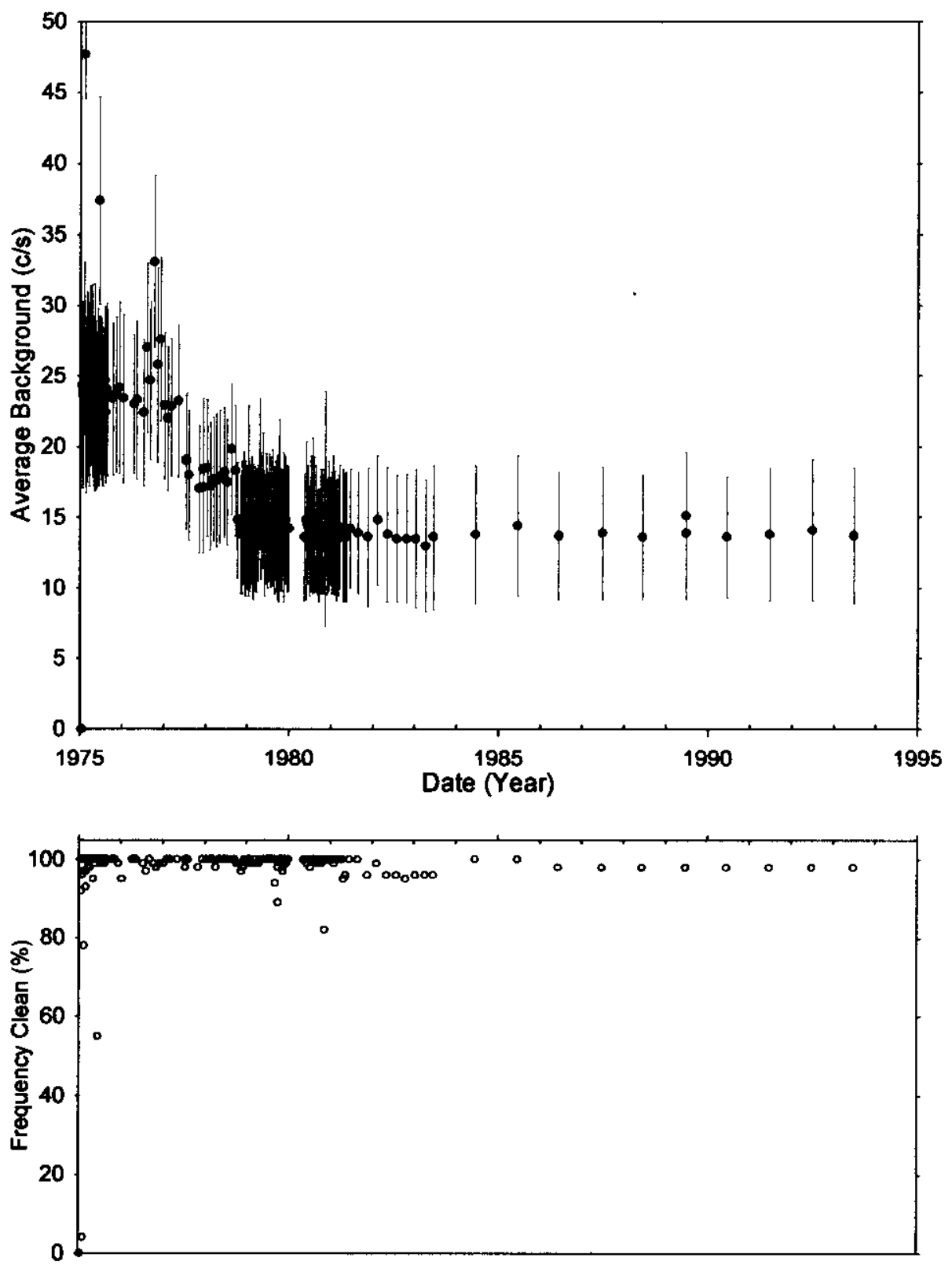

Analysis by: Three Rivers Scientific 
RPP-6088, Rev.0.

\section{Tank T-101 Wells}

Table of Contents Page

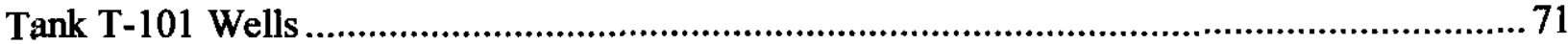

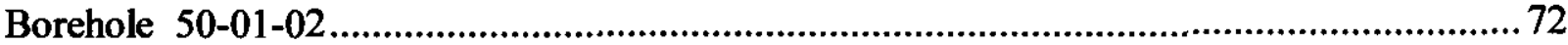

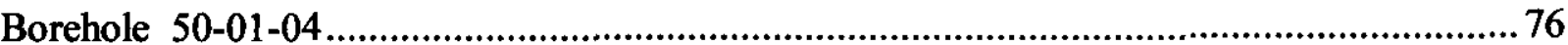

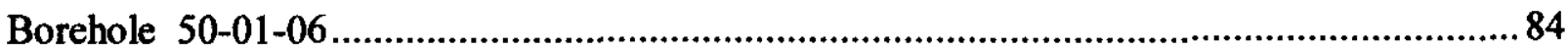

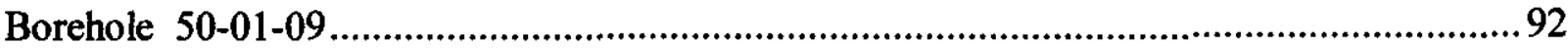

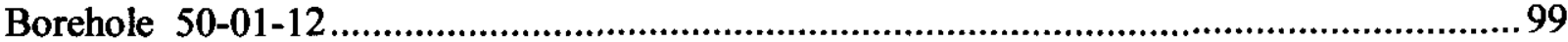

This section contains the analysis results for vadose zone boreholes (dry wells) associated with Tank 101 in the "T" Tank Farm.

Special Note:

None 


\section{Borehole 50-01-02}

\section{No Gamma Ray Emitting Contamination Identified.}

No significant levels of gamma ray contamination are present, based upon gross gamma data, above the survey probe detection threshold between 1975 and 1995 in the vadose zone from 2 to 93 feet. The HPGe logging system detected Cs-137 at less than $1 \mathrm{pCi} / \mathrm{g}$.

The average background plot shows a step decrease after 9-16-80.

Gross Gamma Survey Information

\begin{tabular}{|r|l|}
\hline Probe Type Processed : & $04:$ NaI \\
\hline Other Probe Types : & $\begin{array}{l}\text { 03: Neutron(3); 02: Red GM(1); } \\
14: \text { Shielded NaI(1) }\end{array}$ \\
\hline Survey Depth : & $95 \mathrm{ft}$ \\
\hline First Survey Date : & $1 / 13 / 1975$ \\
\hline Last Survey Date : & $5 / 26 / 1994$ \\
\hline Number Surveys Processed : & 440 \\
\hline
\end{tabular}

Analysis Notes

Method Used to Compute Background : Threshold $0<$ val $<50$

Depth(s) where Contamination Identified NONE

in Gross Gamma Surveys :

Analyst Name : R.R. Randall

Company Name : $\quad$ Three Rivers Scientific 


\section{RPP-6088, Rev.0.}

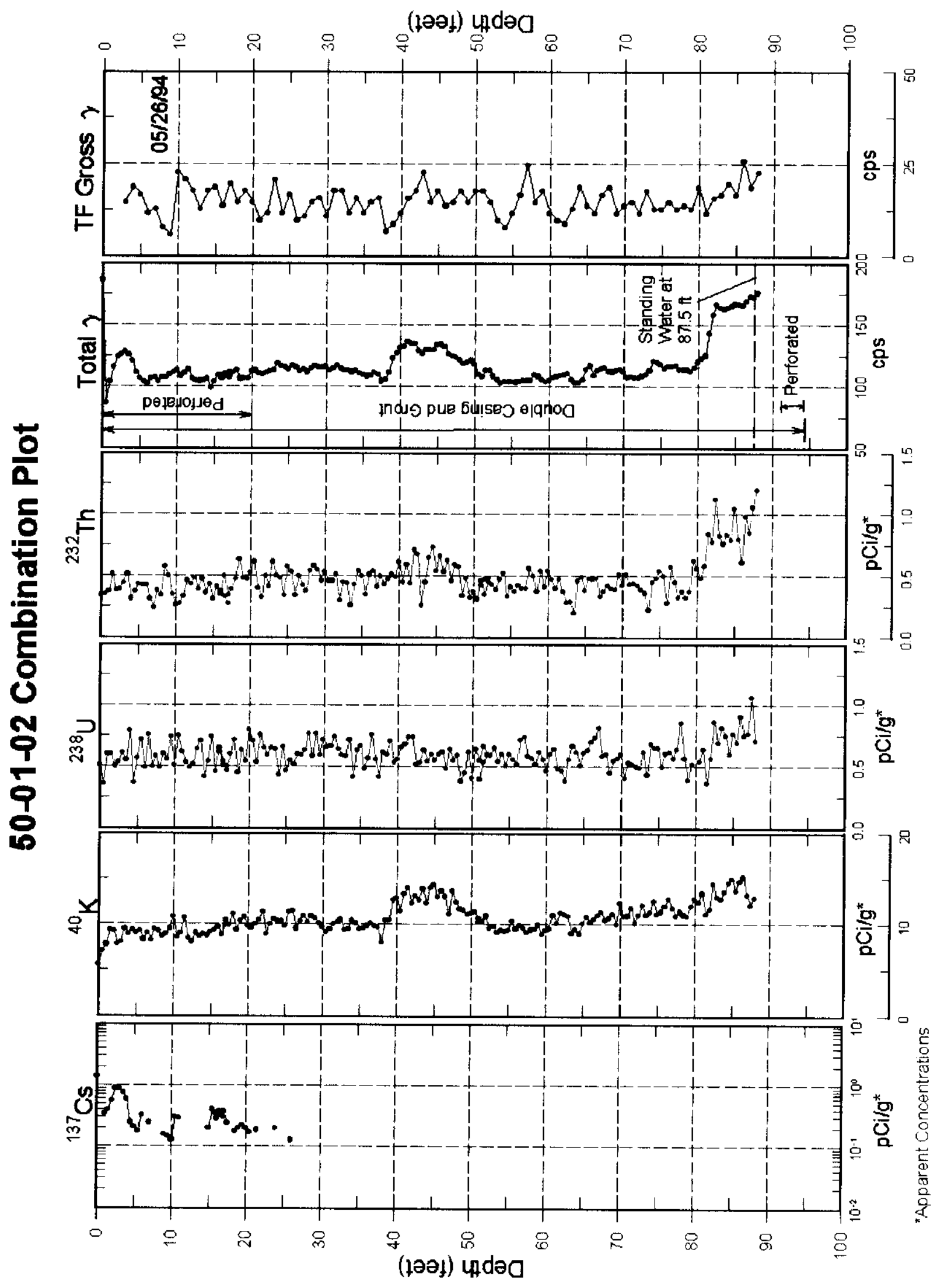

Tank T-101

Page 73 
RPP-6088, Rev.0.

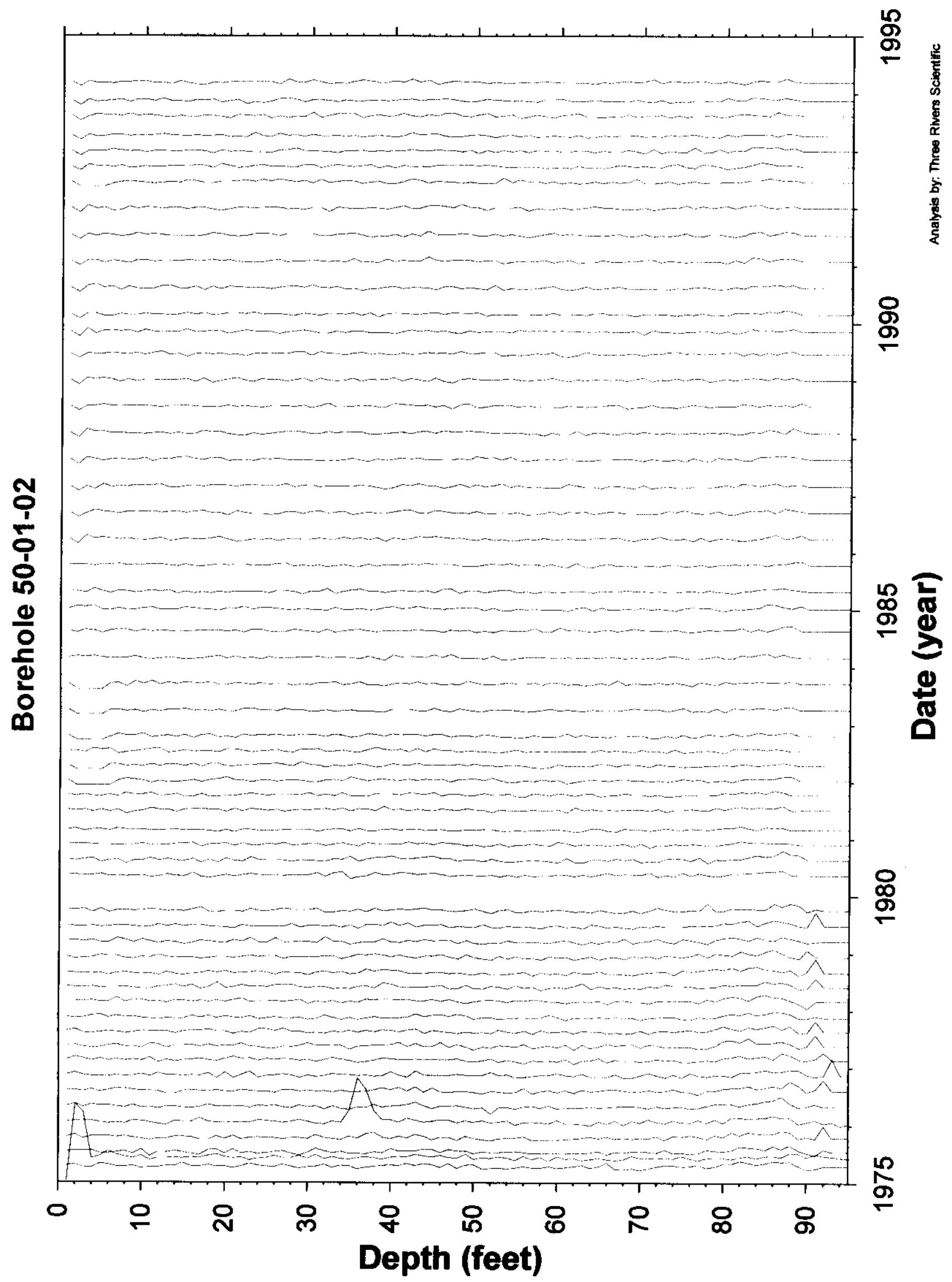

Tank T-101

Page 74 


\section{Borehole 50-01-02}

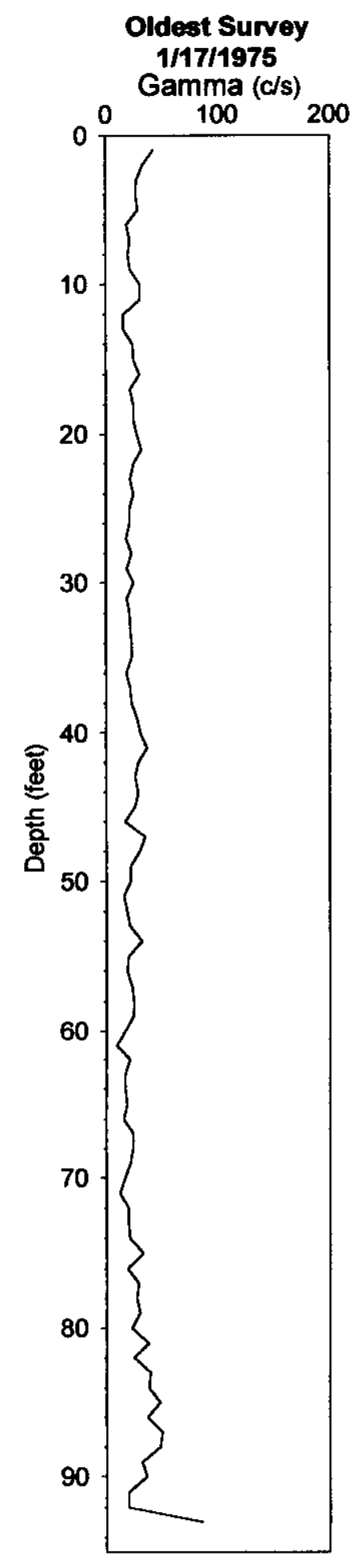

\section{No Gamma-Ray Emitting Contamination \\ Above Survey Detection Threshold}
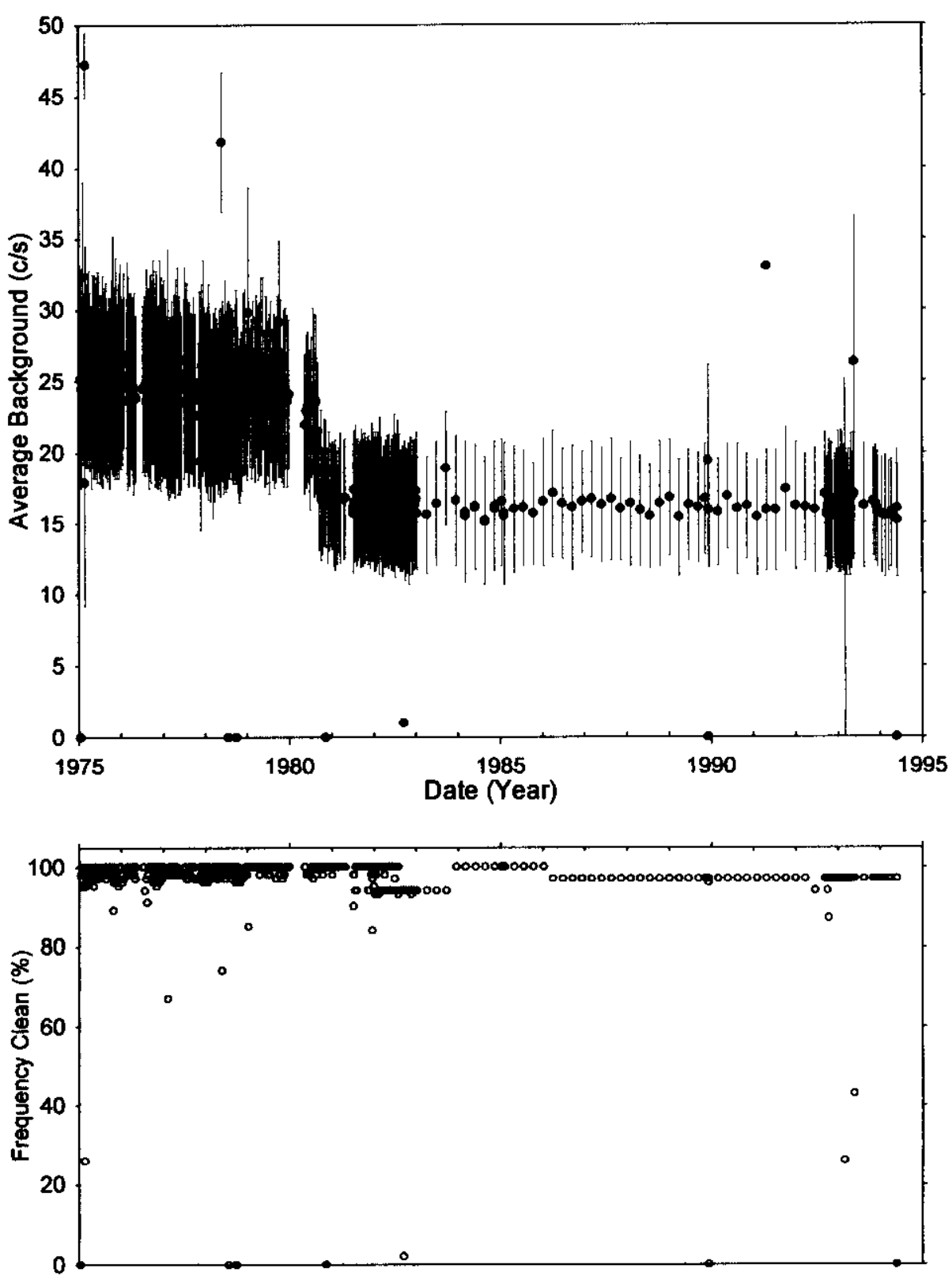

Analysis by: Three Rivers Scientific 
RPP-6088, Rev.0.

\section{Borehole 50-01-04}

\section{Contamination (Cs-137) from 15-40 feet is Stable. Contamination (Cs-137) from 40-55 feet is Stable. Contamination (Cs-137) from 55-70 feet is Stable. Contamination (Cs-137) from 75-90 feet is Undetermined.}

The average background plot shows a step decrease after 3-10-81. The survey depth increased from 86 to 125 feet after this date. Also, the distribution of contaminant over 40 to 55 feet changed character after this date.

Grade thickness product over the depth intervals of 15-40, 40-55, and 55-70 feet is decreasing consistent with Cs-137 (HPGe identified) decay. The Red GM probe (type 02) experienced design changes from 1975 to 1982 , and consistent design after 1982. Therefore, the categorization of stable is based upon the time match after 1982, and the data before 1982 is not used. (Note, the HPGe detector system experienced high count rate limitations, but only Cs-137 is identified above and below the intervals.)

Grade thickness product over 75 to 90 feet is zero after the depth of the surveys increased. The HPGe identified Cs- 137 at levels above $1000 \mathrm{pCi} / \mathrm{g}$, however this amount may not be detectable by the Red GM instrumentation. Before the depth increase, the known red GM probe design changes interfere with any determination of zone condition, thus the classification is undetermined.

Gross Gamma Survey Information

\begin{tabular}{|r|l|}
\hline Probe Type Processed : & 02: Red GM \\
\hline Other Probe Types : & $\begin{array}{l}\text { 03: Neutron(5); 01: Green GM(8); } \\
04: \text { NaI(25); 14: Shielded NaI(1) }\end{array}$ \\
\hline Survey Depth : & $125 \mathrm{ft}$ \\
\hline First Survey Date : & $1 / 15 / 1975$ \\
\hline Last Survey Date : & $5 / 31 / 1994$ \\
\hline Number Surveys Processed : & 444 \\
\hline
\end{tabular}

Analysis Notes

Method Used to Compute Background : $\quad$ Threshold $0<$ val $<20$

Depth(s) where Contamination Identified $15-40,40-55, \&$ 55-70 ft Stable

in Gross Gamma Surveys : $75-90 \mathrm{ft}$ Undetermined

Analyst Name : $\quad$ R.R. Randall

Company Name : Three Rivers Scientific 
RPP-6088, Rev.0.

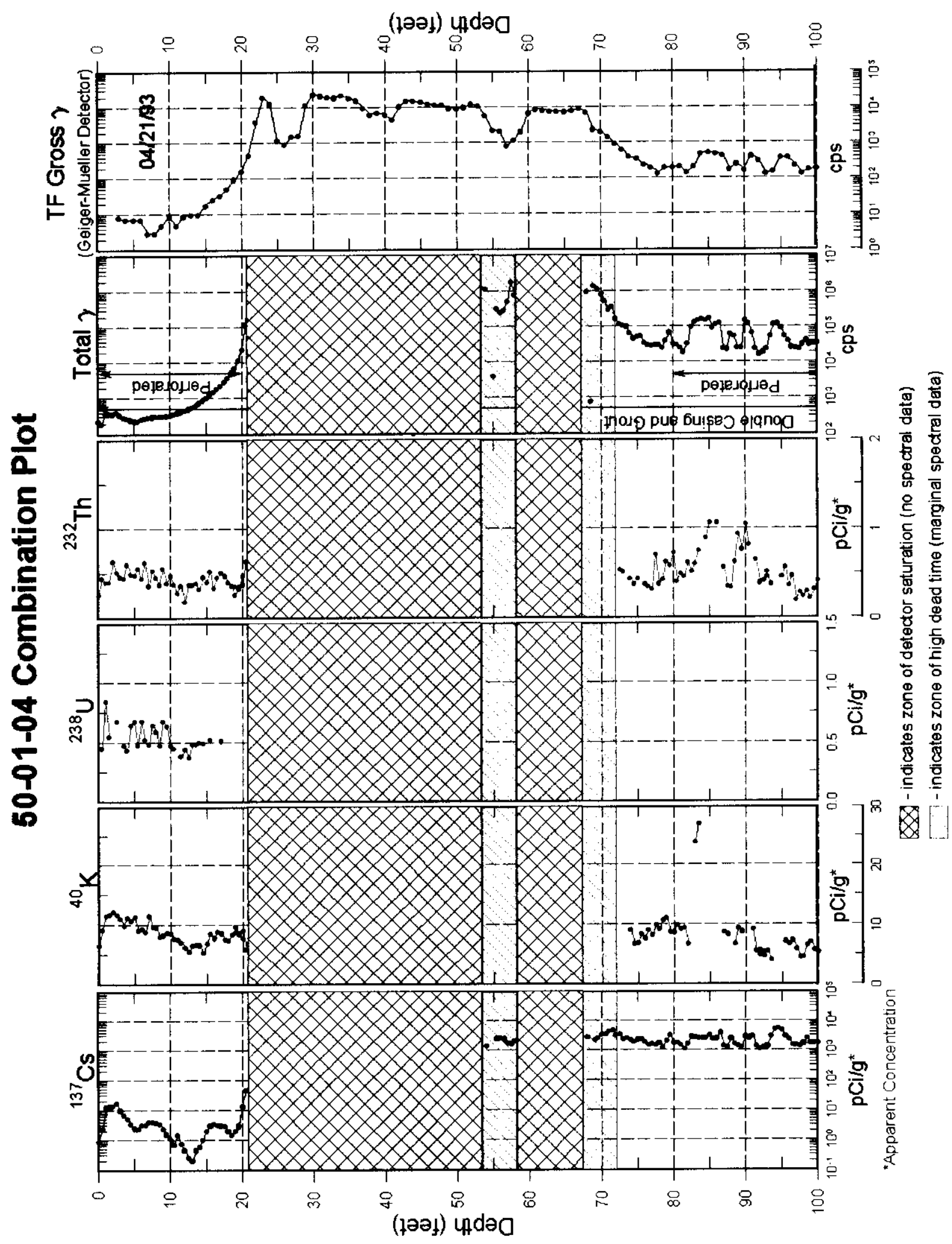




\section{RPP-6088, Rev.0.}

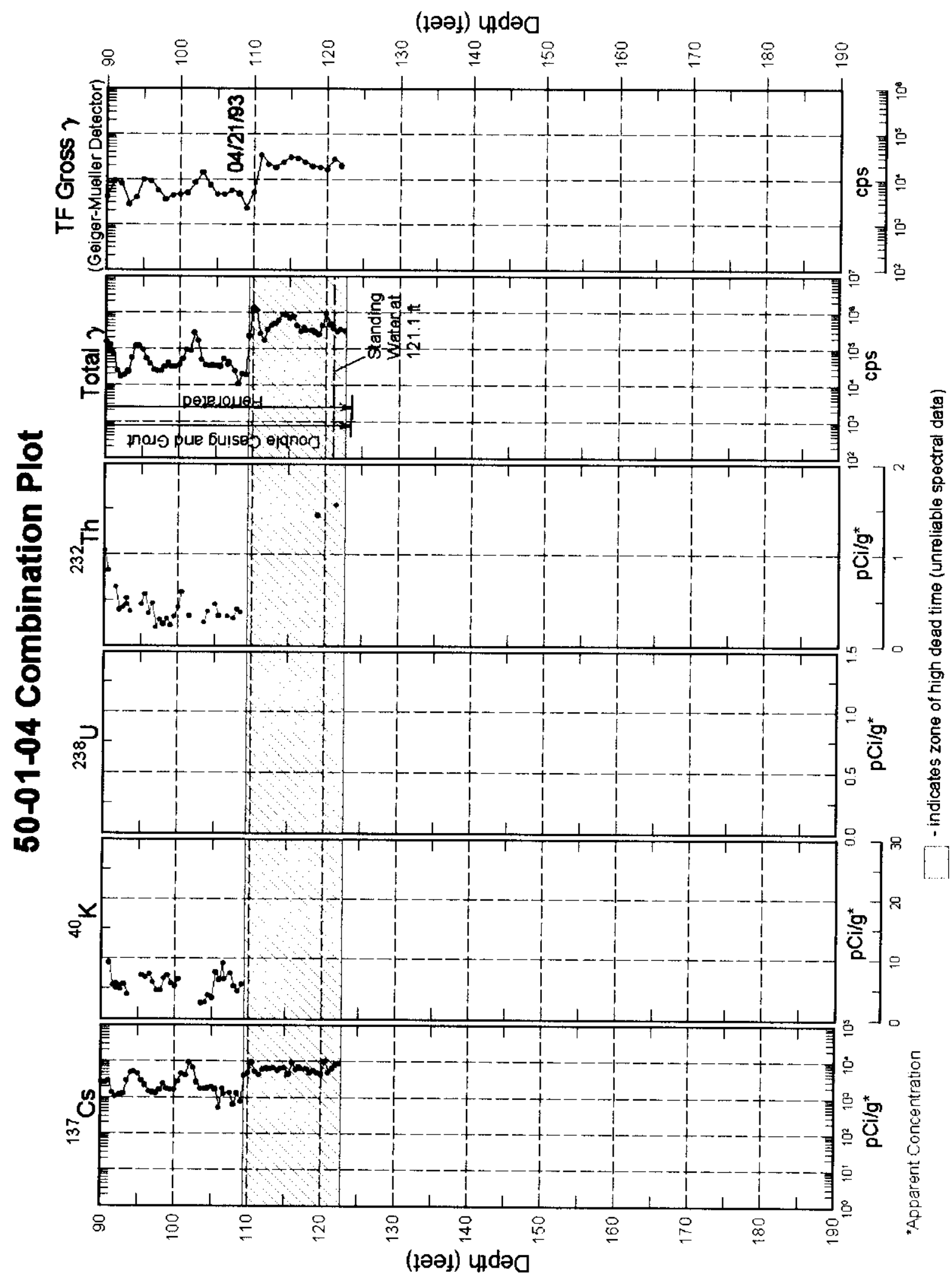


RPP-6088, Rev.0.

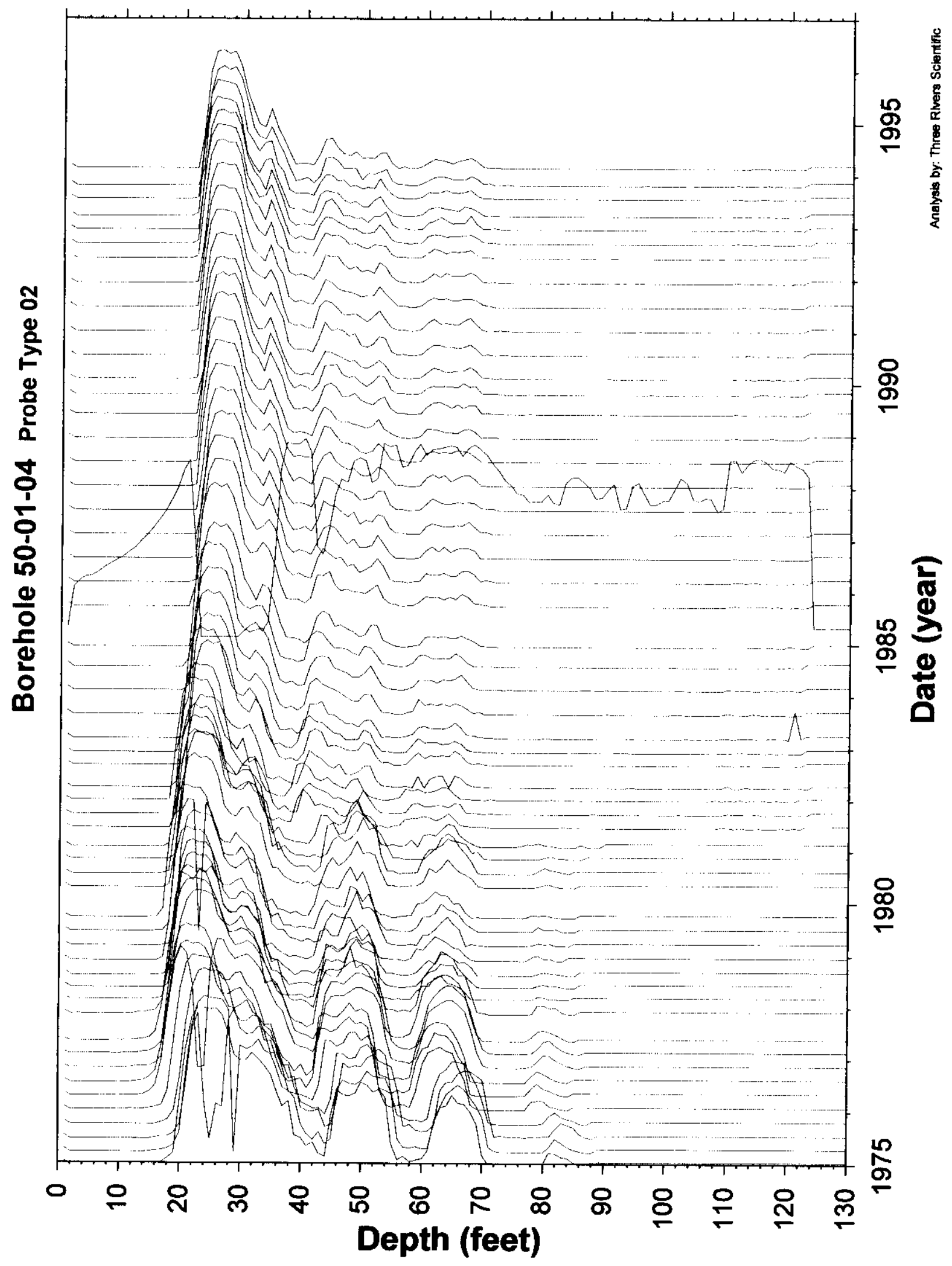

Tank T-101

Page 79 
RPP-6088, Rev.0.
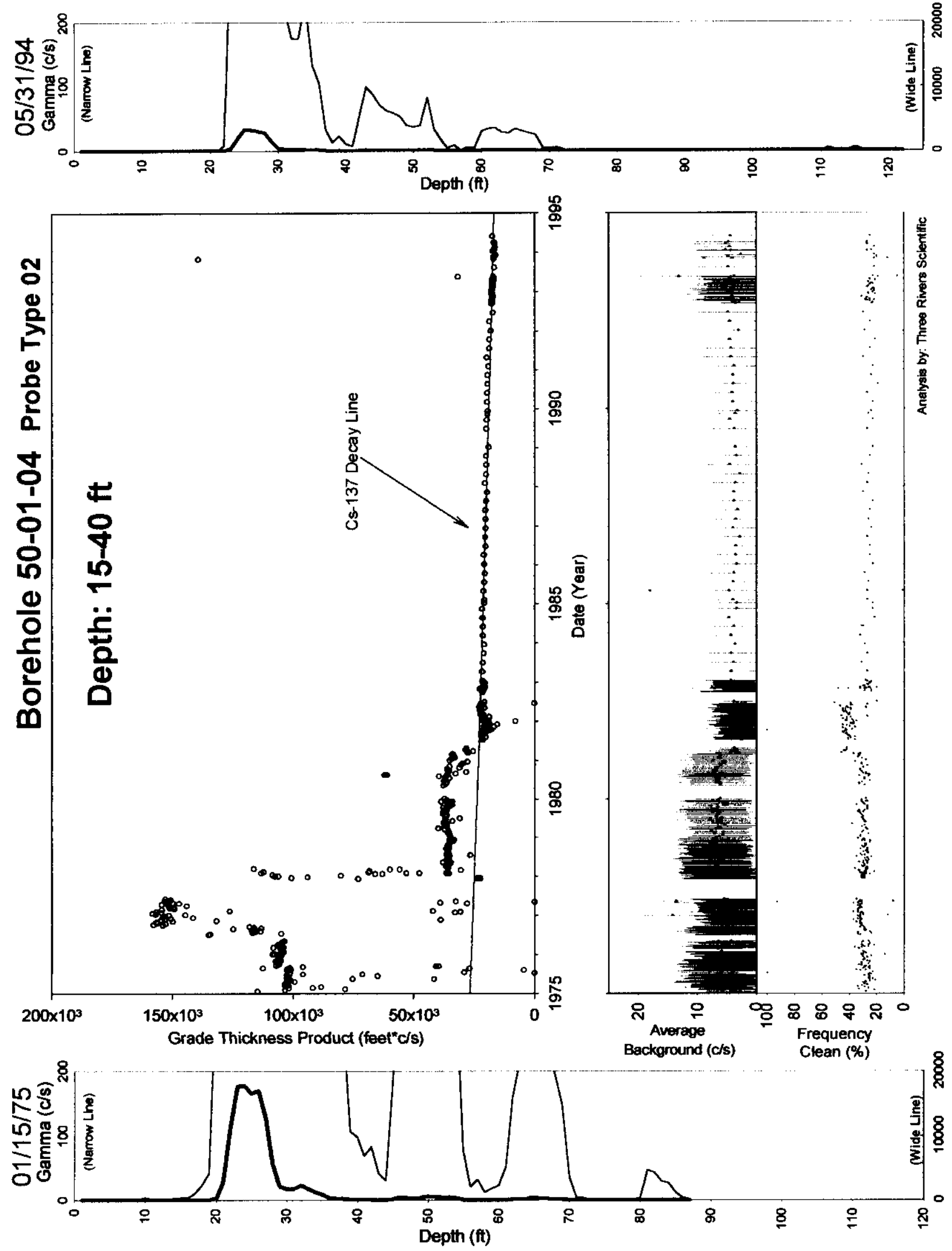

Tank T-101 
RPP-6088, Rev.0.
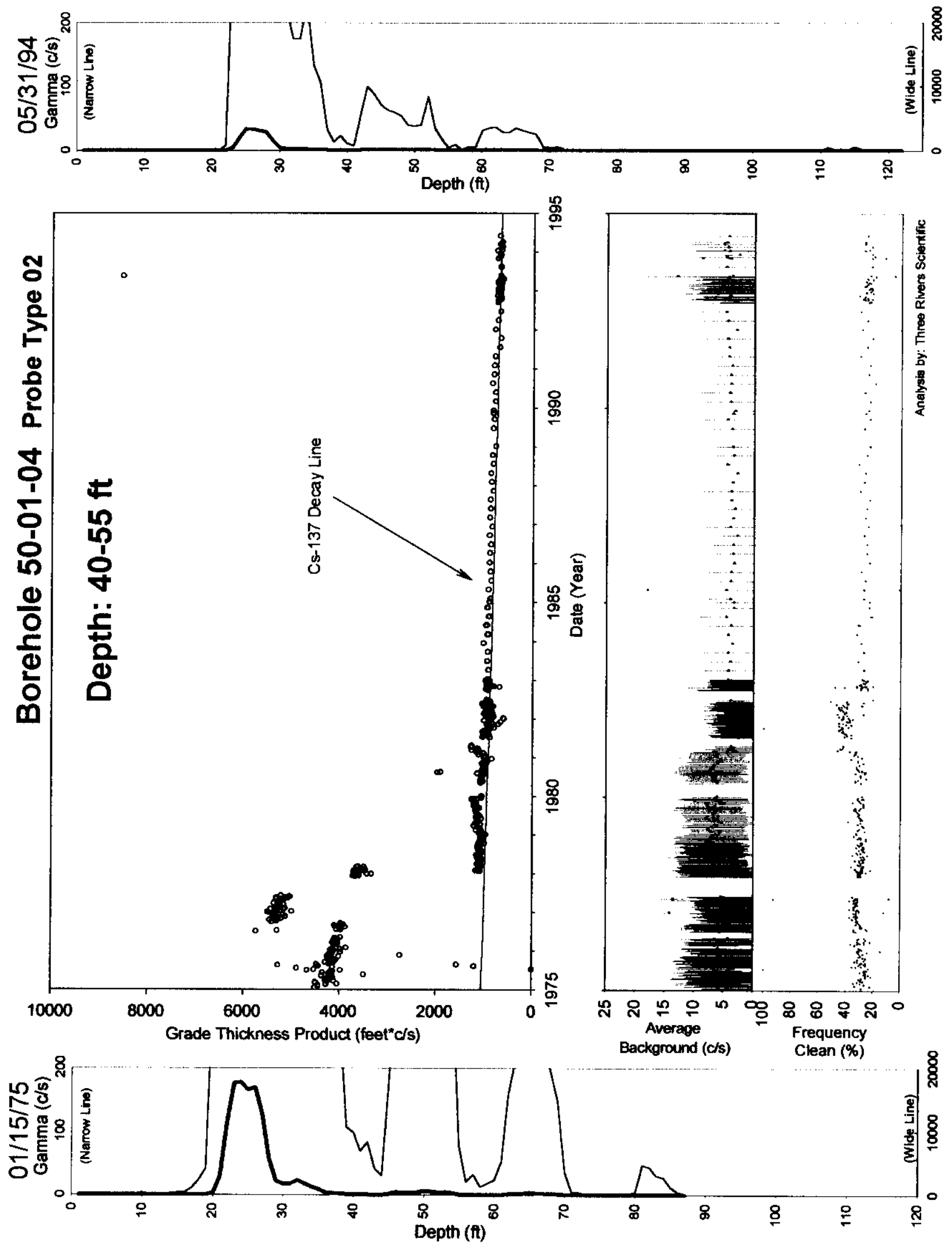

Tank T-101 
RPP-6088, Rev.0.
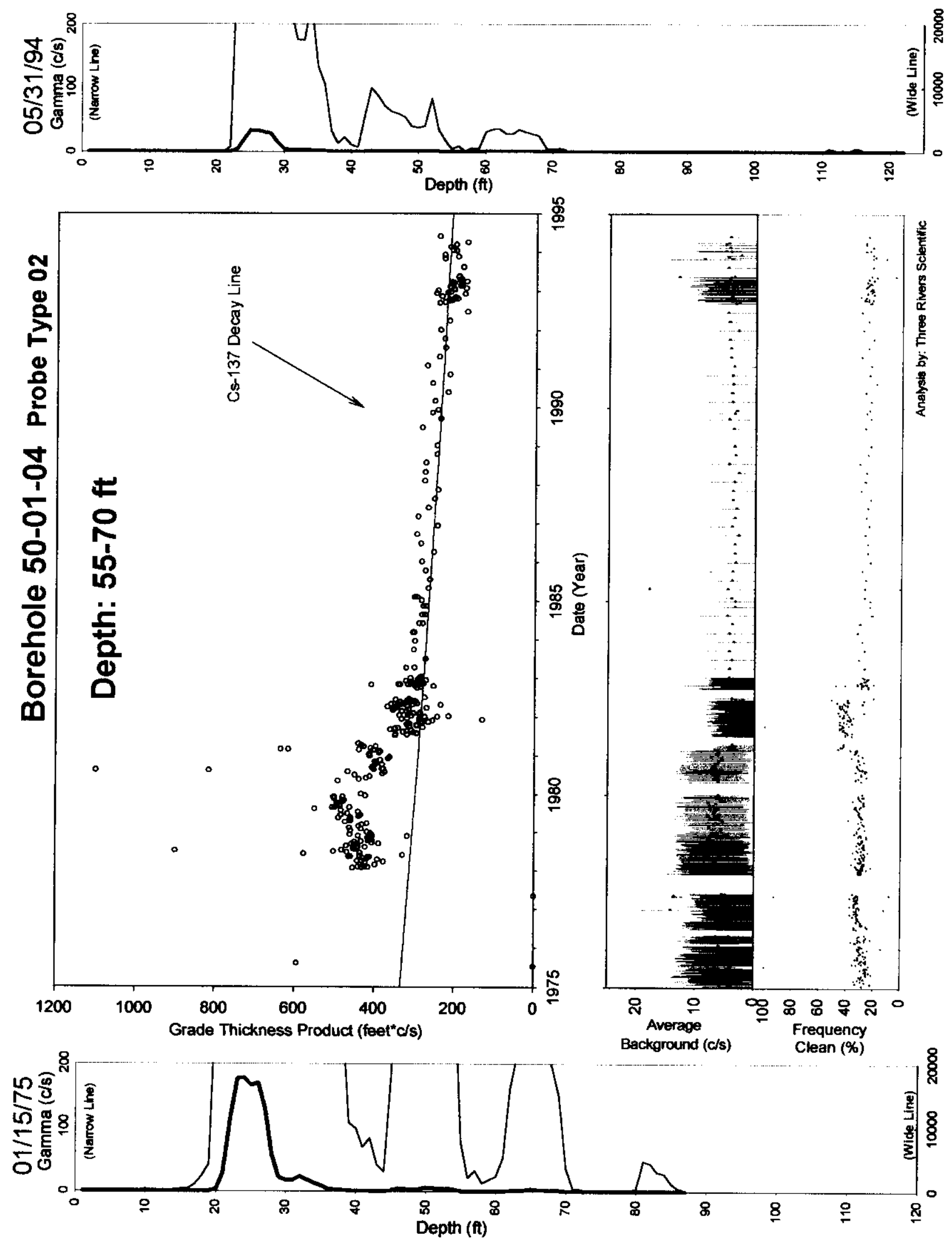

Tank T-101

Page 82 
RPP-6088, Rev.0.
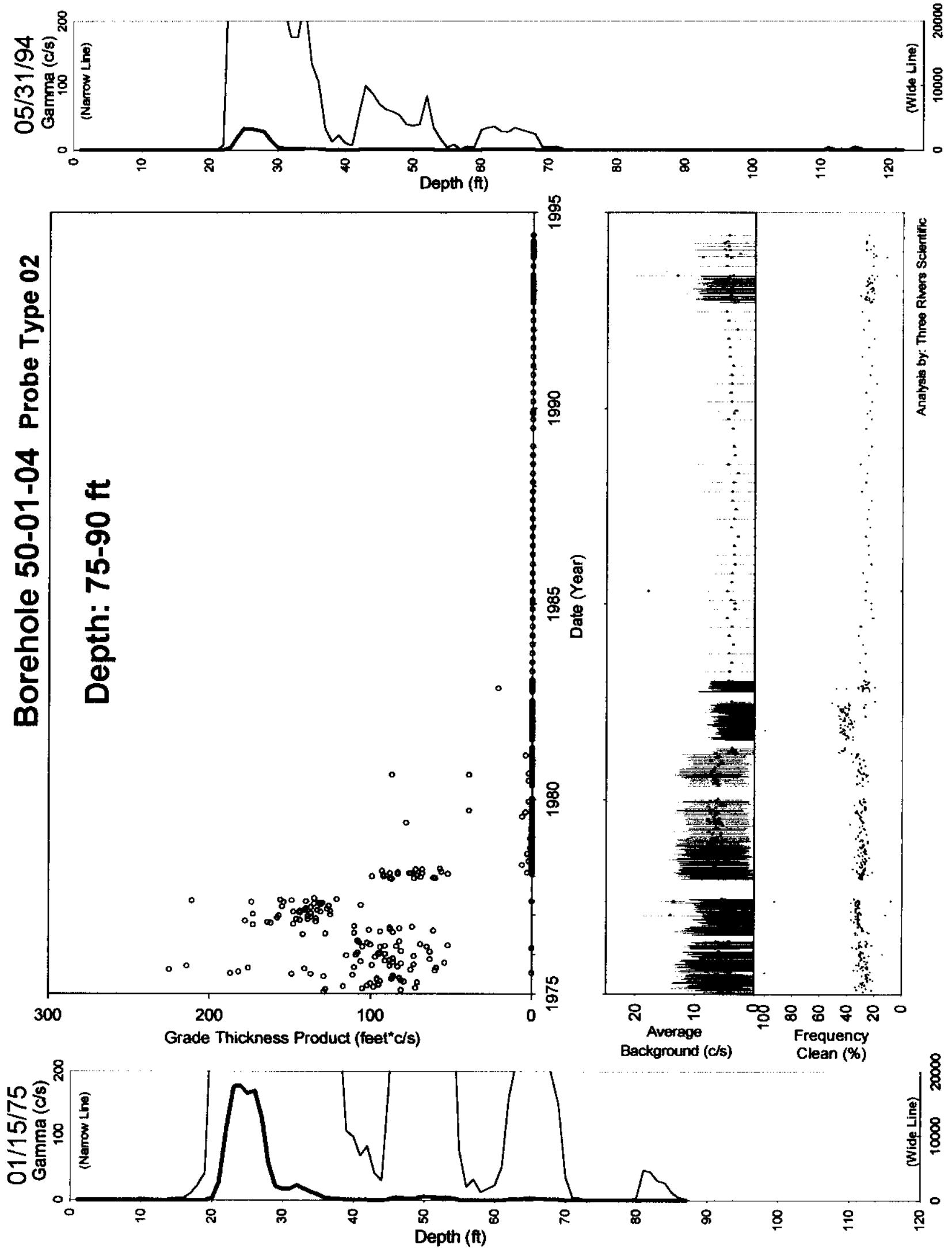

Tank T-101 


\title{
Borehole 50-01-06
}

\author{
Contamination (Cs-137) from 0-8 feet is Tank Farm Activity. \\ Contamination (Co-60 \& Ru-106) from 45-69 feet is Unstable Early. \\ Contamination (Co-60) from 69-78 feet is Undetermined. \\ Contamination (Co-60) from 78-90 feet is Undetermined.
}

Grade thickness product over 0 to 8 feet shows large deviations from 1975 until mid 1982, and after 1984 the consistency improves, but systematic cyclic (yearly) changes occur. The time period of large variations (1975-1982) may be a result of depth control error near the surface before 1984. From 1984 through 1994 the average decline is much faster than Cs-137 (HPGe identified) decay.

The interval from 45 to 69 feet exhibits complex character in the grade thickness plot. A disconunity exists in mid 1976 where before this time the decline is linear, and from 1976 until 1980 the grade thickness decreases consistent with Co-60 (HPGe identified) and Ru-106 (hypothesized). A step decrease in both the average background and grade thickness product occurs after 9-16-80. Since no least square fit is possible for all time periods, no scaling derived from the average background change was computed. Eu-152 and Eu-154 were also HPGe identified in this interval. There is a contaminant influx in 1985, when there is good depth control and no average background changes. The grade thickness product is declining consistent with a least square fit for Co-60, Eu-154 (both HPGe identified), and Ru-106 (hypothesized). Rapid decay is visible from 1986, suggesting the presence of Ru-106. Note that the use of more than a three decay rate least square fit is not unique for such a short time span of 1986 to 1995 . The ratio of gross gamma contributions from $\mathrm{Ru}: \mathrm{Co}: \mathrm{Eu}$ is 1.6:412:296 as of 5-26-1994. Since the grade thickness product is a consistent decline since 1986 the classification is unstable early.

The grade thickness product over 69 to 78 feet shows two distinct influx events. One starts in mid 1975, with a rapid increase, and the second influx starts near 1980, with a slow increase until 1987. From mid 1990 until mid 1994 there is a good match with the Co-60 (HPGe identified) decay. The stack plot shows the lower portion of this interval increasing from 1990 to 1994 . This could be slight downward movement, or a result of influx in the lower zone from 78 to 90 feet. Thus the classification is undetermined.

The grade thickness product over 78 to 90 feet shows an early decline, with a slow influx starting in 1984, and mixed influx intensity character until 1991. After 1991 there appears to be a match with the Co-60 (HPGe identified) decay. The stack plot shows a clear build-up in a horizontal manner. Since there is not enough time period of stability, the classification is undetermined. 


\section{RPP-6088, Rev.0.}

Gross Gamma Survey Information

\begin{tabular}{|r|l|}
\hline Probe Type Processed : & $04:$ NaI \\
\hline Other Probe Types : & $\begin{array}{l}\text { 03: Neutron(6) 01: Green GM(1) } \\
\text { 14: Shielded NaI(1) }\end{array}$ \\
\hline Survey Depth : & $90 \mathrm{ft}$ \\
\hline First Survey Date : & $1 / 13 / 1975$ \\
\hline Last Survey Date : & $5 / 26 / 1994$ \\
\hline Number Surveys Processed : & 853 \\
\hline
\end{tabular}

Analysis Notes

Method Used to Compute Background : $\quad$ Threshold $0<$ val $<50$

Depth(s) where Contamination Identified $0-8 \mathrm{ft}$ Tank Farm Activity, in Gross Gamma Surveys : $45-69 \mathrm{ft}$ Unstable Early, 69-78 \& 78-90 ft Undetermined

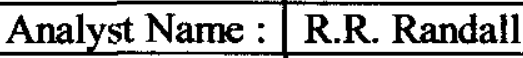

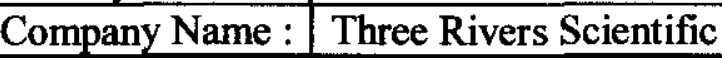


RPP-6088, Rev.0.

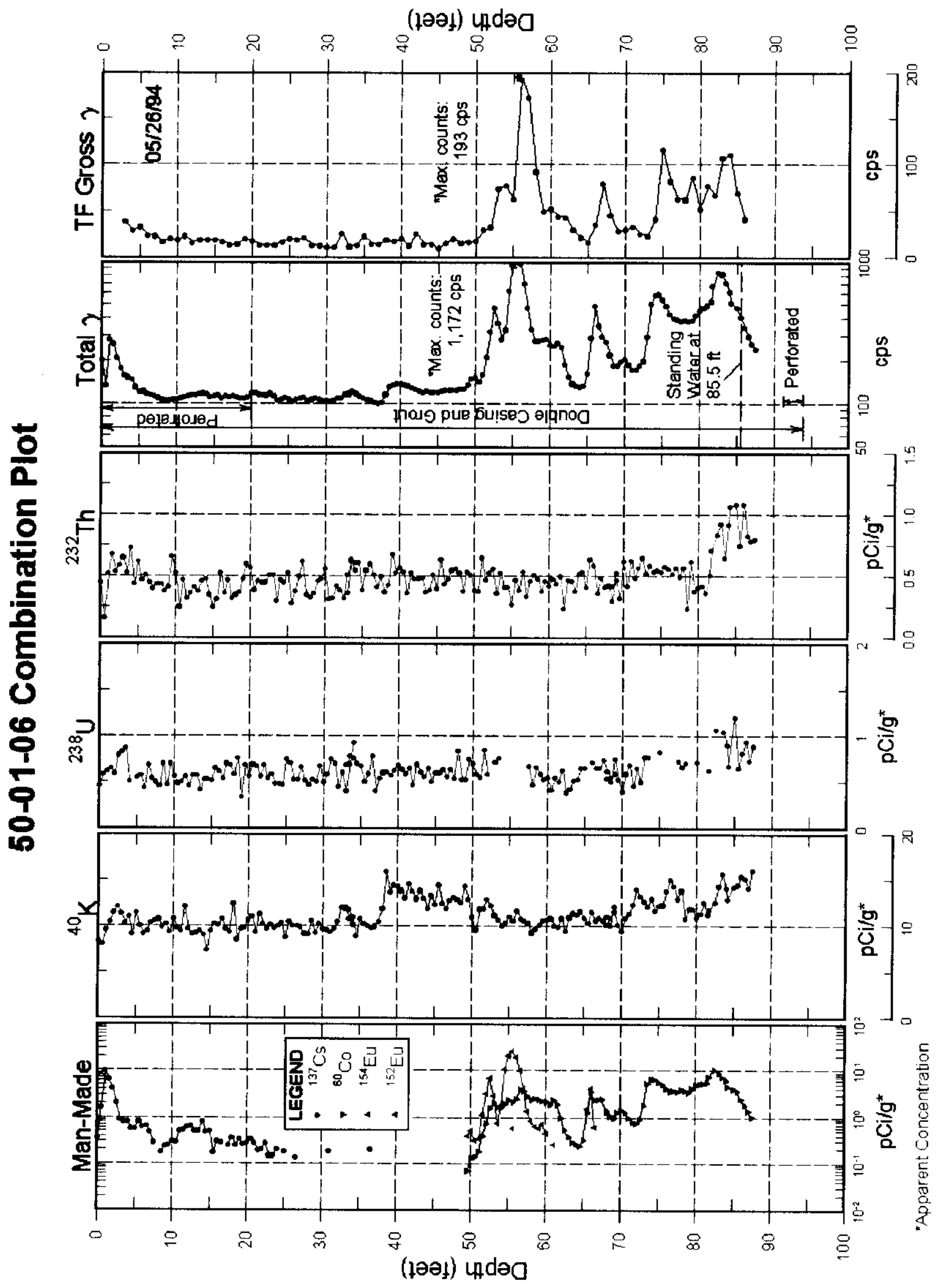

Tank T-101

Page 86 
RPP-6088, Rev.0.

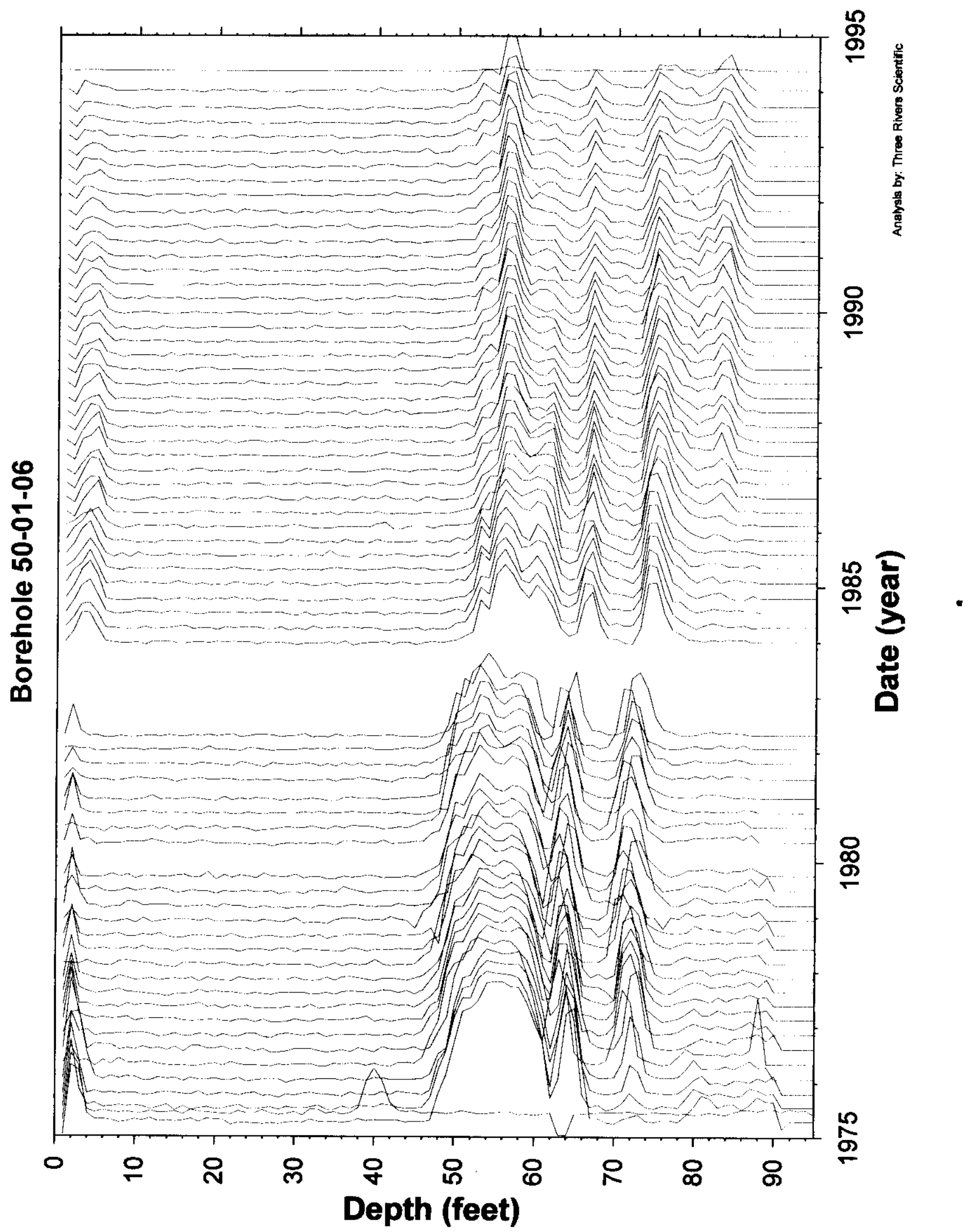

Tank T-101

Page 87 
RPP-6088, Rev.0.
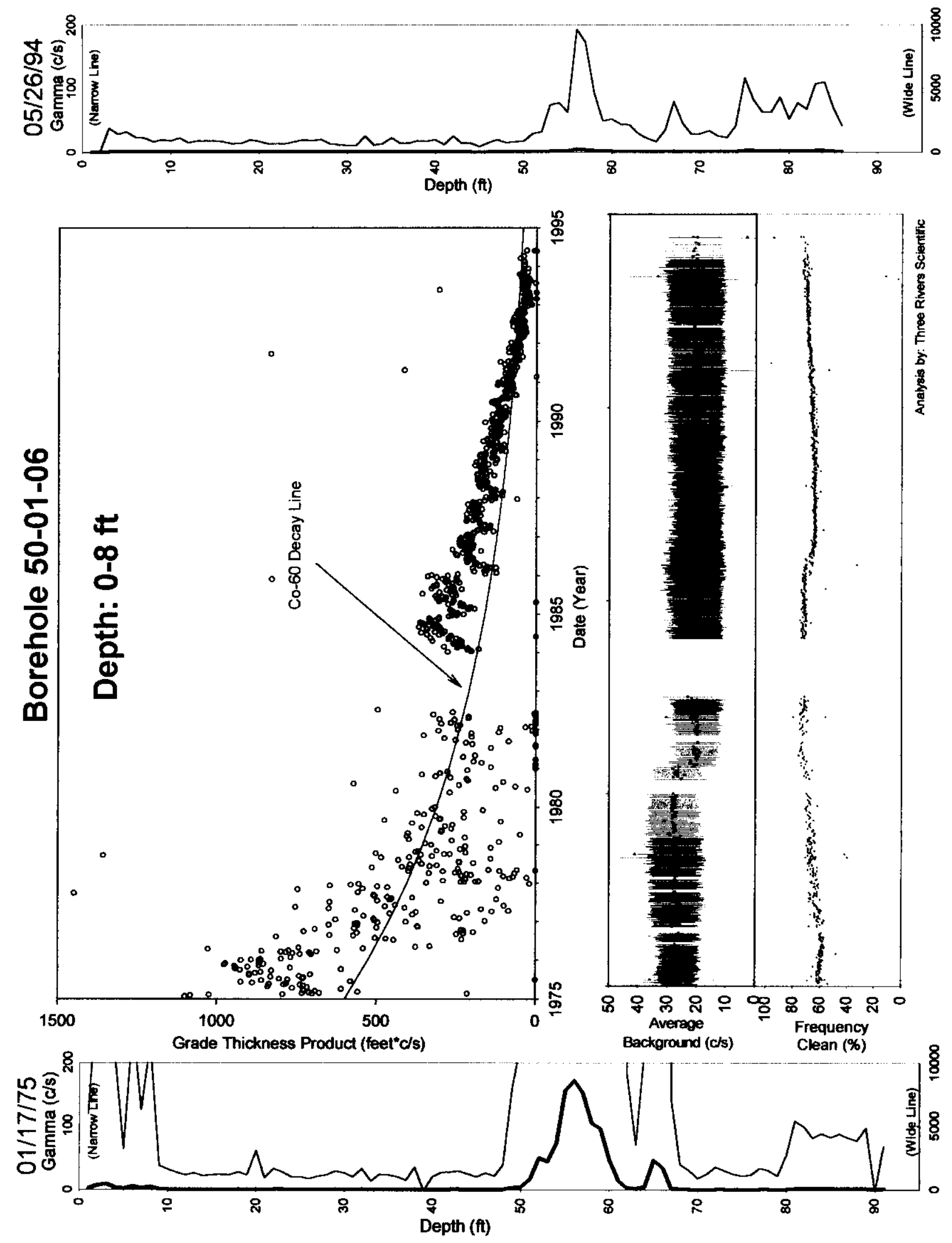

Tank T-101 
RPP-6088, Rev.0.
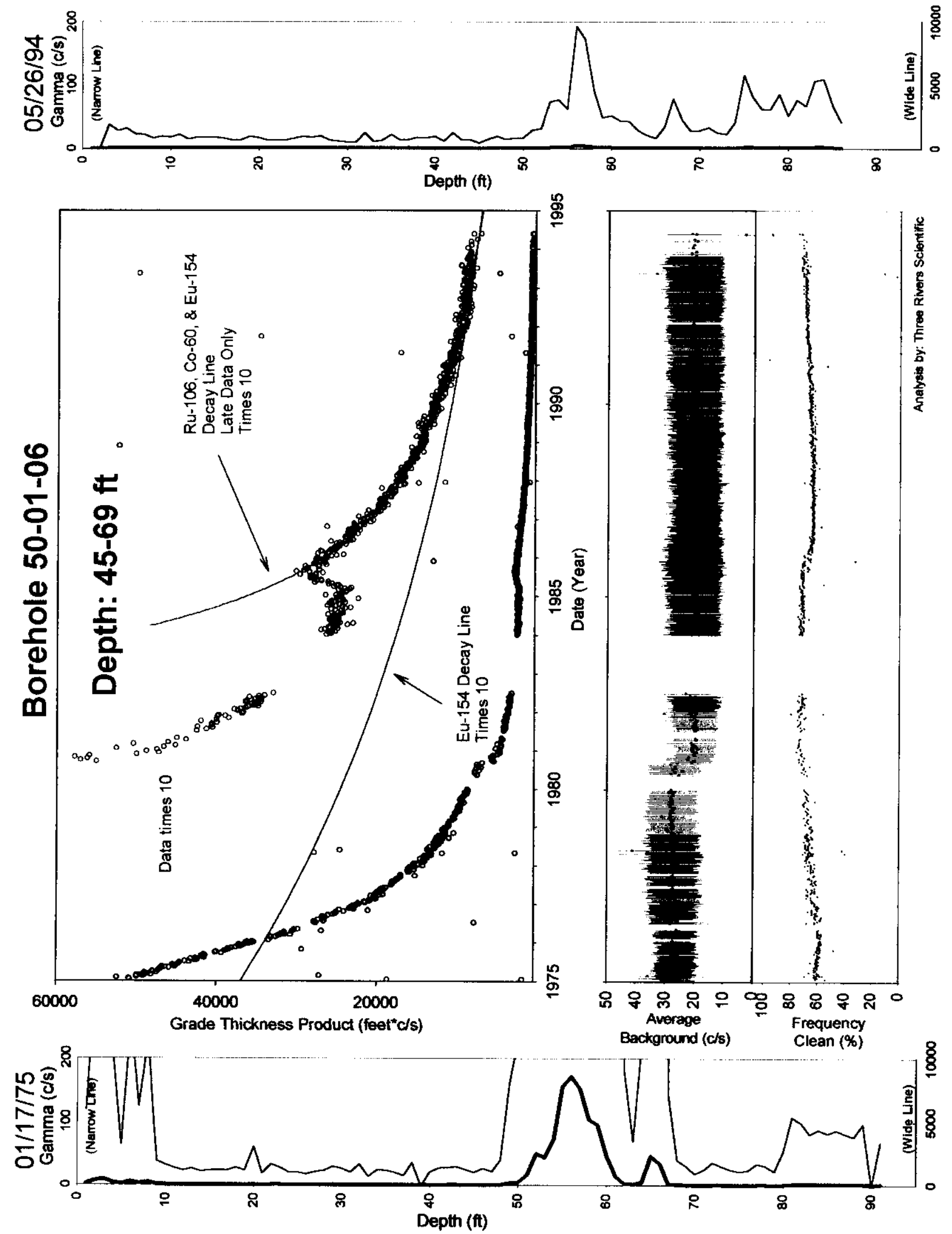
RPP-6088, Rev.0.
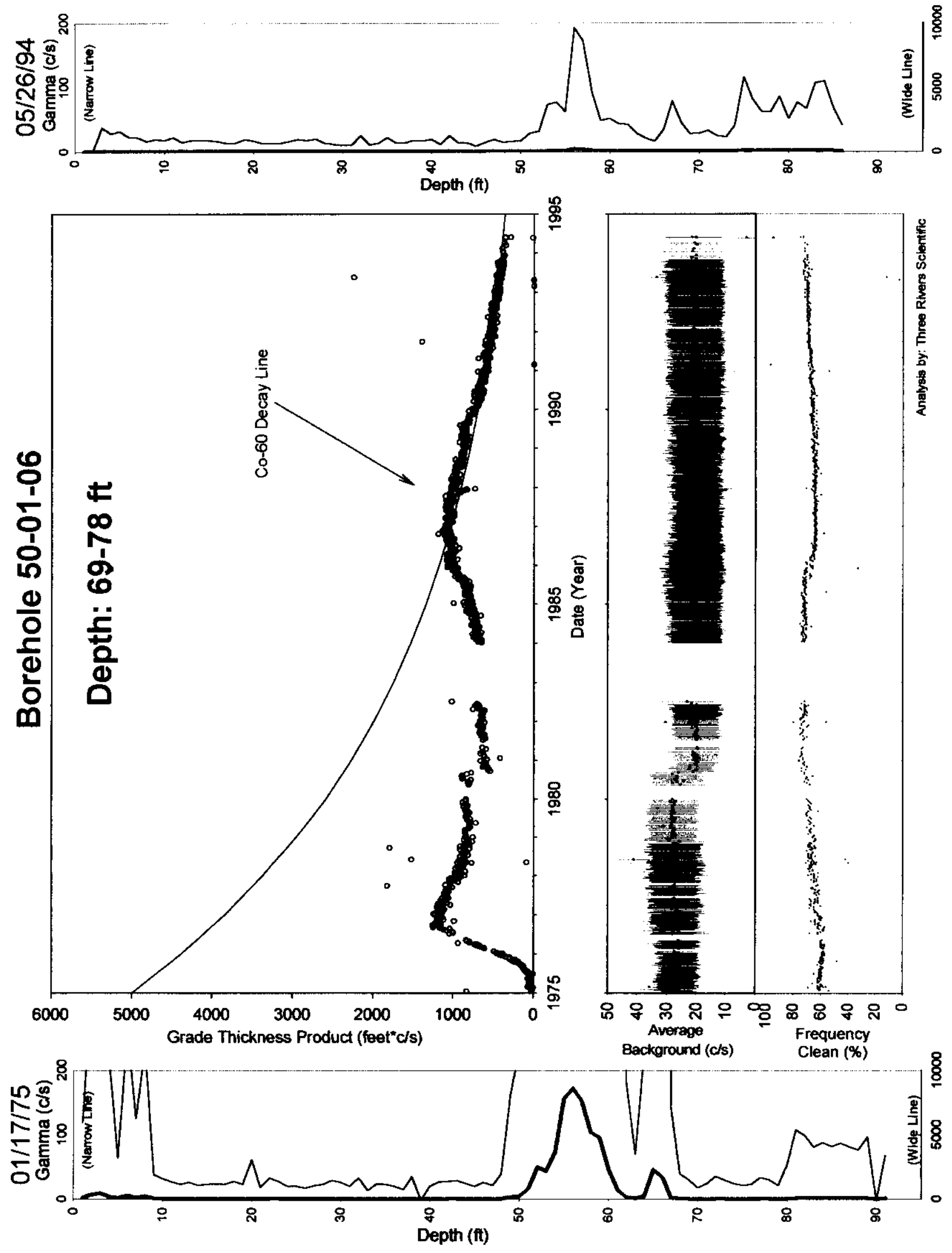

Tank T-101

Page 90 
RPP-6088, Rev.0.
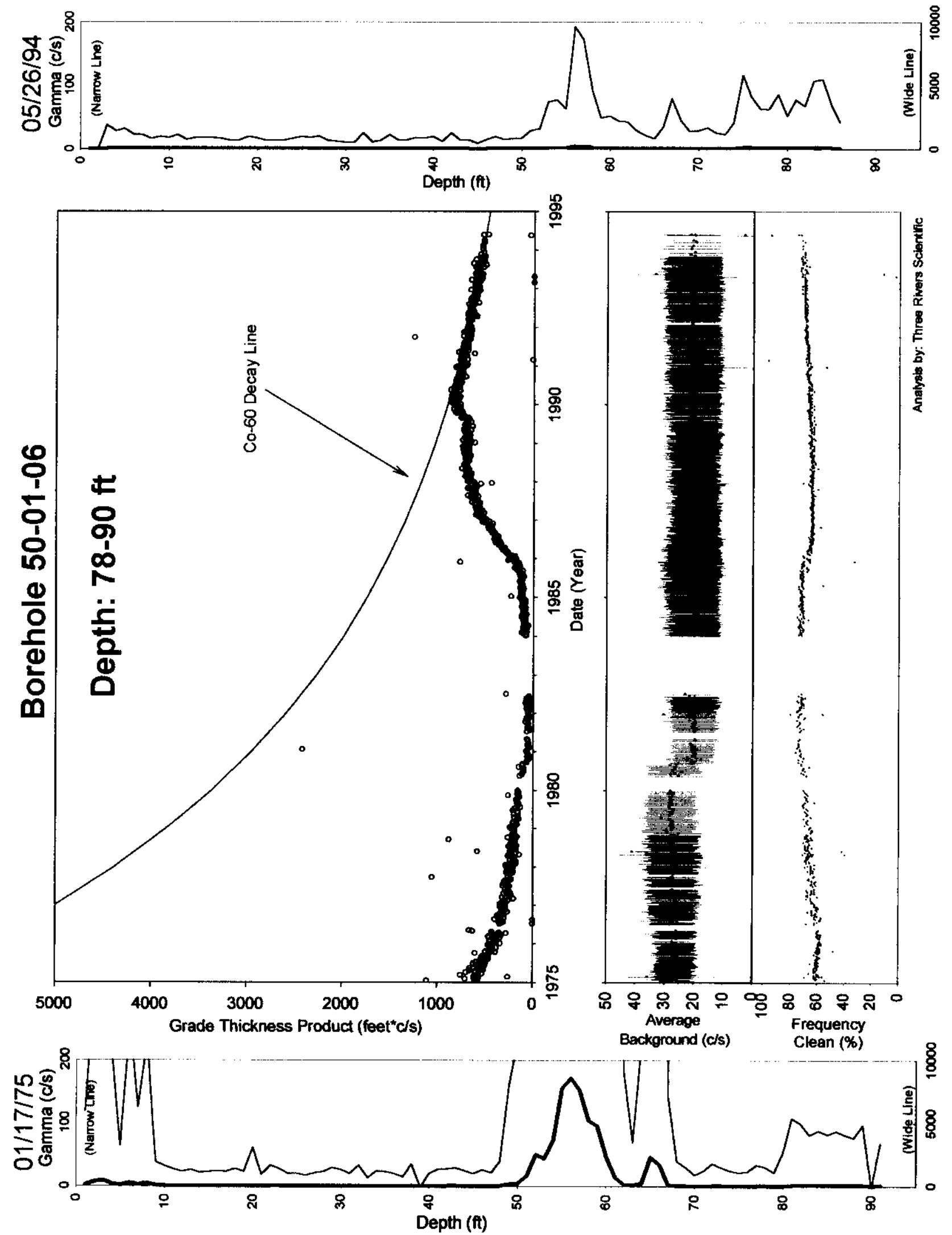
RPP-6088, Rev.0.

\section{Borehole 50-01-09}

\section{Contamination (Cs-137) from 0-12 feet is Tank Farm Activity. Contamination (Cs-137) from 12-28 feet is Unstable Early. Contamination (Co-60) from $32-45$ feet is Unstable.}

Grade thickness product over 0 to 12 feet changes abruptly after 1977 to a very high level until mid 1978 when a step change to much lower readings are observed. From mid 1978 until 1982 a more rapid decline exists than Cs-137 decay. The average background shows a step decrease after 9-16-1980, but scaling the grade thickness product with the average change in background would not change the rate of decline over this period; thus no requirement for application of a scaling factor. After 1982, the grade thickness product is decreasing consistent with Cs-137 (HPGe identified). The very large dynamic range of grade thickness product dictates the log scale.

Grade thickness product over 12 to 28 feet show a step decrease after 9-16-80, and the average background shows a step decrease after this same date. Scaling of the Cs-137 generated grade thickness product with the same ratio of change for the background does not bring the grade thickness product into continuity. An additional $25 \%$ reduction prior to $9-16-80$ does yield a consistent pattern, and this scaling is plotted. (The attenuation of the possible extra casing may affect the Cs-137 derived signal differently than the KUT derived natural background.) After scaling to achieve continuity, the grade thickness product decline does not match the Cs- 137 (HPGe identified) decay. From 1981 to 1987 the grade thickness product over 12 to 28 feet is consistently lower than from 1987 to 1994 . This time period does not have the step change interference, and thus the trend is real. Before 1984 depth control errors could cause some small changes in this trend, but from 1984 until 1987 the grade thickness product is still consistently lower than after 1987. After 1986 the grade thickness product matches the Cs-137 decay, thus the classification is unstable early.

Grade thickness product over 32 to 45 feet shows two distinct periods of influx (first starts in late 1975 and the second starts in mid 1981). Co-60 is HPGe identified in 1994. The Co-60 decay line is normalized to the last years of historical gross gamma data. A classification of stable at the end of the historical data is not possible given the lack of duration. The grade thickness product decline after 1986 is greater than the decay of Co-60, thus the classification is unstable. 
RPP-6088, Rev.0.

Gross Gamma Survey Information

\begin{tabular}{|r|l|}
\hline Probe Type Processed : & $04:$ NaI \\
\hline Other Probe Types : & 03: Neutron \\
\hline Survey Depth : & $95 \mathrm{ft}$ \\
\hline First Survey Date : & $1 / 14 / 1975$ \\
\hline Last Survey Date : & $5 / 26 / 1994$ \\
\hline Number Surveys Processed : & 444 \\
\hline
\end{tabular}

Analysis Notes

Method Used to Compute Background : $\quad$ Threshold $0<$ val $<50$

Depth(s) where Contamination Identified $0-12 \mathrm{ft}$ is Tank Farm Activity,

in Gross Gamma Surveys : $12-28 \& 75-90 \mathrm{ft}$ is Undetermined, $32-45 \mathrm{ft}$ is Unstable

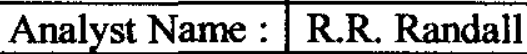

Company Name: Three Rivers Scientific 
RPP-6088, Rev.0.

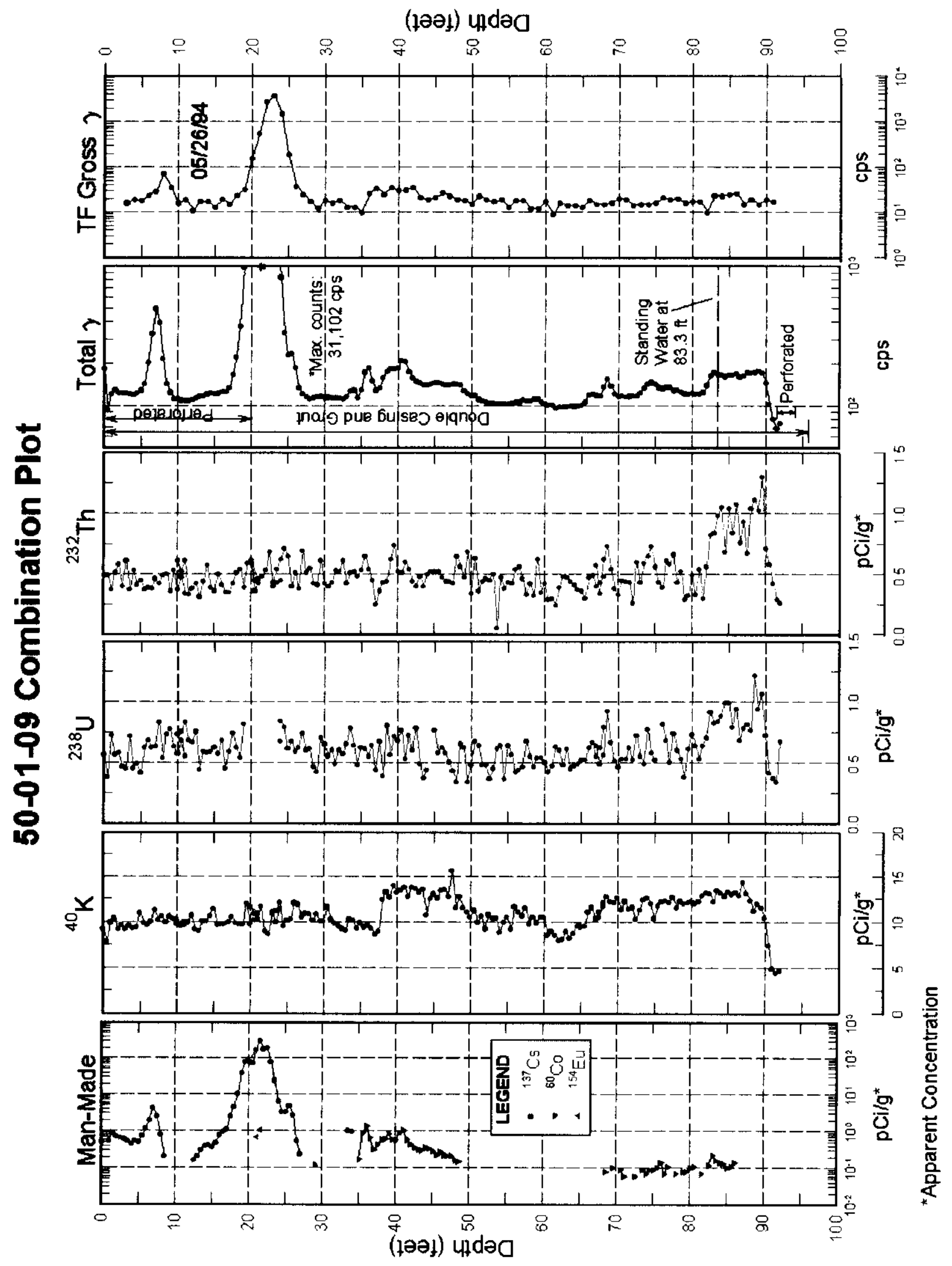

Tank T-101 
RPP-6088, Rev.0.

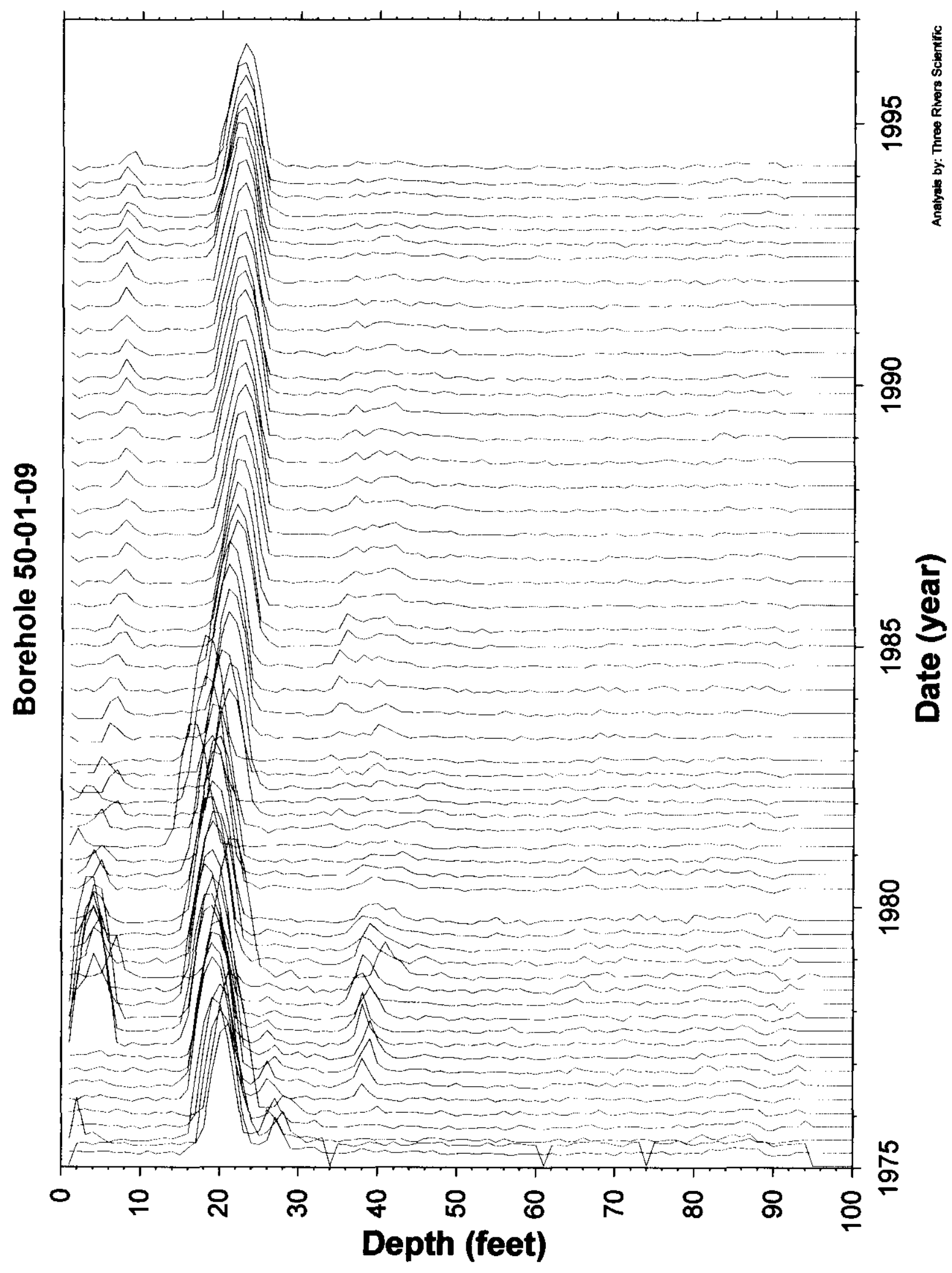

Tank T-101

Page 95 
RPP-6088, Rev.0.
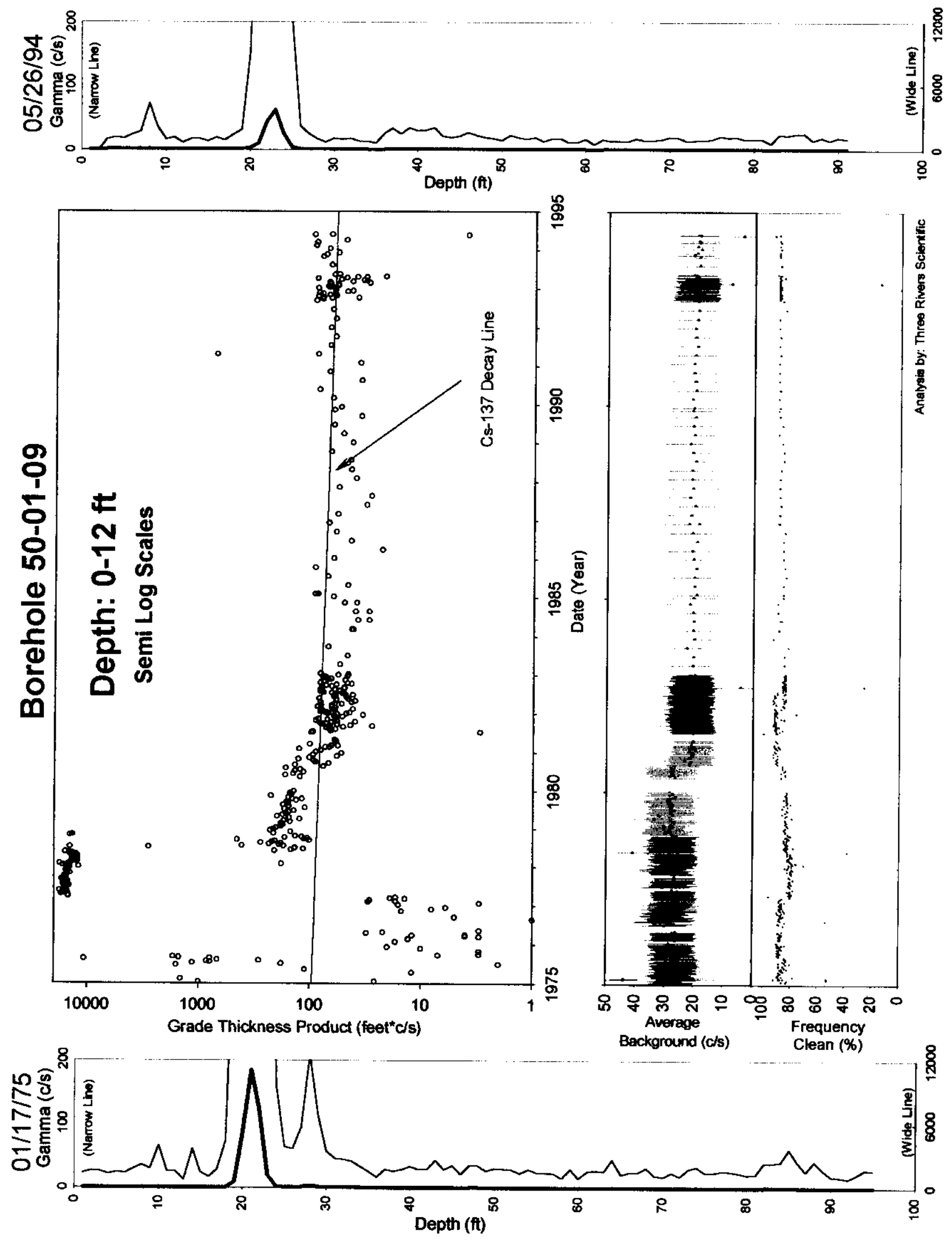

Tank T-101 
RPP-6088, Rev.0.
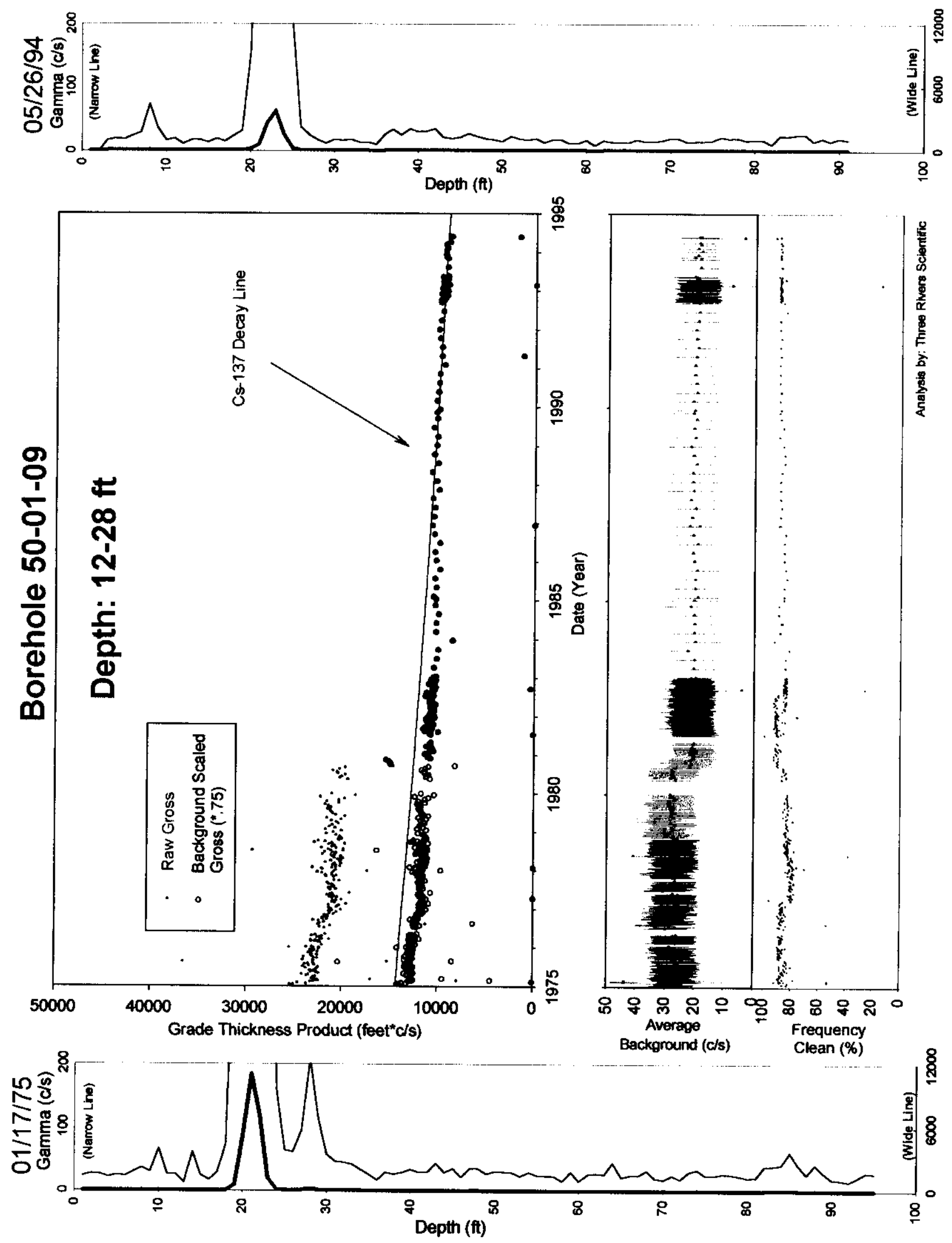
RPP-6088, Rev.0.
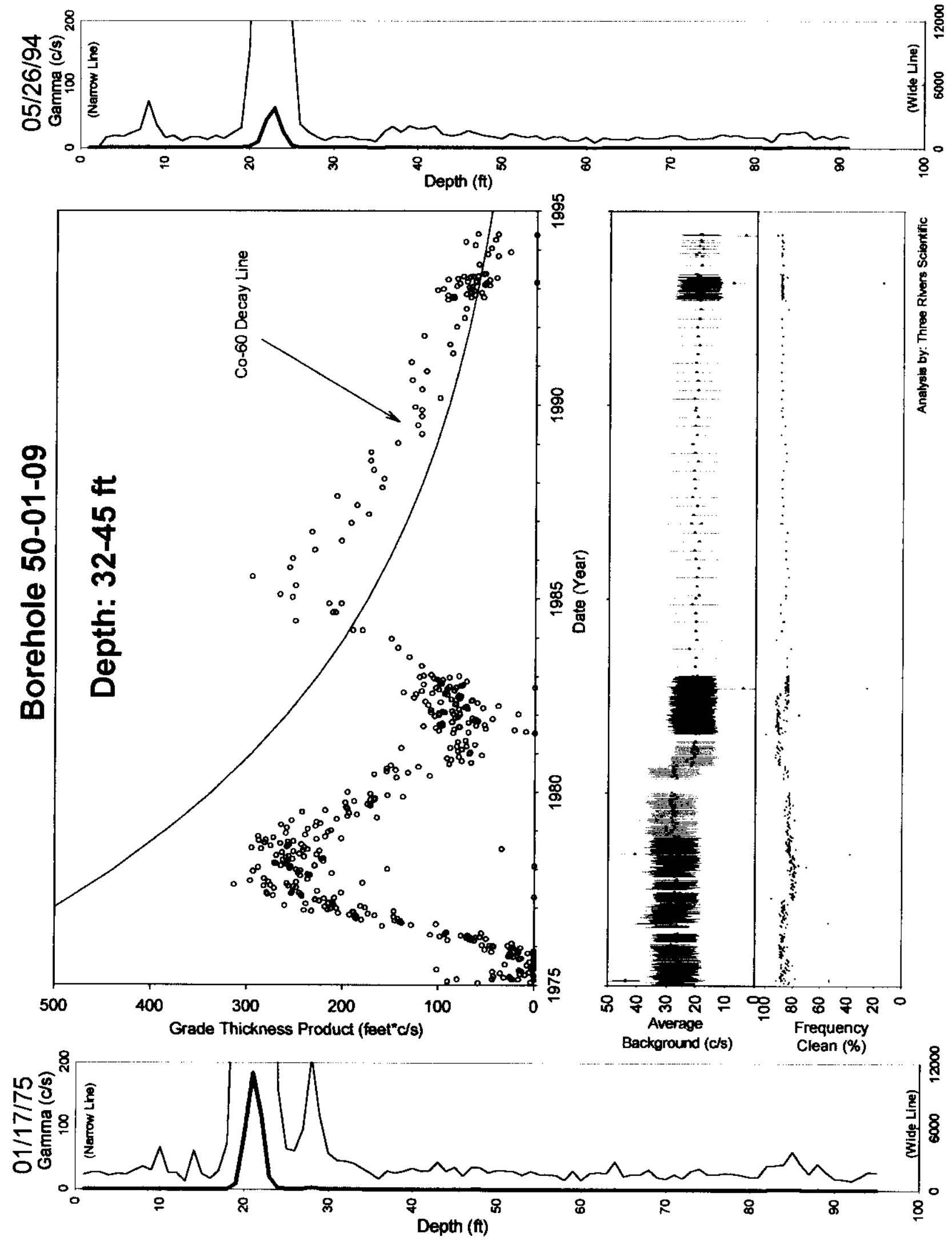

Tank T-101 
RPP-6088, Rev.0.

\section{Borehole 50-01-12}

\section{Contamination (Co-60 \& Ru-106) from 30-40 feet is Stable.}

Grade thickness product over $\mathbf{3 0}$ to $\mathbf{4 0}$ feet is decreasing consistent with a least square fit to Co60 (HPGe identified) and Ru-106 (hypothesized) decay. The ratio of gross gamma contribution from Ru-106 to the gross gamma contribution from Co-60 is 2.4 as of 1-13-75. Note that Eu-154 was also HPGe identified, but does not affect the results of the least squares fit.

The average background plot shows a step decrease after 9-16-80.

Gross Gamma Survey Information

\begin{tabular}{|r|l|}
\hline Probe Type Processed : & $04:$ NaI \\
\hline Other Probe Types : & $03:$ Neutron \\
\hline Survey Depth : & $93 \mathrm{ft}$ \\
\hline First Survey Date : & $1 / 13 / 1975$ \\
\hline Last Survey Date : & $5 / 26 / 1994$ \\
\hline Number Surveys Processed : & 438 \\
\hline
\end{tabular}

Analysis Notes

Method Used to Compute Background : $\quad$ Threshold $0<$ val $<50$

Depth(s) where Contamination Identified $30-40 \mathrm{ft}$ Stable in Gross Gamma Surveys :

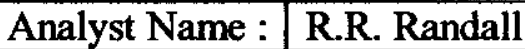

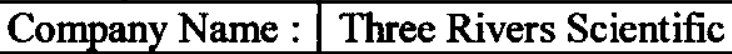


RPP-6088, Rev.0.

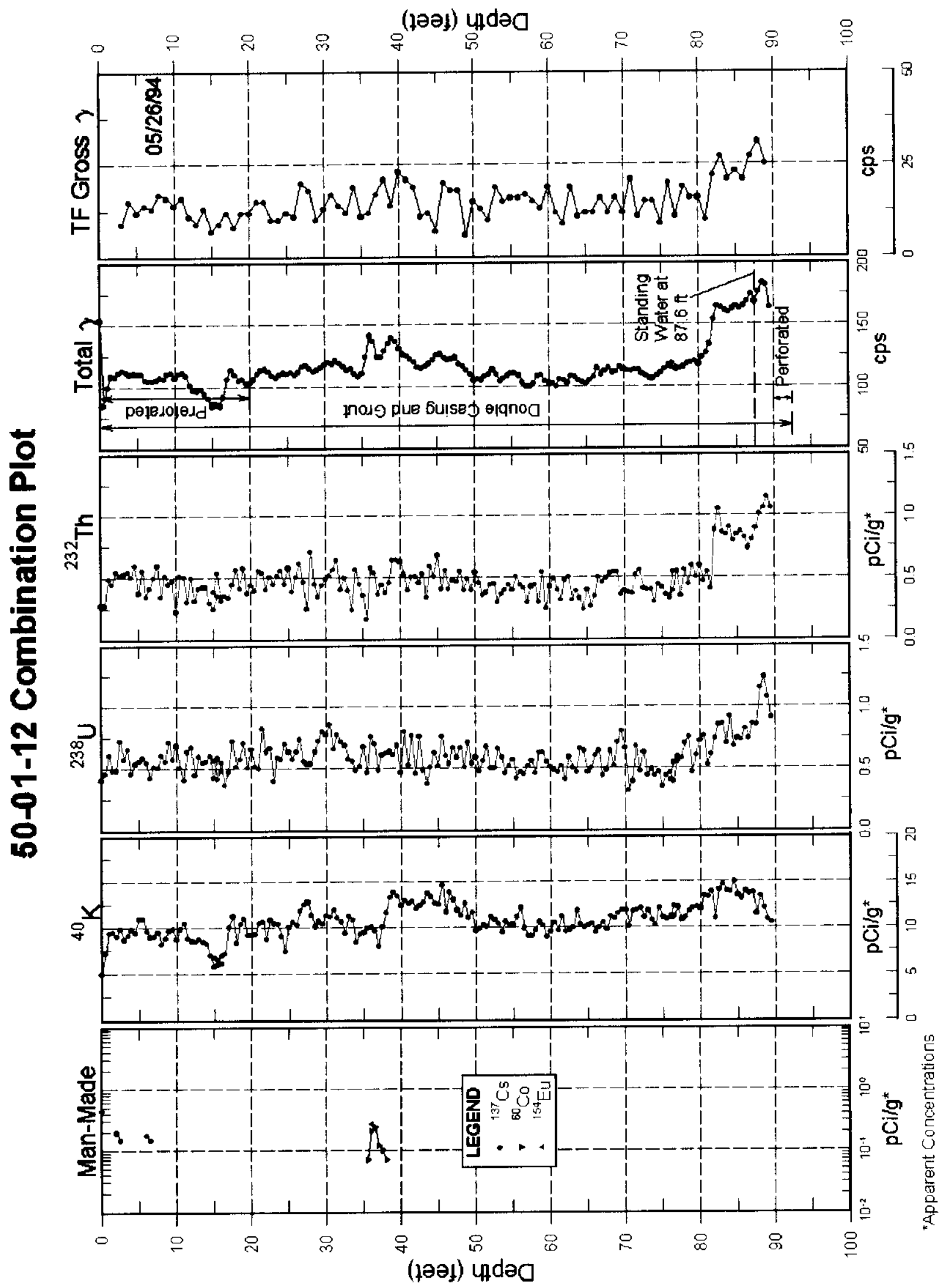

Tank T-101 
RPP-6088, Rev.0.

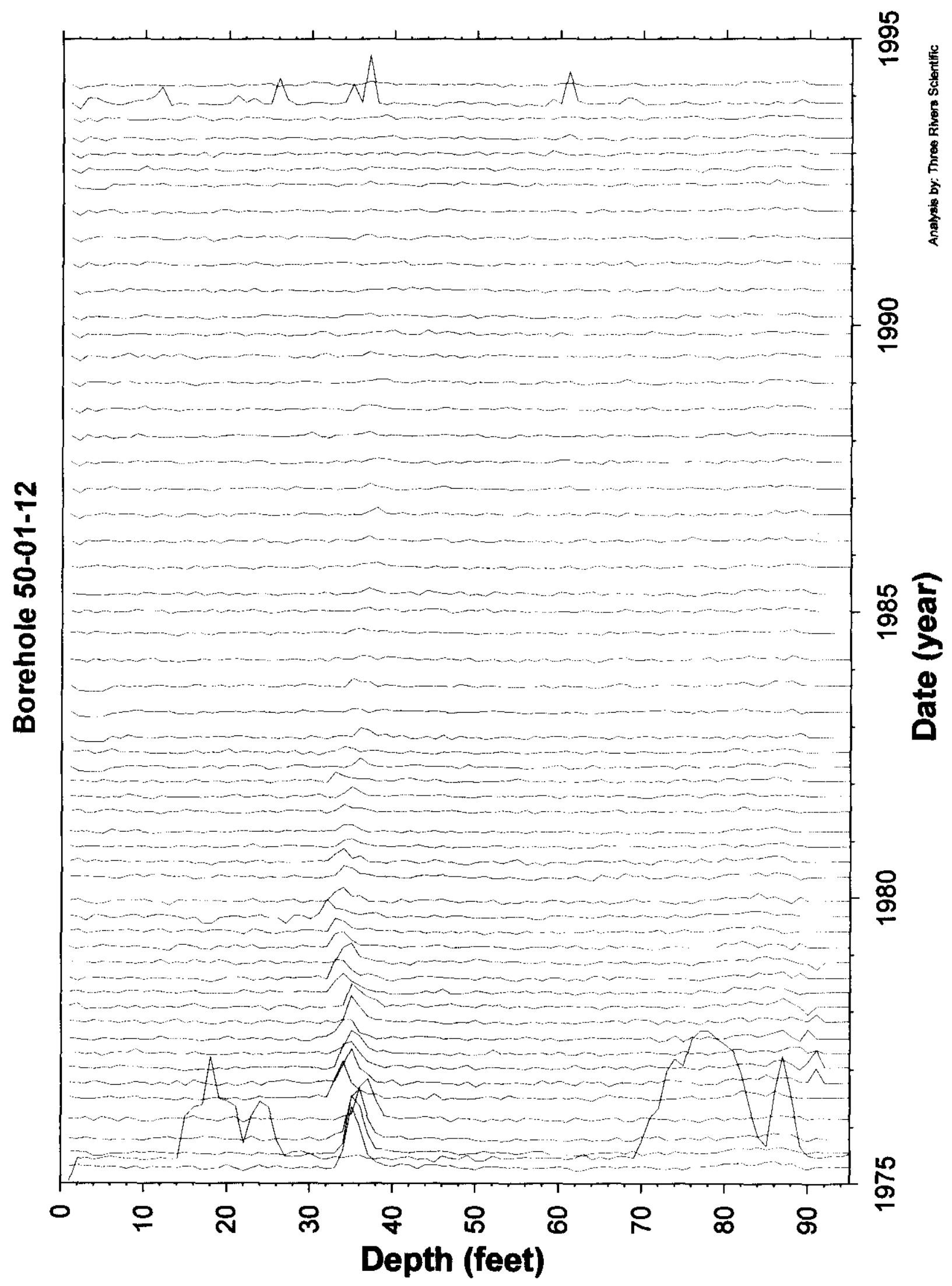

Tank T-101

Page 101 
RPP-6088, Rev.0.
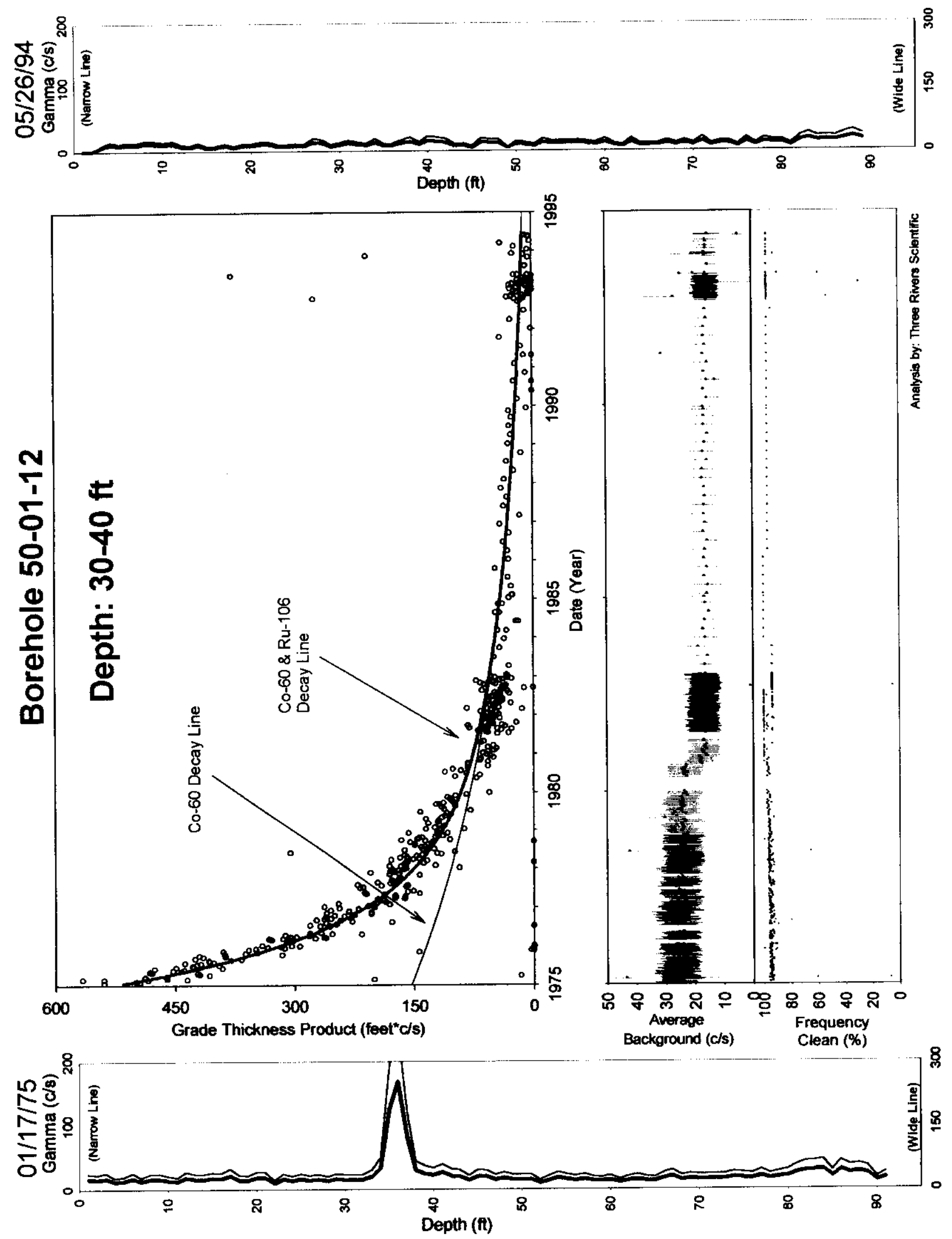

Tank T-101 
RPP-6088, Rev.0.

\section{Tank T-102 Wells}

Table of Contents Page

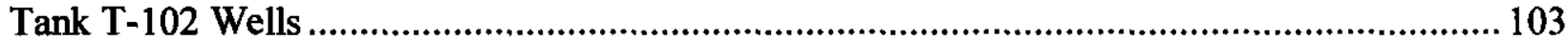

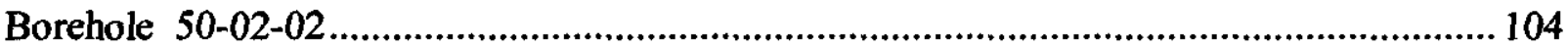

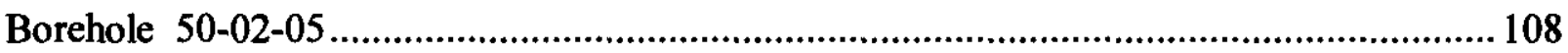

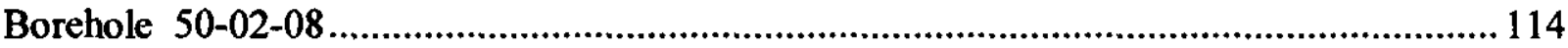

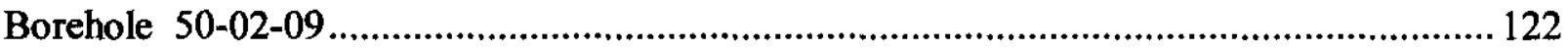

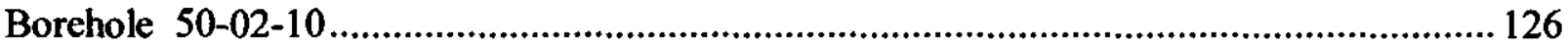

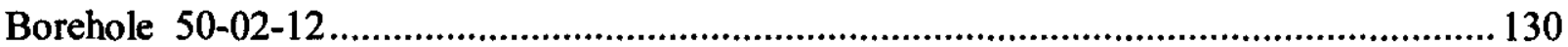

This section contains the analysis results for vadose zone boreholes (dry wells) associated with Tank 102 in the "T" Tank Farm.

Special Note:

None 


\section{Borehole 50-02-02}

\section{No Gamma Ray Emitting Contamination Identified.}

No significant levels of gamma ray contamination are present, based upon gross gamma data, above the survey probe detection threshold between 1975 and 1995 in the vadose zone from 2 to 86 feet. The HPGe logging system detected Cs-137 at less than $1 \mathrm{pCi} / \mathrm{g}$.

The average background plot shows a step decrease after 9-16-80.

Gross Gamma Survey Information

\begin{tabular}{|r|l|}
\hline Probe Type Processed : & $04:$ NaI \\
\hline Other Probe Types : & $03:$ Neutron \\
\hline Survey Depth : & $88 \mathrm{ft}$ \\
\hline First Survey Date : & $1 / 13 / 1975$ \\
\hline Last Survey Date : & $5 / 26 / 1994$ \\
\hline Number Surveys Processed : & 282 \\
\hline
\end{tabular}

Analysis Notes

\begin{tabular}{|r|l|}
\hline Method Used to Compute Background : & Threshold $0<$ val $<50$ \\
\hline $\begin{array}{r}\text { Depth(s) where Contamination Identified } \\
\text { in Gross Gamma Surveys : }\end{array}$ & NONE \\
\hline Analyst Name : & R.R. Randall \\
\hline Company Name : & Three Rivers Scientific \\
\hline
\end{tabular}


RPP-6088, Rev.0.

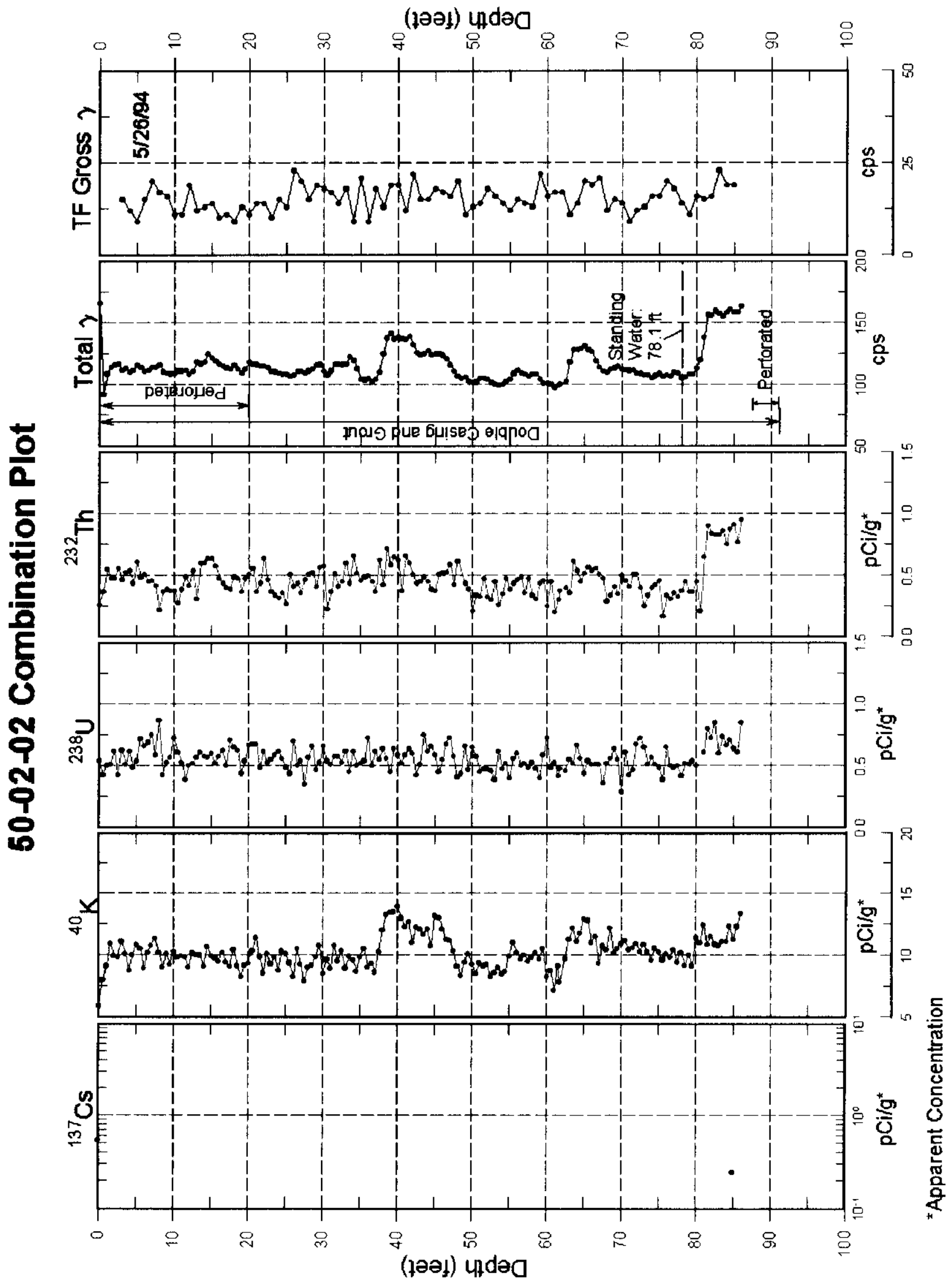

Tank T-102 
RPP-6088, Rev.0.

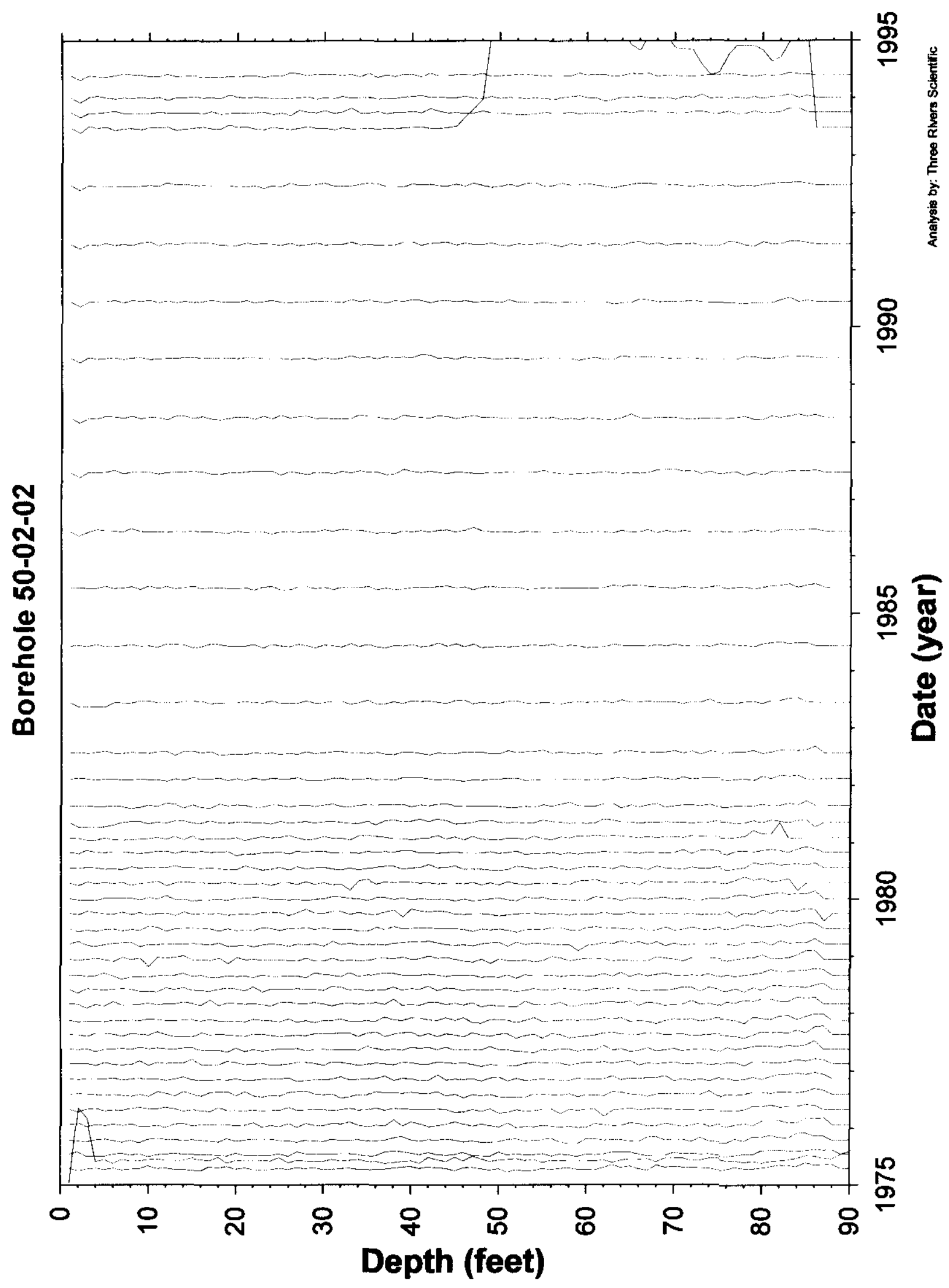

Tank T-102

Page 106 
RPP-6088, Rev.0.

\section{Borehole 50-02-02}

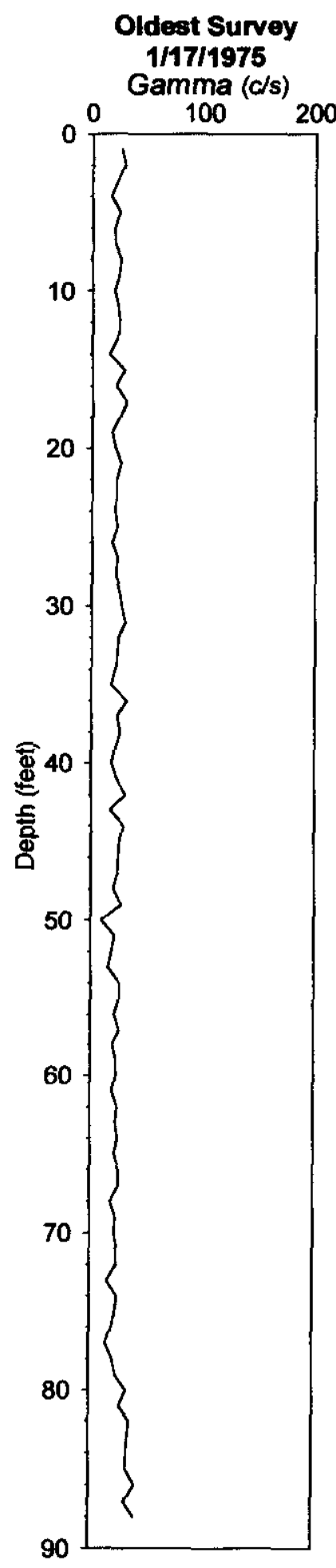

No Gamma-Ray Emitting Contamination

Above Survey Detection Threshold
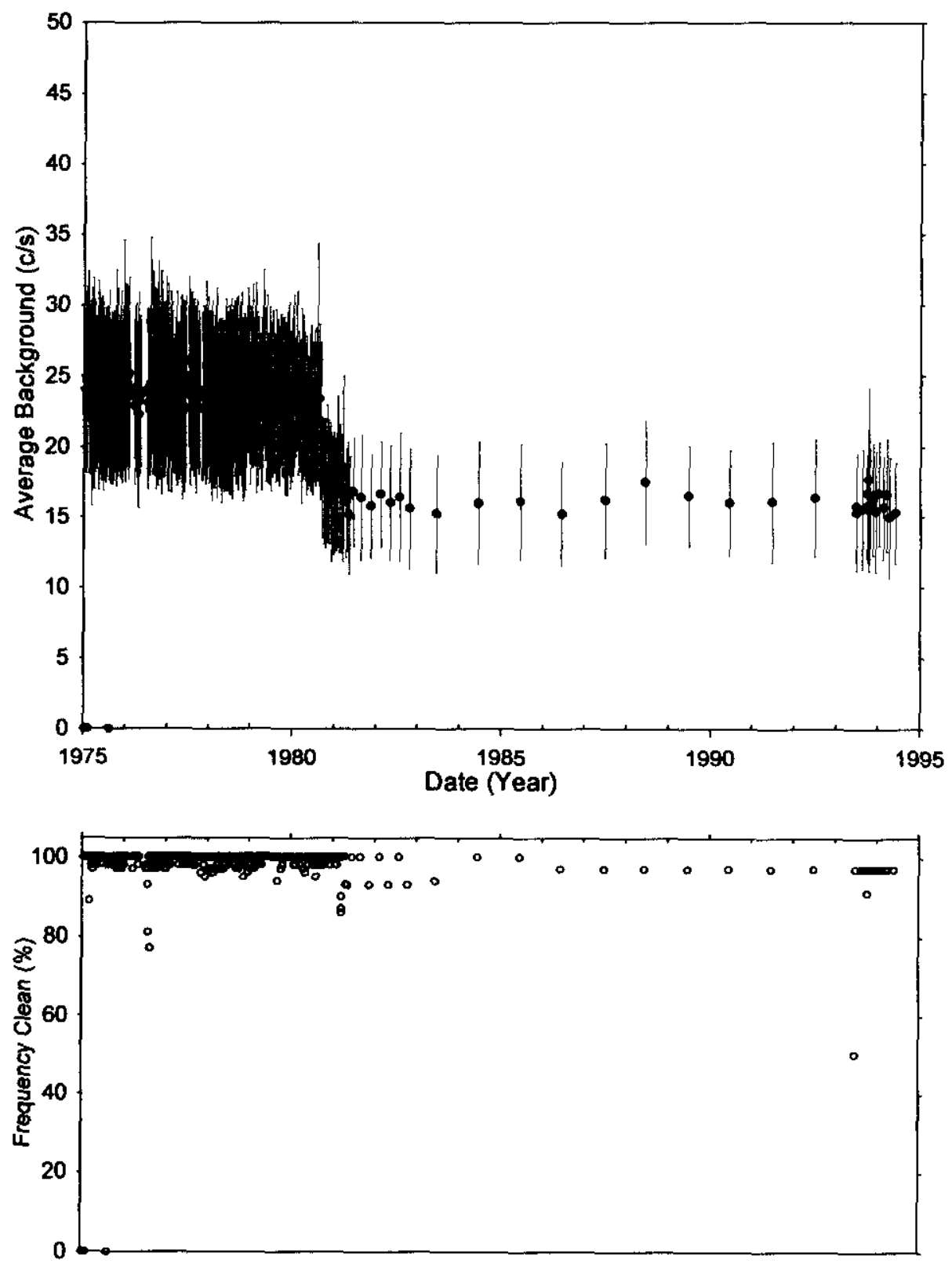

Analysis by. Three Rivers Scientific 


\section{Borehole 50-02-05}

\section{Contamination (Cs-137) from 30-45 feet is Stable*. Contamination (Co-60) from 45-54 feet is Unstable. Contamination (Co-60) from 54-70 feet is Unstable.}

Grade thickness product over 30 to 45 feet shows a step decrease after 2-18-81, and the average background also shows a step decrease after this date. Other wells in this tank farm exhibited a step decrease in both the average background and grade thickness products that were highly correlated. In this well, there is insufficient data before the step change to make a rigorous scaling factor adjustment to the data. If the early data are ignored, then, the zone matches the Cs-137 (HPGe identified) decay. Since there is some small ambiguity, the classification is stable with an asterisk.

Grade thickness product over 45 to 54 feet shows a dramatic increase beginning in 1990, and some evidence of decrease over the last 6 months of logging that is faster than Co-60 decay. No decay line is plotted since no match with Co-60 (HPGe identified) decay is possible. Clearly, the zone is unstable.

Grade thickness product over 54 to 70 feet does not match Co-60 (HPGe identified) decay over any time period long enough to label the zone as stable. The classification is unstable.

Gross Gamma Survey Information

\begin{tabular}{|r|l|}
\hline Probe Type Processed : & $04: \mathrm{NaI}$ \\
\hline Other Probe Types : & $\begin{array}{l}\text { 03: Neutron(3); 01: Green GM(1); } \\
\text { 14: Shielded NaI(20) }\end{array}$ \\
\hline Survey Depth : & $85 \mathrm{ft}$ \\
\hline First Survey Date : & $7 / 25 / 1980$ \\
\hline Last Survey Date : & $5 / 26 / 1994$ \\
\hline Number Surveys Processed : & 116 \\
\hline
\end{tabular}

Analysis Notes

\begin{tabular}{|r|l|}
\hline Method Used to Compute Background : & Threshold $0<$ val $<50$ \\
\hline Depth(s) where Contamination Identified & $30-45 \mathrm{ft}$ Stable, \\
in Gross Gamma Surveys : & $45-54$ \& 54-70 ft Instable \\
\hline Analyst Name : & R.R. Randall \\
\hline Company Name : & Three Rivers Scientific \\
\hline
\end{tabular}


RPP-6088, Rev.0.

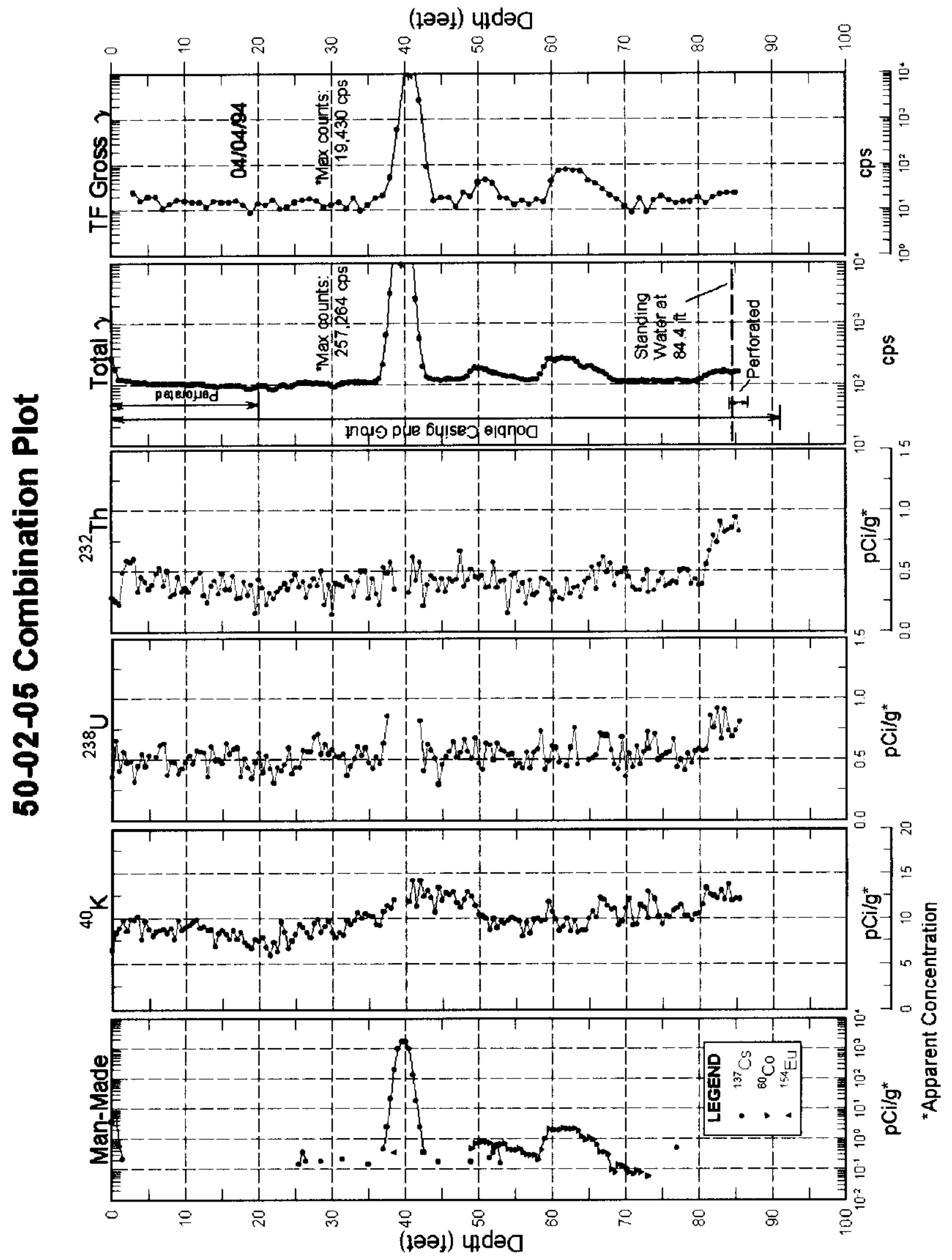

Tank T-102 
RPP-6088, Rev.0.

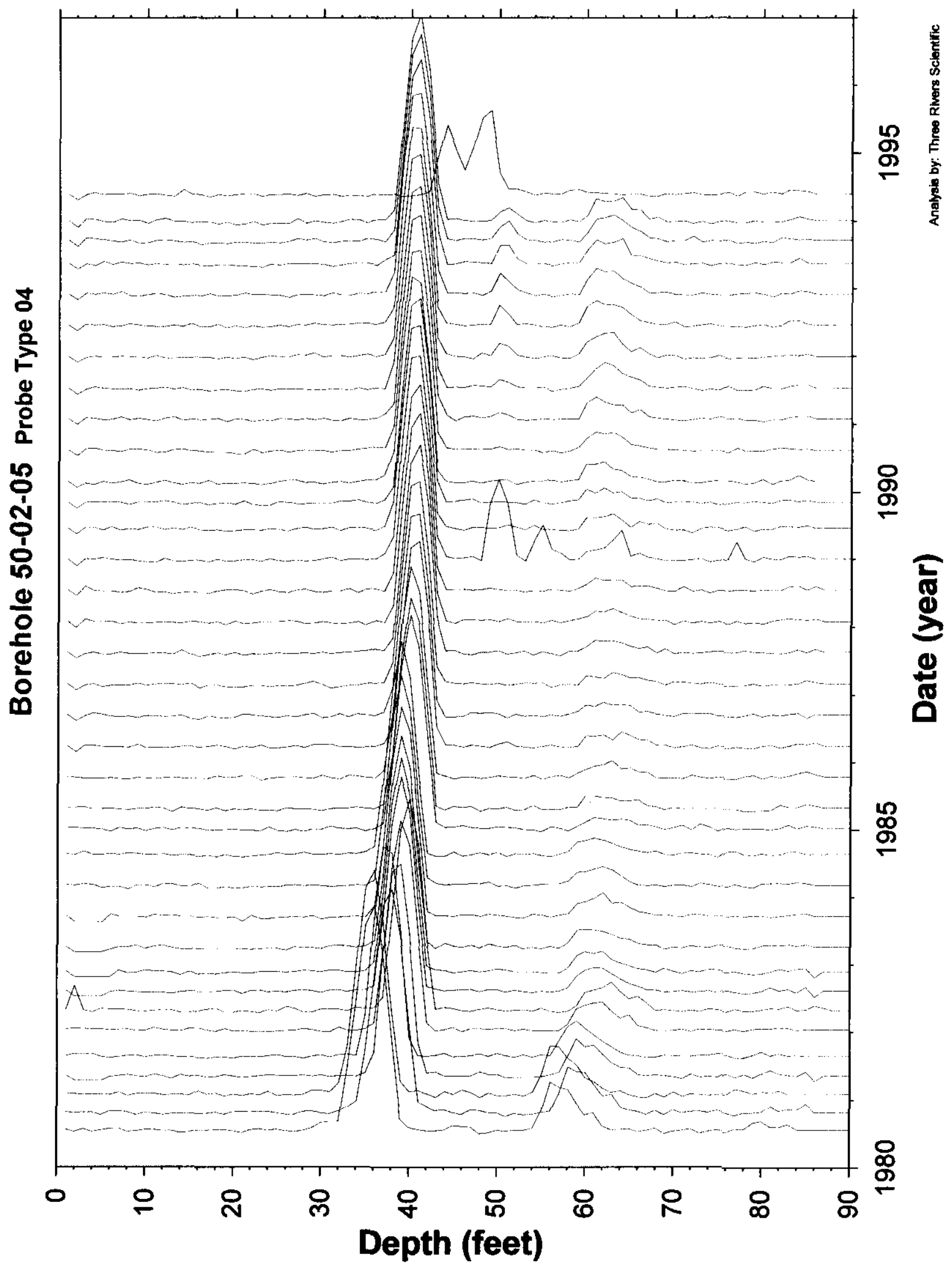

Tank T-102

Page 110 
RPP-6088, Rev.0.
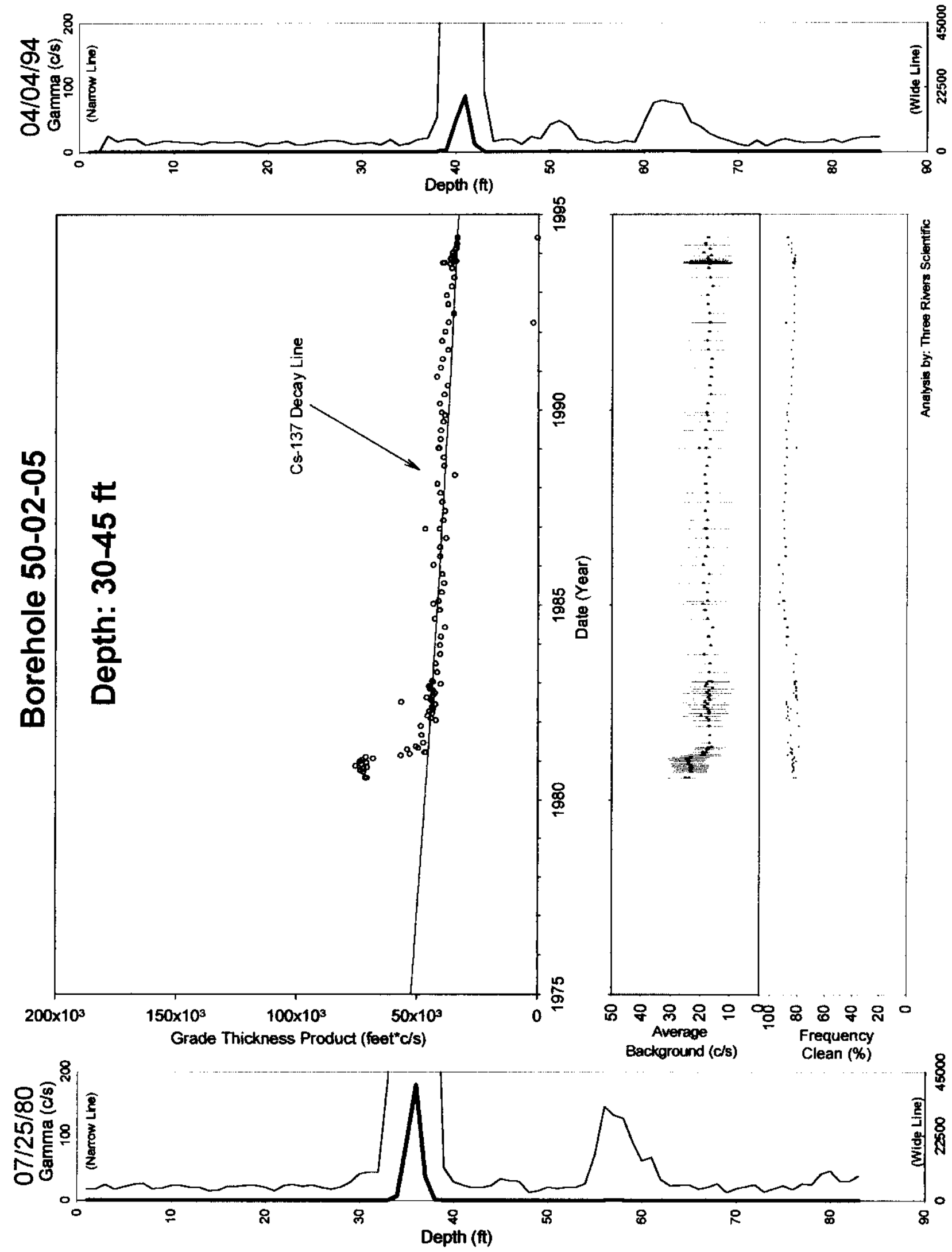

Tank T-102 
RPP-6088, Rev.0.
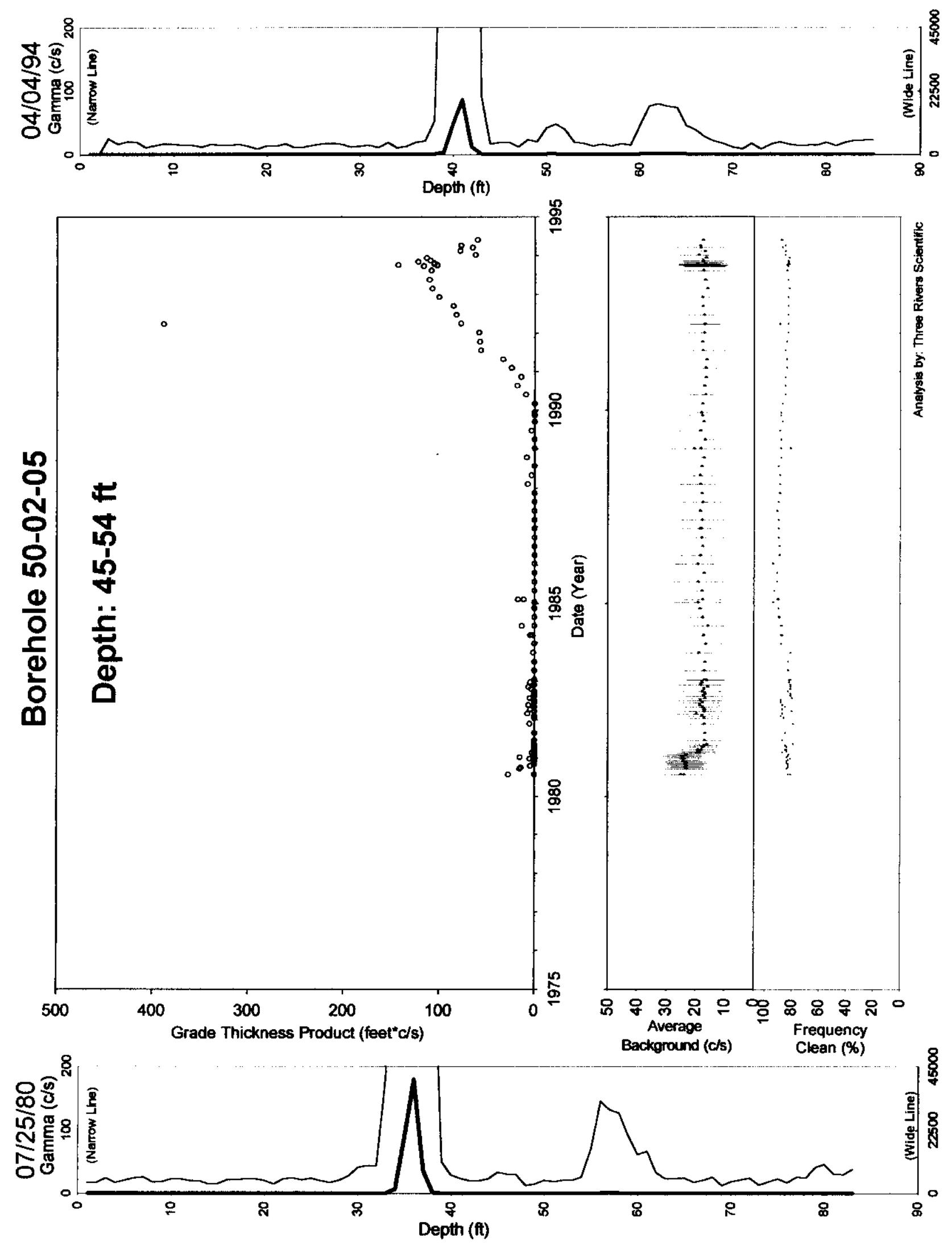

Tank T-102 
RPP-6088, Rev.0.
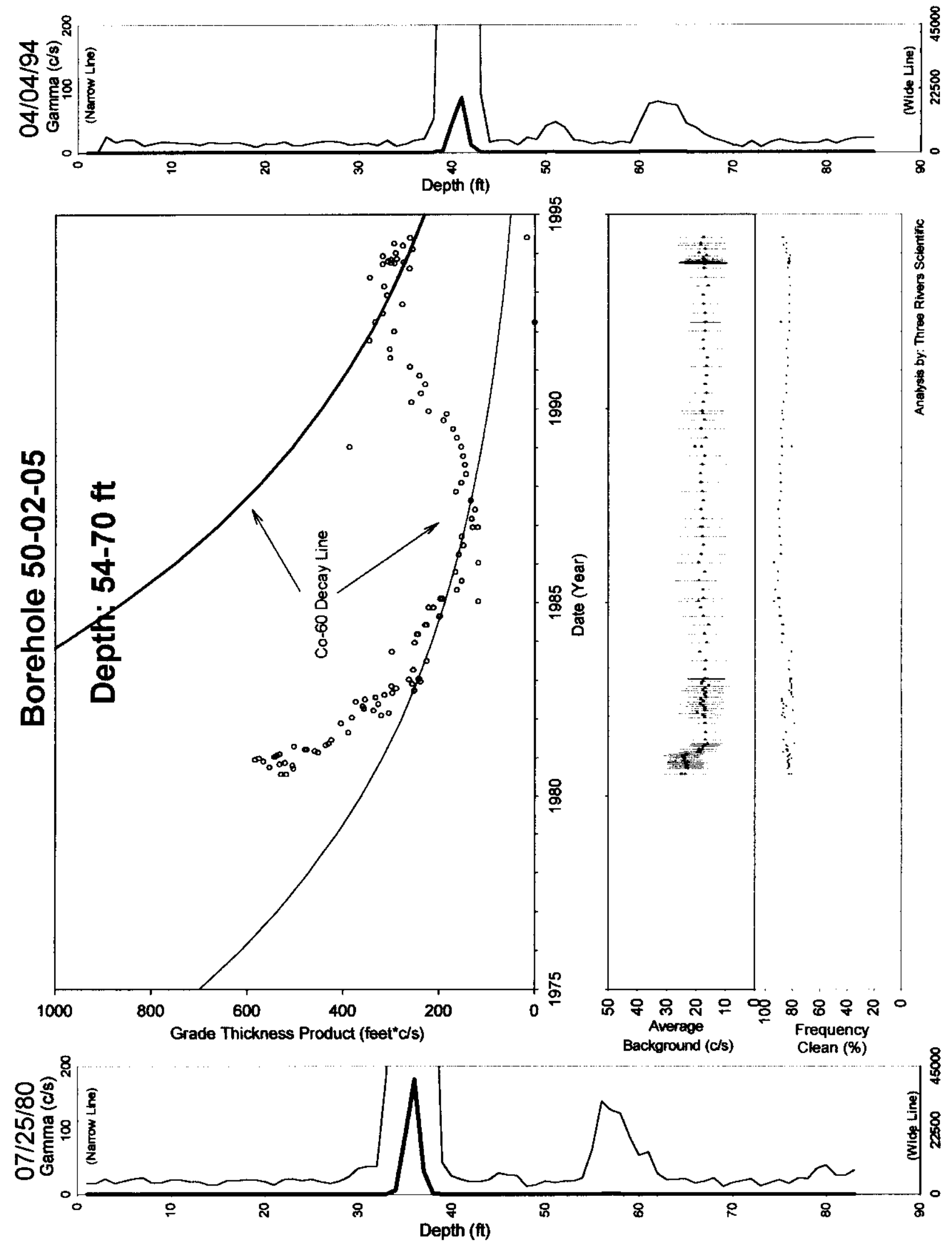

Tank T-102

Page 113 
RPP-6088, Rev.0.

\section{Borehole 50-02-08}

\section{Contamination (Co-60, Ru-106 \& Eu-154) from 32-50 feet is Stable. Contamination (Ru-106) from 50-56 feet is Stable. Contamination (Ru-106) from 60-72 feet is Stable. Contamination ( $\mathrm{Ru}-106)$ from $78-85$ feet is Undetermined.}

The interval from 32 to 50 feet has a high level of contamination, with Co-60, Eu-152, Eu-154, $\mathrm{Nb}-94$, and U-238 identified with the HPGe logging system. The grade thickness product for this interval has a step change at the same date that a step change occurs in the average background. Given that extra casing and/or grout was added to the original casing configuration, the average background before this date $(9-5-80)$ was ratioed to the average background after this date and this same ratio was applied to the grade thickness product. The raw grade thickness product data are plotted as small blue circles, and the scaled grade thickness product data are plotted as large open black circles. The scaled grade thickness data were fit with a least square to three components of Co-60, Ru-106, and Eu-154, and the match suggests stability. Multiple decay components with similar decay constants can generate non-uniqueness for such least square fitting calculations. The results of the applied least square fit yields a gross gamma contribution ratio for Co:Eu:Ru of 4370:7314:79560 $\left(\mathrm{ft}^{*} \mathrm{c} / \mathrm{s}\right)$ as of 1-13-75.

Grade thickness product over 50 to 56 and 60 to 72 feet is decreasing consistent with Ru-106 (hypothesis) decay. The scaling for average background is not necessary in these cases since the gamma response has decayed to such low levels at the time of the step change in the average background.

Grade thickness product over 78 to 85 feet is not clearly matching the decrease of Ru-106 only. Two items interfere with such a match. First, an extra amount of constant background of 25 $\mathrm{ft}^{*} \mathrm{c} / \mathrm{s}$ is required for a proper fit from 1981 to 1994 ; this is most likely a background subtraction problem. Second, early time character does not closely match the decay before the step change in the average background. However, the statistical variations for this zone do not allow a rigorous classification, and thus the category is undetermined. 
RPP-6088, Rev.0.

Gross Gamma Survey Information

\begin{tabular}{|r|l|}
\hline Probe Type Processed : & $04:$ NaI \\
\hline Other Probe Types : & $\begin{array}{l}03: \text { Neutron(3) 02: Red GM(1) } \\
\text { 14: Shielded NaI(64) }\end{array}$ \\
\hline Survey Depth : & $04: 100 \mathrm{ft}$ \\
\hline First Survey Date : & $1 / 13 / 1975$ \\
\hline Last Survey Date : & $5 / 26 / 1994$ \\
\hline Number Surveys Processed : & 284 \\
\hline
\end{tabular}

Analysis Notes

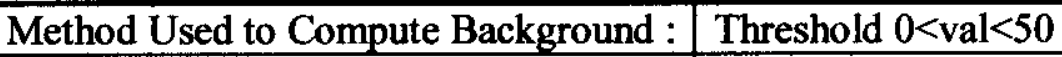

Depth(s) where Contamination Identified $32-50,50-56, \&$ 56-72 ft Stable

in Gross Gamma Surveys : $78-85 \mathrm{ft}$ Undetermined

Analyst Name : $\quad$ R.R. Randall

Company Name : Three Rivers Scientific 
RPP-6088, Rev.0.

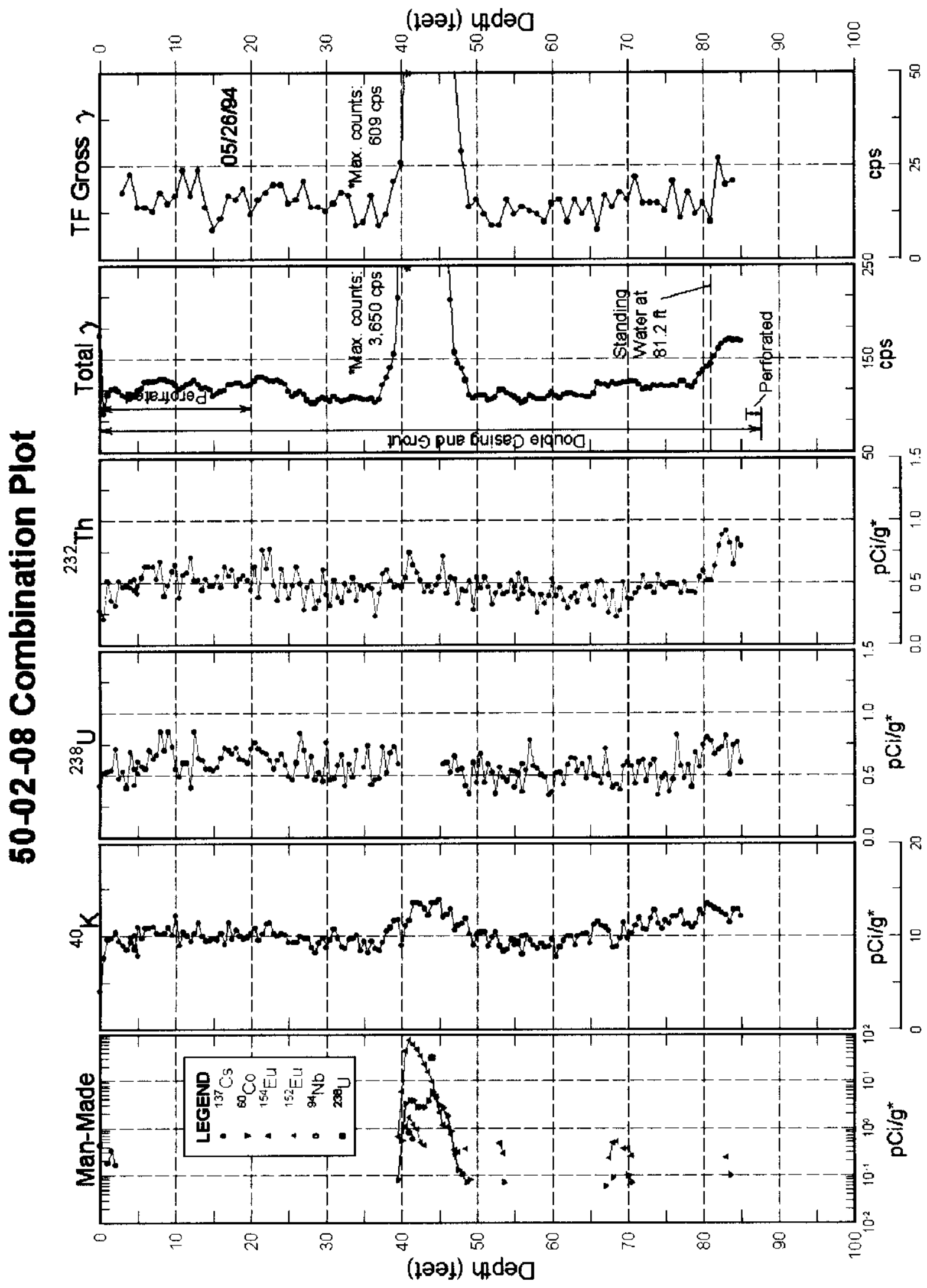

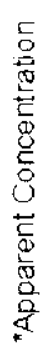

Tank T-102

Page 116 
RPP-6088, Rev.0.

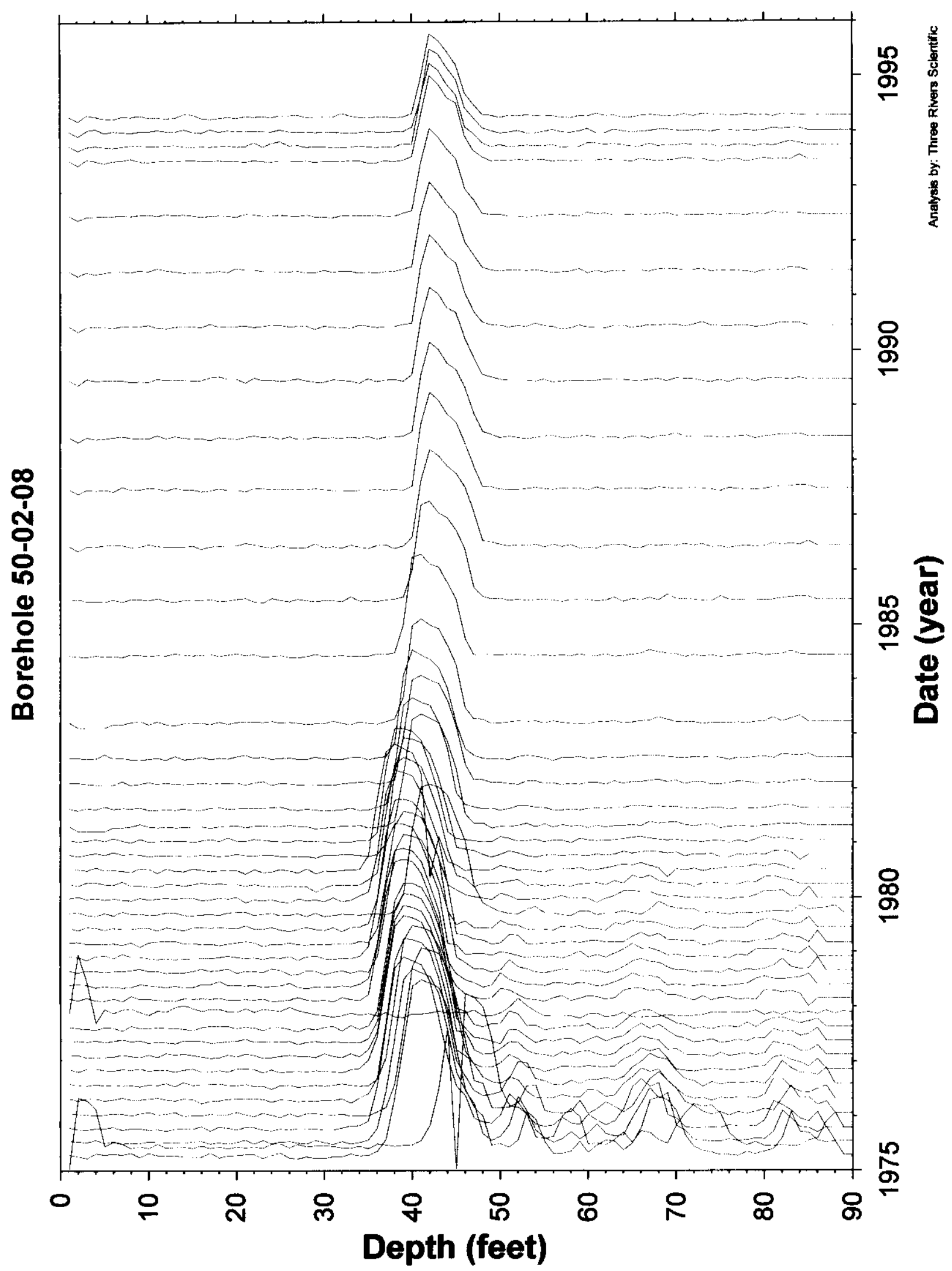

Tank T-102

Page 117 
RPP-6088, Rev.0.
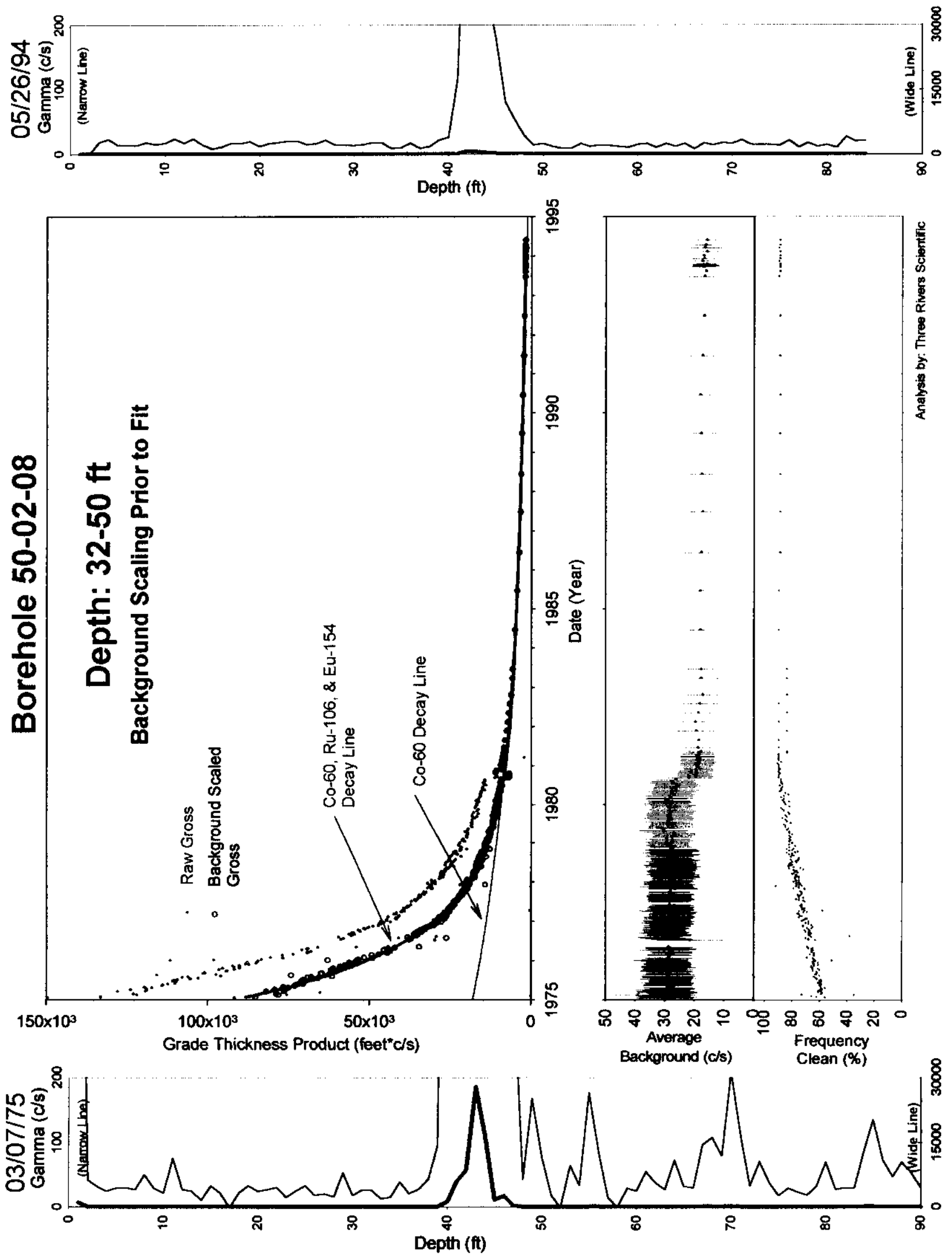

Tank T-102 
RPP-6088, Rev.0.
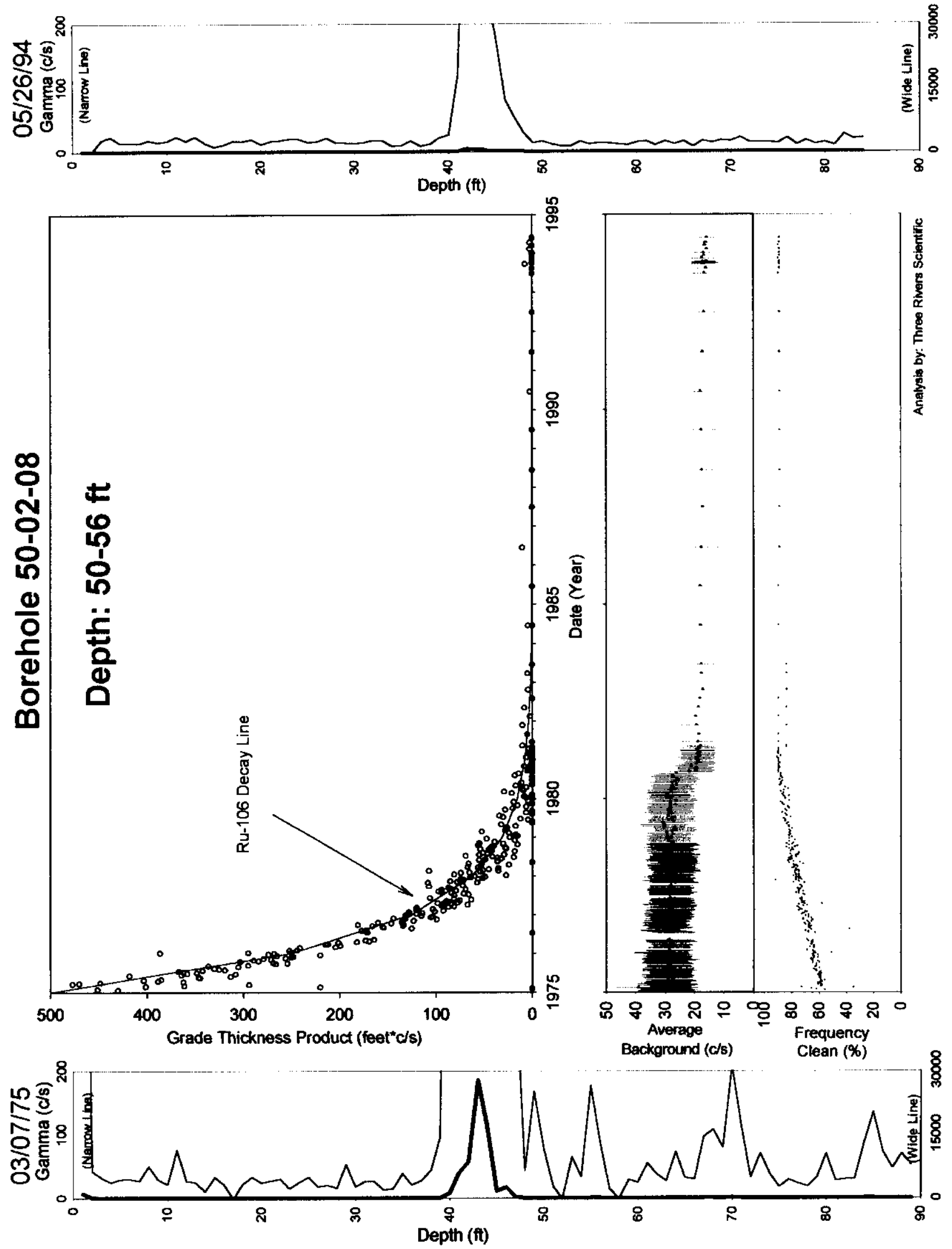

Tank T-102 
RPP-6088, Rev.0.
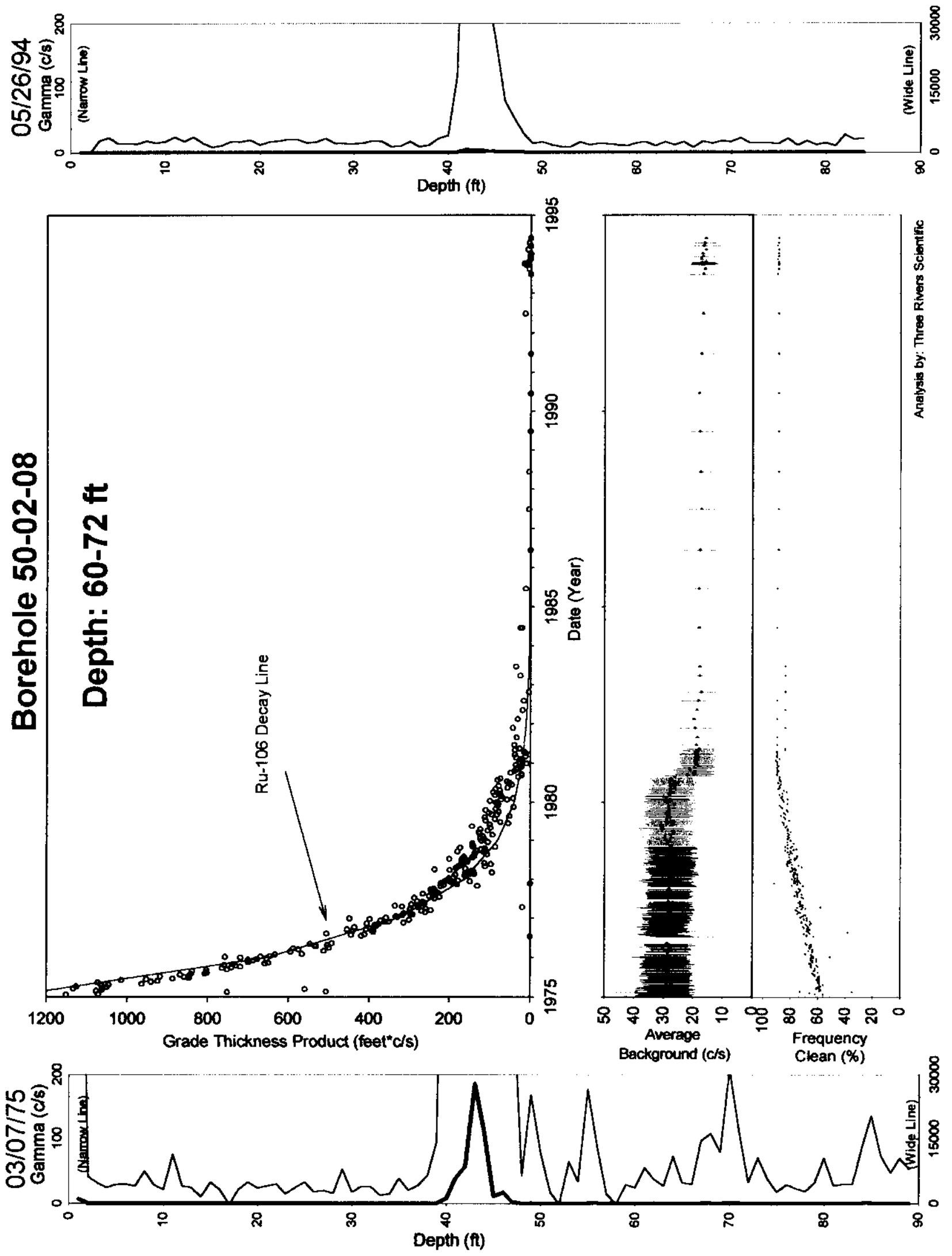

Tank T-102

Page 120 
RPP-6088, Rev.0.
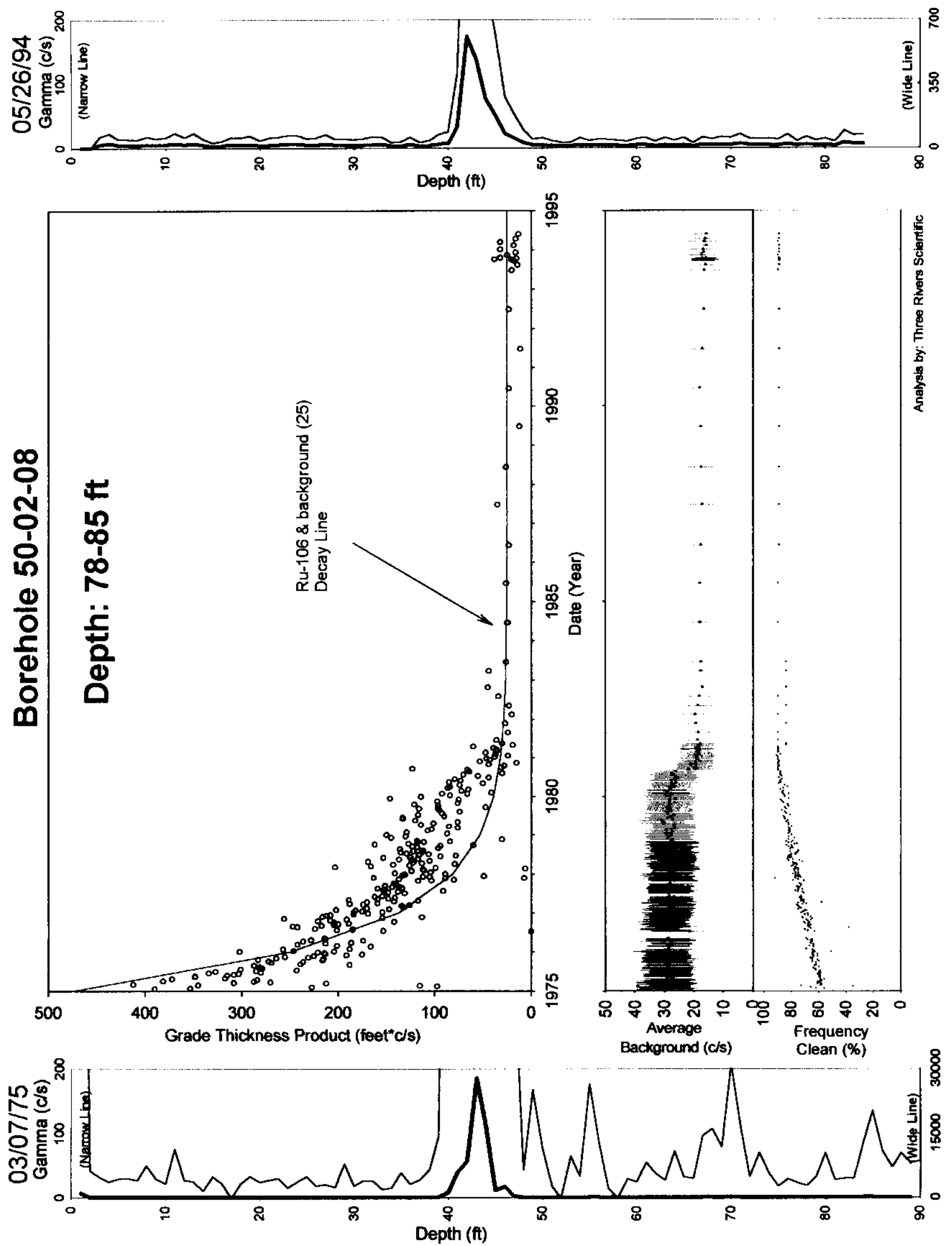

Tank T-102 
RPP-6088, Rev.0.

\section{Borehole 50-02-09}

\section{Contamination (Ru-106, Sb-125, \& Eu-154) from 32-48 feet is Unstable Early.}

The interval from 32 to 48 feet has a moderate level of contamination, with Co-60, Eu-154, and Cs-137 identified with the HPGe logging system at levels less than $1 \mathrm{pCi} / \mathrm{g}$. The grade thickness product for this interval has a step change that coincides with a step change in the average background (9-3-1980). The raw grade thickness product data are plotted as small blue circles, and the scaled ( $20 \%$ more reduction of early data over average background ratio) grade thickness product data are plotted as large open black circles. The scaled grade thickness data were fit with a least square to three components of $\mathrm{Ru}-106, \mathrm{Sb}-125$, and Eu-154, and the match suggest stability after mid 1976. The shorter lived $\mathrm{Sb}-125$ is required for a reasonable least square fit, but is not HPGe identified in this well. However, such a short lived isotope can decay to levels not detectable with the HPGe run in 1994 and be visible in the historical gross gamma data. The data before mid 1976 shows the tail end of a build-up and a second influx in mid 1976, thus the classification of unstable early. The ratio of gross gamma from the components of $\mathrm{Eu}: \mathrm{Sb}: \mathrm{Ru}$ is $317: 1406: 3410$ as of 5-7-1976.

Gross Gamma Survey Information

\begin{tabular}{|r|l|}
\hline Probe Type Processed : & $04: \mathrm{NaI}$ \\
\hline Other Probe Types : & $03:$ Neutron \\
\hline Survey Depth : & $88 \mathrm{ft}$ \\
\hline First Survey Date : & $1 / 13 / 1975$ \\
\hline Last Survey Date : & $5 / 26 / 1994$ \\
\hline Number Surveys Processed : & 285 \\
\hline
\end{tabular}

Analysis Notes

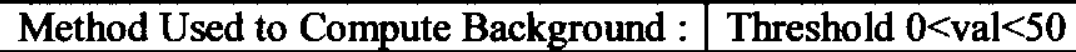

Depth(s) where Contamination Identified $32-48 \mathrm{ft}$ Unstable Early in Gross Gamma Surveys :

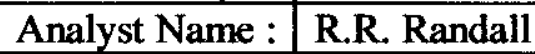

Company Name : Three Rivers Scientific 
RPP-6088, Rev.0.

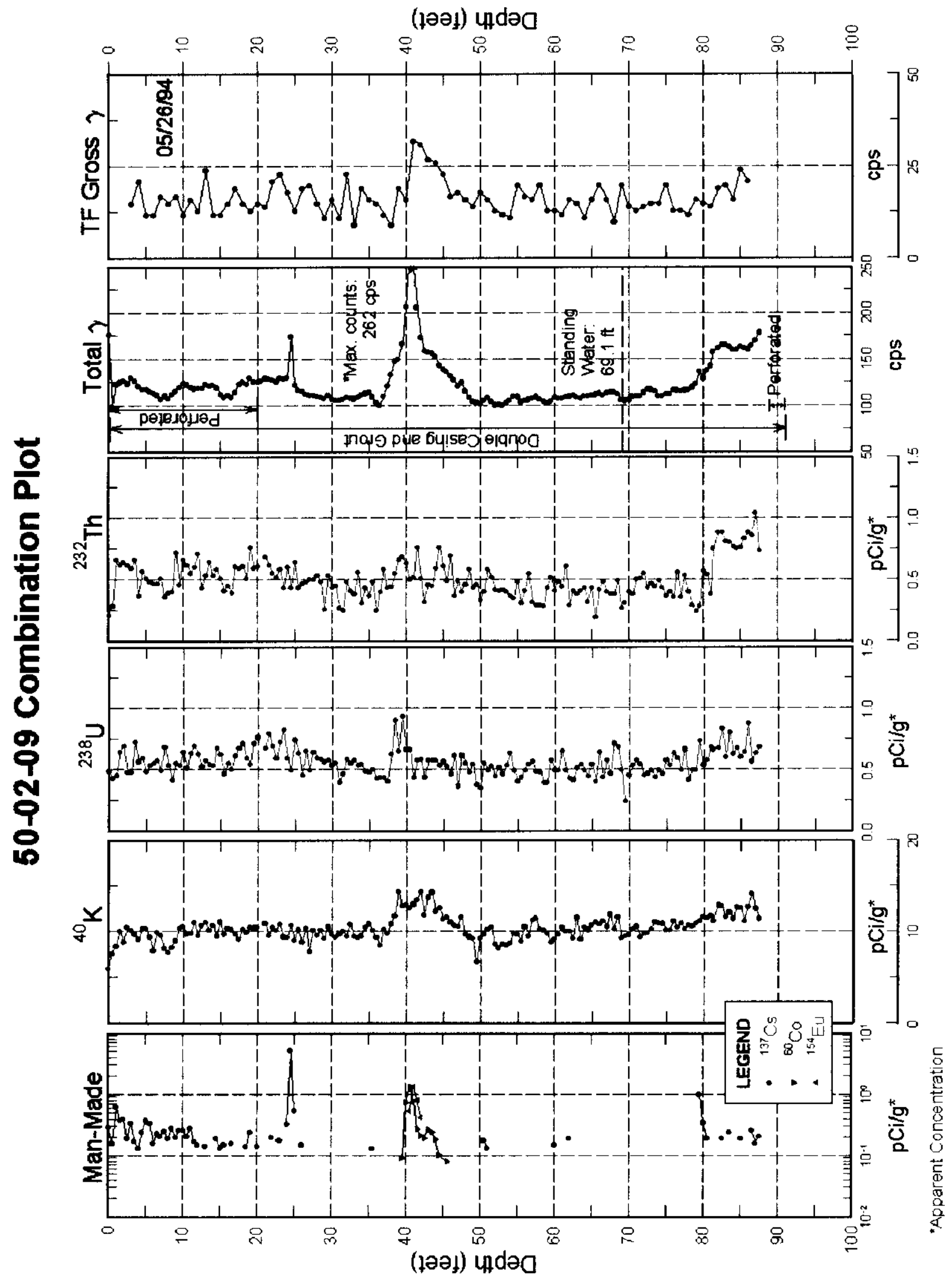

Tank T-102

Page 123 


\section{RPP-6088, Rev.0.}

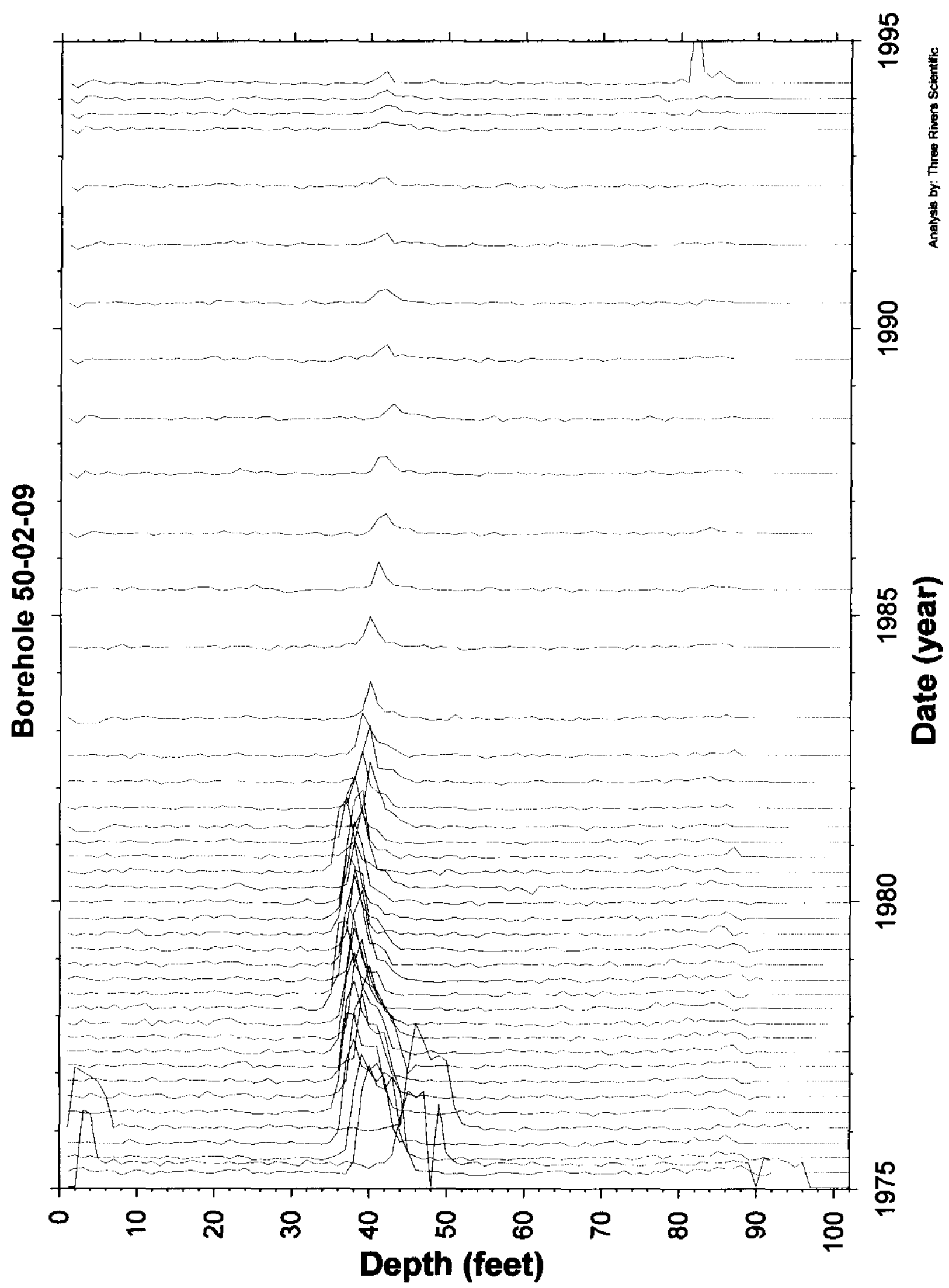

Tank T-102

Page 124 
RPP-6088, Rev.0.
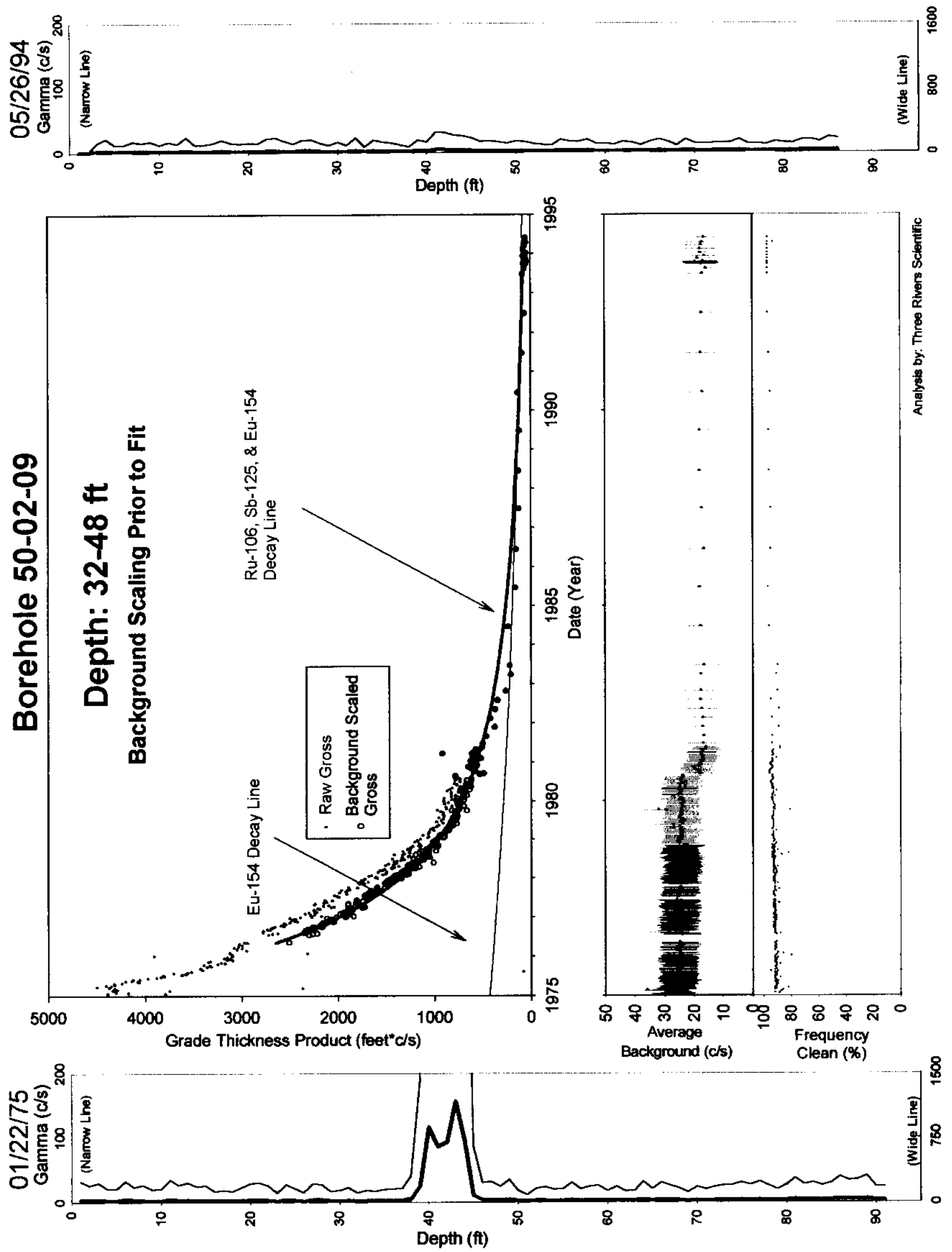

Tank T-102 
RPP-6088, Rev.0.

\section{Borehole 50-02-10}

\section{No Gamma Ray Emitting Contamination Identified.}

No significant levels of gamma ray contamination are present, based upon gross gamma data, above the survey probe detection threshold between 1975 and 1995 in the vadose zone from 2 to 83 feet. The HPGe logging system detected Cs-137 at less than $1 \mathrm{pCi} / \mathrm{g}$.

The average background plot shows a step decrease after 9-3-80.

Gross Gamma Survey Information

\begin{tabular}{|r|l|}
\hline Probe Type Processed : & $04:$ NaI \\
\hline Other Probe Types : & $03:$ Neutron \\
\hline Survey Depth : & $85 \mathrm{ft}$ \\
\hline First Survey Date : & $1 / 13 / 1975$ \\
\hline Last Survey Date : & $5 / 26 / 1994$ \\
\hline Number Surveys Processed : & 286 \\
\hline
\end{tabular}

Analysis Notes

Method Used to Compute Background : $\quad$ Threshold $0<$ val $<50$

Depth(s) where Contamination Identified NONE

in Gross Gamma Surveys :

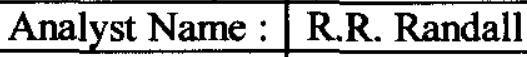

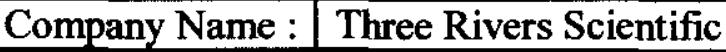


RPP-6088, Rev.0.

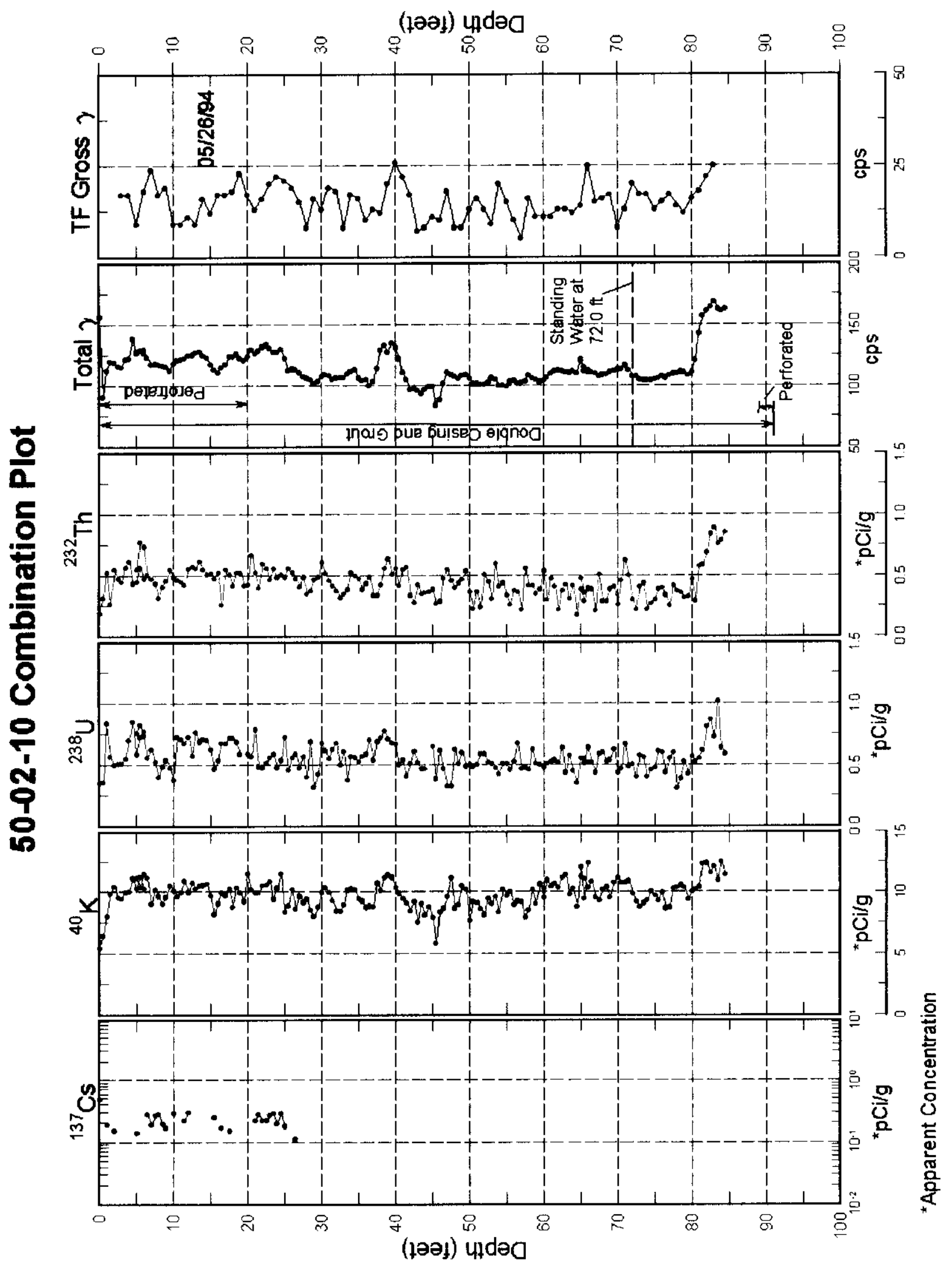

Tank T-102 
RPP-6088, Rev.0.

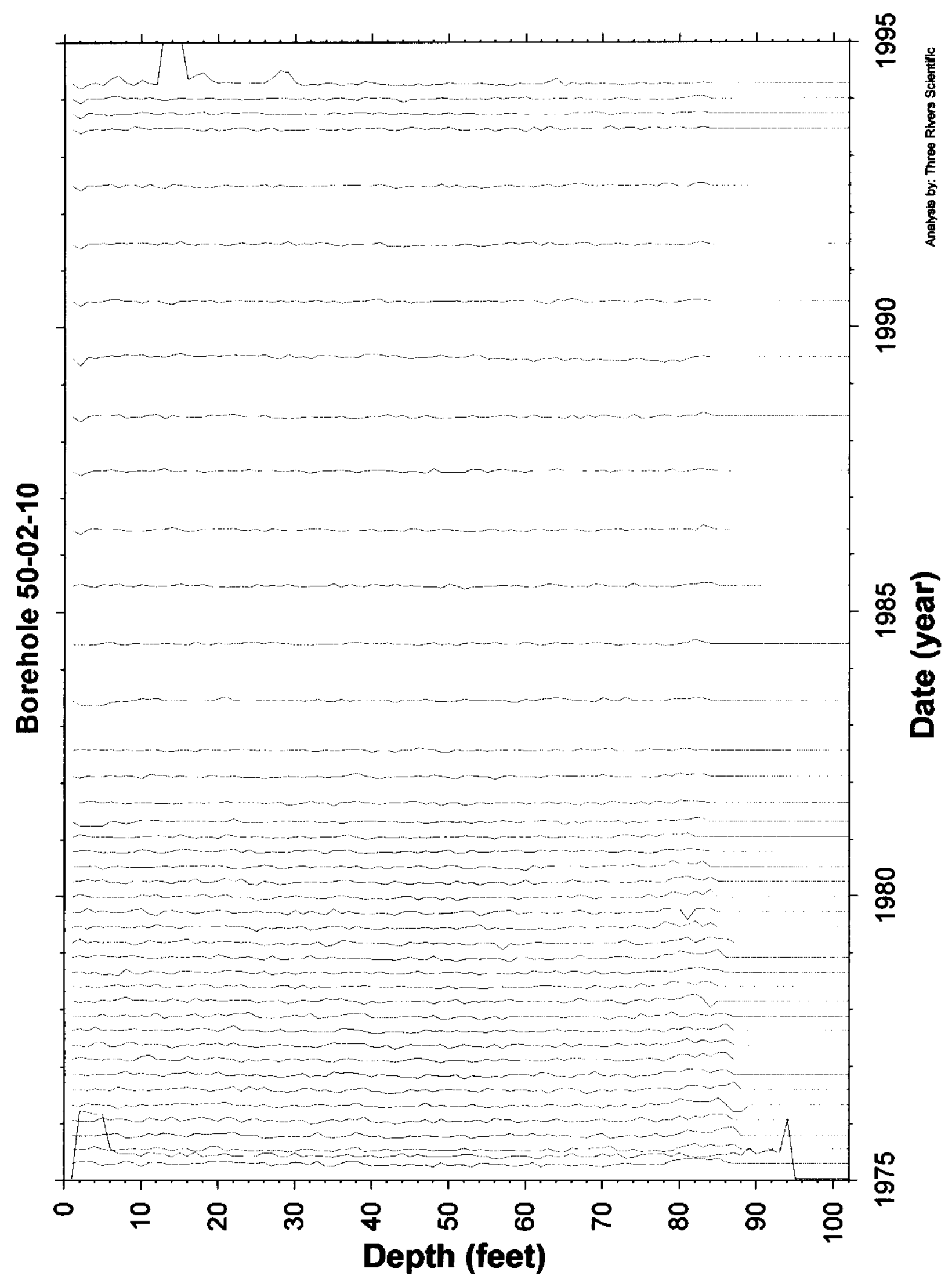

Tank T-102

Page 128 
RPP-6088, Rev.0.

\section{Borehole 50-02-10}

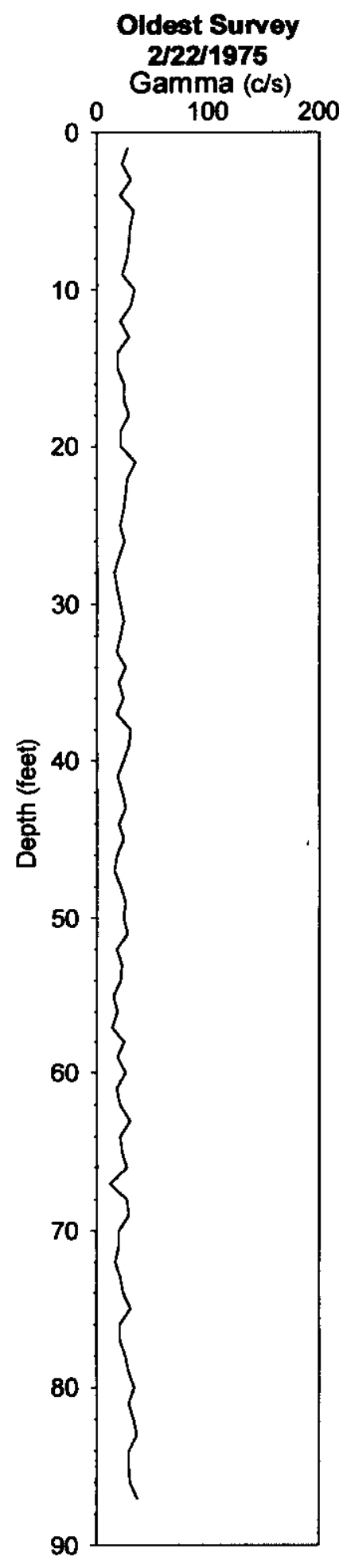
No Gamma-Ray Emitting Contamination
Above Survey Detection Threshold
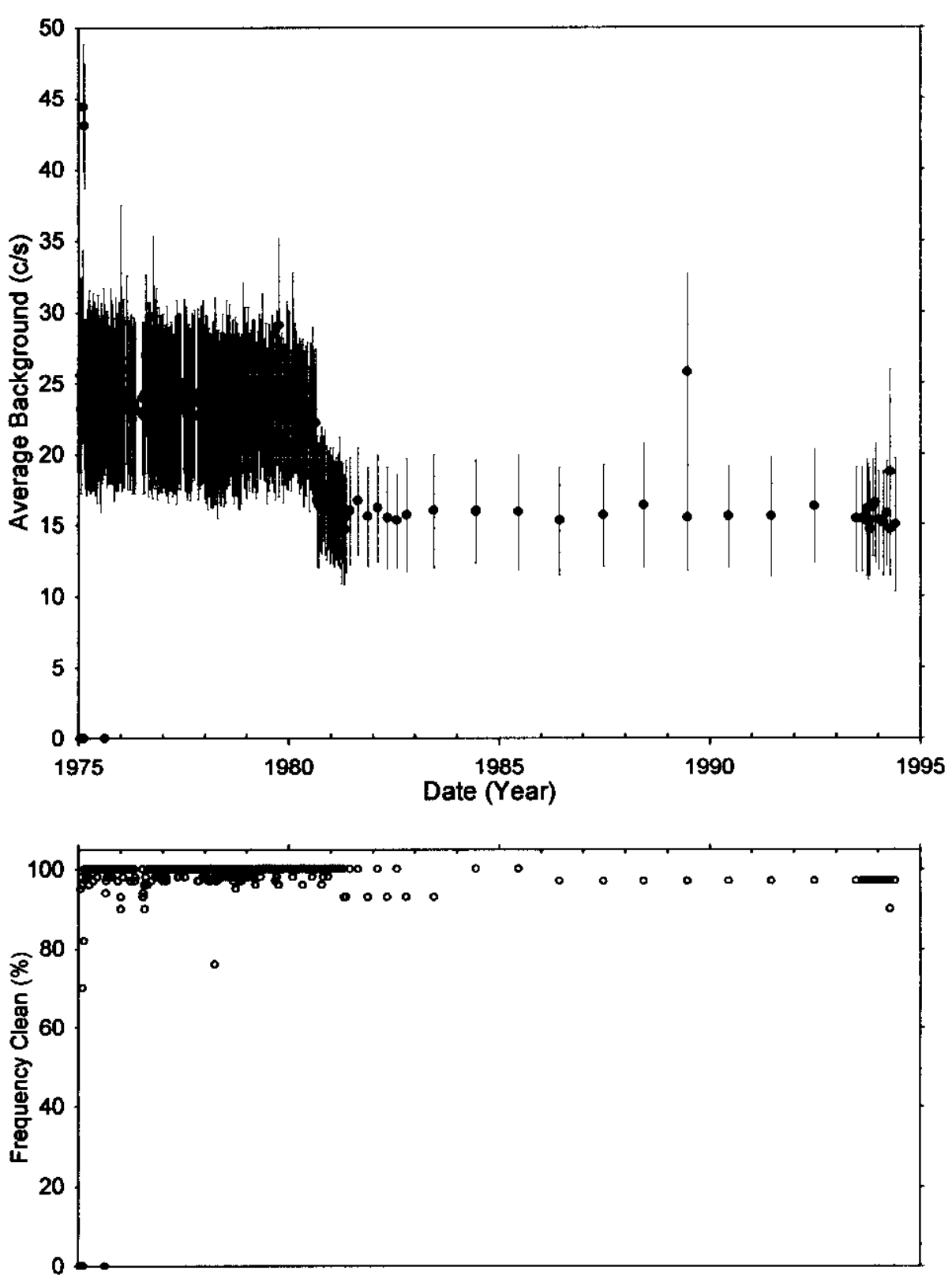

Analysis by: Three Rivers Scientific 
RPP-6088, Rev.0.

\section{Borehole 50-02-12}

\section{No Gamma Ray Emitting Contamination Identified.}

No significant levels of gamma ray contamination are present, based upon gross gamma data, above the survey probe detection threshold between 1975 and 1995 in the vadose zone from 2 to 88 feet. The HPGe logging system detected Cs-137 at less than $1 \mathrm{pCi} / \mathrm{g}$.

The average background plot shows a step decrease after 9-3-80.

Gross Gamma Survey Information

\begin{tabular}{|r|l|}
\hline Probe Type Processed : & $04:$ NaI \\
\hline Other Probe Types : & $03:$ Neutron \\
\hline Survey Depth : & $90 \mathrm{ft}$ \\
\hline First Survey Date : & $1 / 13 / 1975$ \\
\hline Last Survey Date : & $5 / 26 / 1994$ \\
\hline Number Surveys Processed : & 285 \\
\hline
\end{tabular}

Analysis Notes

Method Used to Compute Background : $\quad$ Threshold $0<$ val $<50$

Depth(s) where Contamination Identified NONE

in Gross Gamma Surveys :

Analyst Name : R.R. Randall

Company Name : Three Rivers Scientific 
RPP-6088, Rev.0.

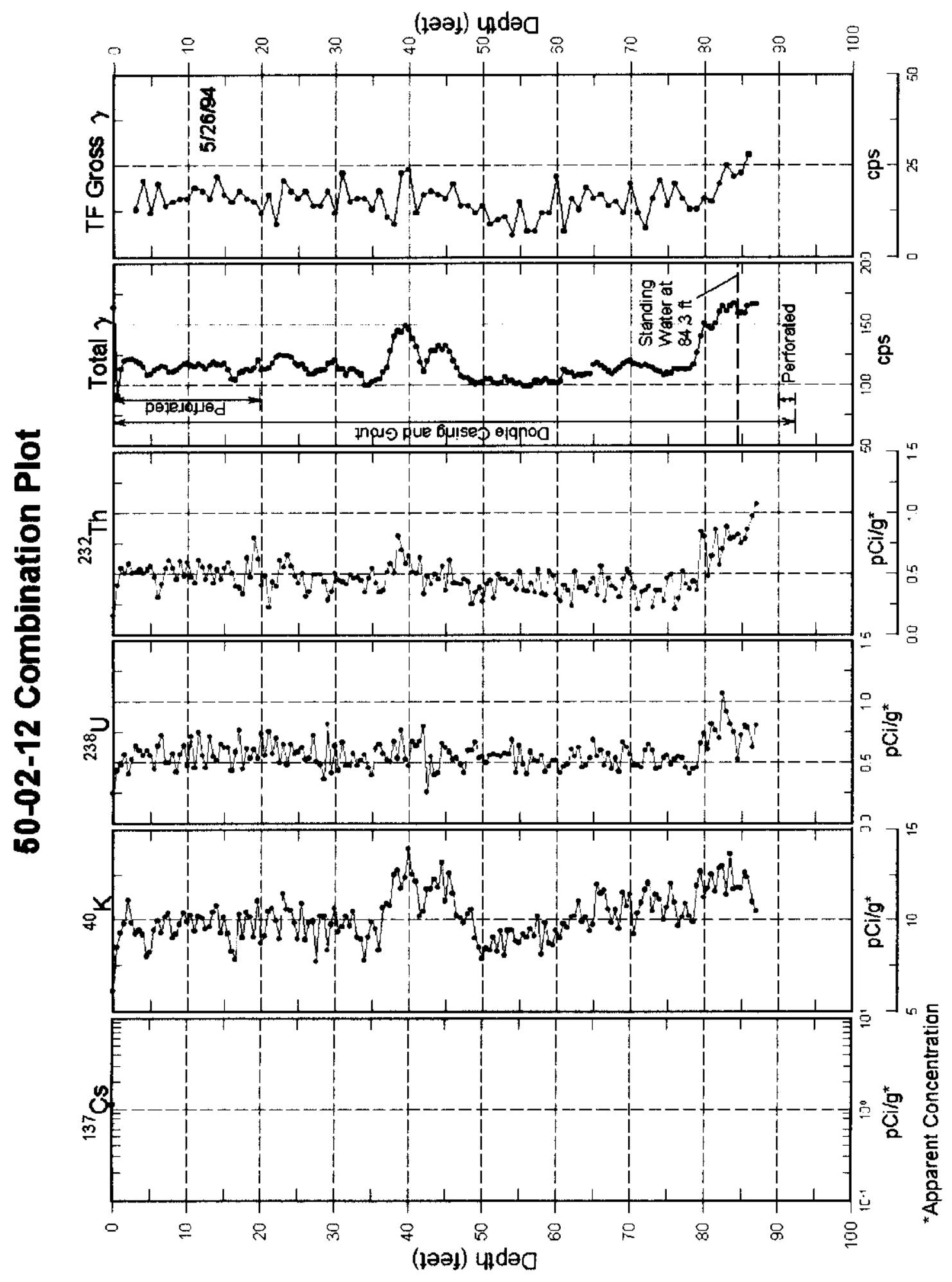

Tank T-102

Page 131 
RPP-6088, Rev.0.

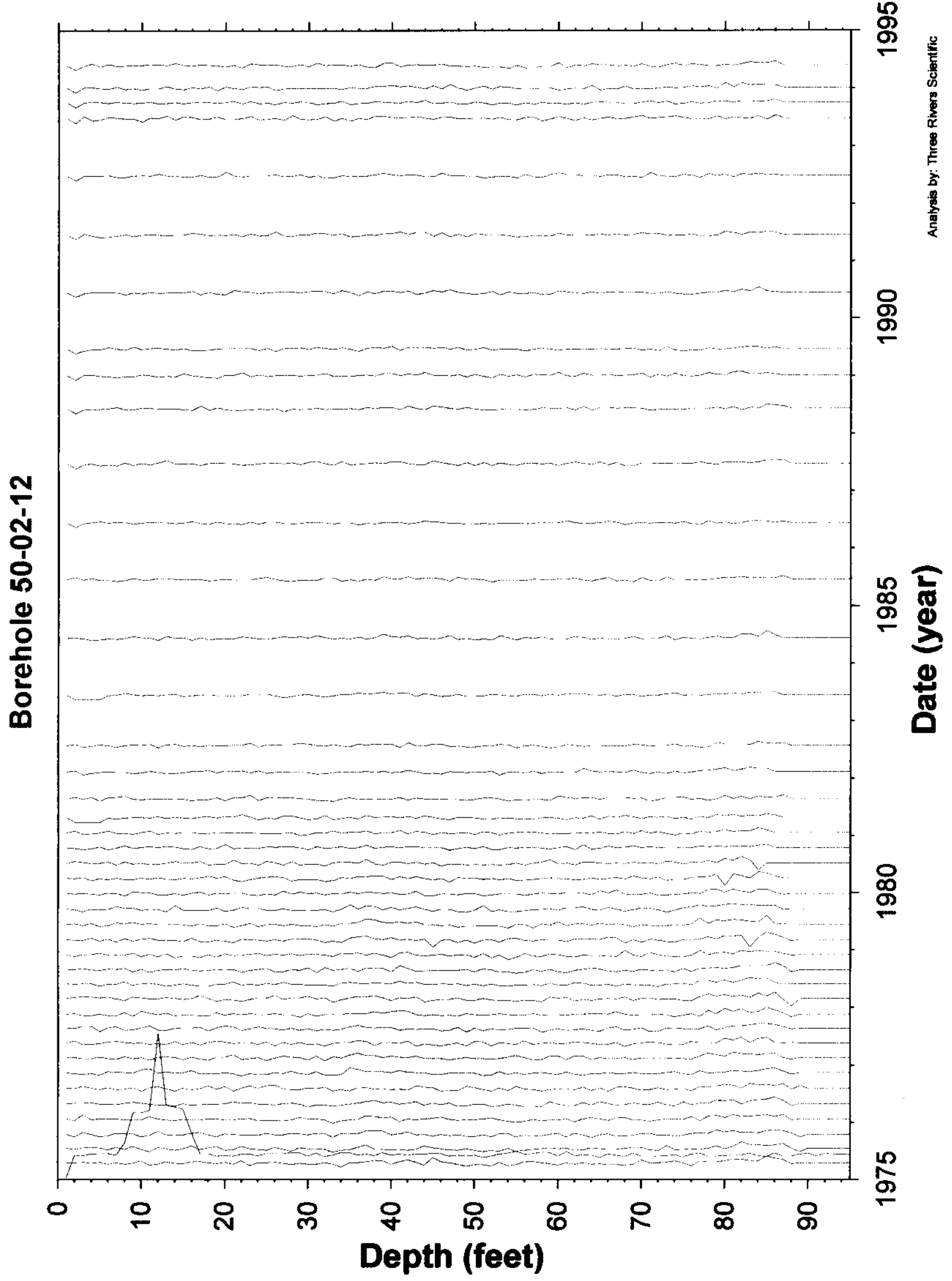

Tank T-102

Page 132 
RPP-6088, Rev.0.

\section{Borehole 50-02-12}

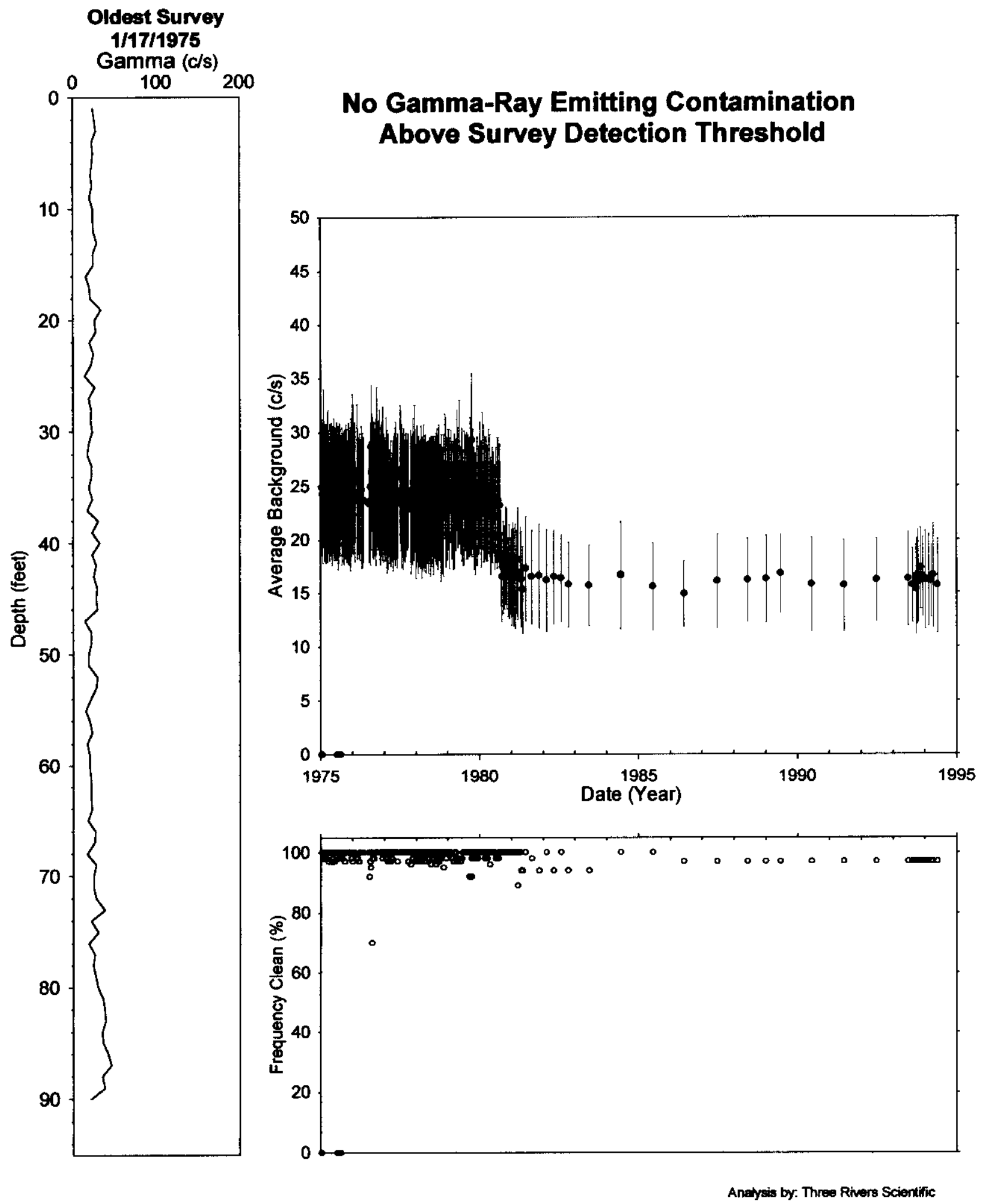

Tank T-102 
RPP-6088, Rev.0.

\section{Tank T-103 Wells}

Table of Contents
Tank T-103 Wells $\ldots(13)$
Borehole 50-03-01
Borehole 50-03-04
Borehole 50-03-05
Borehole 50-03-06
Borehole 50-03-08
Borehole 50-03-10

This section contains the analysis results for vadose zone boreholes (dry wells) associated with Tank 103 in the "T" Tank Farm.

Special Note:

None 
RPP-6088, Rev.0.

\section{Borehole 50-03-01}

\section{No Gamma Ray Emitting Contamination Identified.}

No significant levels of gamma ray contamination are present, based upon gross gamma data, above the survey probe detection threshold between 1975 and 1995 in the vadose zone from 2 to 88 feet. The HPGe logging system detected $\mathrm{Cs}-137$ at less than $1.3 \mathrm{pCi} / \mathrm{g}$.

The average background plot shows a step decrease after 9-3-80.

Gross Gamma Survey Information

\begin{tabular}{|r|l|}
\hline Probe Type Processed : & $04:$ NaI \\
\hline Other Probe Types : & $03:$ Neutron \\
\hline Survey Depth : & $90 \mathrm{ft}$ \\
\hline First Survey Date : & $1 / 13 / 1975$ \\
\hline Last Survey Date : & $5 / 26 / 1994$ \\
\hline Number Surveys Processed : & 176 \\
\hline
\end{tabular}

Analysis Notes

Method Used to Compute Background : Threshold $0<$ val $<50$

Depth(s) where Contamination Identified NONE

in Gross Gamma Surveys :

Analyst Name : $\quad$ R.R. Randall

Company Name : Three Rivers Scientific 
RPP-6088, Rev.0.

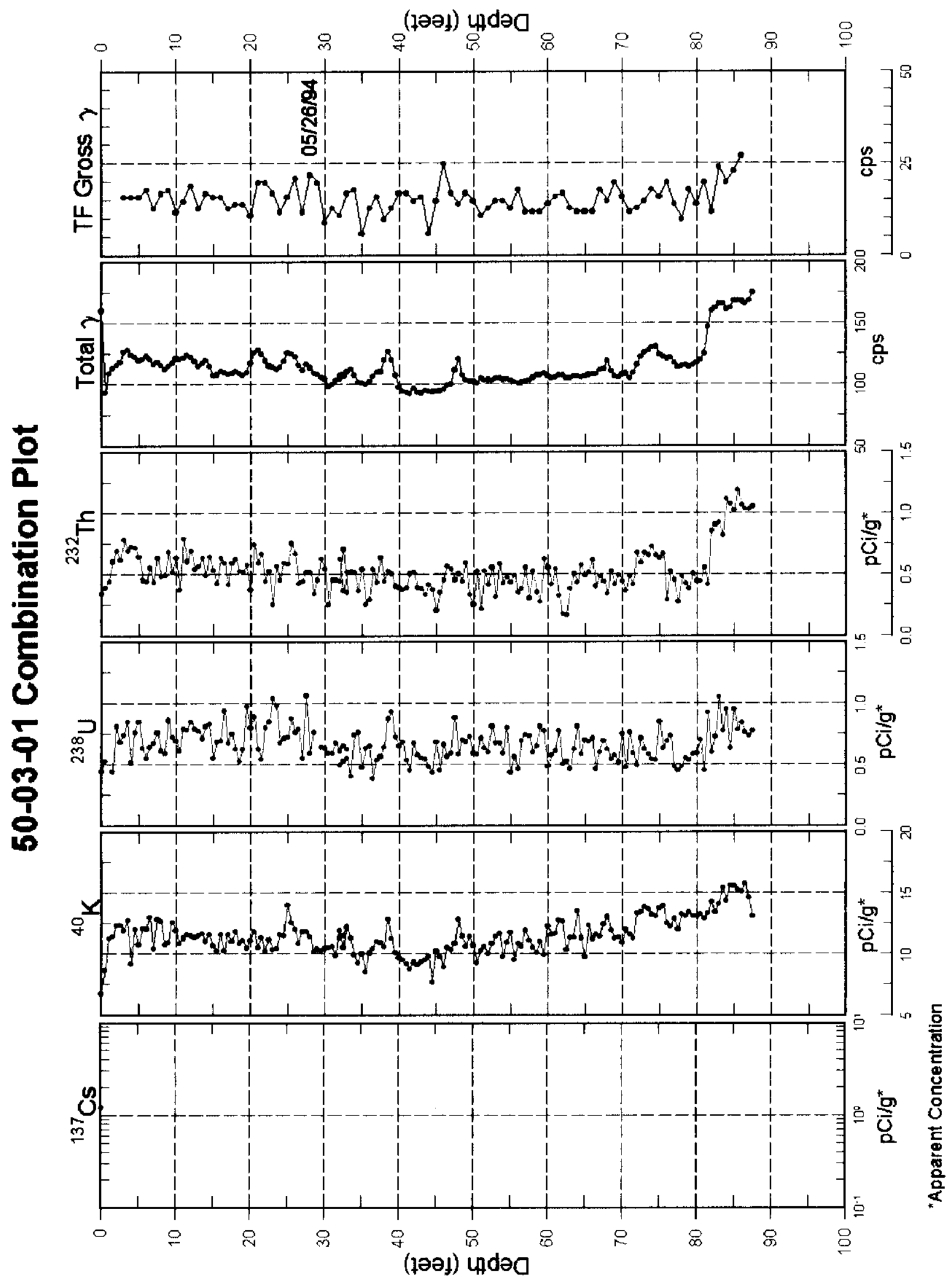

Tank T-103 
RPP-6088, Rev.0.

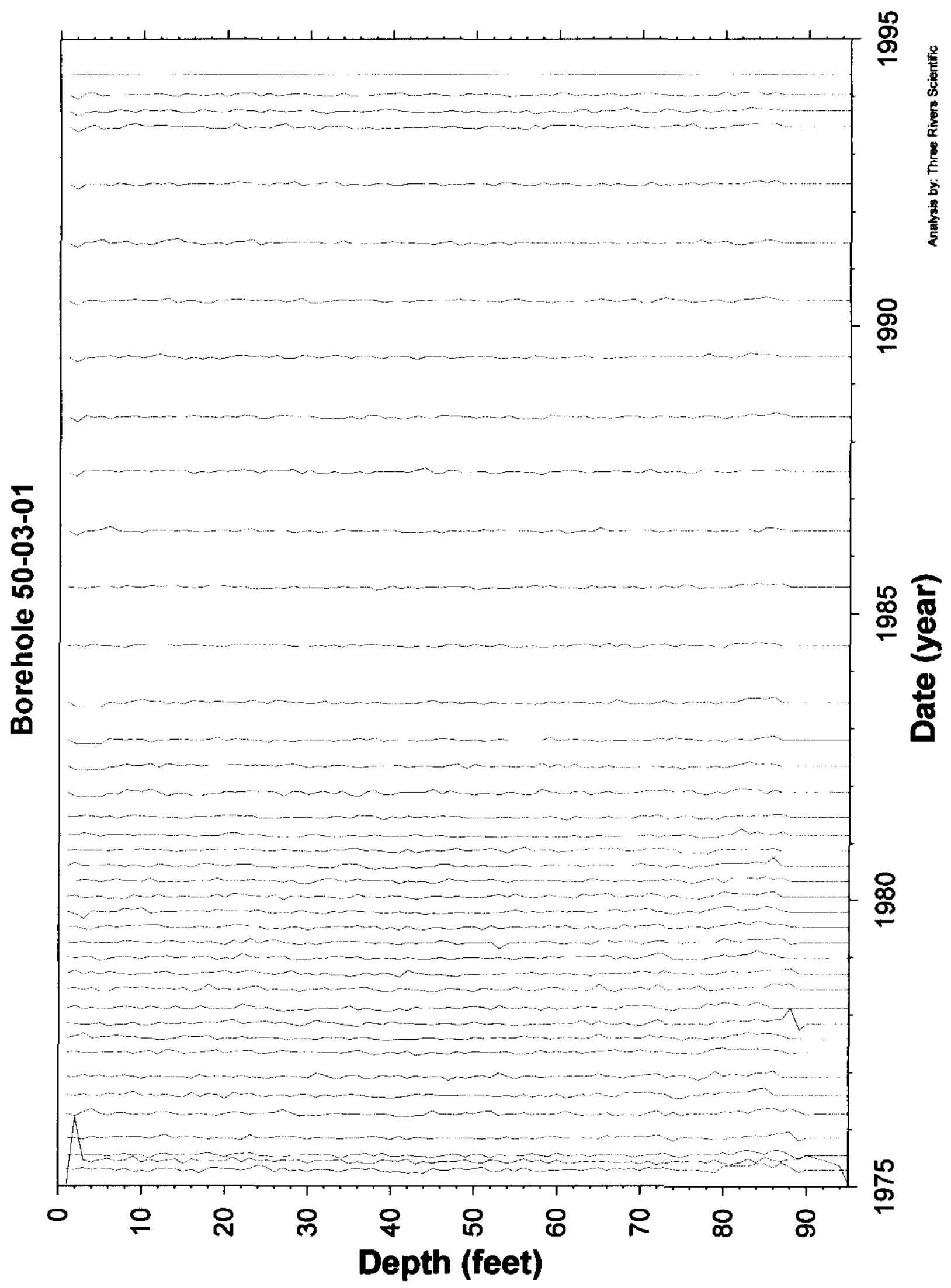

Tank T-103

Page 137 
RPP-6088, Rev.0.

\section{Borehole 50-03-01}

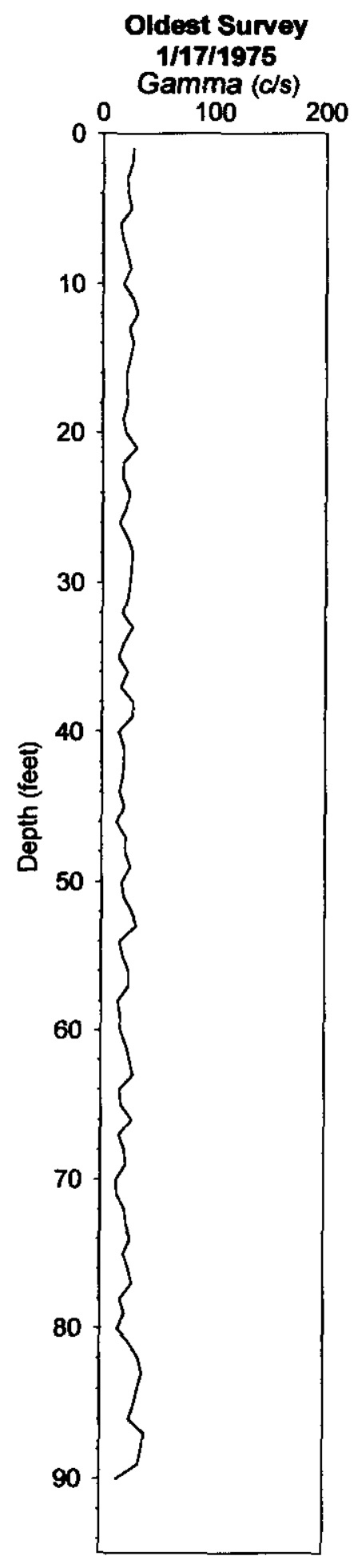
No Gamma-Ray Emitting Contamination Above Survey Detection Threshold
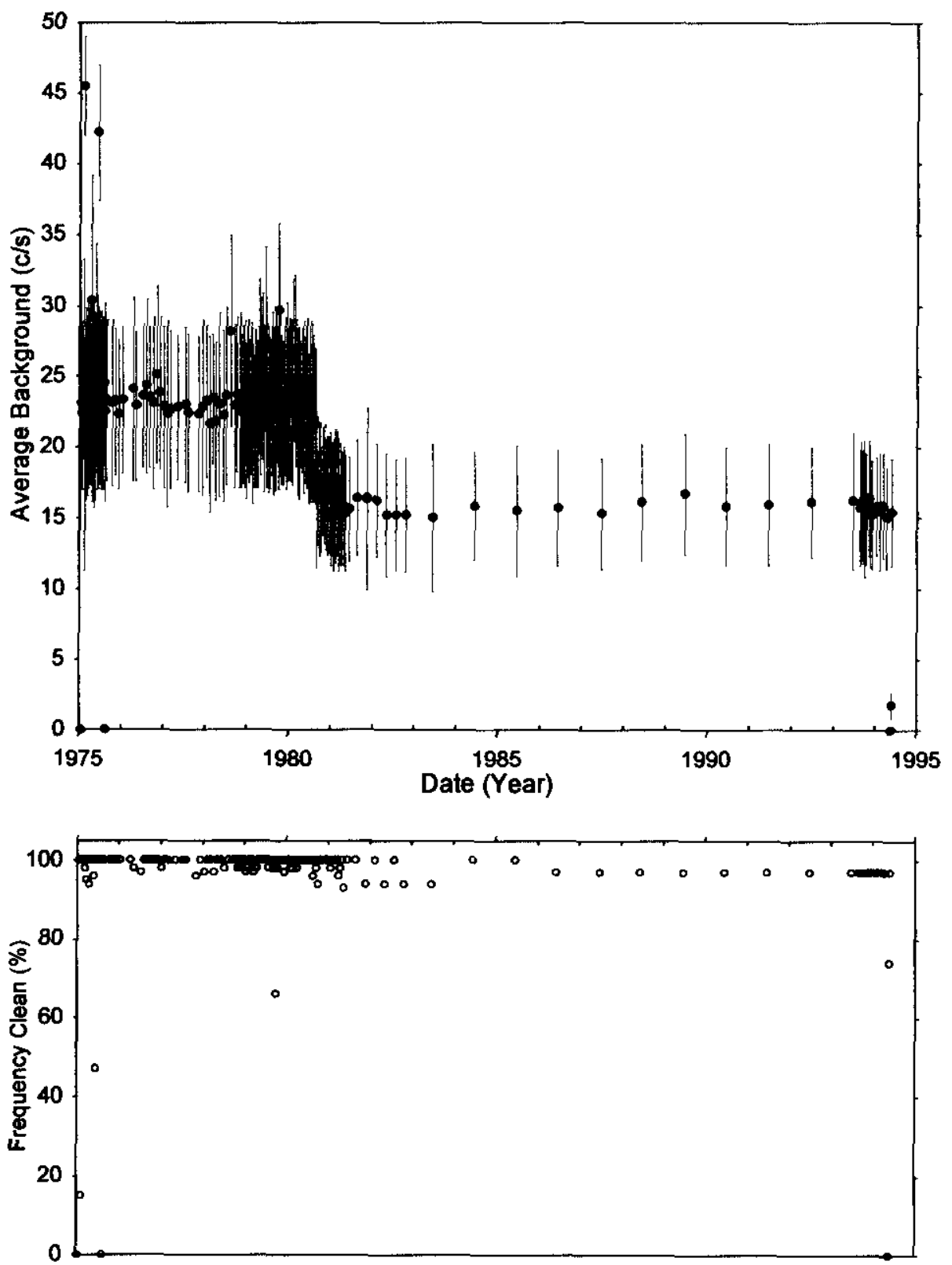

Analysis by. Three Rivers Scientific 


\section{Borehole 50-03-04}

\section{Contamination (Co-60, Eu-154, \& Ru-106) from 12-52 feet is Stable. Contamination (Ru-106) from 52-60 feet is Stable*. Contamination (Co-60 \& Sb-125) from 60-75 feet is Stable*. Contamination (Co-60, Eu-154, \& Ru-106) from 75-90 feet is Stable.}

The average background shows a step decrease that coincides with deeper logging after 4-28-81. This is consistent with extra casing for a deepened dry well. When necessary, the ratio of the average background before to after this date is used to adjust a grade thickness product in the analysis. When this adjustment is performed, the raw grade thickness product data are plotted as small blue circles, and the scaled grade thickness product data are plotted as large open black circles.

The interval from 12 to 52 feet has a high level of contamination, with Co-60, Eu-154, Eu-152, Cs-137, Nb-94, Sn-126, Sb-125, and U238 identified with the HPGe logging system (refer to the HPGe plot). The scaled grade thickness product data were fit with a least square to three components of Co-60, Eu-154, and Ru-106 (hypothesized), and the match suggests stability. More than three components used in a least square fit can be misleading for data covering such a relatively short time period, unless known constraints can be used on the relative contribution of the gross gamma response from the isotopic concentrations. The results of the applied least square fit yields a gross gamma contribution ratio for Co:Eu:Ru of 42690:62600:475300 (ft*c/s) as of 1-13-75.

Grade thickness product over 52 to 60 feet matches Ru-106 (hypothesized) decay from 1975 until 1981. After the speculated wellbore re-working, some more contaminant appears to be introduced in this interval, with a subsequent rapid decay. Since the levels are so low, these data are not scaled for the average background change. Given the low levels and lack of rigorous conclusion, the classification is stable, but denoted with an asterisk.

Drilling to deeper depths after 1981 may have introduced contaminant in the interval from 60 to 75 feet. The grade thickness product after 4-28-81 is decreasing consistent with Co-60 (HPGe identified) and Sb-125 (hypothesized) decay. No scaling was used since only the data after 1981 were used in the least square fitting process. The classification of stable is further noted with an asterisk in order to note the smaller time period of existence from 1975 to mid 1975 . Note that relatively small levels of $\mathrm{Sb}-125$ were HPGe identified in the zone above this interval. The results of the applied least square fit yields a gross gamma contribution ratio for $\mathrm{Co:Sb}$ of 12.2:7.6 $(\mathrm{ft} * \mathrm{c} / \mathrm{s})$ as of 5-26-94.

The interval from 75 to 90 feet has a moderate level of contamination, with Co-60 and Eu-154 identified with the HPGe logging system. The scaled grade thickness product data were fit with a least square to three components of Co-60, Eu-154, and Ru-106 (hypothesized), and the match 
RPP-6088, Rev.0.

suggests stability. The results of the applied least square fit yields a gross gamma contribution ratio for Co:Eu:Ru of 30.2:190:851 (ft* c/s) as of 1-13-75.

Gross Gamma Survey Information

Probe Type Processed : $04: \mathrm{NaI}$

Other Probe Types : 03: Neutron(2); 02: Red GM(1);

14:Shielded NaI(45)

Survey Depth : $125 \mathrm{ft}$

First Survey Date : $1 / 13 / 1975$

\begin{tabular}{l|l} 
Last Survey Date : & $5 / 26 / 1994$
\end{tabular}

Number Surveys Processed : 175

Analysis Notes

Method Used to Compute Background : $\quad$ Threshold $0<$ val $<50$

Depth(s) where Contamination Identified $12-52$ \& 75-90 ft Stable, in Gross Gamma Surveys : $52-60$ \& 60-75 ft Stable*

Analyst Name : R.R. Randall

Company Name : $\quad$ Three Rivers Scientific 
RPP-6088, Rev.0.

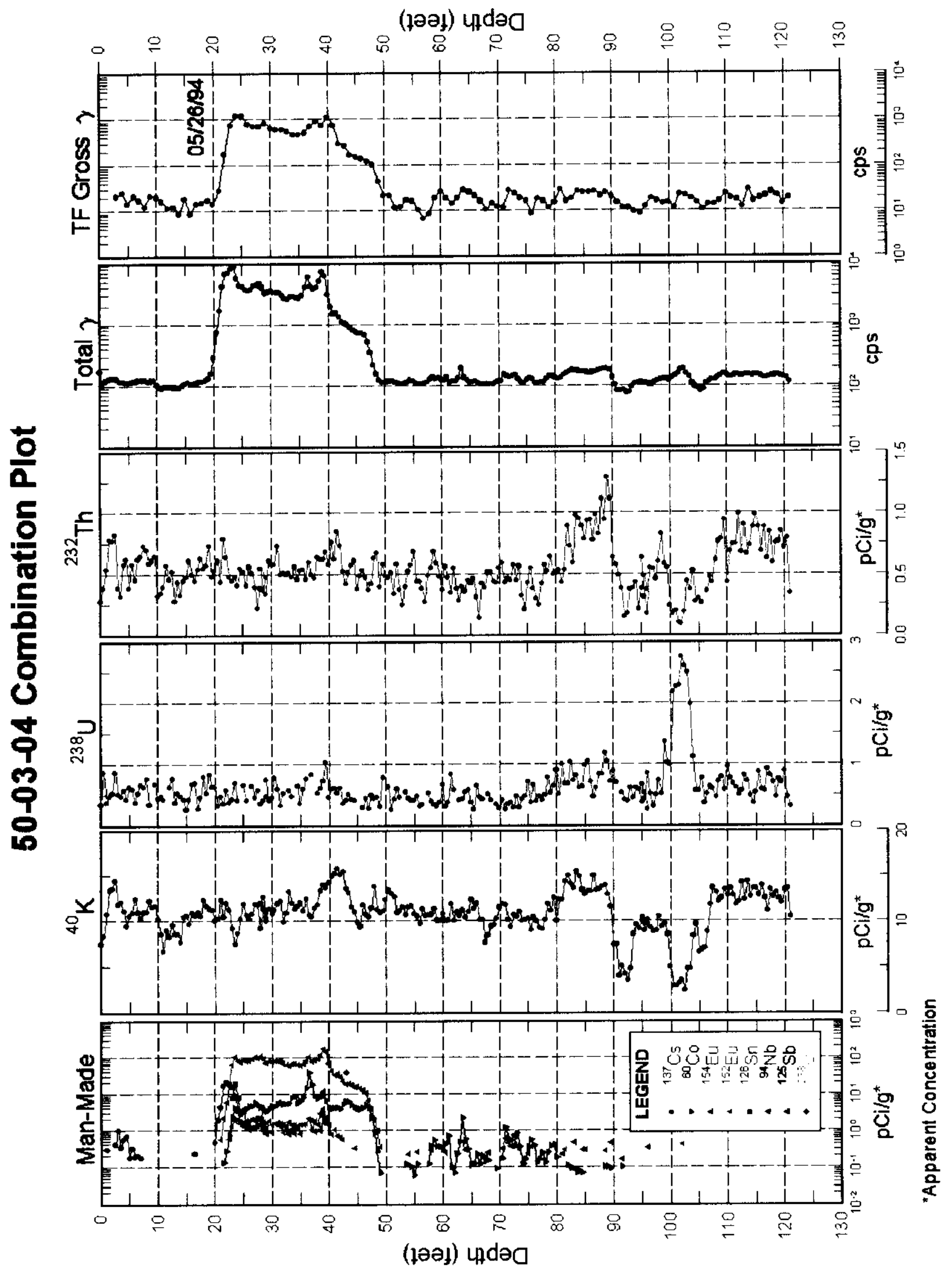

Tank T-103

Page 141 
RPP-6088, Rev.0.

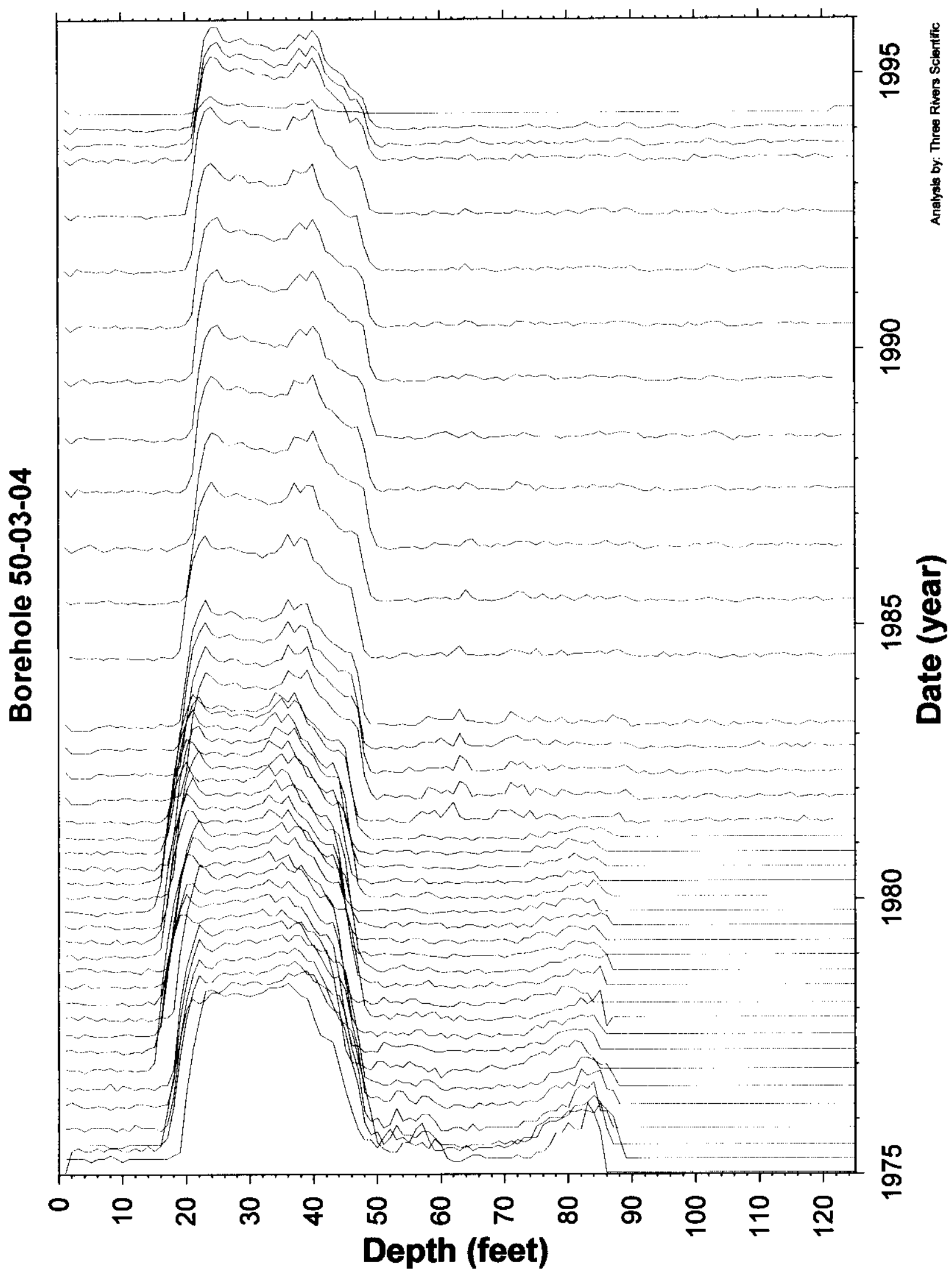

Tank T-103

Page 142 
RPP-6088, Rev.0.
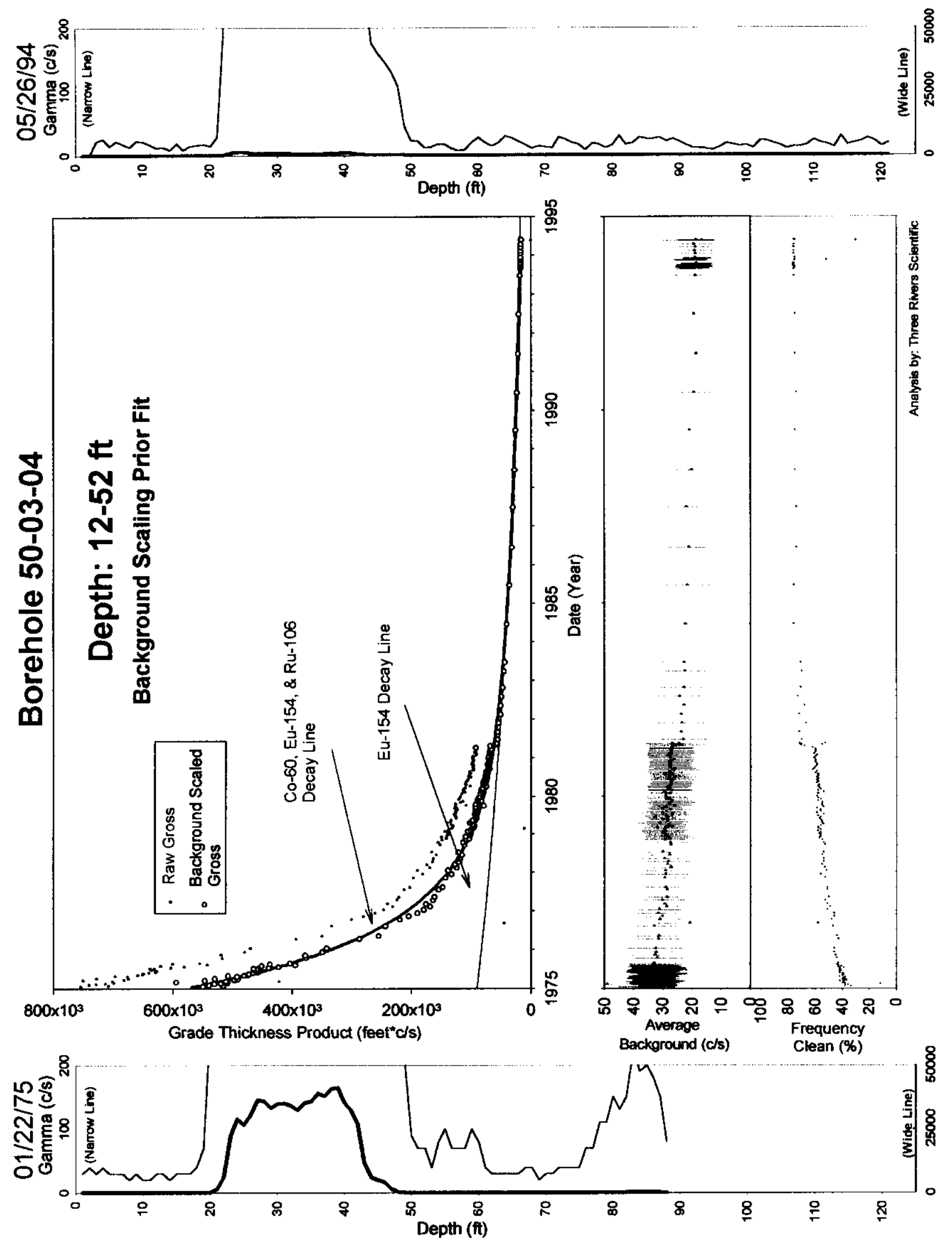

Tank T-103

Page 143 
RPP-6088, Rev.0.
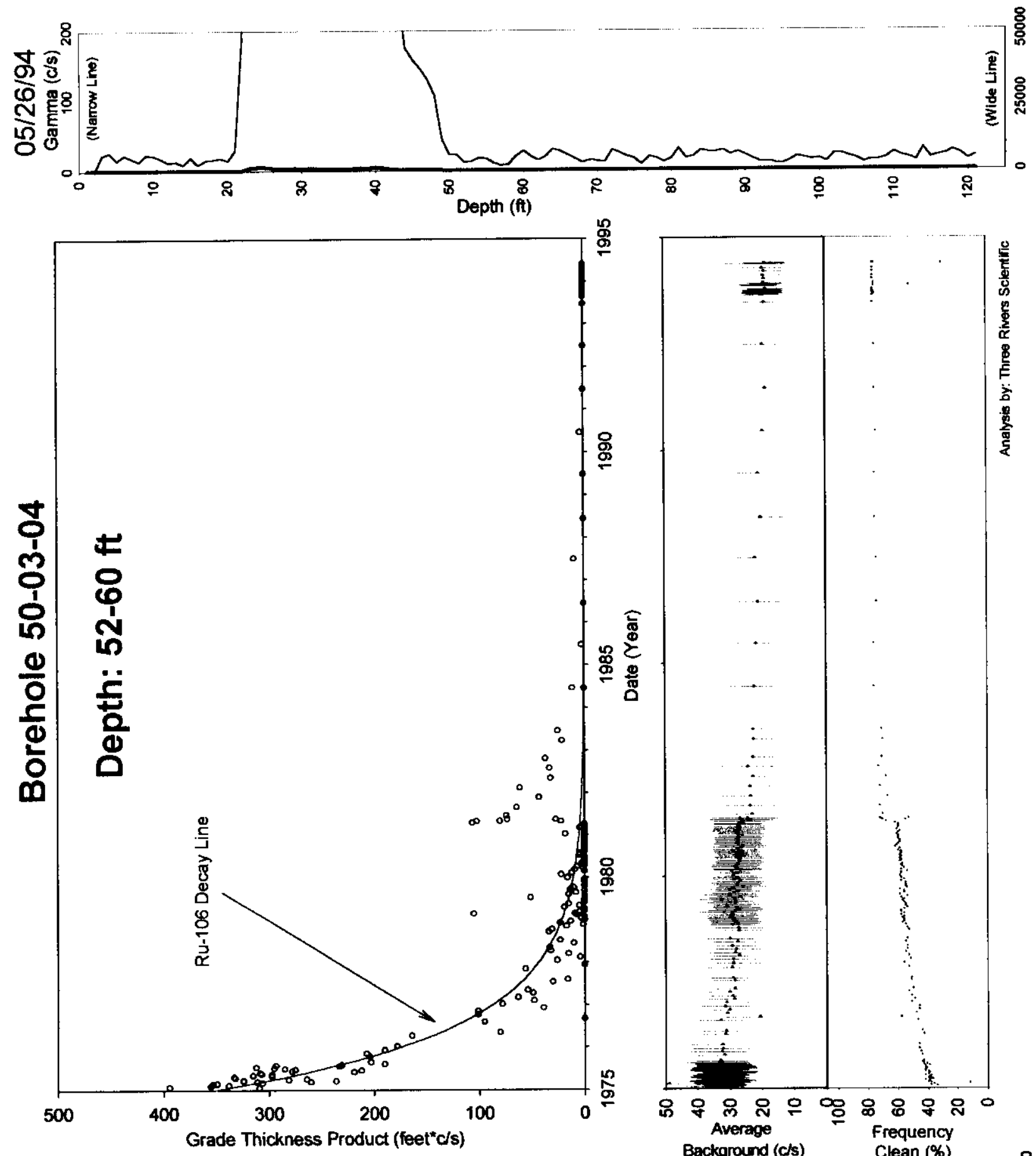

兽
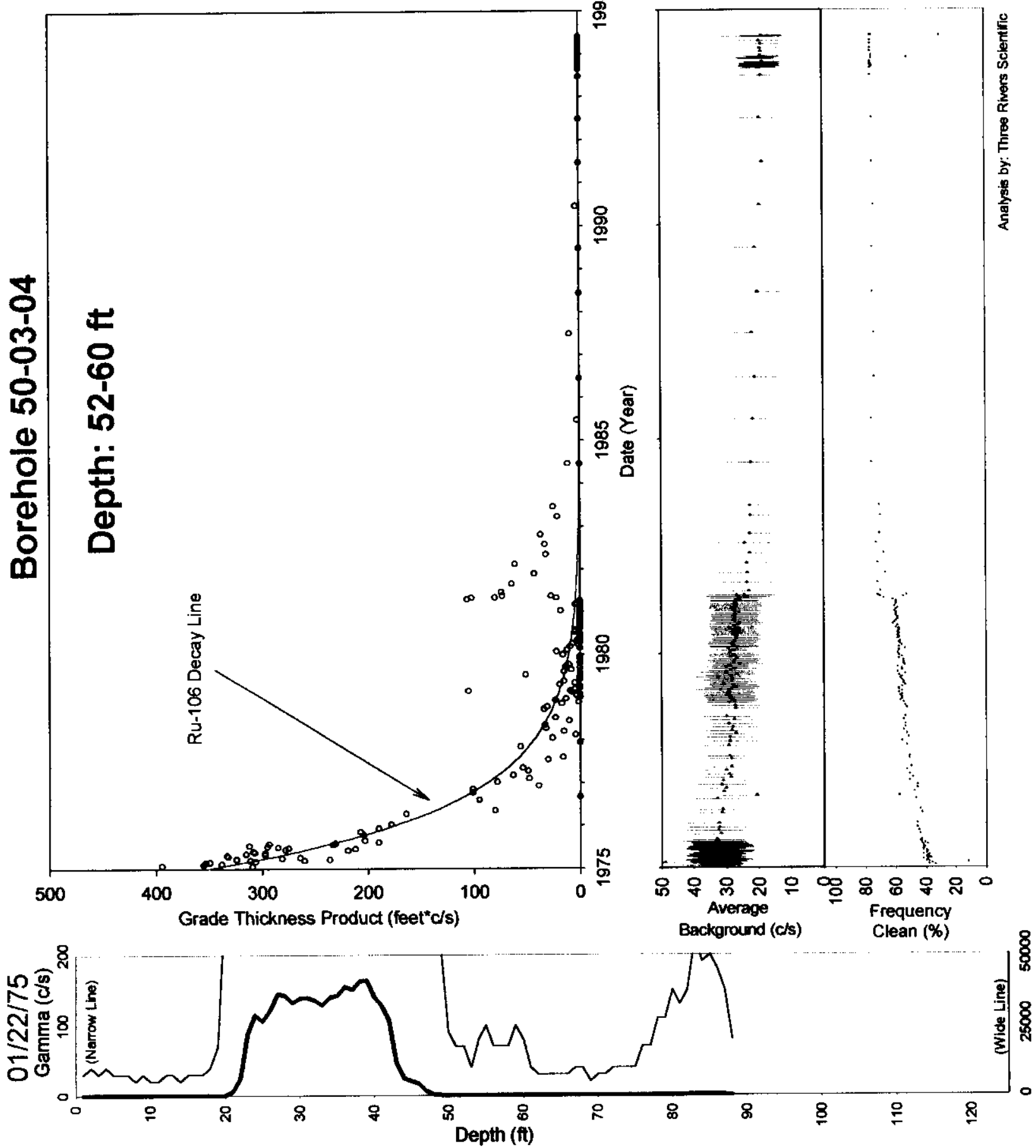

Tank T-103 
RPP-6088, Rev.0.
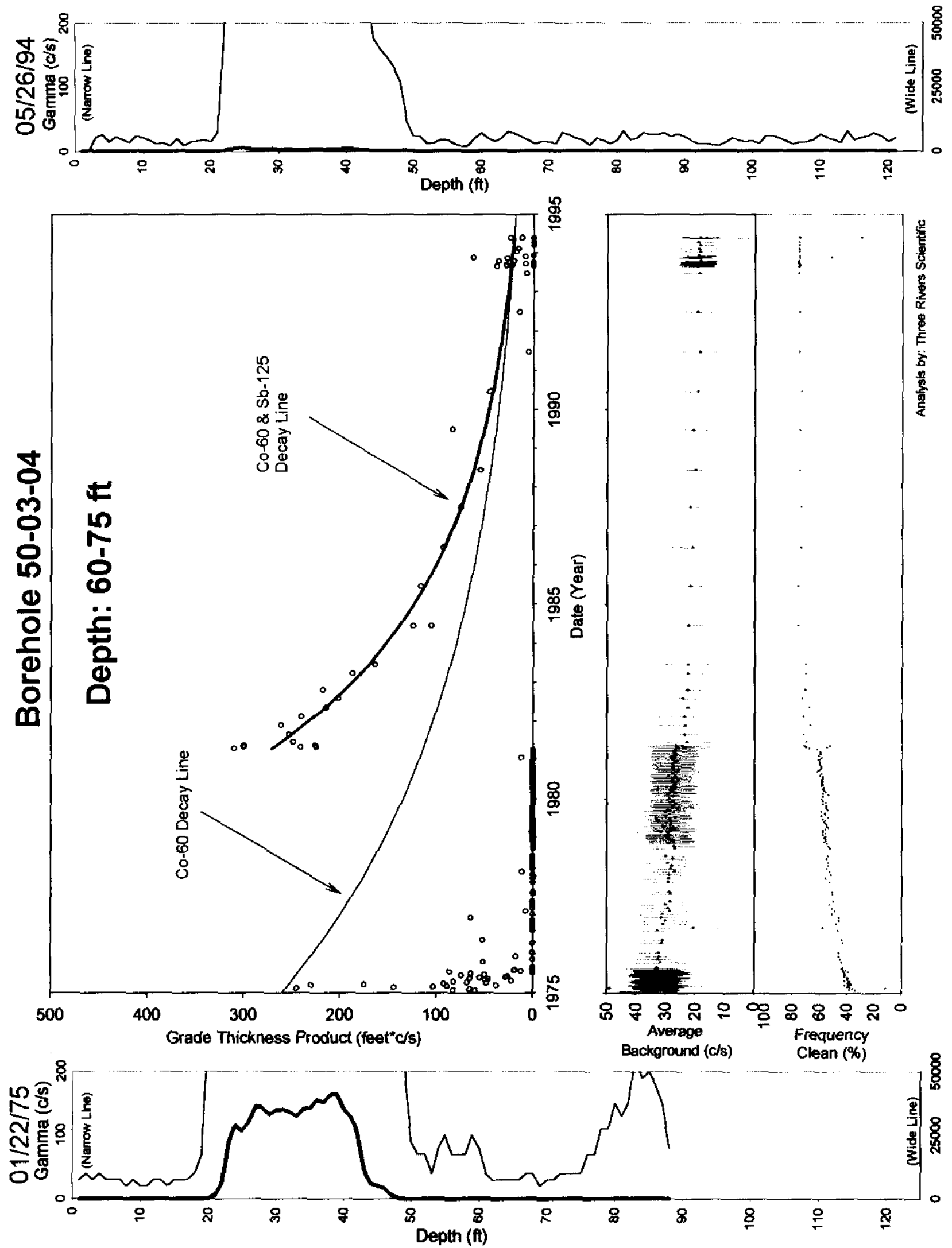

Tank T-103 
RPP-6088, Rev.0.
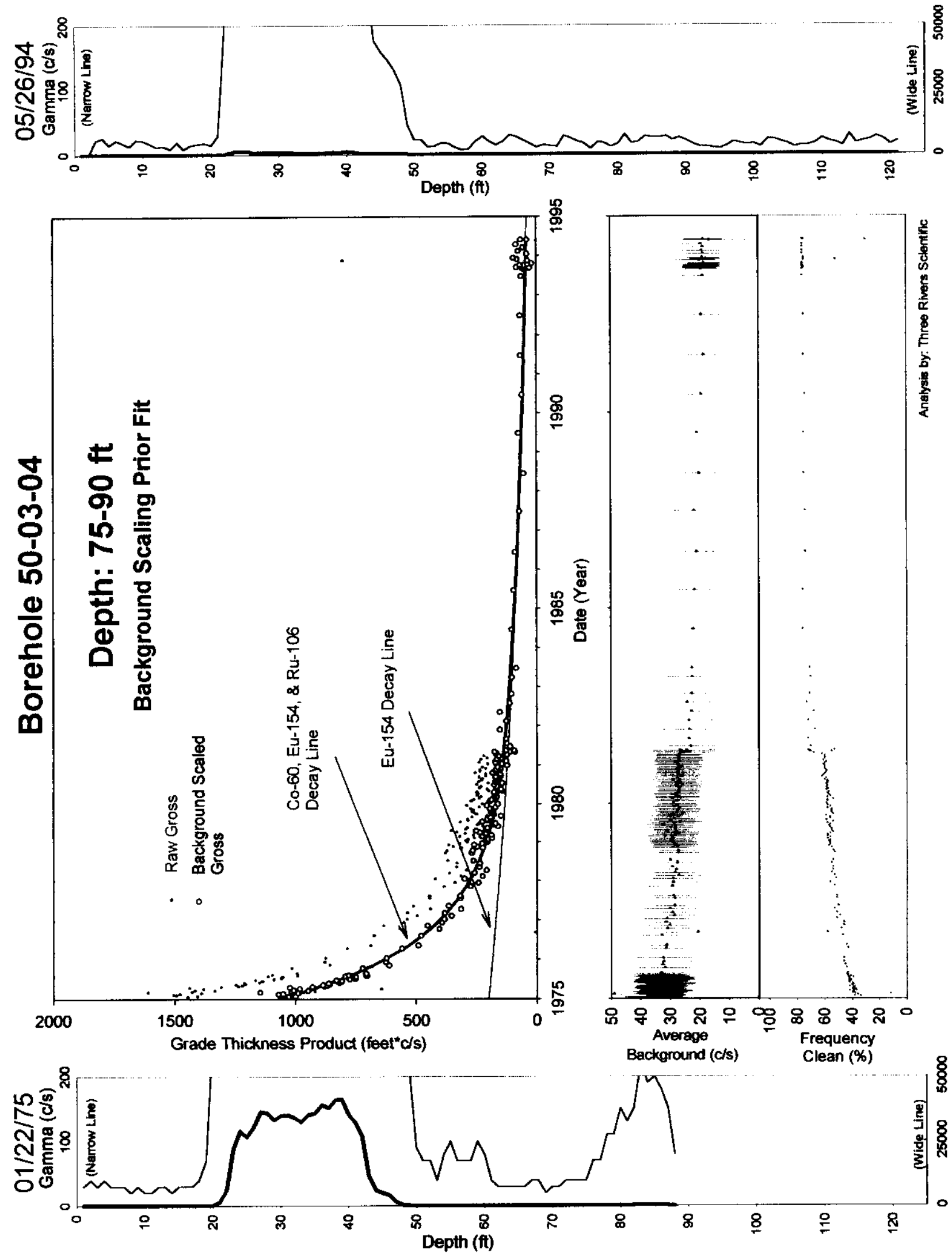

Tank T-103 
RPP-6088, Rev.0.

\section{Borehole 50-03-05}

\section{Contamination (Eu-154, Co-60, \& Ru-106) from 32-52 feet is Stable. Contamination (Eu-154 \& Ru-106) from 52-65 feet is Undetermined. Contamination (Ru-106) from 65-72 feet is Undetermined. Contamination (Eu-154 \& Ru-106) from 75-90 feet is Stable.}

A step decrease in average background and grade thickness product occurs after 3-31-81. Likewise, the survey depths increased from 95 to 120 feet after this same date. This observation is consistent with well deepening and addition of a second string of casing.

The interval from 32 to 52 feet has a moderate level of contamination, with Co-60, Eu-154, and Eu-152 identified with the HPGe logging system (refer to the HPGe plot). The average background before the date of 3-31-81 was ratioed to the average background after this date and this same ratio was applied to the grade thickness product. The raw grade thickness product data are plotted as small blue circles, and the scaled grade thickness product data are plotted as large open black circles. The scaled grade thickness product data were fit with a least square to three components of Eu-154, Co-60, and Ru-106 (hypothesized), and the match suggest stability. A slight indication of grade thickness increase at the very beginning of the data may be due to depth control errors (refer to the stack plot). More than three components used in a least square fit can be misleading for data covering such a relatively short time period, unless known constraints were used on the relative contribution of the gross gamma response from the isotopic concentrations. The results of the applied least square fit yields a gross gamma contribution ratio for $\mathrm{Eu}: \mathrm{Co}: \mathrm{Ru}$ of $6000: 4479: 70000(\mathrm{ft} * \mathrm{c} / \mathrm{s})$ as of 1-13-75.

The interval from 52 to 65 feet has a small level of contamination, with Co-60 and Eu-154 identified with the HPGe logging system (refer to the HPGe plot). The scaling was not applied to the grade thickness product for this interval, since the levels decayed to very low levels by the time of the scale change. The grade thickness product data were fit with a least square to the components of Eu-154 and Ru-106 (hypothesized). The match is not excellent, but depth control errors can cause some interference from edges of the upper more intense zone. Generation of a single zone to encompass 32 to 65 feet would make insignificant any details in the much less intense zone from 52 to 65 feet. Due to the lack of statistical precision for this interval, depth control errors, the classification for this interval is undetermined. The results of the applied least square fit yields a gross gamma contribution ratio for Eu:Ru of 381:7000 ( $\left.\mathrm{ft}^{*} \mathrm{c} / \mathrm{s}\right)$ as of 1-13-75.

Grade thickness product over 65 to 72 feet shows rapid decay from 1975 until 1980, indicative of Ru-106 (hypothesis). After 1980 only natural background levels are present in the gross gamma response. However, small levels of Eu-154 and Co-60 were HPGe identified. The grade thickness product match with the $\mathrm{Ru}-106$ is not excellent, but again interference from near by zones is possible due to depth control errors before 1984. Due to the lack of statistical precision, and possible depth errors, the classification for this zone is undetermined. 
The interval from 75 to 90 feet has a small level of contamination, with Co-60 and Eu-154 identified with the HPGe logging system (refer to the HPGe plot). The average background before the date of 3-31-81 was ratioed to the average background after this date and this same ratio was applied to the grade thickness product. The raw grade thickness product data are plotted as small blue circles, and the scaled grade thickness product data are plotted as large open black circles. The scaled grade thickness product data were fit with a least square to components of Eu-154 and Ru-106 (hypothesized), and the match suggest stability. Levels of Eu-154 in this interval are lower than for the interval 65 to 72 feet, and the effects of Eu-154 are not visible in the gross gamma in the upper zone (65-72 ft), but are fit in this interval(75-90 ft). The results of the applied least square fit yields a gross gamma contribution ratio for Eu:Ru of 138:500 ( $\mathrm{ft} * \mathrm{c} / \mathrm{s})$ as of 1-13-75.

Gross Gamma Survey Information

\begin{tabular}{|r|l|}
\hline Probe Type Processed : & $04: \mathrm{NaI}$ \\
\hline Other Probe Types : & $03:$ Neutron(2) 02: Red GM(1) \\
\hline Survey Depth : & $120 \mathrm{ft}$ \\
\hline First Survey Date : & $1 / 13 / 1975$ \\
\hline Last Survey Date : & $5 / 26 / 1994$ \\
\hline Number Surveys Processed : & 173 \\
\hline
\end{tabular}

Analysis Notes

Method Used to Compute Background : $\quad$ Threshold $0<$ val $<50$

Depth(s) where Contamination Identified $32-52$ \& 75-90 ft Stable, in Gross Gamma Surveys : $52-65$ \& 65-72 ft Undetermined

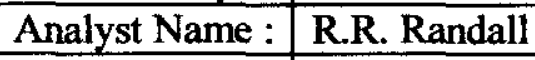

Company Name : $\quad$ Three Rivers Scientific 
RPP-6088, Rev.0.

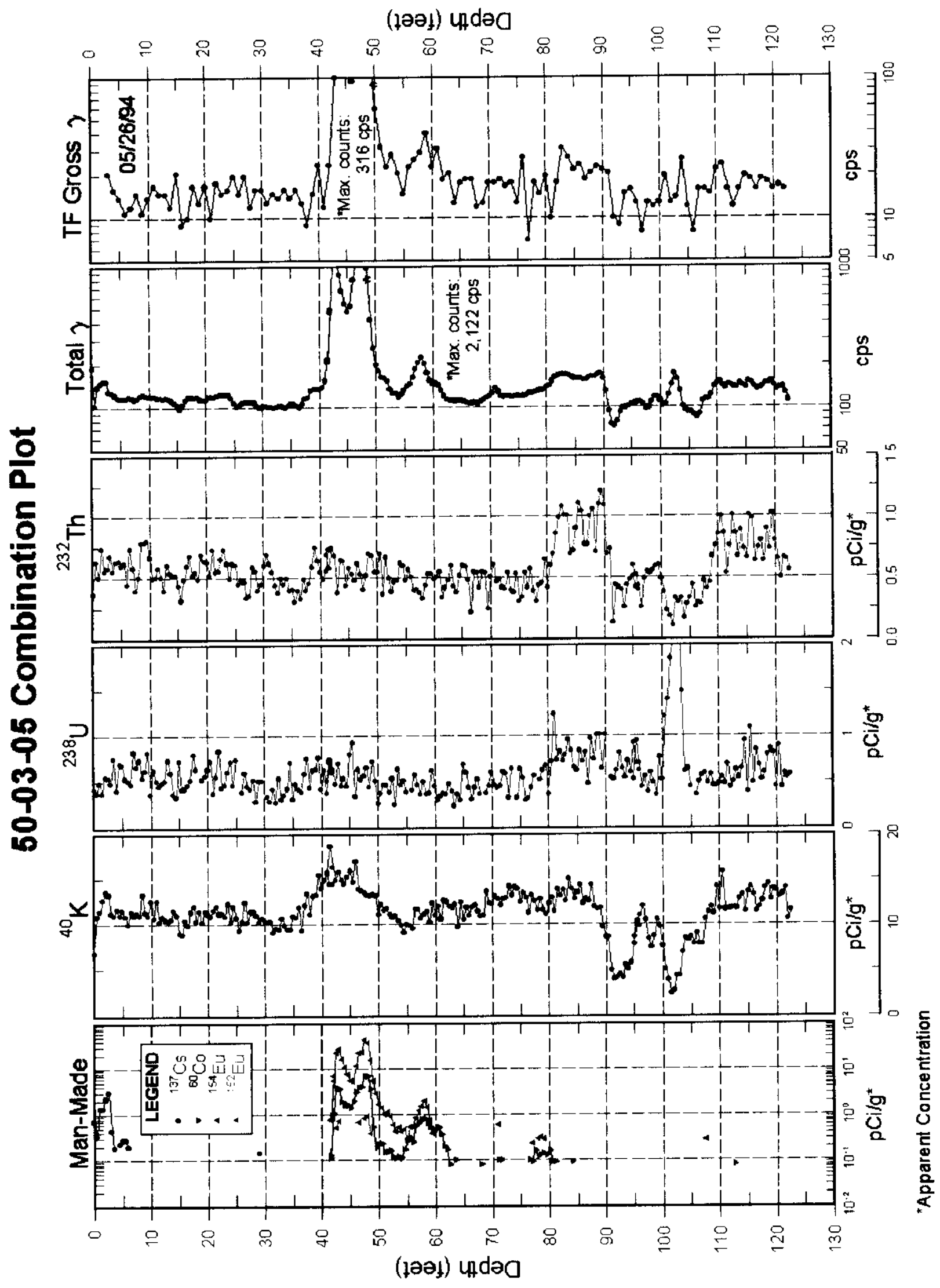

Tank T-103 
RPP-6088, Rev.0.

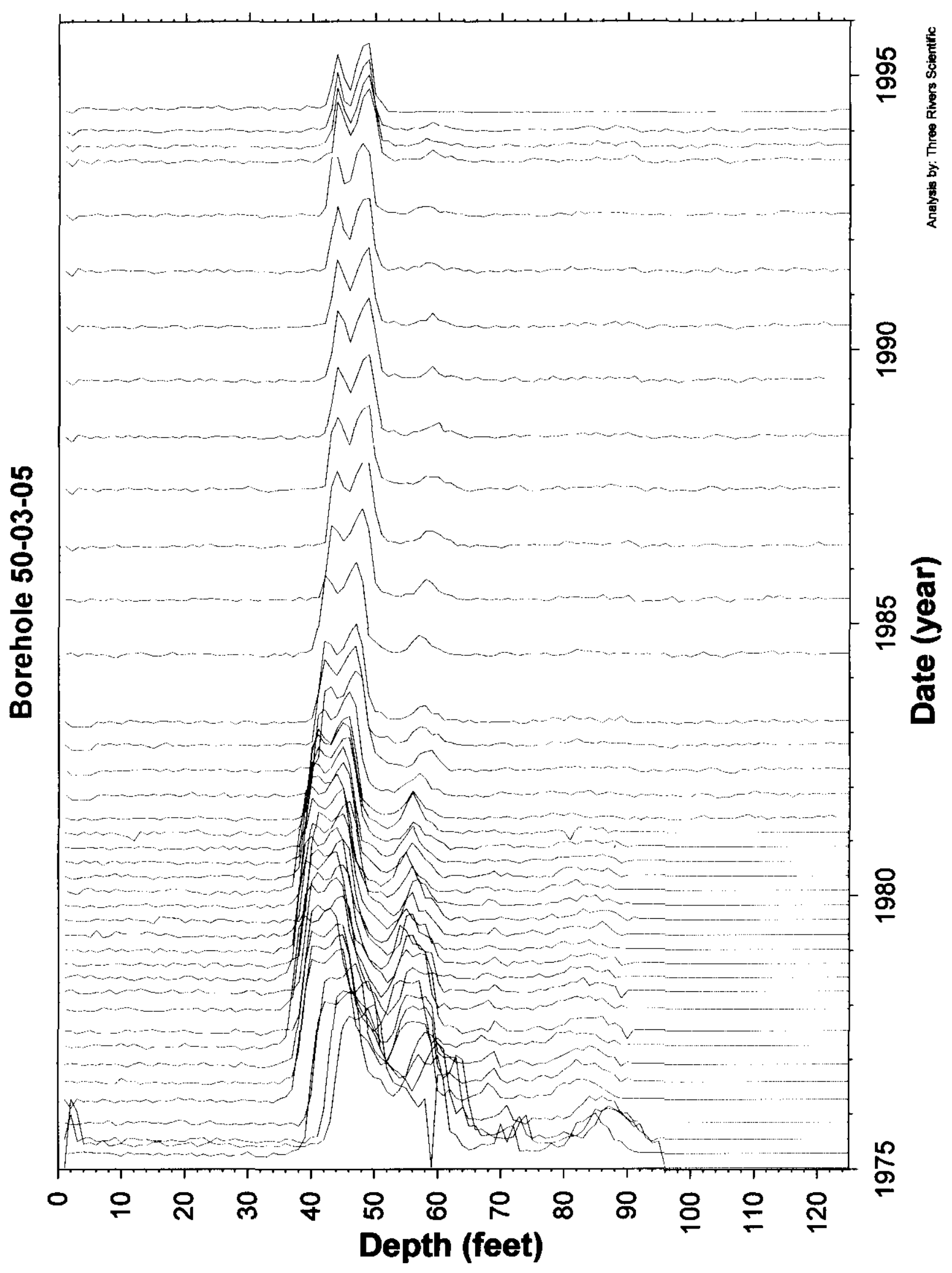

Tank T-103

Page 150 
RPP-6088, Rev.0.
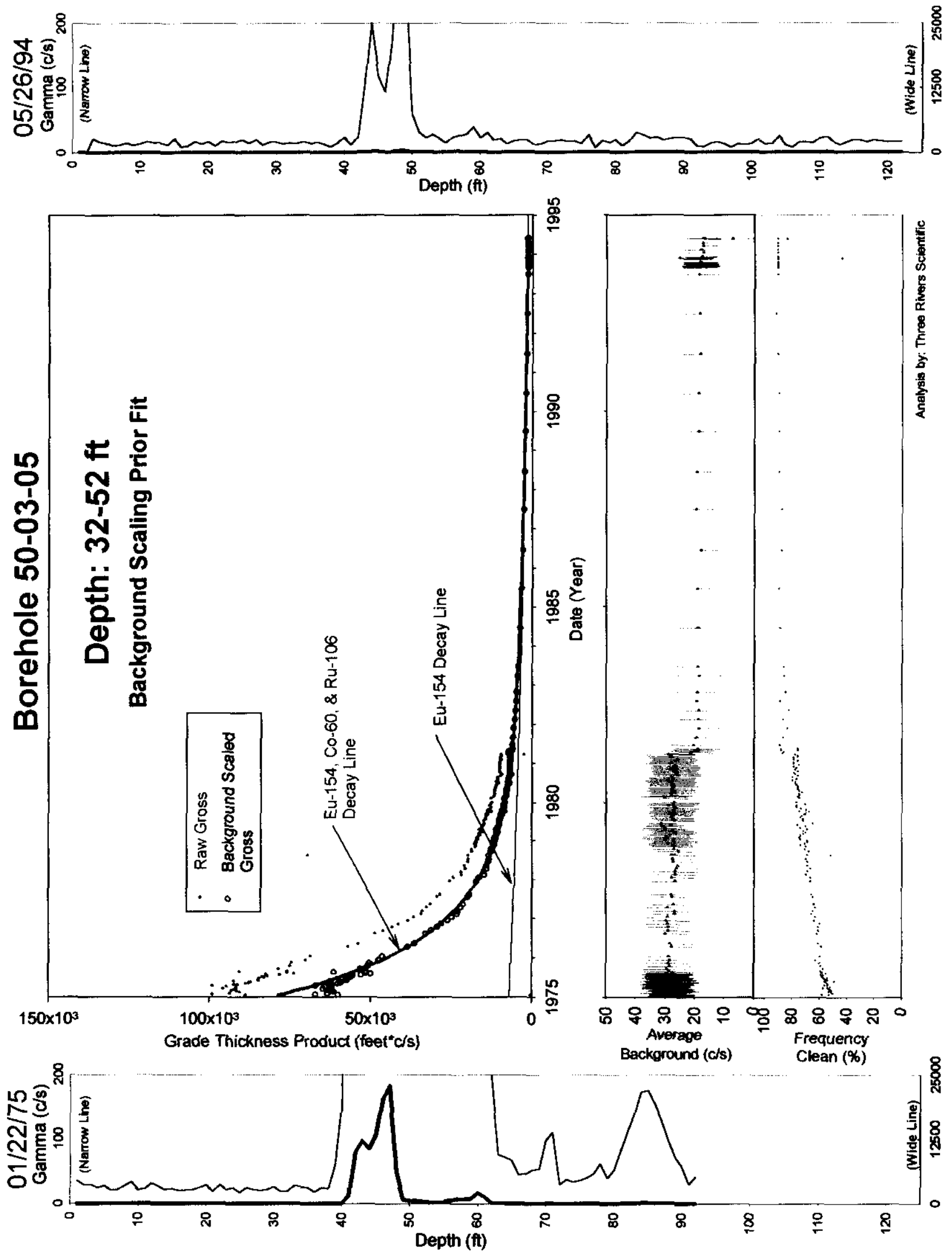

Tank T-103 
RPP-6088, Rev.0.
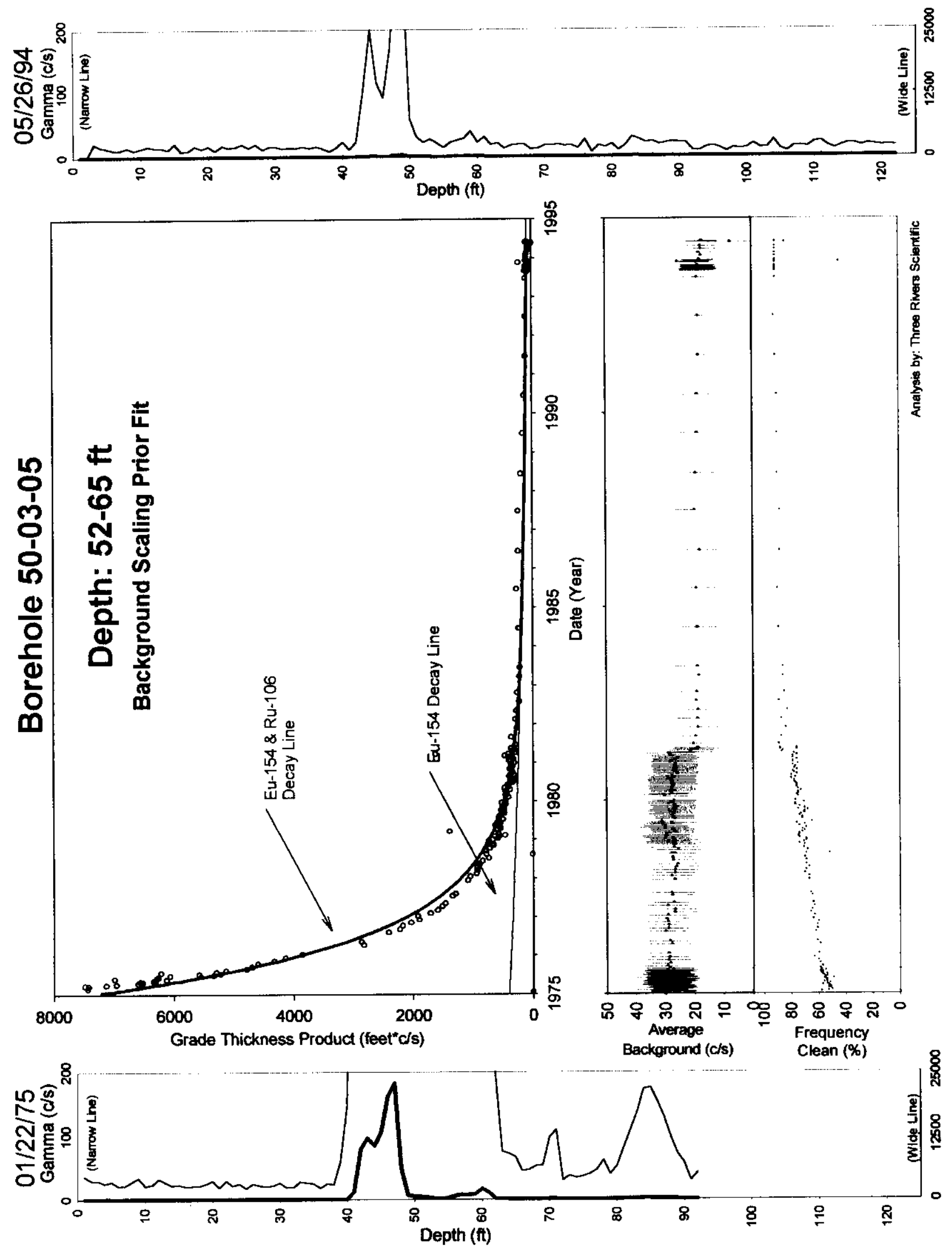

Tank T-103 
RPP-6088, Rev.0.
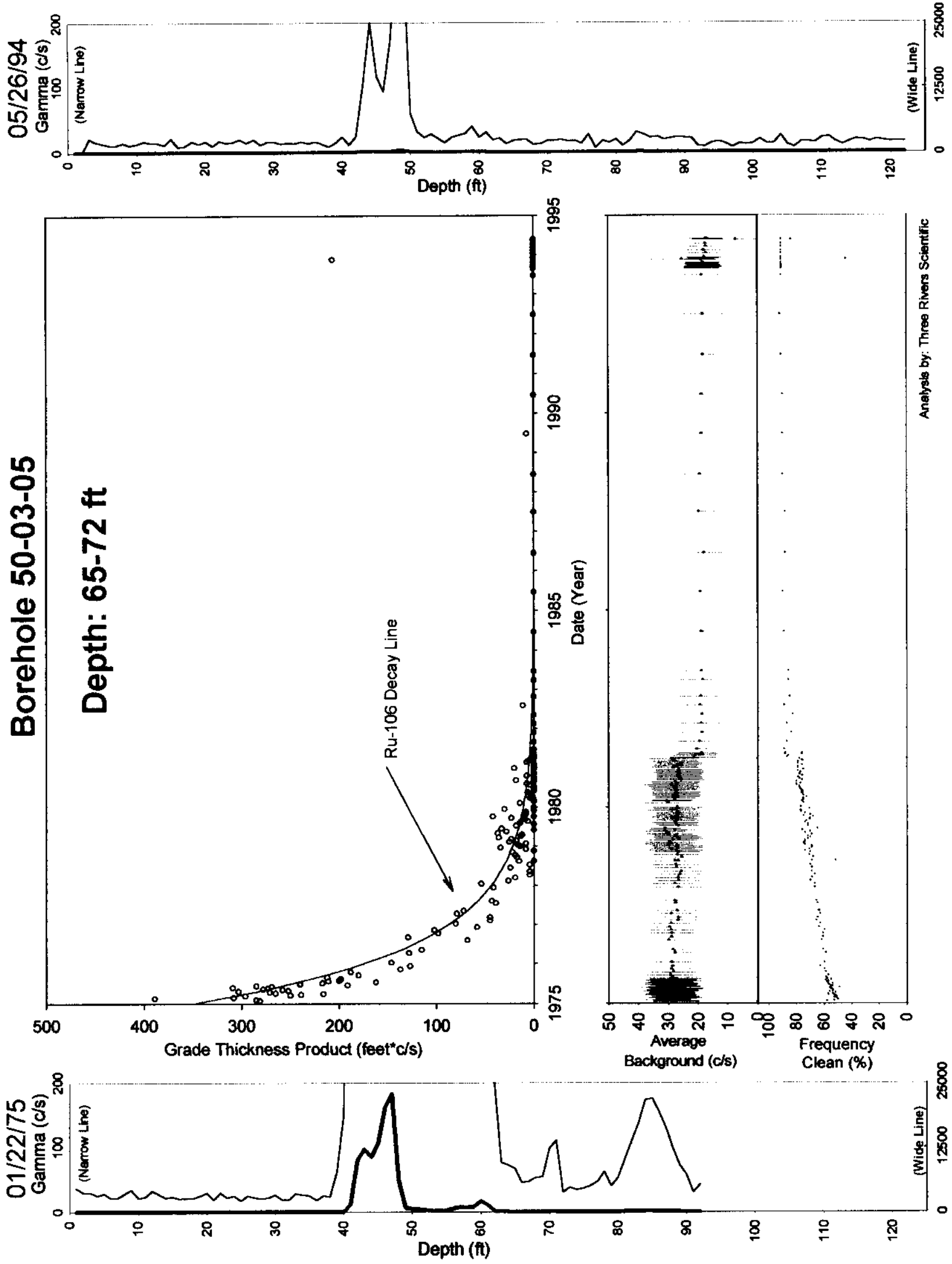

Tank T-103 
RPP-6088, Rev.0.
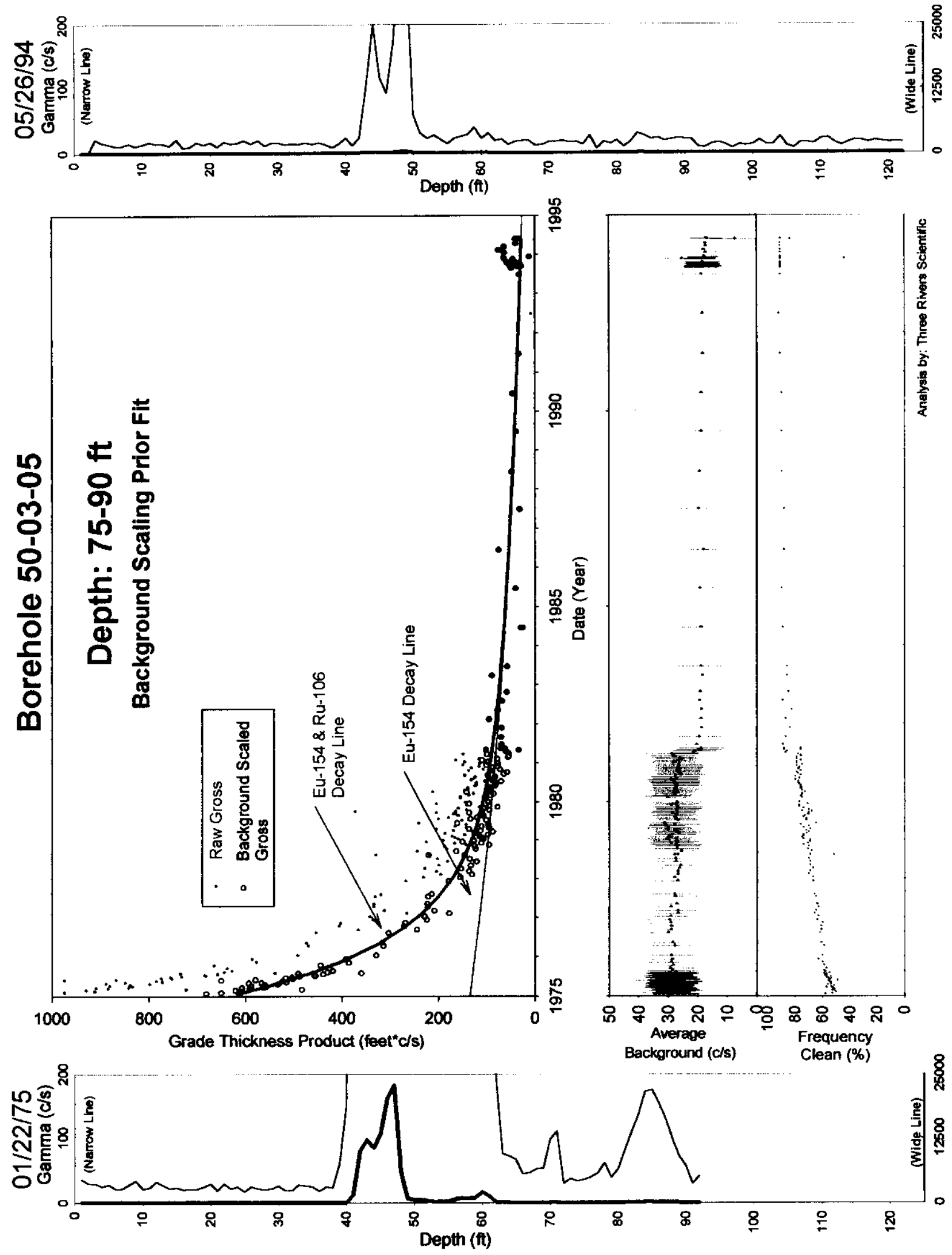

Tank T-103 
RPP-6088, Rev.0.

\section{Borehole 50-03-06}

\section{Contamination (Co-60, Eu-154, \& Ru-106) from 50-98 feet is Undetermined.}

A step decrease in average background and the grade thickness product occurs after 9-15-78. The survey depths increased from 100 to 120 feet after 4-8-77.

The interval from 50 to 98 feet has a high level of contamination early, with a rapid decay to low levels in 1994. Co-60 and Eu-154 were identified with the HPGe logging system. The average background before 9-15-78 was ratioed to the average background after this date and applied to the grade thickness product. In addition, the data between 4-8-77 and 9-15-78 were omitted from the least square fit computations due to discontinuities. The raw grade thickness product data are plotted as small blue circles, and the scaled grade thickness product data are plotted as large open black circles. The scaled grade thickness product data were fit with a least square to three components of Eu-154, Co-60, and Ru-106 (hypothesized), and the match suggest stability. The results of the applied least square fit yields a gross gamma contribution ratio for Eu:Co:Ru of 338:1174:5819 $\left(\mathrm{ft}^{*} \mathrm{c} / \mathrm{s}\right)$ as of 4-2-75.

There is some indication of downward movement in the interval from 50 to 98 feet (refer to the stack plot). The indication is not absolute due to the rapid decay to very low levels. Sub dividing the zone cannot generate quantitative analysis due to possible downward movement in the presence of possible depth control errors. Thus no sub-zoning was computed. The Ru-106 may have been preferentially located at the top of the zone and the rapid decay makes the character of the zone appear to change in a fashion similar to downward movement. Given this lack of a definitive conclusion the classification is undetermined. 
RPP-6088, Rev.0.

Gross Gamma Survey Information

\begin{tabular}{|r|l|}
\hline Probe Type Processed : & $04:$ NaI \\
\hline Other Probe Types : & $03:$ Neutron(3) 14:Shielded NaI(1) \\
\hline Survey Depth : & $125 \mathrm{ft}$ \\
\hline First Survey Date : & $4 / 2 / 1975$ \\
\hline Last Survey Date : & $5 / 26 / 1994$ \\
\hline Number Surveys Processed : & 156 \\
\hline
\end{tabular}

Analysis Notes

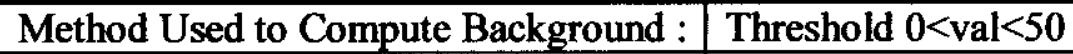

Depth(s) where Contamination Identified $50-98 \mathrm{ft}$ Undetermined in Gross Gamma Surveys :

Analyst Name : $\quad$ R.R. Randall

Company Name : Three Rivers Scientific 
RPP-6088, Rev.0.

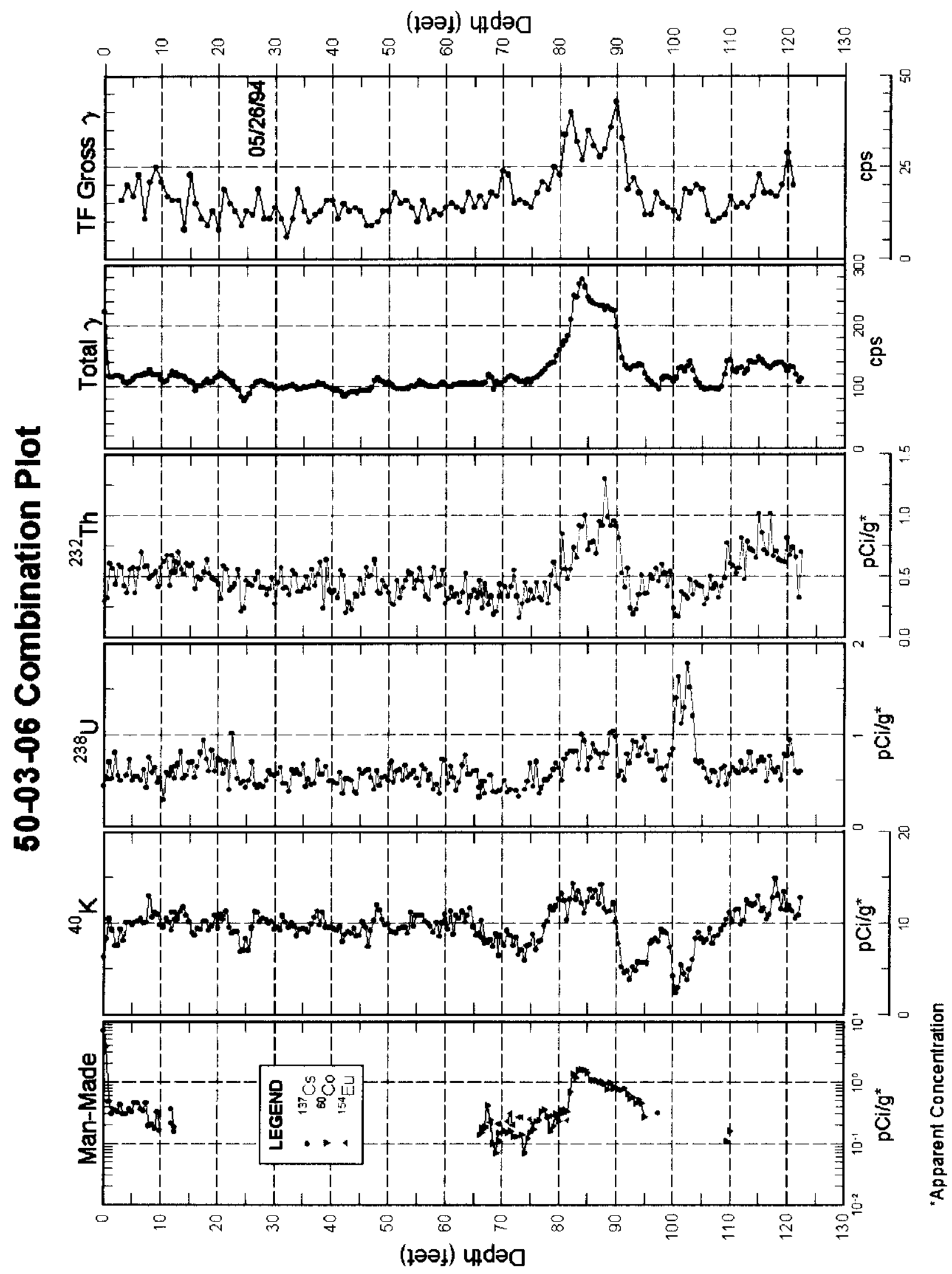

Tank T-103

Page 157 
RPP-6088, Rev.0.

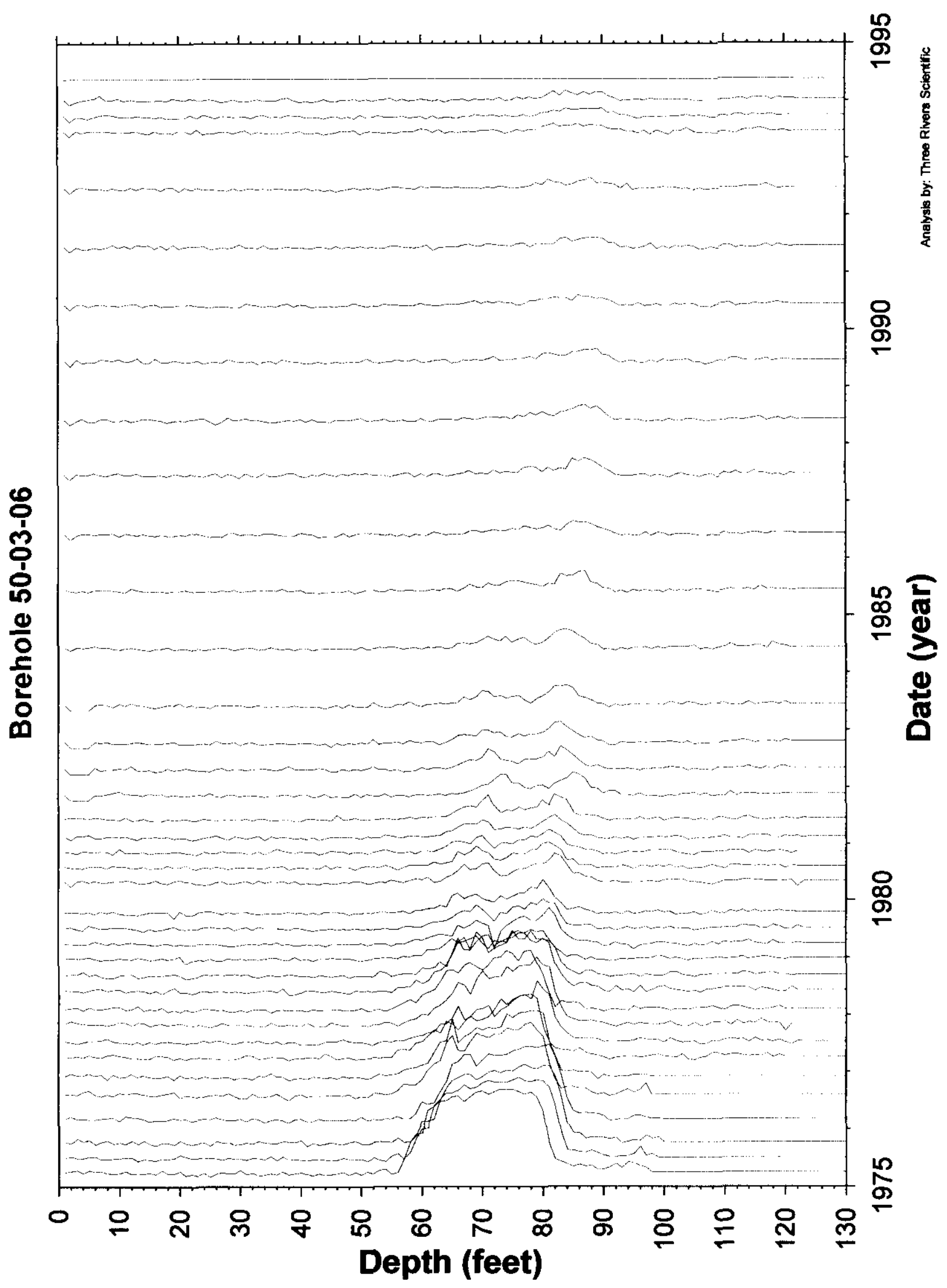

Tank T-103

Page 158 
RPP-6088, Rev.0.
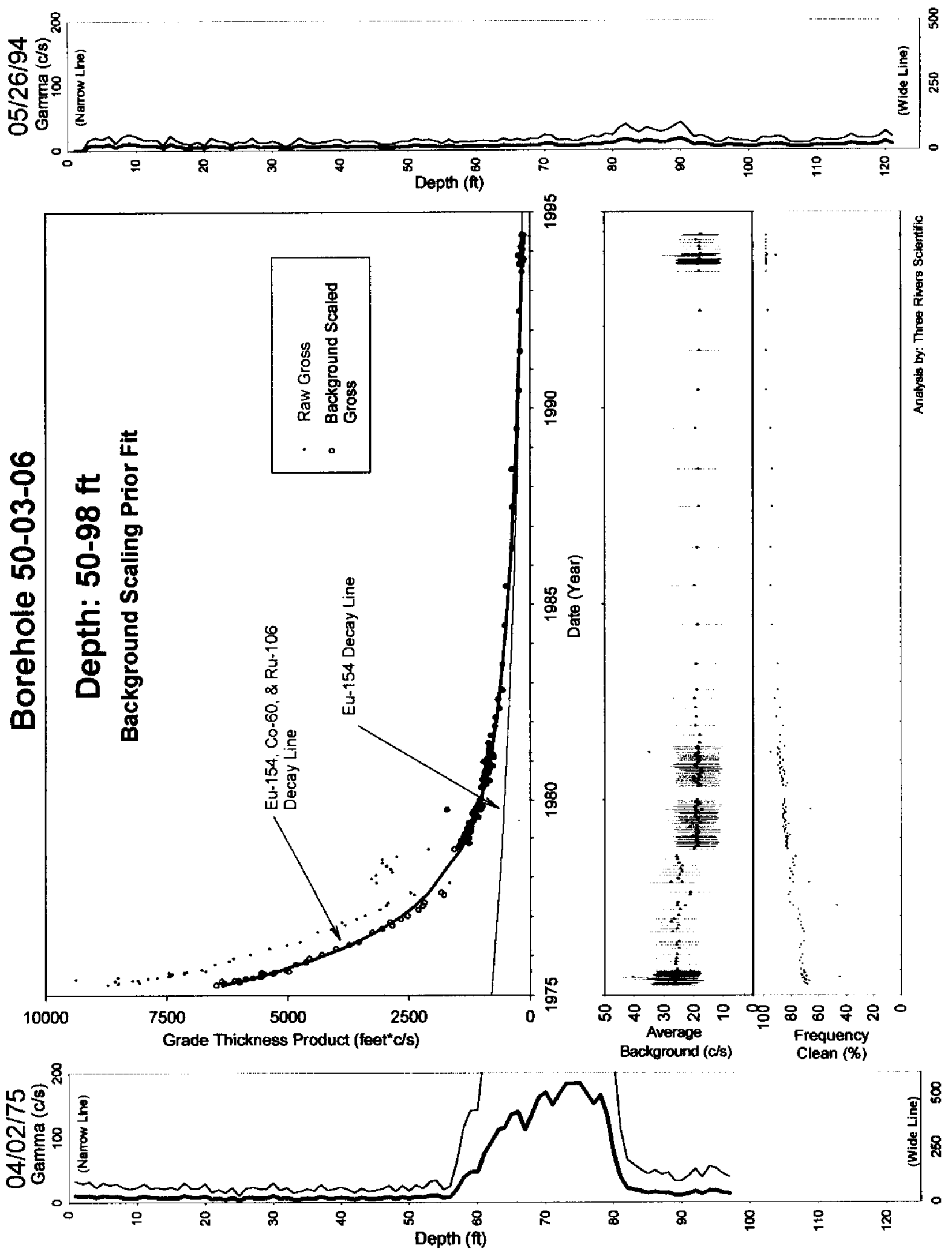

Tank T-103 
RPP-6088, Rev.0.

\section{Borehole 50-03-08}

\section{No Gamma Ray Emitting Contamination Identified.}

No significant levels of gamma ray contamination are present, based upon gross gamma data, above the survey probe detection threshold between 1975 and 1995 in the vadose zone from 2 to 88 feet. The HPGe logging system detected Cs-137 at less than $2 \mathrm{pCi} / \mathrm{g}$.

The average background plot shows a step decrease after 9-3-80.

\section{Gross Gamma Survey Information}

\begin{tabular}{|r|l|}
\hline Probe Type Processed : & $04:$ NaI \\
\hline Other Probe Types : & $03:$ Neutron \\
\hline Survey Depth : & $90 \mathrm{ft}$ \\
\hline First Survey Date : & $1 / 13 / 1975$ \\
\hline Last Survey Date : & $5 / 26 / 1994$ \\
\hline Number Surveys Processed : & 179 \\
\hline
\end{tabular}

Analysis Notes

Method Used to Compute Background : $\quad$ Threshold $0<$ val $<50$

Depth(s) where Contamination Identified NONE

in Gross Gamma Surveys :

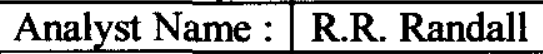

Company Name : Three Rivers Scientific 
RPP-6088, Rev.0.

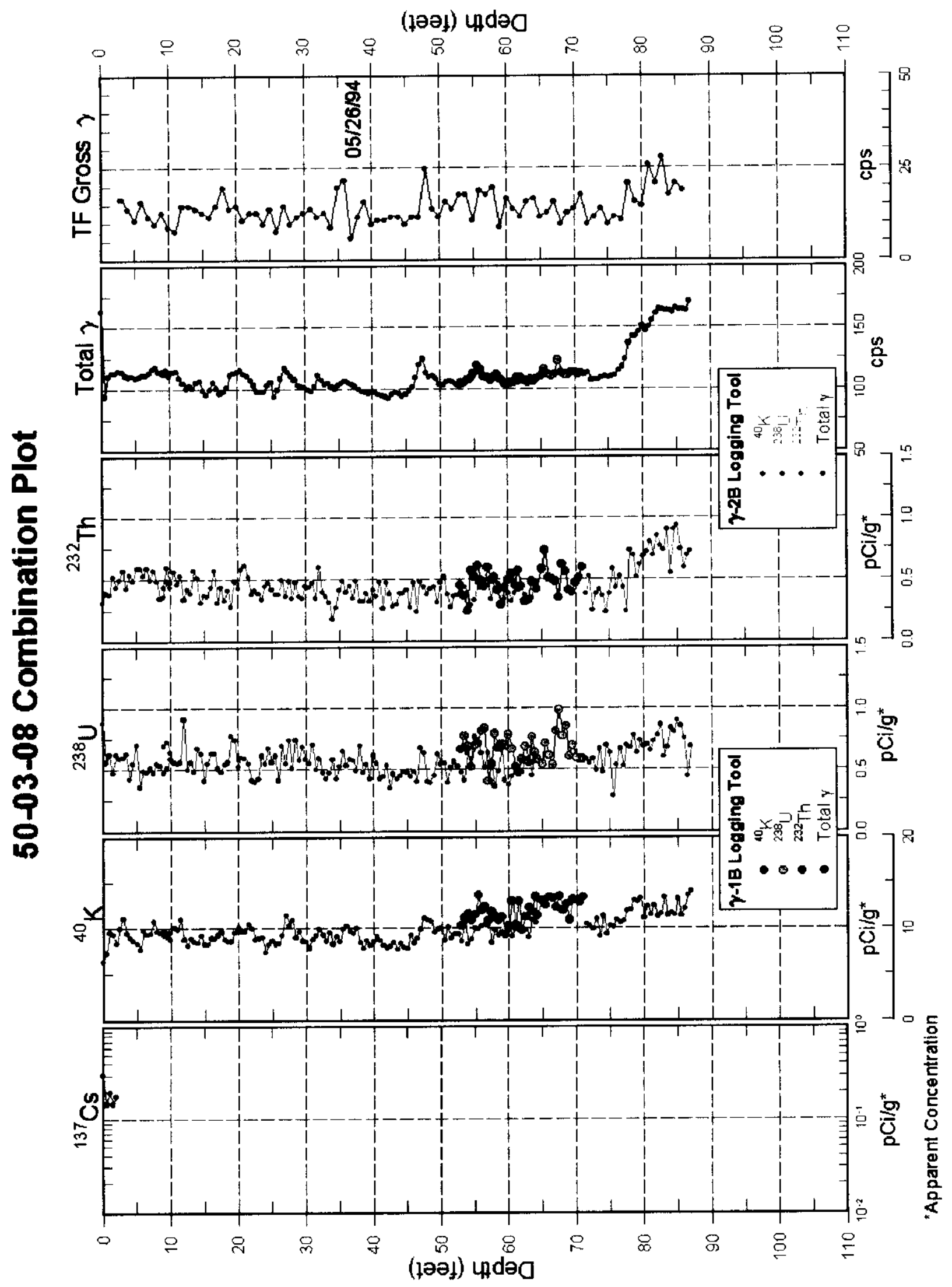

Tank T-103

Page 161 
RPP-6088, Rev.0.

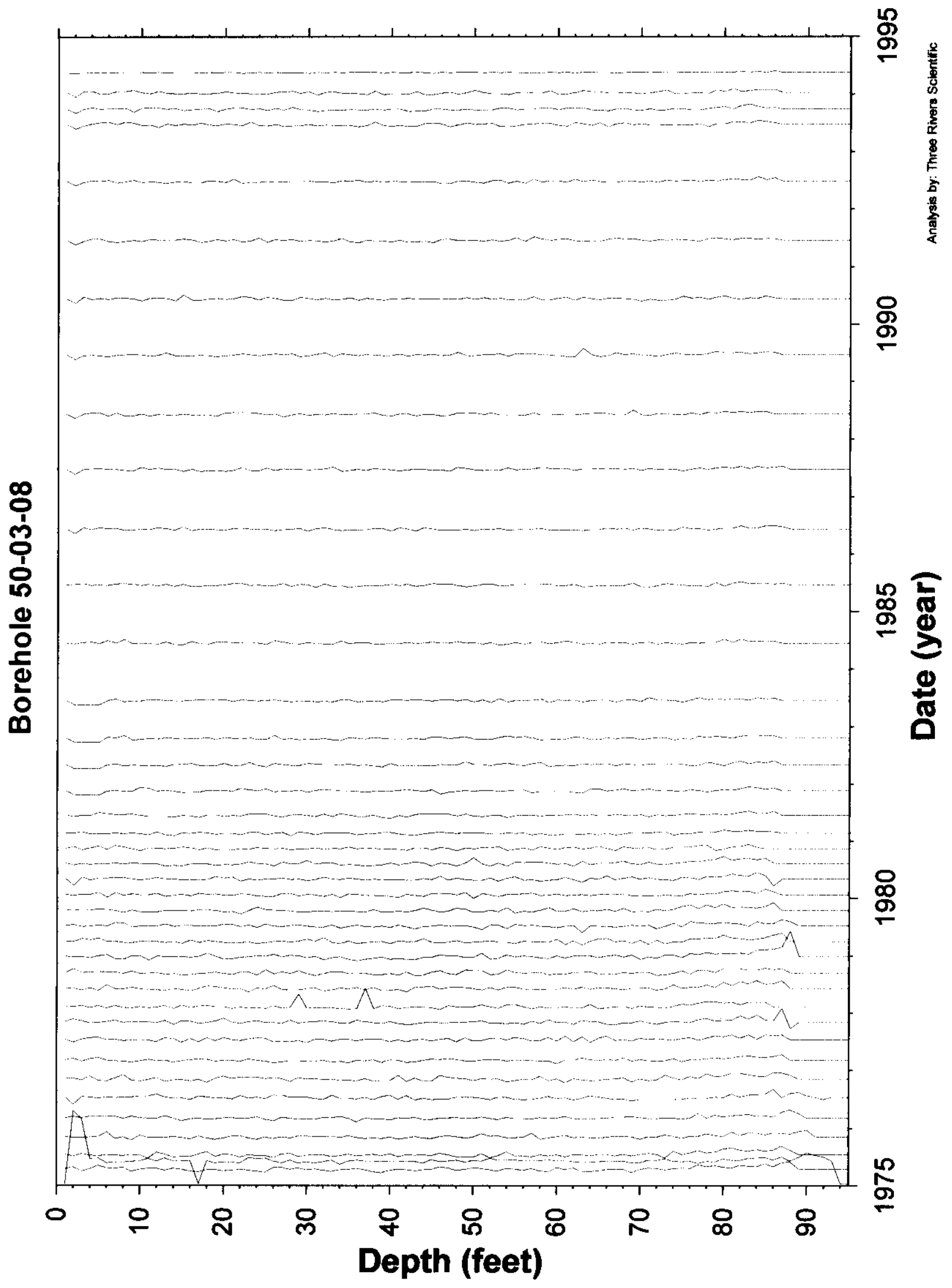

Tank T-103

Page 162 
RPP-6088, Rev.0.

\section{Borehole 50-03-08}

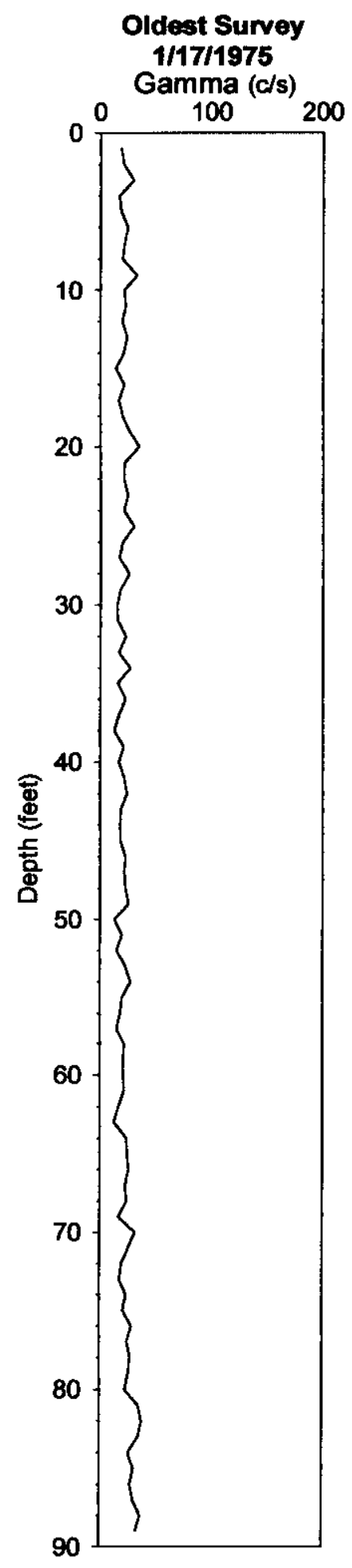
No Gamma-Ray Emitting Contamination
Above Survey Detection Threshold
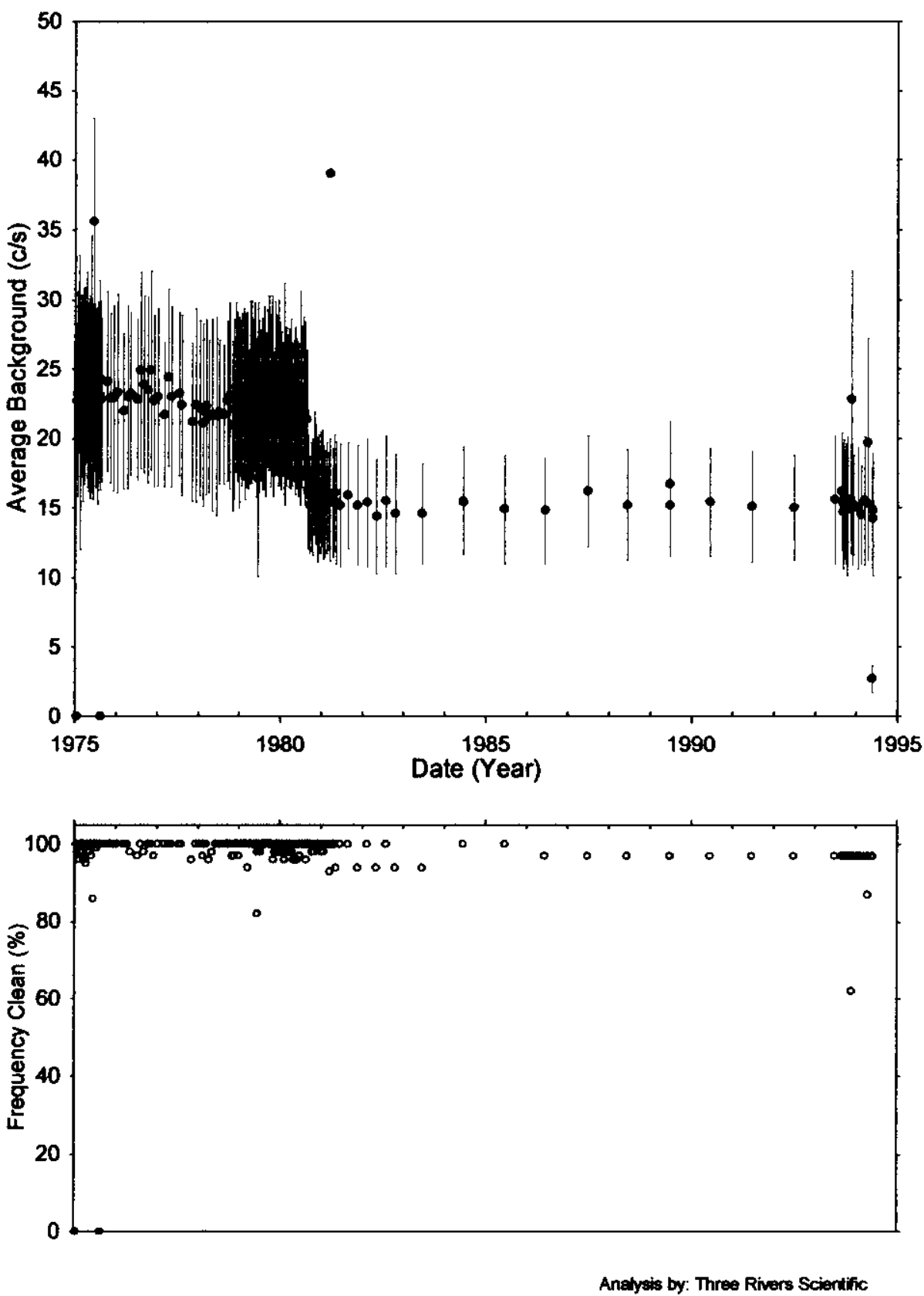
RPP-6088, Rev.0.

\section{Borehole 50-03-10}

\section{No Gamma Ray Emitting Contamination Identified.}

No significant levels of gamma ray contamination are present, based upon gross gamma data, above the survey probe detection threshold between 1975 and 1995 in the vadose zone from 2 to 88 feet. The HPGe logging system did not detected Cs-137 below 1 foot.

The average background plot shows a step decrease after 9-3-80.

Gross Gamma Survey Information

\begin{tabular}{|r|l|}
\hline Probe Type Processed : & $04: \mathrm{NaI}$ \\
\hline Other Probe Types : & $03:$ Neutron \\
\hline Survey Depth : & $90 \mathrm{ft}$ \\
\hline First Survey Date : & $1 / 13 / 1975$ \\
\hline Last Survey Date : & $5 / 26 / 1994$ \\
\hline Number Surveys Processed : & 179 \\
\hline
\end{tabular}

Analysis Notes

Method Used to Compute Background : $\quad$ Threshold $0<$ val $<50$

Depth(s) where Contamination Identified NONE

in Gross Gamma Surveys :

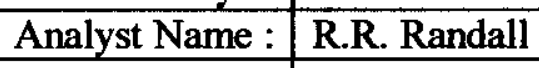

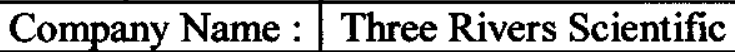


RPP-6088, Rev.0.

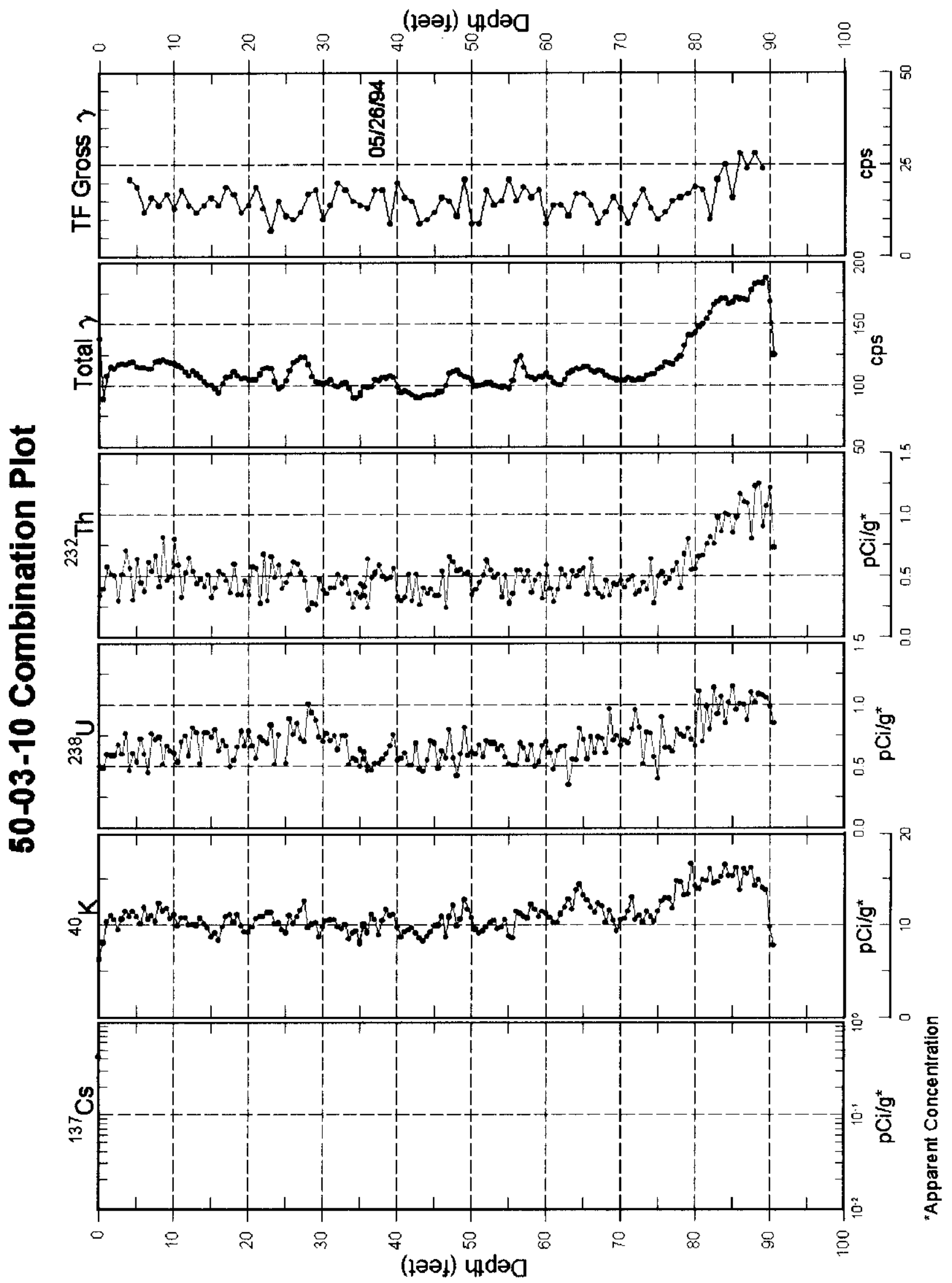

Tank T-103 
RPP-6088, Rev.0.

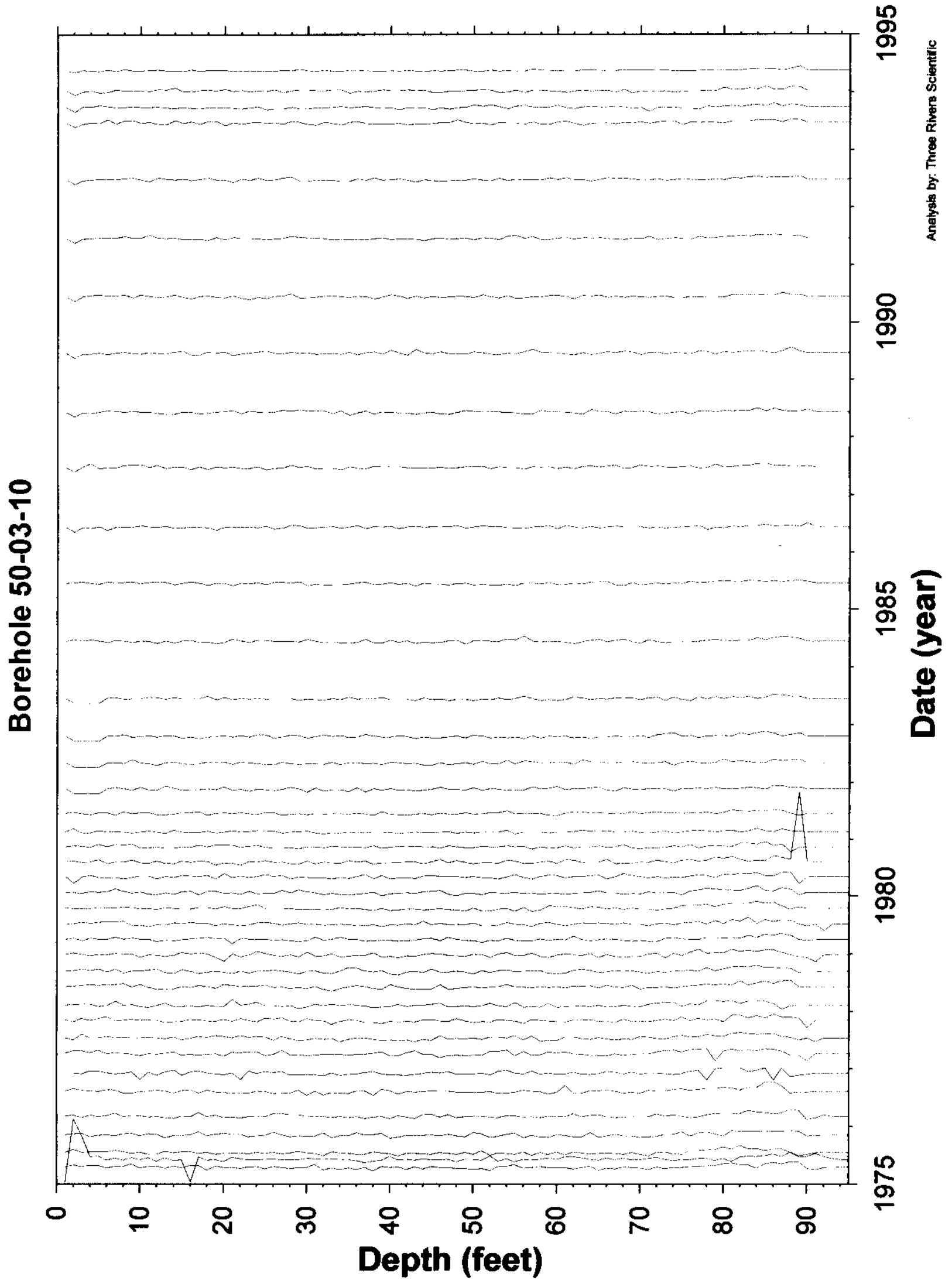

Tank T-103

Page 166 
RPP-6088, Rev.0.

\title{
Borehole 50-03-10
}

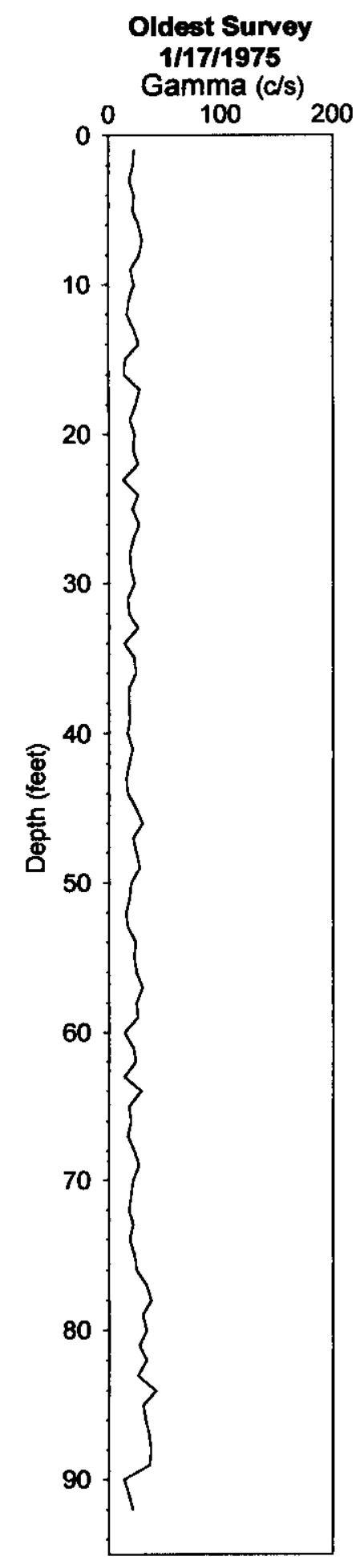

\author{
No Gamma-Ray Emitting Contamination \\ Above Survey Detection Threshold
}
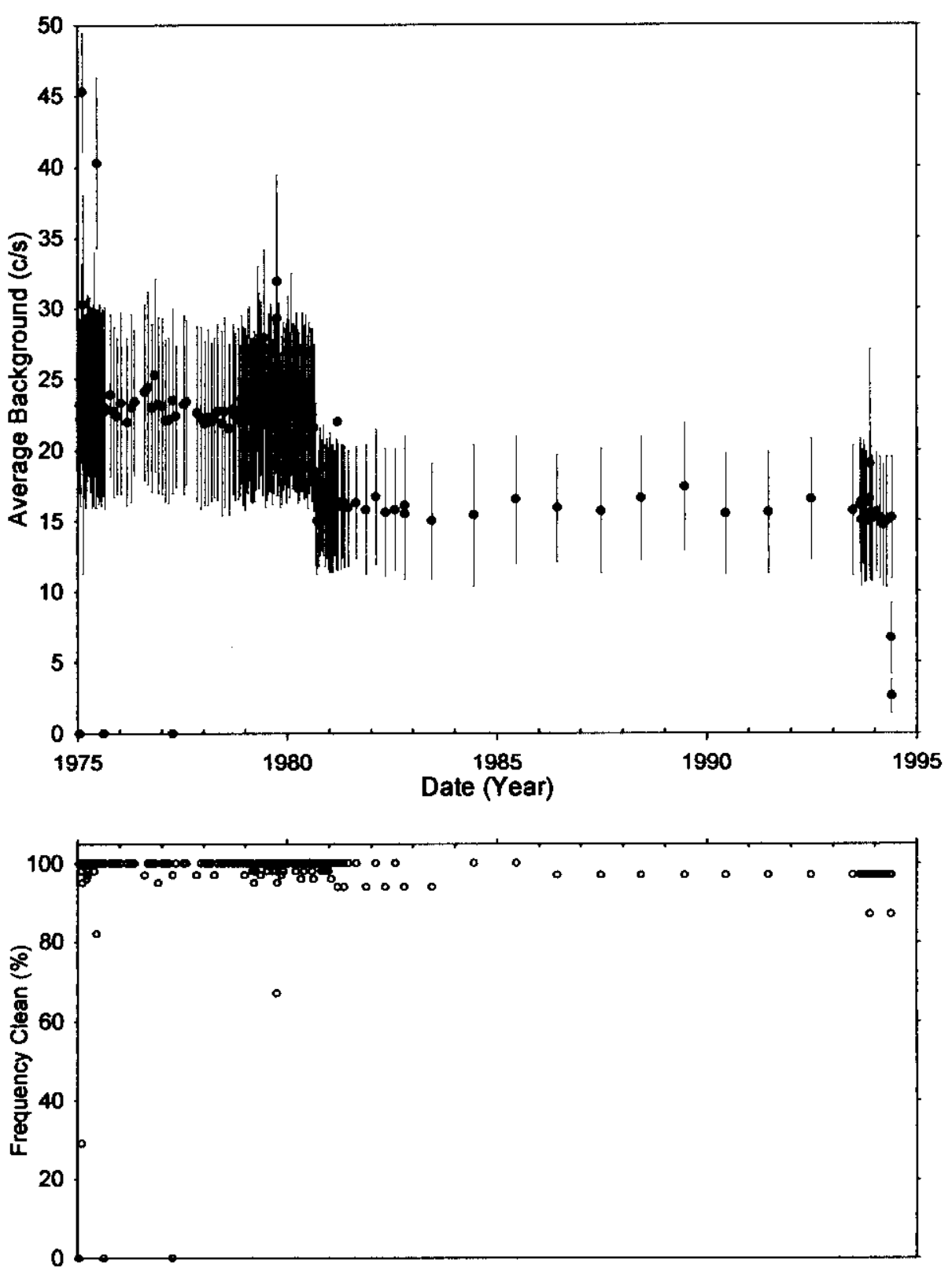

Analysis by: Three Rivers Scientific

Tank T-103

Page 167 
RPP-6088, Rev.0.

\section{Tank T-104 Wells}

Table of Contents $\quad$ Page

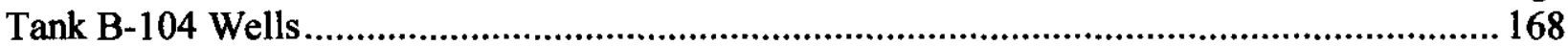

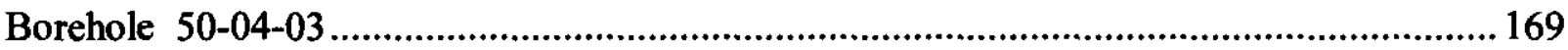

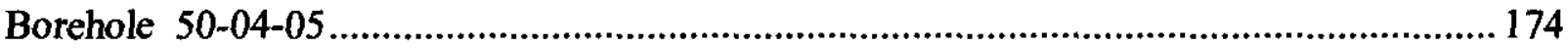

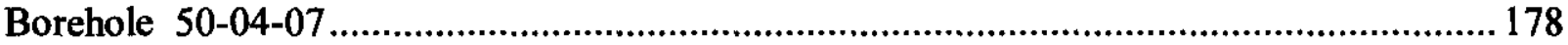

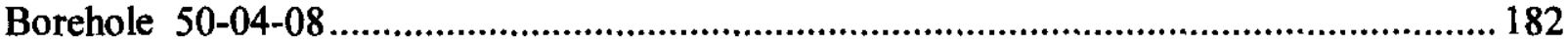

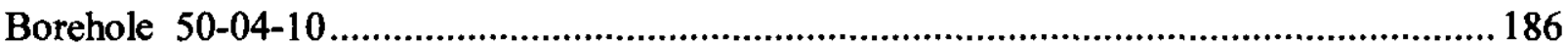

This section contains the analysis results for the vadose zone boreholes (dry wells) associated with Tank 104 in the "T" Tank Farm.

Special Note:

None 
RPP-6088, Rev.0.

\section{Borehole 50-04-03}

\section{Contamination (Cs-137) from 0-12 feet is Tank Farm Activity. Contamination (Cs-137) from 18-30 feet is Stable.}

A step decrease in average background and the grade thickness products computed occur after 217-81. This observation is consistent with the addition of a second string of casing.

The interval from 0 to 12 feet has a high level of contamination of Cs-137 identified with the HPGe logging system. The scaling of the grade thickness product for the step decrease in average background is not performed. The zone appears stable since 1986.

The interval from 18 to 30 feet has a low level of contamination, Cs-137 identified with the HPGe logging system. The average background before 2-17-81 was ratioed to the average background after the step change and was applied to the grade thickness product. The raw and the scaled grade thickness products are plotted. The scaled grade thickness product data were matched with a Cs-137 decay line. The agreement with the scatter as a random deviation from the decay curve yields a classification of stable.

Gross Gamma Survey Information

\begin{tabular}{|r|l|}
\hline Probe Type Processed : & $04: \mathrm{NaI}$ \\
\hline Other Probe Types : & $03:$ Neutron(5) 14: Shielded NaI(3) \\
\hline Survey Depth : & $93 \mathrm{ft}$ \\
\hline First Survey Date : & $4 / 2 / 1975$ \\
\hline Last Survey Date : & $11 / 1 / 1993$ \\
\hline Number Surveys Processed : & 819 \\
\hline
\end{tabular}

Analysis Notes

\begin{tabular}{|r|l|}
\hline Method Used to Compute Background : & Threshold $0<$ val $<50$ \\
\hline $\begin{array}{r}\text { Depth(s) where Contamination Identified } \\
\text { in Gross Gamma Surveys : }\end{array}$ & $0-12 \mathrm{ft}$ Tank Farm Activity, \\
\hline Analyst Name : & R.R. Randall \\
\hline Company Name : & Three Rivers Scientific \\
\hline
\end{tabular}


RPP-6088, Rev.0.

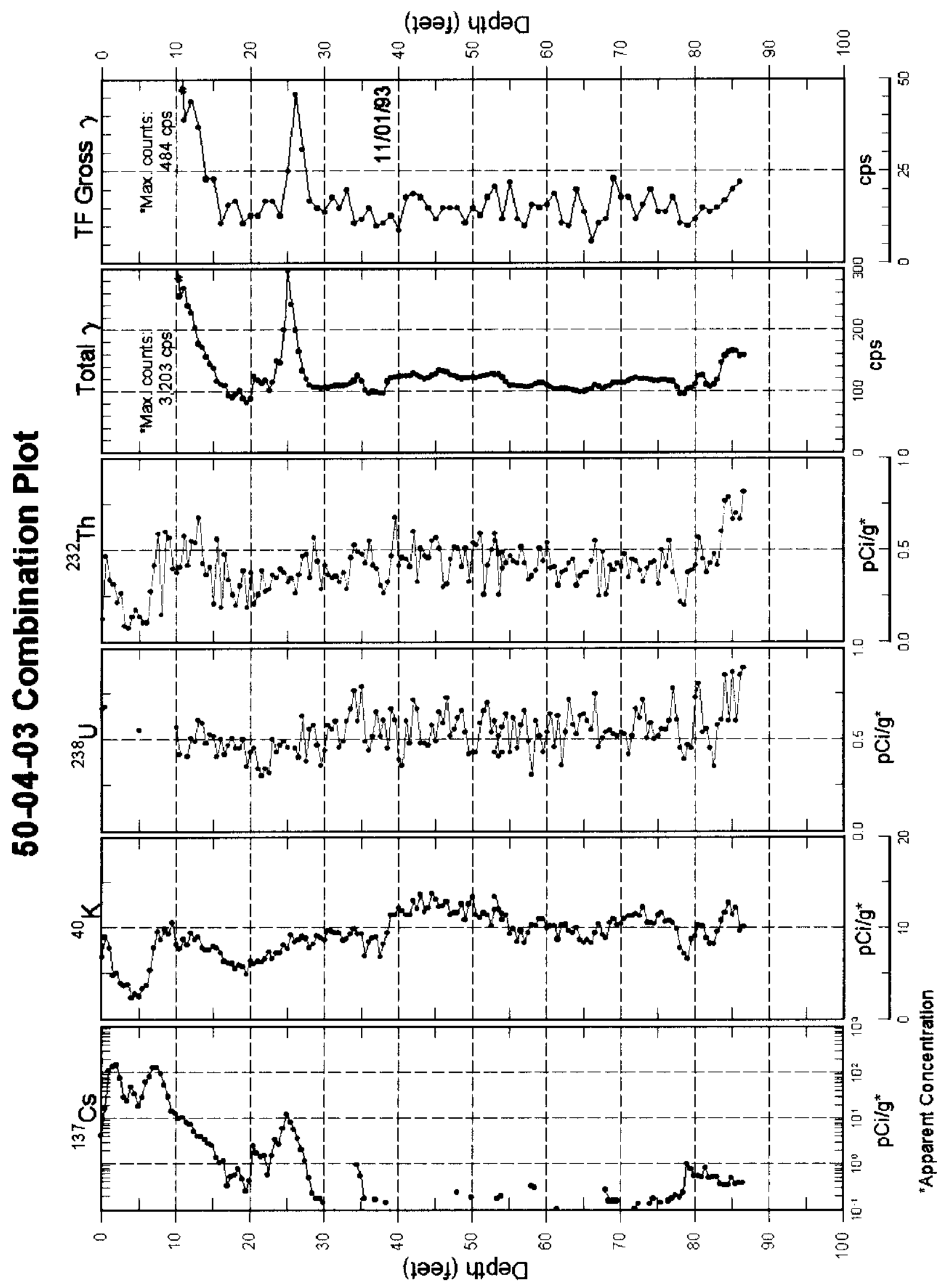


RPP-6088, Rev.0.

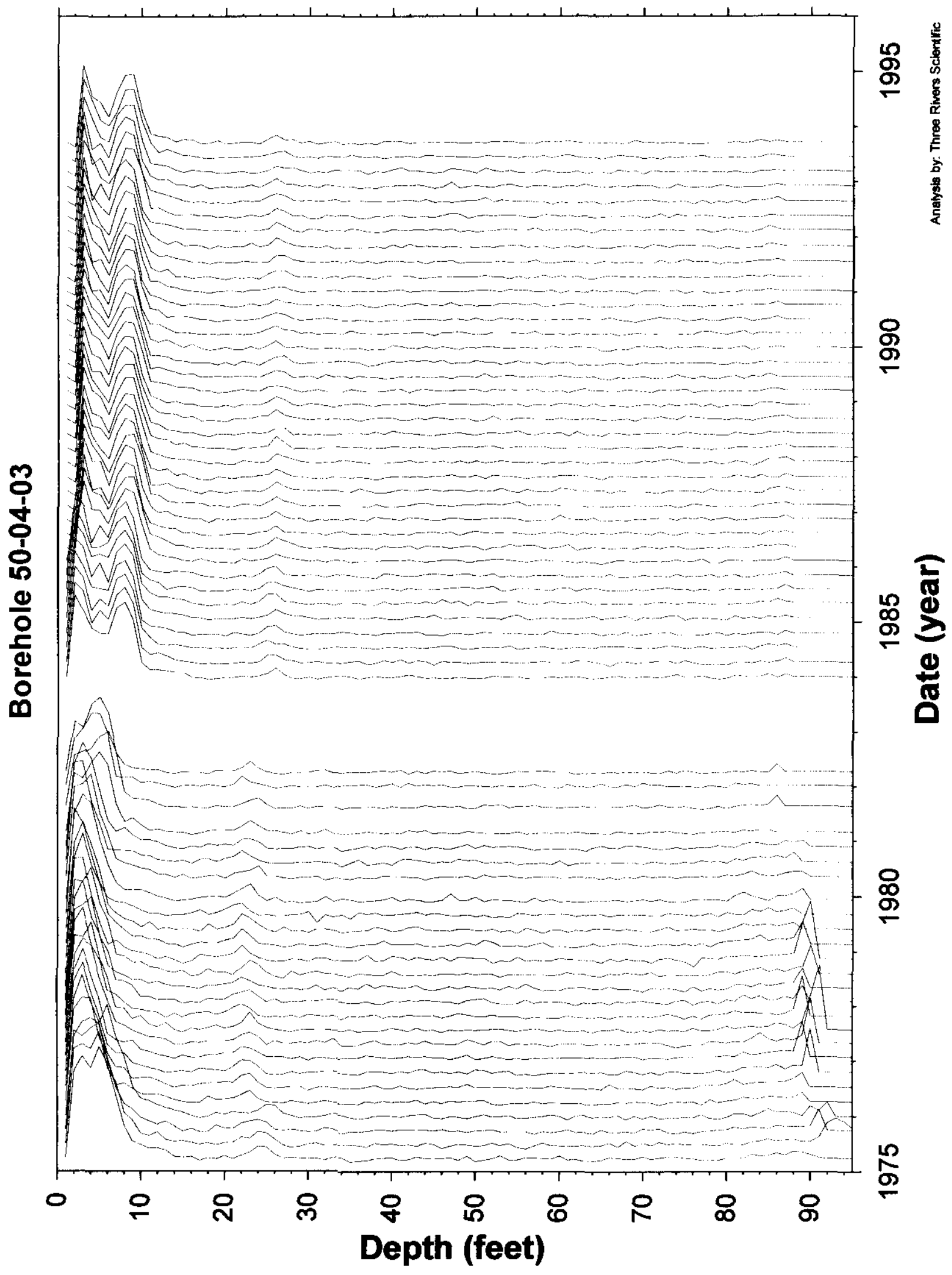

Tank T-104

Page 171 
RPP-6088, Rev.0.
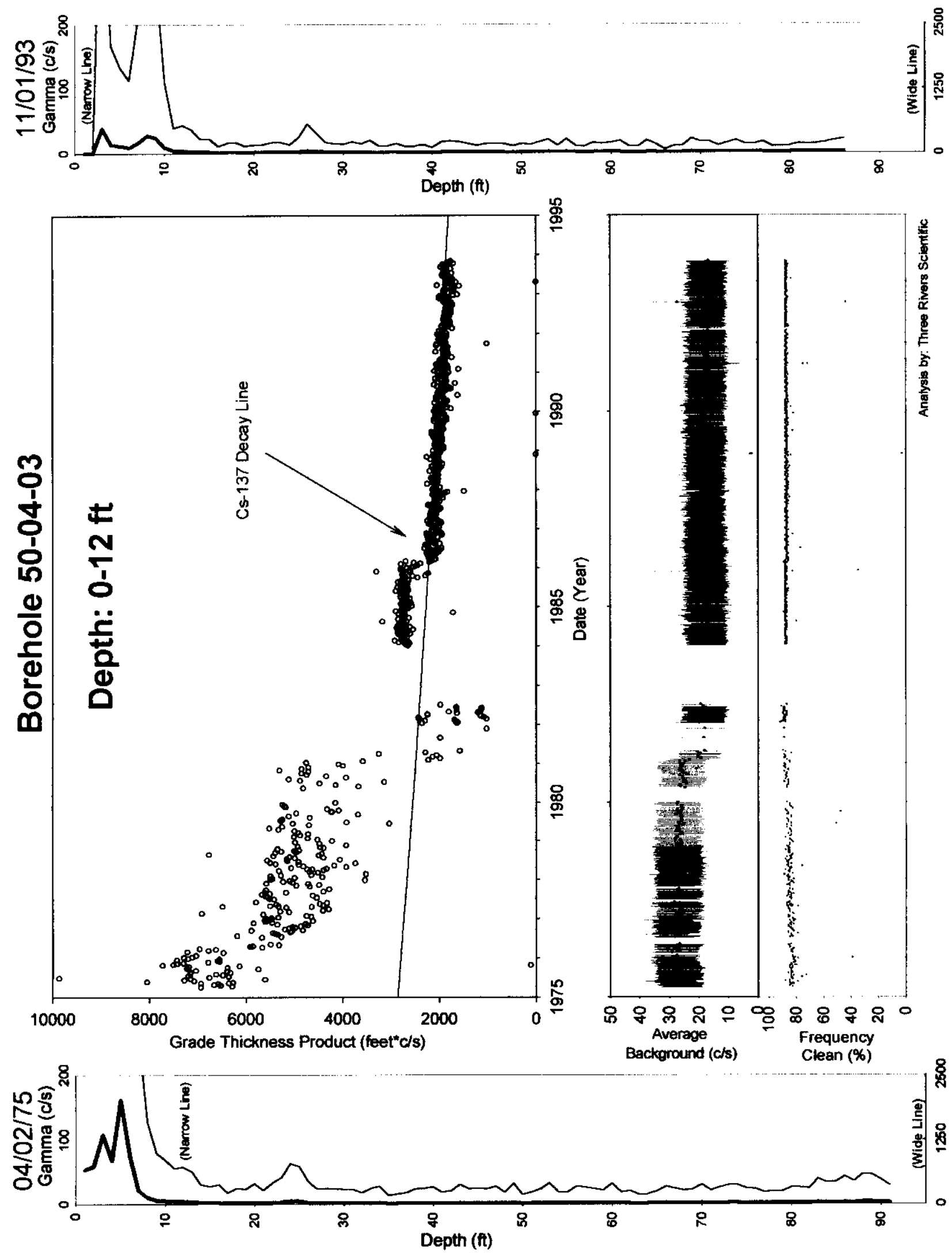

Tank T-104 
RPP-6088, Rev.0.
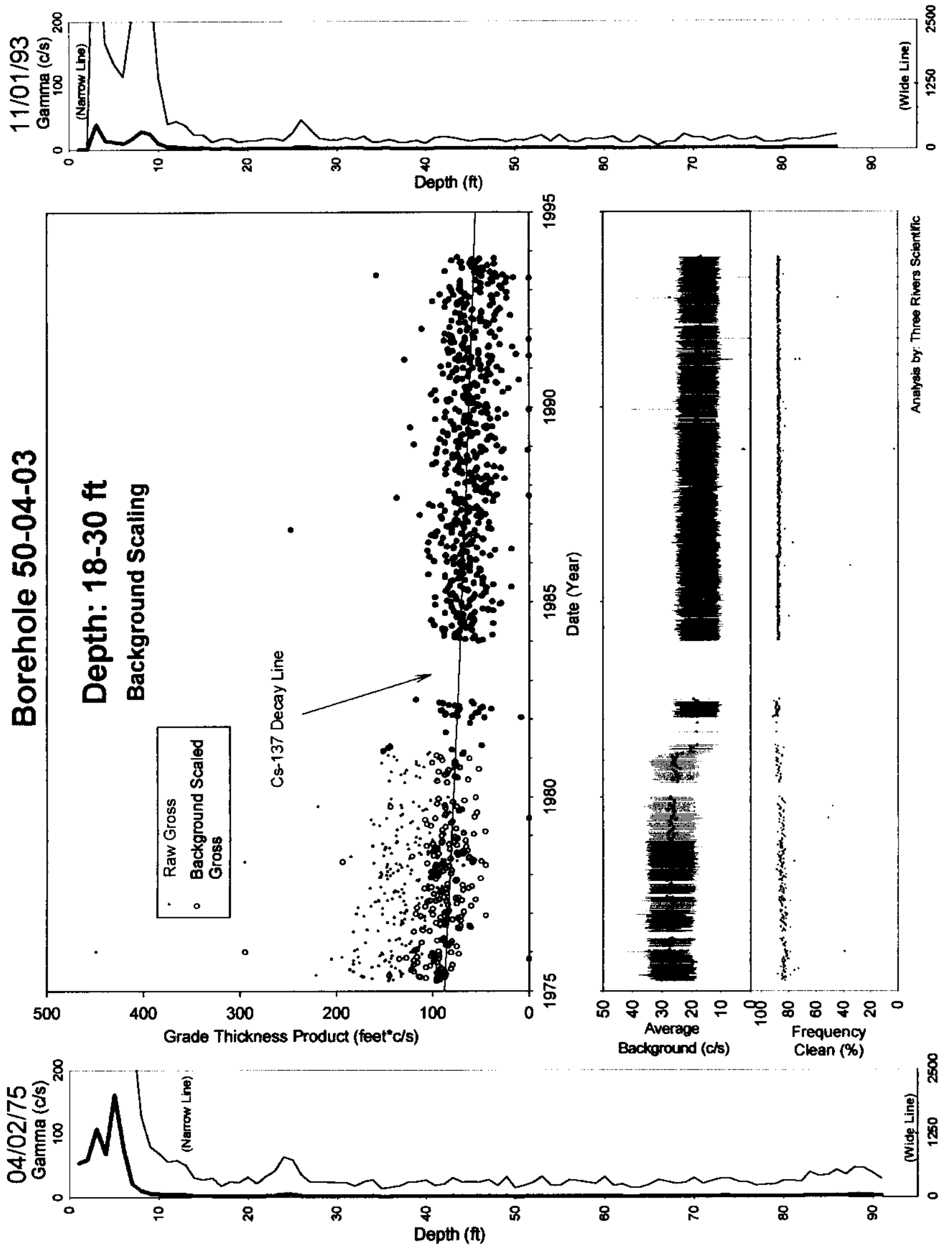
RPP-6088, Rev.0.

\section{Borehole 50-04-05}

\section{Contamination (Cs-137) from 0-10 feet is Tank Farm Activity.}

A step decrease in average background and the grade thickness products computed occur after 127-81. This observation is consistent with the addition of a second string of casing.

The interval from 0 to 10 feet has a moderate level of contamination of Cs-137 identified with the HPGe logging system. The scaling of the grade thickness product for the step decrease in average background is not performed since tank farm activity remains the dominant character. The zone appears stable since 1986.

Gross Gamma Survey Information

\begin{tabular}{|r|l|}
\hline Probe Type Processed : & $04:$ NaI \\
\hline Other Probe Types : & $03:$ Neutron(5) 02:Red GM(1) \\
& $14:$ Shielded NaI(2) \\
\hline Survey Depth : & $90 \mathrm{ft}$ \\
\hline First Survey Date : & $1 / 10 / 1975$ \\
\hline Last Survey Date : & $11 / 1 / 1993$ \\
\hline Number Surveys Processed : & 684 \\
\hline
\end{tabular}

Analysis Notes

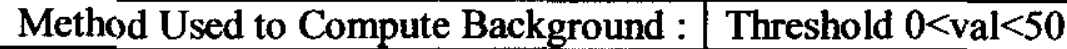

Depth(s) where Contamination Identified $0-10 \mathrm{ft}$ Tank Farm Activity in Gross Gamma Surveys :

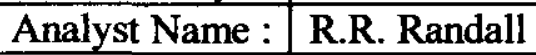

Company Name : Three Rivers Scientific 
RPP-6088, Rev.0.

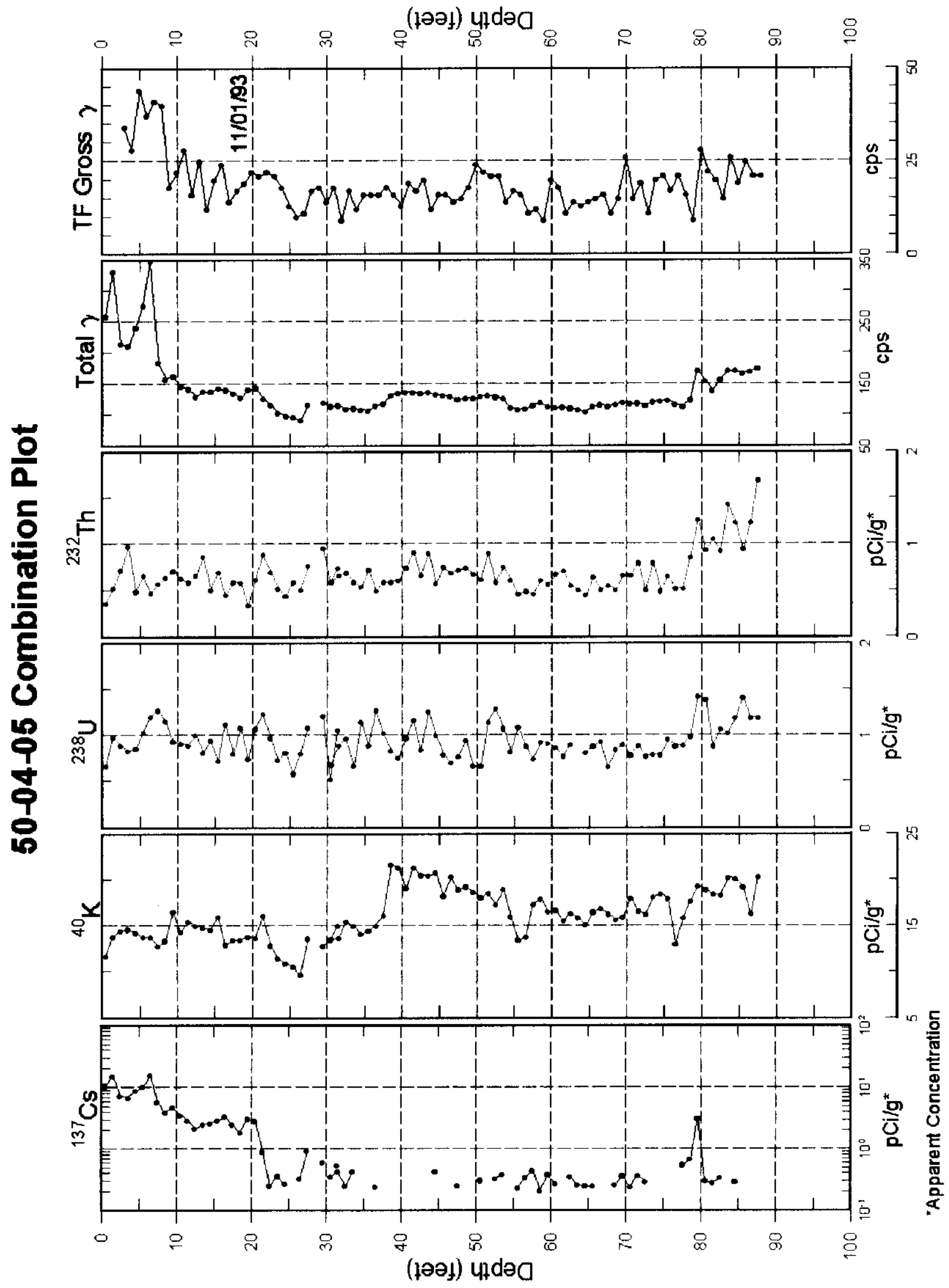


RPP-6088, Rev.0.

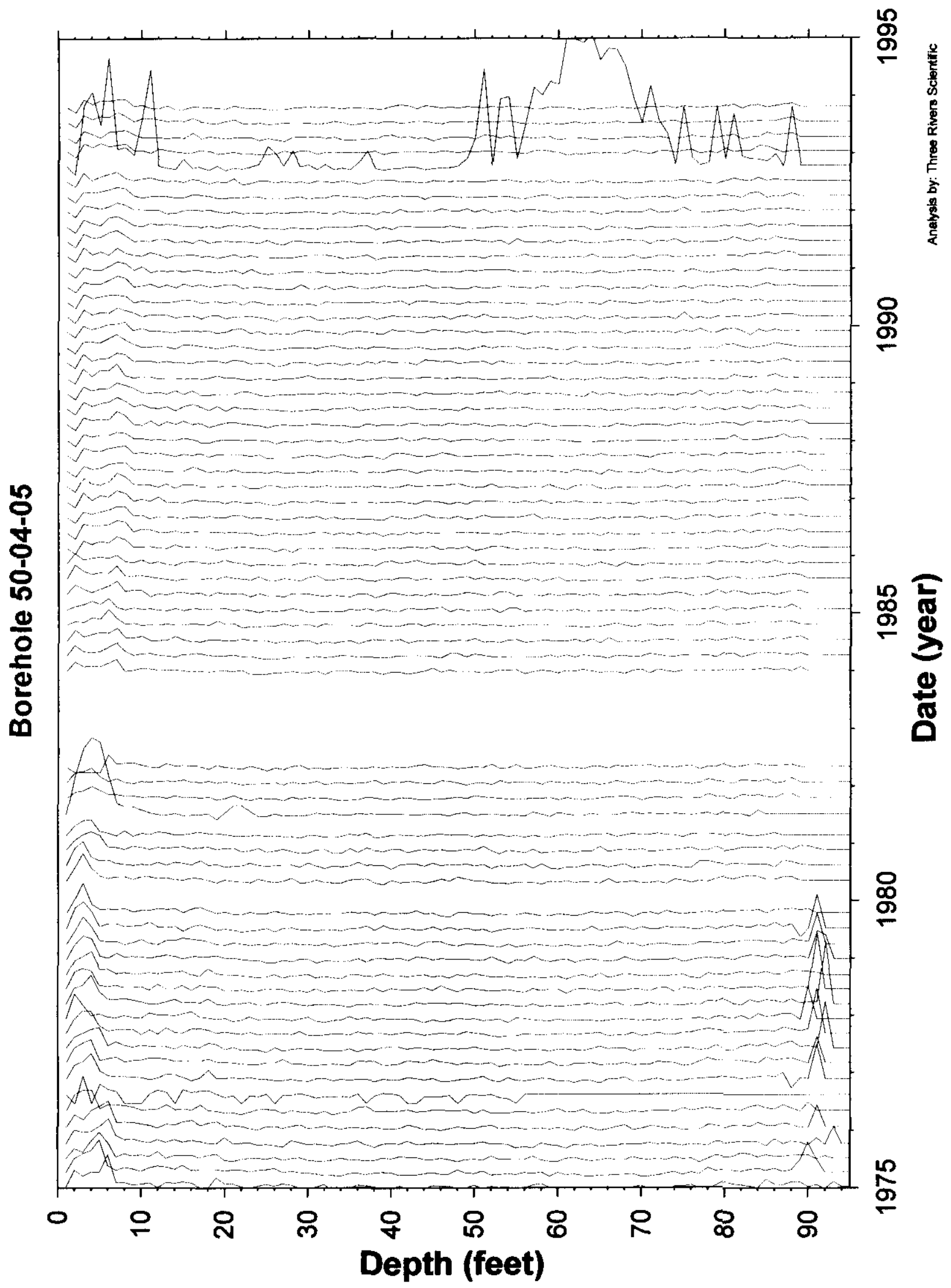

Tank T-104

Page 176 
RPP-6088, Rev.0.
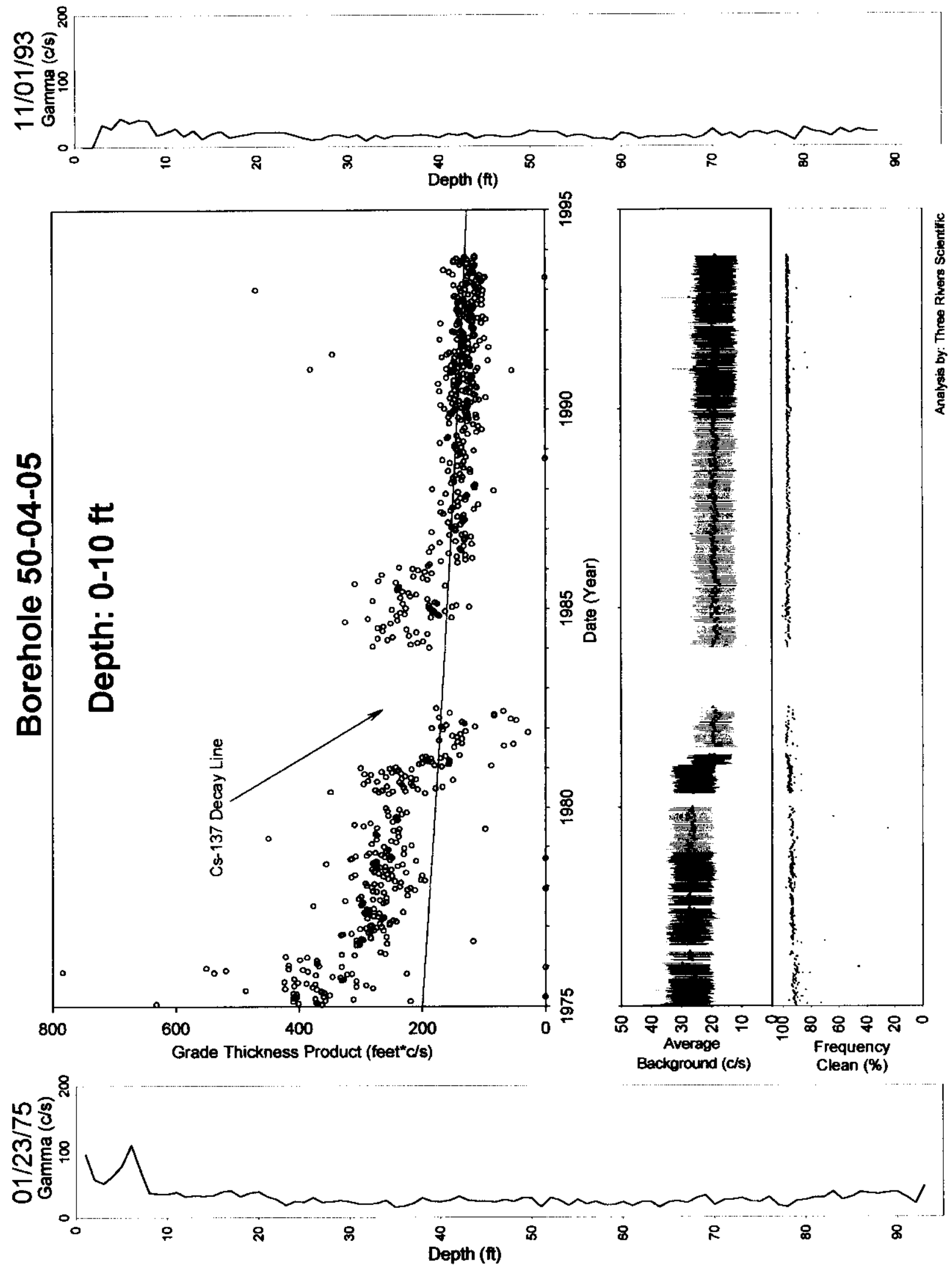
RPP-6088, Rev.0.

\section{Borehole 50-04-07}

\section{Contamination (Cs-137) from 0-28 feet is Tank Farm Activity.}

A step decrease in average background and the grade thickness product occurs after 2-10-81. No change observed for deeper gross gamma surveys.

The interval from 0 to 28 feet has a high level of contamination of Cs-137 identified with the HPGe logging system. The zone appears stable since 1986. Depth control errors before 1984 prevent analysis for sub zones.

Gross Gamma Survey Information

\begin{tabular}{|r|l|}
\hline Probe Type Processed : & $04:$ Nal \\
\hline Other Probe Types : & $\begin{array}{l}03: \text { Neutron(5) 02: Red GM(1) } \\
14: \text { Shielded Nal(1) }\end{array}$ \\
\hline Survey Depth : & $100 \mathrm{ft}$ \\
\hline First Survey Date : & $4 / 2 / 1975$ \\
\hline Last Survey Date : & $11 / 1 / 1993$ \\
\hline Number Surveys Processed : & 676 \\
\hline
\end{tabular}

Analysis Notes

Method Used to Compute Background : $\quad$ Threshold $0<$ val $<50$

Depth(s) where Contamination Identified $0-28 \mathrm{ft}$ Tank Farm Activity in Gross Gamma Surveys :

Analyst Name : $\quad$ R.R. Randall

Company Name: Three Rivers Scientific 
RPP-6088, Rev.0.

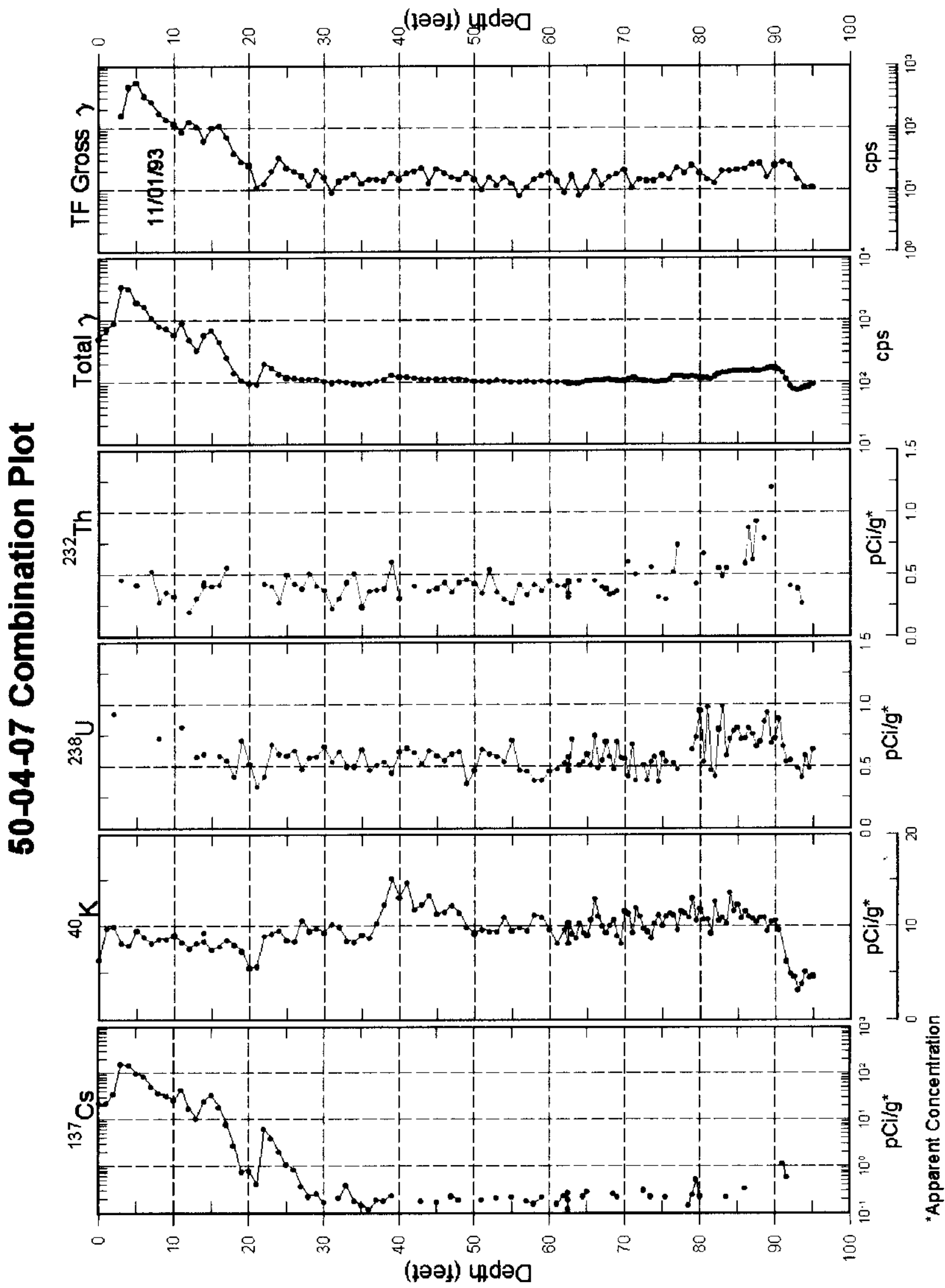


RPP-6088, Rev.0.

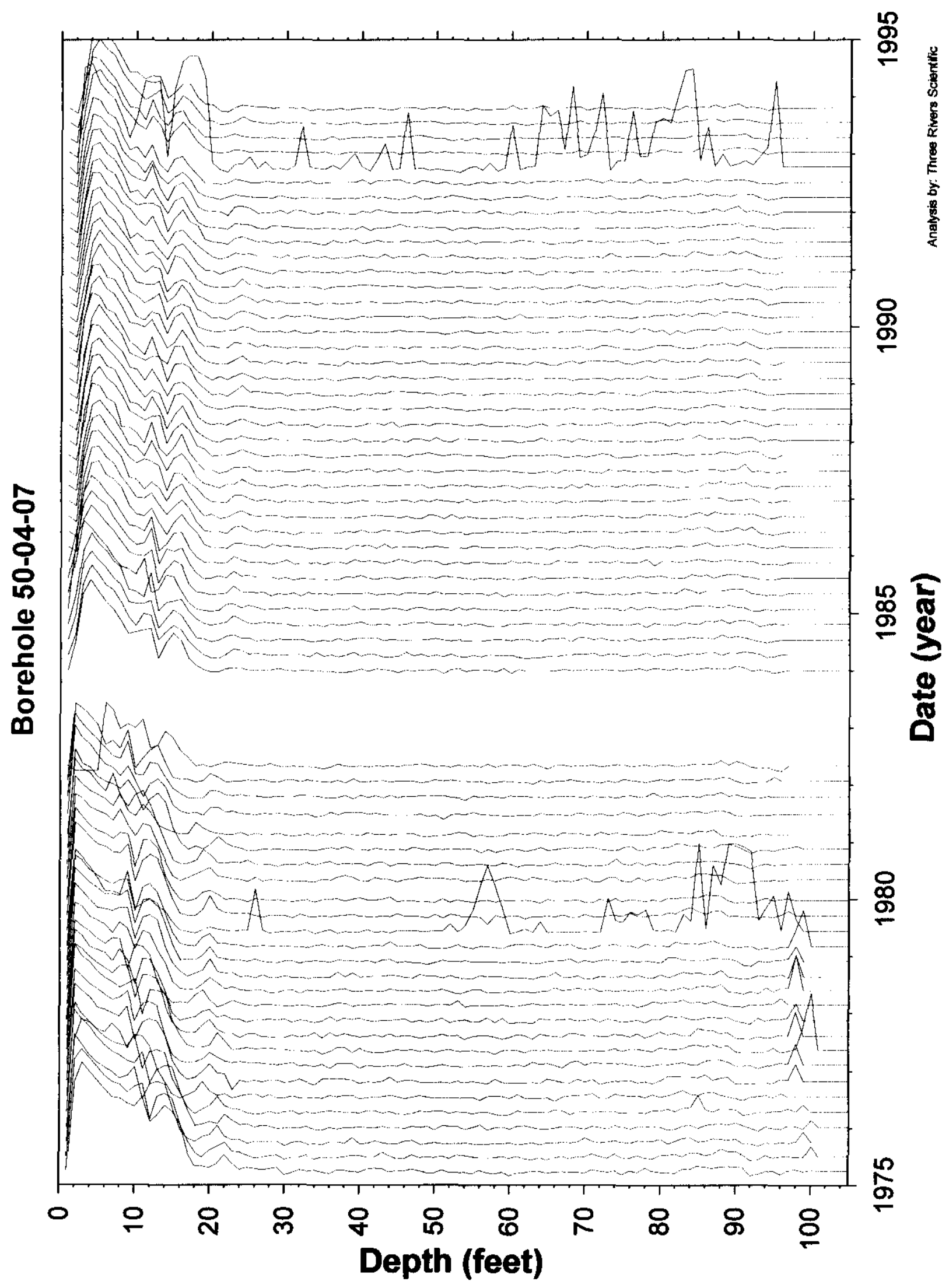

Tank T-104

Page 180 
RPP-6088, Rev.0.
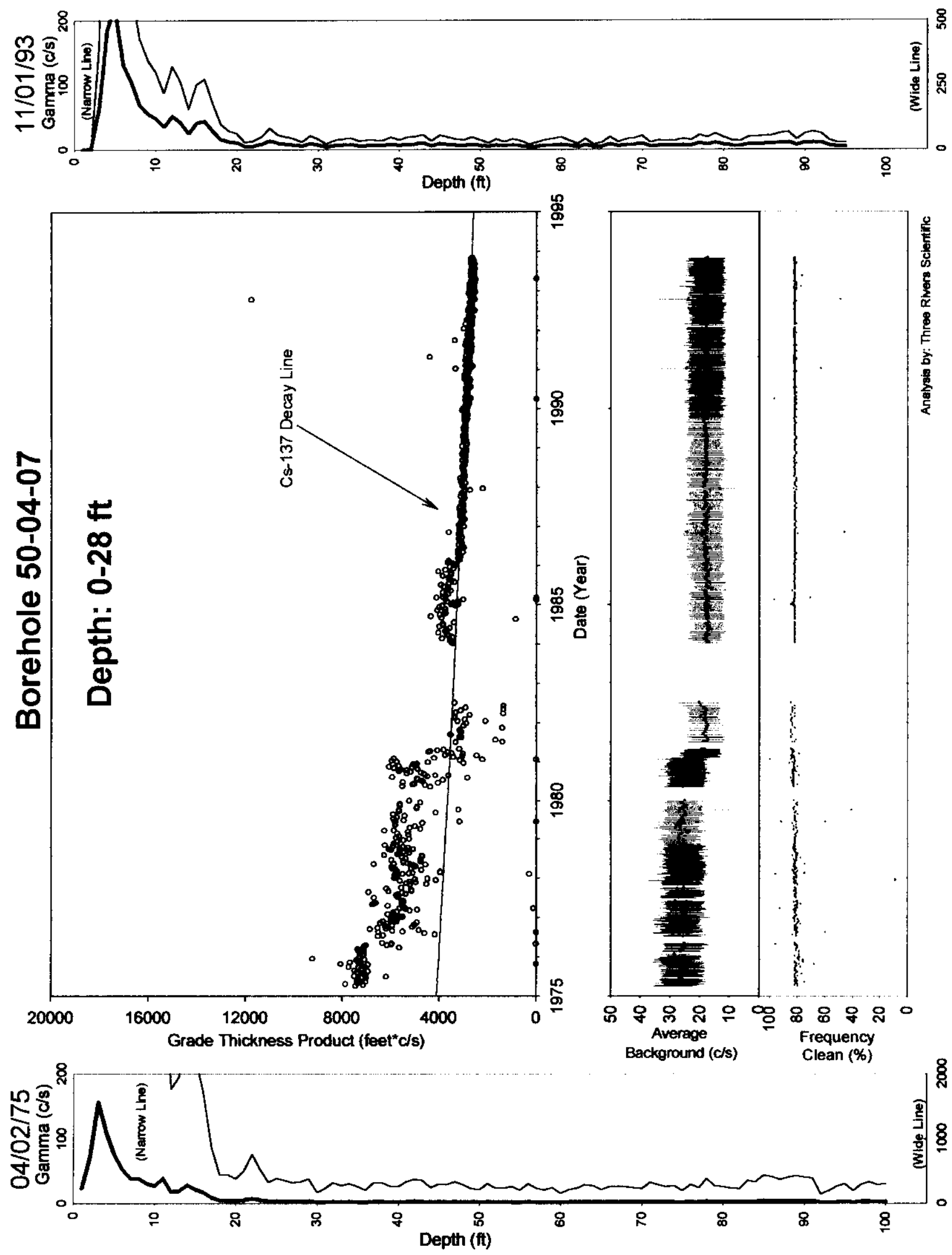


\section{Borehole 50-04-08}

\section{Contamination (Co-60) from 63-72 feet is Unstable.}

A step decrease in average background and the grade thickness product occurs after 2-10-81.

The interval from 63 to 72 feet has a low level of Co-60 identified with the HPGe logging system. There is clear influx of contaminant starting in 1975 and peaking in 1981. A possible match with the Co-60 decay line does not cover enough time interval at the end of the data to rigorously determine stability, thus the classification of unstable. Note, Co-60 is HPGe identified at less than $1 \mathrm{pCi} / \mathrm{g}$ from 72 to 82 feet.

The slight increase in gross gamma over the interval from 80 to 90 feet is due to the increase in the natural radionuclides.

Gross Gamma Survey Information

\begin{tabular}{|r|l|}
\hline Probe Type Processed : & 04: NaI \\
\hline Other Probe Types : & $\begin{array}{l}\text { 03: Neutron(4) 02: Red GM(1) } \\
14: \text { Shielded NaI(2) }\end{array}$ \\
\hline Survey Depth : & $102 \mathrm{ft}$ \\
\hline First Survey Date : & $4 / 3 / 1975$ \\
\hline Last Survey Date : & $11 / 1 / 1993$ \\
\hline Number Surveys Processed : & 653 \\
\hline
\end{tabular}

Analysis Notes

Method Used to Compute Background : $\quad$ Threshold $0<$ val $<50$ for

Depth(s) where Contamination Identified $63-72 \mathrm{ft}$ Unstable in Gross Gamma Surveys :

Analyst Name : R.R. Randall

Company Name : Three Rivers Scientific 
RPP-6088, Rev.0.

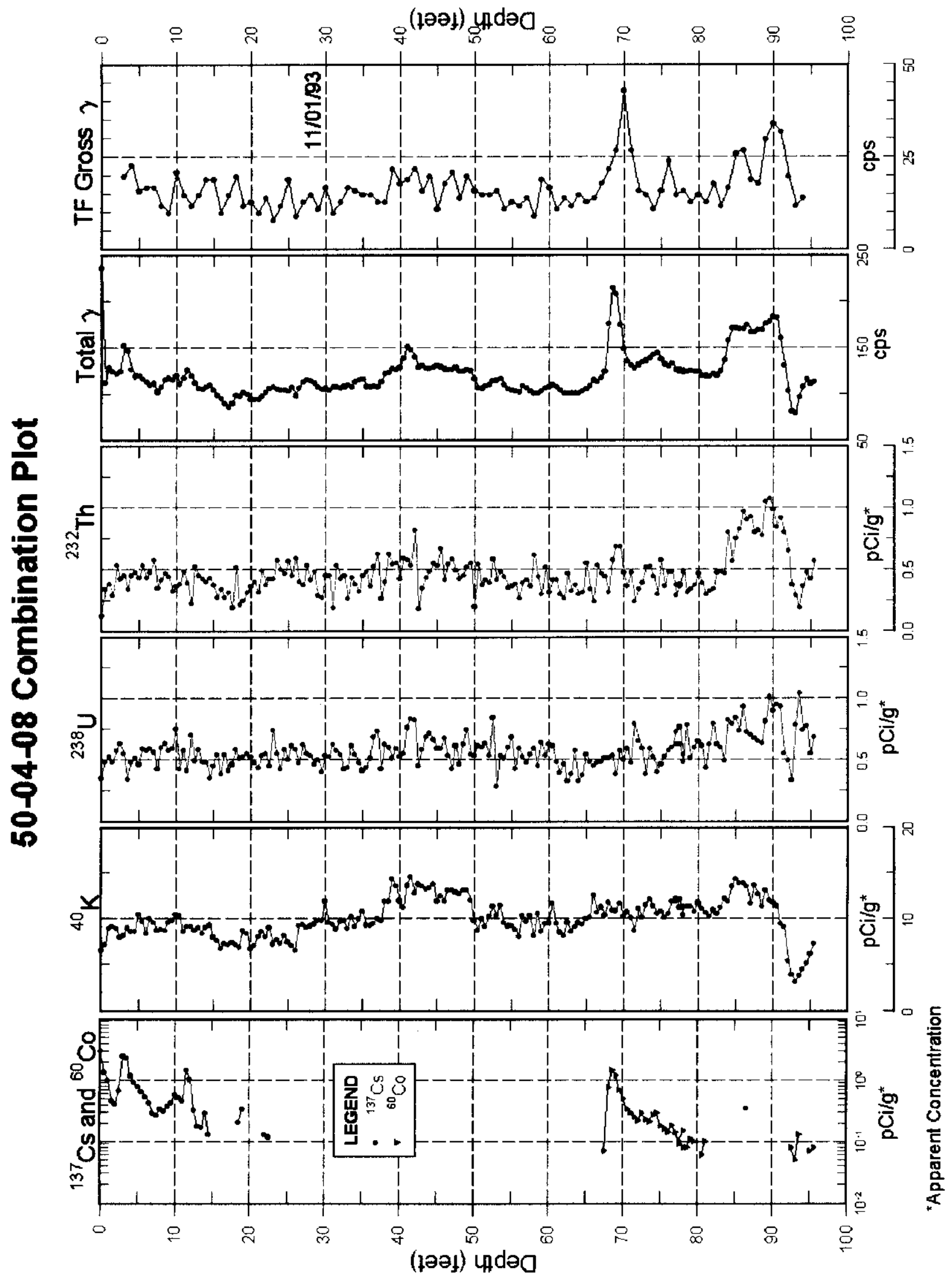


RPP-6088, Rev.0.

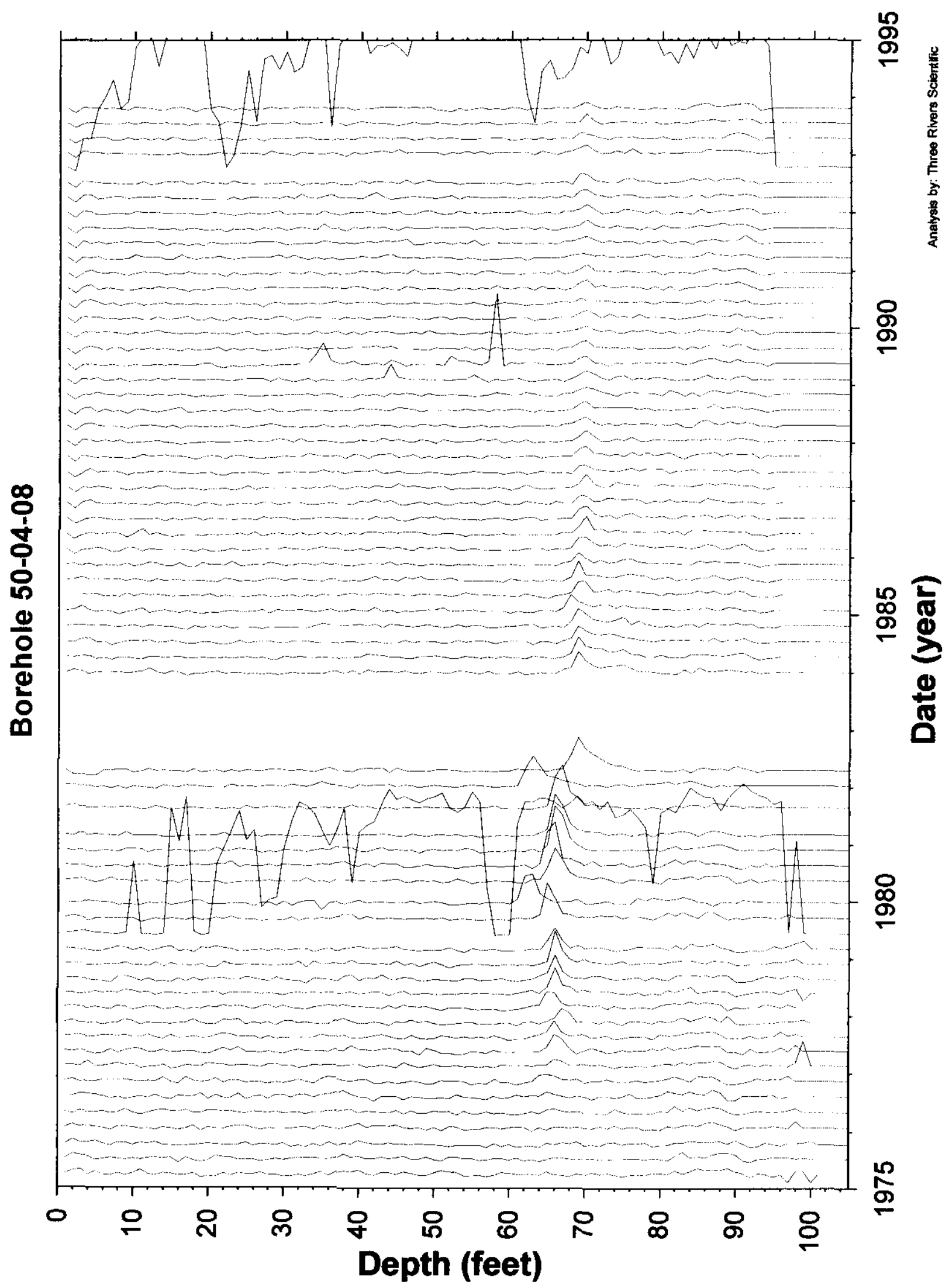

Tank T-104

Page 184 
RPP-6088, Rev.0.
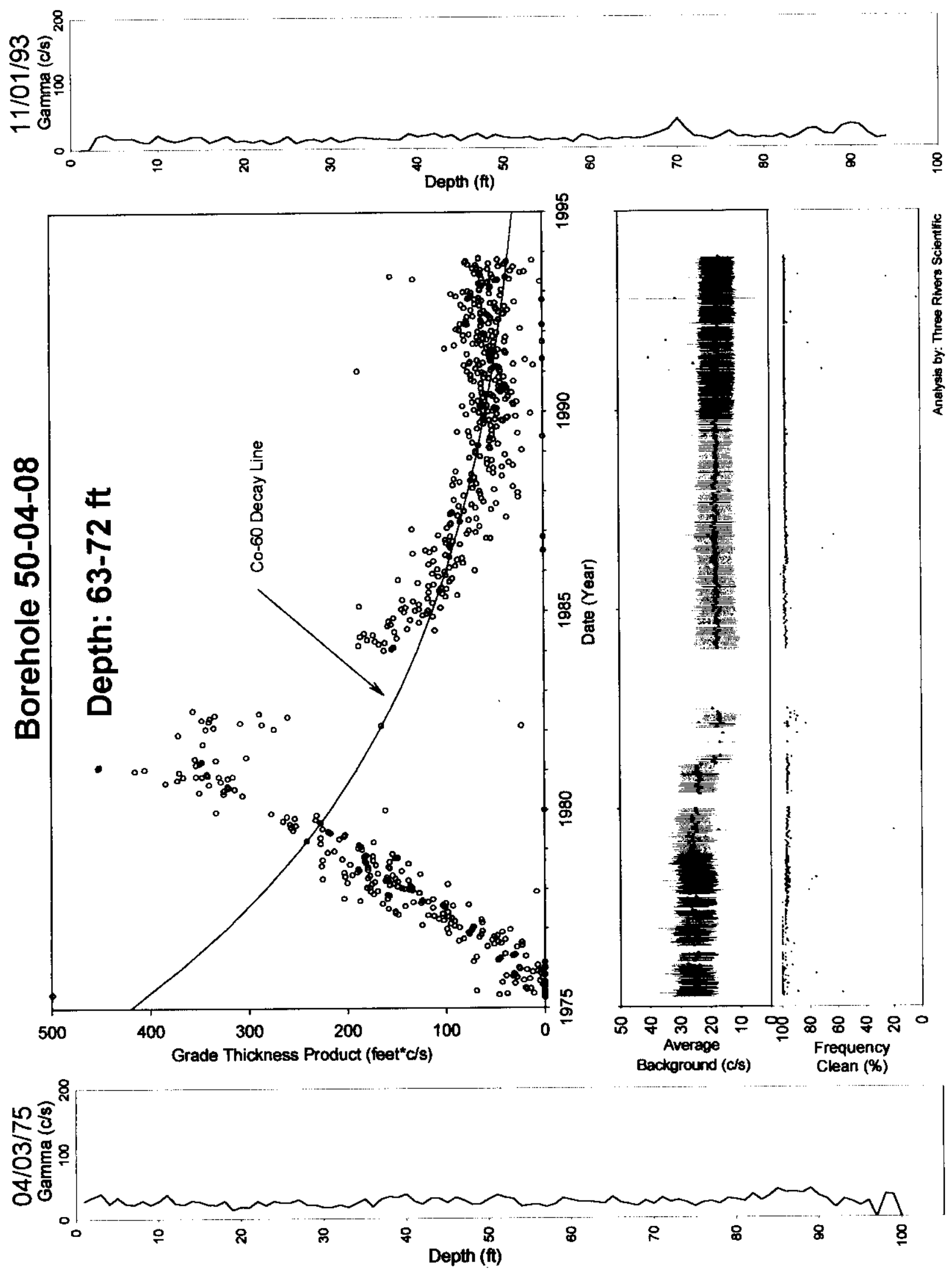

Tank T-104 
RPP-6088, Rev.0.

\section{Borehole 50-04-10}

\section{Contamination (Co-60) from 62-71 feet is Unstable. Contamination (Co-60) from 82-90 feet is Unstable Early.}

A step decrease in average background occurs after 9-16-80.

The interval from 62 to 71 feet has a low level of contamination of Co-60 identified with the HPGe logging system (refer to the HPGe plot). The scaling of the grade thickness product for the step decrease in average background is not performed since continuity would not affect the results. The zone observes a dramatic increase starting in 1975, and a more rapid decrease than Co-60 decay from 1983 to 1988 . From 1992 to 1994 there is an indication of a small increase. Therefore the classification is unstable.

Another feature (refer to the stack plot) is the relative intensity of the top half of this interval (6271 feet) to the bottom half of this interval over the history of these data. It is possible that the top part of this interval builds to some break point and then moves down into the lower interval. One possibility that is ruled out is the presence of different decay rates in the top and bottom halves of this interval. This possibility if it exists still exhibits changes other than stability in the grade thickness product.

Grade thickness product over 82 to 90 feet shows early changes and the most recent influx starting in 1984. However, the zone appears stable since 1988 due to the match with the Co-60 (HPGe identified) decay.

In order to assist the determination of possible downward movement in the interval from 62 to 71 feet, a grade thickness product was computed over the entire interval from 62 to 90 feet. The instability still exists; and, the slight increase from 1989 to 1994 is still present indicating lateral influx into this entire zone. 
RPP-6088, Rev.0.

Gross Gamma Survey Information

\begin{tabular}{|r|l|}
\hline Probe Type Processed : & $04:$ Nal \\
\hline Other Probe Types : & $03:$ Neutron \\
\hline Survey Depth : & $90 \mathrm{ft}$ \\
\hline First Survey Date : & $1 / 10 / 1975$ \\
\hline Last Survey Date : & $10 / 25 / 1993$ \\
\hline Number Surveys Processed : & 502 \\
\hline
\end{tabular}

Analysis Notes

\begin{tabular}{|r|l|}
\hline Method Used to Compute Background : & Threshold 0<val $<50$ \\
\hline Depth(s) where Contamination Identified & $62-71 \mathrm{ft}$ Unstable \\
in Gross Gamma Surveys : & $82-90 \mathrm{ft}$ Unstable Early \\
\hline Analyst Name : & R.R. Randall \\
\hline Company Name : & Three Rivers Scientific \\
\hline
\end{tabular}


RPP-6088, Rev.0.

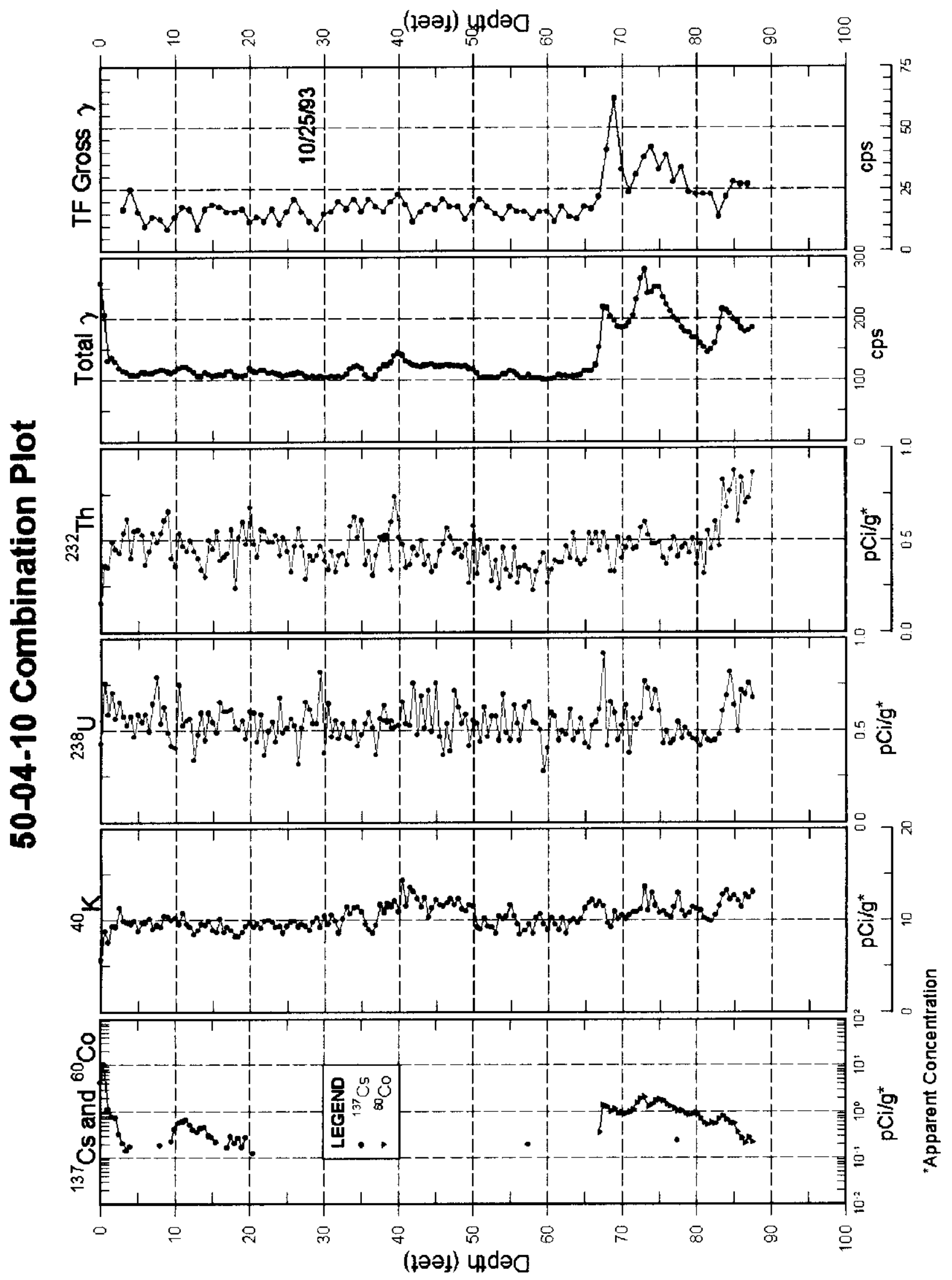


RPP-6088, Rev.0.

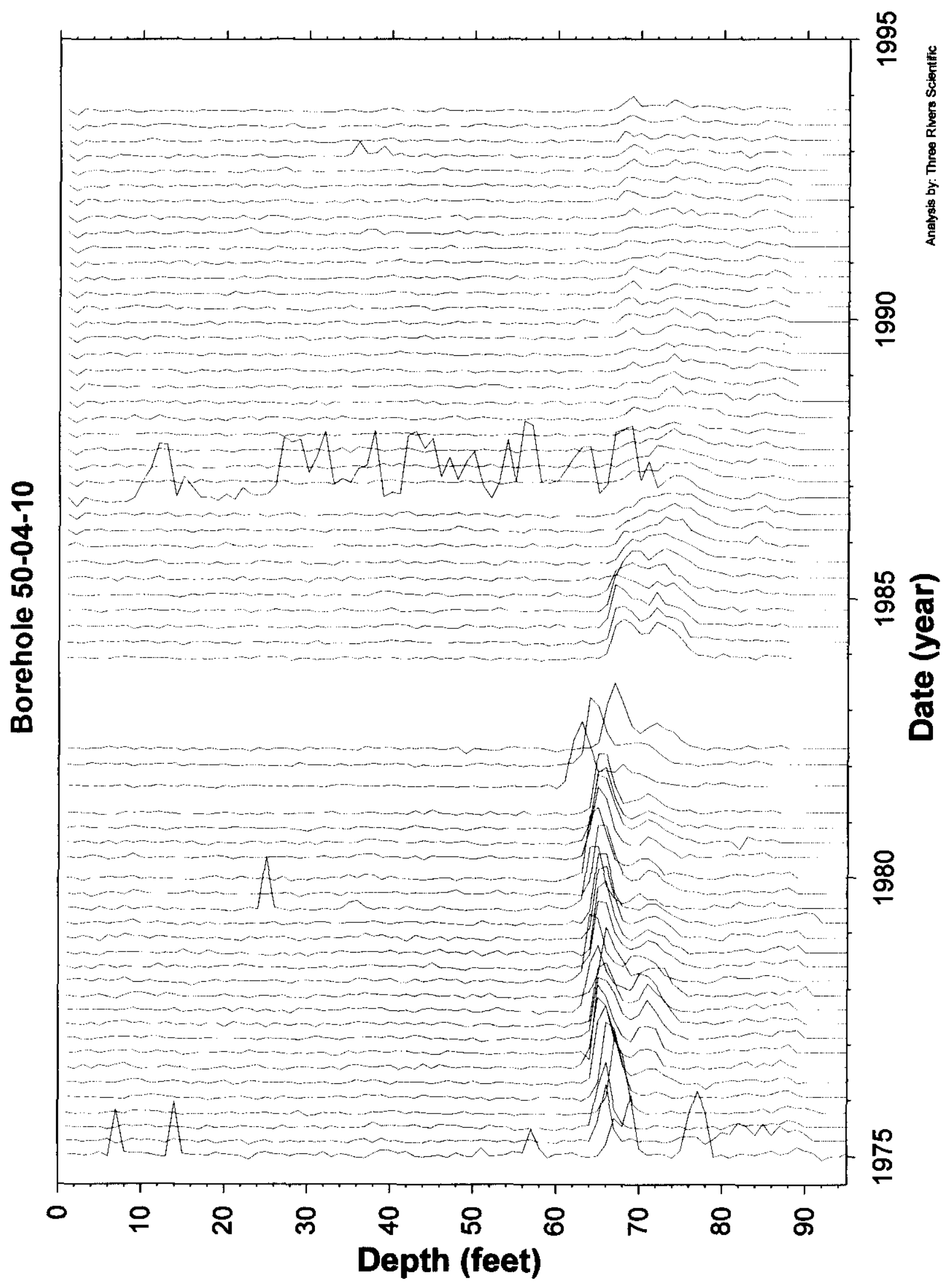

Tank T-104

Page 189 
RPP-6088, Rev.0.
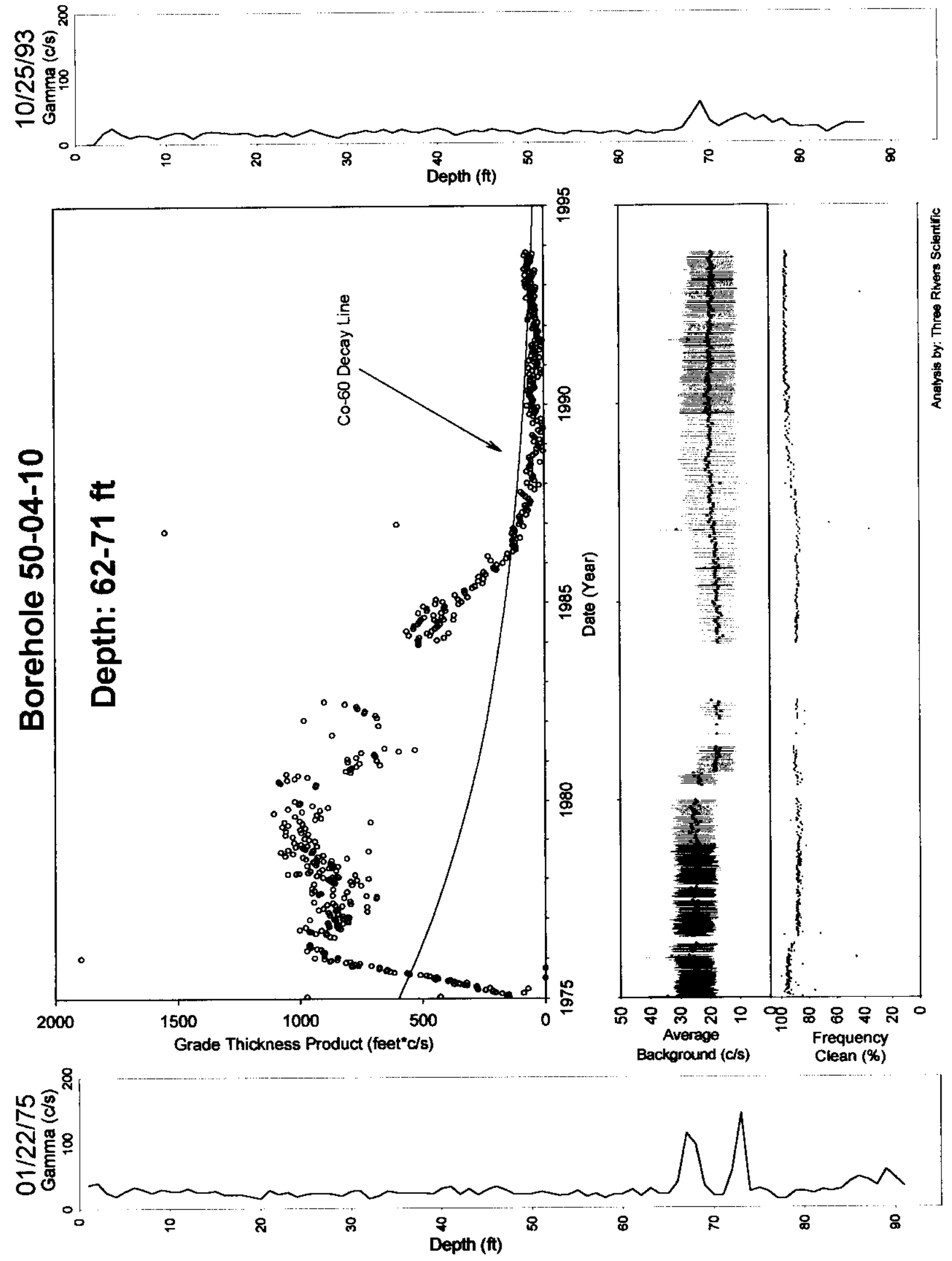
RPP-6088, Rev.0.
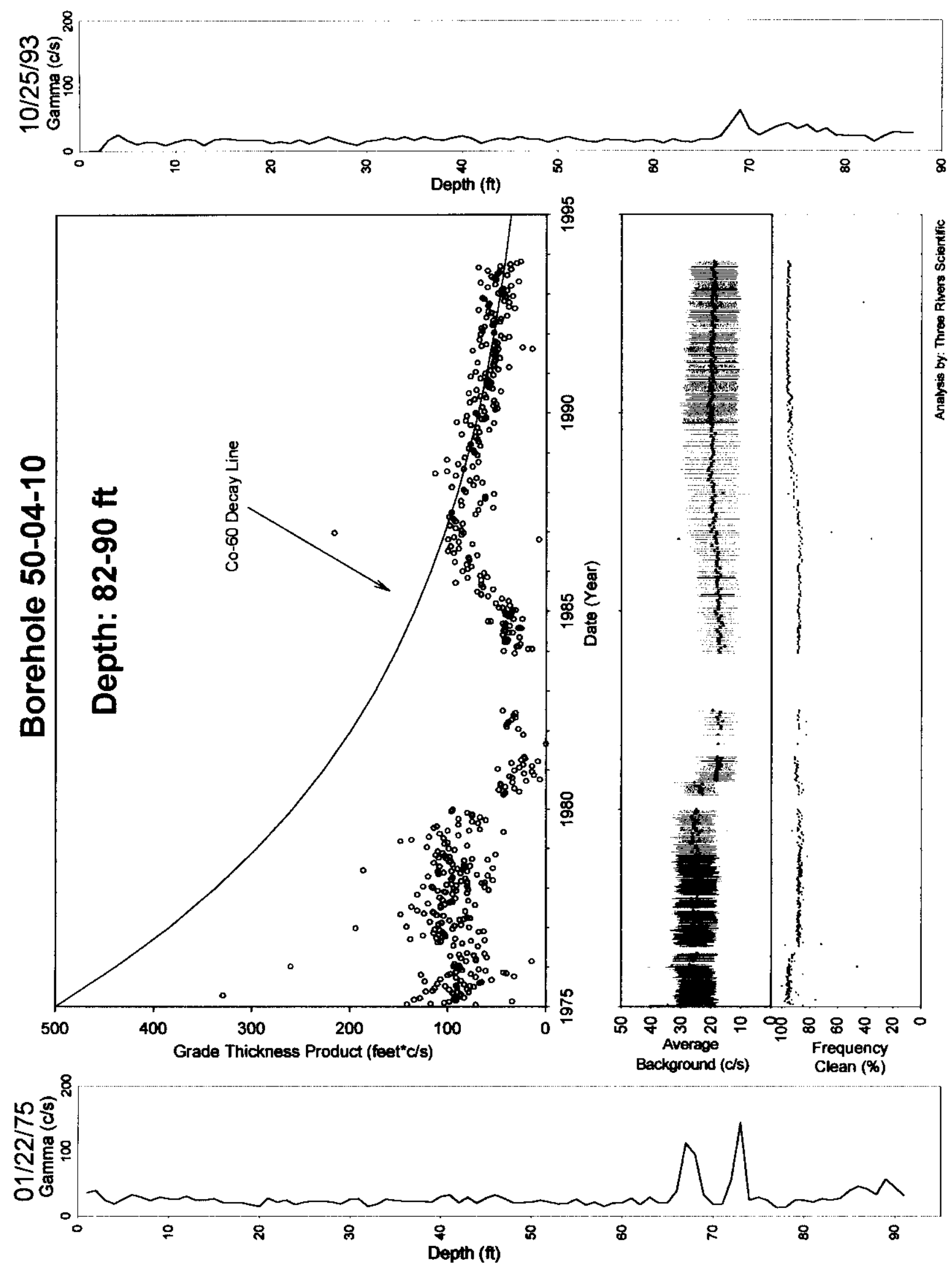
RPP-6088, Rev.0.
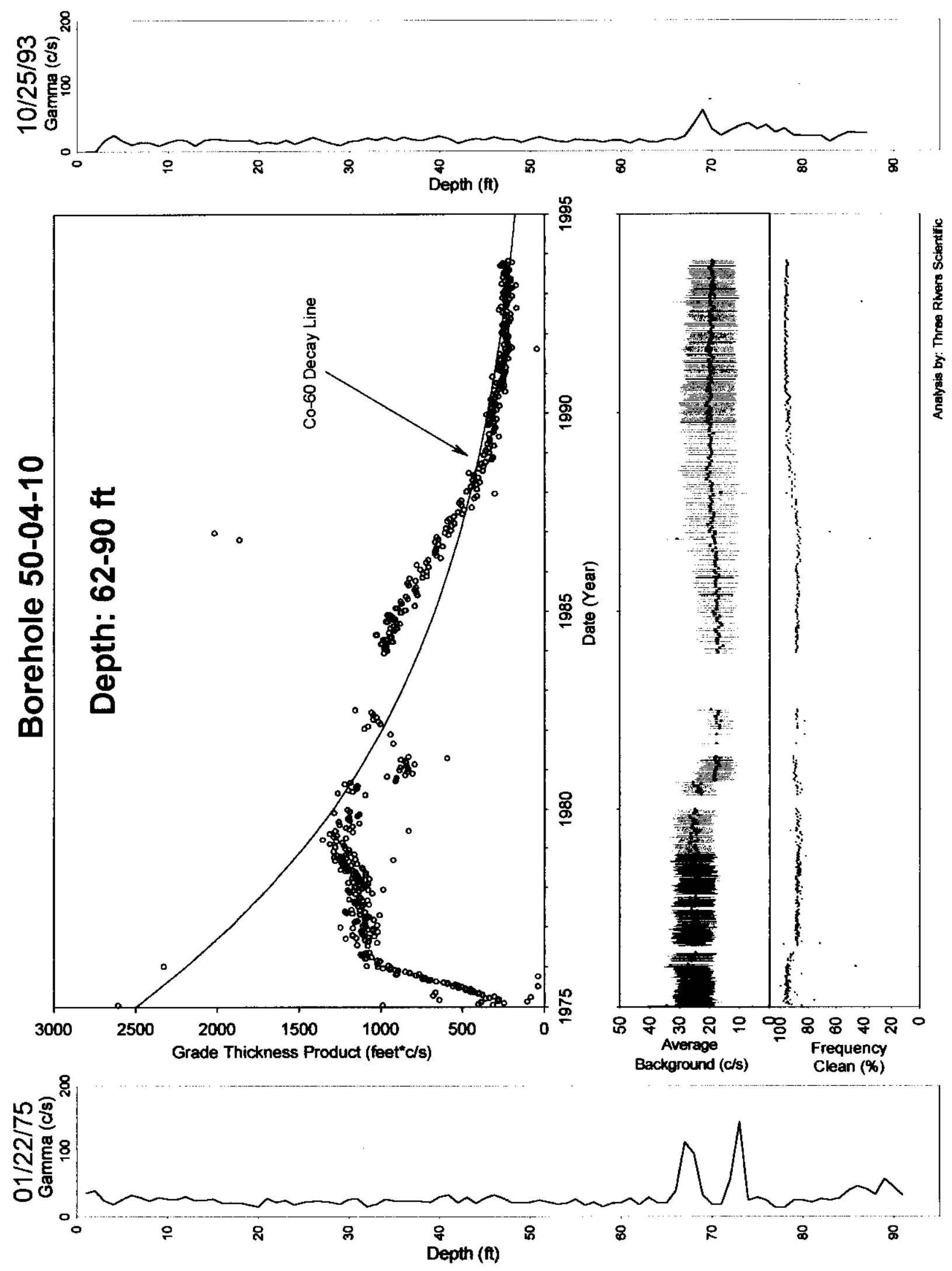

Tank T-104

Page 192 


\section{Tank T-105 Wells}

Table of Contents $\quad$ Page

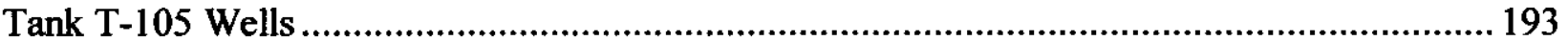

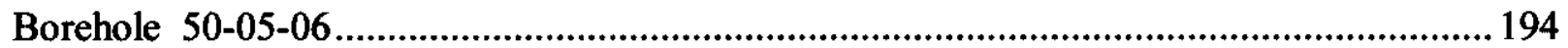

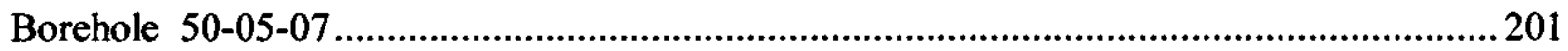

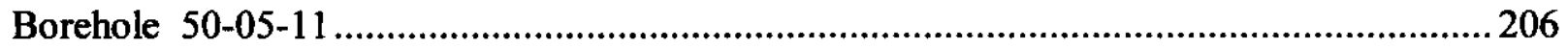

This section contains the analysis results for the vadose zone boreholes (dry wells) associated with Tank 105 in "T" Tank Farm.

Special Note:

None 


\section{Borehole 50-05-06}

\section{Contamination (Cs-137) from 0-20 feet is Undetermined. Contamination (Ru-106) from 58-74 feet is Unstable Early. Contamination (Co-60) from 70-82 feet is Unstable Early.}

A step decrease in average background occurs after 9-14-78. Borehole survey depths deepened from 90 feet to 120 feet after 5-13-77.

Grade thickness product over 0 to 20 feet shows a small but noticeable decline from 1975 until 1978 that is faster than Cs-137 (HPGe identified) decay. This deviation also coincides with the average background change, and scaling with the average background change does not generate a full match. The scaling of the background may be different for Cs-137 due to Compton downscatter. Thus the classification for this zone is undetermined; the zone has been stable since 1979.

The interval from 58 to 74 feet has a complex and large dynamic range character. Two distinct onsets of rapid influx occur in 1975 and mid 1977. Ru-106 (hypothesized) does match the decline after 1981. From 1989 to 1994 the levels of Ru-106 have disappeared and only a small level of Co-60 is present (HPGe identified). The first influx, just before 1975 subsequently shows a linear decline from late 1975 until mid 1977. This linear decline is not decay in place. After the date that the survey depths show an increase (e.g. 5/13/77), a second rapid influx begins. This second wave peaks in late 1978 with subsequent decline faster than the Ru-106. From 1981 the decline in grade thickness product matches the Ru-106. The possibility exists that the zone had a small level of instability when the well was deepened (hypothesis), and this drilling activity enhanced the instability or mobilization of the contaminant.

The interval from 70 to 82 feet shows abrupt changes in the grade thickness product in late 1977. This date is well after the survey depths have increased, but well before the average background changed. After the abrupt increase the decline in grade thickness product continues from early 1978 with a discontinuity that coincides with the average background decrease. Co-60 is HPGe identified in the interval, but at levels too low to be observed with these gross gamma data after 1993. Possibly, the contaminated zone above experienced some leakage into this interval or drilling activities influenced the vadose zone dynamics in this interval. The grade thickness product exhibits unstable early character. 
RPP-6088, Rev.0.

Gross Gamma Survey Information

\begin{tabular}{|r|l|}
\hline Probe Type Processed : & 04: NaI \\
\hline Other Probe Types : & $03:$ Neutron; 14: Shielded NaI \\
\hline Survey Depth : & $120 \mathrm{ft}$ \\
\hline First Survey Date : & $1 / 10 / 1975$ \\
\hline Last Survey Date : & $5 / 24 / 1994$ \\
\hline Number Surveys Processed : & 402 \\
\hline
\end{tabular}

Analysis Notes

Method Used to Compute Background : $\quad$ Threshold $0<\mathrm{val}<50$

Depth(s) where Contamination Identified 0 -20 ft Undetermined; in Gross Gamma Surveys : $\quad 58-74$ \& 70-82 ft Unstable Early Analyst Name : R.R. Randall

\begin{tabular}{l|l} 
Company Name : & Three Rivers Scientific \\
\hline
\end{tabular} 
RPP-6088, Rev.0.

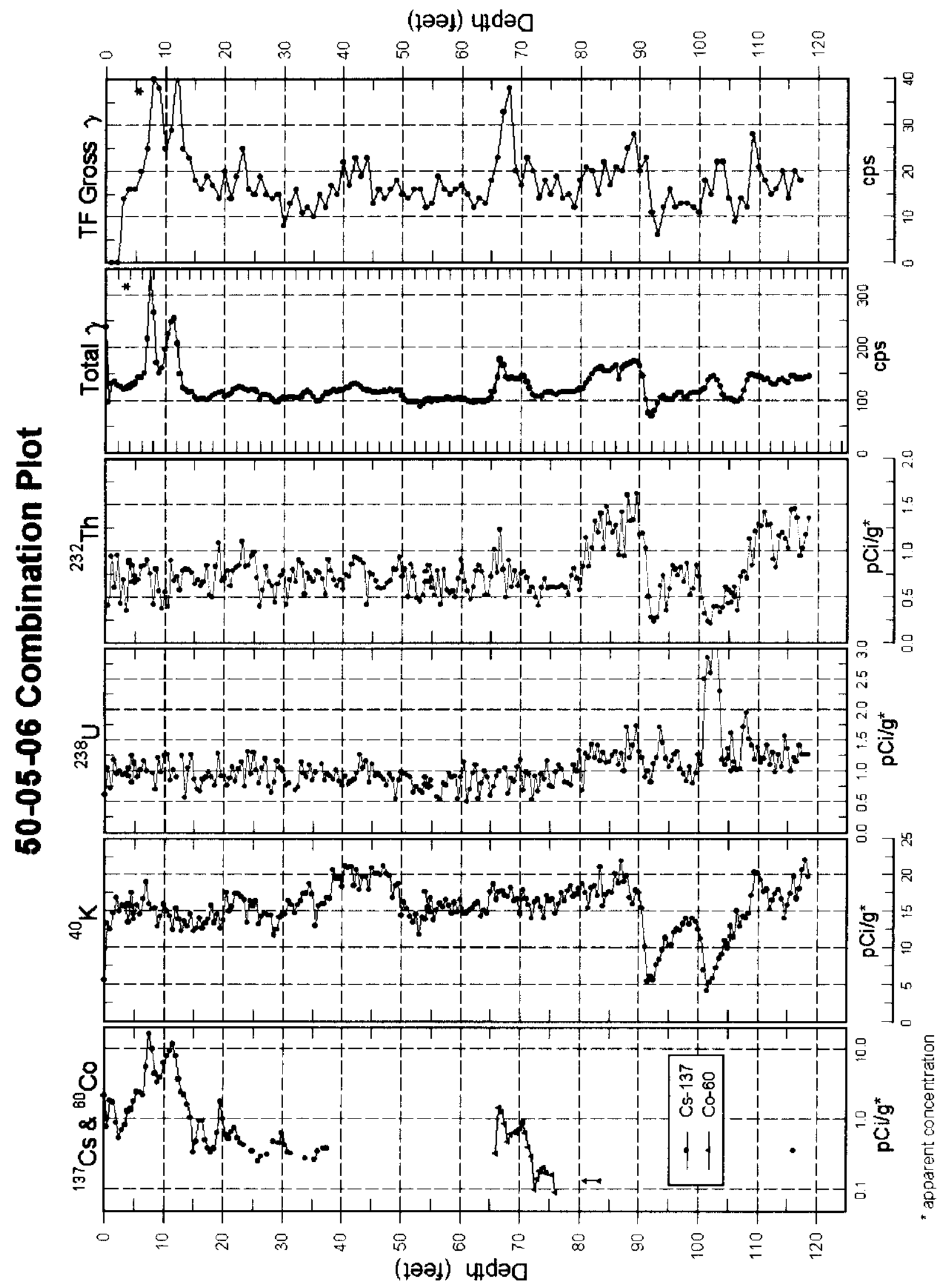


RPP-6088, Rev.0.

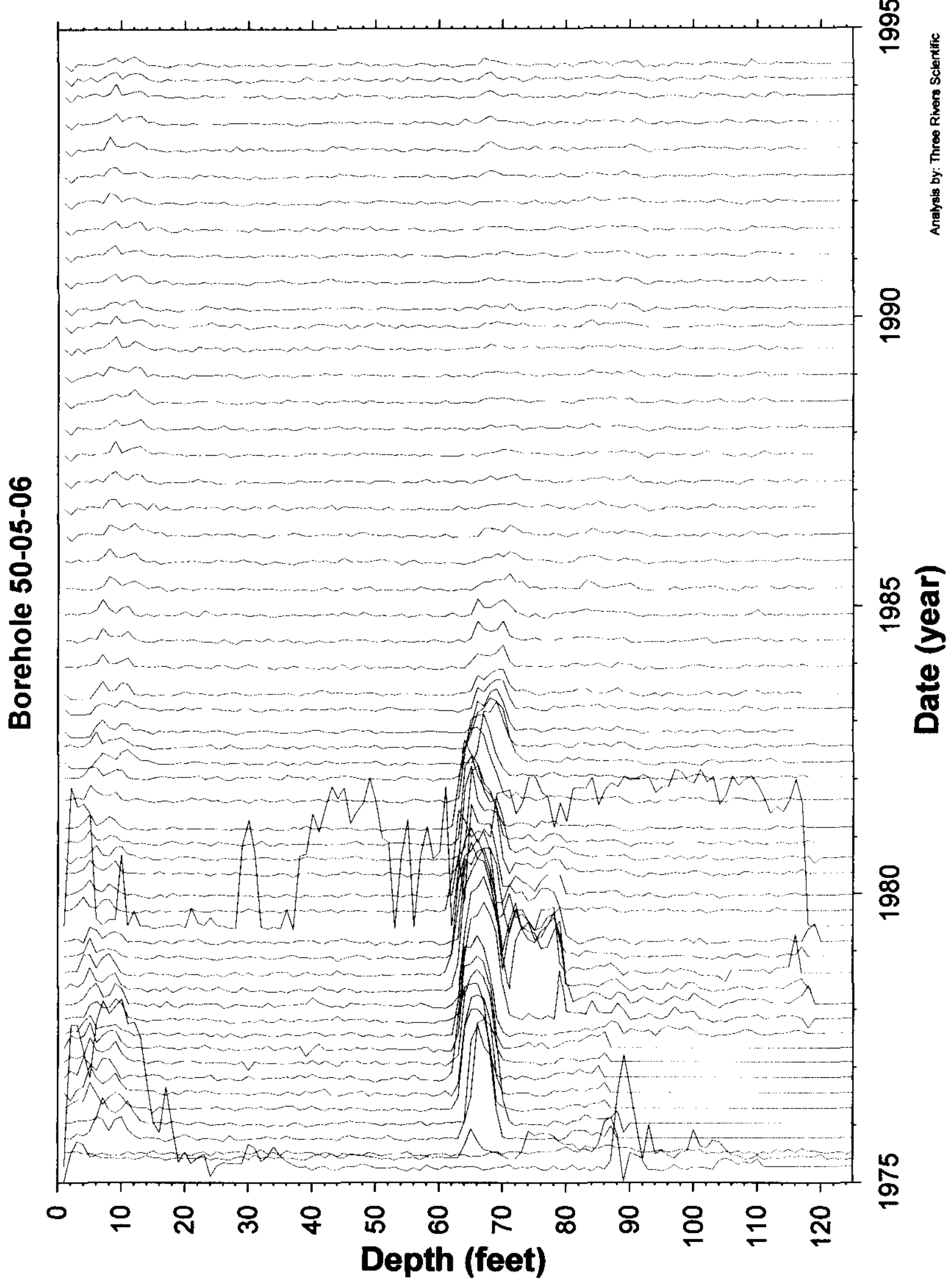

Tank T-105

Page 197 
RPP-6088, Rev.0.
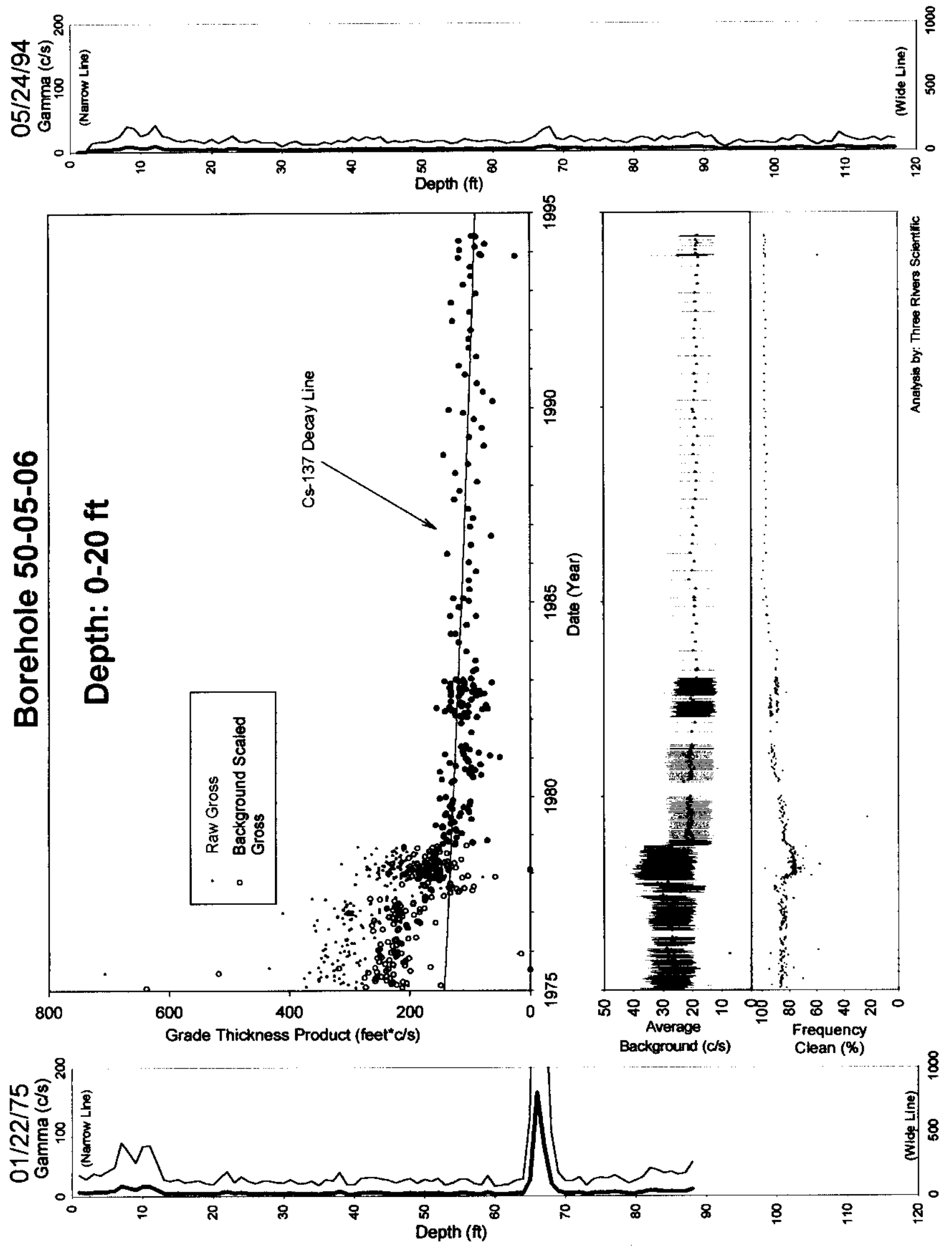

Tank T-105 
RPP-6088, Rev.0.
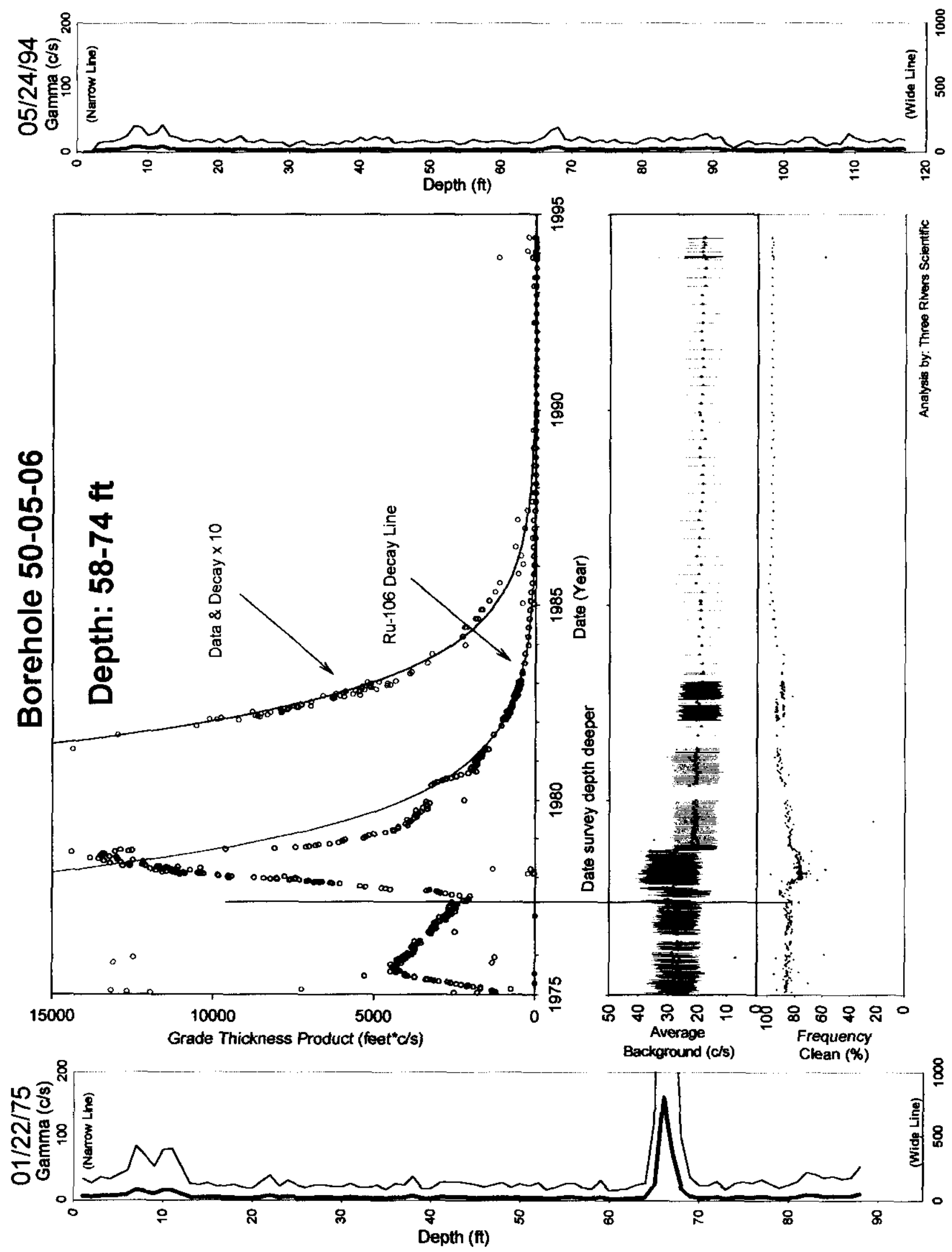

Tank T-105

Page 199 


\section{RPP-6088, Rev.0.}
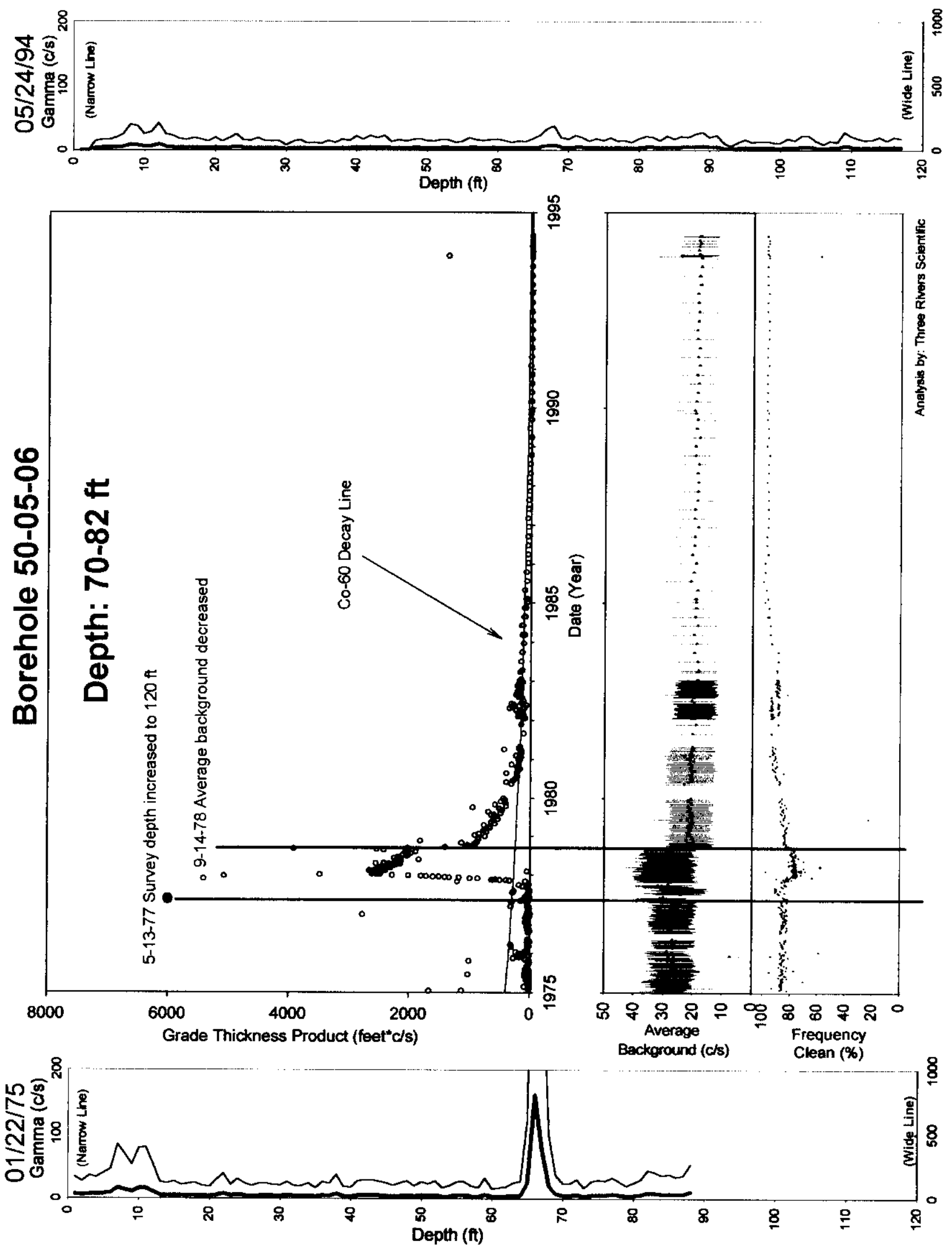

Tank T-105

Page 200 


\section{Borehole 50-05-07}

\section{Contamination (Ru-106) from 4-18 feet is Stable. Contamination (Co-60) from 58-90 feet is Unstable Early.}

The average background is significantly lower than usual for the NaI probe type. Thus the error bars are larger due to the lowered count rates observed. A slight indication of a step decrease in average background occurs after 10-20-1975.

The interval from 4 to 18 feet demonstrates a rapid change early. Grade thickness product is plotted with a Ru-106 (hypothesized) decay curve and an extra background of $50 \mathrm{ft} * \mathrm{c} / \mathrm{s}$. The rapid decay to background levels requires the true background level in this interval from 4 to 18 feet, but nearby depths may have different background levels, thus the additional $50 \mathrm{ft} * \mathrm{c} / \mathrm{s}$ over the threshold method. The match is excellent, with low levels, thus the classification of stable. Cs-137 is HPGe identified, but at levels too low for gross gamma sensitivity.

The interval from 58 to 90 feet is complex. Shielded NaI probe, 14, was run in this dry well, but not for a sufficient length of time to add information. Co-60 is HPGe identified in this interval, but the grade thickness product declines faster than Co-60 and slower than Ru-106. The decline shows discontinuities in 1976 and 1981. Thus the classification of unstable early. The grade thickness product shows stability after 1986, but at very low levels. Poor depth control does not allow an accurate subdivision of the interval into sub zones. The stack plot suggests that the upper section (58-80ft) may be declining faster than the rest of the zone. Either a faster decay component is present in the top portion, or movement out of the top portion is occuring. The discontinuities indicate instability regardless of the specific details of movement.

Gross Gamma Survey Information

\begin{tabular}{|r|l|}
\hline Probe Type Processed : & $04:$ NaI \\
\hline Other Probe Types : & $03:$ Neutron(4) 14: Shielded NaI(61) \\
\hline Survey Depth : & $88 \mathrm{ft}$ \\
\hline First Survey Date : & $8 / 16 / 1975$ \\
\hline Last Survey Date : & $5 / 26 / 1994$ \\
\hline Number Surveys Processed : & 349 \\
\hline
\end{tabular}

Analysis Notes

\begin{tabular}{|c|c|}
\hline Method Used to Compute Background : & Threshold $0<$ val $<50$ \\
\hline $\begin{array}{r}\text { Depth(s) where Contamination Identified } \\
\text { in Gross Gamma Surveys : }\end{array}$ & $\begin{array}{l}4-18 \mathrm{ft} \text { Stable; } \\
58-90 \mathrm{ft} \text { Unstable Early }\end{array}$ \\
\hline Analyst Name & R.R. Randall \\
\hline Company Name & Three Rivers Scientific \\
\hline
\end{tabular}


RPP-6088, Rev.0.

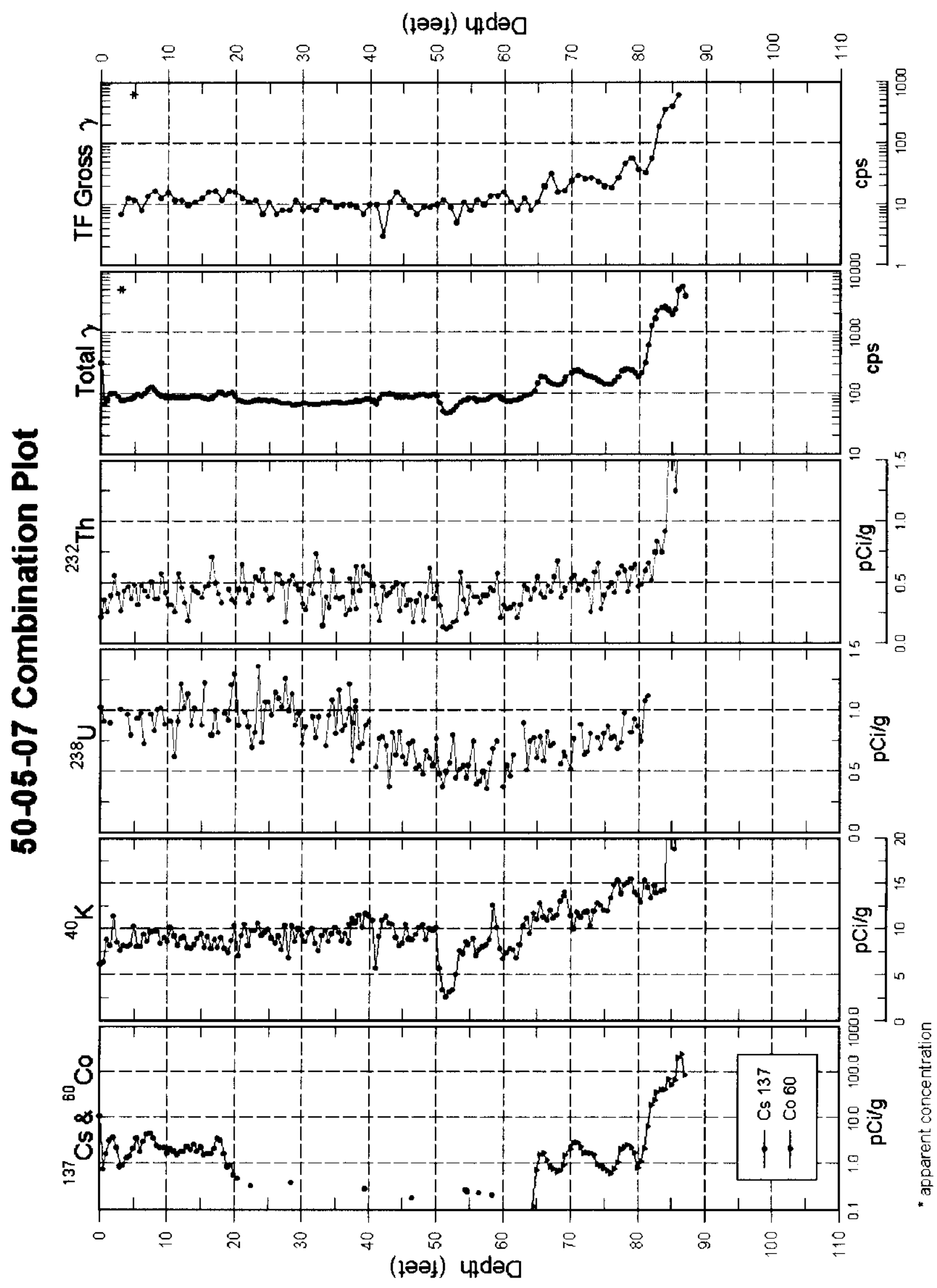

Tank T-105

Page 202 
RPP-6088, Rev.0.

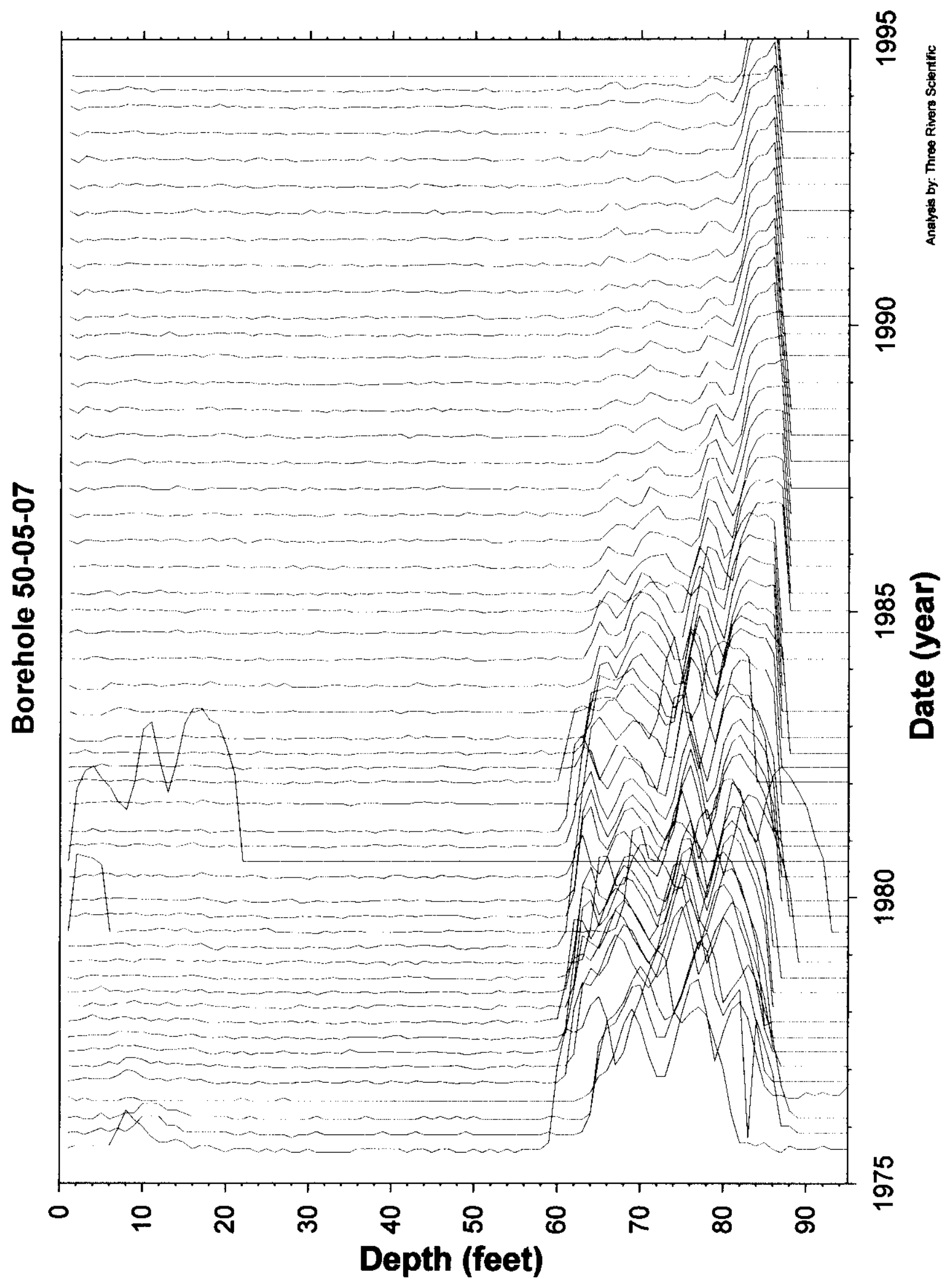

Tank T-105

Page 203 
RPP-6088, Rev.0.
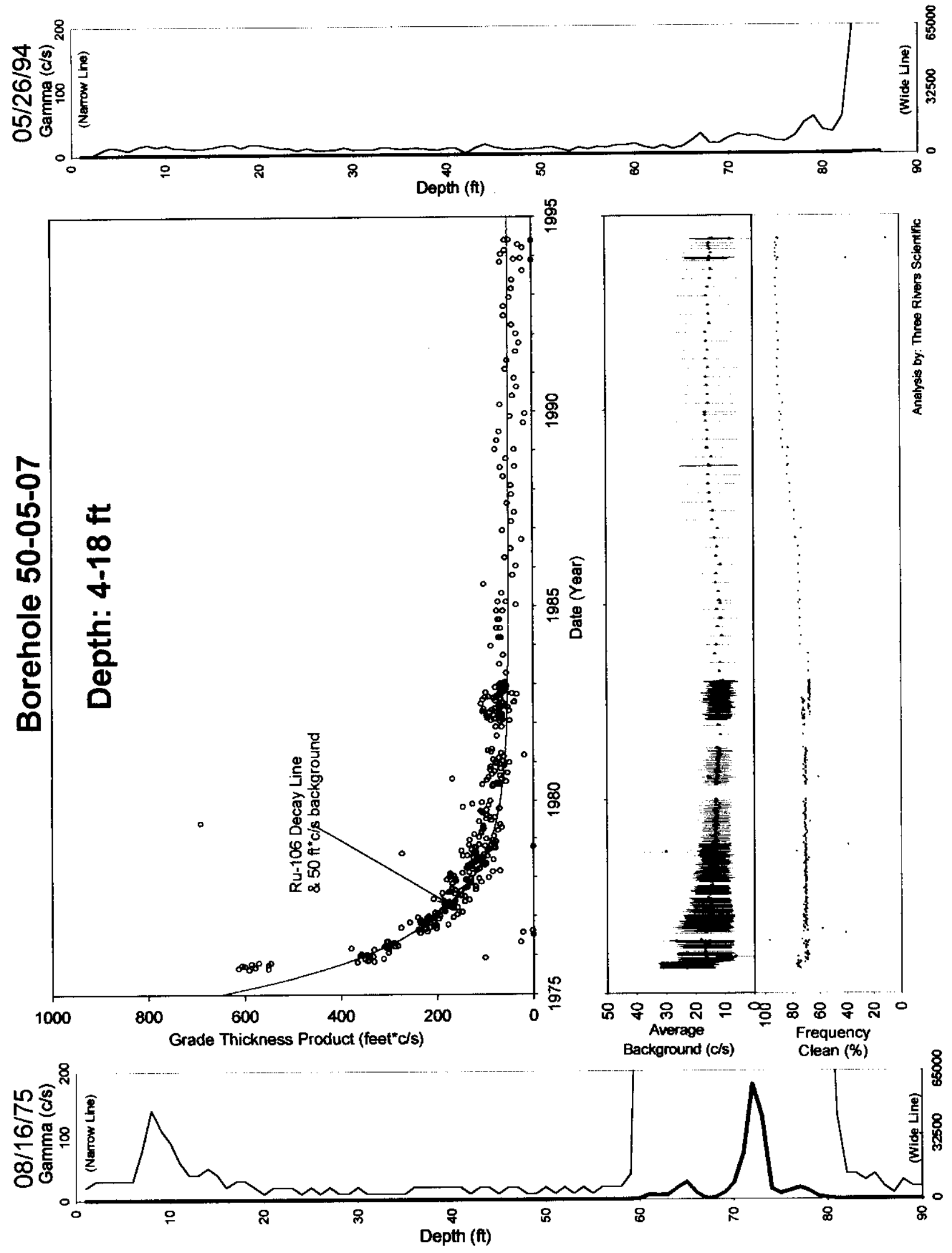

Tank T-105 
RPP-6088, Rev.0.
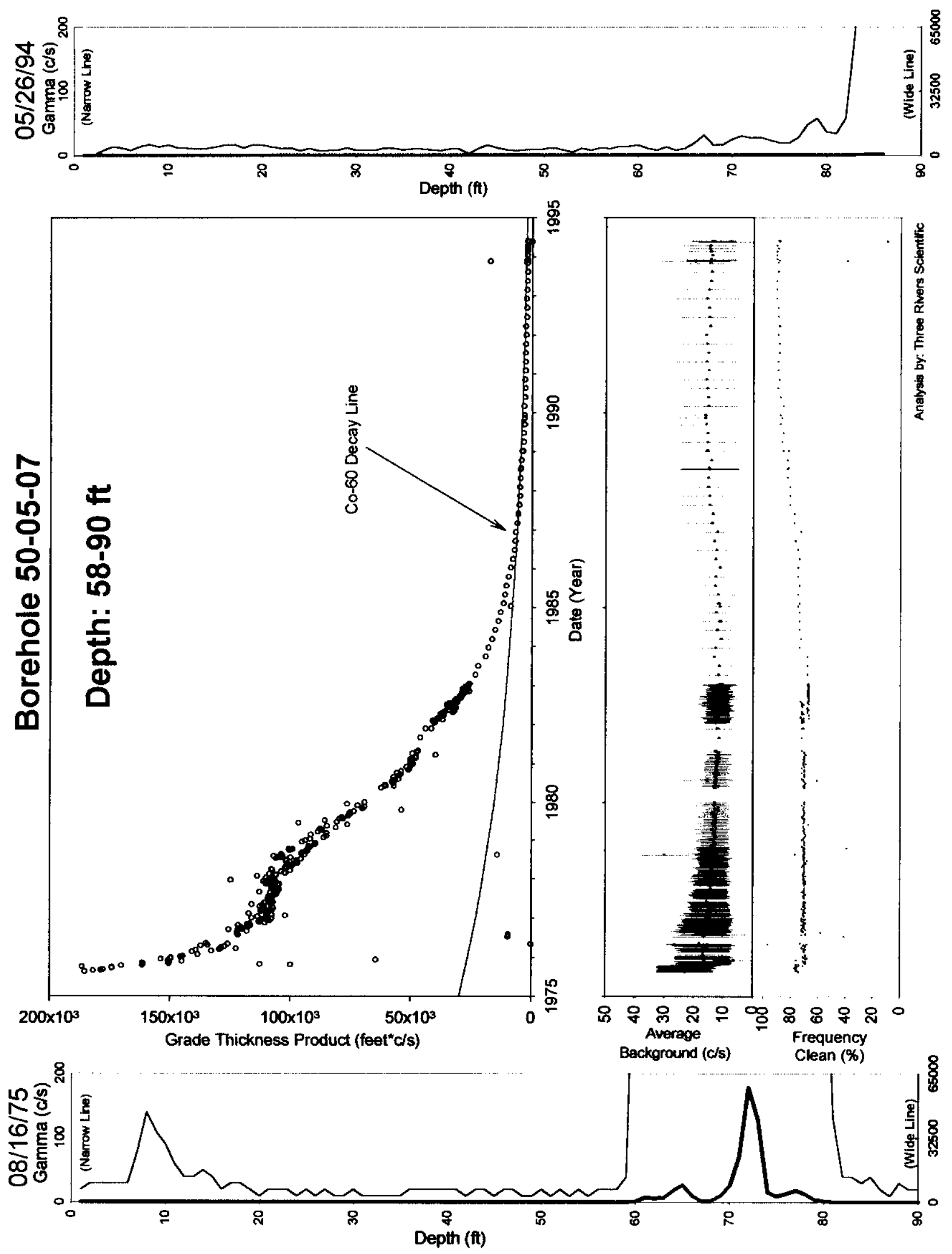

Tank T-105 
RPP-6088, Rev.0.

\section{Borehole 50-05-11}

\section{Contamination (Ru-106) from 50-60 feet is Undetermined. Contamination (Ru-106) from 68-92 feet is Unstable Early. Contamination (Co-60) from 92-106 feet is Stable.}

A step decrease in average background occurred after 3-31-81. Likewise, the survey depths increased from 92 to 122 feet after this same date.

The interval from 50 to 60 feet experienced a rapid build up starting in 1976 and a rapid decline from 1977 to 1981 . Ru-106 (hypothesized) is plotted with the grade thickness product. There is neither enough intensity nor time period for a rigorous classification, thus undetermined.

The interval from 68 to 90 feet experienced a rapid build up starting before 1975 and a rapid decline after 1976. Ru-106 (hypothesized) is plotted with the grade thickness product. No good match between the decay curve and Ru-106 yields an unstable early classification. Possibility of downward movement exists, but cannot be clearly delineated.

The interval from 92 to 106 feet is only valid after 3-31-81, after the borehole surveys were extended. The grade thickness product over this interval matches the Co-60 (HPGe identified) decay curve. The interval shows stability after 1990. Thus the classification is stable.

Gross Gamma Survey Information

\begin{tabular}{|r|l|}
\hline Probe Type Processed : & $04:$ NaI \\
\hline Other Probe Types : & $03:$ Neutron \\
\hline Survey Depth : & $122 \mathrm{ft}$ \\
\hline First Survey Date : & $1 / 14 / 1975$ \\
\hline Last Survey Date : & $5 / 26 / 1994$ \\
\hline Number Surveys Processed : & 341 \\
\hline
\end{tabular}

Analysis Notes

\begin{tabular}{|r|l|}
\hline Method Used to Compute Background : & $\begin{array}{l}\text { Threshold 0<val<50: } 50-60 \& \text { \&8-92 ft } \\
\text { Fixed Background }(20-40 \mathrm{ft}): 92-106 \mathrm{ft}\end{array}$ \\
\hline Depth(s) where Contamination Identified & $50-60 \mathrm{ft}$ Undetermined; \\
in Gross Gamma Surveys : & $\begin{array}{l}68-92 \mathrm{ft} \text { Unstable Early; } \\
92-106 \mathrm{ft} \text { Stable }\end{array}$ \\
\hline Analyst Name : & R.R. Randall \\
\hline Company Name : & Three Rivers Scientific \\
\hline
\end{tabular}


RPP-6088, Rev.0.

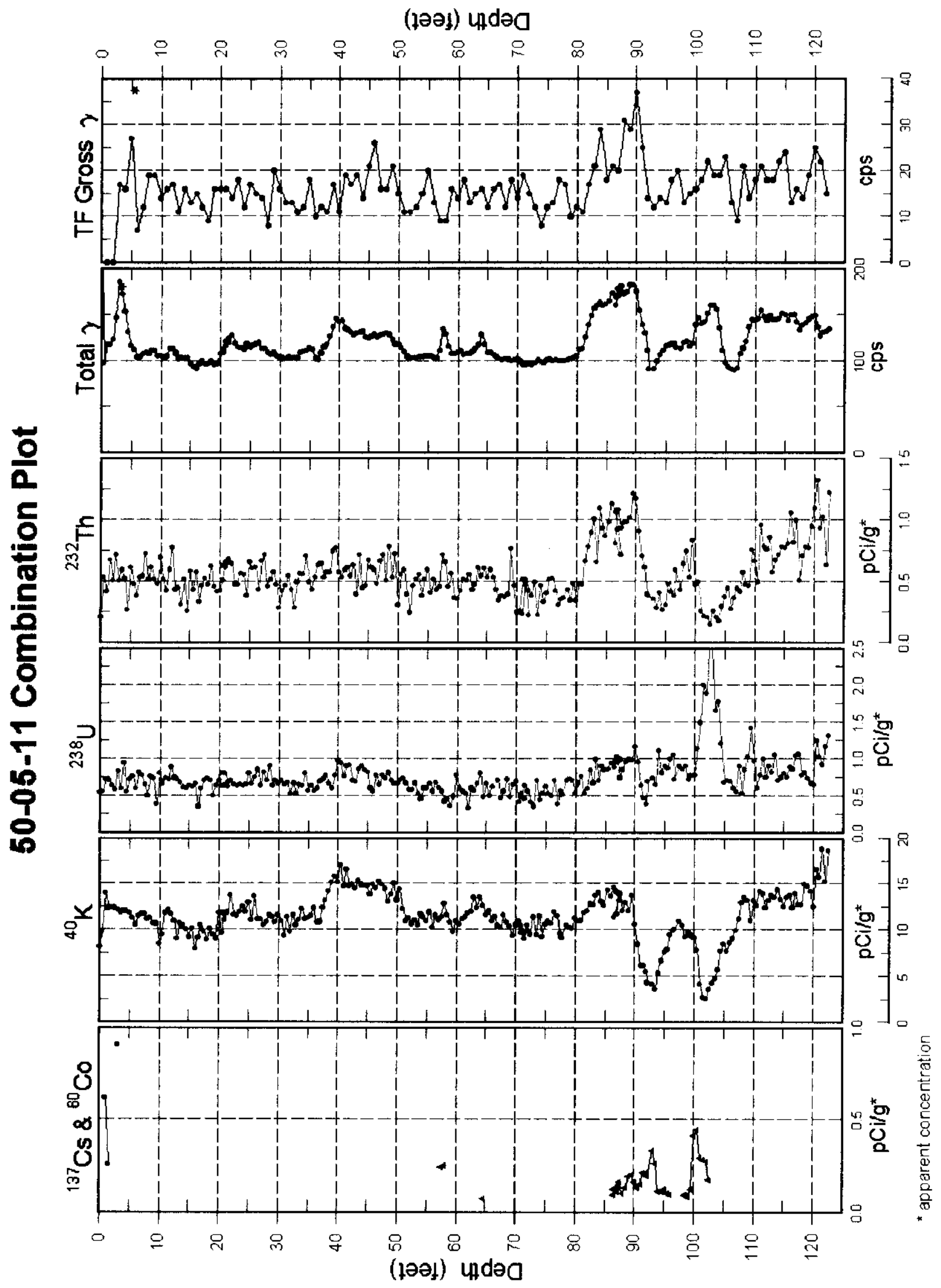

Tank T-105 
RPP-6088, Rev.0.

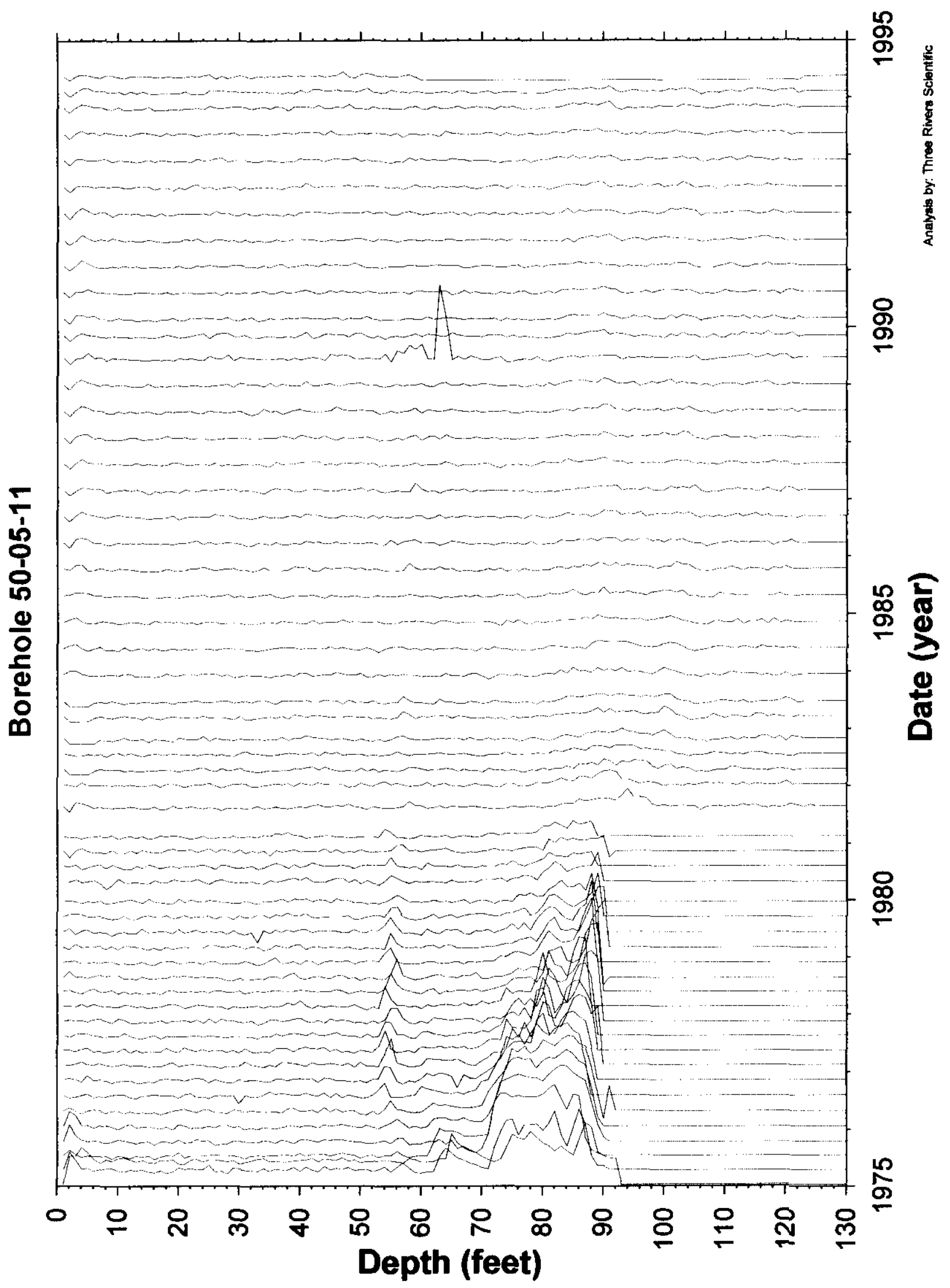

Tank T-105

Page 208 
RPP-6088, Rev.0.
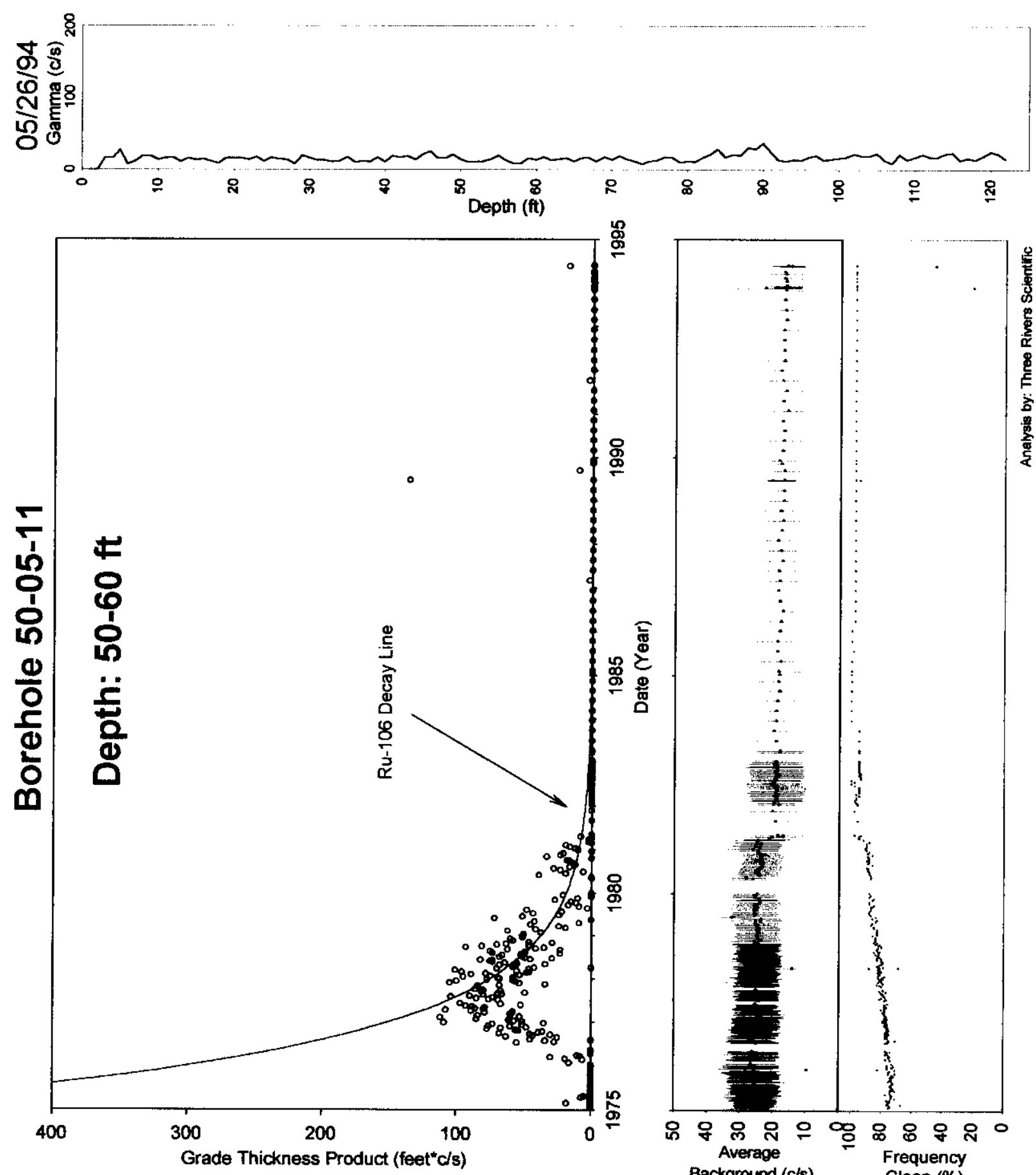

怘

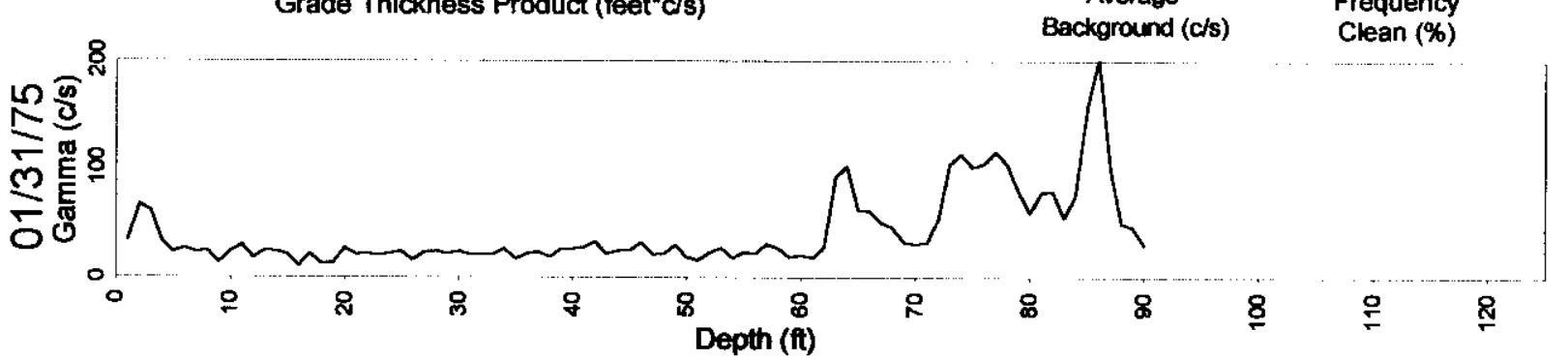


RPP-6088, Rev.0.
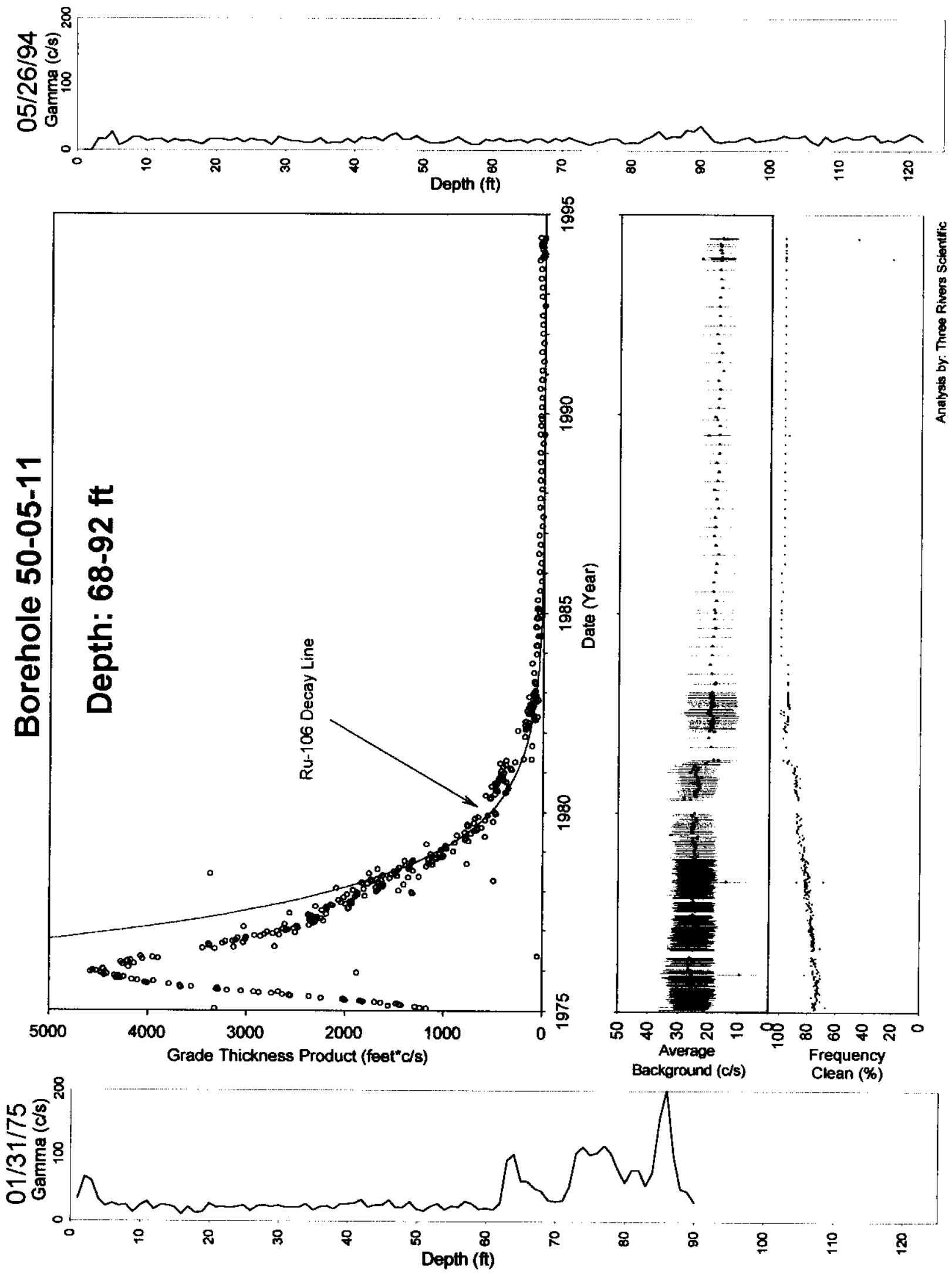

Tank T-105 
RPP-6088, Rev.0.
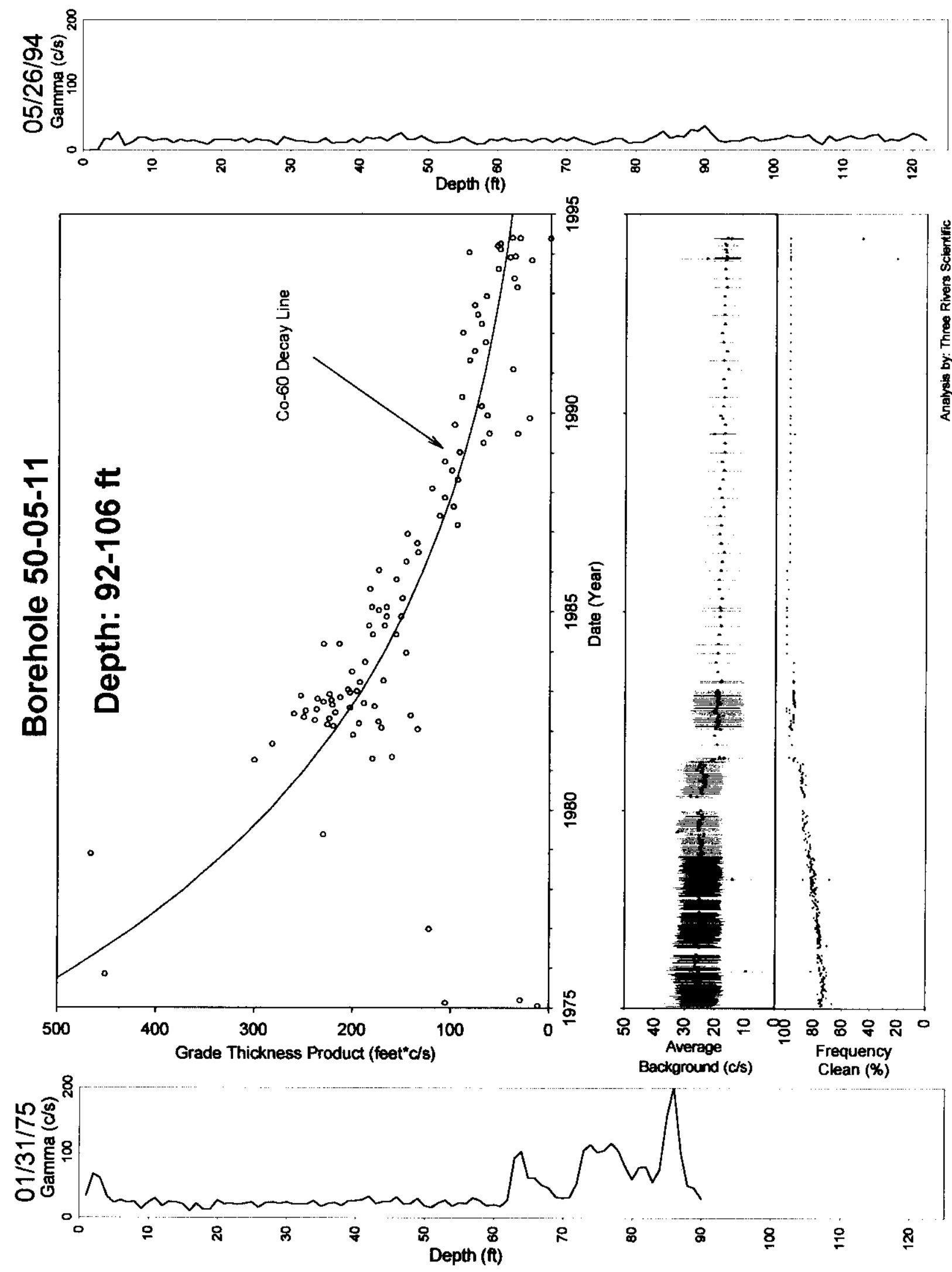

Tank T-105

Page 211 
RPP-6088, Rev.0.

\section{Tank T-106 Wells}

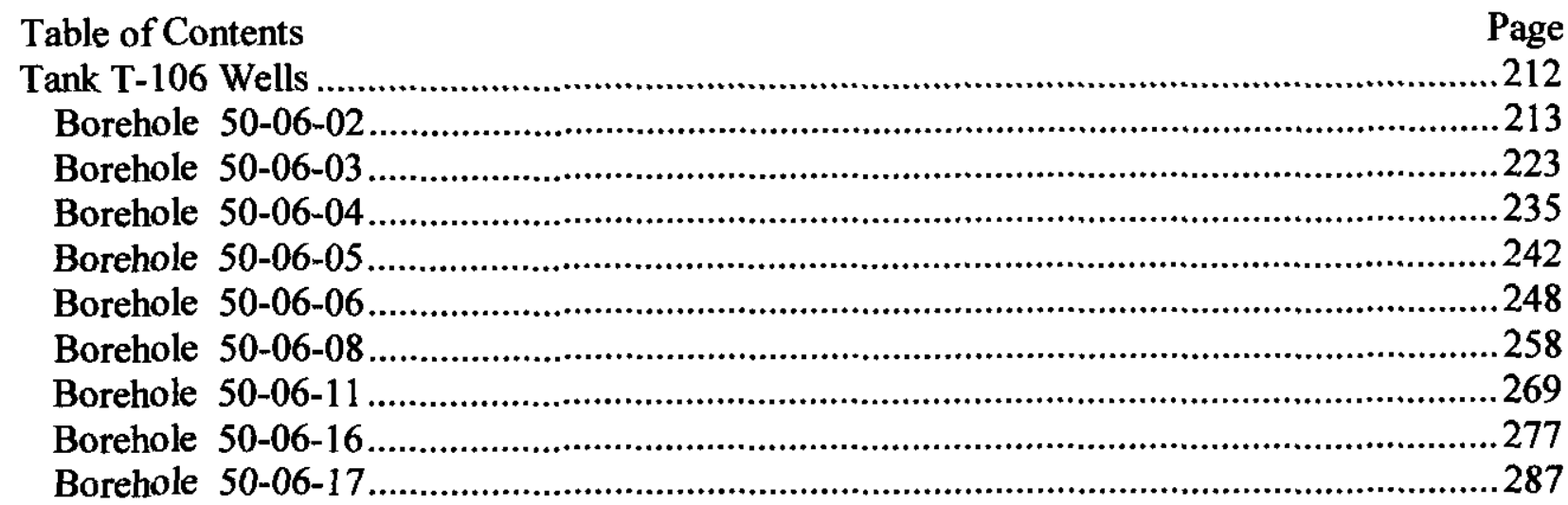

This section contains the analysis results for vadose zone boreholes (dry wells) associated with Tank 106 in the "T" Tank Farm.

Special Note: (none) 


\section{Borehole 50-06-02}

\section{Contamination (Co-60, Eu-154, Ru-106) from 38 to 100 feet is Stable. Contamination (Ru-106) from 100 to 124 feet is Unstable Early.}

Grade thickness product (GTP) over 38 to 100 feet is decreasing consistent with decay of Co-60 and Eu-154 (both HPGe identified), and Ru-106 (hypothesis) and is characterized as stable. The ratio of gross contribution from Co-60 to Eu-154 to Ru-106 is 10400:19400:4 as of 1-1-1996. Three probe types (02:Red GM, 14:Shielded NaI, and $04: \mathrm{NaI})$, were required to monitor the contamination interval due to the high rate of change of activity from 1975 to 1980 . The GTP plot for each probe type is included. The early surveys (1975-1978) for probe type 04 are invalid due to detector saturation in the high count rate interval. The decay line on the GTP plot for probe types 02 and 14 show that Ru-106 alone fits the limited time span of the survey data.

Grade thickness product over 100 to 124 feet is decreasing consistent with a least square fit for a constant background and Ru-106 (hypothesis) from 1979 to 1995 . The ratio of gross contributin from the background to Ru-106 is $2170: 1$ as of 5-24-1994. Before 1979, the GTP computed from the gross gamma response for both probe types 14:Shielded NaI (16 surveys) and 04:NaI (2 surveys) is decreasing at a rate that is greater than the decay of Ru-106 with a short half life decay of 1.02 years. The category is unstable early. The borehole depth was extended from 95 to 124 feet after the 05-1977 survey.

Gross Gamma Survey Information

\begin{tabular}{|r|l|}
\hline Probe Type Processed: & 02: Red GM, 04: NaI, \& 14: Shielded NaI \\
\hline Other Probe Types : & $01:$ Green GM \& 03: Neutron \\
\hline Survey Depth : & $125 \mathrm{ft}(95 \mathrm{ft}$ before 05/1977) \\
\hline First Survey Date : & $02: 1 / 15 / 1975,04: 1 / 13 / 1975, \quad 14: 12 / 03 / 1976$ \\
\hline Last Survey Date : & $02: 10 / 17 / 1978,04: 5 / 24 / 1994,14: 9 / 03 / 1980$ \\
\hline Number Surveys Processed: & $02: 49,04: 82, \& \quad 14: 76$ \\
\hline
\end{tabular}

Analysis Notes

\begin{tabular}{|r|l|}
\hline Method Used to Compute Background : & $10-30$ feet \\
\hline Depth(s) where Contamination was & $38-100$ feet Stable \\
Identified in Gross Gamma Surveys : & $100-124$ feet Unstable Early \\
\hline Analyst Name : & R. K. Price \\
\hline Company Name : & Three Rivers Scientific \\
\hline
\end{tabular}


RPP-6088, Rev.0.

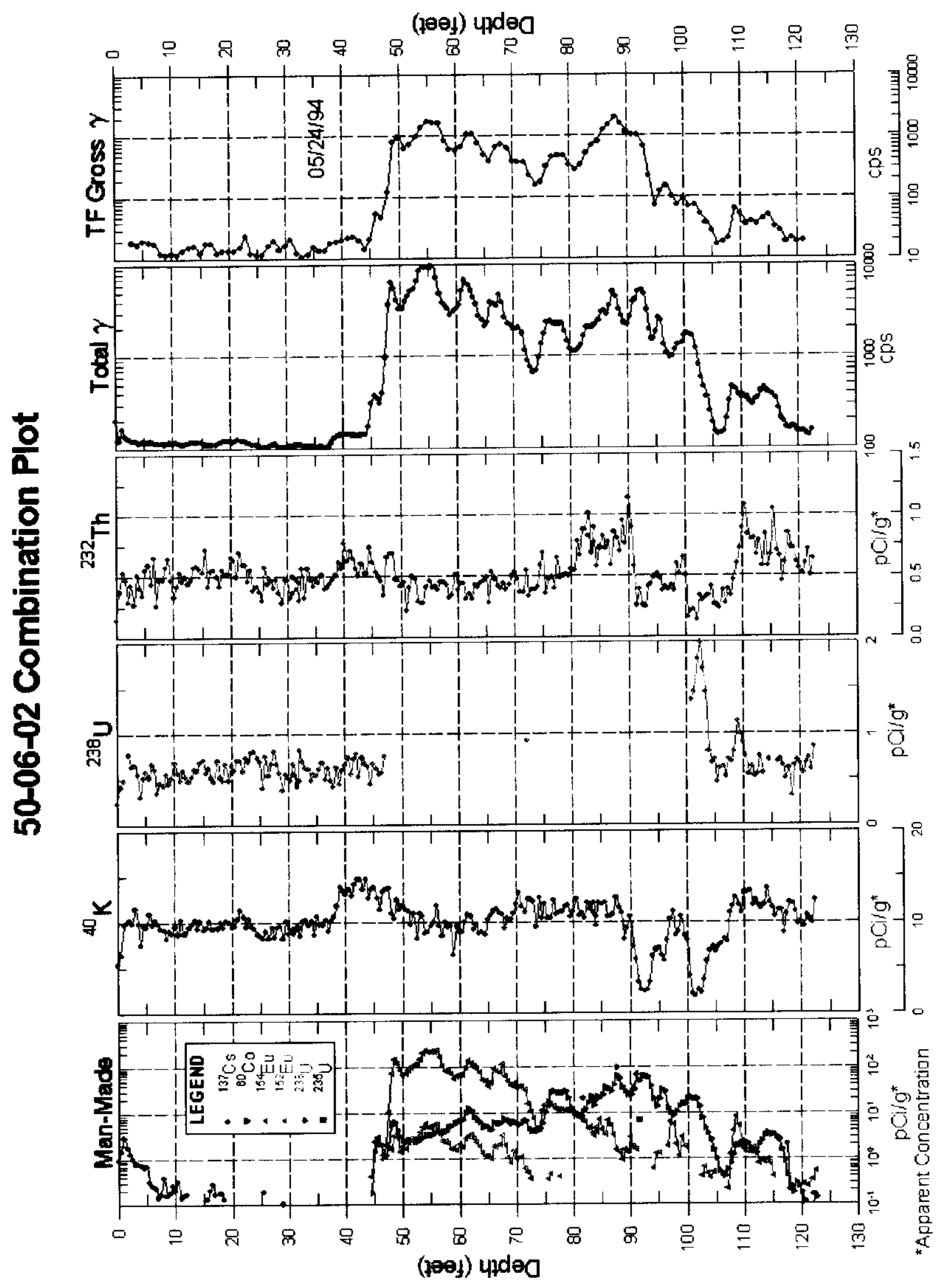


RPP-6088, Rev.0.

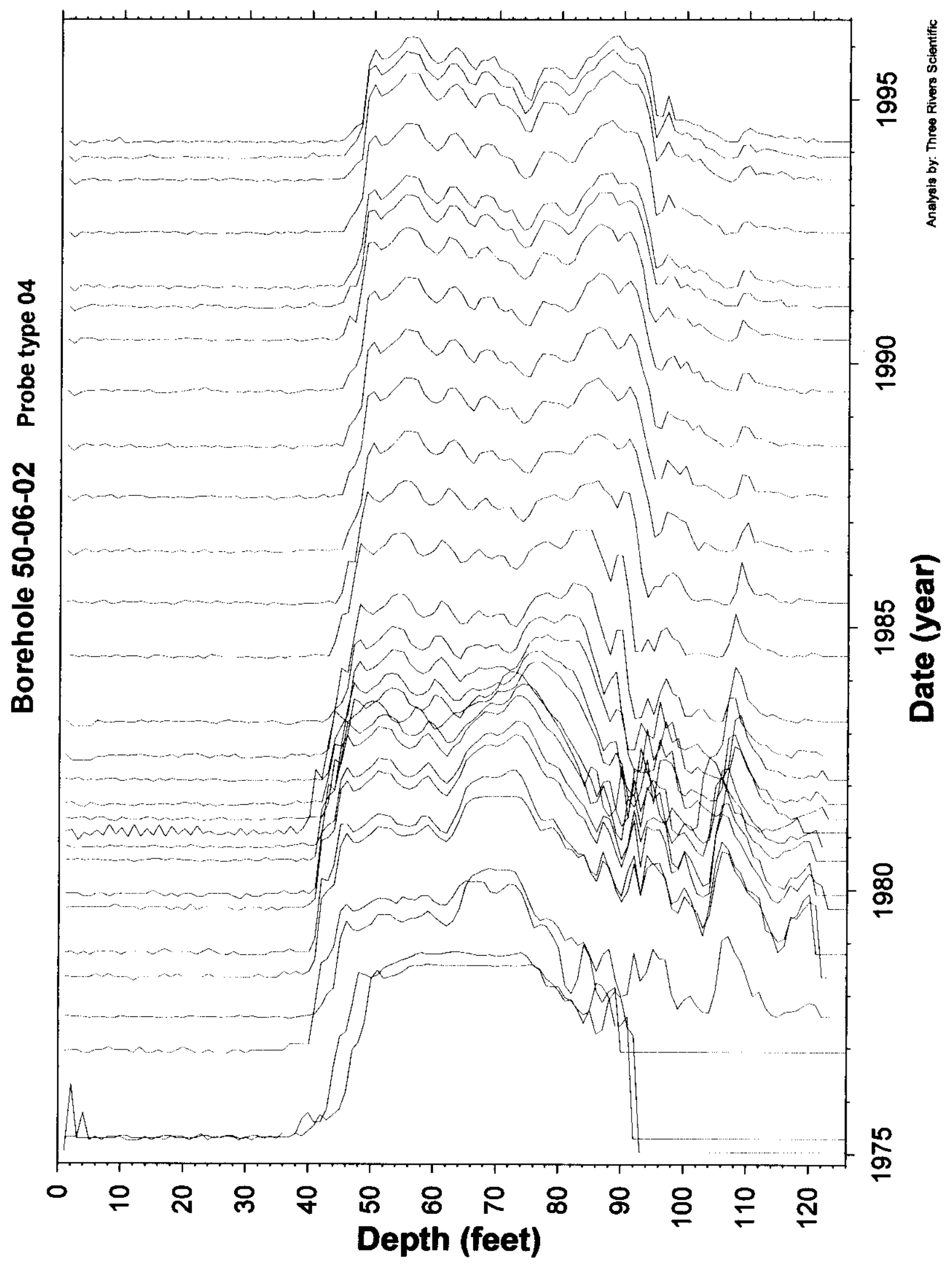

Tank T-106

Page 215 
RPP-6088, Rev.0.

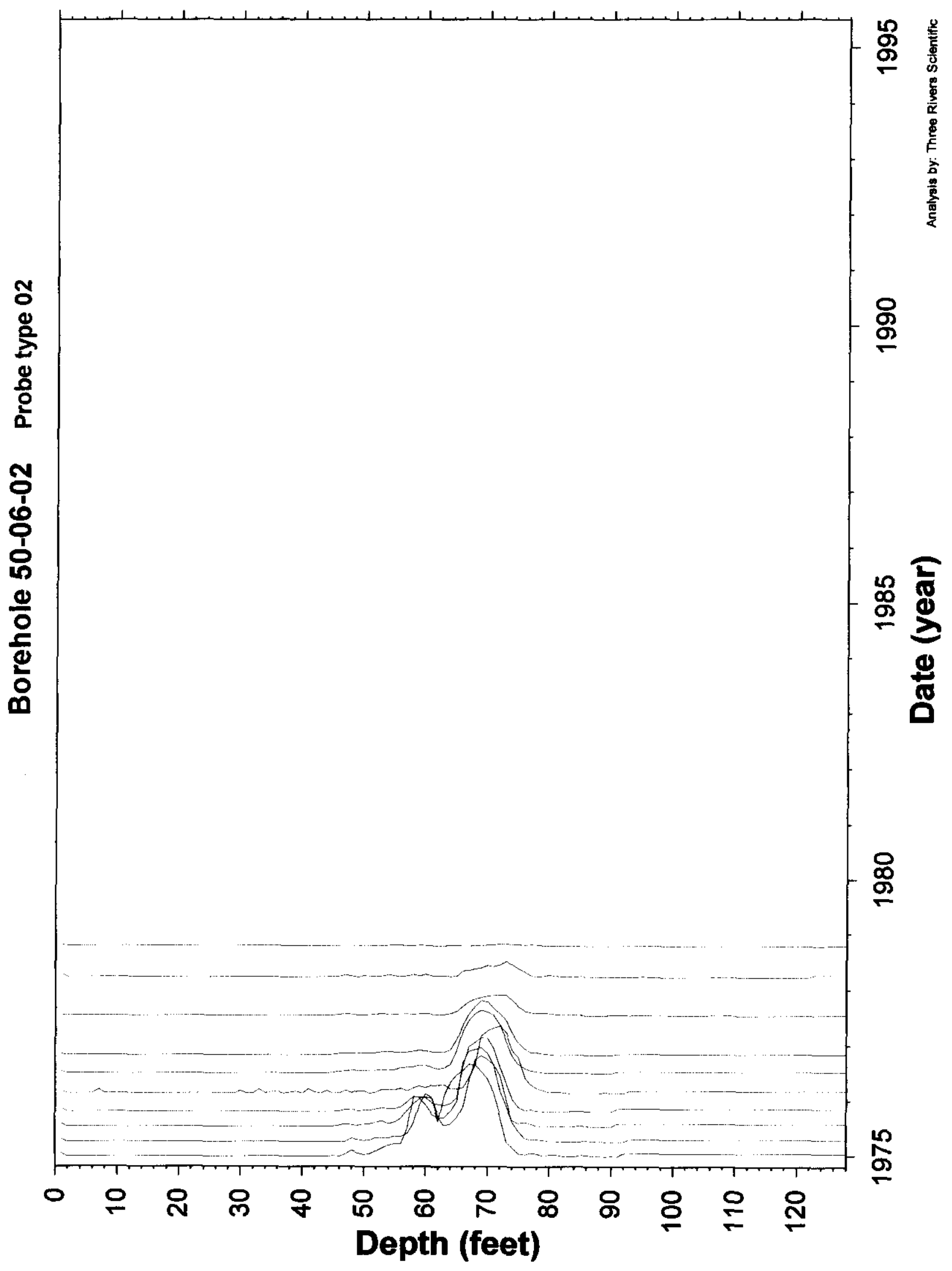

Tank T-106

Page 216 
RPP-6088, Rev.0.

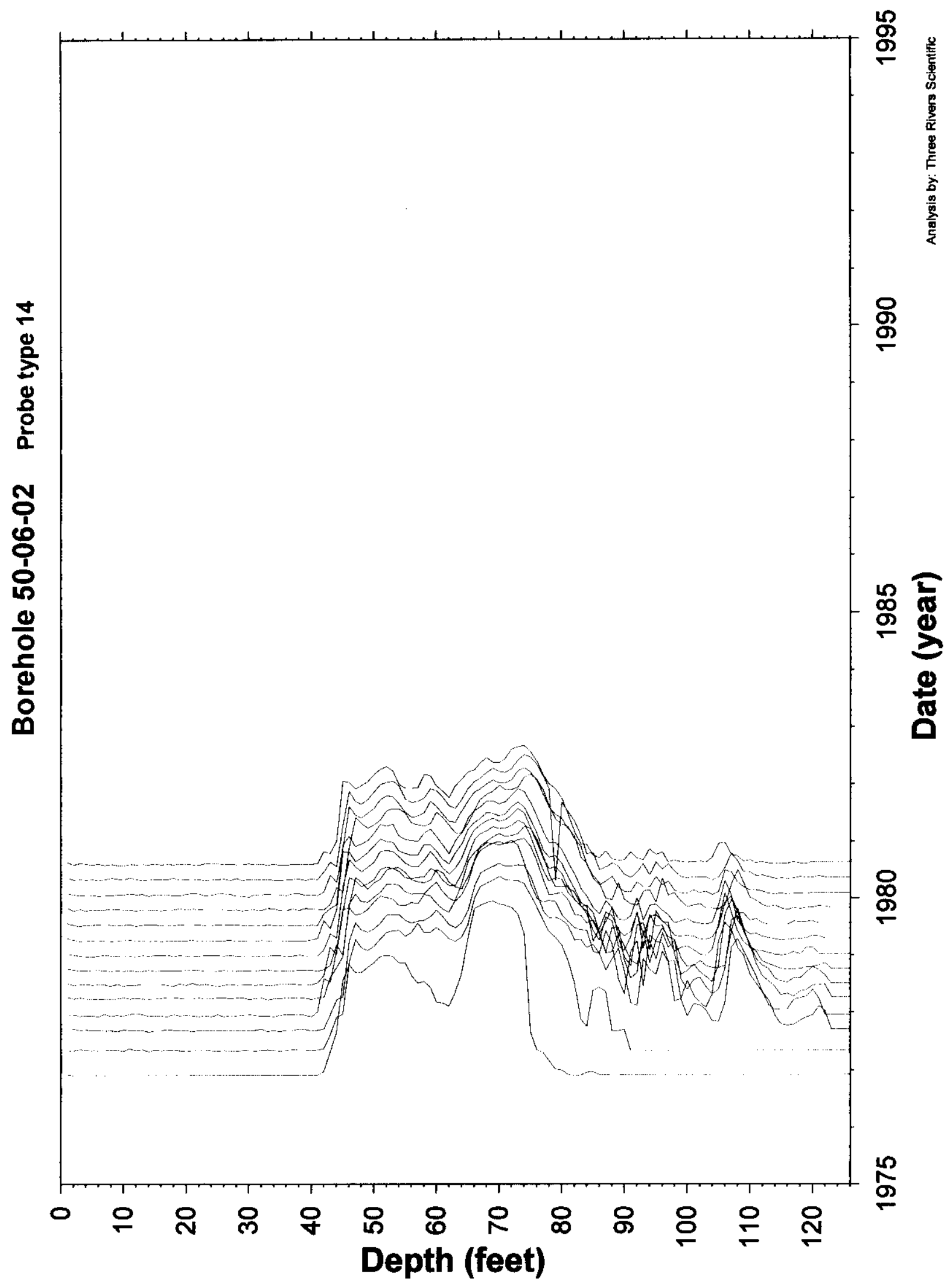

Tank T-106

Page 217 
RPP-6088, Rev.0.
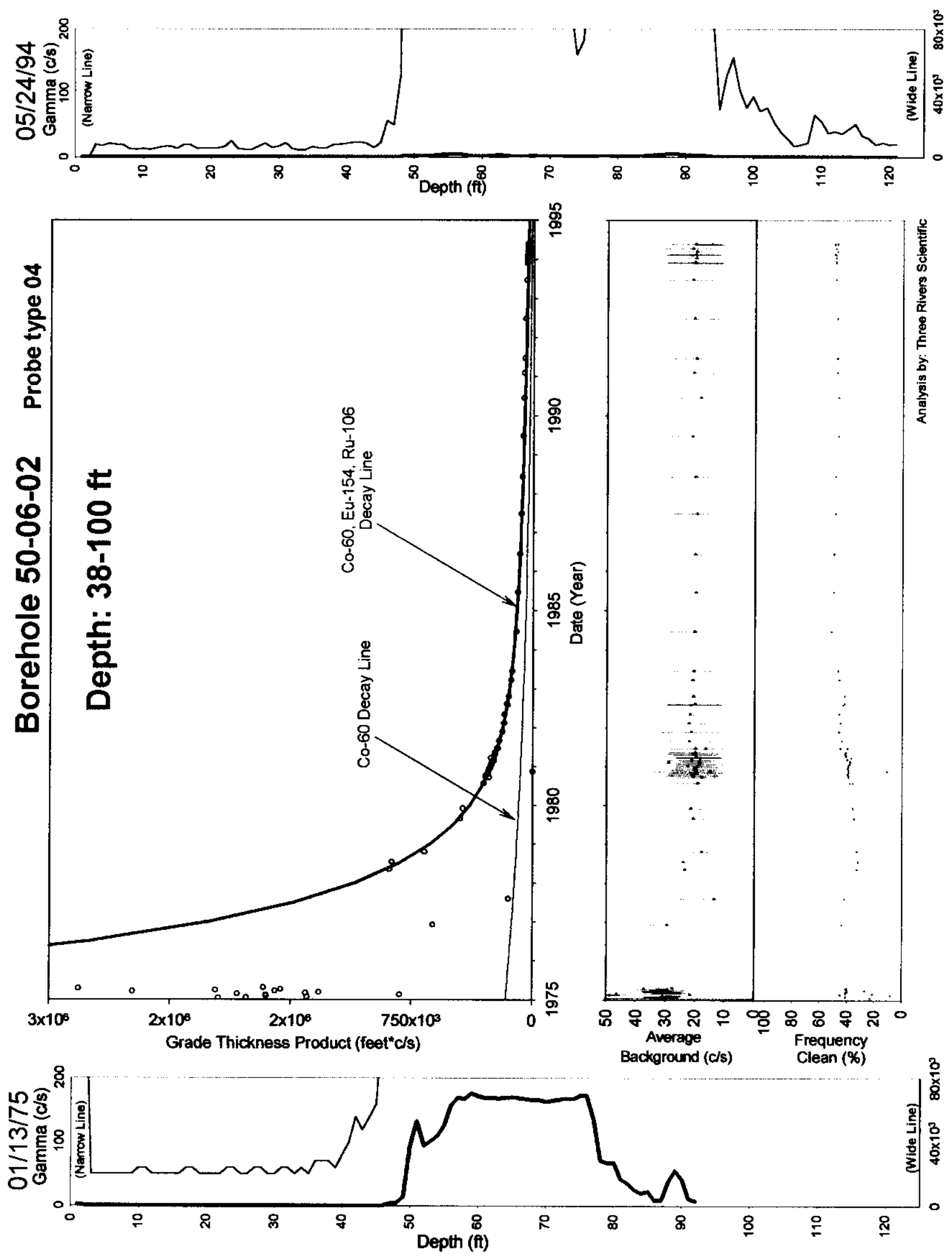

Tank T-106

Page 218 
RPP-6088, Rev.0.
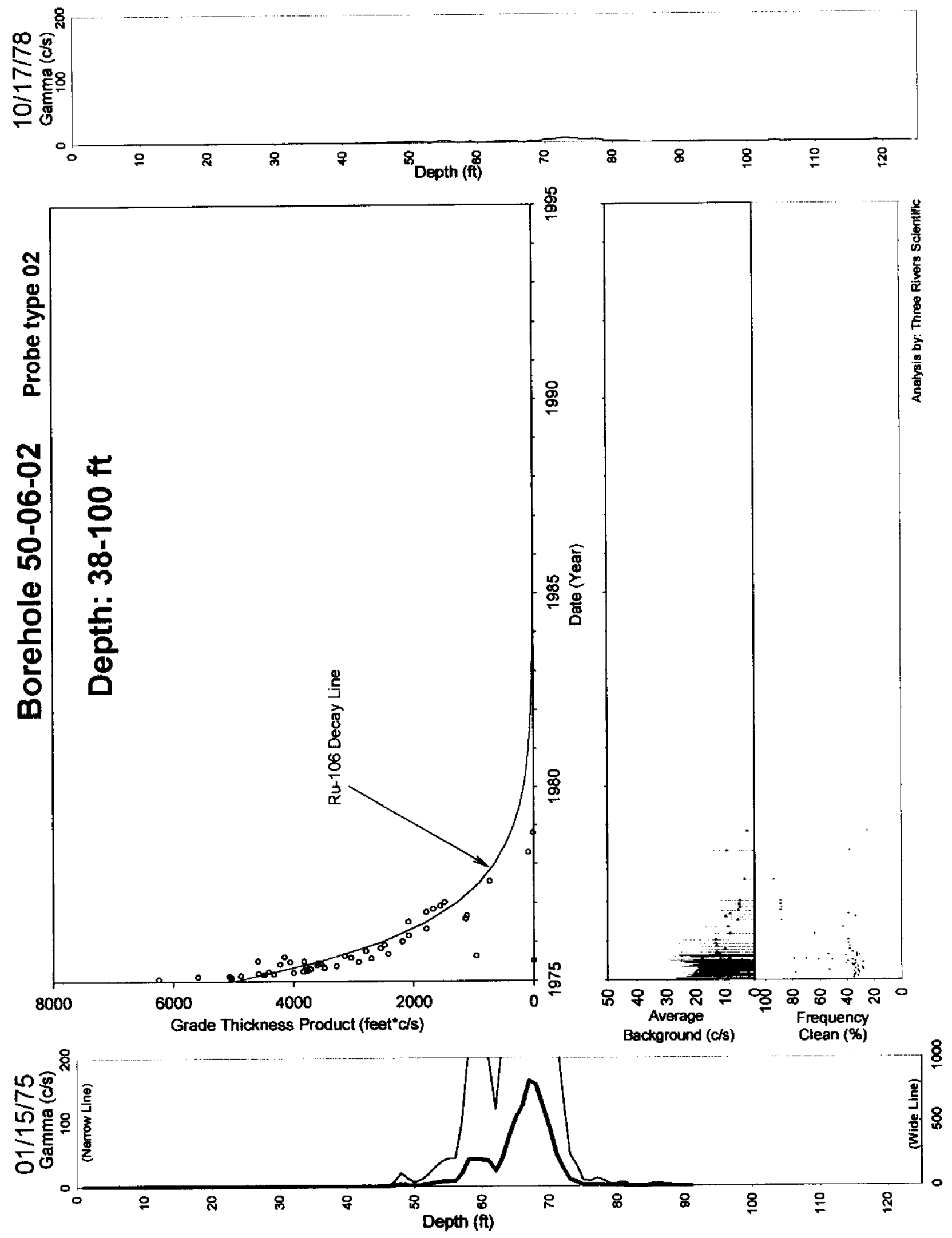

Tank T-106 
RPP-6088, Rev.0.
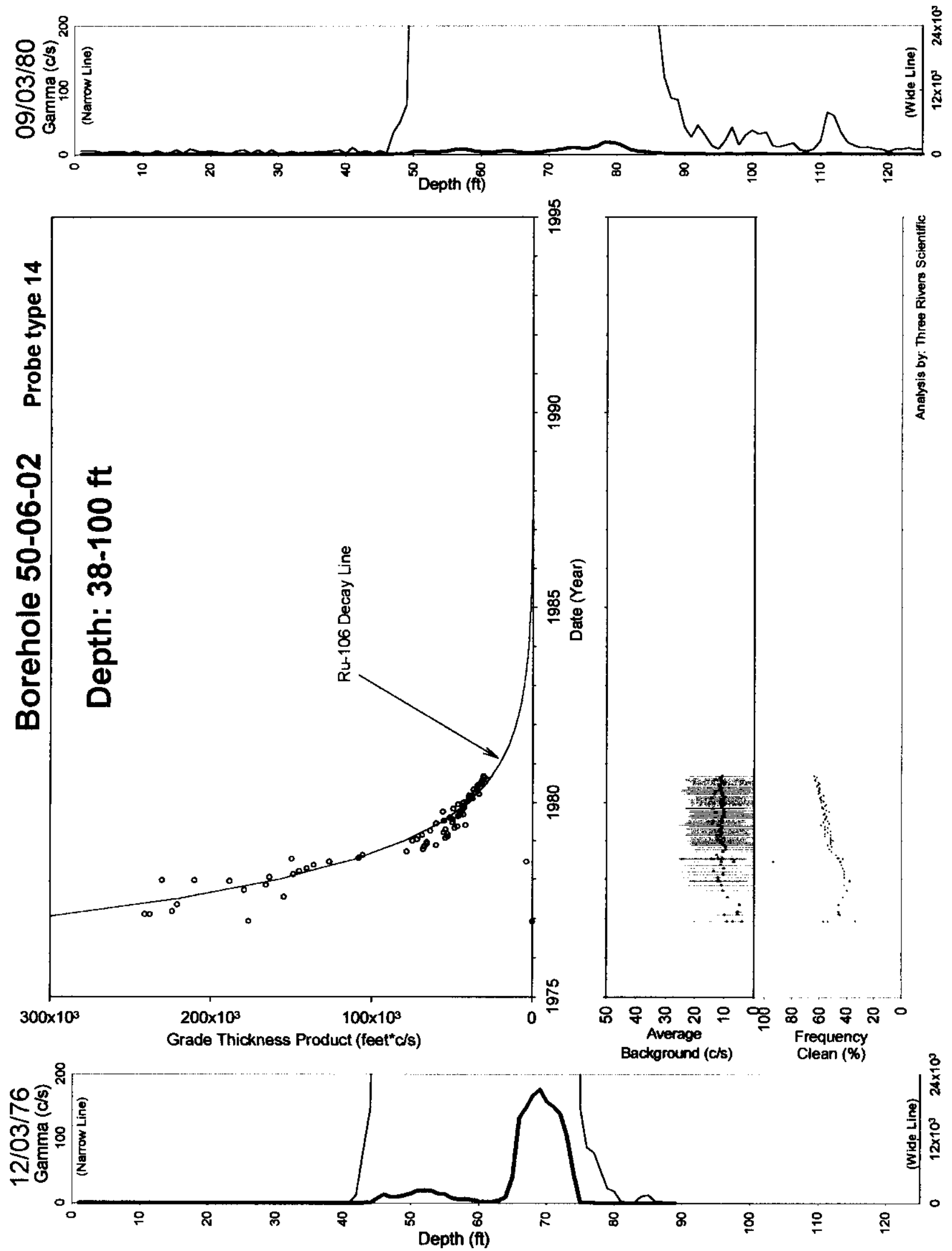

Tank T-106 
RPP-6088, Rev.0.
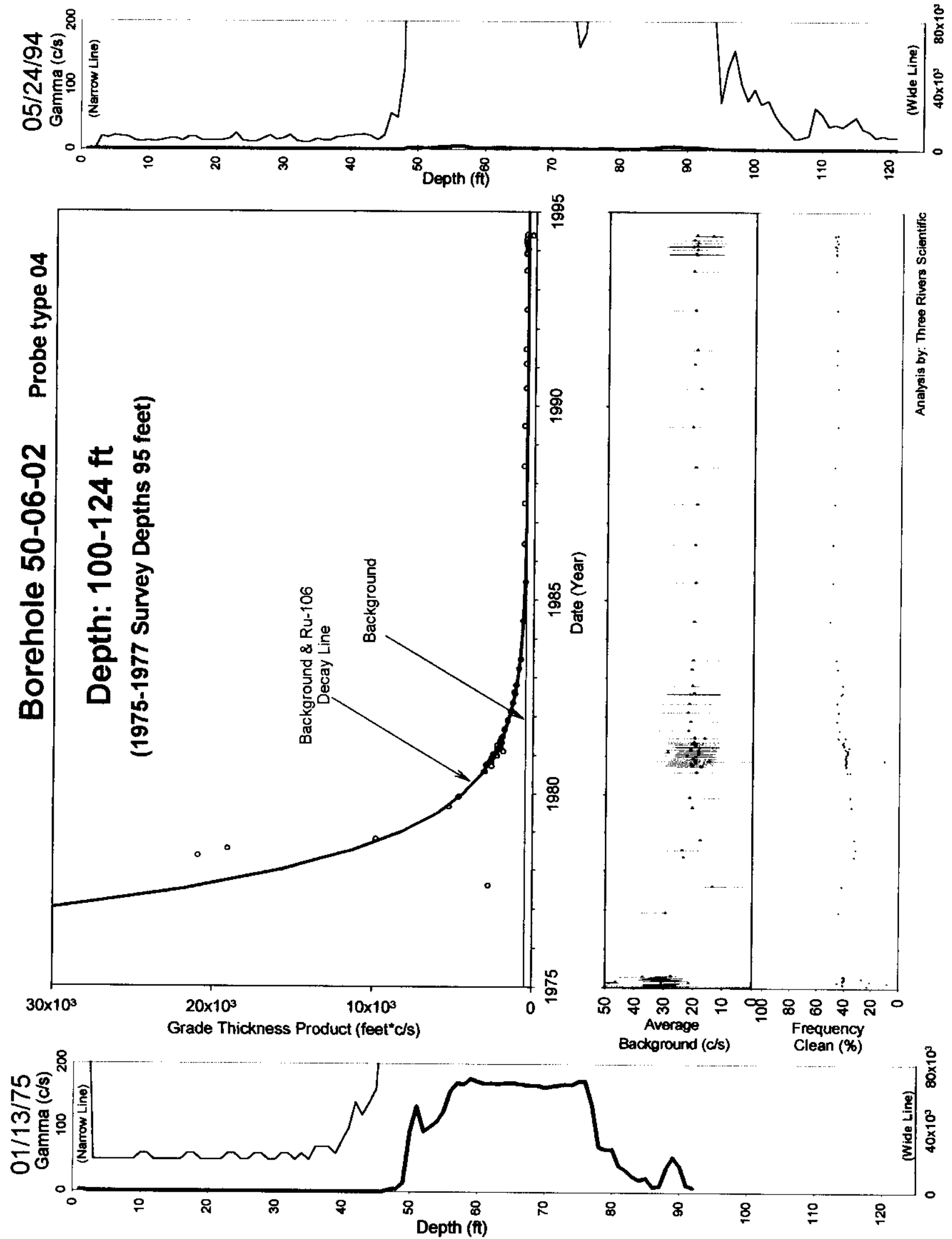

Tank T-106 
RPP-6088, Rev.0.
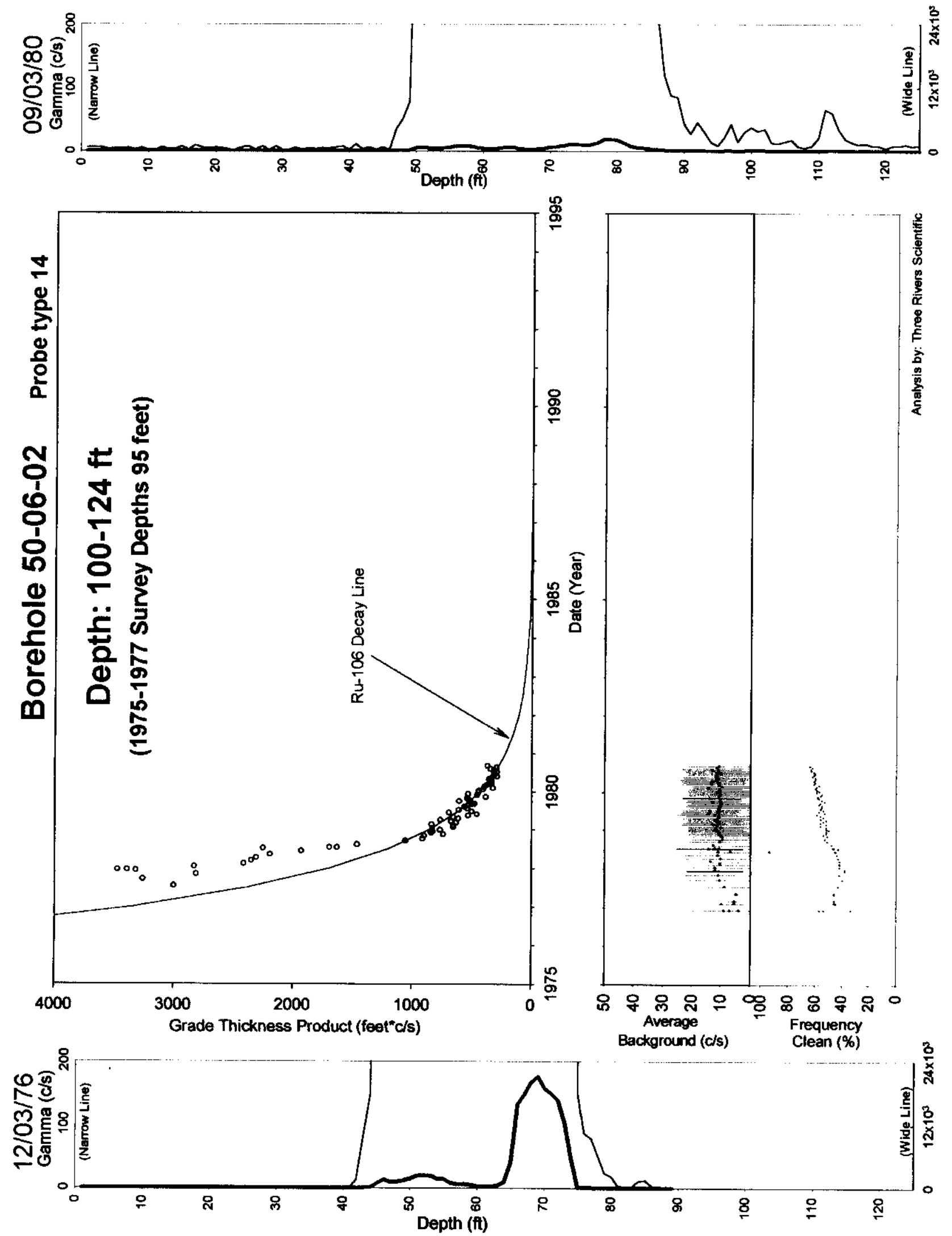

Tank T-106 


\section{Borehole 50-06-03}

Contamination (Cs-137) from 16 to 24 feet is Stable.

Contamination (Co-60, Ru-106) from 30 to 60 feet is Unstable Early. Contamination (Co-60, Ru-106) from 60 to 98 feet is Unstable Early. Contamination (Co-60, Eu-154, Ru-106) 98-120 feet is Unstable Early.

Grade thickness product (GTP) over 16 to 24 feet is low level and is decreasing consistent with the decay of Cs-137 (HPGe identified).

Tank farms used three probe types (02:Red GM, 14:Shielded NaI, and 04:NaI) to monitor the high levels of contamination. The GTP plots are included for relevant probe types. Probe type 02 had multiple sensitivity configurations (1975-1978) which complicates contaminant stability analysis. Early surveys (1975-1980) of probe type 04 are invalid due to detector saturation.

Grade thickness product over 30 to 60 feet after 1979 is decreasing consistent with a least square fit for Co-60 (HPGe identified) and Ru-106 (hypothesis). The GTP for probe type 14 shows prior to 1979 that the rate of decrease is greater than the decay of Ru-106 (1.02 year half life). The ratio of gross contribution for Co-60 to Ru-106 is $1137: 1$ as of $11-26-1993$ for probe type 04 . This zone is categorized as unstable early.

Grade thickness product over 60 to 98 feet after 1980 is decreasing consistent with a least square fit for Co-60 (HPGe identified) and Ru-106 (hypothesis). Prior to 1980 the GTP for probe type 14 has a poor agreement with the fitted decay line. The ratio of gross contribution from Co- 60 to $\mathrm{Ru}-106$ is $276: 1$ as of $11-26-1993$ (04 probe). This zone is categorized as unstable early.

Grade thickness product (98 to $120 \mathrm{ft}$ ) after 1985 is decreasing consistent with a least square fit for Co-60 and Eu-154 (both HPGe identified), and Ru-106 (hypothesis). Between 1980 and 1985 the GTP shows a slight increase that does not fit the projected decay line. The zone is categorized as unstable early. The gross ratio of gross contribution from Co-60:Eu-154:Ru-106 is 642:1819:0.1 on 1-1-1996. Before 1985 the GTP shows a rapid decrease that is much greater than the Ru-106 half life.

Gross Gamma Survey Information

\begin{tabular}{|c|c|}
\hline Probe Type Processed : & 04: NaI, \& 14: Shielded NaI \\
\hline Other Probe Types: & 02: Red GM, 01: Green GM \& 03: Neutron \\
\hline Survey Depth : & $120 \mathrm{ft}$ \\
\hline First Survey Date : & $02: 1 / 15 / 1975 \quad 04: 1 / 13 / 1975 \quad 14: 12 / 03 / 1976$ \\
\hline Last Survey Date : & $02: 1 / 14 / 1980 \quad 04: 11 / 26 / 1993 \quad 14: 5 / 24 / 1994$ \\
\hline Number Surveys Processed : & $\begin{array}{lll}02: 105 & 04: 49 & 14: 165\end{array}$ \\
\hline
\end{tabular}

Analysis Notes

Method Used to Compute Background : 5 5-16 feet

Depth(s) where Contamination was $16-24$ Stable;

Identified in Gross Gamma Surveys : $30-60,60-98,98-120$ feet Unstable Early

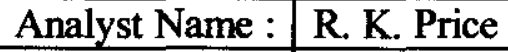

Company Name : Three Rivers Scientific 
RPP-6088, Rev.0.

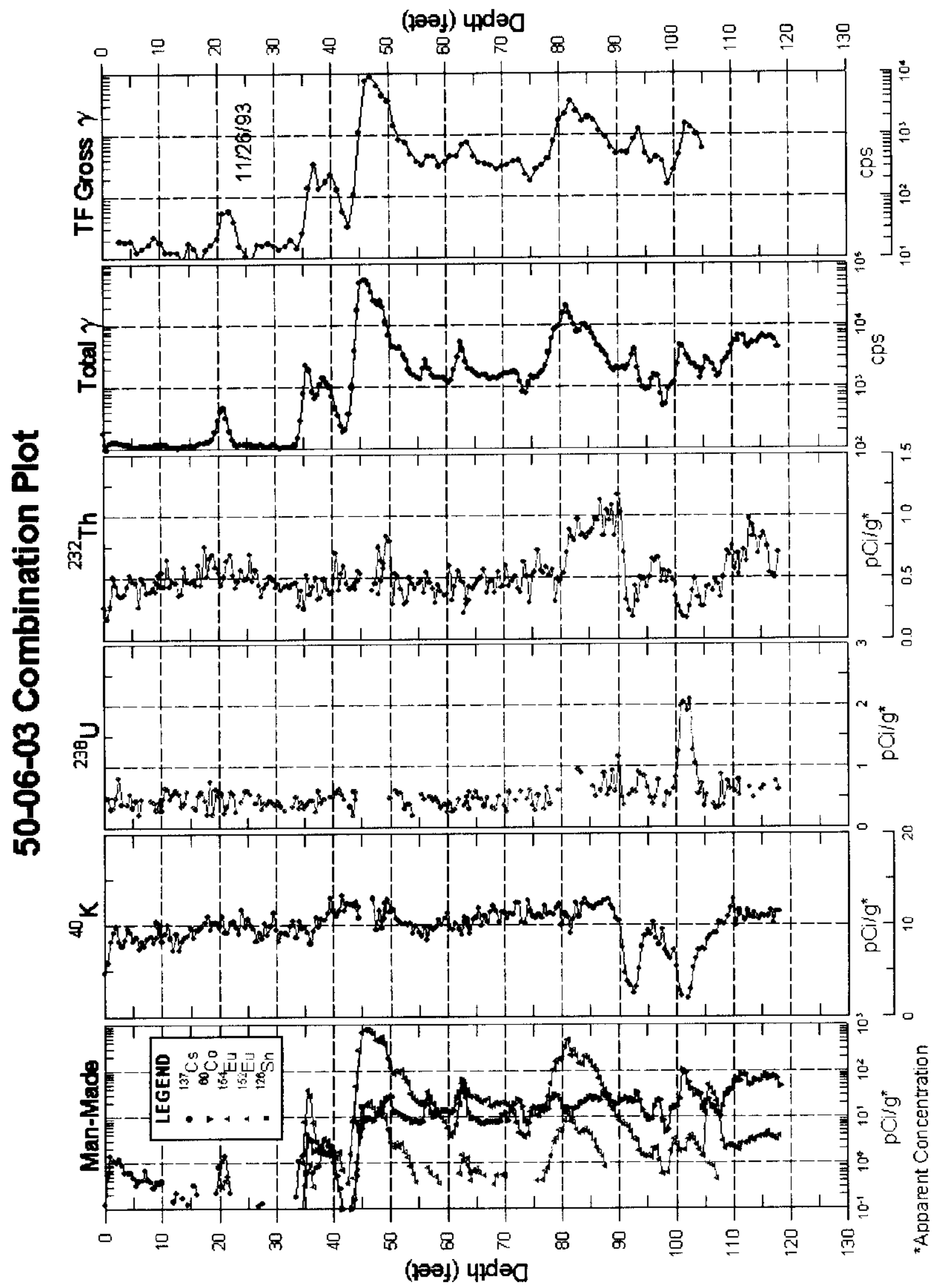


RPP-6088, Rev.0.

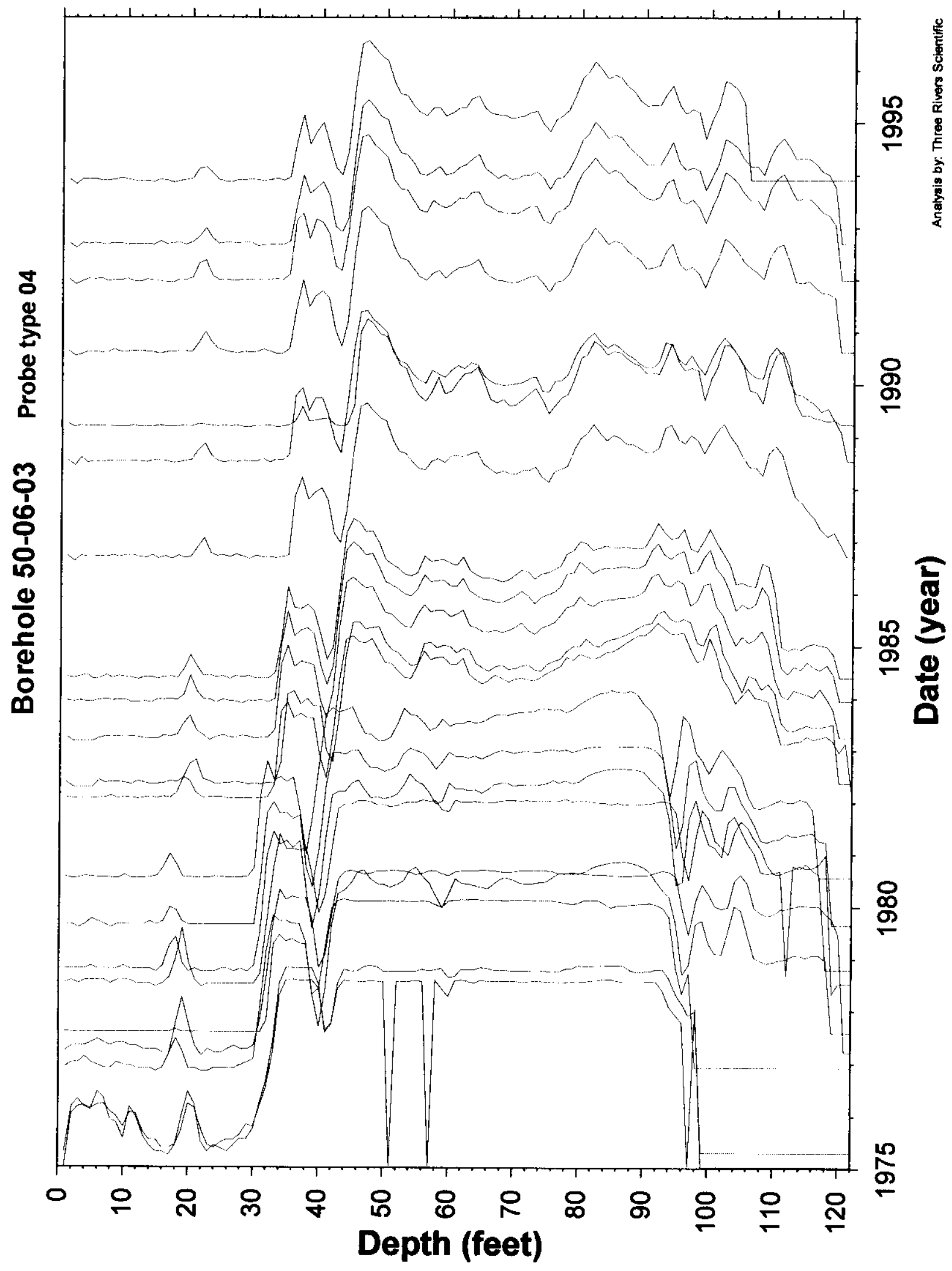

Tank T-106

Page 225 
RPP-6088, Rev.0.

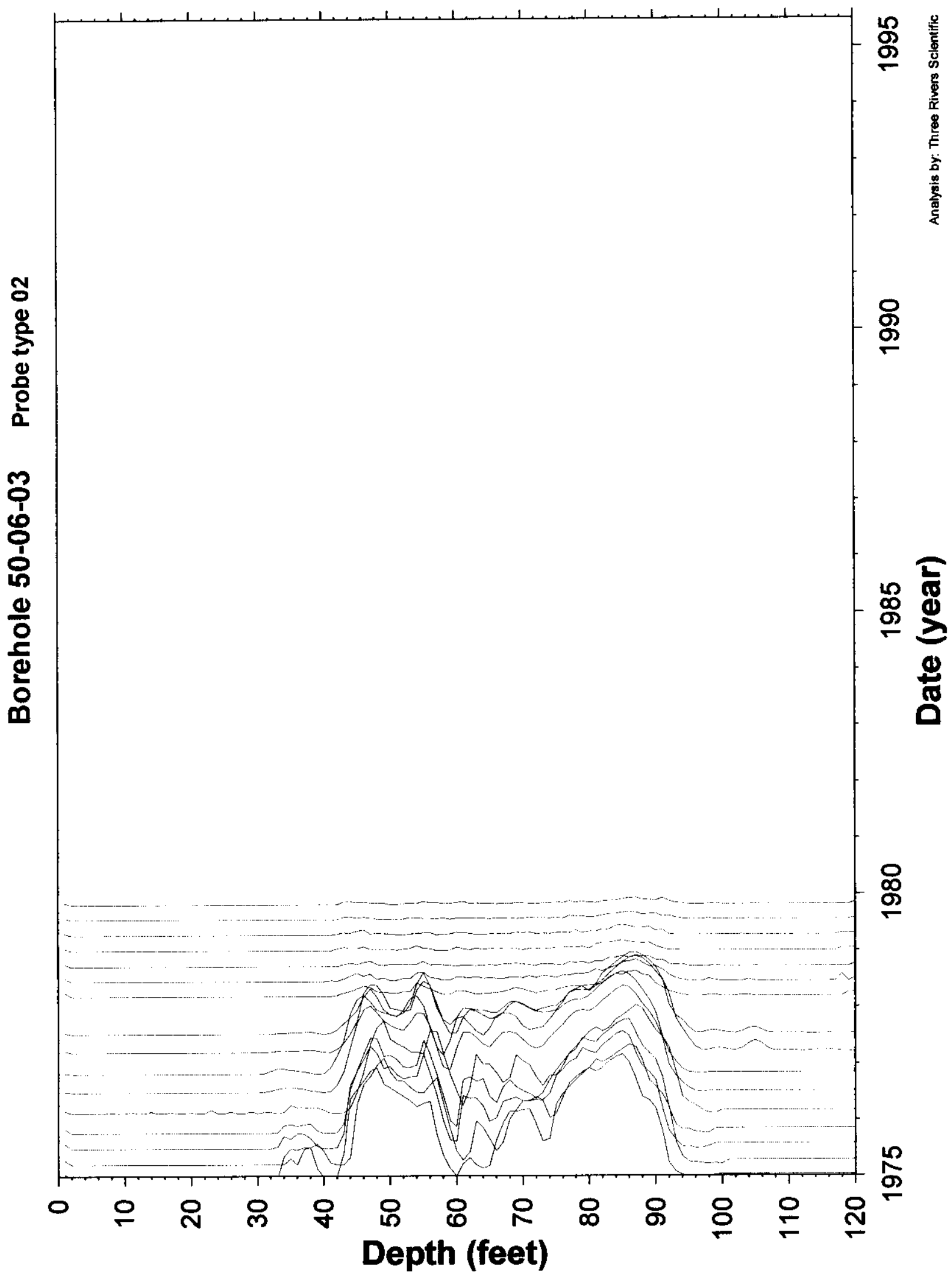

Tank T-106

Page 226 
RPP-6088, Rev.0.

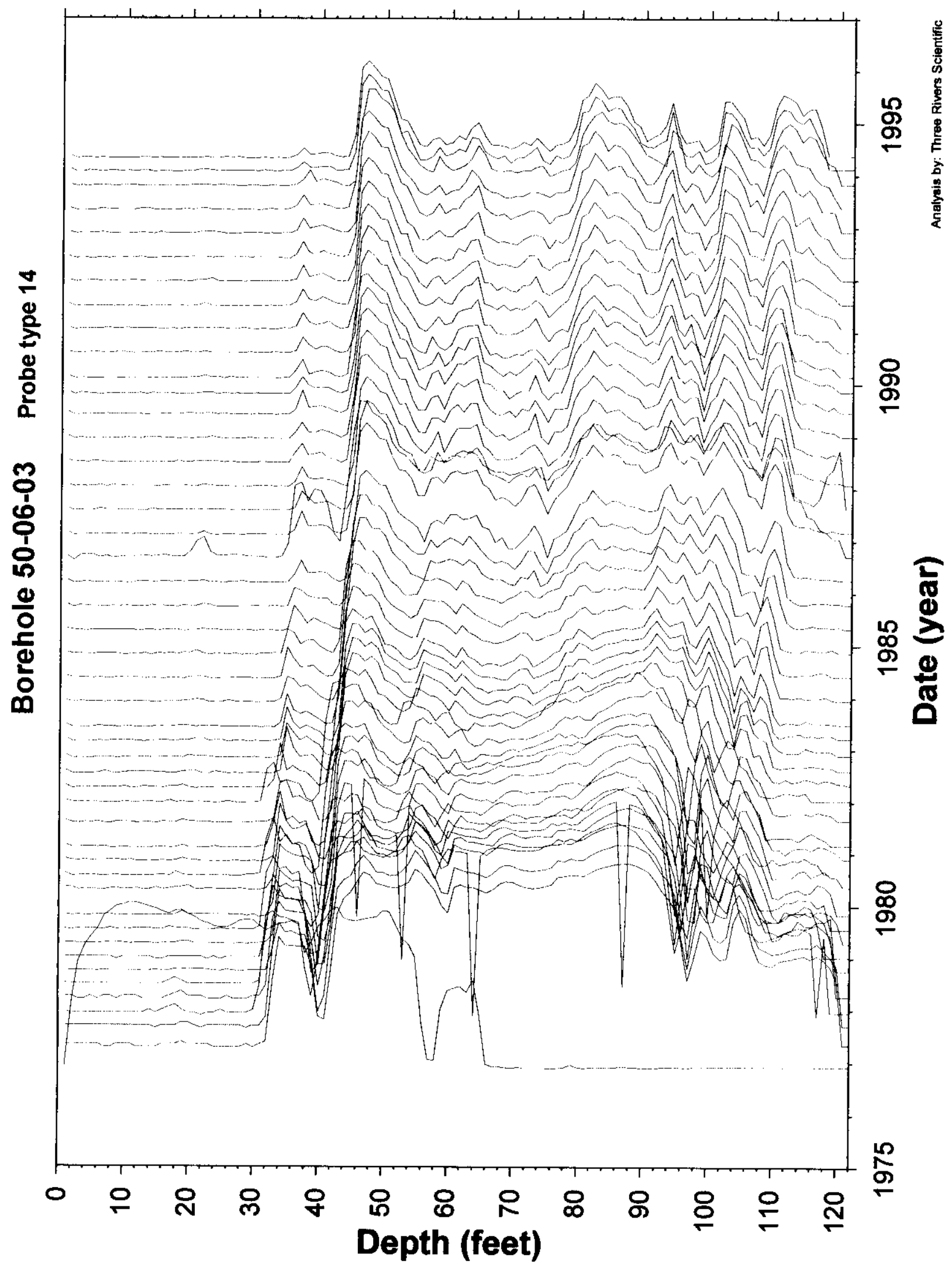

Tank T-106

Page 227 
RPP-6088, Rev.0.
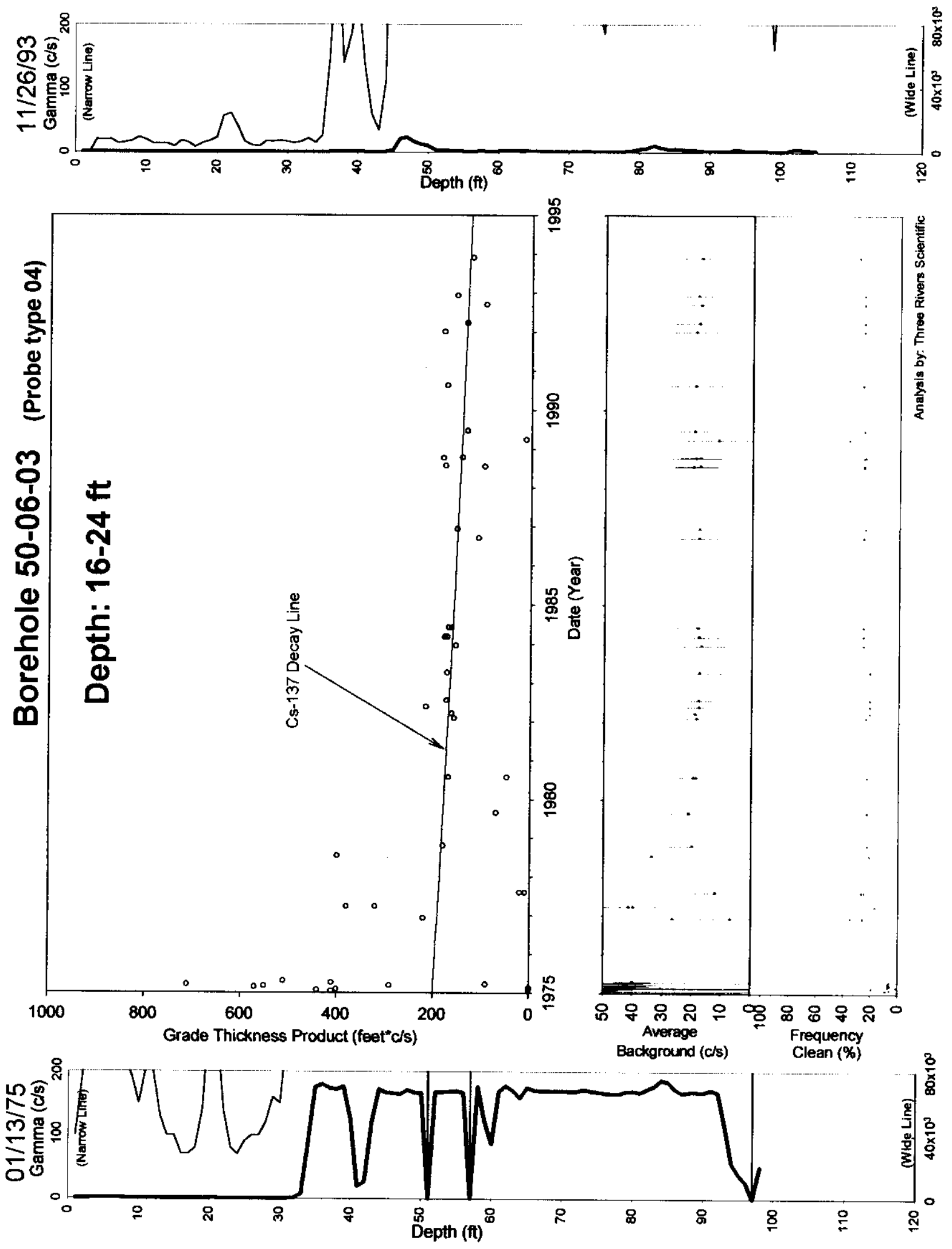

Tank T-106

Page 228 
RPP-6088, Rev.0.
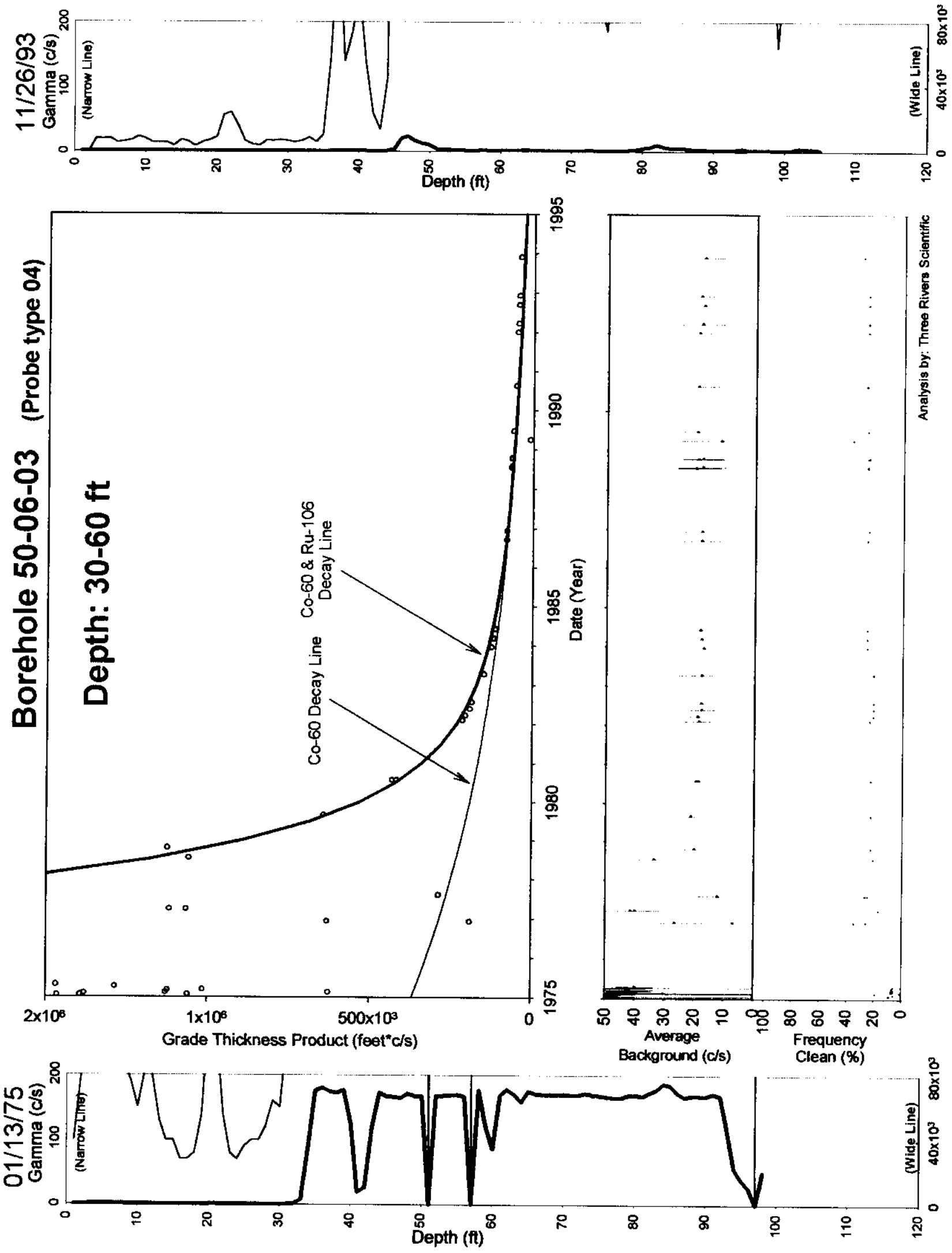

Tank T-106

Page 229 
RPP-6088, Rev.0.
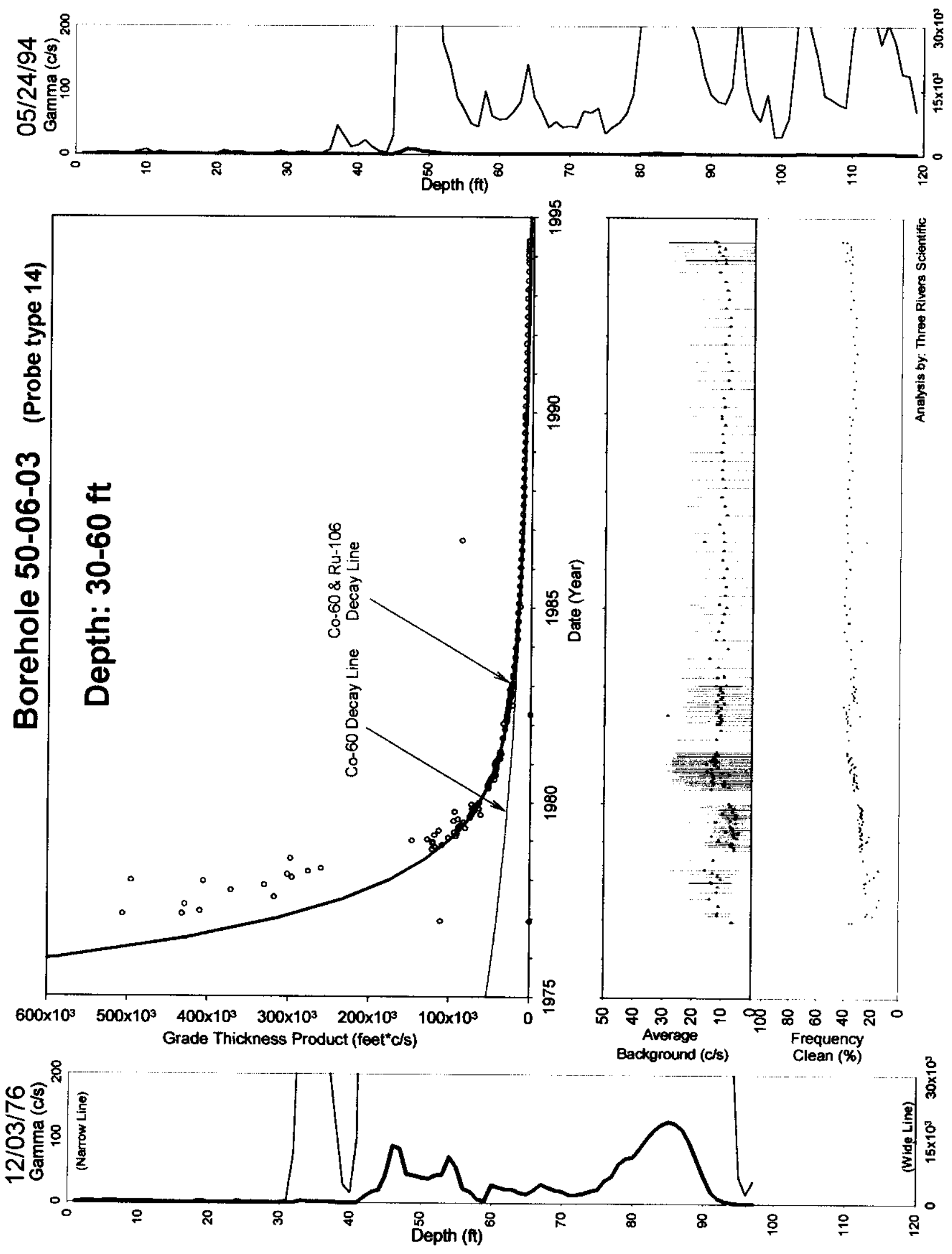

Tank T-106

Page 230 
RPP-6088, Rev.0.
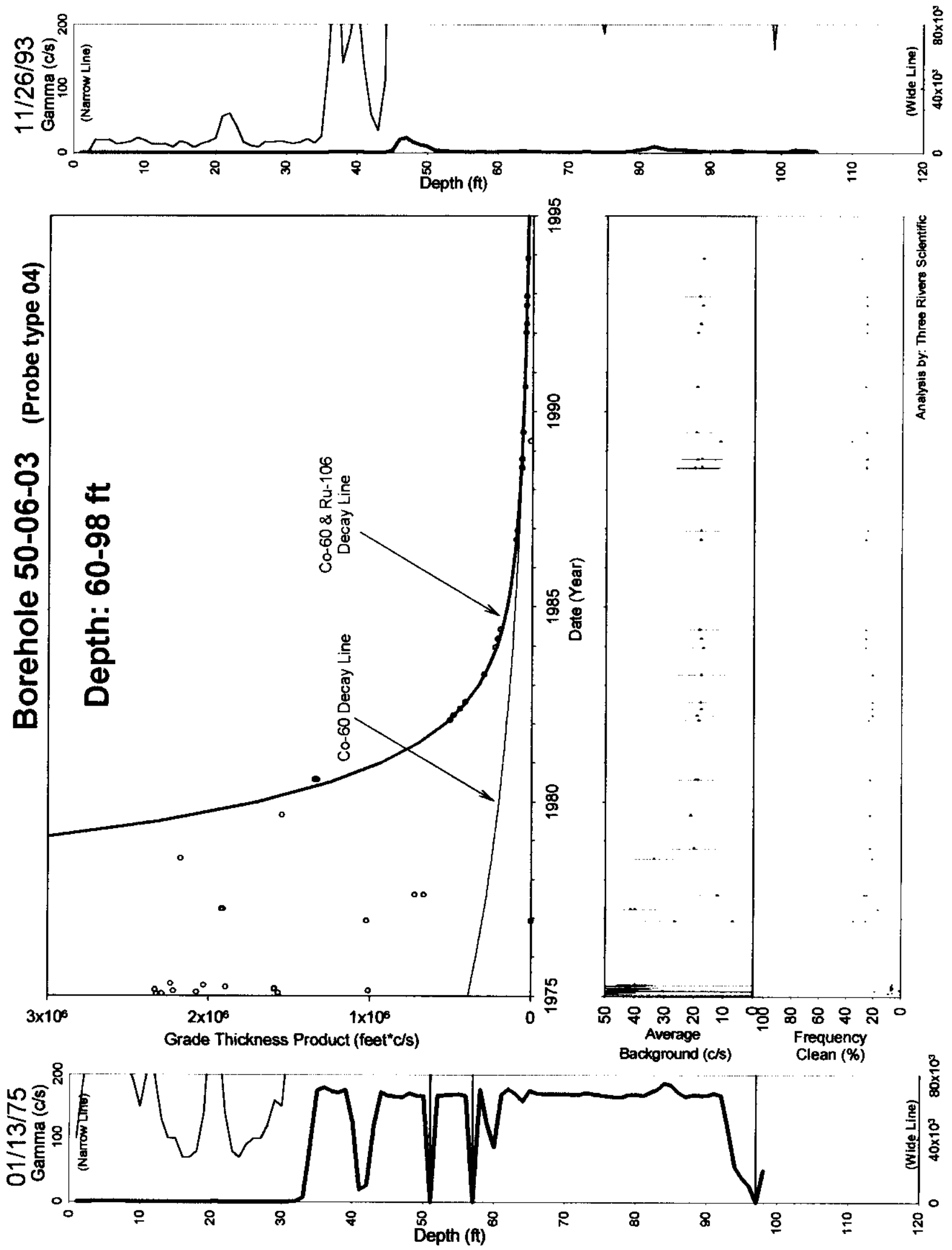
RPP-6088, Rev.0.
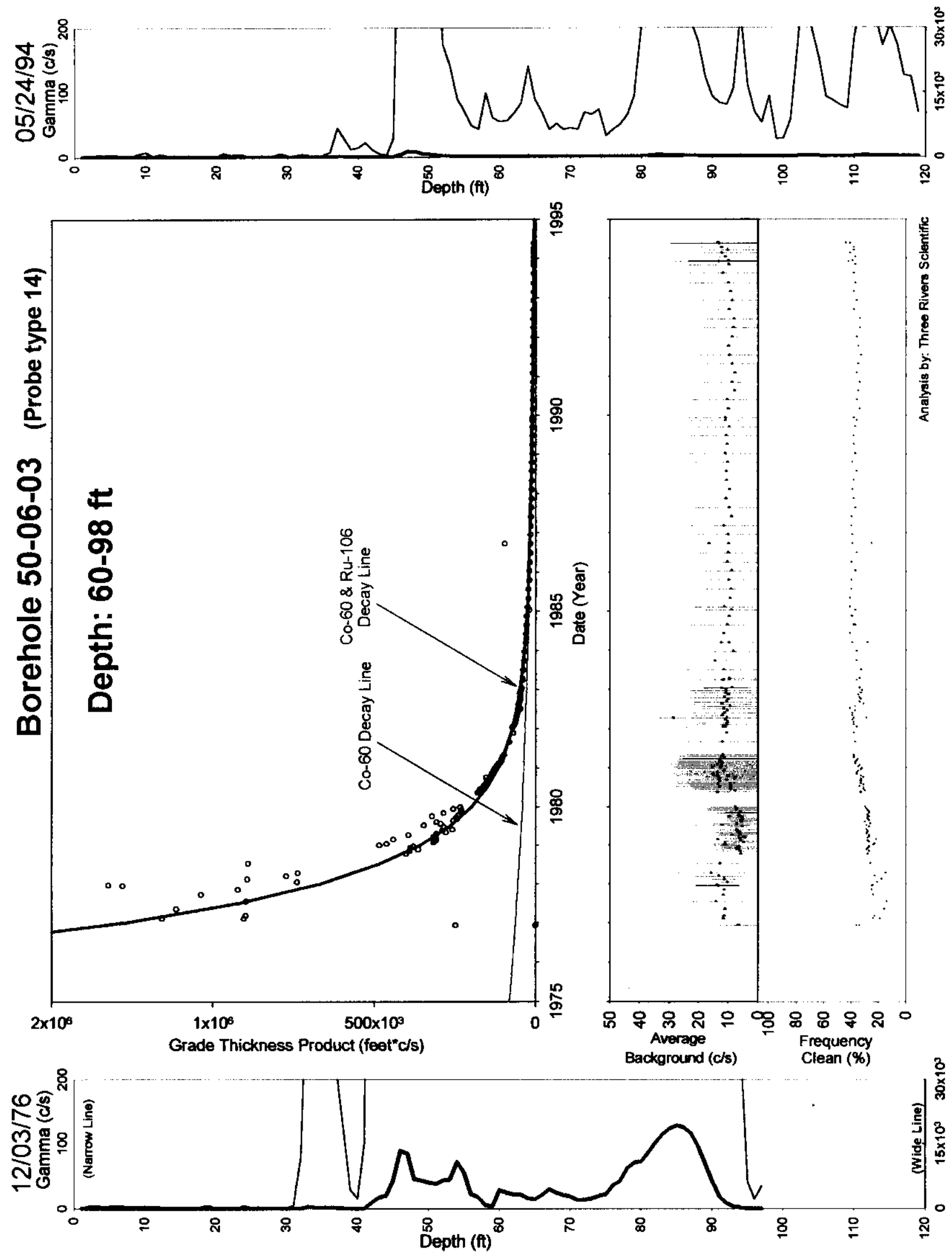

Tank T-106

Page 232 
RPP-6088, Rev.0.
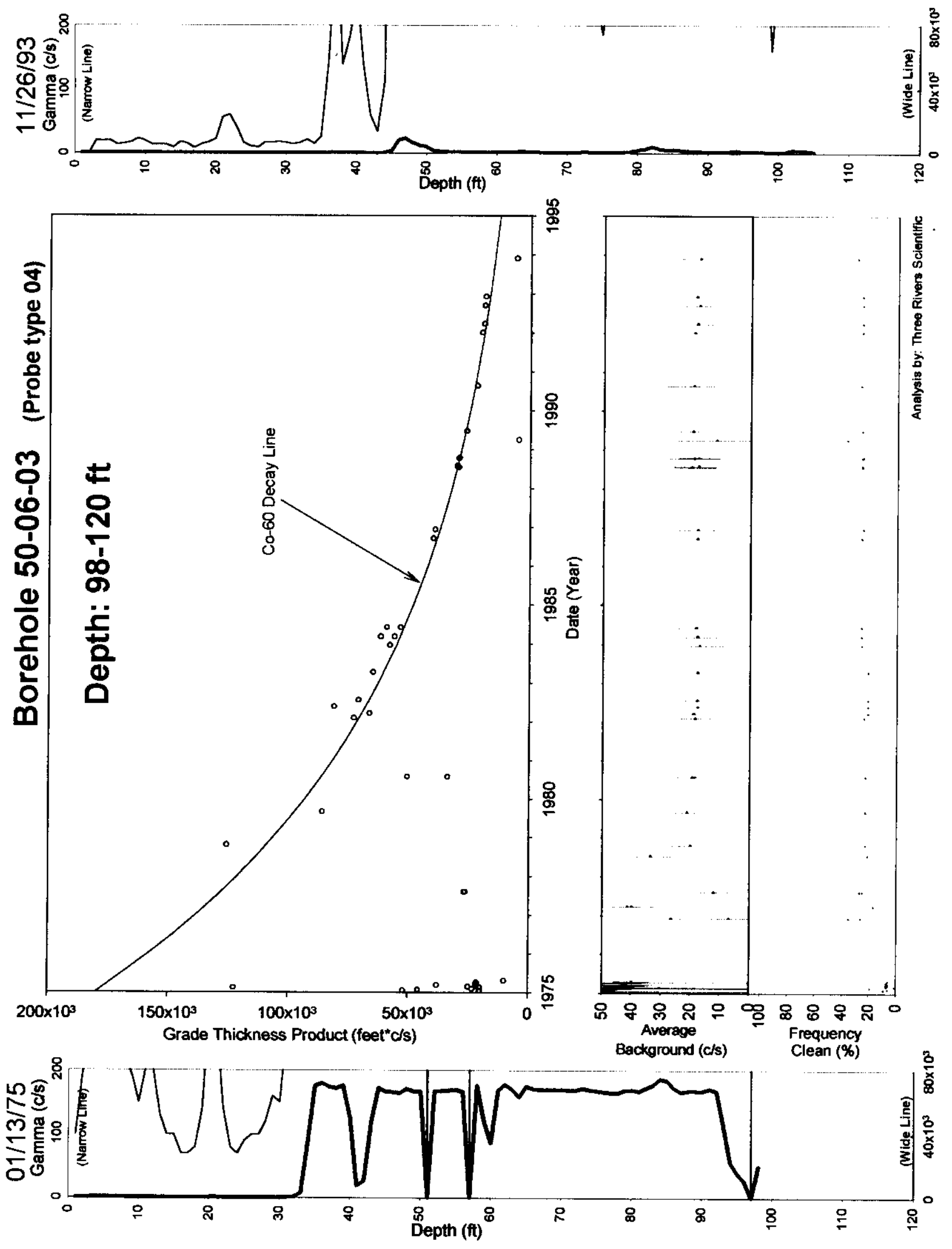

Tank T-106

Page 233 
RPP-6088, Rev.0.
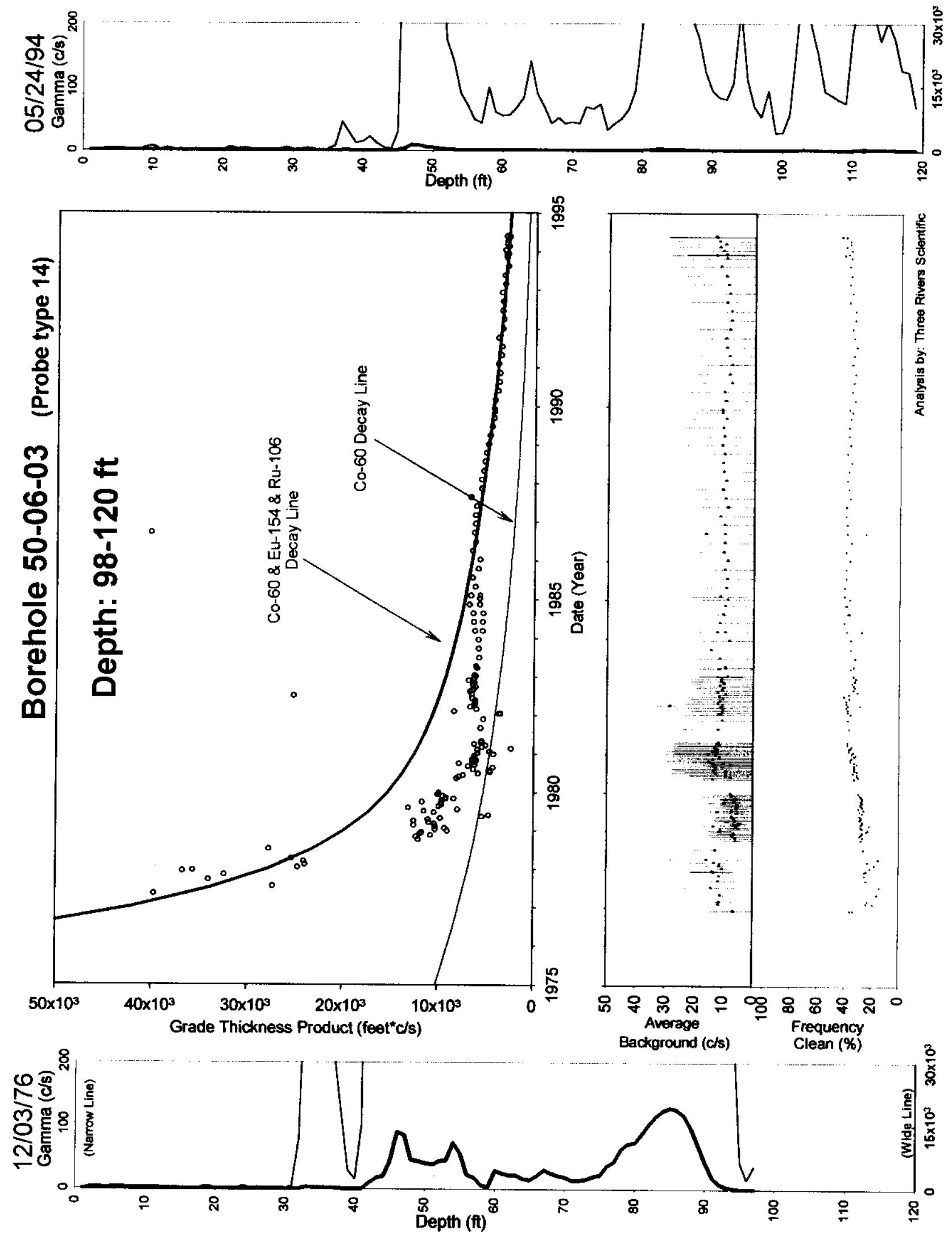
RPP-6088, Rev.0.

\section{Borehole 50-06-04}

\section{Contamination (Cs-137) from 29 to 42 feet is Stable. Contamination (Ru-106) from 42 to 66 feet is Undetermined. Contamination (Ru-106) from 66 to 90 feet is Undetermined.}

Probe type 02 had multiple sensitivity configurations (1975-1978) which complicates contaminant stability analysis (clearly shown in borehole 50-06-17). Probe type 04 (23 surveys between 1975 and 1994) is paralyzed in the high radiation interval and is inappropriate for contaminant stability in this borehole (stack plot included).

Grade thickness product (GTP) over 29 to 42 feet is decreasing consistent with Cs-137 (HPGe identified) and the category is stable. Surveys before 1978 show multiple detector sensitivities.

Grade thickness product over 42 to 66 feet is decreasing consistent with $\mathrm{Ru}-106$ (hypothesis) from 1975 to 1978 . Low sensitivity of probe type 02 is inappropriate for contamination stability analysis after 1978. The category is undetermined.

Grade thickness product over 66 to 90 feet is decreasing consistent with Ru-106 (hypothesis) from 1977 to 1978 during a time period of constant detector sensitivity. Before 1978, during another period of apparently constant detector sensitivity (see 29-42 feet interval) the GTP is increasing, indicating an unstable time period. The low sensitivity of probe type 02 is inappropriate for contaminant stability analysis after 1978 . The category is undetermined.

Gross Gamma Survey Information

\begin{tabular}{|r|l|}
\hline Probe Type Processed : & 02: Red GM \\
\hline Other Probe Types : & $03:$ Neutron, 04: NaI, \& 14: Shielded NaI \\
\hline Survey Depth : & $95 \mathrm{ft}$ \\
\hline First Survey Date : & $1 / 15 / 1975$ \\
\hline Last Survey Date : & $5 / 31 / 1994$ \\
\hline Number Surveys Processed : & 181 \\
\hline
\end{tabular}

Analysis Notes

\begin{tabular}{|r|l|}
\hline Method Used to Compute Background : & $5-20$ feet \\
\hline Depth(s) where Contamination was & $29-42$ feet Stable \\
Identified in Gross Gamma Surveys : & $42-66,66-90$ feet Undetermined \\
\hline Analyst Name : & R. K. Price \\
\hline Company Name : & Three Rivers Scientific \\
\hline
\end{tabular}


RPP-6088, Rev.0.

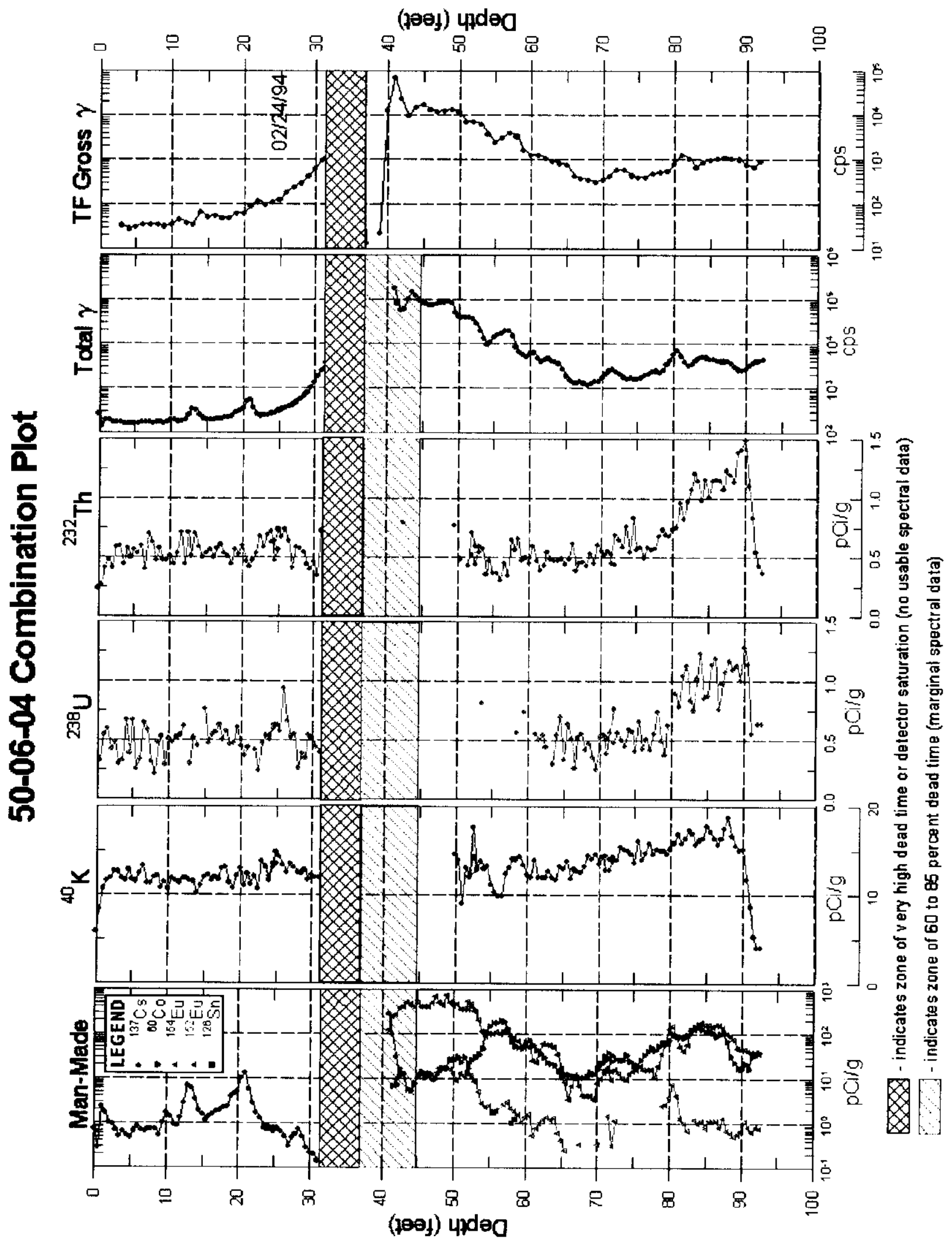


RPP-6088, Rev.0.

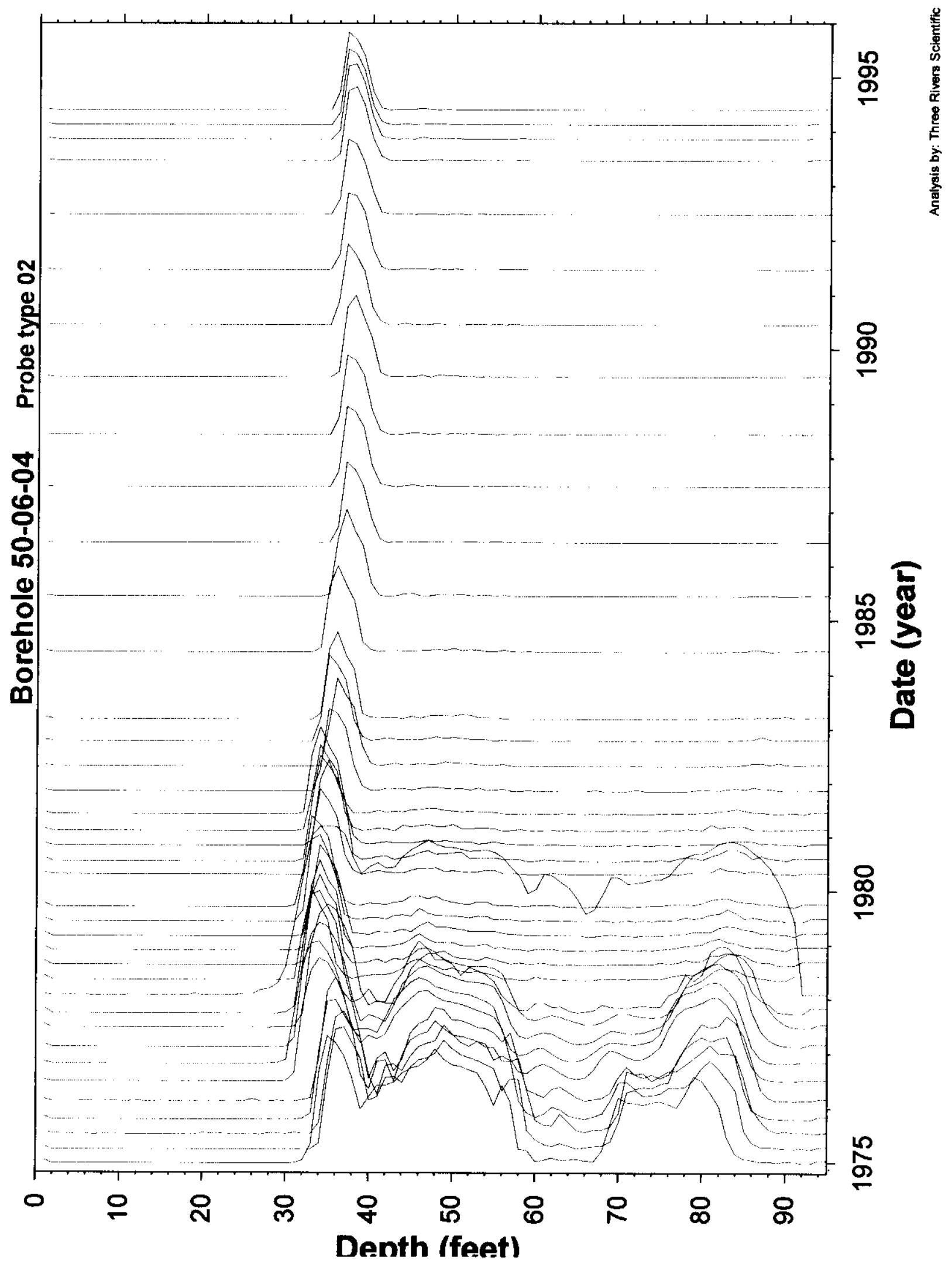

Tank T-106

Page 237 
RPP-6088, Rev.0.

w

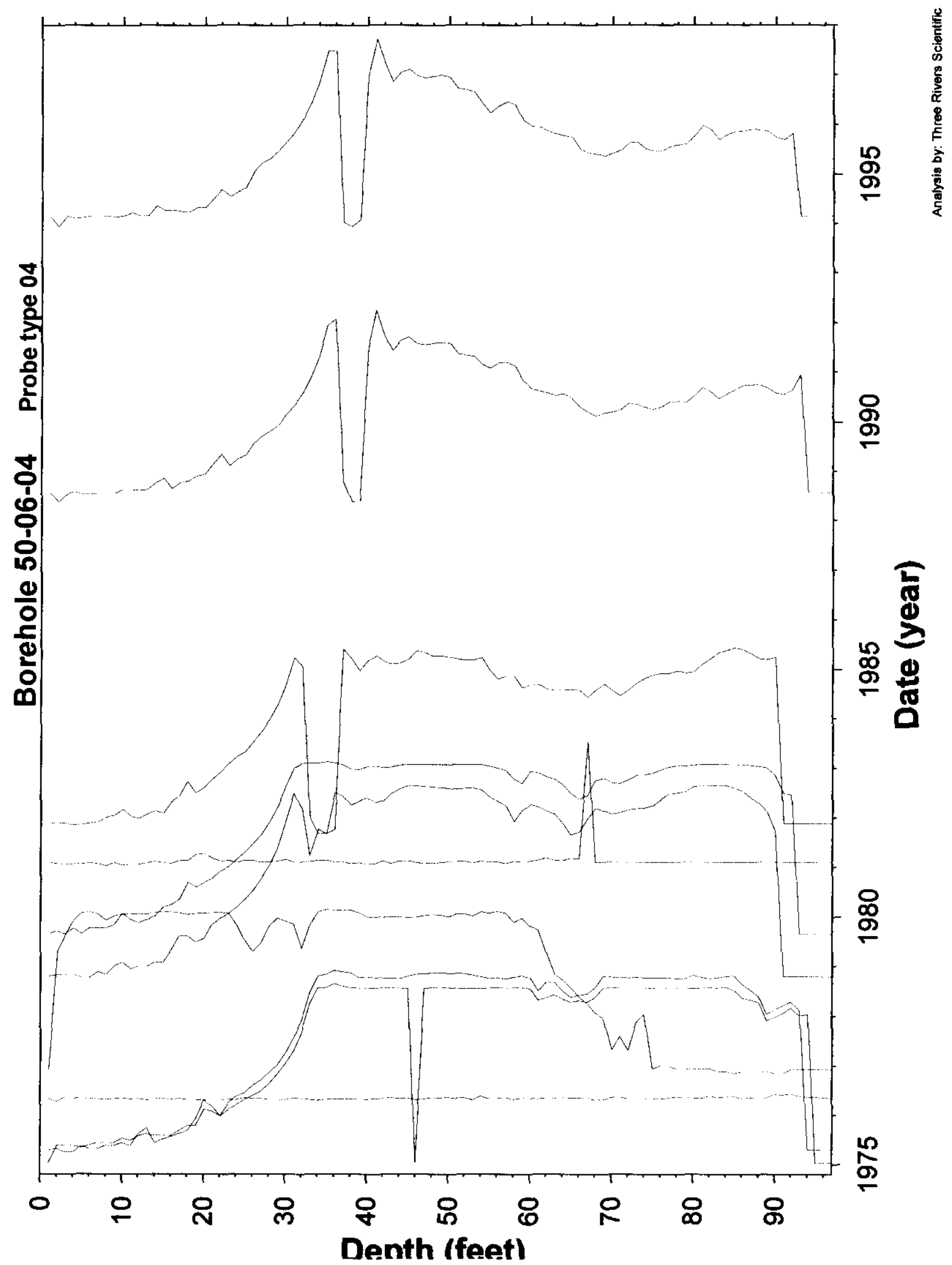

Tank T-106

Page 238 
RPP-6088, Rev.0.
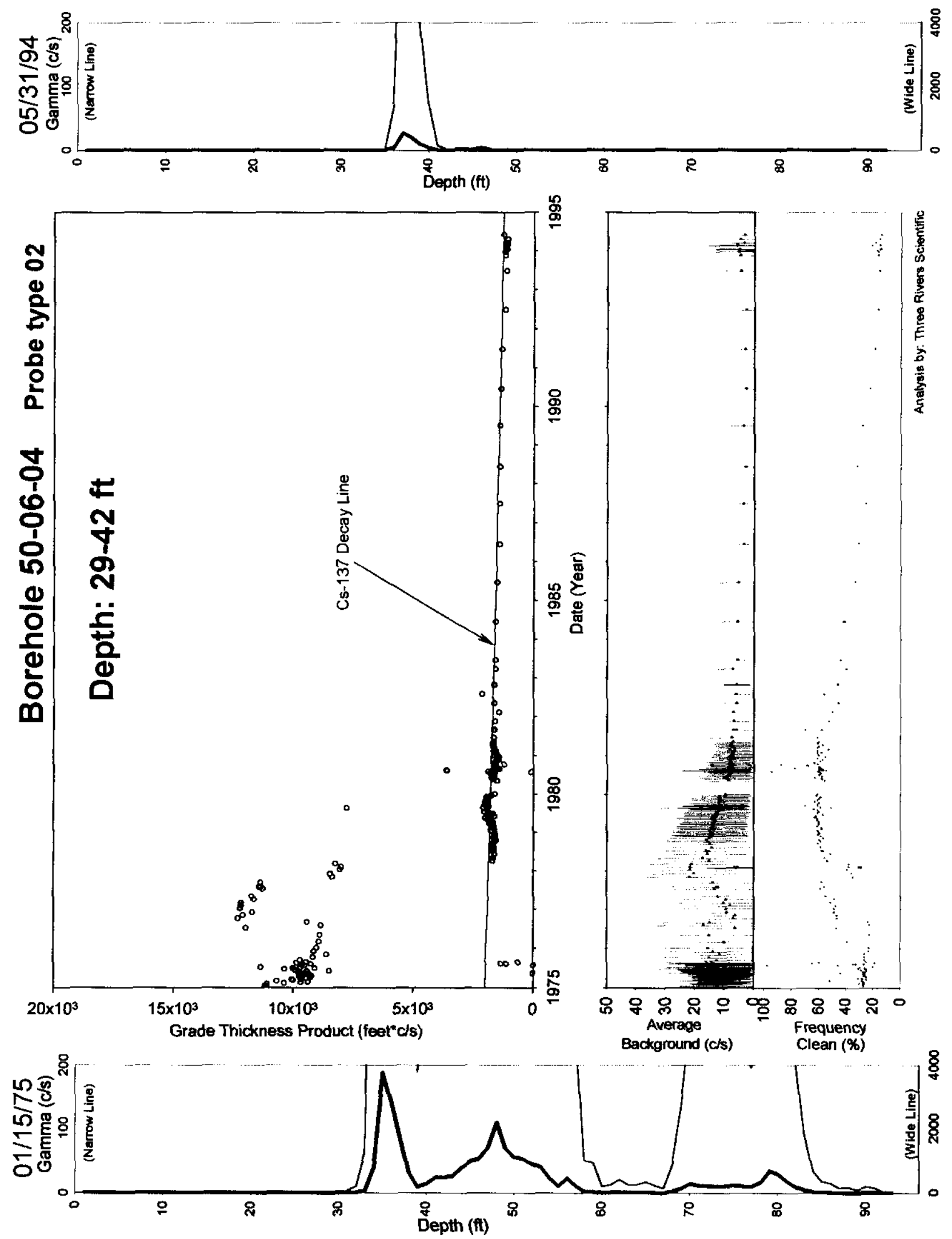
RPP-6088, Rev.0.
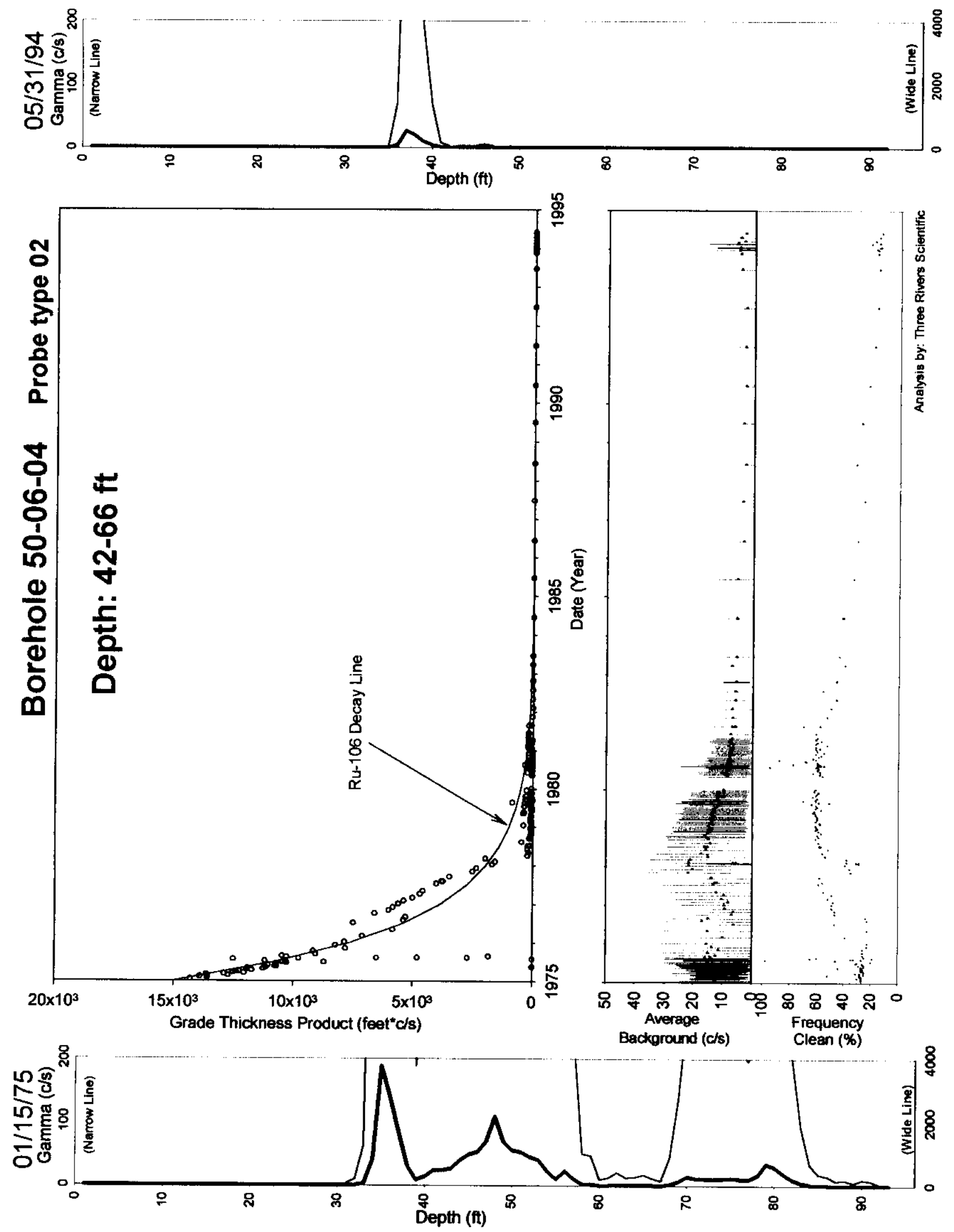
RPP-6088, Rev.0.
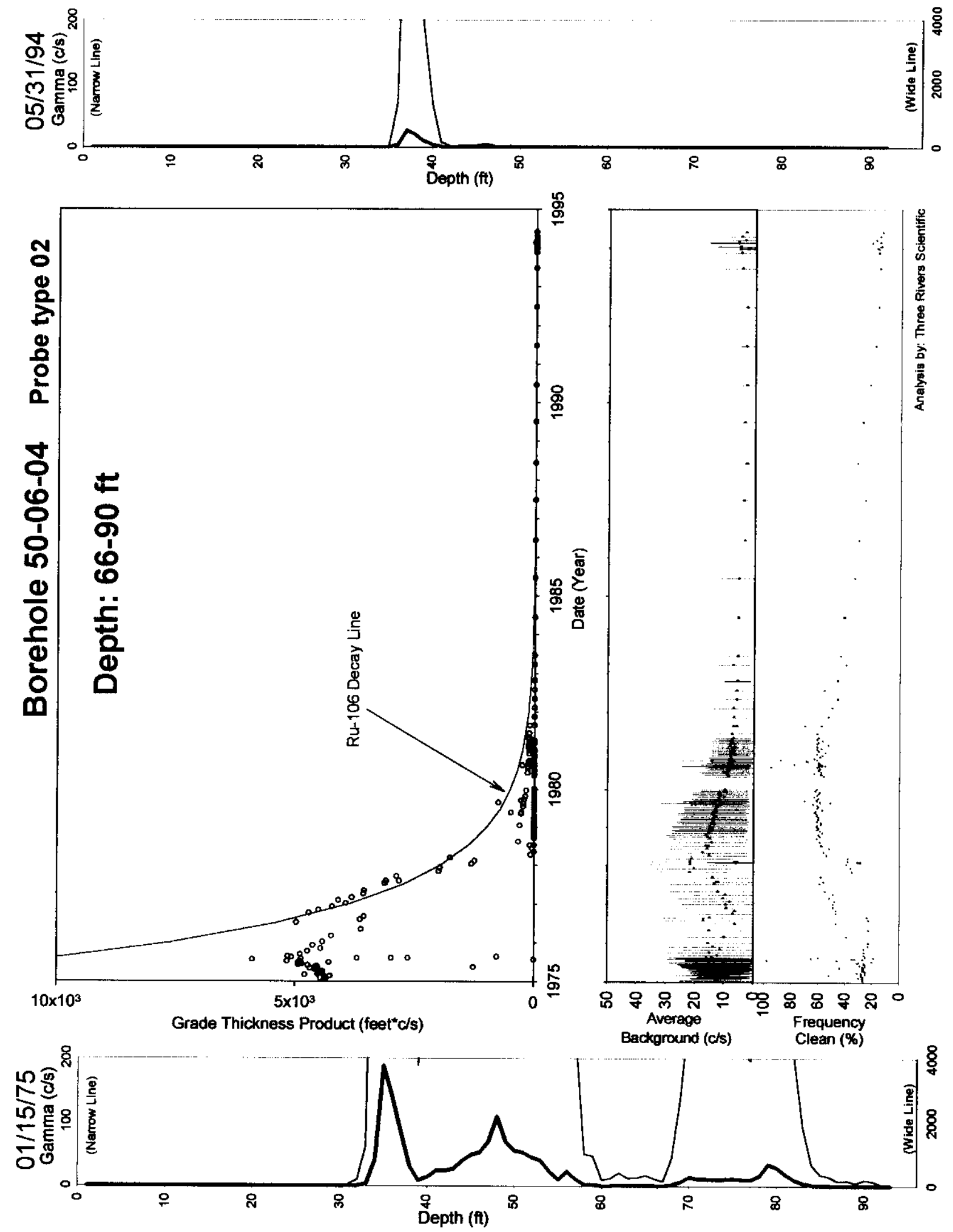


\section{Borehole 50-06-05}

\section{Contamination (Cs-137) from 27 to 60 feet is Stable. Contamination (Cs-137) from 60 to 94 feet is Stable. Contamination (Cs-137) from 94 to 120 feet is Stable.}

Probe type 02 had multiple sensitivity configurations (1975-1979) which complicates contaminant stability analysis (clearly shown in borehole 50-06-17). Other gross gamma probe types $(01,04,14)$ are inappropriate for contaminant stability analysis in this borehole.

Grade thickness product over 27 to 60 feet is decreasing consistent with Cs-137 (HPGe identified), the category is stable. Surveys before 1979 show multiple detector sensitivities.

Grade thickness product over 60 to 94 feet is decreasing consistent with Cs-137 (HPGe identified), the category is stable. Surveys before 1979 show multiple detector sensitivities.

Grade thickness product over 94 to 120 feet is decreasing consistent with Cs-137 (HPGe identified), the category is stable. Surveys before 1979 show multiple detector sensitivities.

Before July 1977 the maximum survey depth was generally 93 feet.

Gross Gamma Survey Information

\begin{tabular}{|r|l|}
\hline Probe Type Processed : & 02: Red GM \\
\hline Other Probe Types : & $\begin{array}{l}01: \text { Green GM, 03: Neutron, } \\
04: \text { NaI, \& 14: Shielded NaI }\end{array}$ \\
\hline Survey Depth : & $120 \mathrm{ft}$ \\
\hline First Survey Date : & $1 / 15 / 1975$ \\
\hline Last Survey Date : & $5 / 31 / 1994$ \\
\hline Number Surveys Processed : & 189 \\
\hline
\end{tabular}

Analysis Notes

\begin{tabular}{|r|l|}
\hline Method Used to Compute Background : & $5-25$ feet \\
\hline $\begin{array}{r}\text { Depth(s) where Contamination was } \\
\text { Identified in Gross Gamma Surveys : }\end{array}$ & $27-60,60-94,94-120$ feet Stable \\
\hline Analyst Name : & R. K. Price \\
\hline Company Name : & Three Rivers Scientific \\
\hline
\end{tabular}


RPP-6088, Rev.0.

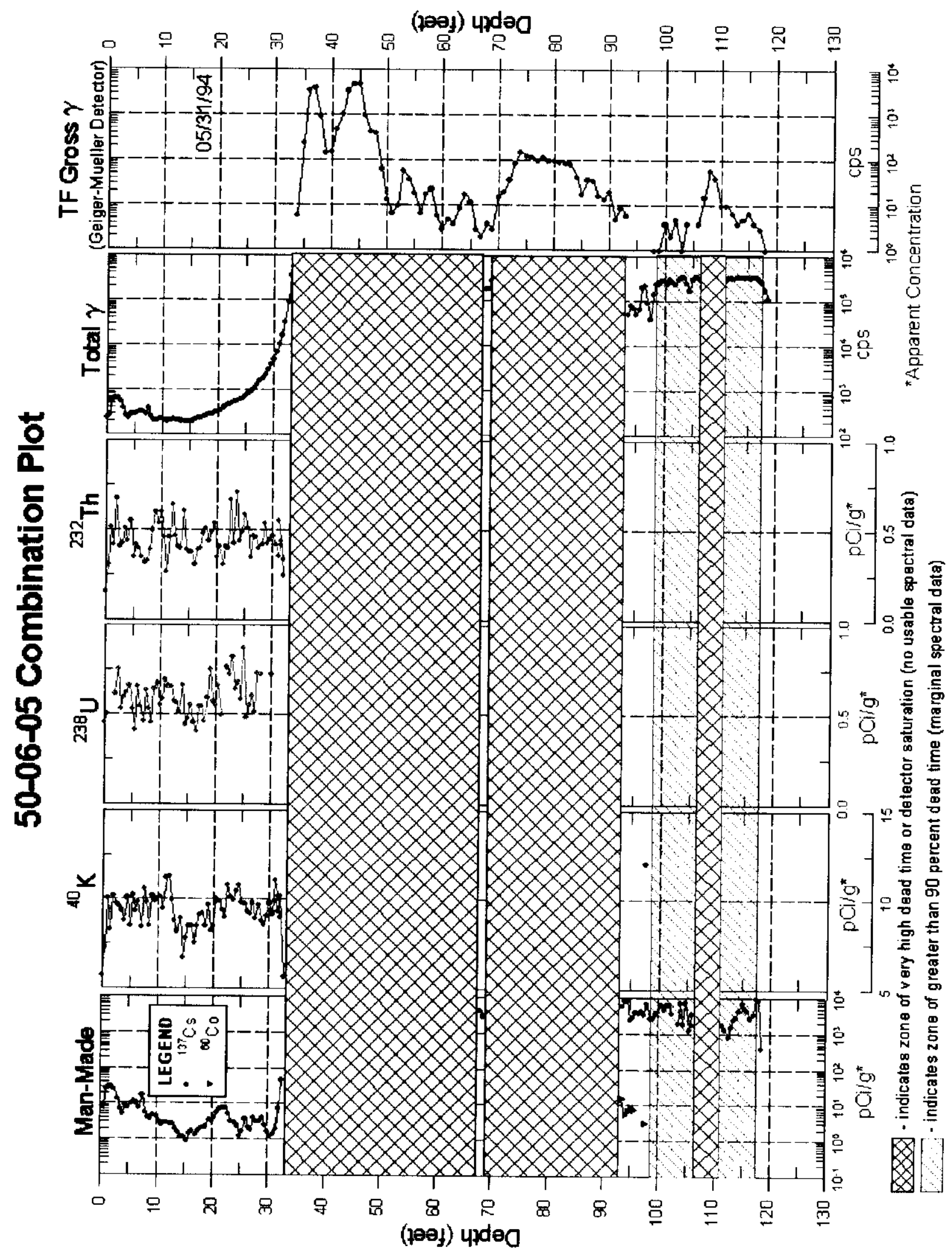


RPP-6088, Rev.0.

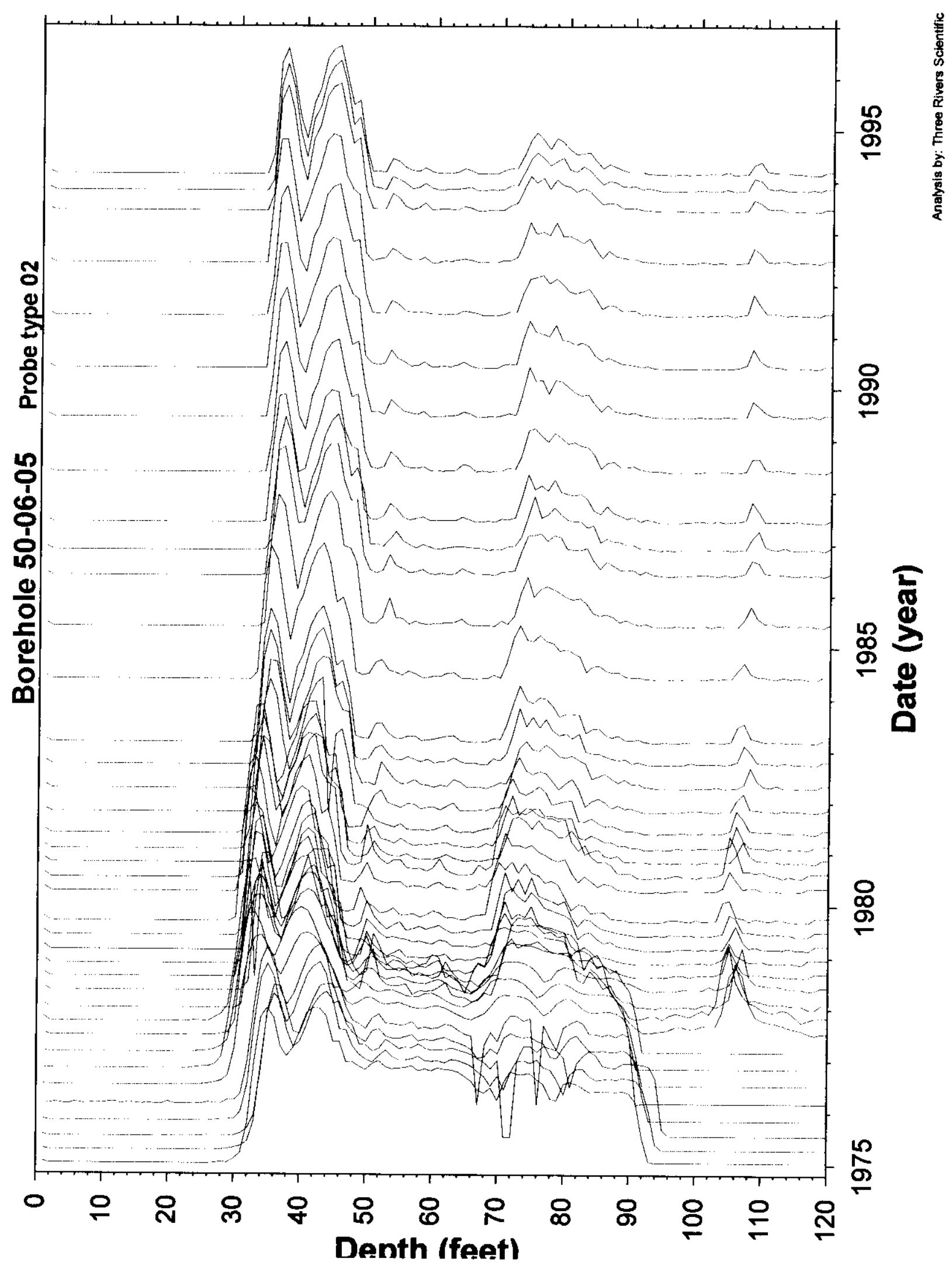

Tank T-106

Page 244 
RPP-6088, Rev.0.
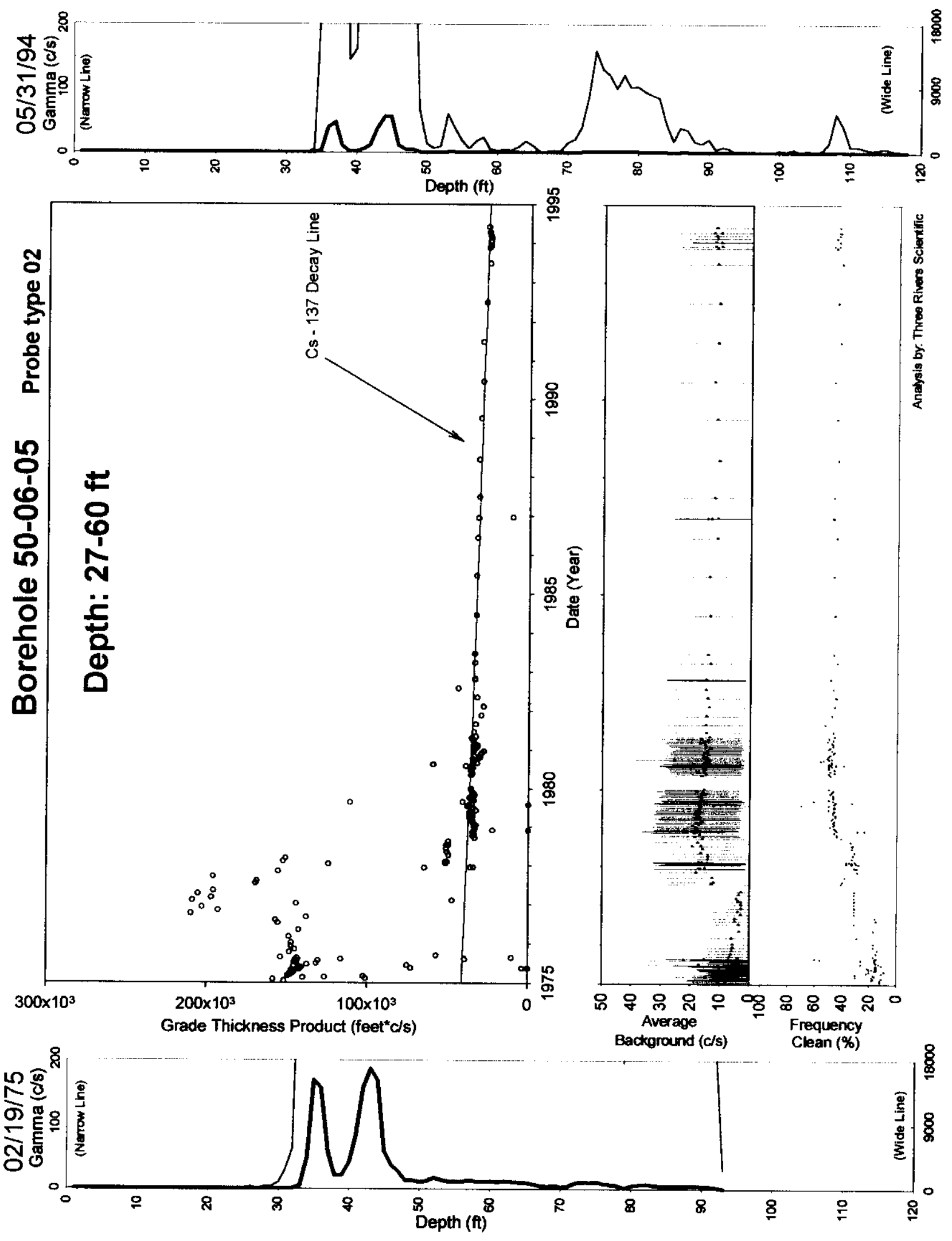

Tank T-106 
RPP-6088, Rev.0.
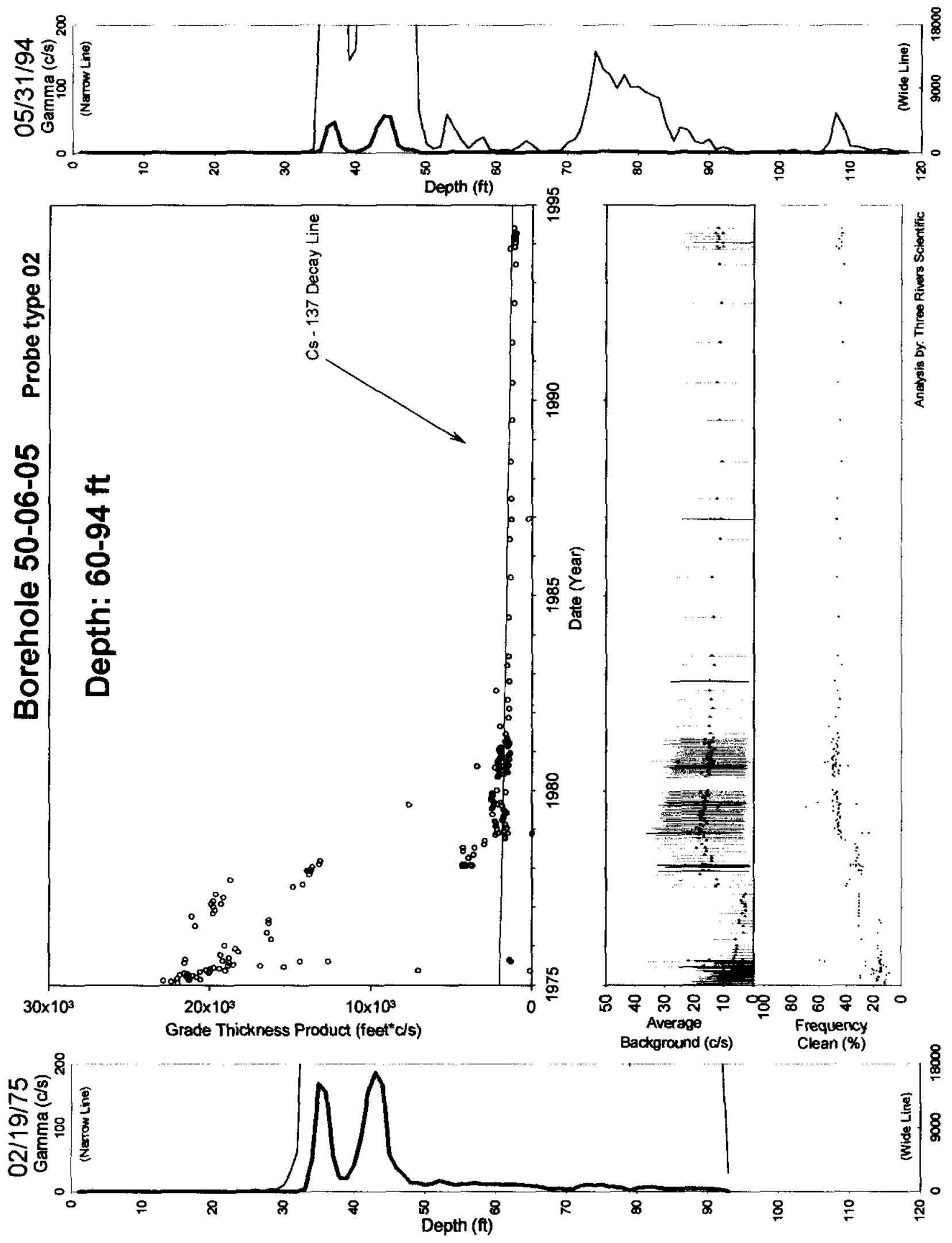

Tank T-106 
RPP-6088, Rev.0.
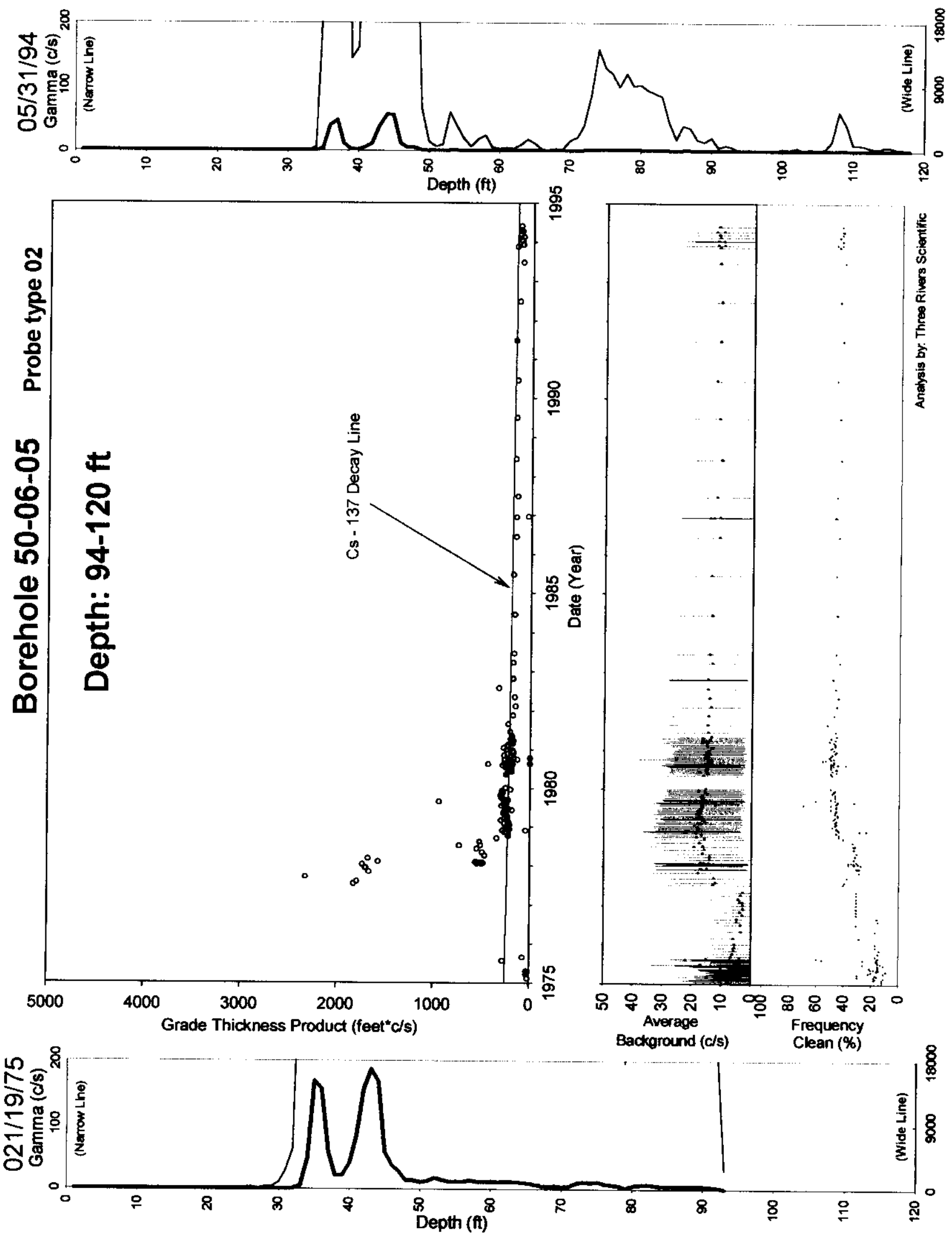

Tank T-106

Page 247 


\section{Borehole 50-06-06}

\section{Contamination (Cs-137, Co-60, Ru-106) 29 to 68 feet is Unstable Early. Contamination (Cs-137, Ru-106) from 68 to 110 feet is Unstable Early. Contamination (Cs-137, Ru-106) from 110 to 120 feet is Stable.}

Tank Farms use two probe types (02:Red GM and 14:Shielded NaI) to monitor the high levels of contamination. The GTP plots are included for relevant probe types. Probe type 02 had multiple sensitivity configurations (1975-1978) which complicates contaminant stability analysis. Survey intervals with high count rates (greater than bout $40,000 \mathrm{c} / \mathrm{g}$ ) are beyond the linear count rate range of the system.

Grade thickness product over 29 to 68 feet is decreasing consistent with a least square fit for Cs137 and Co-60 (both HPGe identified) from 1980 to 1995 . The ratio of gross contribution from Cs-137 to Co-60 is 8:1 as of 5-26-1994. The GTP plot for probe type 02 shows for the limited time span of the surveys, multiple probe sensitivity configurations as apparent parallel contaminant decay. A Ru-106 (hypothesis) decay line is shown as a reference. The category is unstable early.

Grade thickness product over 68 to 110 feet after 1980 is decreasing consistent with a least square fit for Cs-137 (HPGe identified) and Ru-106 (hypothesis), probe type 14. The ratio of gross contribution from Cs-137 to Ru-106 is 1089:1 as of 5-26-1994. Before 1976 the GTP for probe type 02 shows a slight increase instead of the high rate of Ru-106 decay that was demonstrated in the above (29-68 ft) interval. The category is unstable early.

Grade thickness product over 110 to 120 feet is decreasing consistent with a least square fit for Eu-154, Co-60 (both HPGe identified) and Ru-106 (hypothesis) from 1979 to 1995. The ratio of gross contribution from Eu-154:Co-60:Ru-106 is 196:26:0.01 as of 1-1-1996. The limited number of surveys before 1979 inhibit analysis of zone stability.

Gross Gamma Survey Information

\begin{tabular}{|r|l|}
\hline Probe Type Processed : & 02: Red GM \& 14: Shielded NaI \\
\hline Other Probe Types : & $01:$ Green GM, 03: Neutron, 04: NaI \\
\hline Survey Depth : & $120 \mathrm{ft}$ \\
\hline First Survey Date : & $02: 1 / 15 / 1975 \& 14: 12 / 03 / 1976$ \\
\hline Last Survey Date : & $02: 8 / 25 / 1980 \& 14: 5 / 26 / 1994$ \\
\hline Number Surveys Processed : & $02: 128 \& 14: 102$ \\
\hline
\end{tabular}

Analysis Notes

\begin{tabular}{|r|l|}
\hline Method Used to Compute Background : & $5-28$ feet \\
\hline Depth(s) where Contamination was & $29-68$ and 68-110 feet Unstable Early \\
Identified in Gross Gamma Surveys : & $110-120$ feet Stable \\
\hline Analyst Name : & R. K. Price \\
\hline Company Name : & Three Rivers Scientific \\
\hline
\end{tabular}


RPP-6088, Rev.0.

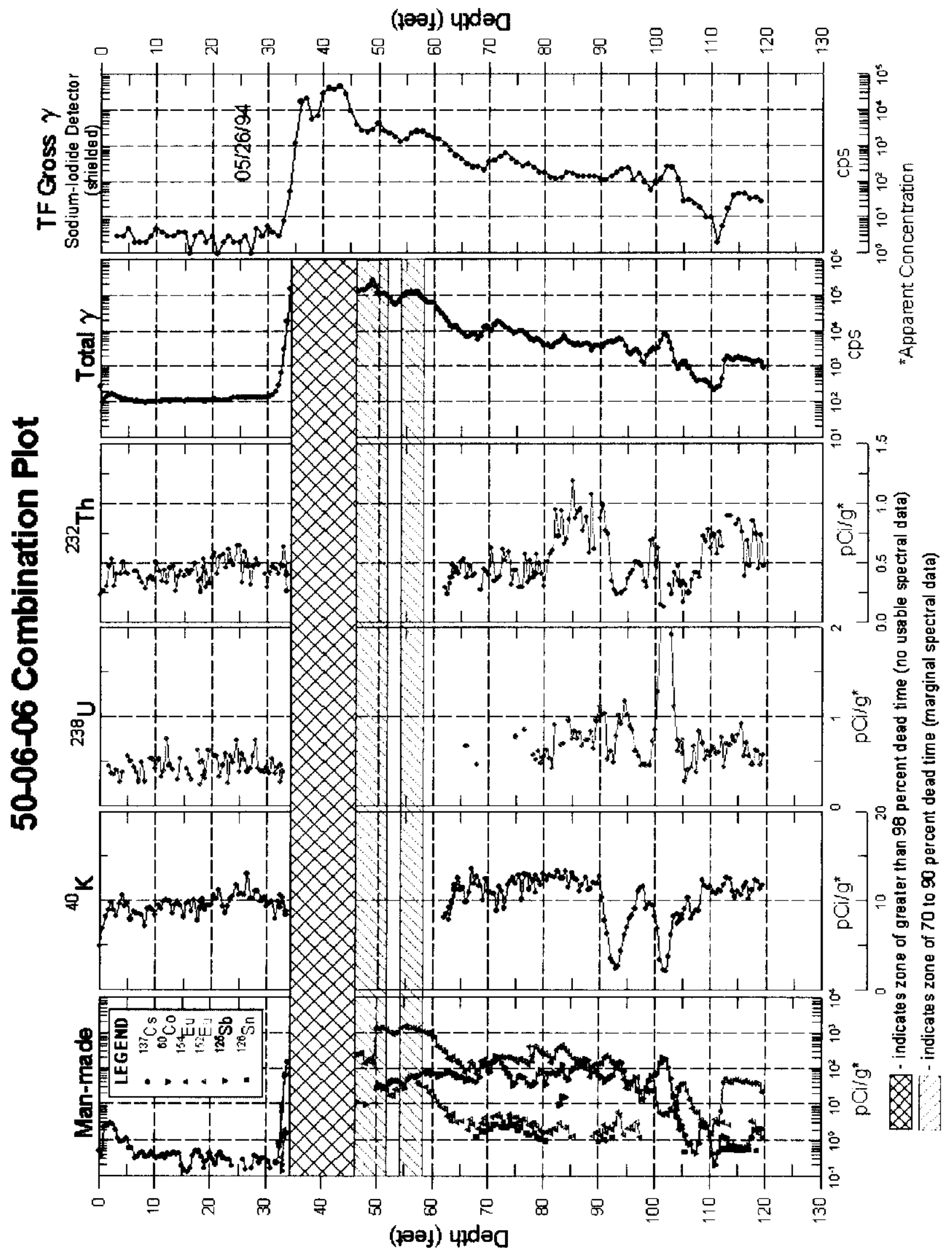

Tank T-106

Page 249 
RPP-6088, Rev.0.

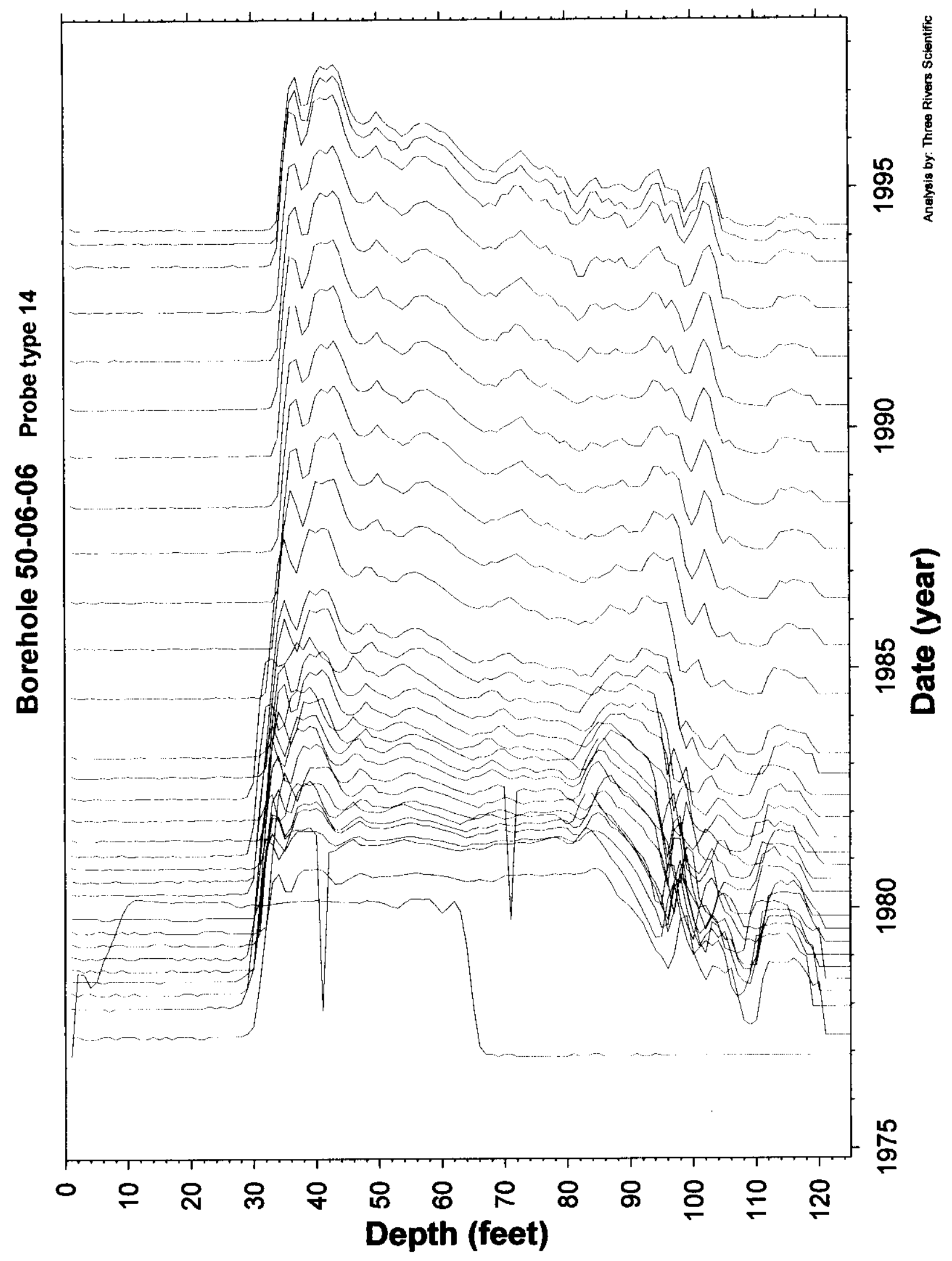

Tank T-106

Page 250 
RPP-6088, Rev.0.

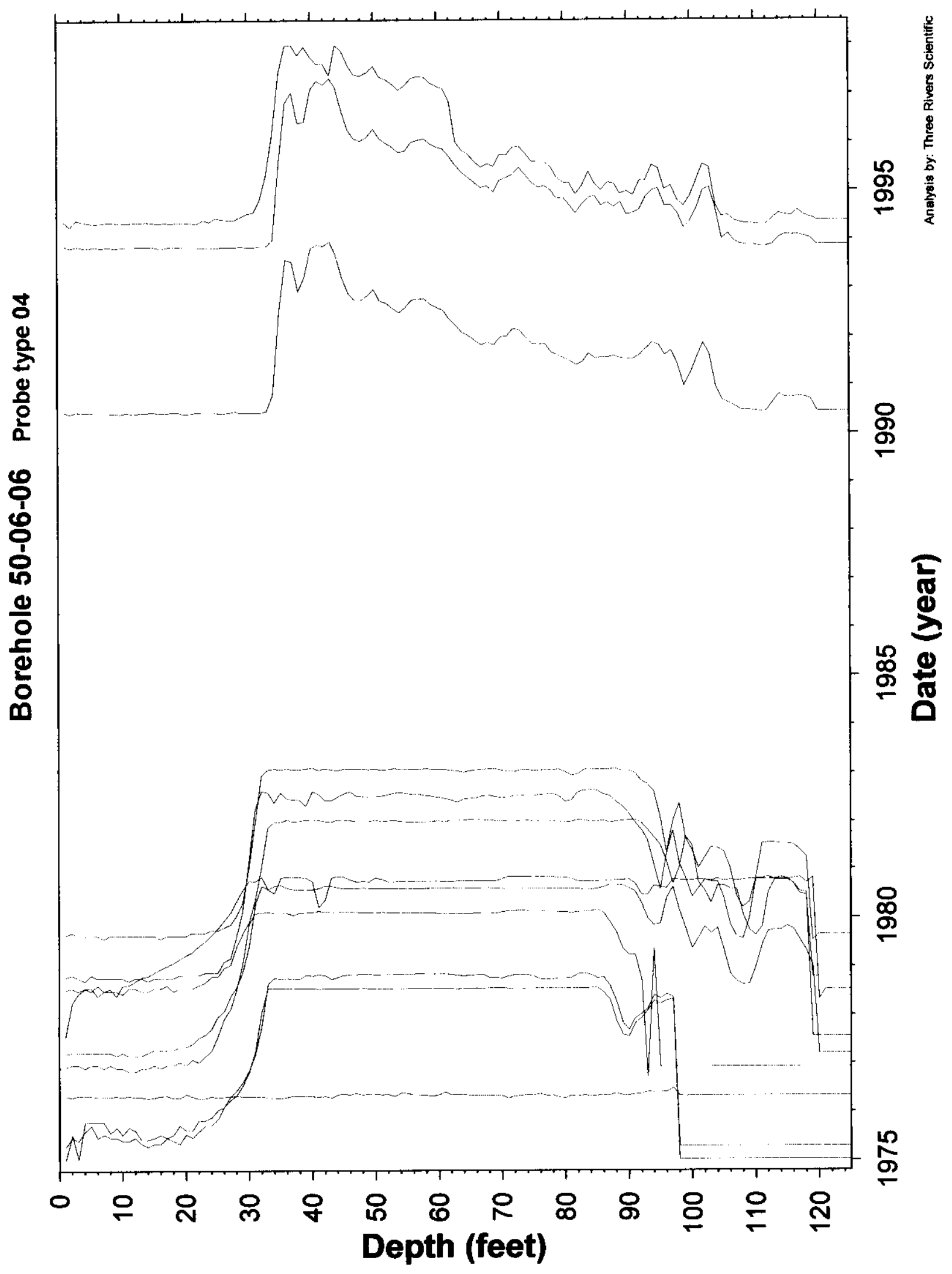

Tank T-106 
RPP-6088, Rev.0.

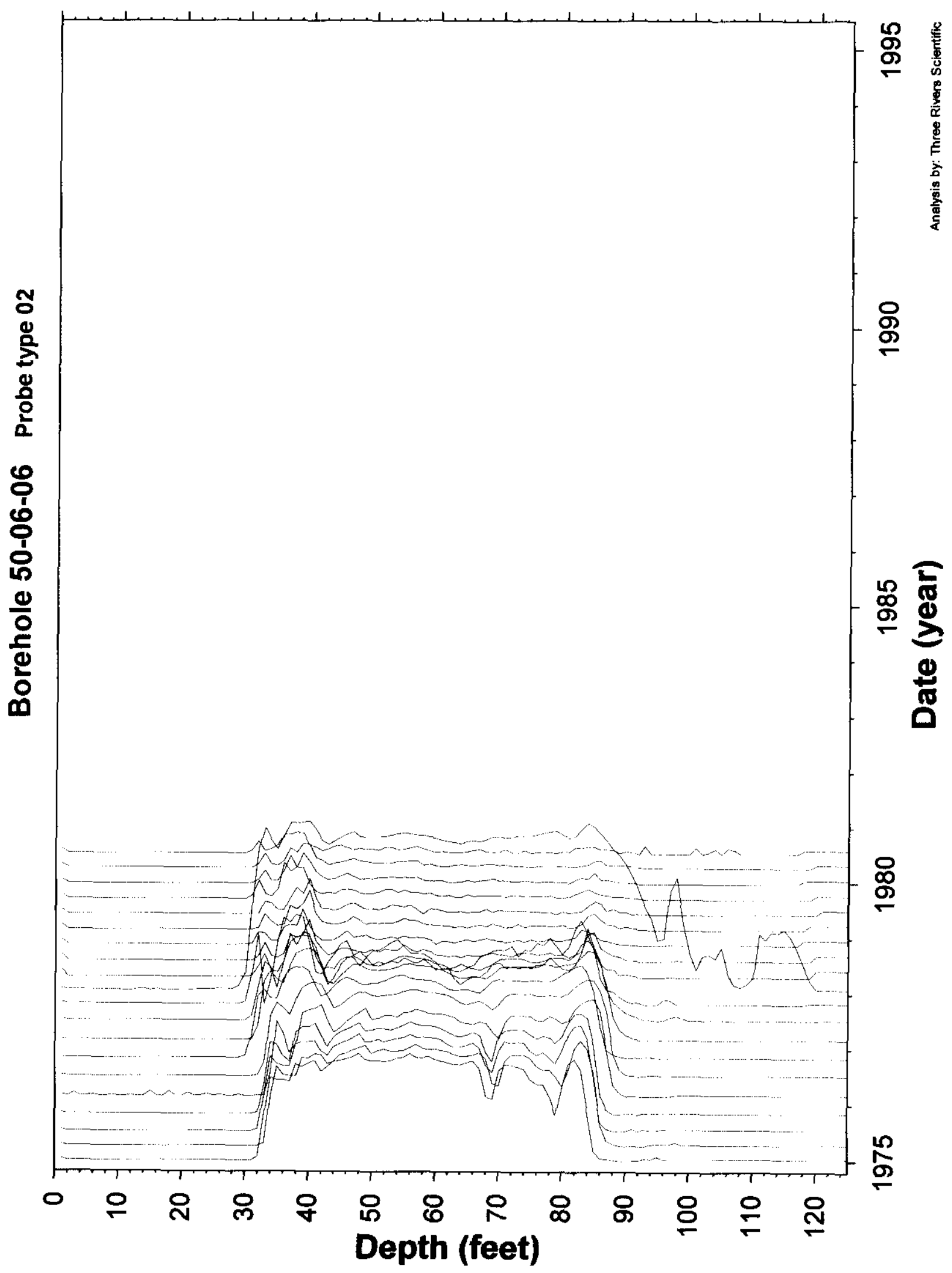

Tank T-106

Page 252 
RPP-6088, Rev.0.
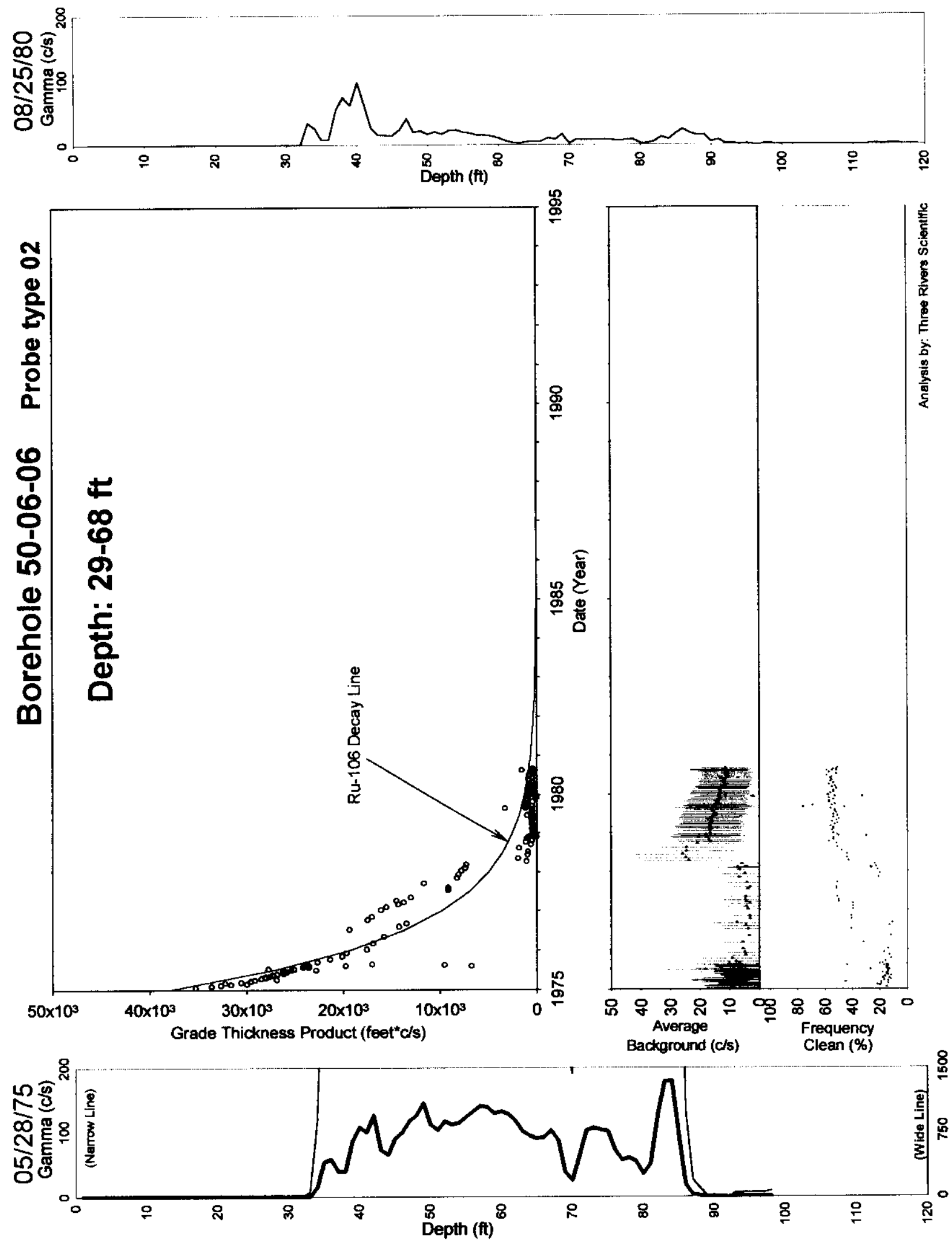
RPP-6088, Rev.0.
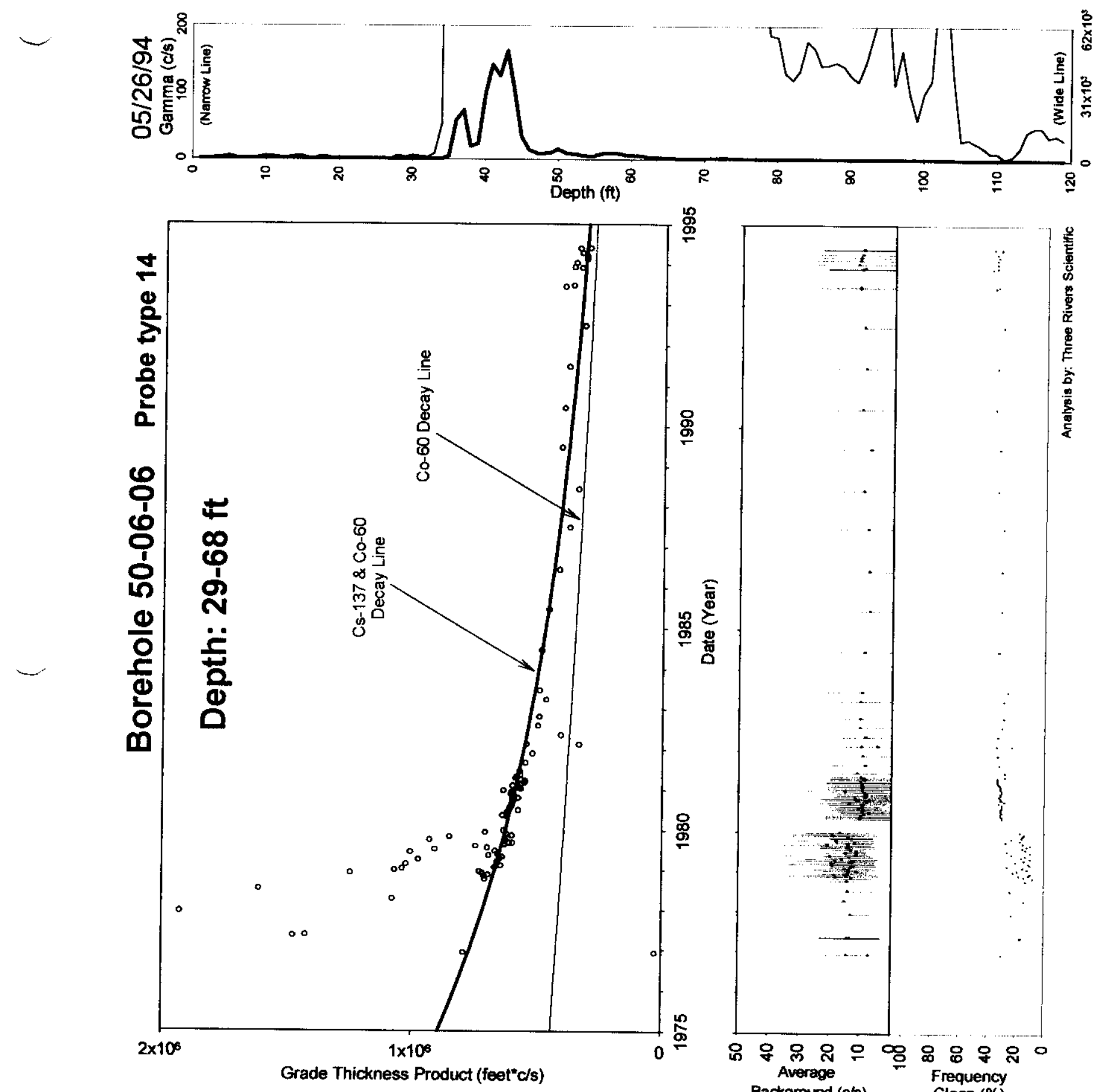

恕
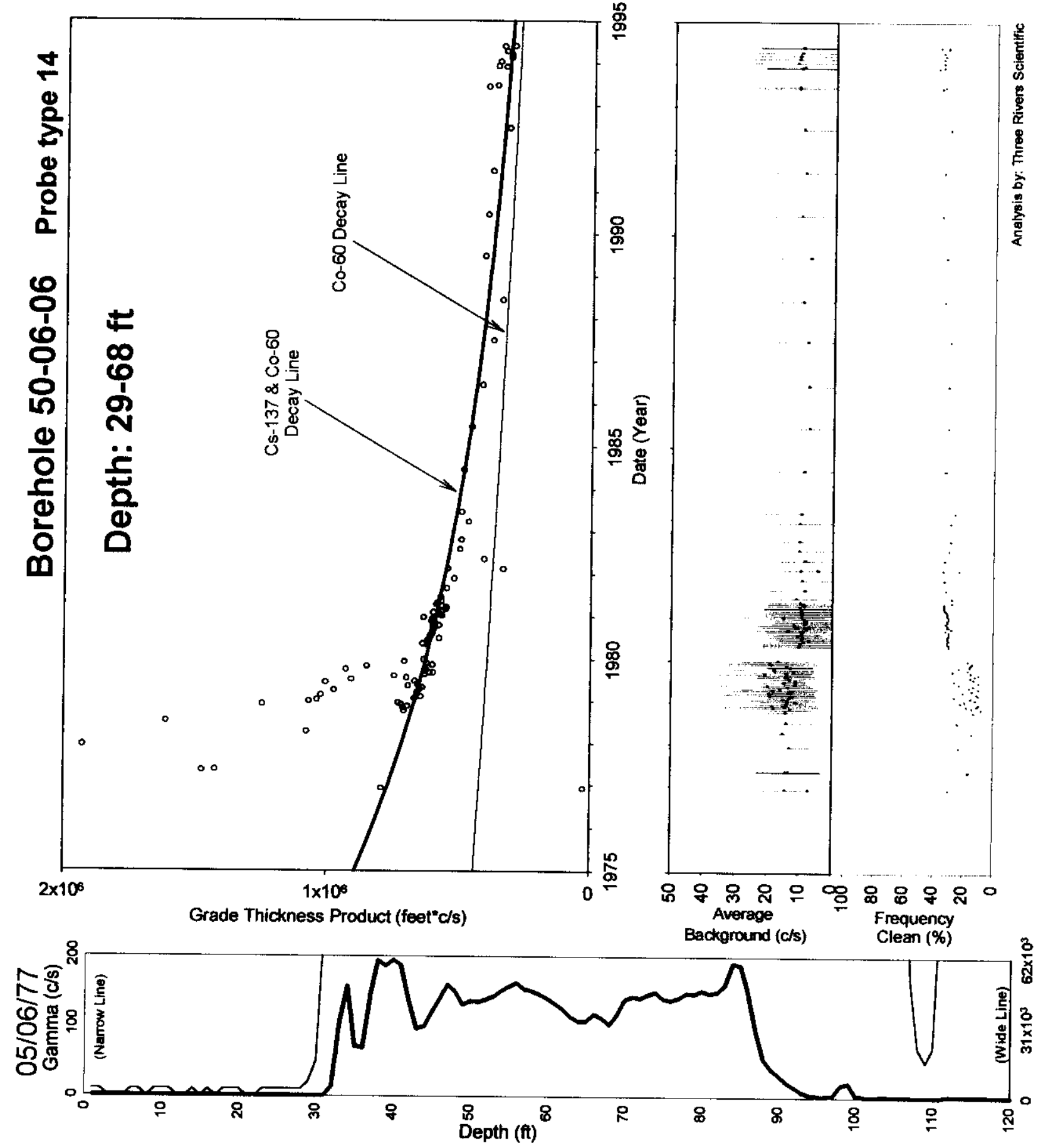
RPP-6088, Rev.0.
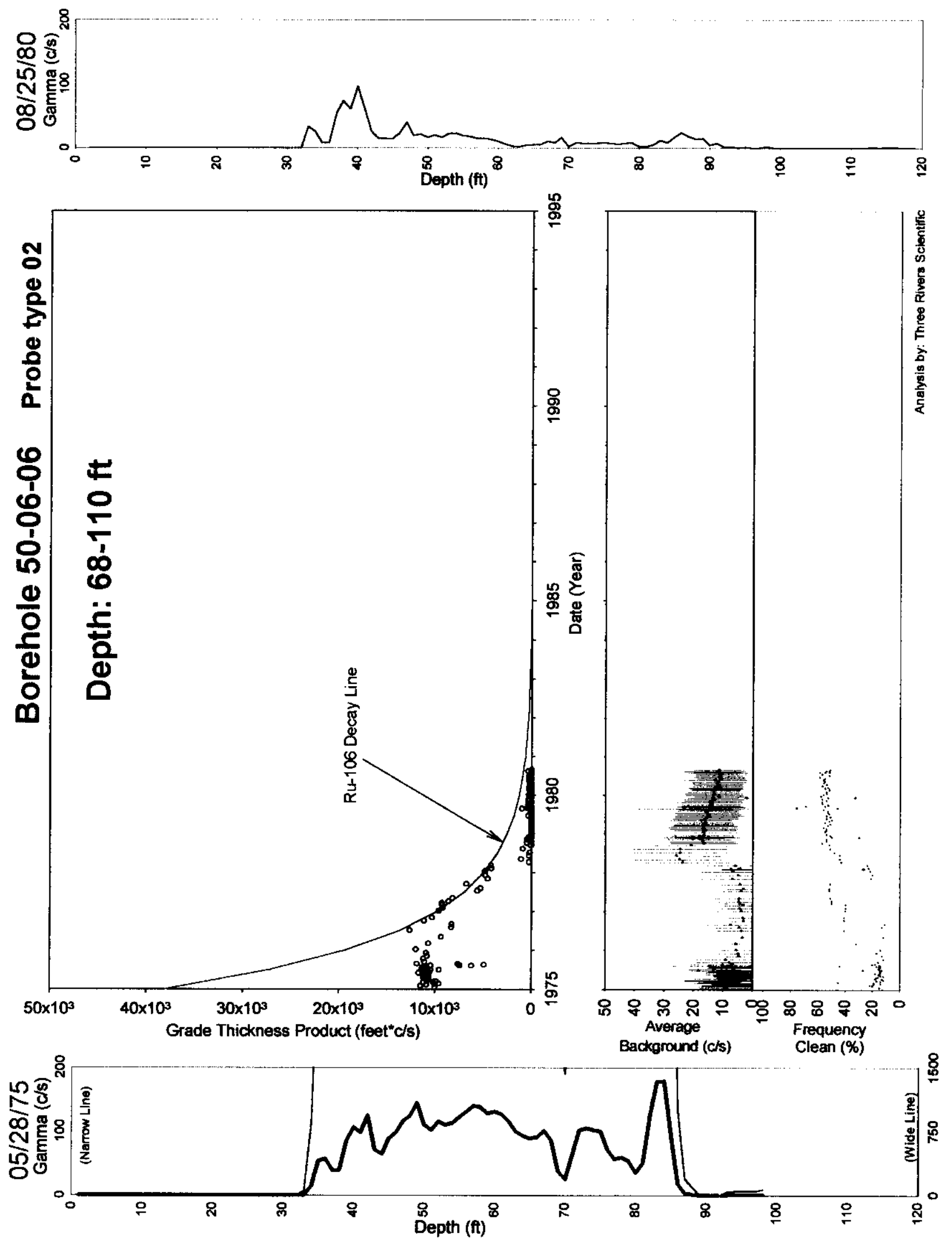

Tank T-106

Page 255 
RPP-6088, Rev.0.
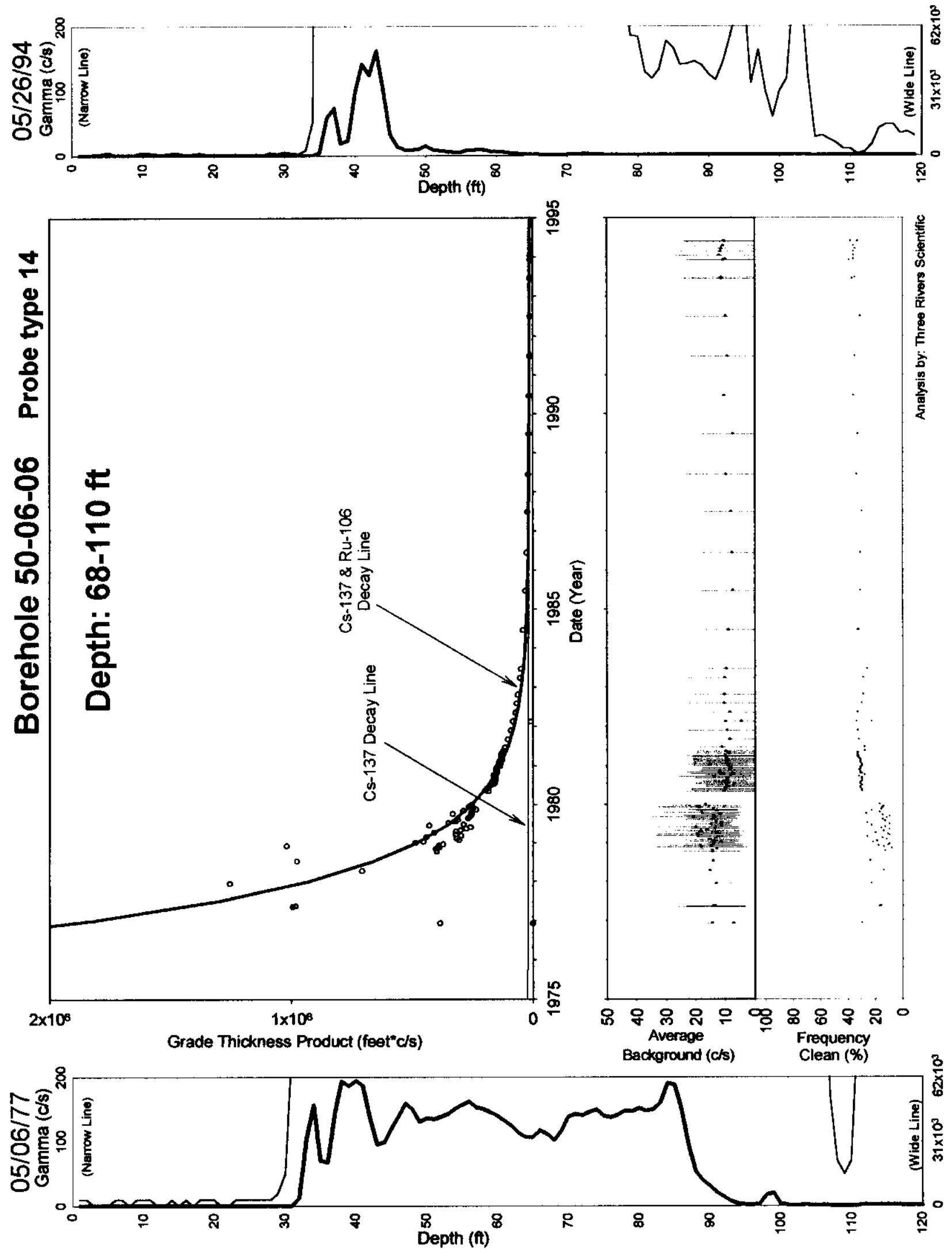

Tank T-106

Page 256 
RPP-6088, Rev.0.
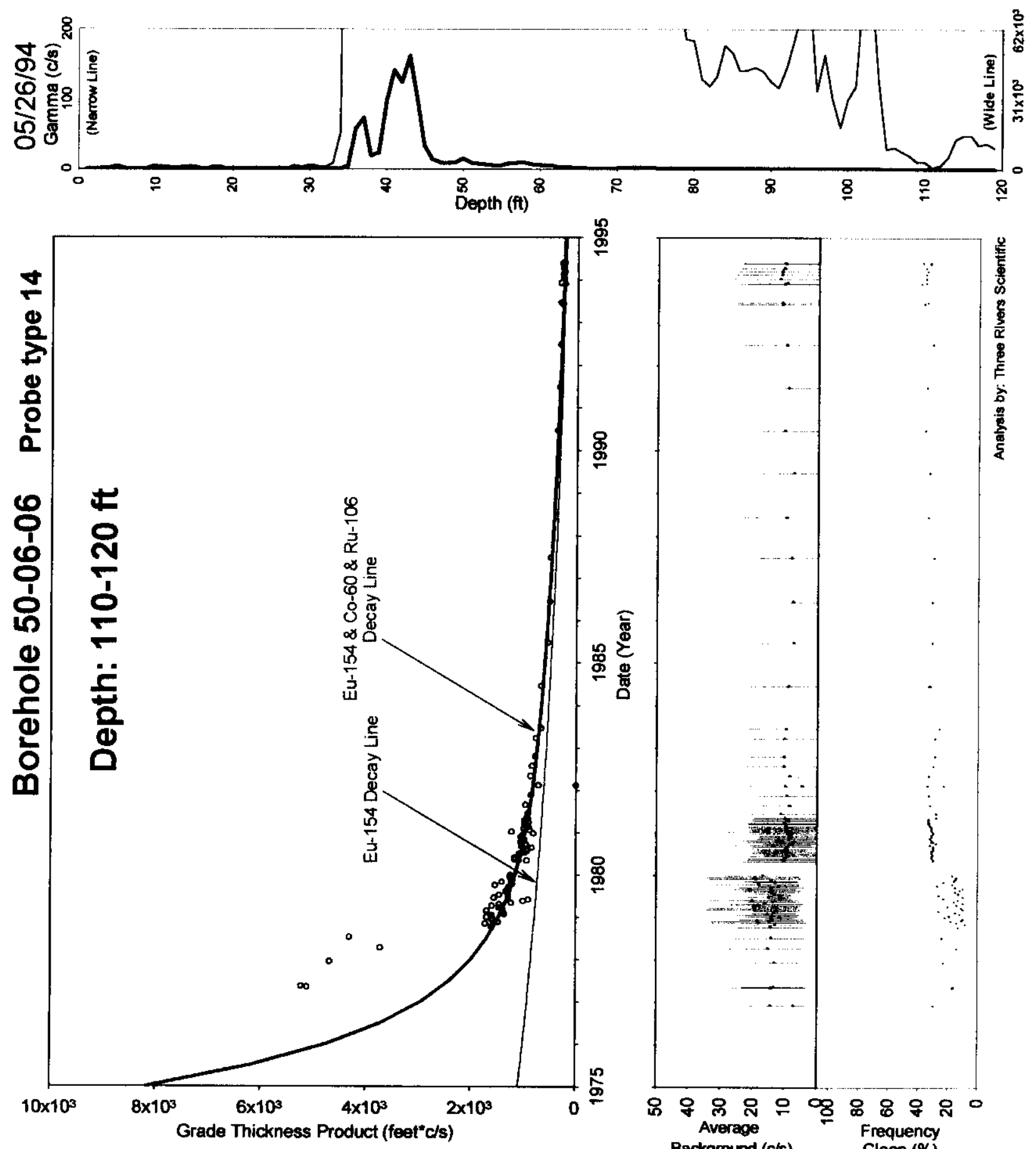

号 


\section{Borehole 50-06-08}

\section{Contamination (Cs-137) from 28 to 44 feet is Stable. Contamination (Cs-137, Co-60, Ru-106) from 44 to 89 feet is Stable. Contamination (Cs-137, Ru-106) from 89 to 120 feet is Undetermined.}

Three probe types (01:Green-GM, 02:Red-GM, and 14:Shielded NaI), were required to monitor the high levels of contamination. The GTP plots are included for relevant probe types. Probe type 02 had multiple sensitivity configurations (1975-1979) which complicate contaminant stability analysis. Surveys in high count rate zones (probe types 01 \& 14) are invalid (detector saturation).

Grade thickness product over 28 to 44 feet is decreasing consistent with Cs-137 (HPGe identified) from 1979 to 1995 . Surveys before 1979 show multiple detector sensitivity.

Grade thickness product over 44 to 89 feet is decreasing consistent with a least square fit for Cs137, Co-60 (both HPGe identified) and Ru-106 (hypothesis) after 1980. The ratio of gross contribution from Cs-137:Co-60:Ru-106 is 4030:1604:1 as of 1-1-1996 (01 probe). The GTP plot for probe type 02 shows the multiple probe sensitivity configurations as apparent parallel contaminant decay. The GTP plots for probe types $02 \& 14$ shows as a reference a Ru-106 decay line.

Grade thickness product over 89 to 120 feet appears to be decreasing from 1979-1980 (probe type 14). The Ru-106 (hypothesis) decay line, plotted as a reference, shows the rate of decrease before 1979 is greater than the decay of Ru-106. Also, after 1980 (probe type 01) the GTP shows increasing activity from 1981 to 1990 , then after 1990 the activity is decreasing. The stack plot (probe type 01) shows the increasing activity into successively lower depth intervals. The category is Undetermined.

Gross Gamma Survey Information

\begin{tabular}{|r|lll|}
\hline Probe Type Processed : & $\begin{array}{l}\text { 01:Green-GM, 02:Red-GM, } \\
\text { 14: Shielded NaI }\end{array}$ \\
\hline Other Probe Types : & $03:$ Neutron \& $04:$ NaI & \\
\hline Survey Depth : & $120 \mathrm{ft}$ & & \\
\hline First Survey Date : & $01: 1 / 17 / 1978$ & $02: 1 / 15 / 1975$ & $14: 12 / 03 / 1976$ \\
\hline Last Survey Date : & $01: 5 / 31 / 1994$ & $02: 5 / 31 / 1994$ & $14: 6 / 13 / 1988$ \\
\hline Number Surveys Processed : & $01: 56 \quad 02: 181$ & $14: 62$ & \\
\hline
\end{tabular}

Analysis Notes

\begin{tabular}{|r|l|}
\hline Method Used to Compute Background : & $5-26$ feet \\
\hline Depth(s) where Contamination was & $28-44,44-89$ feet Stable \\
Identified in Gross Gamma Surveys : & $89-120$ feet Undetermined \\
\hline Analyst Name : & R. K. Price \\
\hline Company Name : & Three Rivers Scientific \\
\hline
\end{tabular}


RPP-6088, Rev.0.

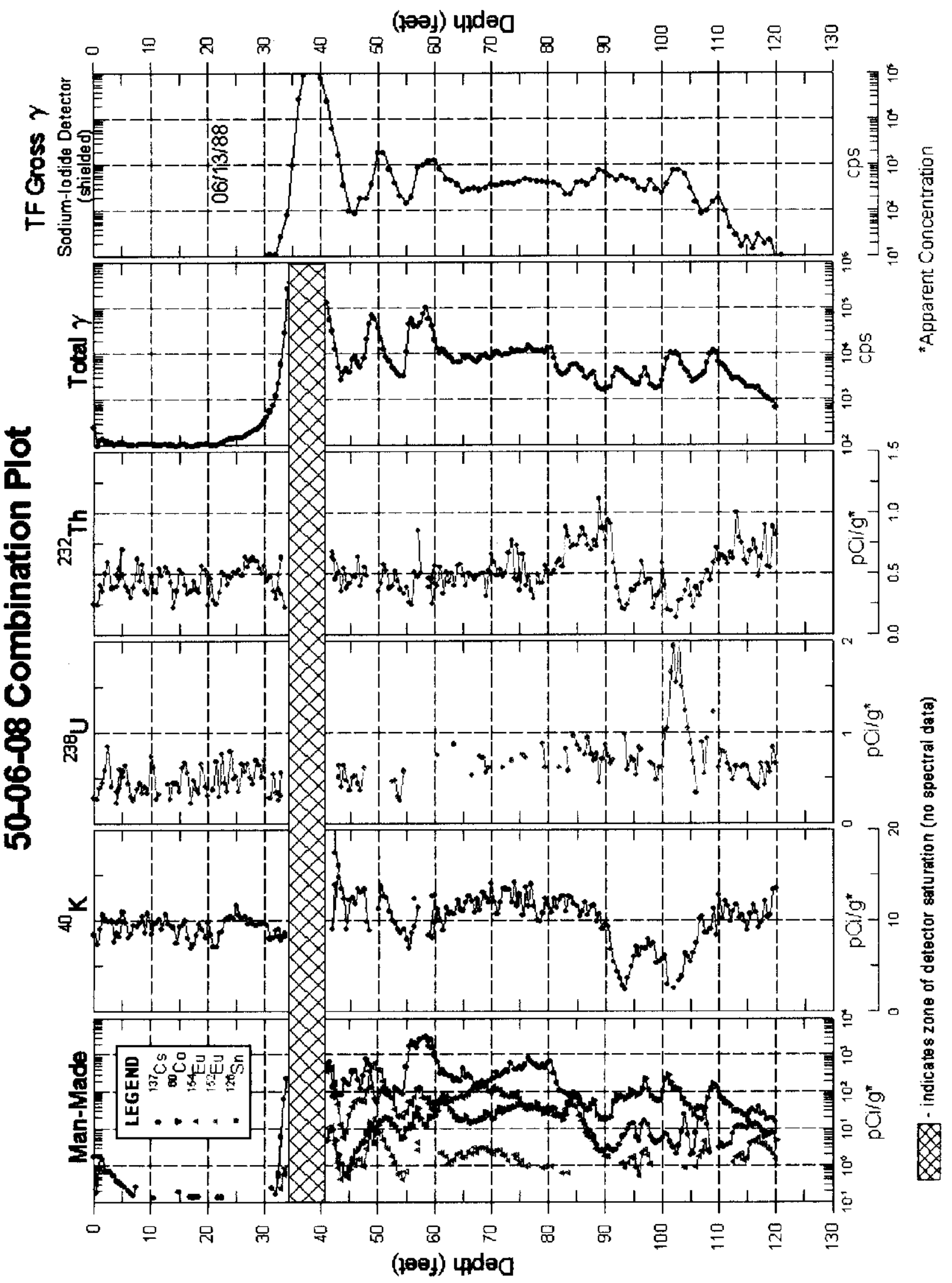

Tank T-106

Page 259 
RPP-6088, Rev.0.

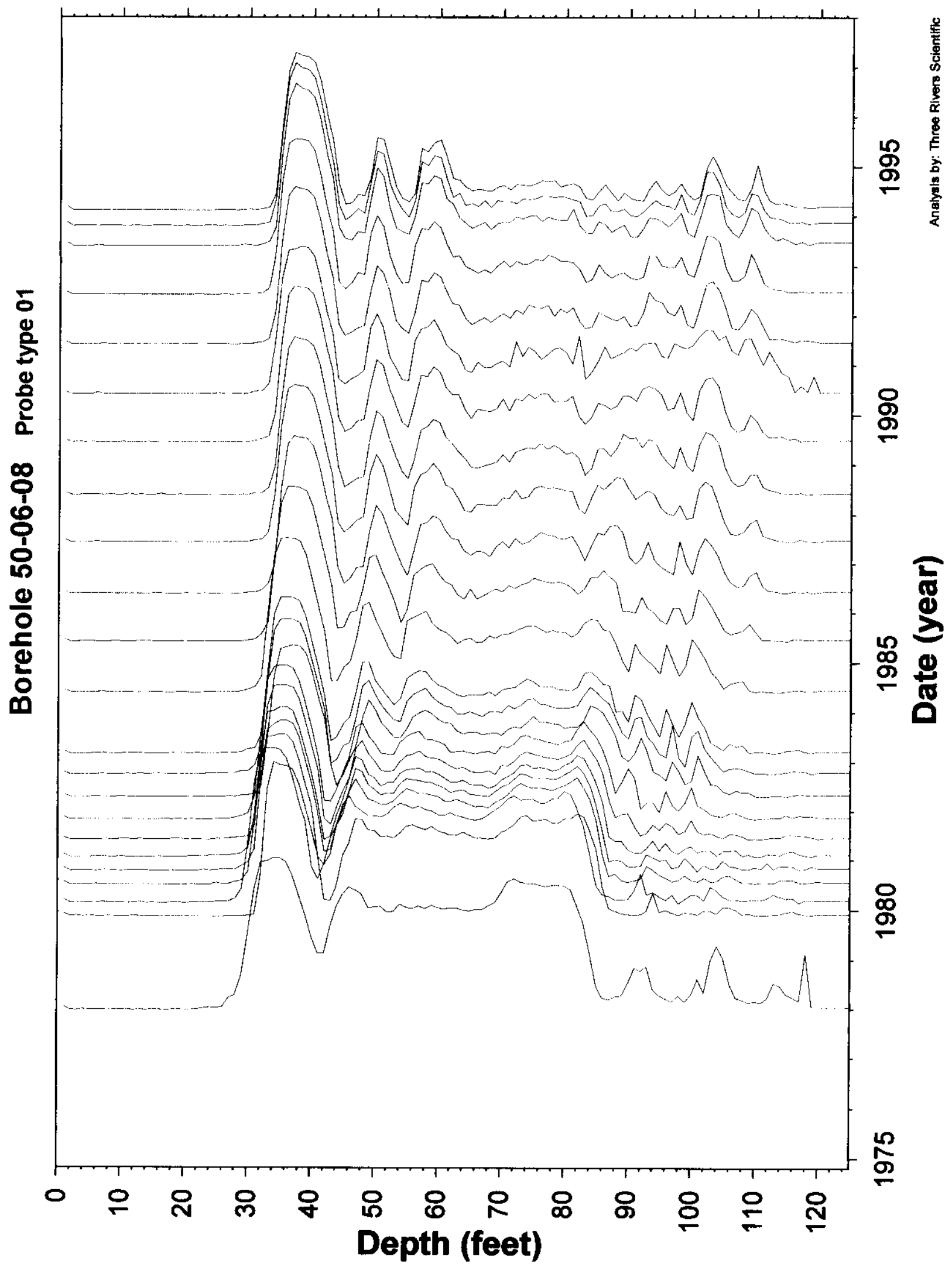

Tank T-106

Page 260 
RPP-6088, Rev.0.

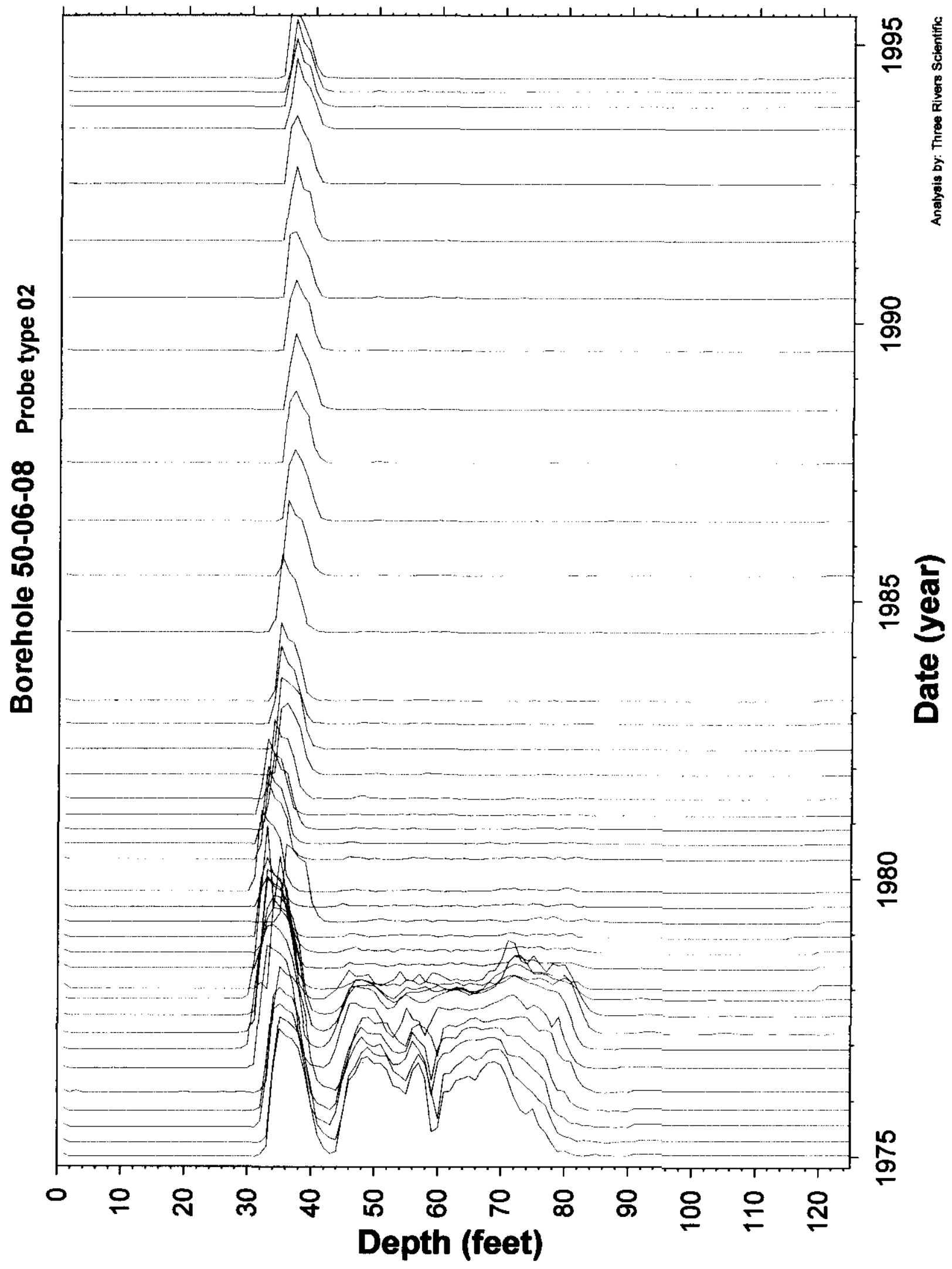

Tank T-106

Page 261 
RPP-6088, Rev.0.

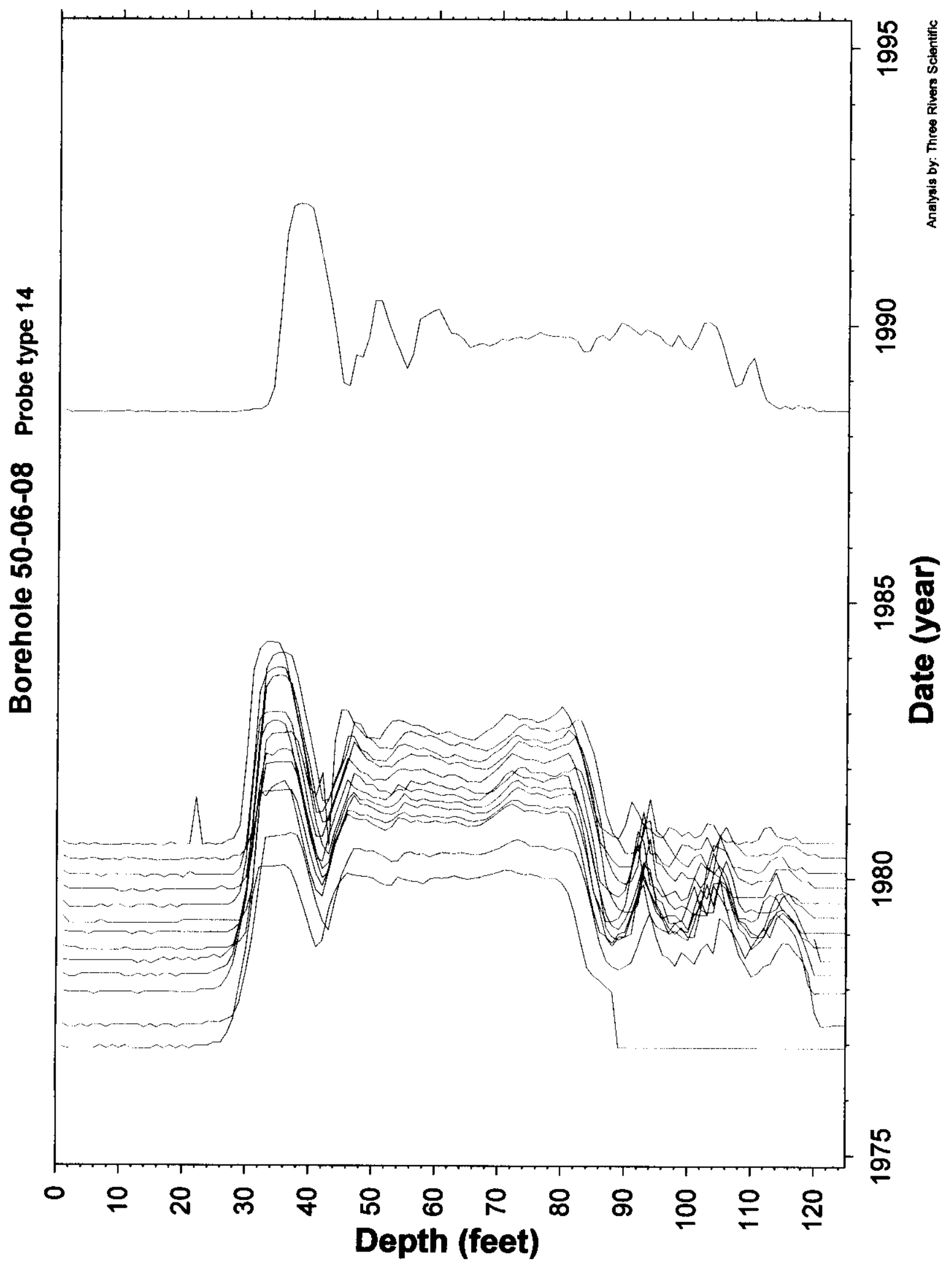

Tank T-106

Page 262 
RPP-6088, Rev.0.
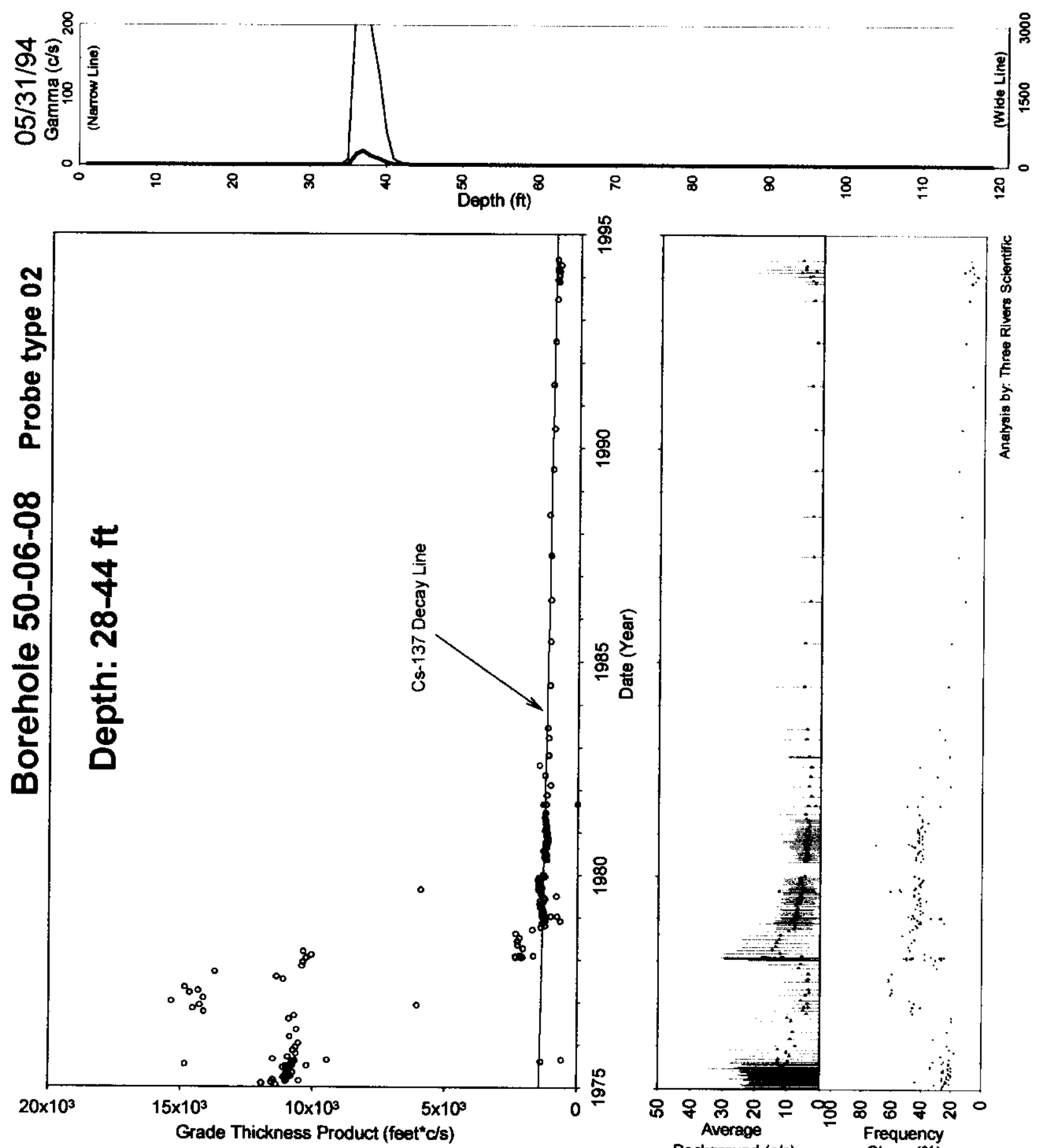

兽 
RPP-6088, Rev.0.
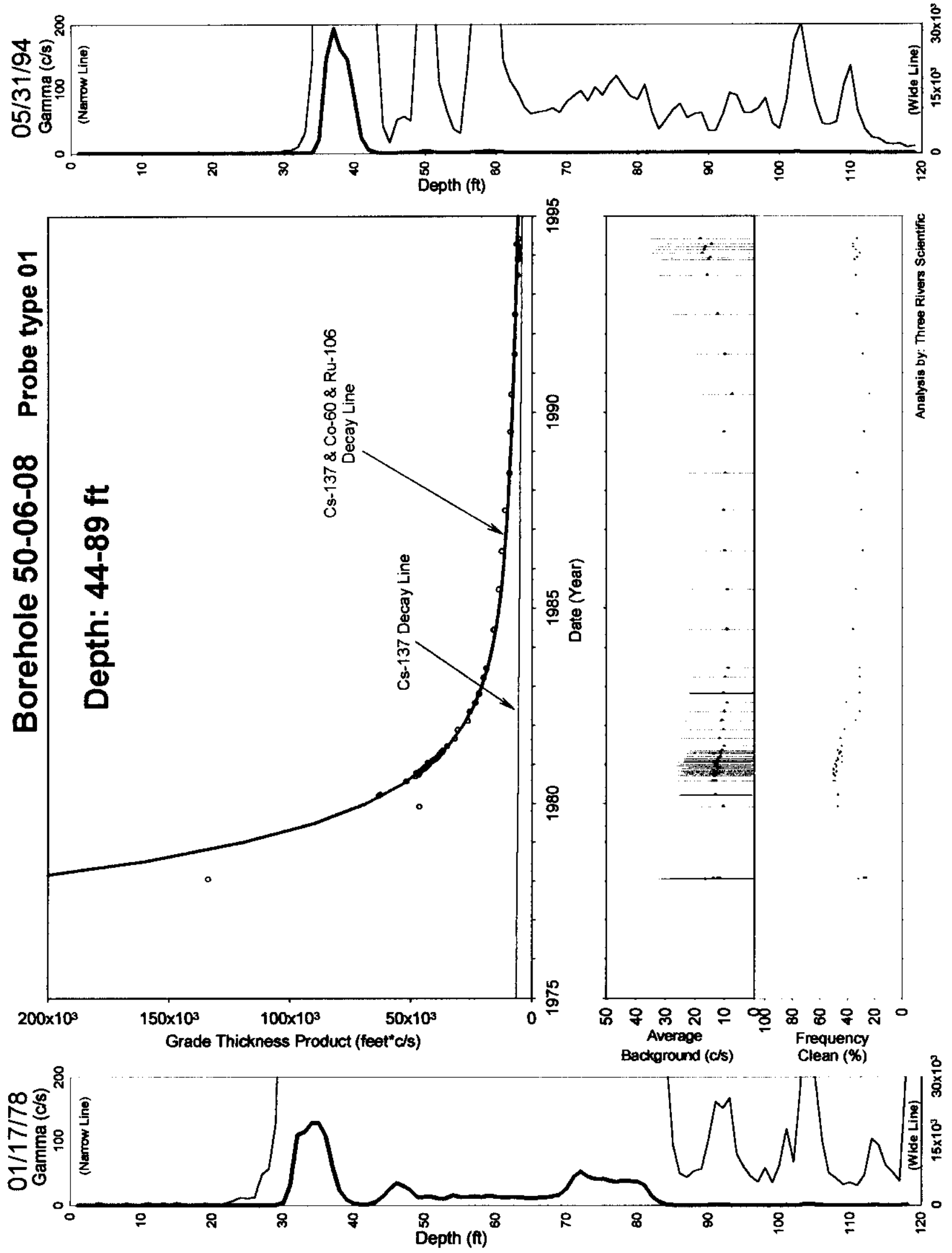

Tank T-106 
RPP-6088, Rev.0.
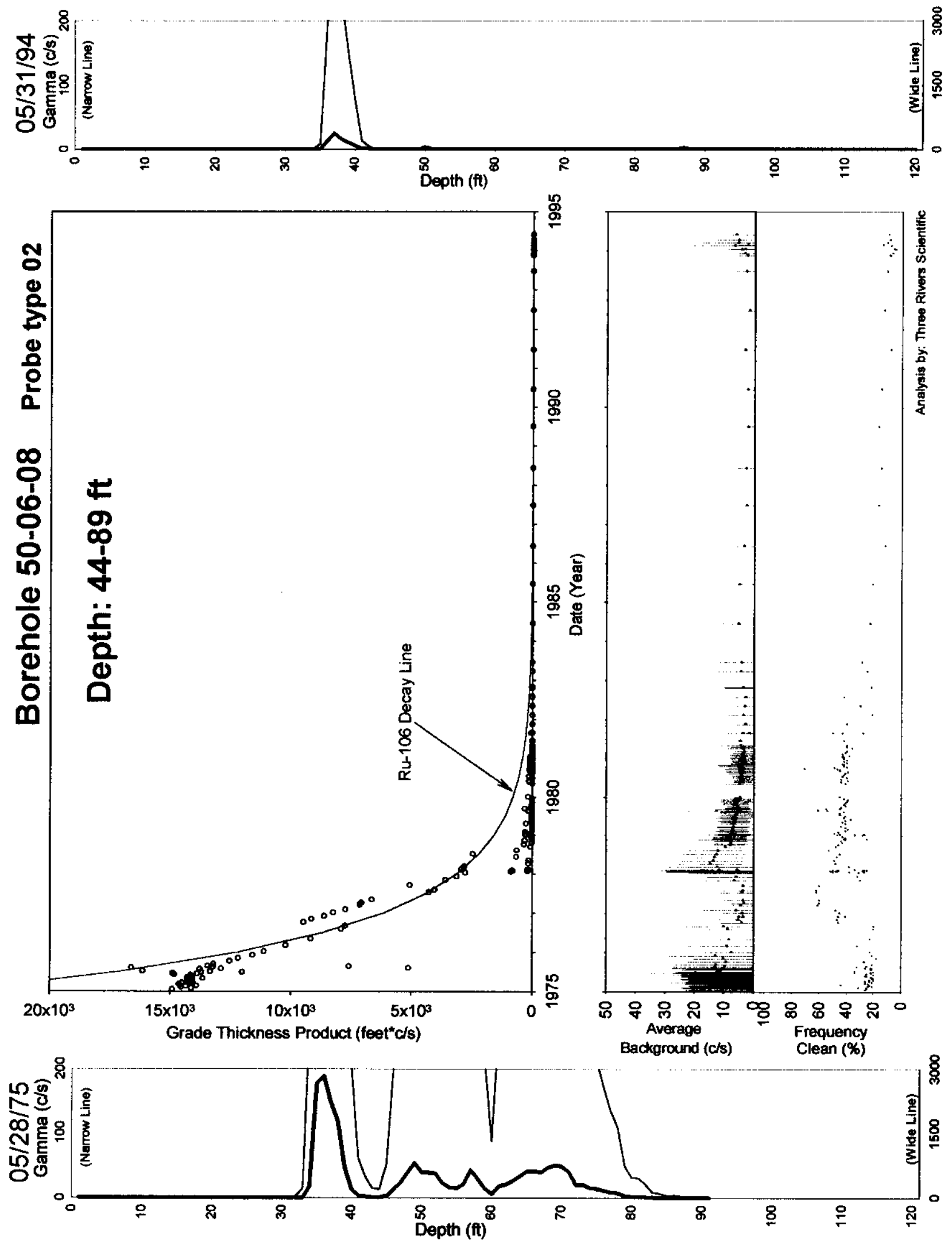

Tank T-106 
RPP-6088, Rev.0.
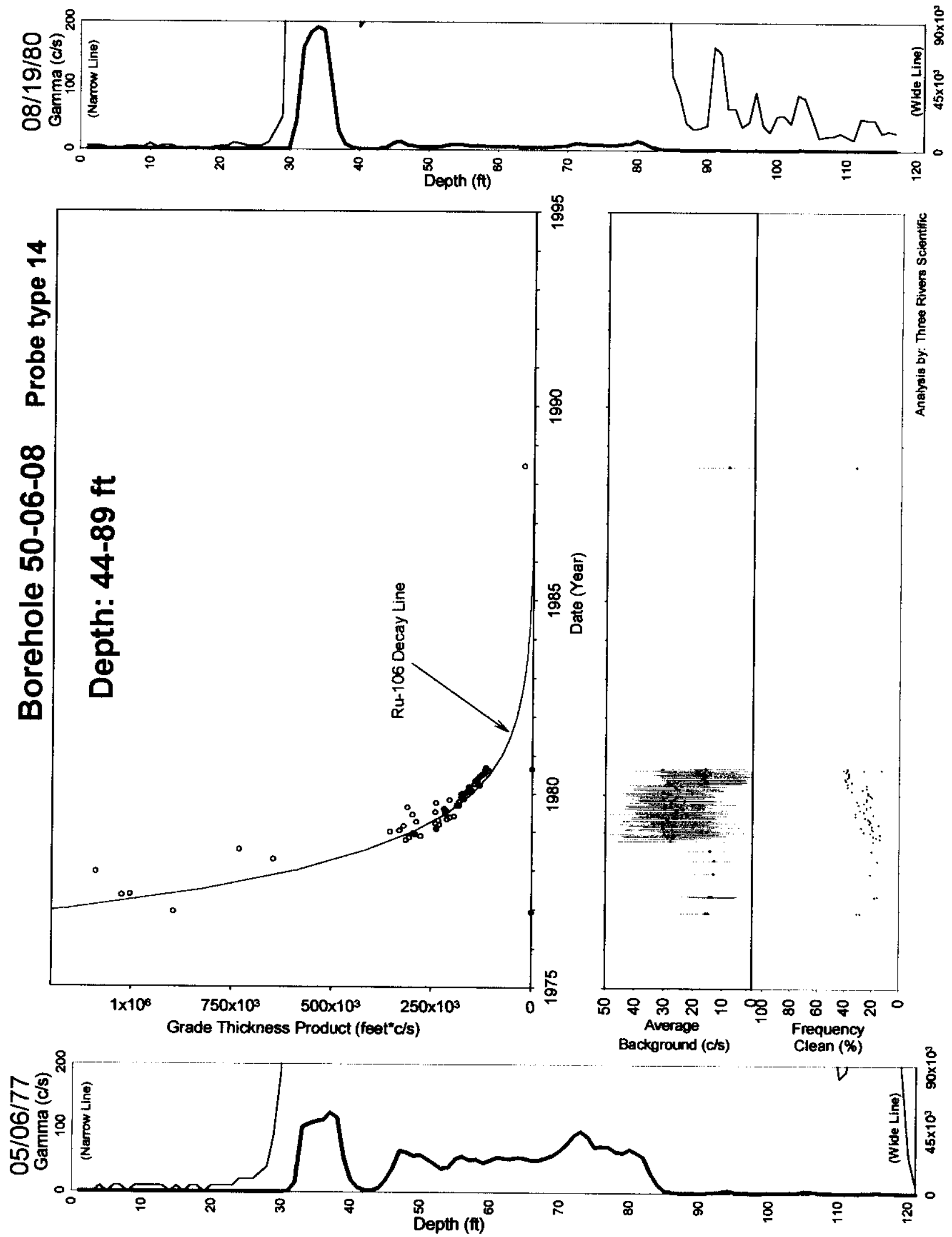

Tank T-106

Page 266 
RPP-6088, Rev.0.
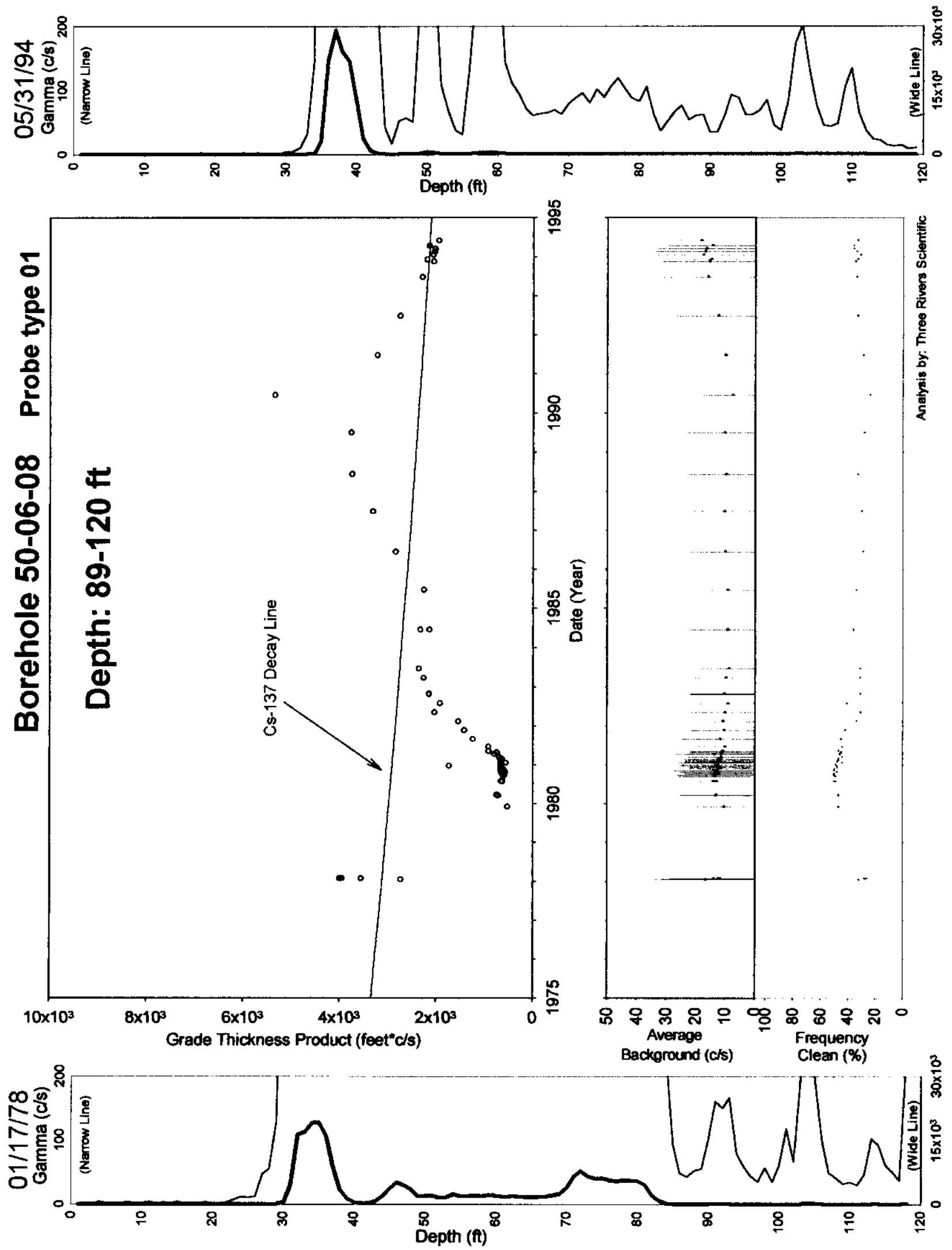

Tank T-106

Page 267 
RPP-6088, Rev.0.
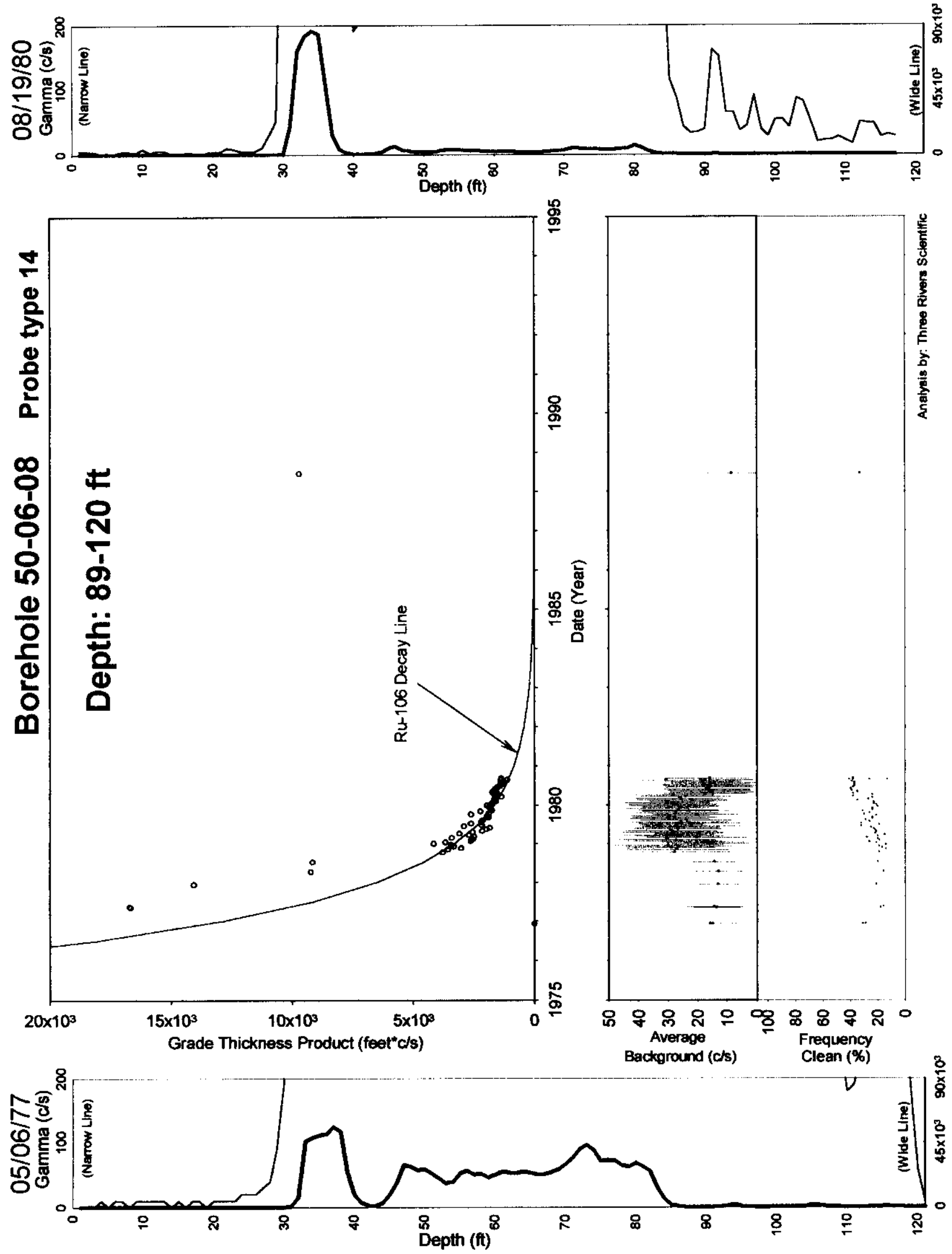

Tank T-106

Page 268 
RPP-6088, Rev.0.

\section{Borehole 50-06-11}

\section{Contamination (Ru-106) from 30 to 44 feet is Stable. Contamination ( $\mathrm{Ru}-106)$ from 44 to 54 feet is Unstable Early.}

Grade thickness product (GTP) over 30 to 44 feet is decreasing consistent with decay of Ru-106 (hypothesis). The GTP does not follow the decay line for probe type 04 in early 1975, however the GTP for probe type 14 has better agreement for the same time period. This response for probe type 04 at $50,000 \mathrm{c} / \mathrm{s}$ is characteristic of detector saturation at high count rates. The category is stable.

Grade thickness product over 44 to 54 feet is decreasing consistent with decay of Ru-106 (hypothesis) from 1977 to 1995 . Before 1977 the rate of decrease for both probe types (04 \& 14) is greater than the decay of Ru-106 indicating an unstable zone. The category is unstable early.

Analysis depth range for probe type 14 differ slightly due to variations in depth reference between surveys.

The average background plot shows a step decrease after the 8/19/1980 survey.

Gross Gamma Survey Information

Probe Type Processed: $104:$ Nal \& 14: Shielded NaI

Other Probe Types : 03: Neutron \& 02: Red GM

Survey Depth : $85 \mathrm{ft}$

First Survey Date : $04: 1 / 13 / 1975 \quad 14: 1 / 13 / 1975$

Last Survey Date : $04: 5 / 26 / 1994$ 14: 8/05/1977

Number Surveys Processed: $04: 169$ 14: 47

Analysis Notes

Method Used to Compute Background :

Depth(s) where Contamination was $30-44$ feet Stable

Identified in Gross Gamma Surveys : $44-54$ feet Unstable Early

Analyst Name : R. K. Price

Company Name : Three Rivers Scientific 
RPP-6088, Rev.0.

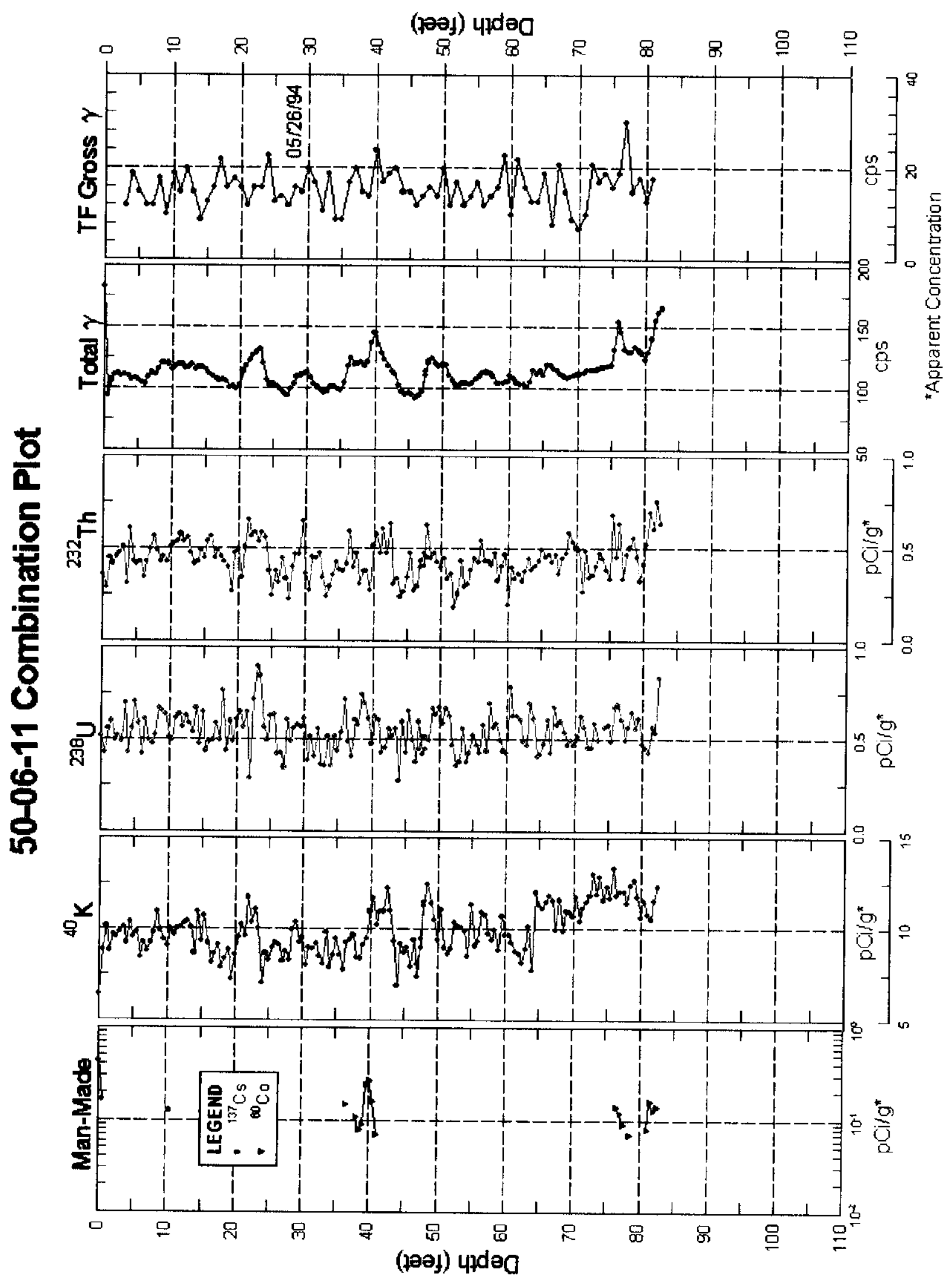

Tank T-106

Page 270 
RPP-6088, Rev.0.

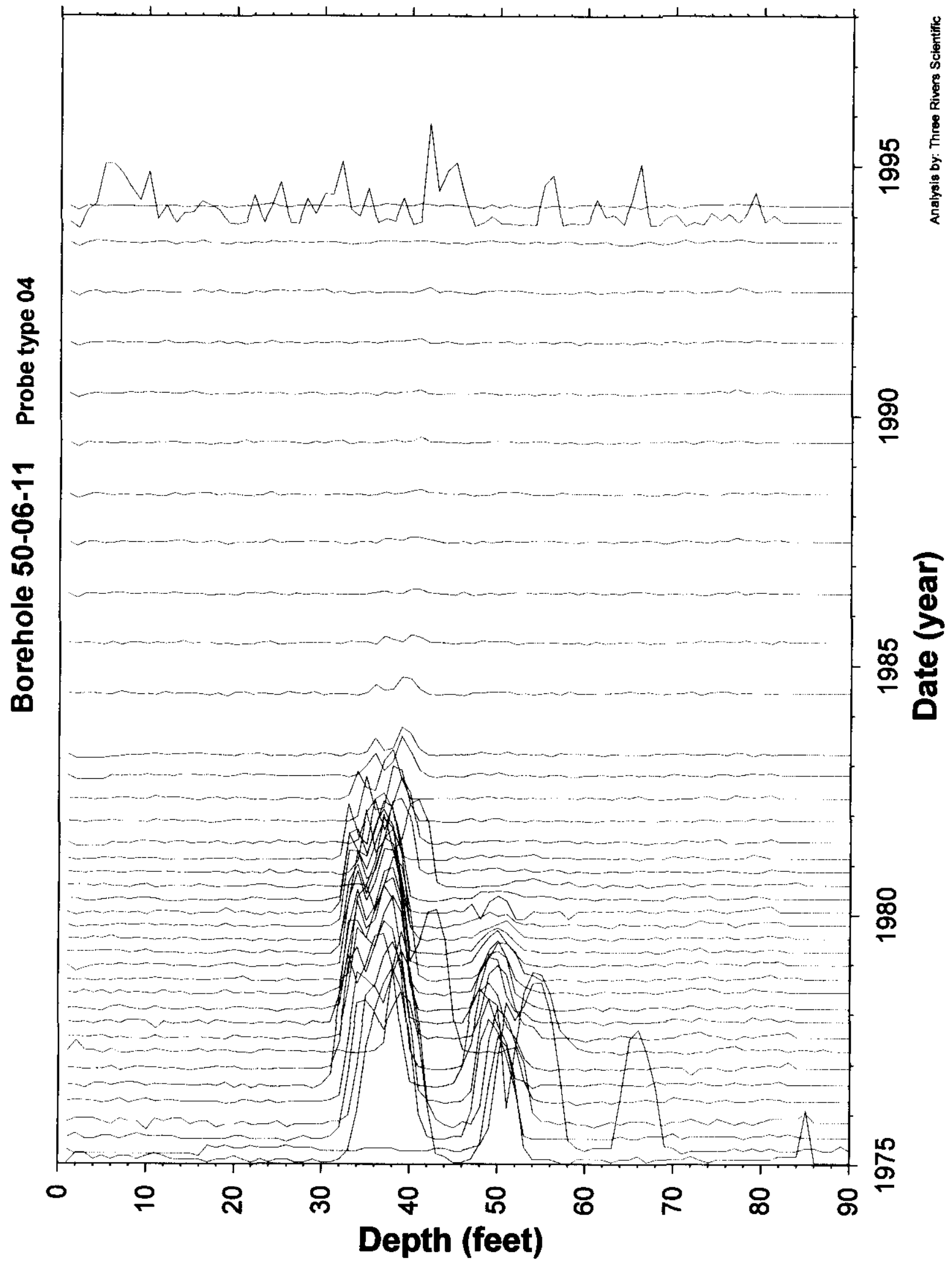

Tank T-106

Page 271 
RPP-6088, Rev.0.

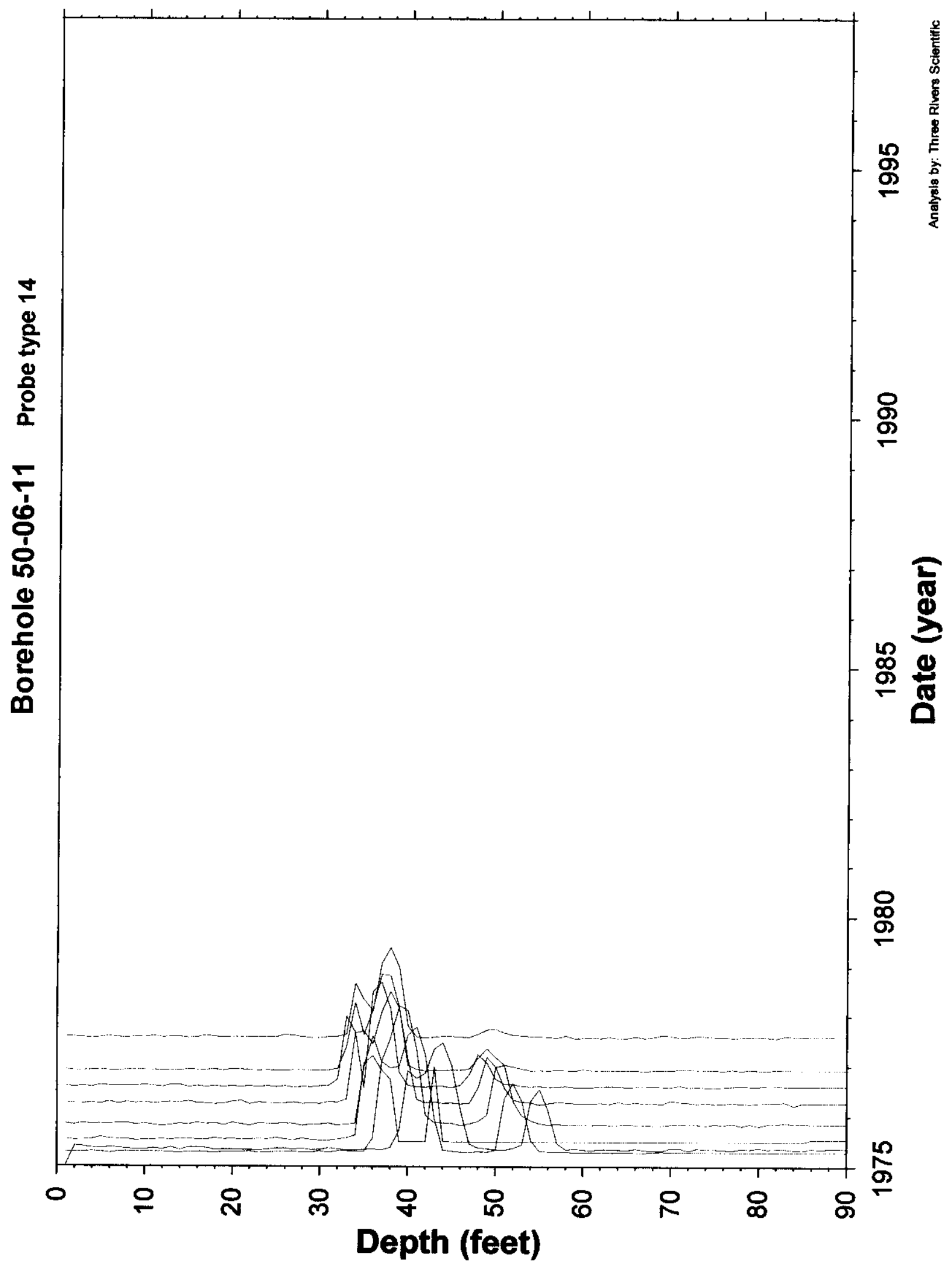

Tank T-106

Page 272 
RPP-6088, Rev.0.
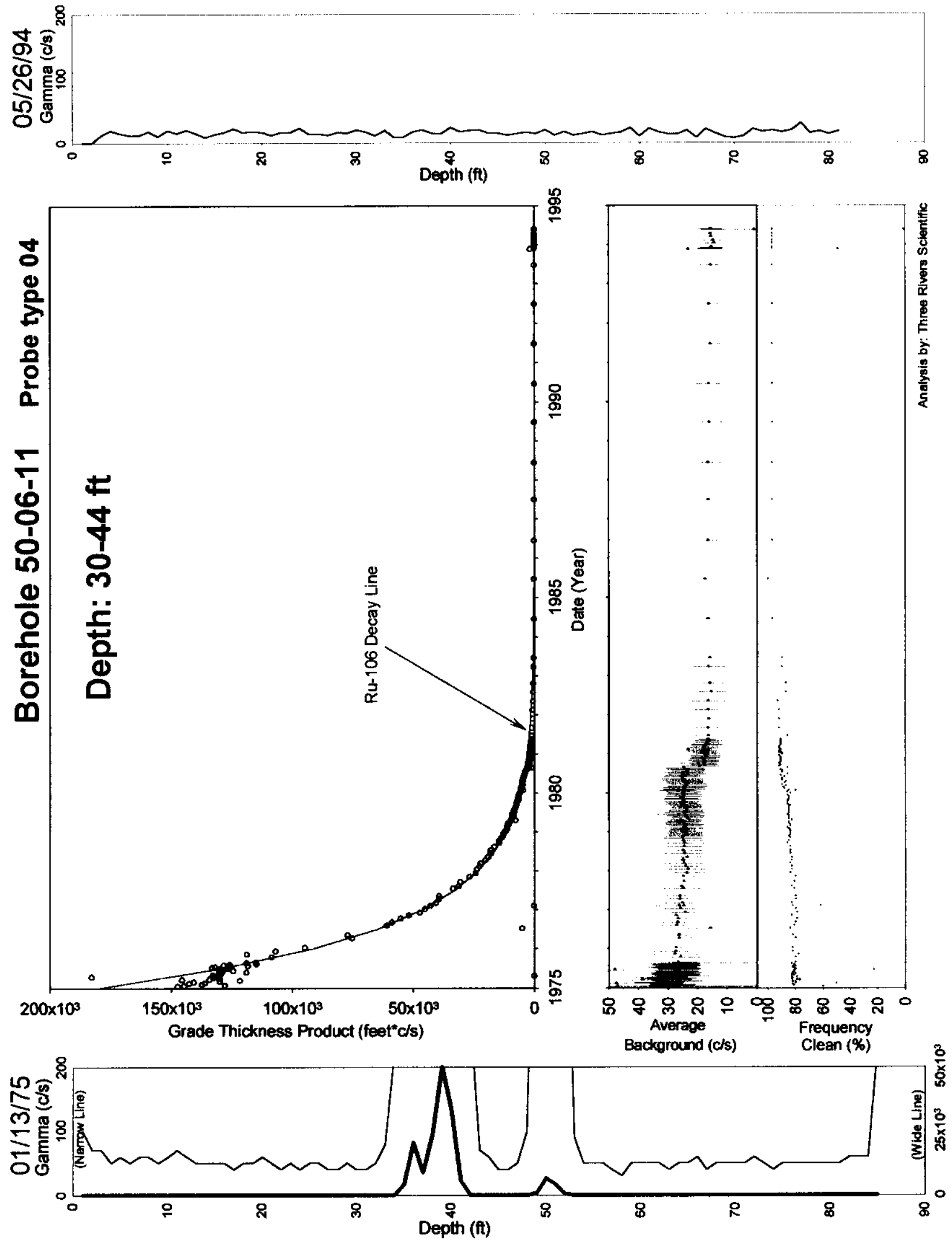

Tank T-106

Page 273 
RPP-6088, Rev.0.
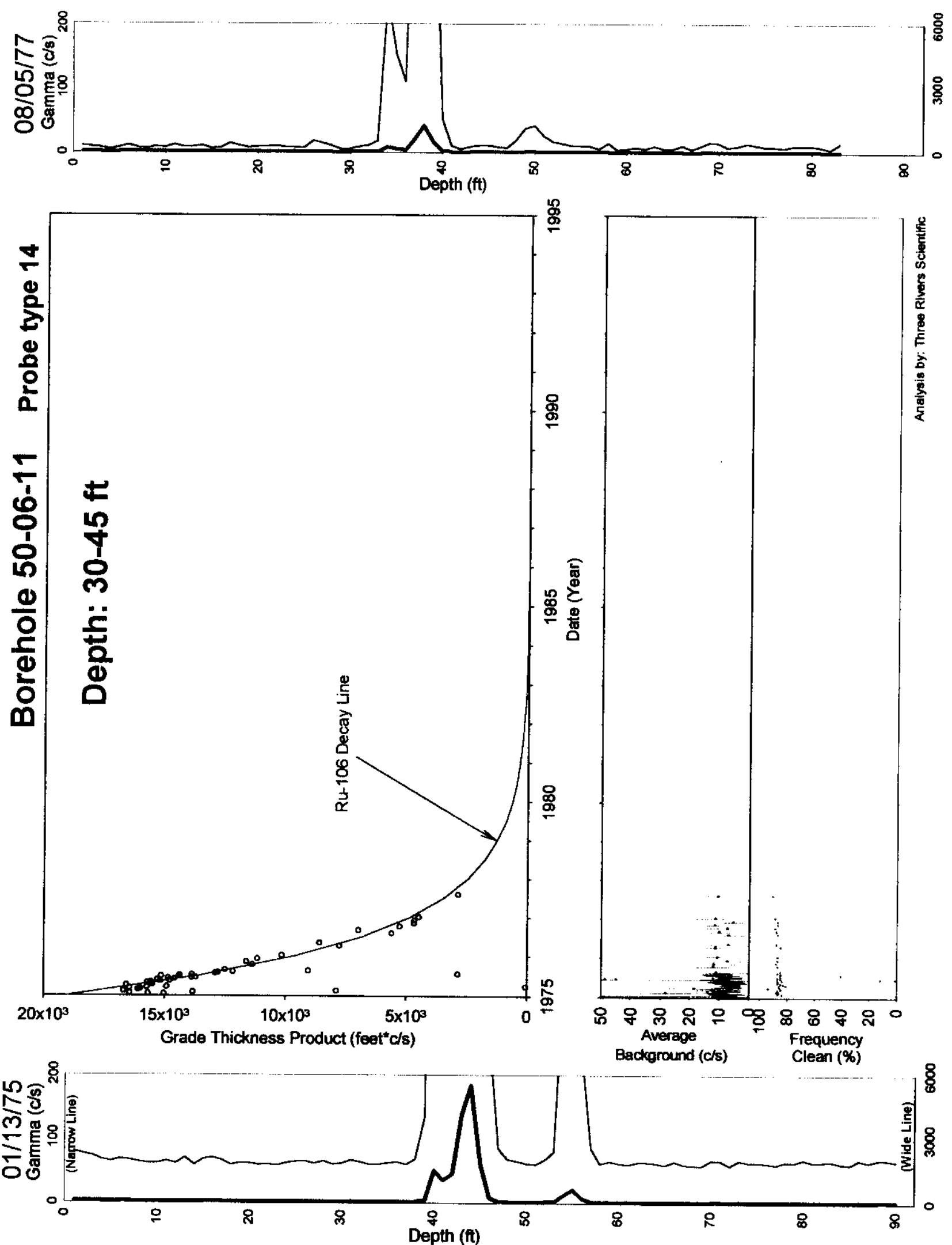

Tank T-106

Page 274 
RPP-6088, Rev.0.
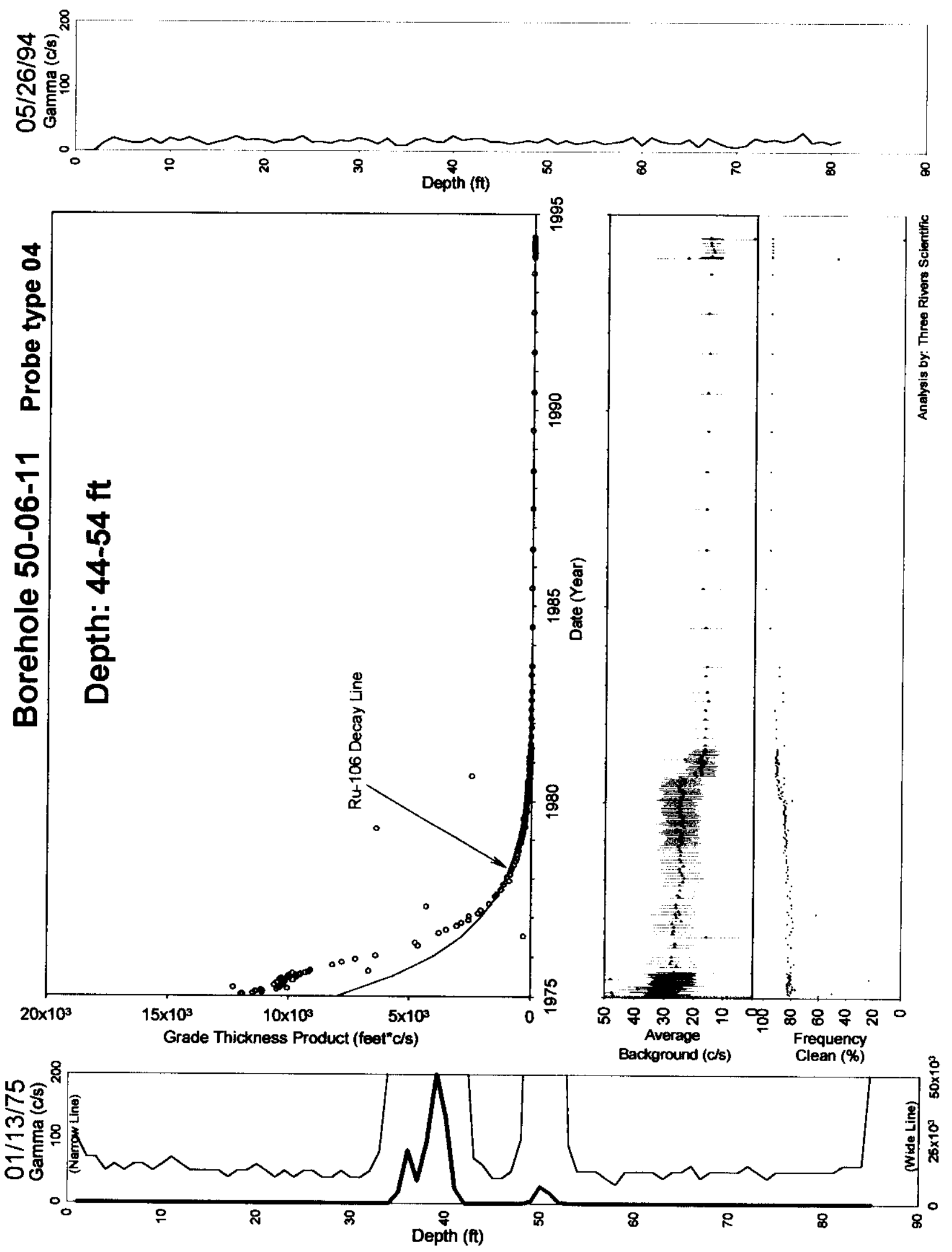

Tank T-106

Page 275 
RPP-6088, Rev.0.
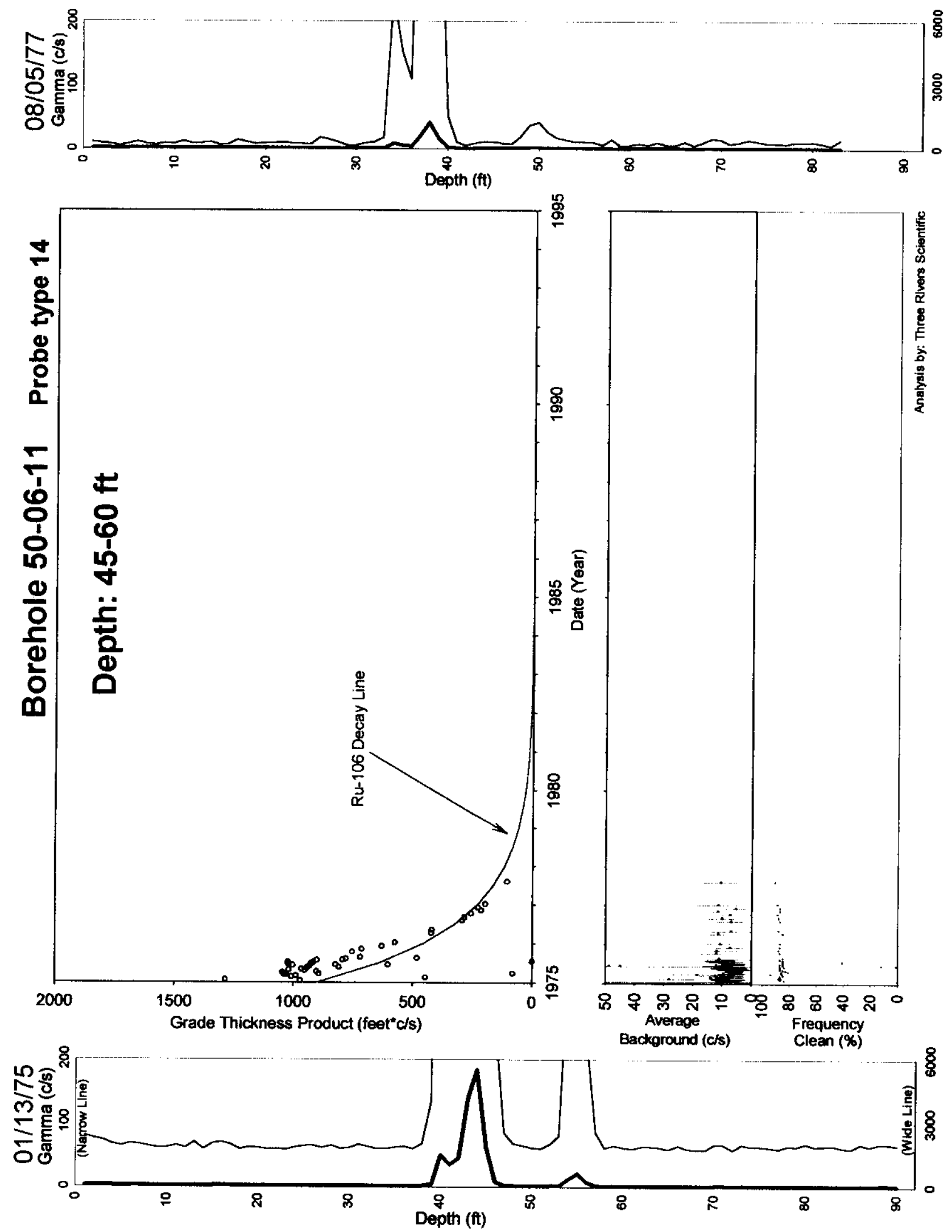

Tank T-106

Page 276 


\section{Borehole 50-06-16}

\section{Contamination (Cs-137) from 10 to 20 feet is Stable. Contamination (Cs-137, Co-60, Ru-106) from 30 to 63 feet is Stable. Contamination (Eu-154, Co-60, Ru-106) from 63 to 90 feet is Stable.}

Grade thickness product (GTP) over 10 to 20 feet is decreasing consistent with Cs-137 (HPGe identified) from 1976 to 1995.

Tank farms used three probe types (02:Red GM, 14:Shielded NaI, and 04:NaI) to monitor the high levels of contamination. The GTP plots are included for relevant probe types. Probe type 02 had multiple sensitivity configurations (1975-1978) which complicates contaminant stability analysis and is not shown. Early surveys (1975-1980) of probe types 04 are invalid due to detector saturation.

Grade thickness product over 30 to 63 feet is decreasing consistent with a least square fit for Cs137 and Co-60 (both HPGe identified), and Ru-106 (hypothesis) and is categorized as stable. The ratio of gross contribution for Cs-137:Co-60:Ru-106 is 17700:3830:1 as of 1-1-1996 for probe type 04.

Grade thickness product over 63 to 90 feet is decreasing consistent with a least square fit for Eu154, Co-60 (both HPGe identified) and Ru-106 (hypothesis) and is categorized as stable. The ratio of gross contribution for Eu-154:Co-60:Ru-106 is 334:260:1 as of 1-1-1996 for probe type 04.

Gross Garnma Survey Information

\begin{tabular}{|r|l|}
\hline Probe Type Processed: & 02: Red GM, 04: NaI \& 14: Shielded NaI \\
\hline Other Probe Types : & $03:$ Neutron \& 01: Green GM \\
\hline Survey Depth : & $90 \mathrm{ft}$ (decreased from 125 ft after 10/10/1975) \\
\hline First Survey Date : & $02: 7 / 23 / 1975 \quad 04: 7 / 25 / 1975 \quad 14: 7 / 25 / 1975$ \\
\hline Last Survey Date : & $02: 2 / 17 / 1994 \quad 04: 5 / 20 / 1994 \quad 14: 6 / 13 / 1988$ \\
\hline Number Surveys Processed: & $02: 81 \quad 04: 66 \quad 14: 144$ \\
\hline
\end{tabular}

Analysis Notes

Method Used to Compute Background : $22-28$ feet

Depth(s) where Contamination was $10-20,30-63,63-90$ feet Stable Identified in Gross Gamma Surveys :

Analyst Name : R. K. Price

Company Name : $\quad$ Three Rivers Scientific 
RPP-6088, Rev.0.

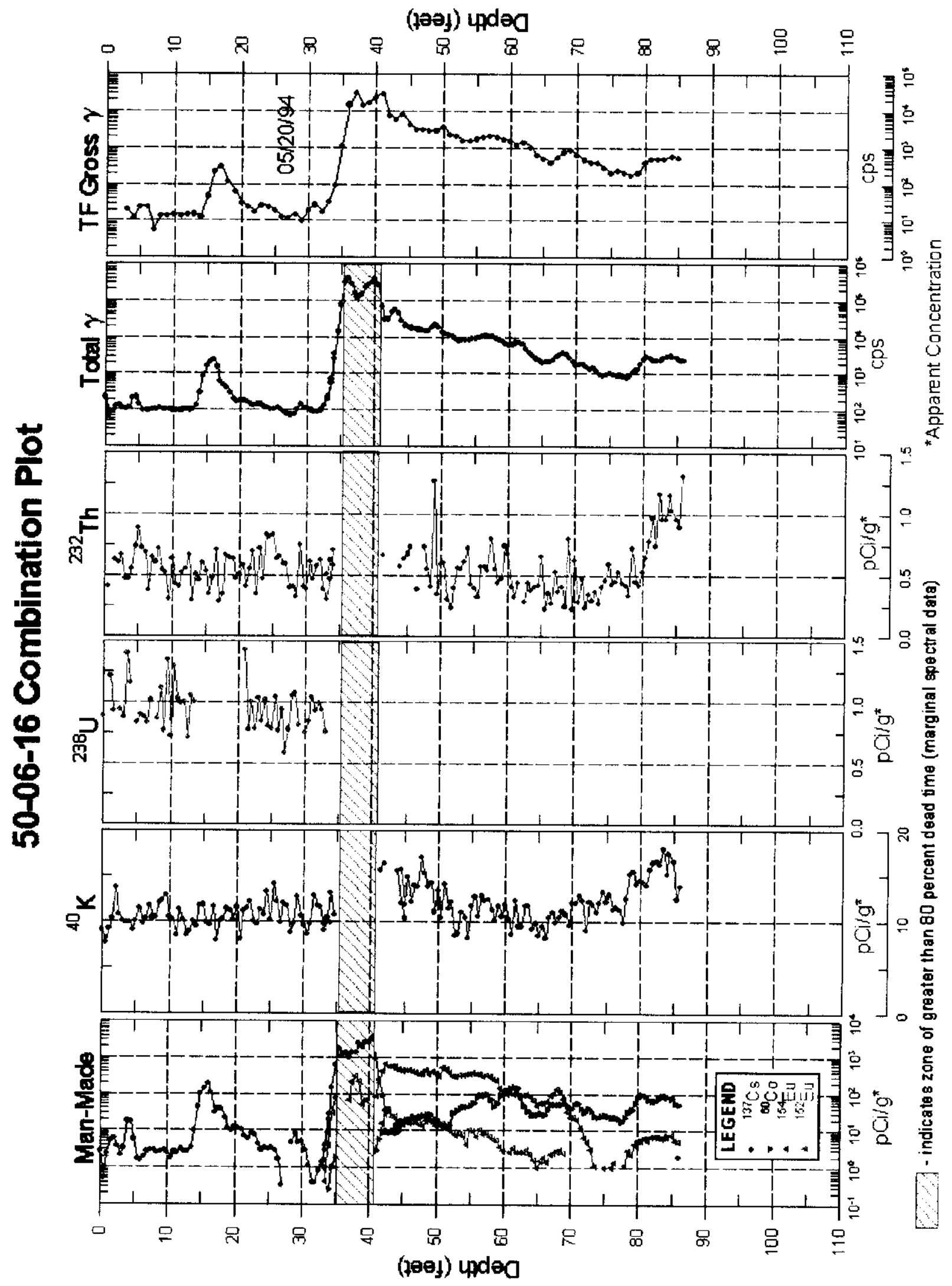


RPP-6088, Rev.0.

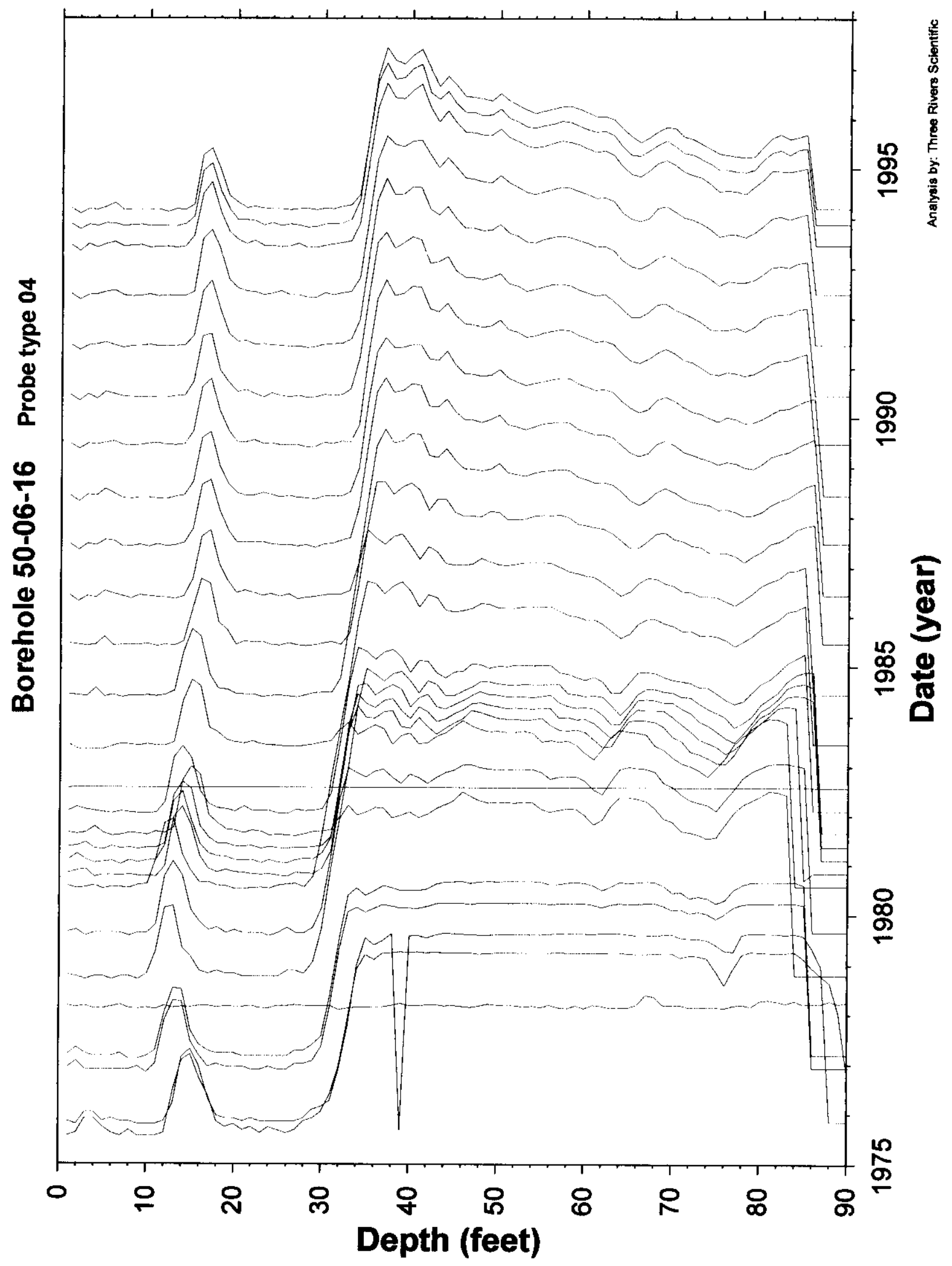

Tank T-106

Page 279 
RPP-6088, Rev.0.

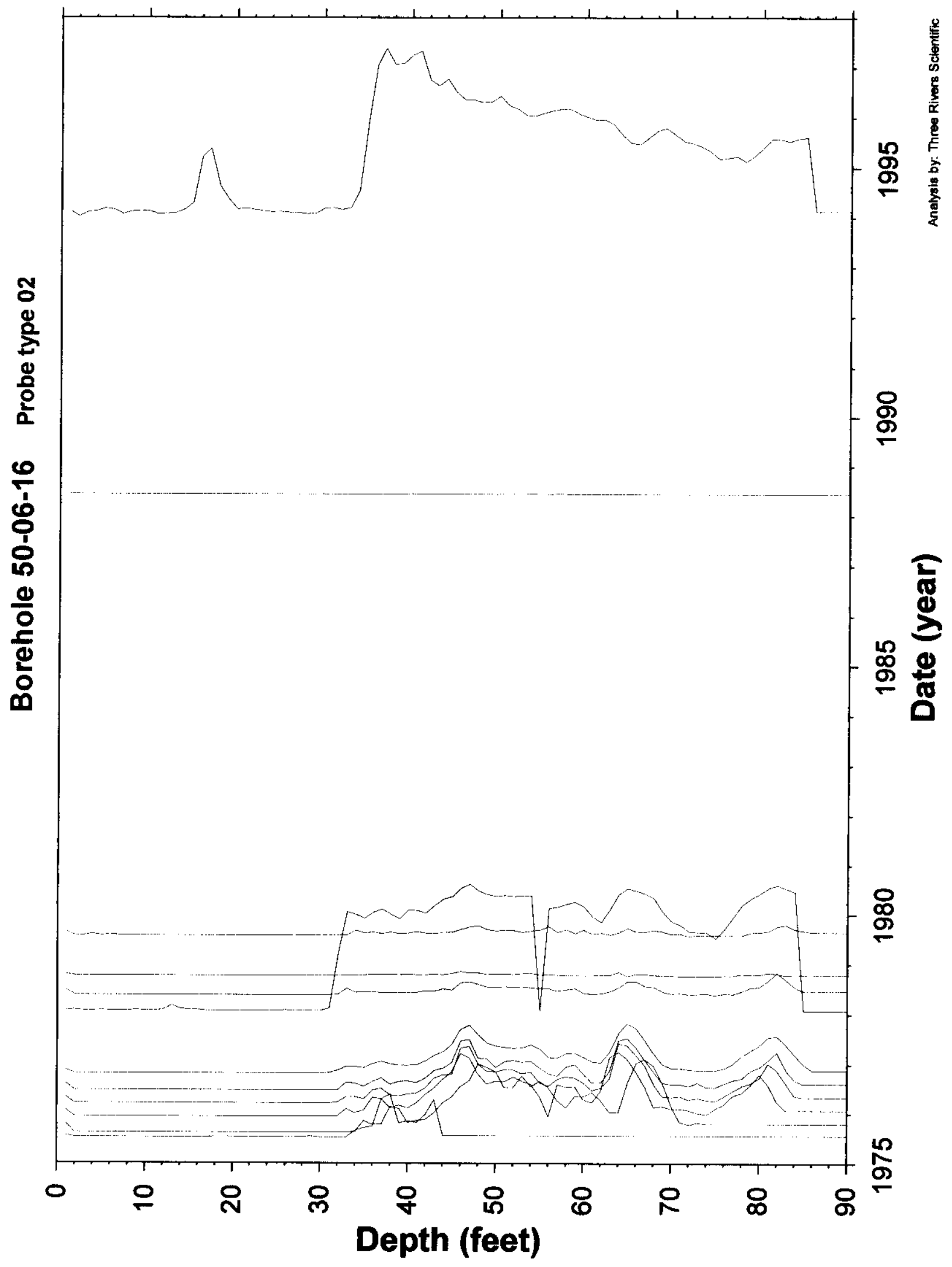

Tank T-106

Page 280 
RPP-6088, Rev.0.

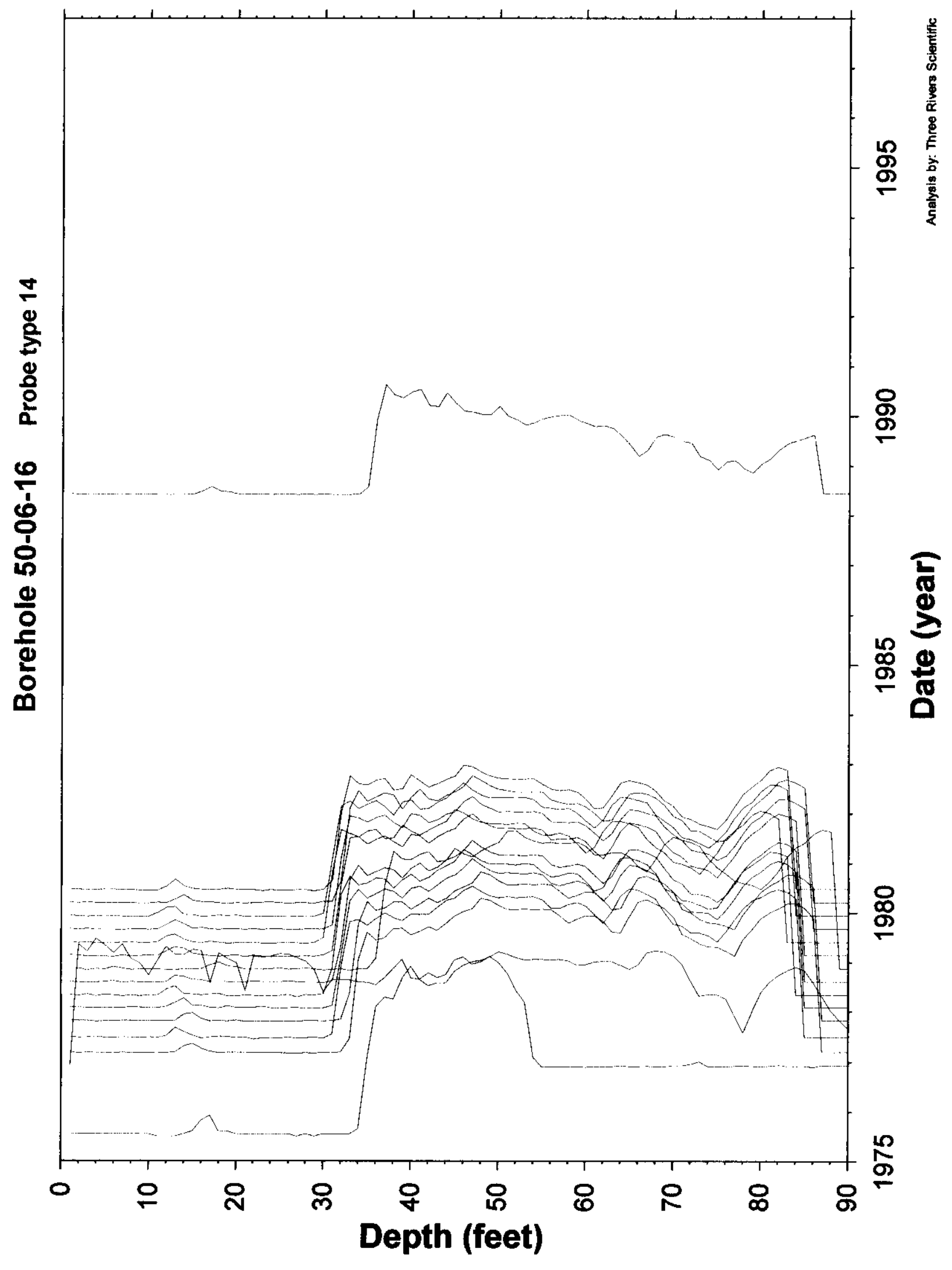

Tank T-106 
RPP-6088, Rev.0.
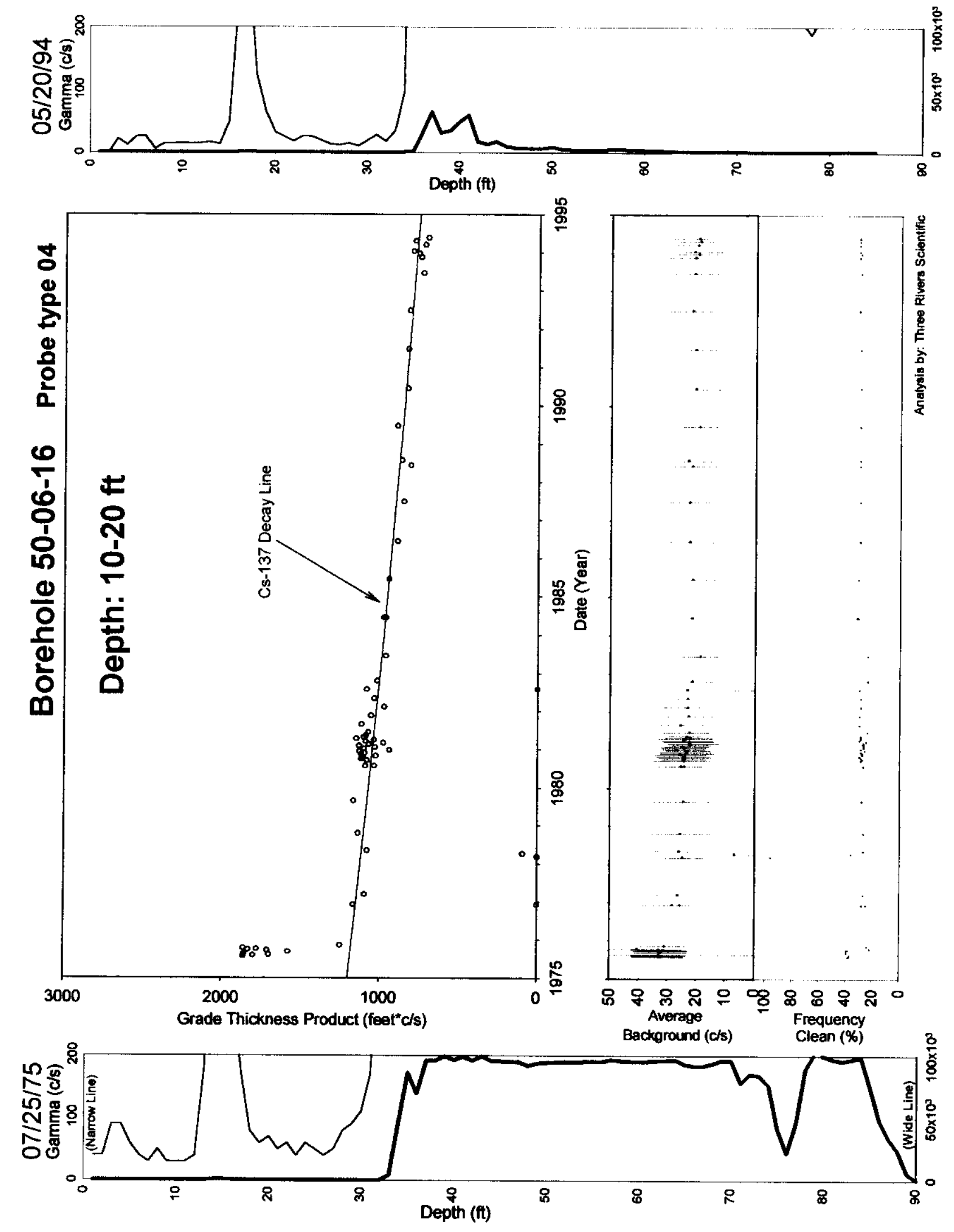

g

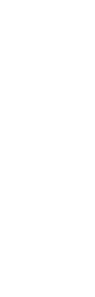

-

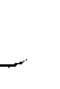

Tank T-106

Page 282 
RPP-6088, Rev.0.
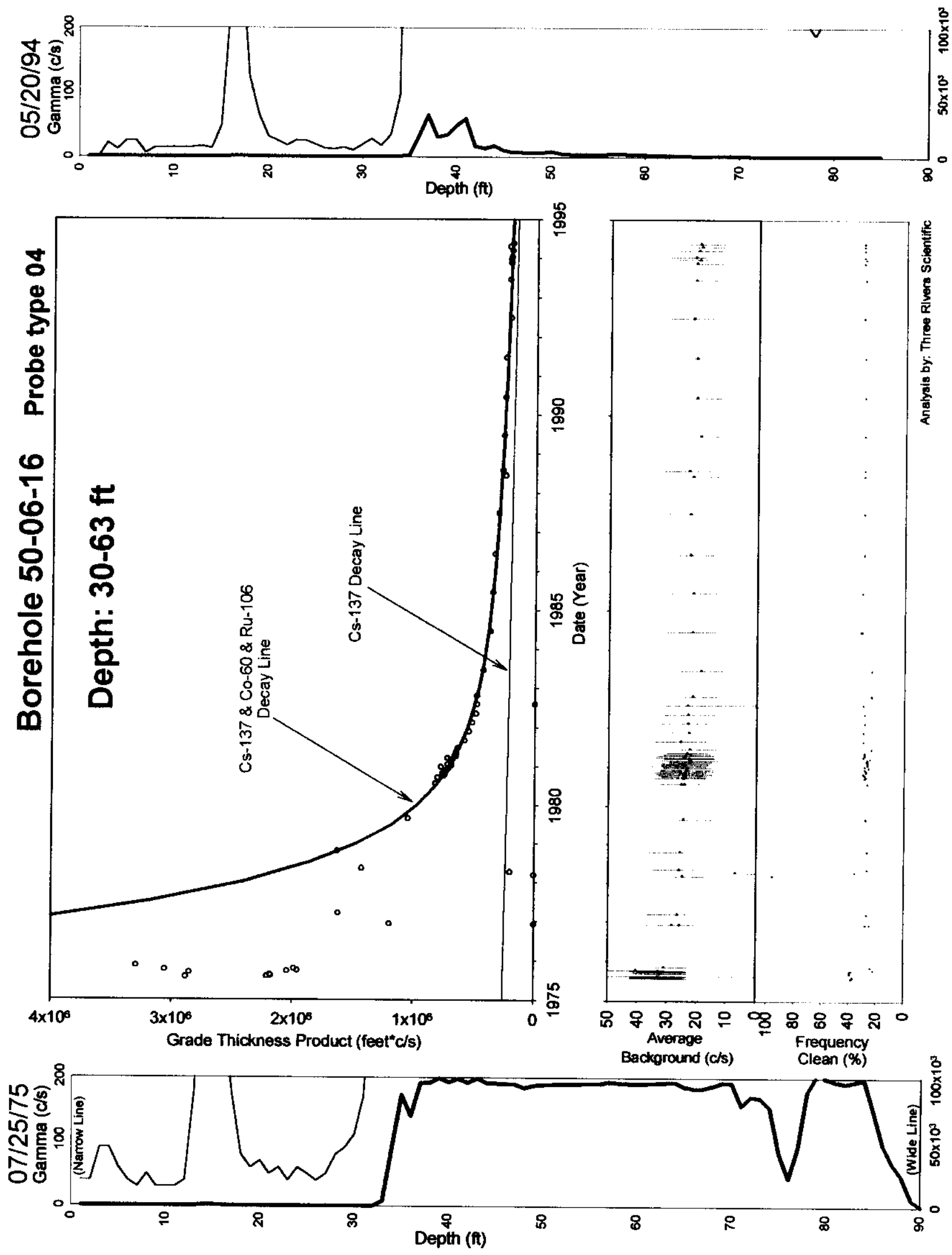

Tank T-106 
RPP-6088, Rev.0.
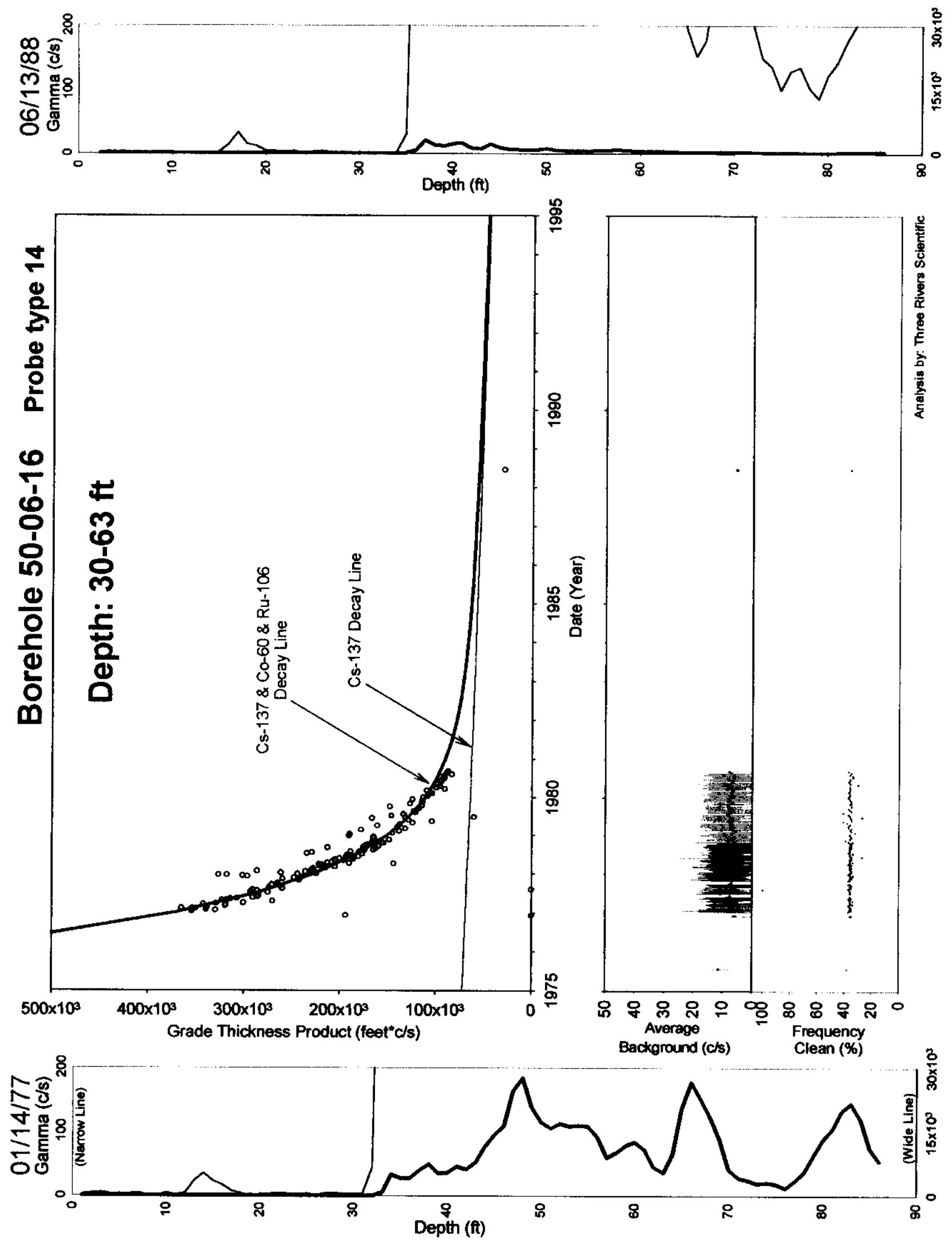
RPP-6088, Rev.0.
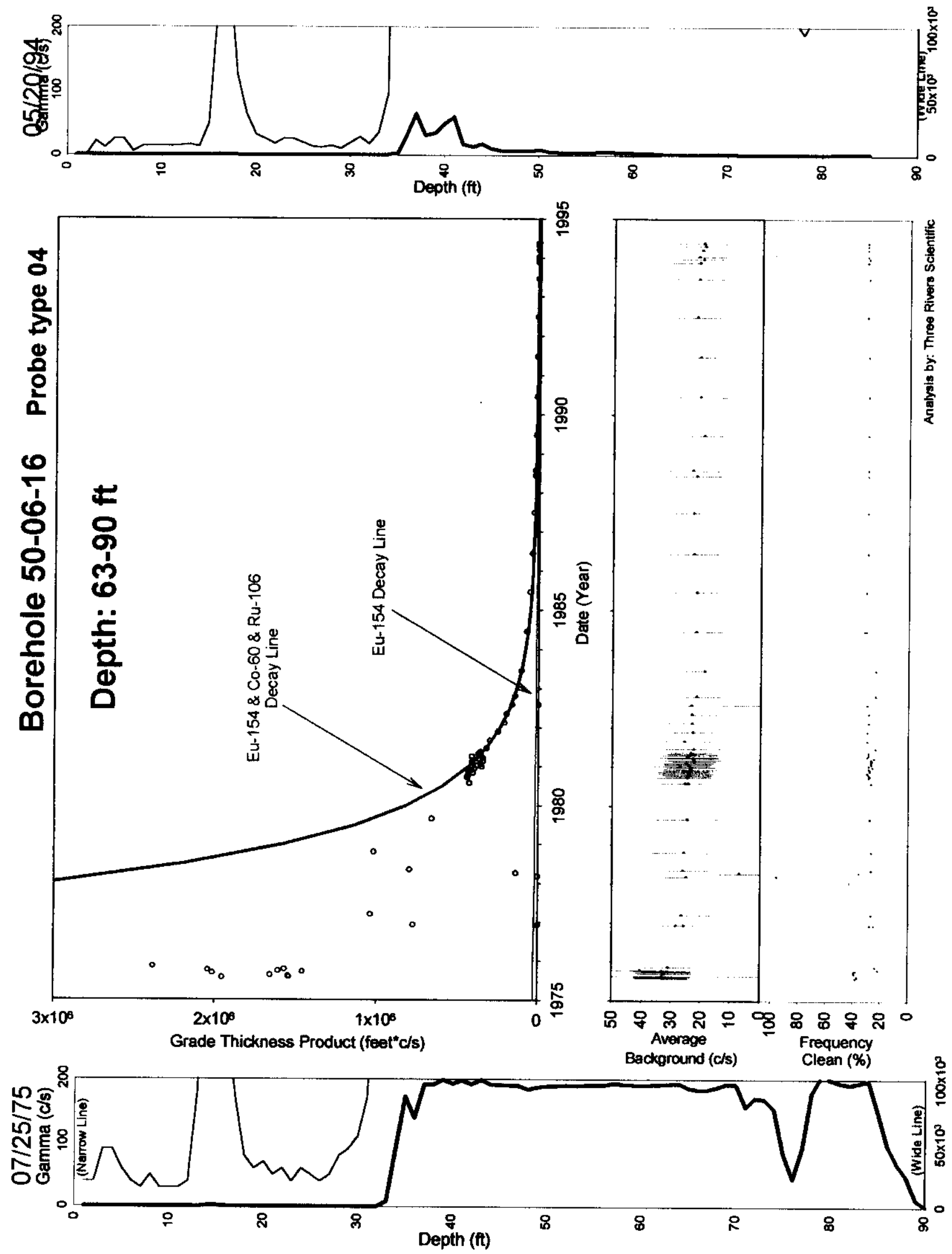

Tank T-106 
RPP-6088, Rev.0.
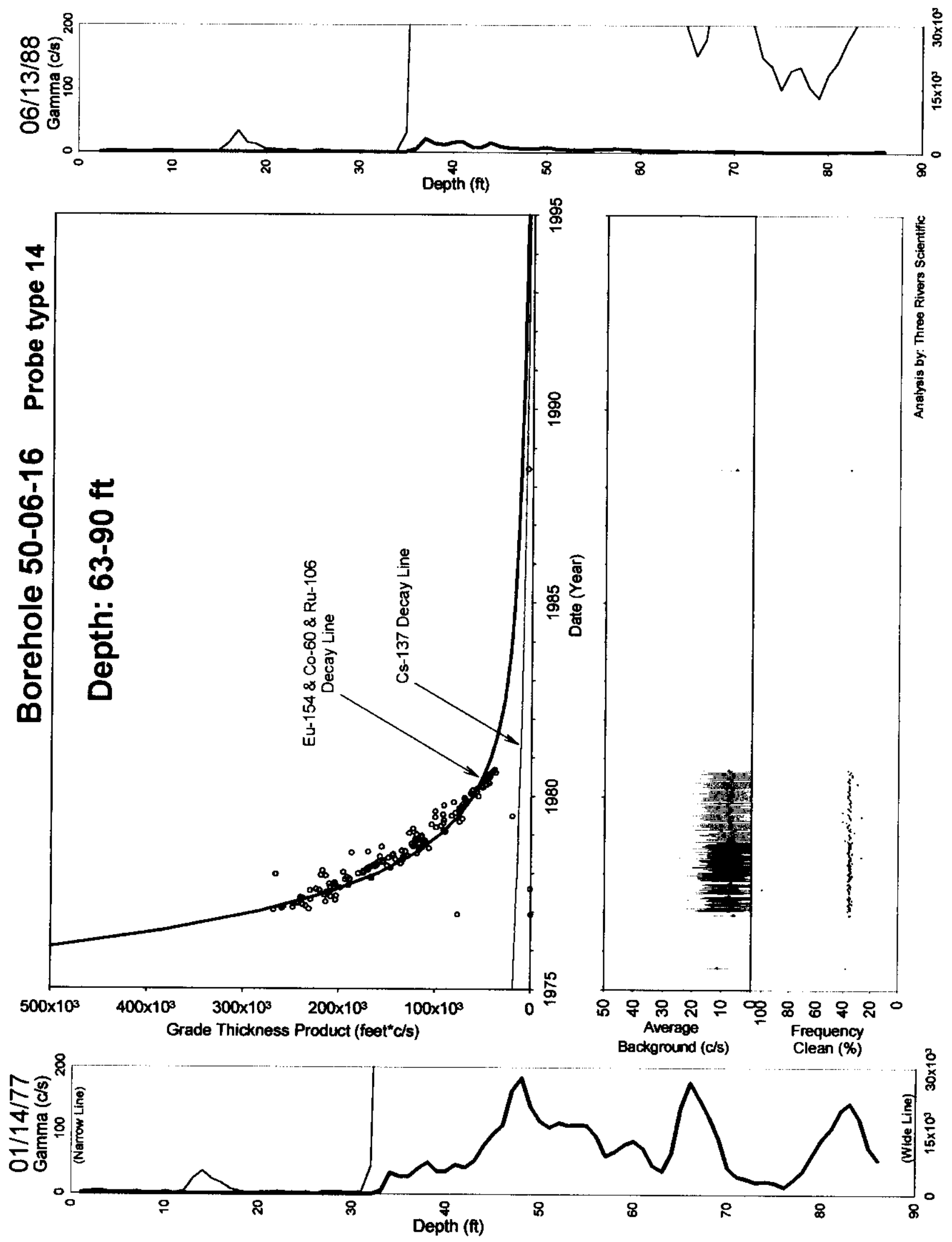
RPP-6088, Rev.0.

\section{Borehole 50-06-17}

\section{Contamination (Cs-137) from 28 to 52 feet is Stable. Contamination (Cs-137, Ru-106) from 52 to 90 feet is Stable.}

Probe type 02 had multiple sensitivity configurations (1975-1978) which complicate contaminant stability analysis.

Grade thickness product over 28 to 52 feet is decreasing consistent with Cs-137 (HPGe identified) from 1978 to 1995 . The GTP plot for probe type 02 shows the multiple probe sensitivity configurations as abrupt changes in contaminant activity.

Grade thickness product over 52 to 70 feet is decreasing consistent with Cs-137 (HPGe identified) and Ru-106 (hypothesis). The GTP plot for probe type 02 shows the multiple probe sensitivity configurations as apparent parallel contaminant decay that exhibit the same slope as the Ru-106 decay (blue line).

Gross Gamma Survey Information

\begin{tabular}{|r|l|}
\hline Probe Type Processed: & 02: Red GM \\
\hline Other Probe Types : & $\begin{array}{l}\text { 01: Green GM, 03: Neutron, } \\
\text { 04: NaI \& \& 14: Shielded NaI }\end{array}$ \\
\hline Survey Depth : & $85 \mathrm{ft}$ \\
\hline First Survey Date : & $7 / 23 / 1975$ \\
\hline Last Survey Date : & $5 / 31 / 1994$ \\
\hline Number Surveys Processed: & 276 \\
\hline
\end{tabular}

Analysis Notes

Method Used to Compute Background : 5 5-25 feet

Depth(s) where Contamination was $28-52,52-70$ feet Stable

Identified in Gross Gamma Surveys :

Analyst Name : $\quad$ R. K. Price

Company Name : $\quad$ Three Rivers Scientific 
RPP-6088, Rev.0.

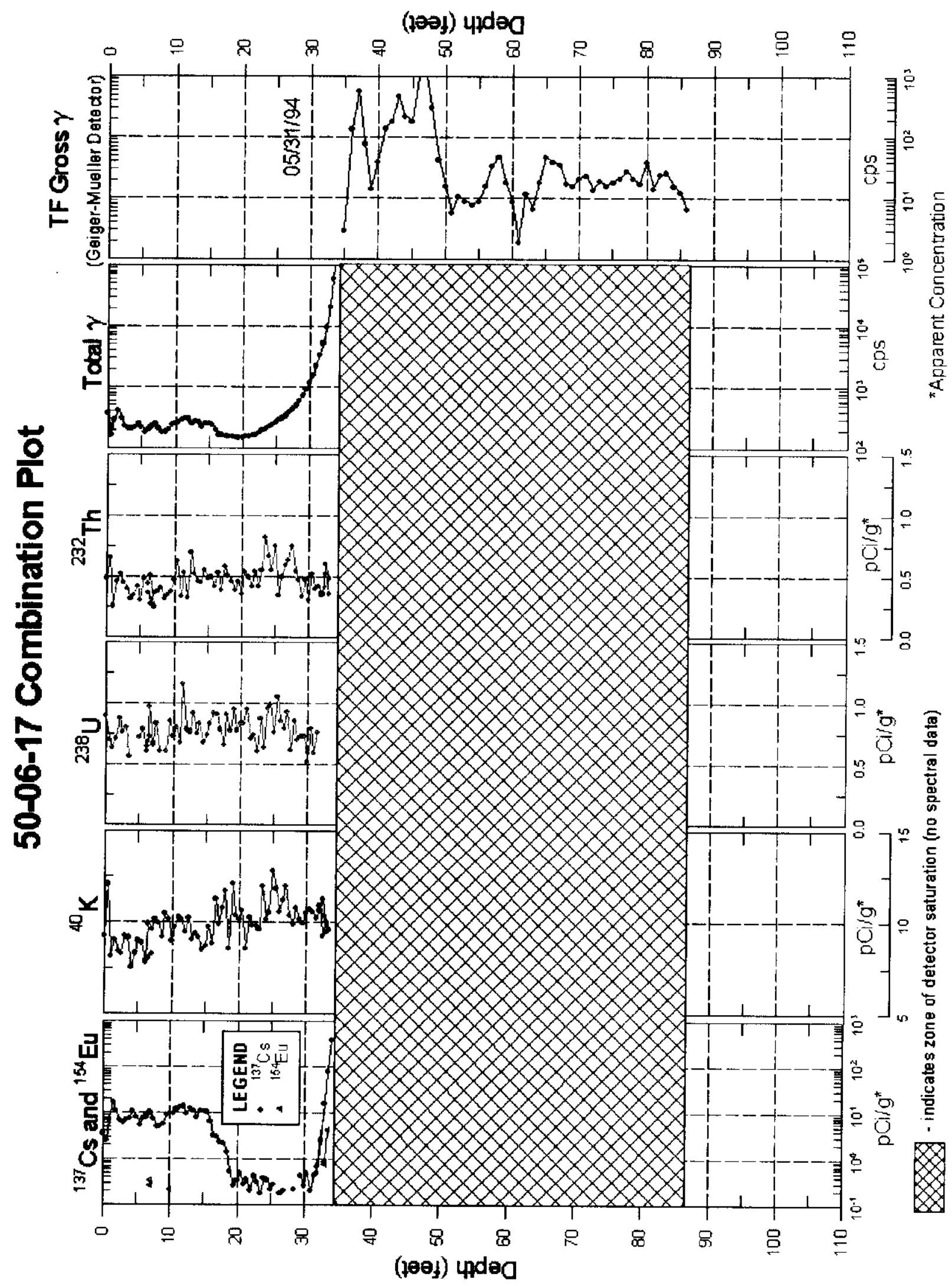

Tank T-106

Page 288 
RPP-6088, Rev.0.

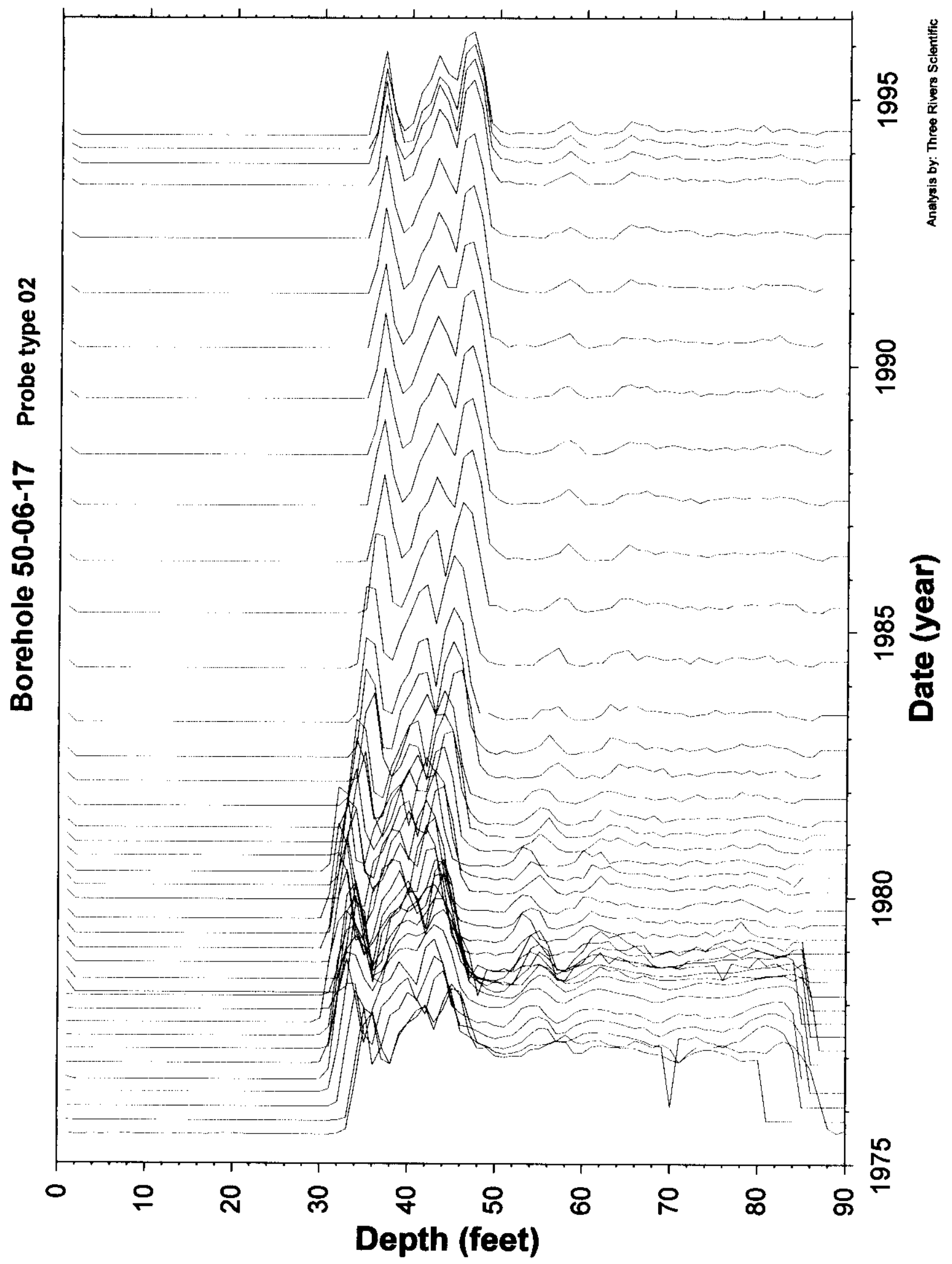

Tank T-106

Page 289 
RPP-6088, Rev.0.
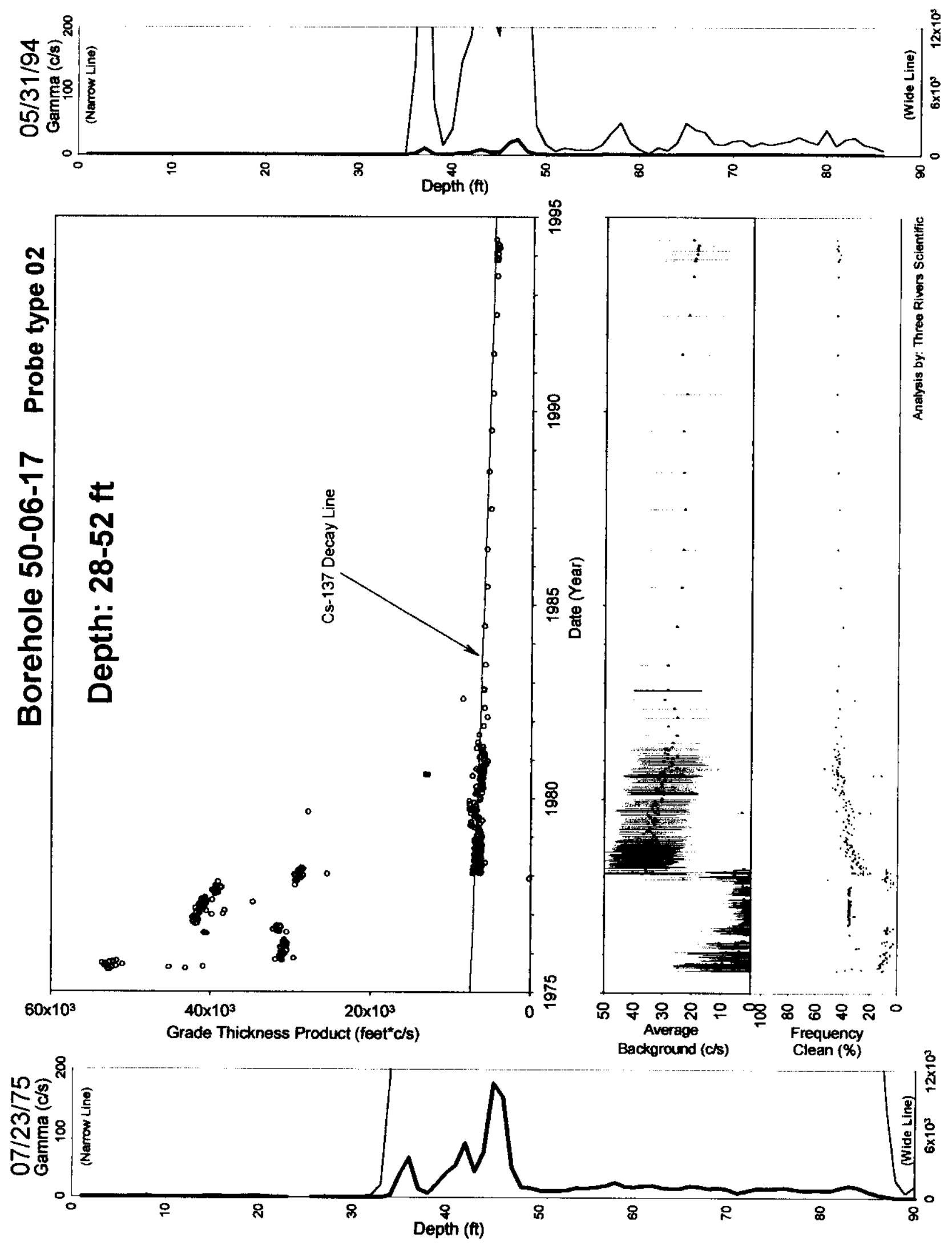

Tank T-106 
RPP-6088, Rev.0.
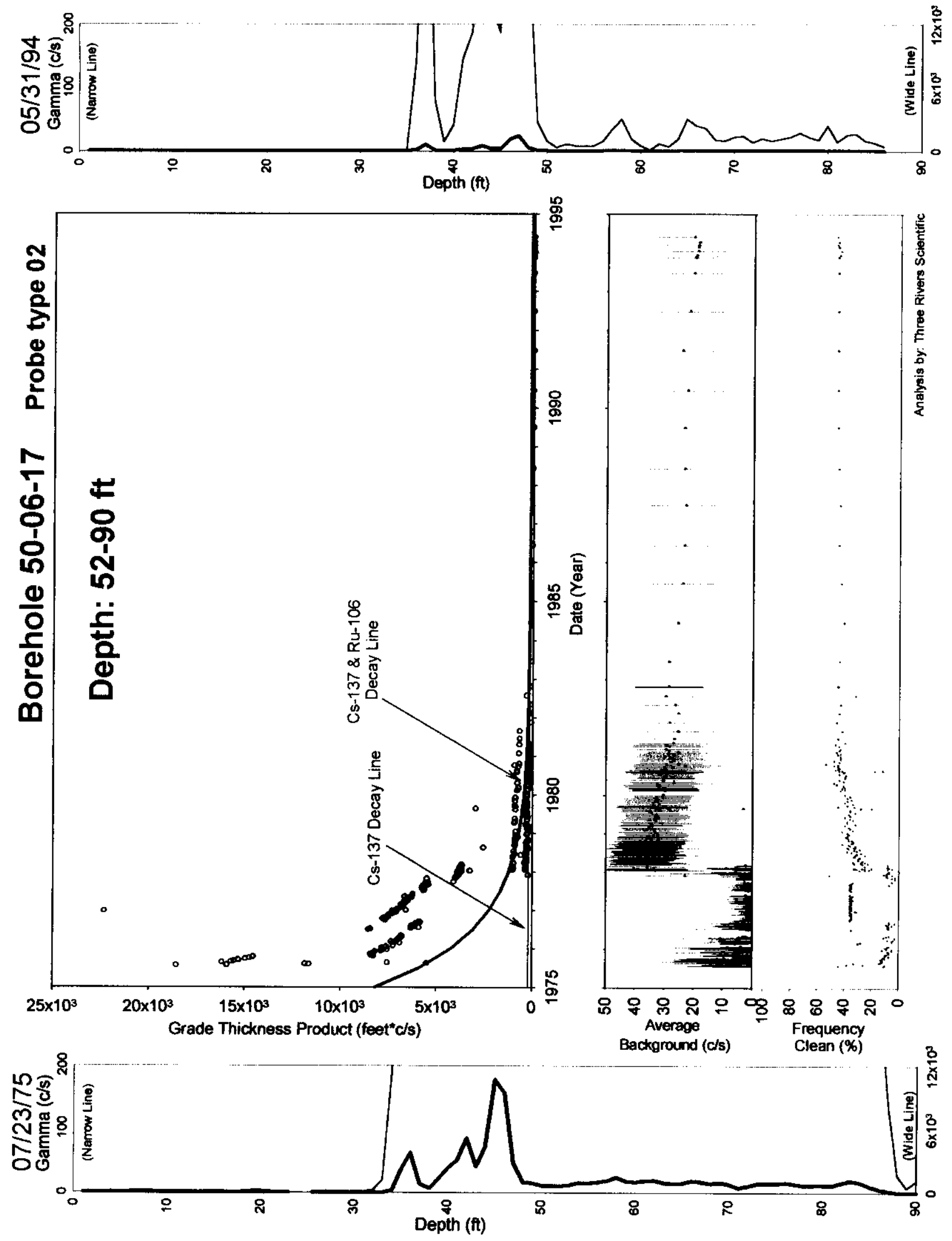

Tank T-106

Page 291 
RPP-6088, Rev.0.

\section{Tank T-107 Wells}

Table of Contents $\quad$ Page

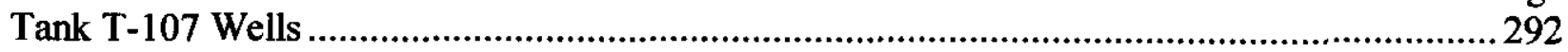

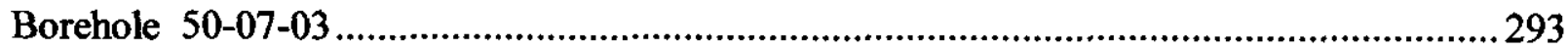

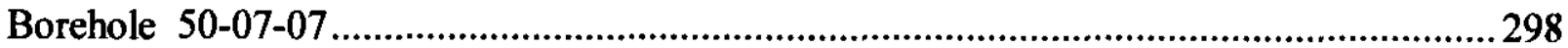

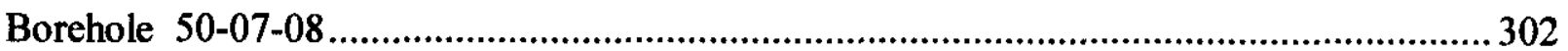

This section contains the analysis results for vadose zone boreholes (dry wells) associated with Tank 107 in the "T" Tank Farm.

Special Note: (none) 


\section{Borehole 50-07-03}

\section{Contamination (Cs-137, Co-60) from 0 to 20 feet is Undetermined. Contamination (Ru-106, Co-60) from 34 to 50 feet is Unstable Early.}

The average background plot shows a step decrease after the $1 / 20 / 1981$ survey that was used to normalize the grade thickness product (GTP) values for the 0 to 20 feet depth interval and fitted decay line. The GTP over 0 to 20 feet is low level. The best least square fit is to Cs-137 (HPGe identified) and Co-60 (hypothesis), however, due to the poor fit the category is undetermined.

Grade thickness product over 34 to 50 feet has a nominal step decrease after the 1/20/1981 survey which has no impact on the interpretation of the grade thickness product for the interval. The GTP values before $1 / 20 / 1981$ were not normalized by the average background values. Before 1978, the GTP computed from the gross gamma response begins at a moderate level in 1975 then increases rapidly to early 1977 . From 1978 to 1995 the GTP is decreasing consistent with the decay rate of Co-60 (HPGe identified) and Ru-106 (hypothesis), and is characterized as unstable early. The GTP deviates from the decay line in 1981 at the same time as the step decrease in the average background which was probably the result of well remediation activities. The GTP deviations in 1981 interfered with the least squares fit.

Gross Gamma Survey Information

\begin{tabular}{|r|l|}
\hline Probe Type Processed : & $04:$ NaI \\
\hline Other Probe Types : & $03:$ Neutron \& 14: Shielded NaI \\
\hline Survey Depth : & $89 \mathrm{ft}$ \\
\hline First Survey Date : & $4 / 25 / 1975$ \\
\hline Last Survey Date : & $10 / 09 / 1995$ \\
\hline Number Surveys Processed : & 403 \\
\hline
\end{tabular}

Analysis Notes

\begin{tabular}{|r|l|}
\hline Method Used to Compute Background : & $20-32$ feet \\
\hline Depth(s) where Contamination was & $0-20$ feet Undetermined \\
Identified in Gross Gamma Surveys : & $34-50$ feet Unstable Early \\
\hline Analyst Name : & R. K. Price \\
\hline Company Name : & Three Rivers Scientific \\
\hline
\end{tabular}


RPP-6088, Rev.0.

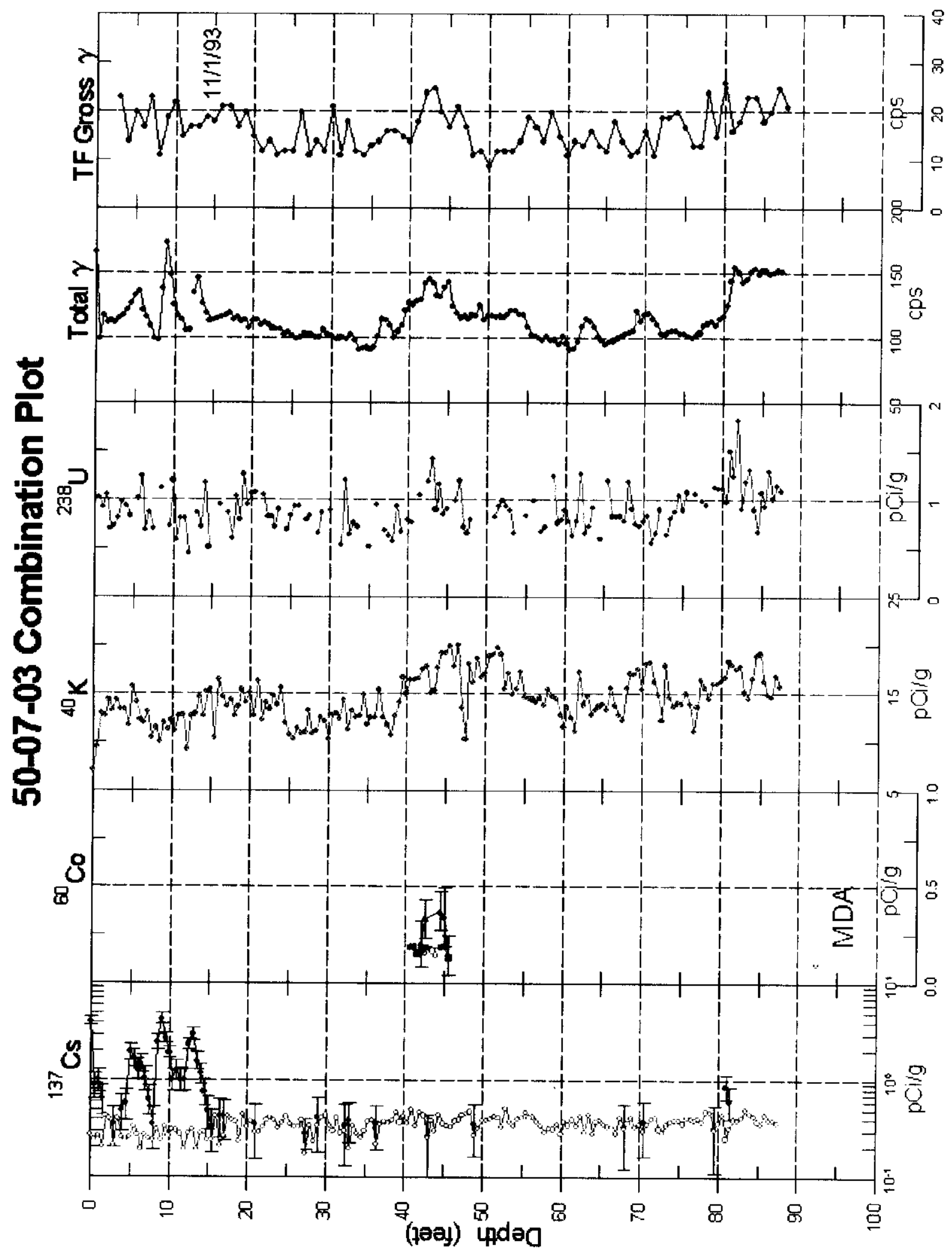


RPP-6088, Rev.0.

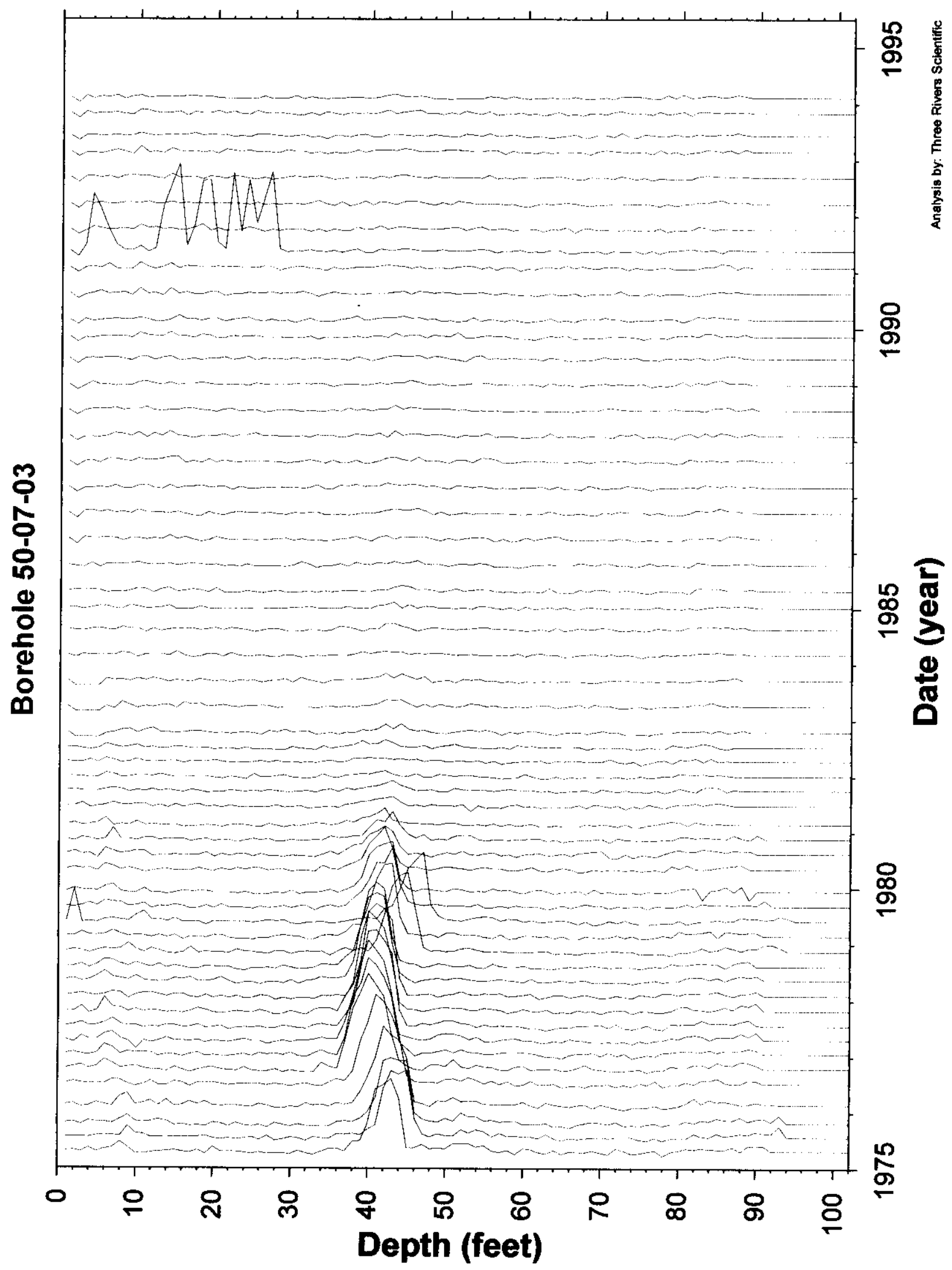

Tank T-107

Page 295 
RPP-6088, Rev.0.
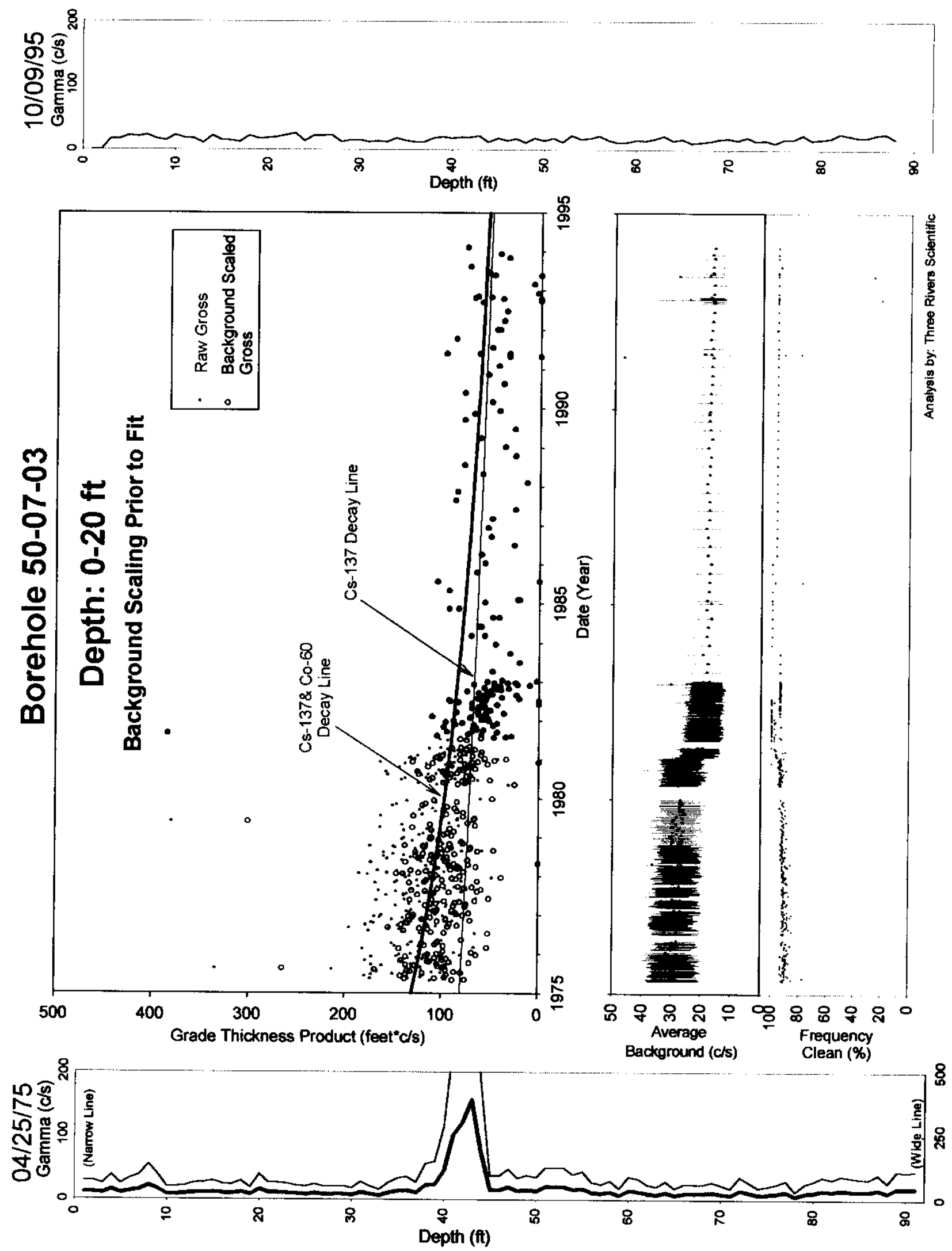
RPP-6088, Rev.0.
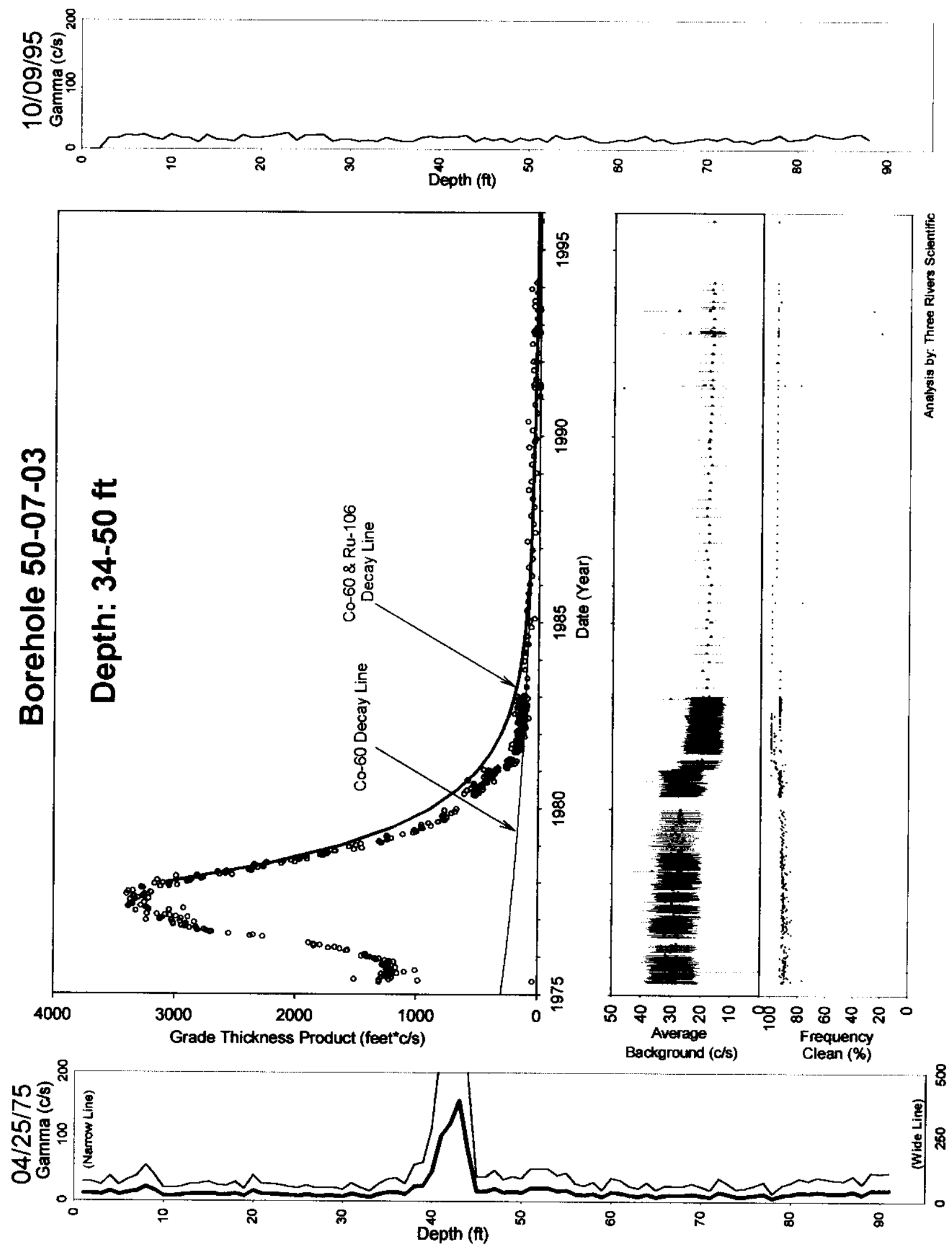

Tank T-107

Page 297 
RPP-6088, Rev.0.

\section{Borehole 50-07-07}

\section{Contamination (Cs-137) from 36 to 48 feet is Undetermined.}

Grade thickness product over 36 to 48 feet and the average background plot both show a step decrease after the $1 / 27 / 1981$ survey. The average background plot was used to normalize the GTP values and fitted decay line. The least square fit of Cs-137 (HPGe identified) and Co-60 (hypothesis) to the low levels of the GTP values is improved after normalizing to the step change in the average background. However, the stability of the contamination in the interval is undetermined.

Gross Gamma Survey Information

Probe Type Processed : $04: \mathrm{NaI}$

Other Probe Types : $03:$ Neutron \& 14: Shielded NaI

Survey Depth : $90 \mathrm{ft}$

First Survey Date : $1 / 10 / 1975$

Last Survey Date : $10 / 09 / 1995$

\begin{tabular}{ll}
\hline Number Surveys Processed : & 375 \\
\hline
\end{tabular}

Analysis Notes

Method Used to Compute Background : $10-30$ feet

Depth(s) where Contamination was $36-48$ feet Undetermined

Identified in Gross Gamma Surveys :

Analyst Name: R. K. Price

Company Name : Three Rivers Scientific 
RPP-6088, Rev.0.

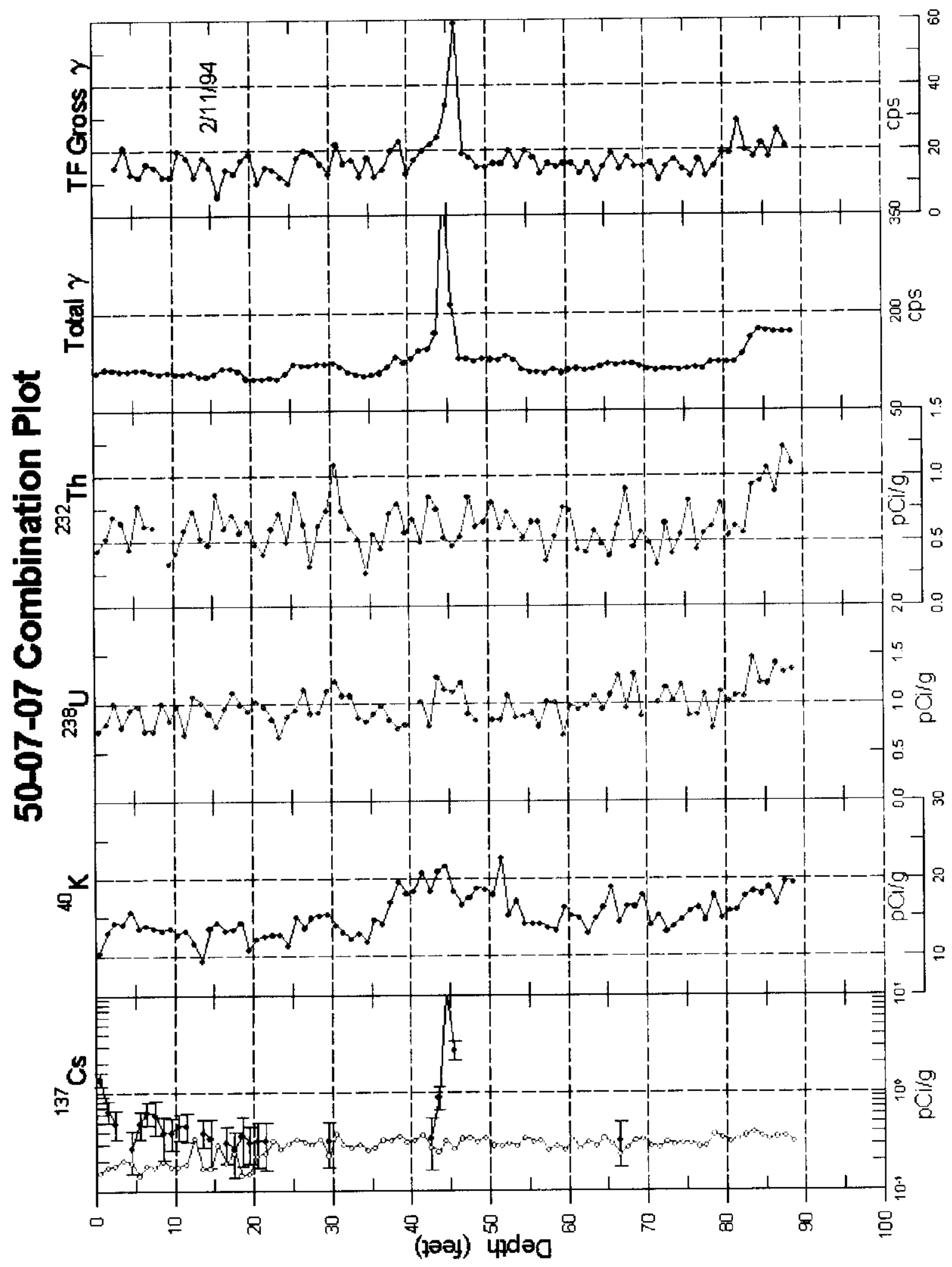


RPP-6088, Rev.0.

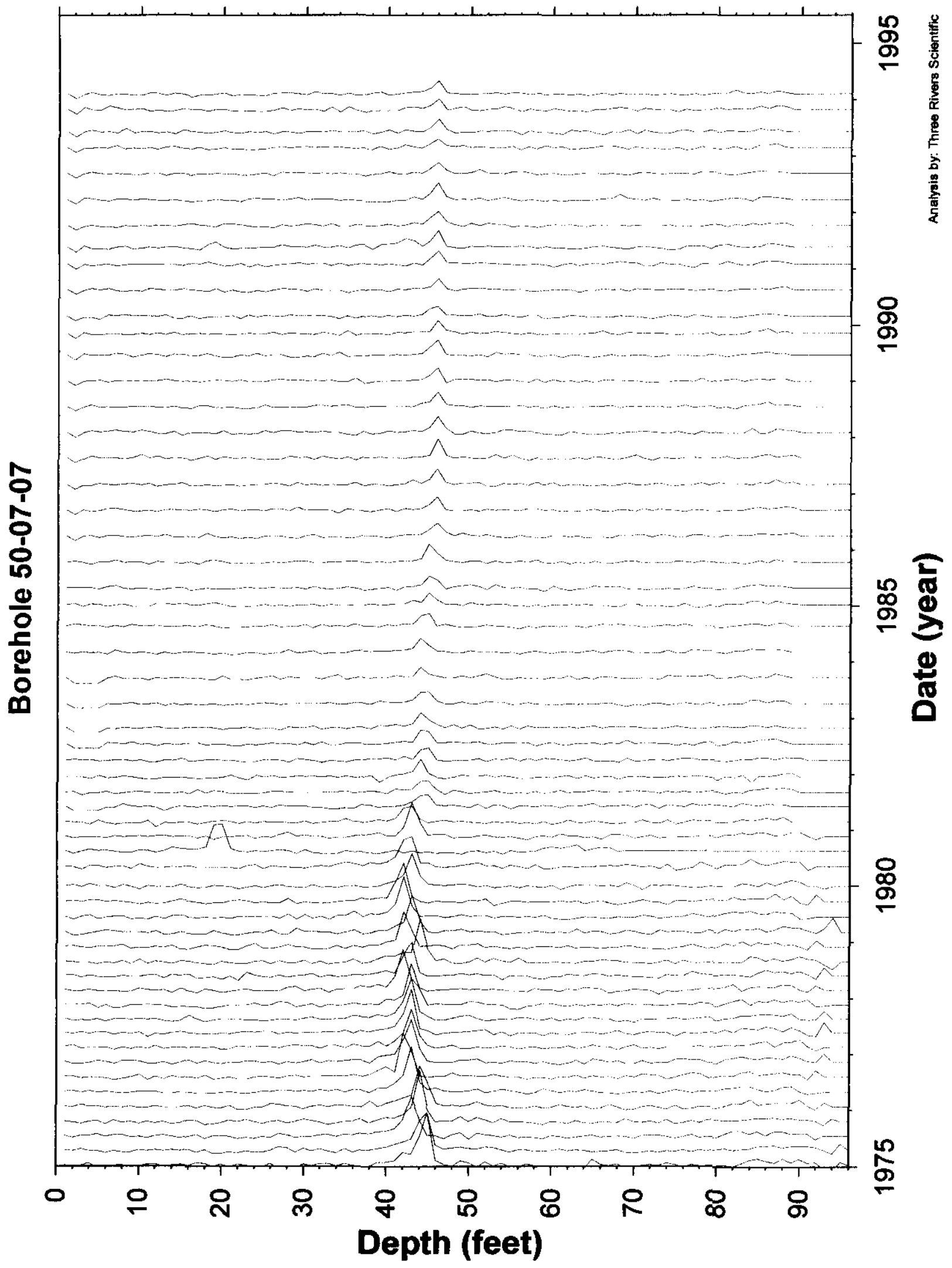

Tank T-107

Page 300 
RPP-6088, Rev.0.
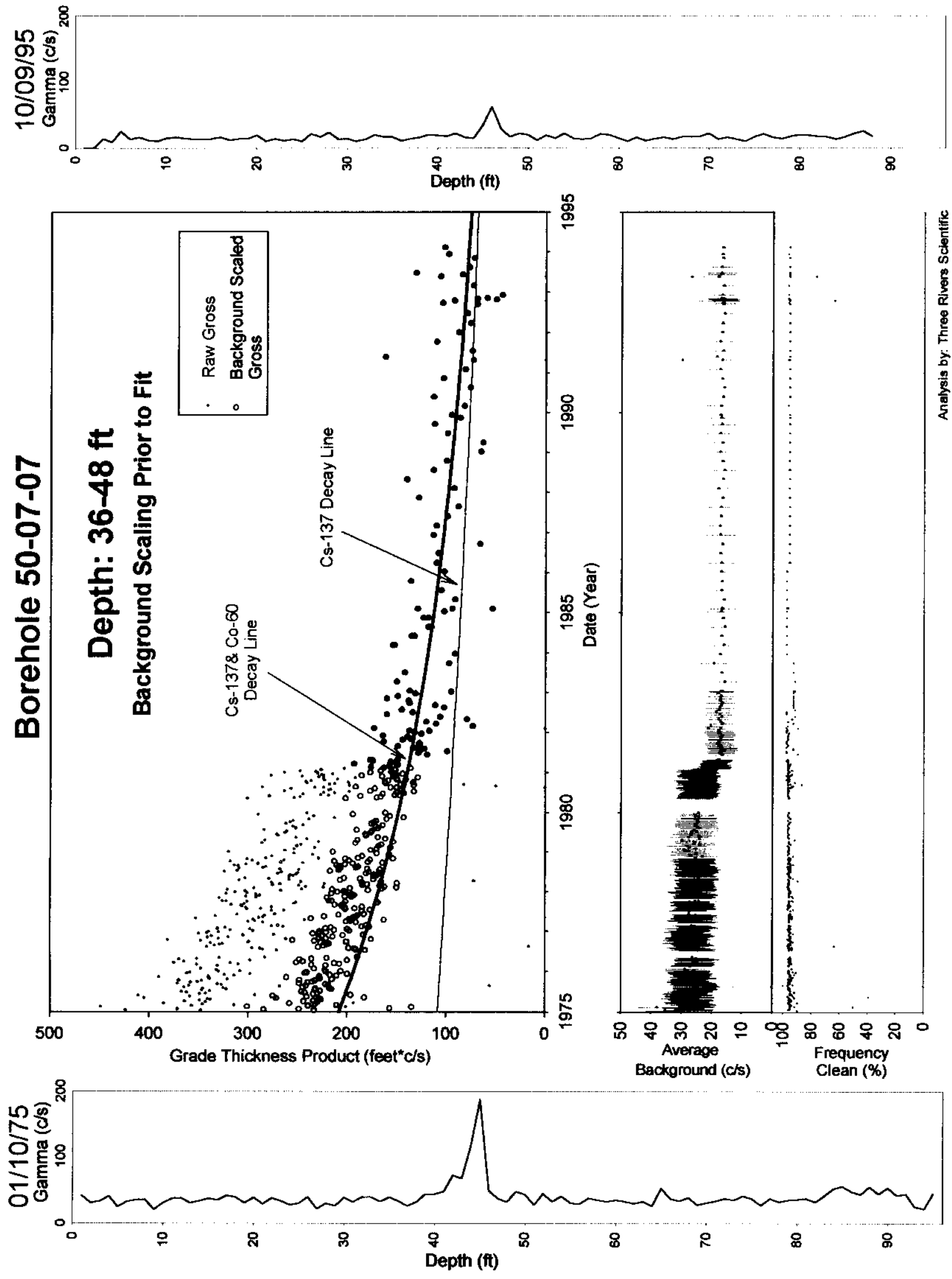

Tank T-107

Page 301 
RPP-6088, Rev.0.

\section{Borehole 50-07-08}

\section{No Gamma Ray Emitting Contamination Identified.}

No significant levels of gamma ray contamination are present, based upon gross gamma data, above the survey probe detection threshold between 1975 and 1995 in the vadose zone from 2 to 89 feet. The HPGe logging system detected Cs-137 from 0 to 8 feet with maximum concentration of $2 \mathrm{pCi} / \mathrm{g}$ at 1 and 5 feet and less than $0.4 \mathrm{pCi} / \mathrm{g}$ for the rest of the interval. The average background plot shows a step decrease after the $2 / 4 / 1981$ survey.

Gross Gamma Survey Information

\begin{tabular}{|r|l|}
\hline Probe Type Processed : & $04: \mathrm{NaI}$ \\
\hline Other Probe Types : & $03:$ Neutron, 14: Shielded Nal \\
\hline Survey Depth : & $89 \mathrm{ft}$ \\
\hline First Survey Date : & $4 / 25 / 1975$ \\
\hline Last Survey Date : & $10 / 09 / 1995$ \\
\hline Number Surveys Processed : & 361 \\
\hline
\end{tabular}

Analysis Notes

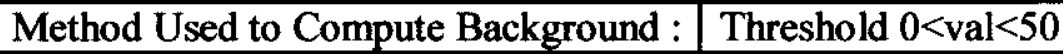

Depth(s) where Contamination was NONE

Identified in Gross Gamma Surveys :

Analyst Name : $\quad$ R. K. Price

Company Name : $\quad$ Three Rivers Scientific 
RPP-6088, Rev.0.

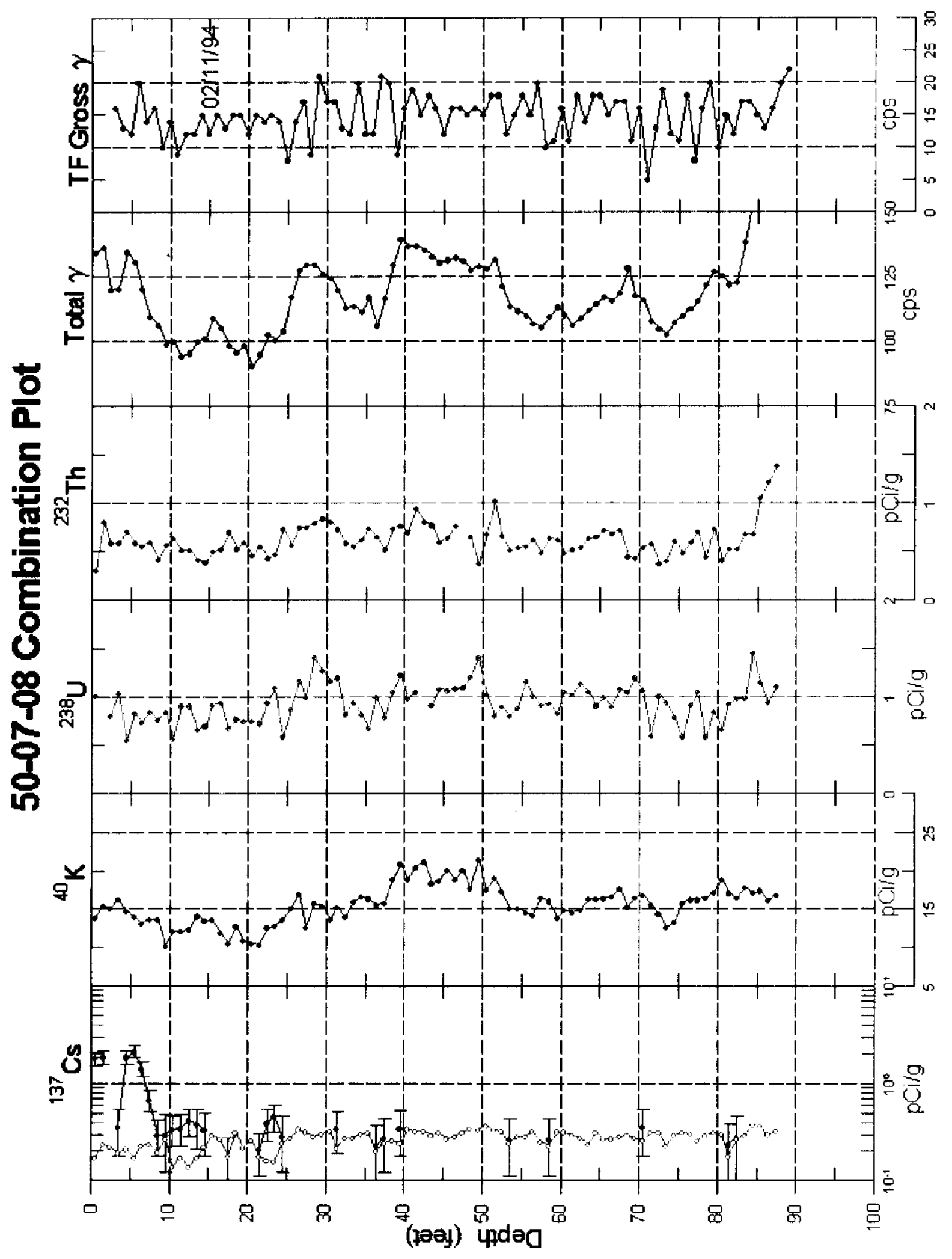


RPP-6088, Rev.0.

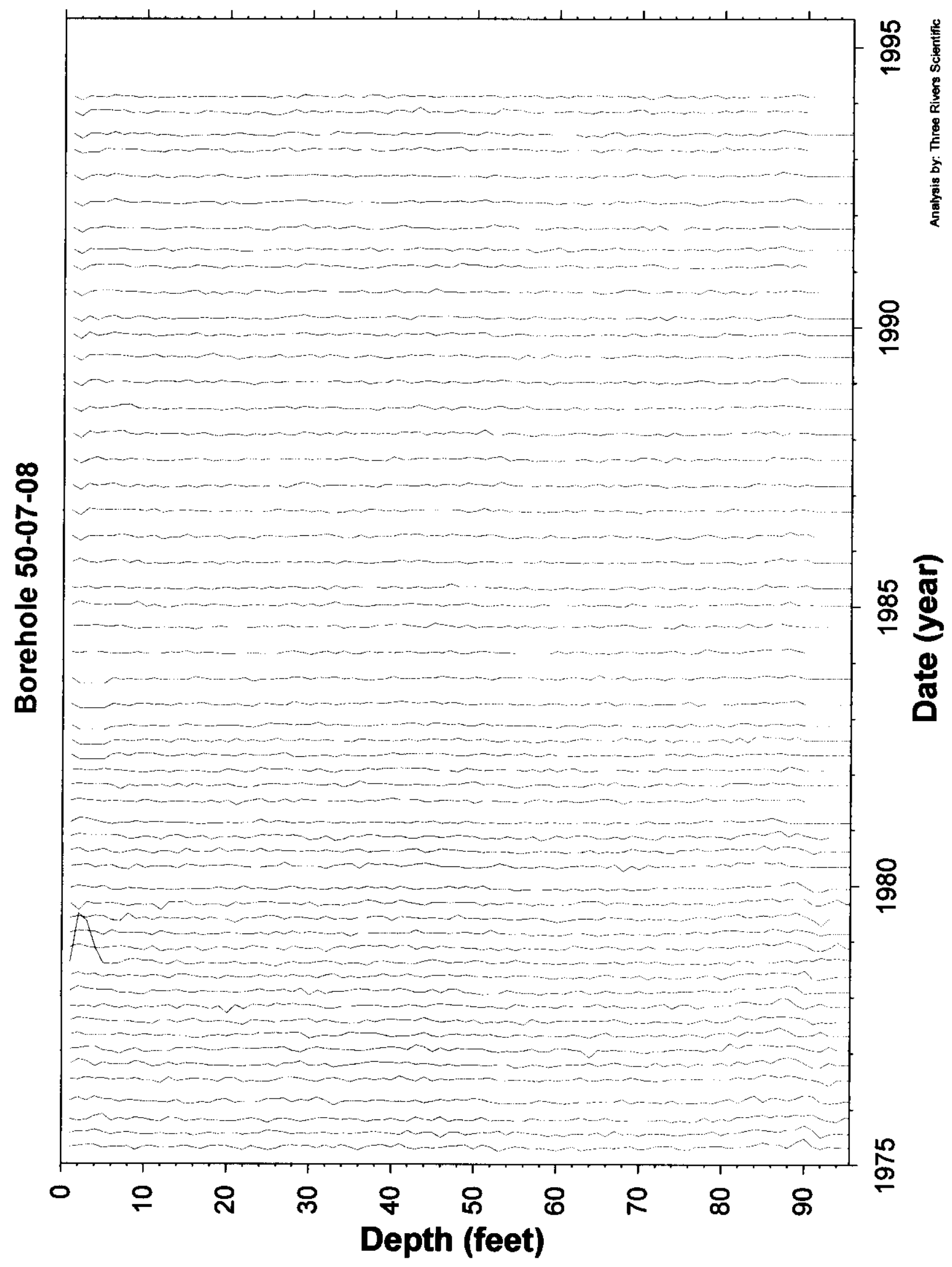

Tank T-107

Page 304 
RPP-6088, Rev.0.

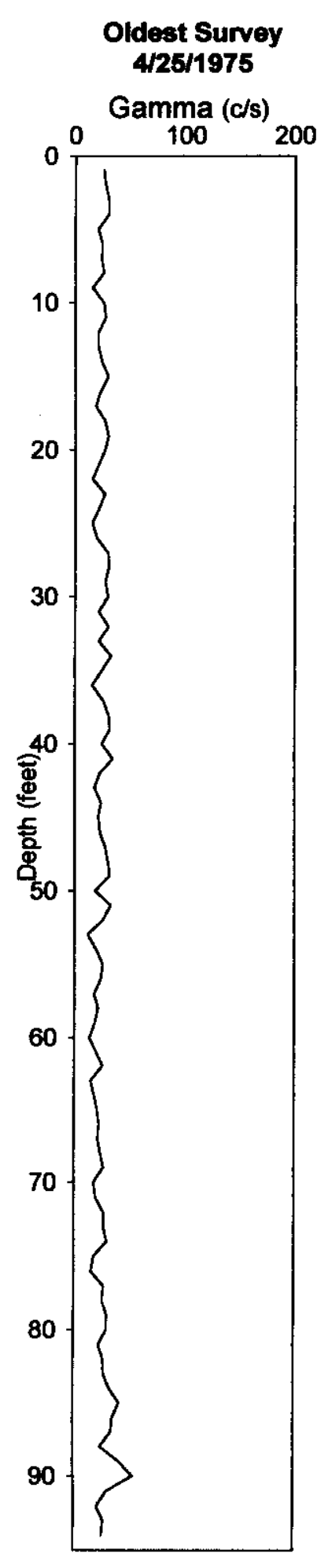

\section{Borehole 50-07-08}

No Gamma-Ray Emitting Contamination

Above Survey Detection Threshold
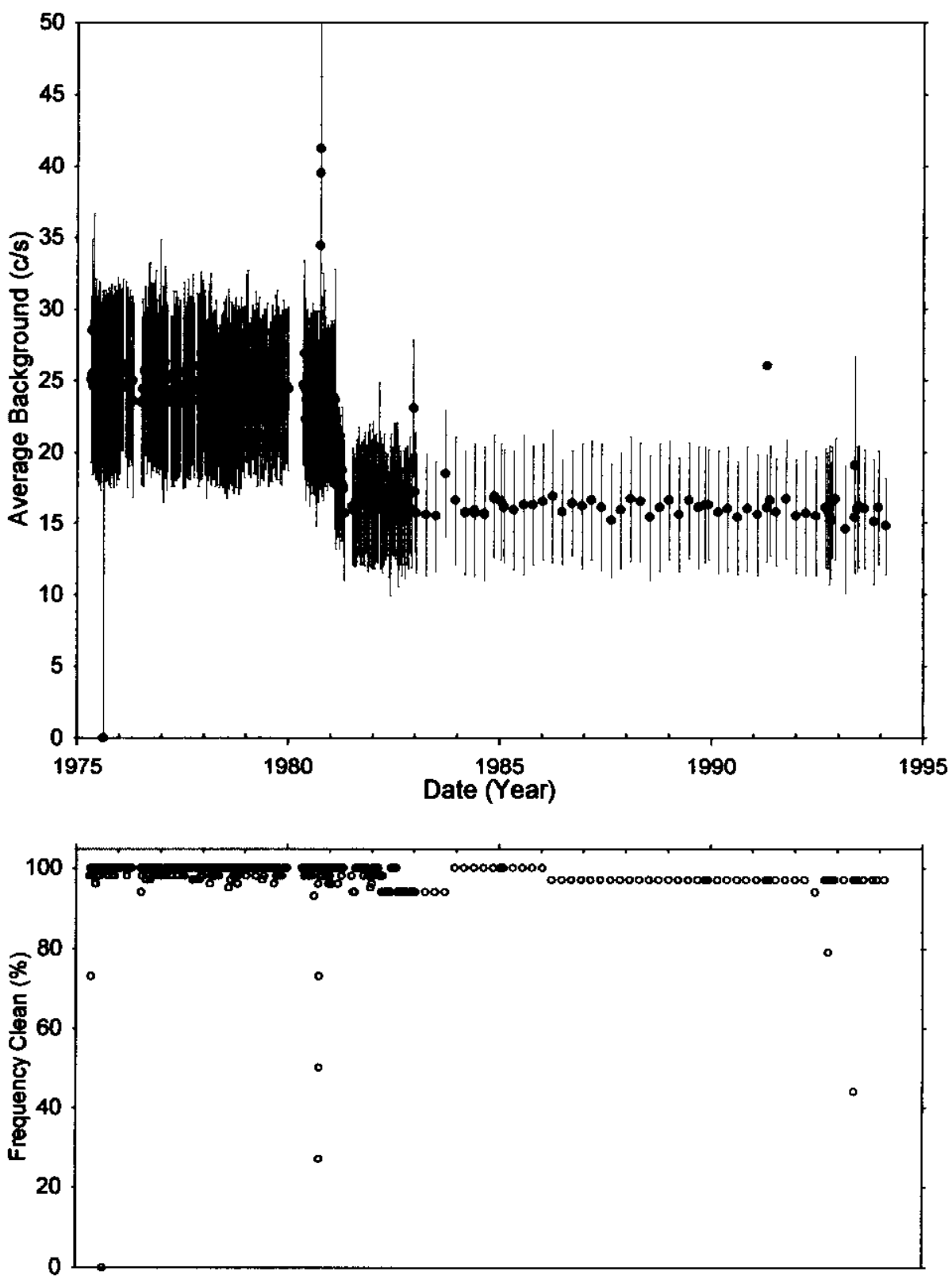

Analysis by: Three Rivers Scientific 


\section{Tank T-108 Wells}

Table of Contents $\quad$ Page

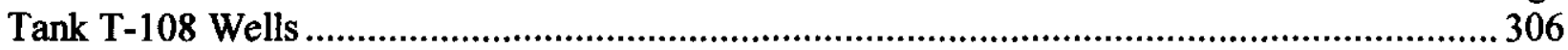

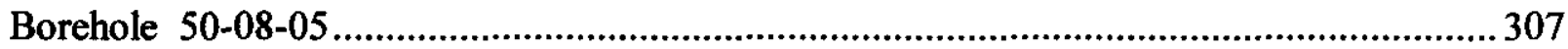

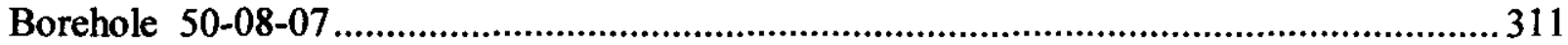

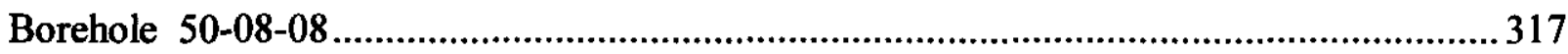

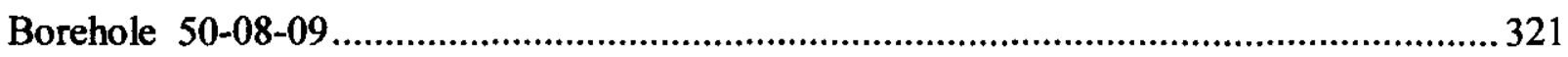

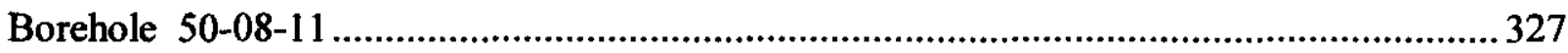

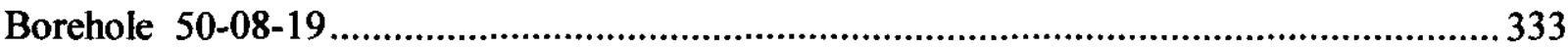

This section contains the analysis results for vadose zone boreholes (dry wells) associated with Tank 108 in the "T" Tank Farm.

Special Note:

Borehole 50-08-07 is characterized as unstable early. The monitoring surveys recorded from 1979 through 1982 a time of rapid increase that apparently stabilized quickly. The data may be used for vadose zone transport rate calculations. 
RPP-6088, Rev.0.

\section{Borehole 50-08-05}

\section{No Gamma Ray Emitting Contamination Identified.}

No significant levels of gamma ray contamination are present, based upon gross gamma data, above the survey probe detection threshold between 1975 and 1994 in the vadose zone from 2 to 90 feet. The HPGe logging system detected Cs-137 at less than $2 \mathrm{pCi} / \mathrm{g}$ in the borehole.

The average background plot shows a step decrease after the $7 / 22 / 1980$ survey.

Gross Gamma Survey Information

\begin{tabular}{|r|l|}
\hline Probe Type Processed : & $04: \mathrm{NaI}$ \\
\hline Other Probe Types : & $03:$ Neutron \\
\hline Survey Depth : & $90 \mathrm{ft}$ \\
\hline First Survey Date : & $1 / 10 / 1975$ \\
\hline Last Survey Date : & $02 / 17 / 1994$ \\
\hline Number Surveys Processed : & 488 \\
\hline
\end{tabular}

Analysis Notes

Method Used to Compute Background : $\quad$ Threshold $0<$ val $<50$

Depth(s) where Contamination was NONE Identified in Gross Gamma Surveys :

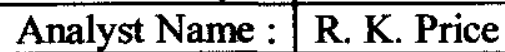

Company Name : Three Rivers Scientific 
RPP-6088, Rev.0.

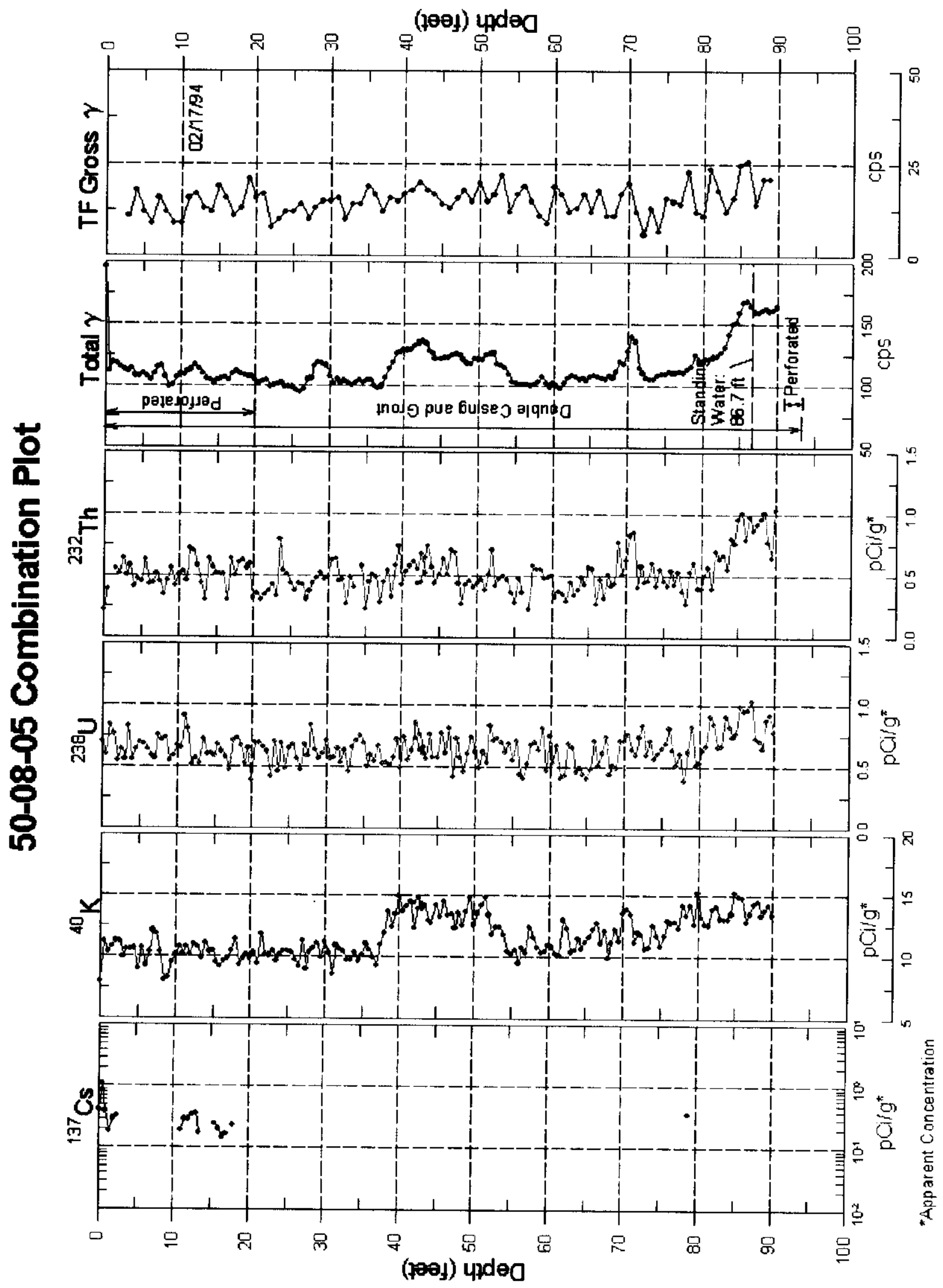

Tank T-108

Page 308 
RPP-6088, Rev.0.

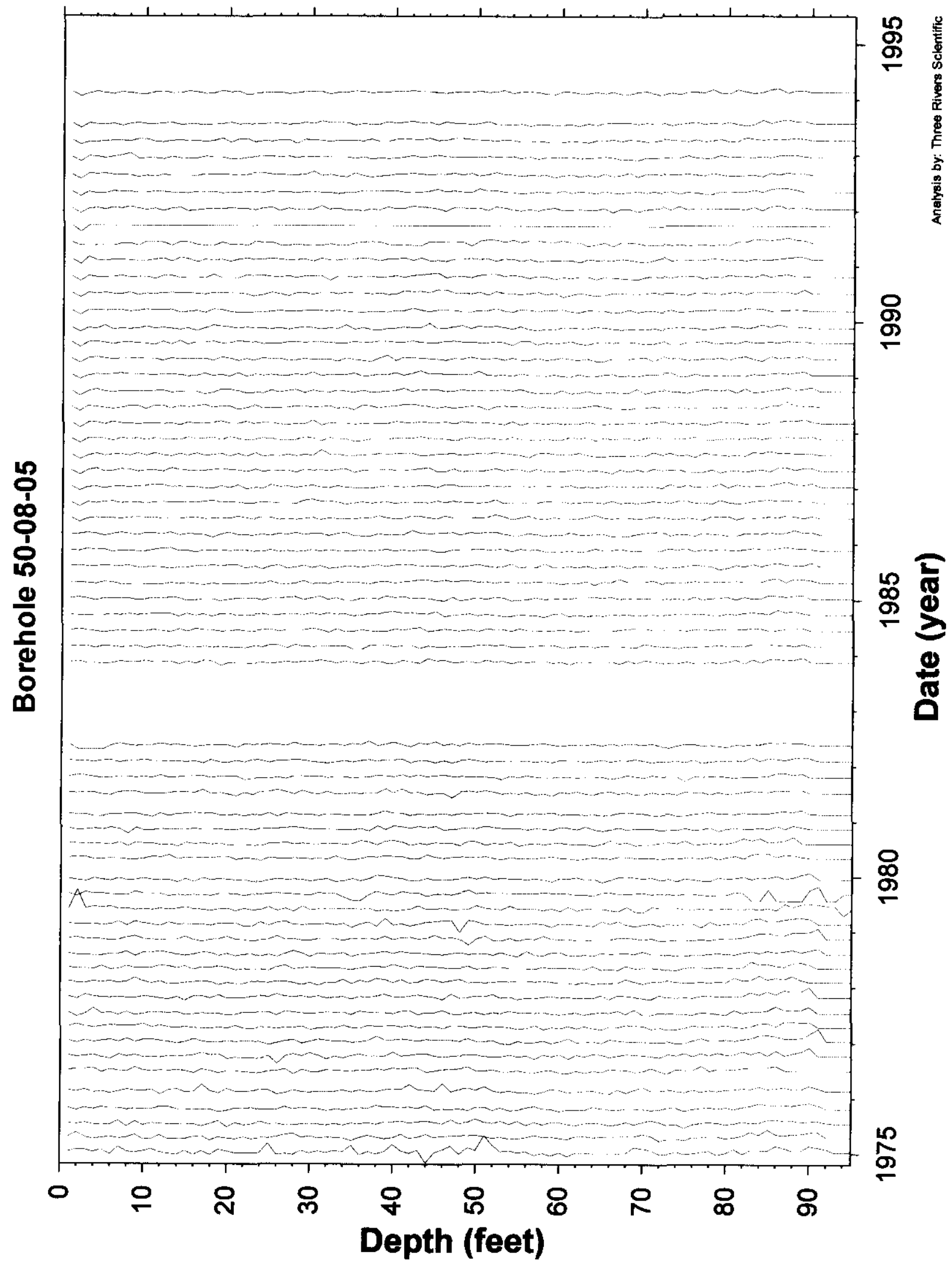

Tank T-108

Page 309 
RPP-6088, Rev.0.

\section{Borehole 50-08-05}
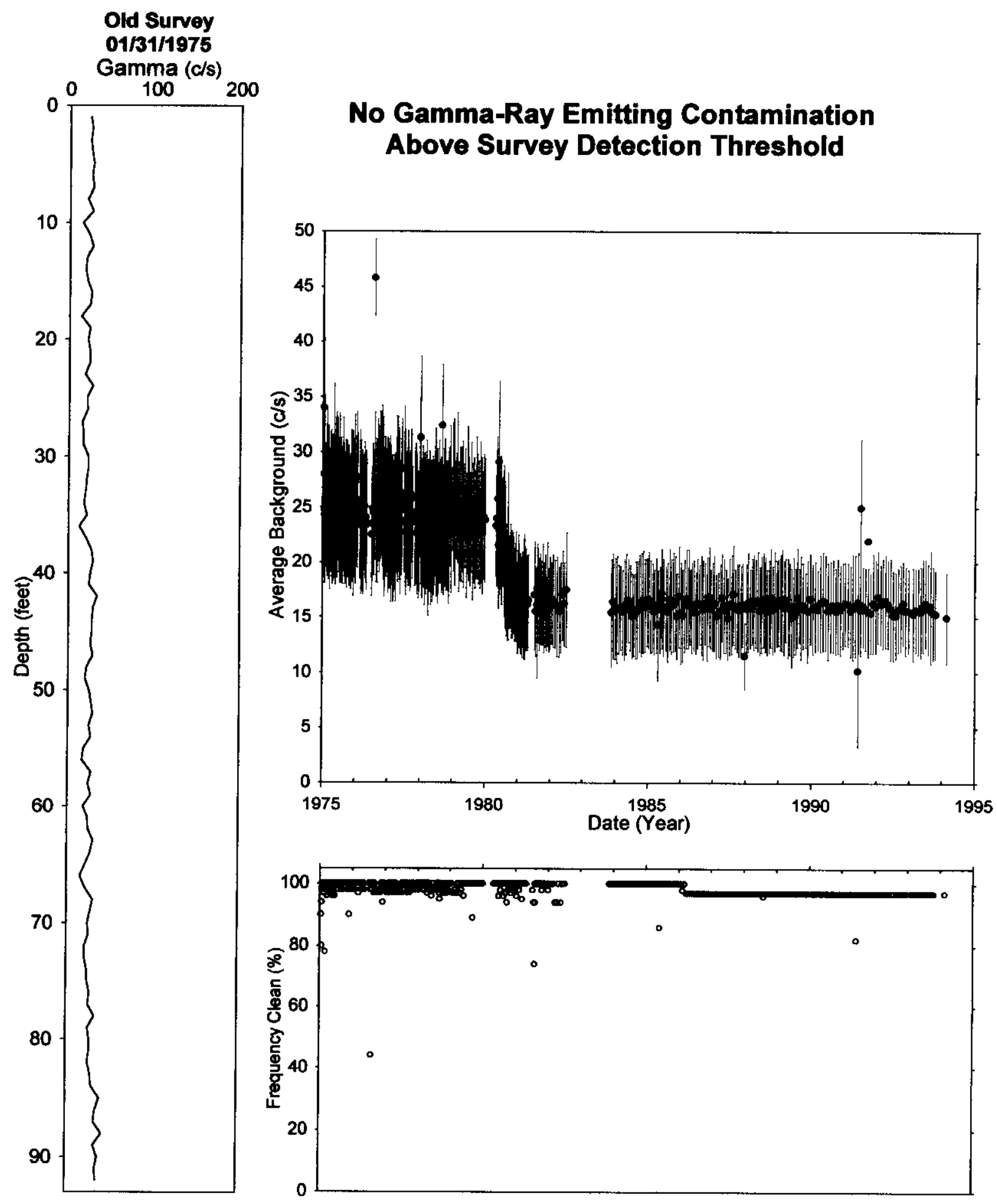

Analysis by: Three Rivers Scientific 
RPP-6088, Rev.0.

\section{Borehole 50-08-07}

\section{Contamination (Co-60 \& Ru-106) from 64 to 76 feet is Unstable Early. Contamination (Co-60 \& Ru-106) from 76 to 95 feet is Unstable Early.}

This borehole was remediated in 1981 because the log survey depths increased from 95 feet to 120 feet after the 3-3-1981 survey and the average background activity decreased at the same time.

Grade thickness product (GTP) for 64 to 76 feet shows background levels from the first survey in 1975 to 1978 , then increases rapidly to early 1980 , and is erratic in 1980 to 1981 . Beginning in 1981 (red dash line) the GTP is decreasing consistent with a least square fit for Co-60 (HPGe identified) and Ru-106 (hypothesis) from 1981 to 1994 and is characterized as unstable early. The ratio of gross contribution from Co-60 to gross contribution from Ru-106 is 223:1 as of 224-1994.

Grade thickness product (GTP) for the interval 76 to 95 feet is similar to the previous contamination interval. The GTP shows background levels from the first survey in 1975 to 1978, then increases slowly to mid year 1980 with rapid increases to early in 1982 (red dash line on GTP). The stack plot indicates that the thickness of the lower contaminated interval increased at the same time that the survey depths increased from 95 to 120 feet. Grade thickness product for the depth interval is decreasing consistent with a least square fit for Co-60 (HPGe identified) and Ru-106 (hypothesis) from early 1982 to 1994 and is characterized as unstable early. The apparent stabilization of the contaminant is quick for this interval as compared to the upper interval. The ratio of gross contribution from Co-60 to gross from Ru-106 is 267:1 as of 2-241994.

Gross Gamma Survey Information

\begin{tabular}{|r|l|}
\hline Probe Type Processed : & $04:$ NaI \\
\hline Other Probe Types : & $03:$ Neutron \& 14: Shielded NaI \\
\hline Survey Depth : & $120 \mathrm{ft}$ \\
\hline First Survey Date : & $1 / 10 / 1975$ \\
\hline Last Survey Date : & $2 / 24 / 1994$ \\
\hline Number Surveys Processed : & 305 \\
\hline
\end{tabular}

Analysis Notes

\begin{tabular}{|r|l|}
\hline Method Used to Compute Background : & $30-60$ feet \\
\hline Depth(s) where Contamination was & $64-76$ feet Unstable Early \\
Identified in Gross Gamma Surveys : & $76-95$ feet Unstable Early \\
\hline Analyst Name : & R. K. Price \\
\hline Company Name : & Three Rivers Scientific \\
\hline
\end{tabular}


RPP-6088, Rev.0.

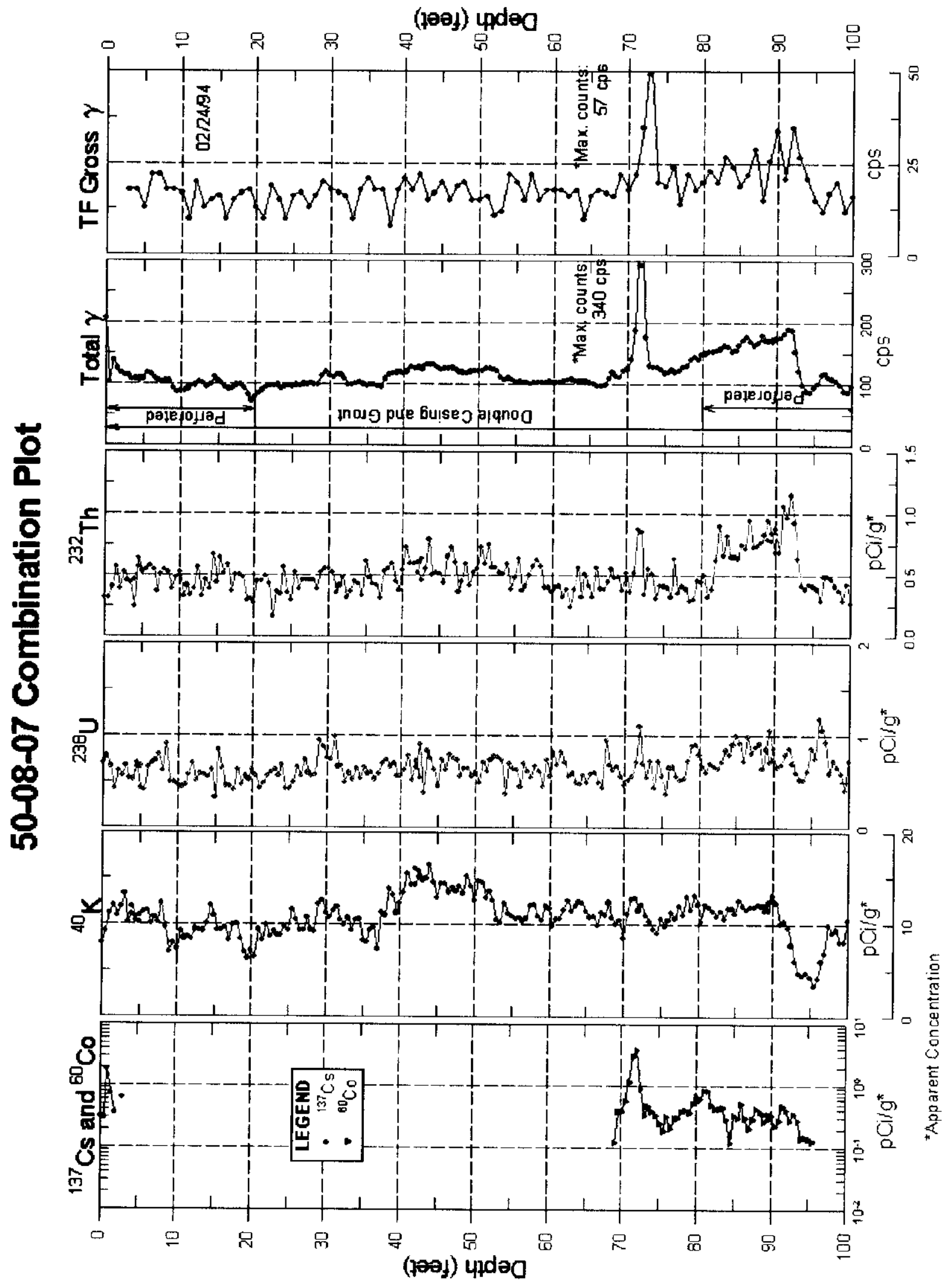

Tank T-108

Page 312 
RPP-6088, Rev.0.

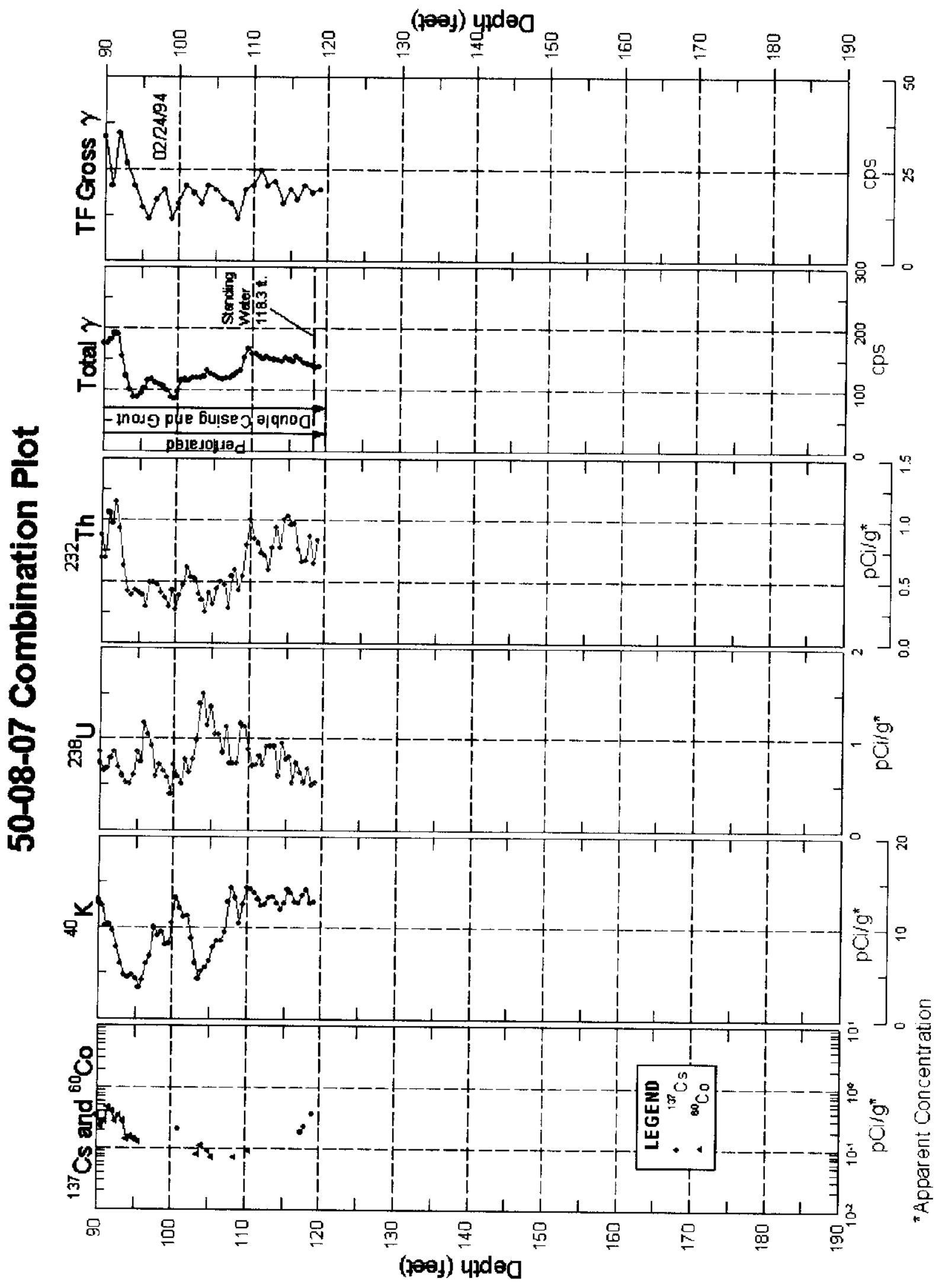

Tank T-108

Page 313 
RPP-6088, Rev.0.

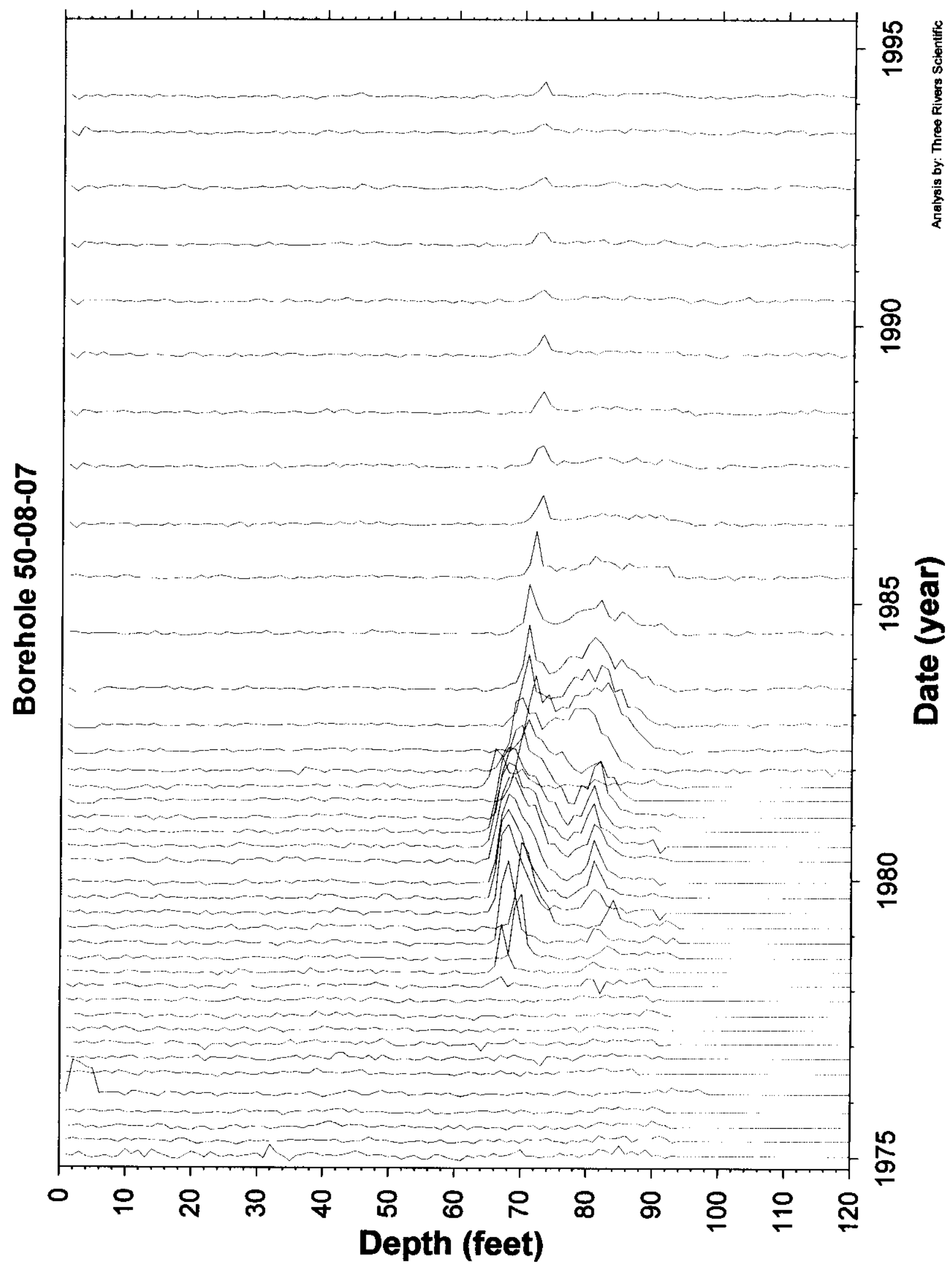

Tank T-108

Page 314 
RPP-6088, Rev.0.
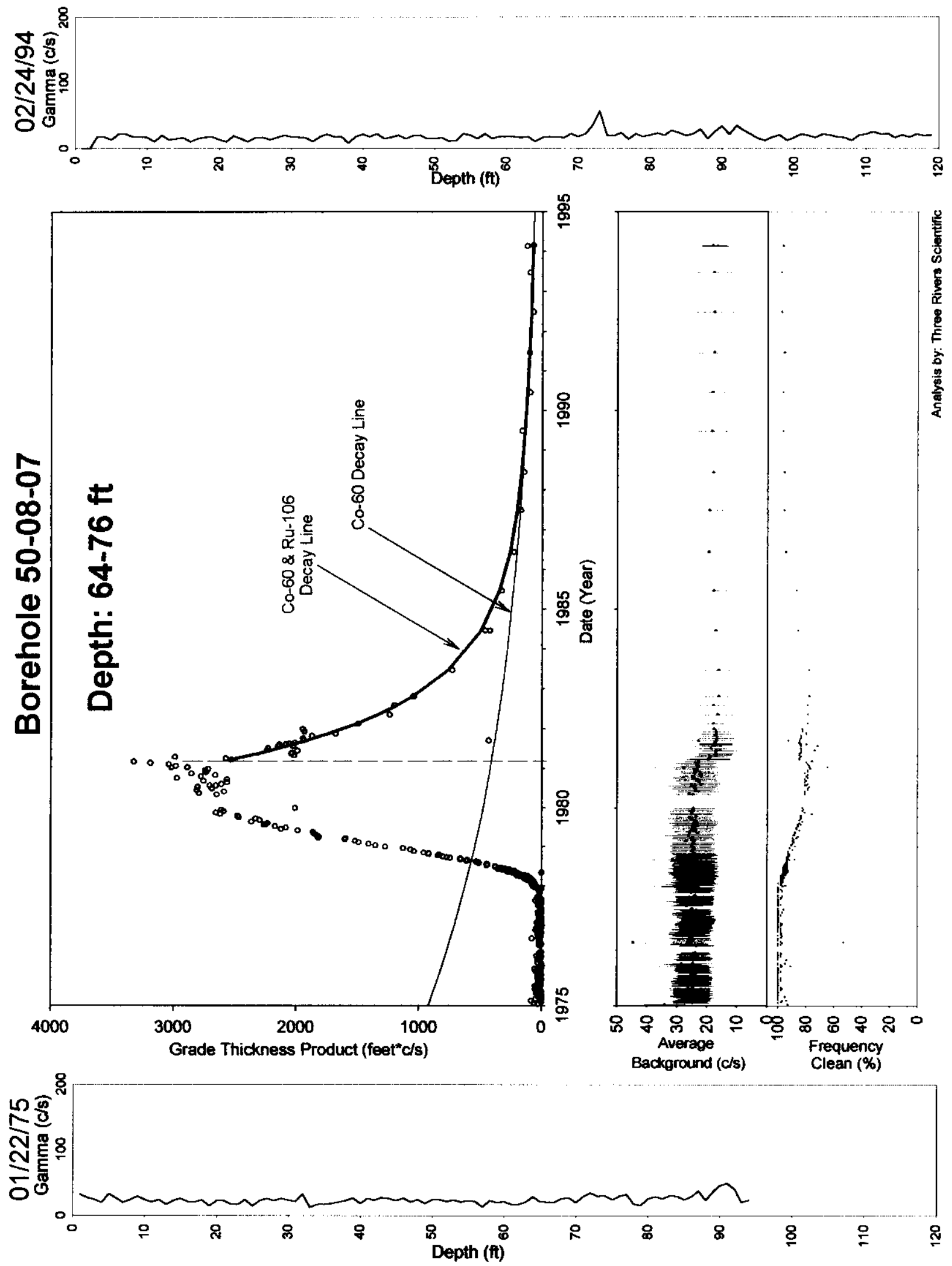

Tank T-108

Page 315 
RPP-6088, Rev.0.
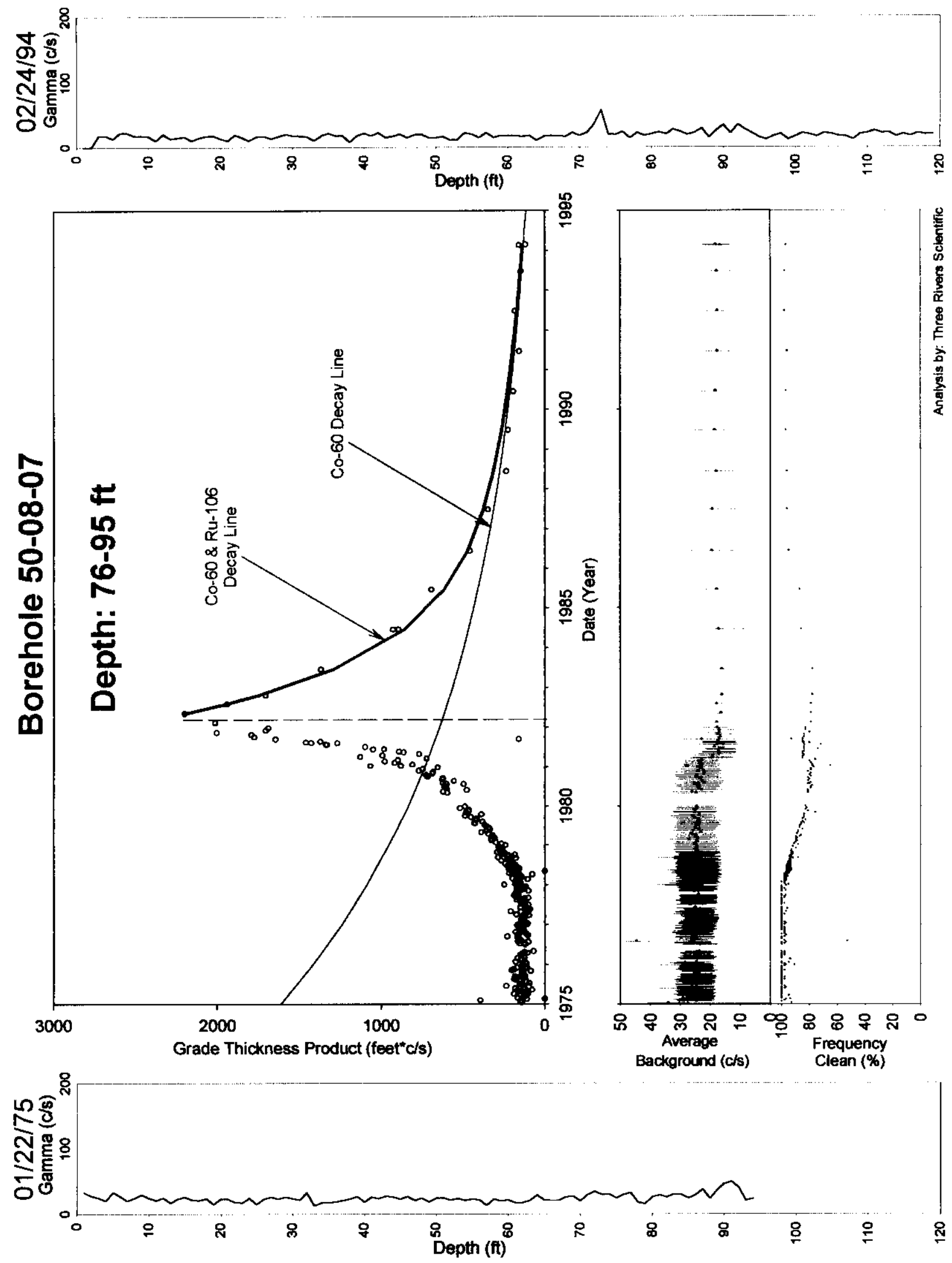

Tank T-108 


\section{Borehole 50-08-08}

\section{Contamination (Co-60 \& Ru-106) from 60 to 72 feet is Unstable Early.}

The grade thickness product (GTP) for depth interval 60 to 72 feet is increasing for the first few surveys in 1978, then before 1980 is decreasing at a rate that is slower than after 1980. Beginning in 1980 the GTP is decreasing consistent with a least square fit for Co-60 (HPGe identified) and Ru-106 (hypothesis). The ratio of gross contribution from Co-60 to gross from $\mathrm{Ru}-106$ is $295: 1$ as of 2-17-1994. The contamination interval is characterized as unstable early.

Gross Gamma Survey Information

\begin{tabular}{|r|l|}
\hline Probe Type Processed : & $04:$ NaI \\
\hline Other Probe Types : & $03:$ Neutron \\
\hline Survey Depth : & $100 \mathrm{ft}$ \\
\hline First Survey Date : & $4 / 27 / 1978$ \\
\hline Last Survey Date : & $2 / 17 / 1994$ \\
\hline Number Surveys Processed : & 119 \\
\hline
\end{tabular}

Analysis Notes

Method Used to Compute Background : $30-55$ feet

Depth(s) where Contamination was 60-72 feet Unstable Early Identified in Gross Gamma Surveys :

Analyst Name : $\quad$ R. K. Price

Company Name : $\quad$ Three Rivers Scientific 
RPP-6088, Rev.0.

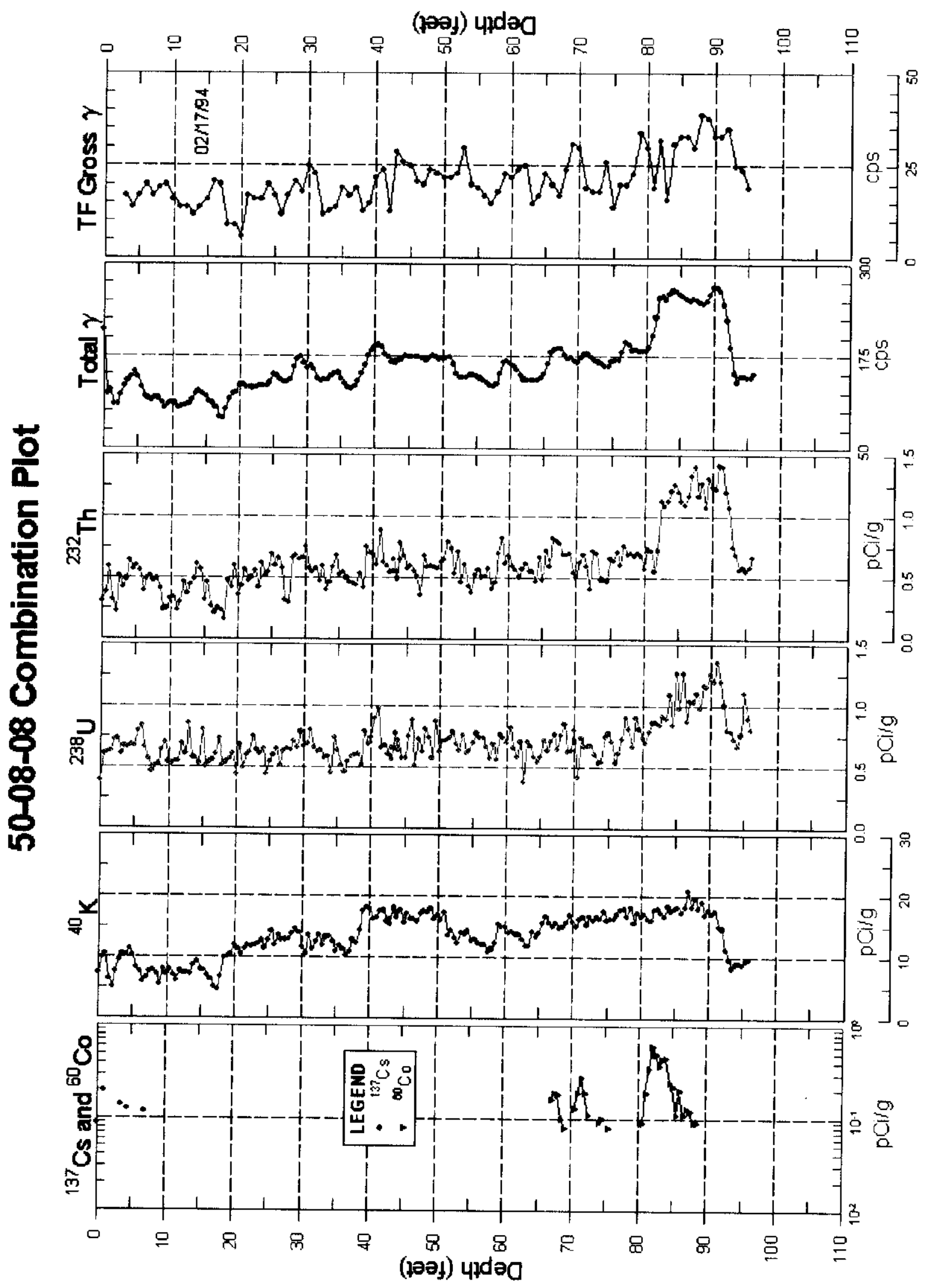

Tank T-108

Page 318 
RPP-6088, Rev.0.

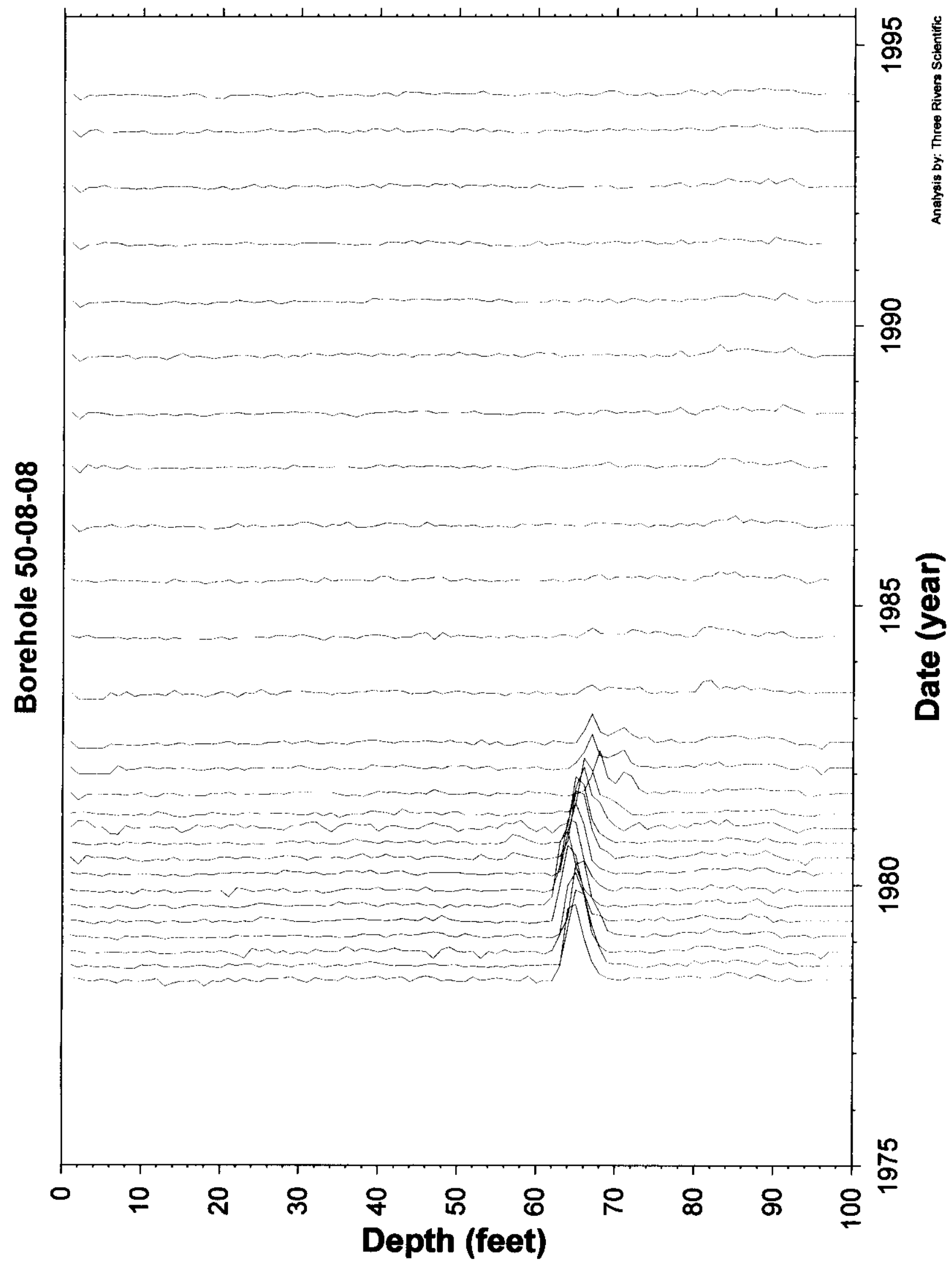

Tank T-108

Page 319 
RPP-6088, Rev.0.
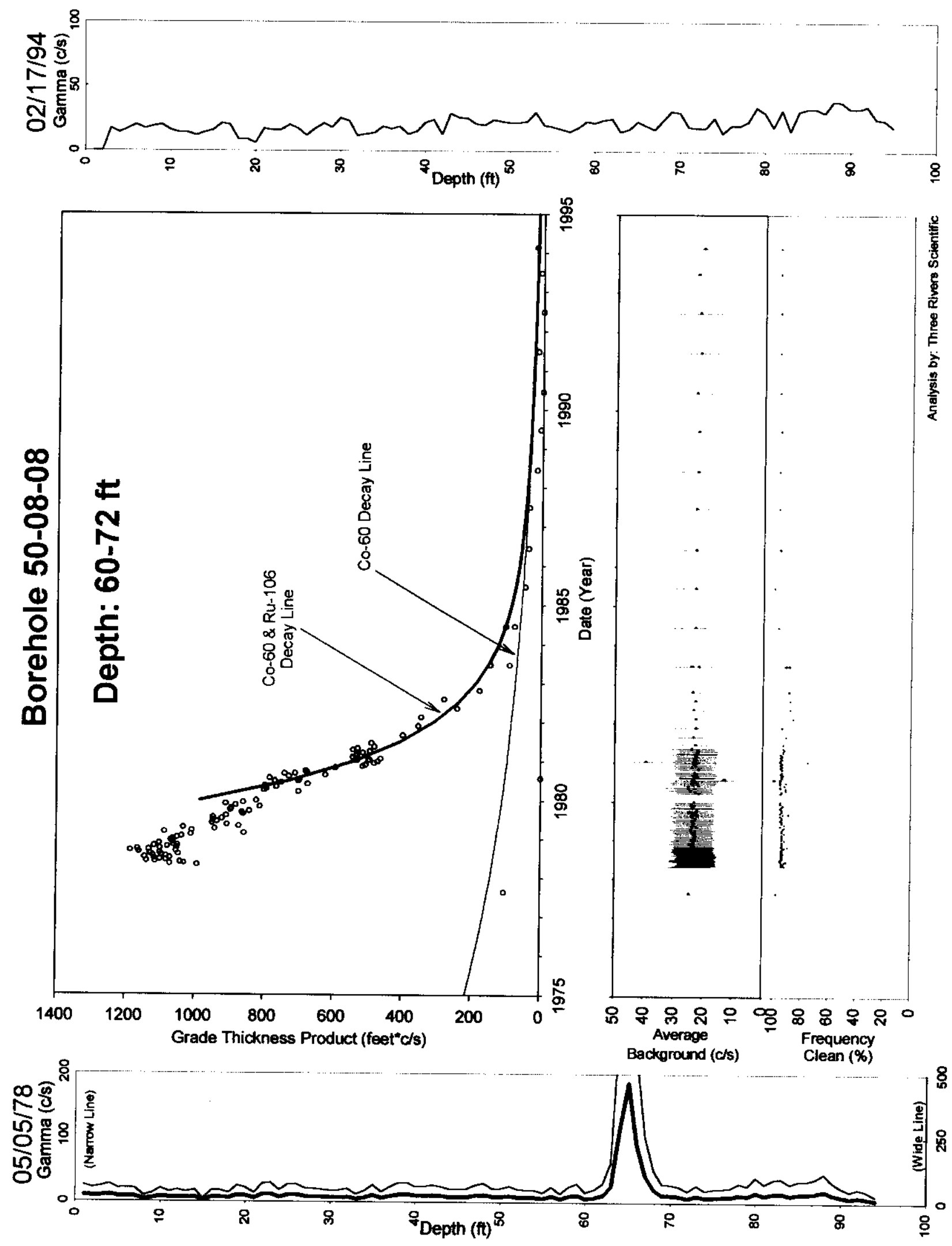

Tank T-108

Page 320 


\section{Borehole 50-08-09}

\section{Contamination (Co-60, Ru-106) from 58 to 92 feet is Unassigned Deviation. Contamination (Co-60, Ru-106) from 92 to 116 feet is Stable.}

Grade thickness product from 58 to 92 feet is decreasing from 1983 to 1990 consistent with a least square fit $\mathrm{Co}-60$ (HPGe identified) and $\mathrm{Ru}-106$ (hypothesis). The ratio of gross contribution from Co-60 to Ru-106 is 25:1 as of 12-6-89. However, from the first survey in 1980 the rate of change in the GTP is slower than the decay rate of the two radionuclides, and there is a change in the GTP character in 1981. The category of the contaminated interval is unassigned deviation.

Grade thickness product from 92 to 116 feet is decreasing consistent with a least square fit for Co-60 (HPGe identified) and Ru-106 (hypothesis) from the first survey in 1980 to the last survey in 1990 and is characterized as stable. The ratio of gross contribution from Co-60 to gross from $\mathrm{Ru}-106$ is $14: 1$ as of $12-6-1989$.

Gross Gamma Survey Information

\begin{tabular}{|r|l|}
\hline Probe Type Processed : & $04:$ NaI \\
\hline Other Probe Types : & $03:$ Neutron \& 14: Shielded NaI \\
\hline Survey Depth : & $120 \mathrm{ft}$ \\
\hline First Survey Date : & $5 / 13 / 1980$ \\
\hline Last Survey Date : & $12 / 06 / 1989$ \\
\hline Number Surveys Processed : & 81 \\
\hline
\end{tabular}

Analysis Notes

Method Used to Compute Background : $30-55$ feet

Depth(s) where Contamination was $58-92$ feet Unassigned Deviation

Identified in Gross Gamma Surveys : $92-116$ feet Stable

Analyst Name: R. K. Price

Company Name : 1 Three Rivers Scientific 
RPP-6088, Rev.0.

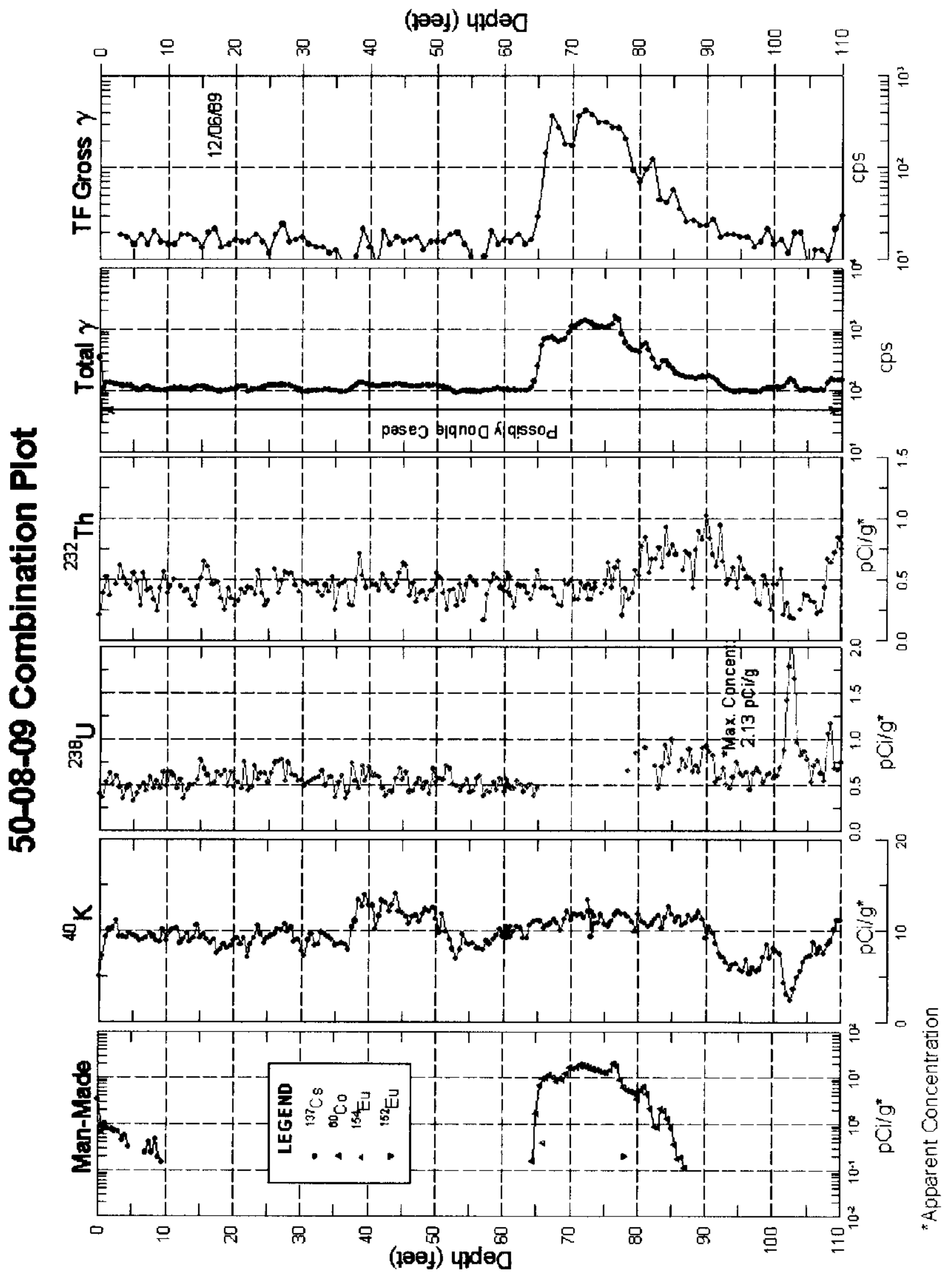

Tank T-108

Page 322 
RPP-6088, Rev.0.

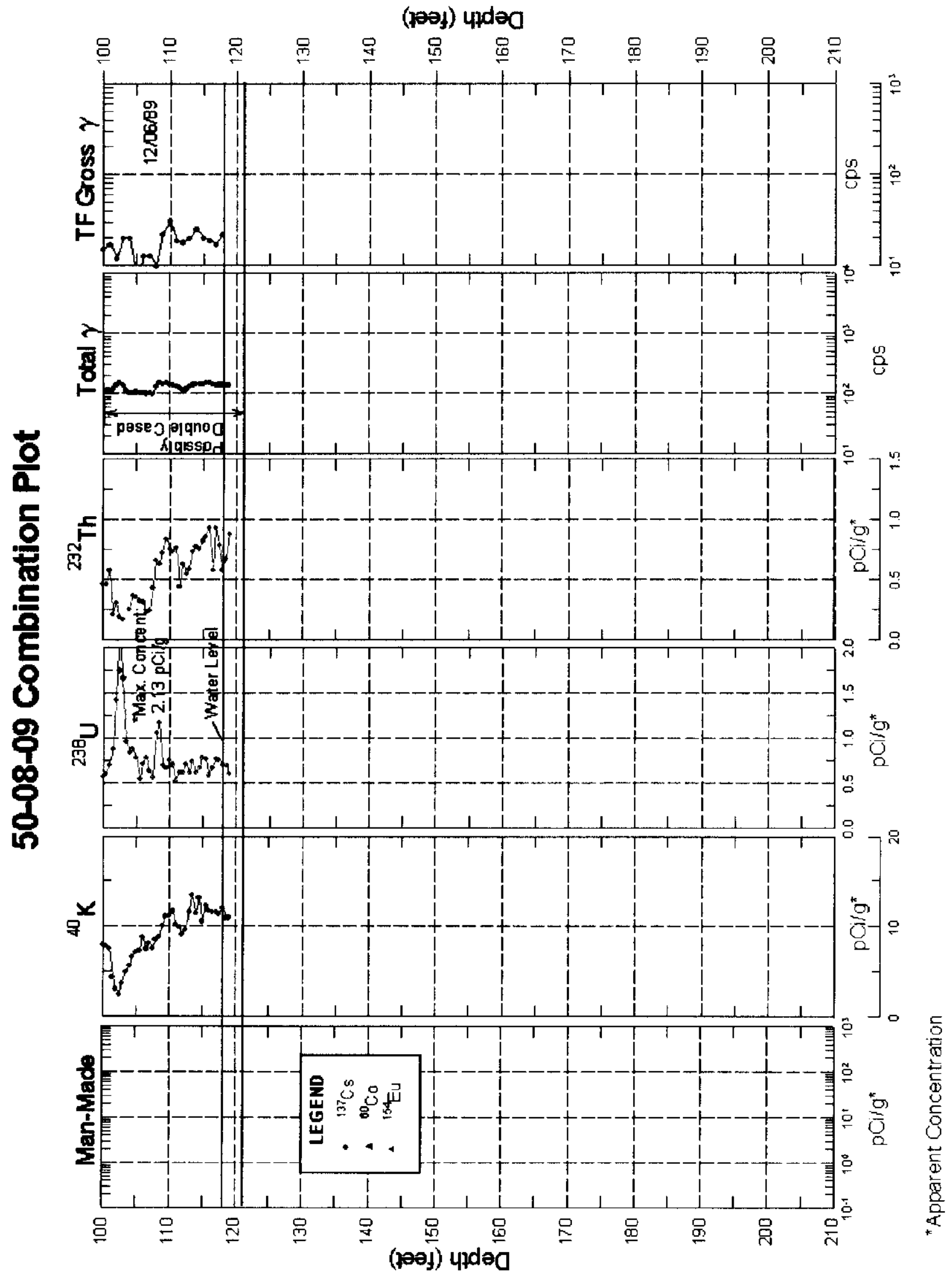

Tank T-108

Page 323 
RPP-6088, Rev.0.

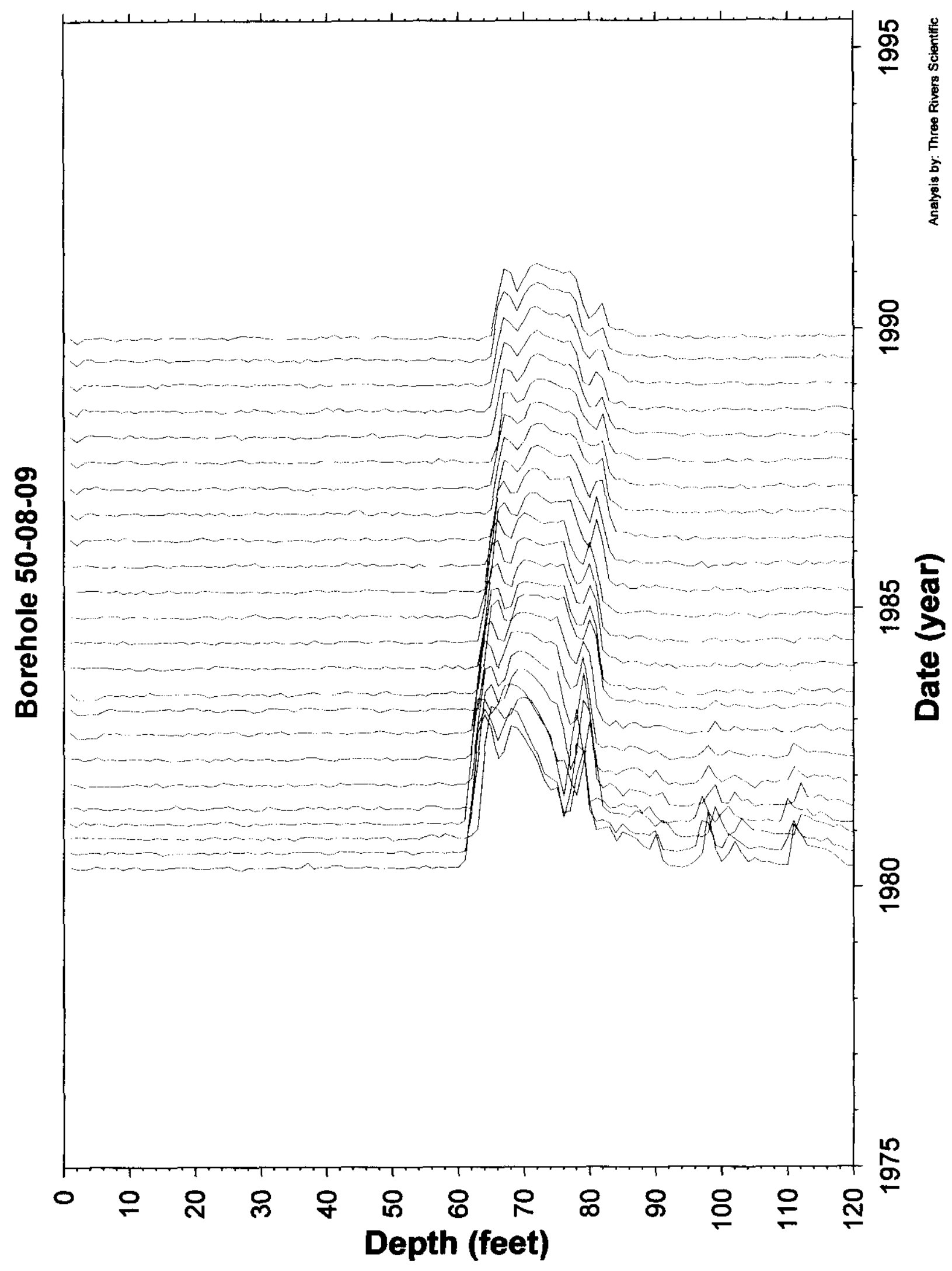

Tank T-108

Page 324 
RPP-6088, Rev.0.
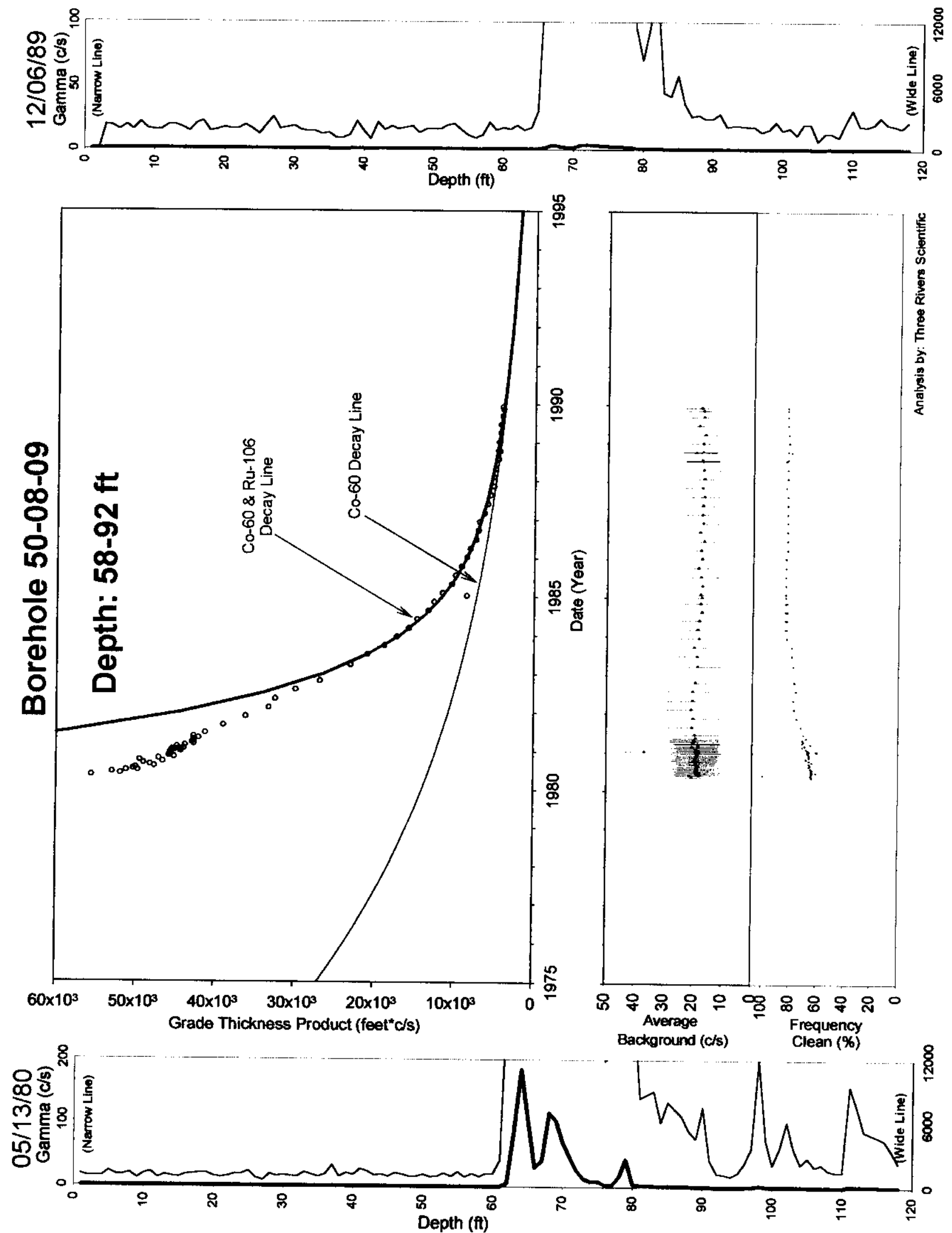

Tank T-108

Page 325 
RPP-6088, Rev.0.
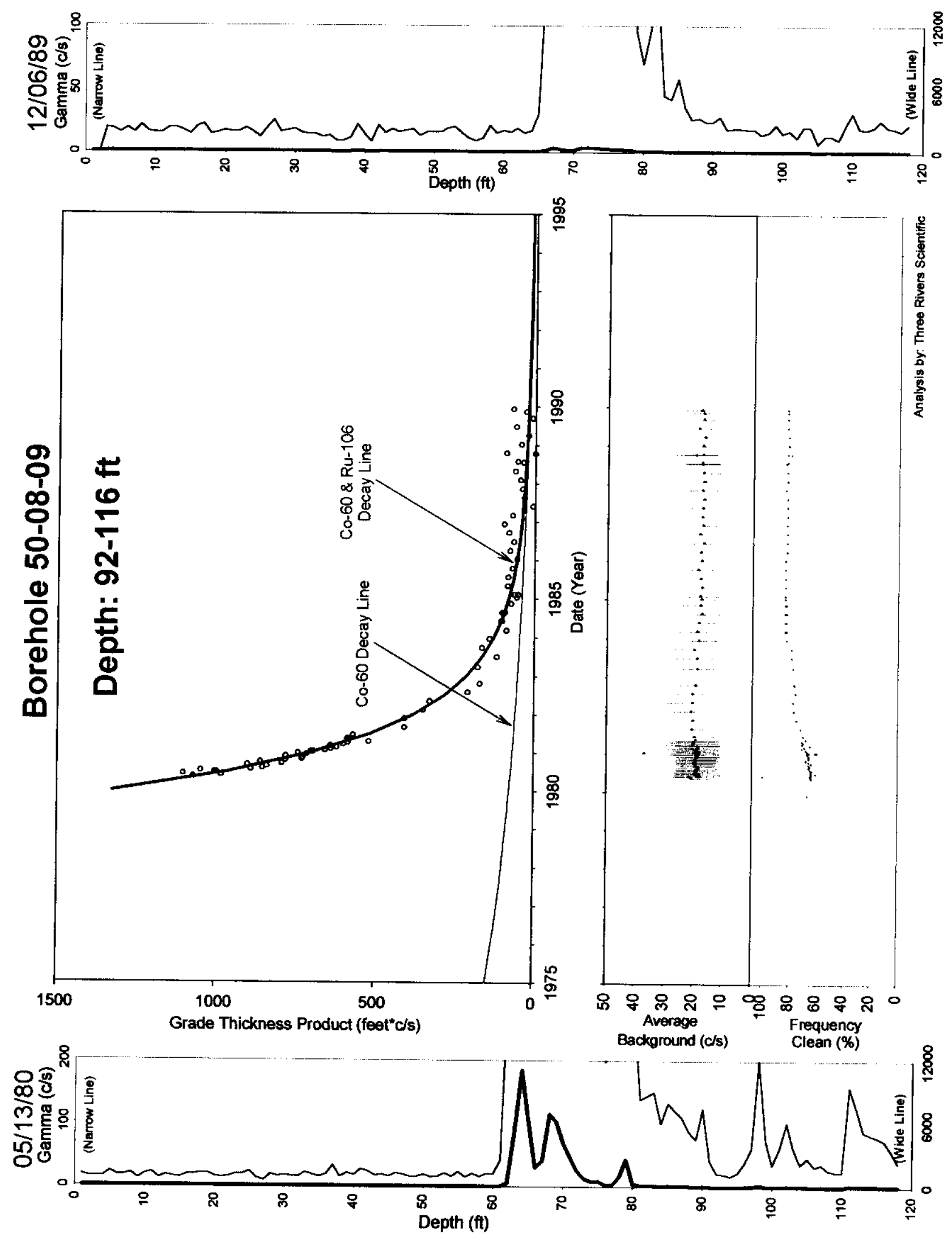
RPP-6088, Rev.0.

\section{Borehole 50-08-11}

\section{Contamination (Co-60 \& Ru-106) from 58 to 88 feet is Stable. Contamination (Co-60 \& Ru-106) from 96 to 106 feet is Stable.}

Grade thickness product from 58 to 88 feet is decreasing consistent with a least square fit for Co60 (HPGe identified) and Ru-106 (hypothesis) from the first survey in 1980 to 1993 and is characterized as stable. The ratio of gross contribution from Co-60 to gross from $\mathrm{Ru}-106$ is 515:1 as of 6-23-1993.

Grade thickness product over 96 to 106 feet is decreasing consistent with a least square fit for Co-60 (HPGe identified) and Ru-106 (hypothesis) from 1980 to 1993 and is characterized as stable. The ratio of gross contribution from Co-60 to gross from Ru-106 is 38:1 as of 6-23-1993.

Gross Gamma Survey Information

\begin{tabular}{|r|l|}
\hline Probe Type Processed : & $14:$ Shielded NaI \\
\hline Other Probe Types : & $\begin{array}{l}\text { 01: Green GM, 02: Red GM, } \\
\text { 03: Neutron, \& 04: NaI }\end{array}$ \\
\hline Survey Depth : & $140 \mathrm{ft}$ \\
\hline First Survey Date : & $5 / 13 / 1980$ \\
\hline Last Survey Date : & $6 / 23 / 1993$ \\
\hline Number Surveys Processed : & 95 \\
\hline
\end{tabular}

Analysis Notes

Method Used to Compute Background : $20-50$ feet

Depth(s) where Contamination was $58-88$ \& 96-106 feet Stable

Identified in Gross Gamma Surveys :

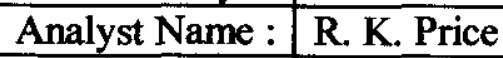

Company Name: Three Rivers Scientific 


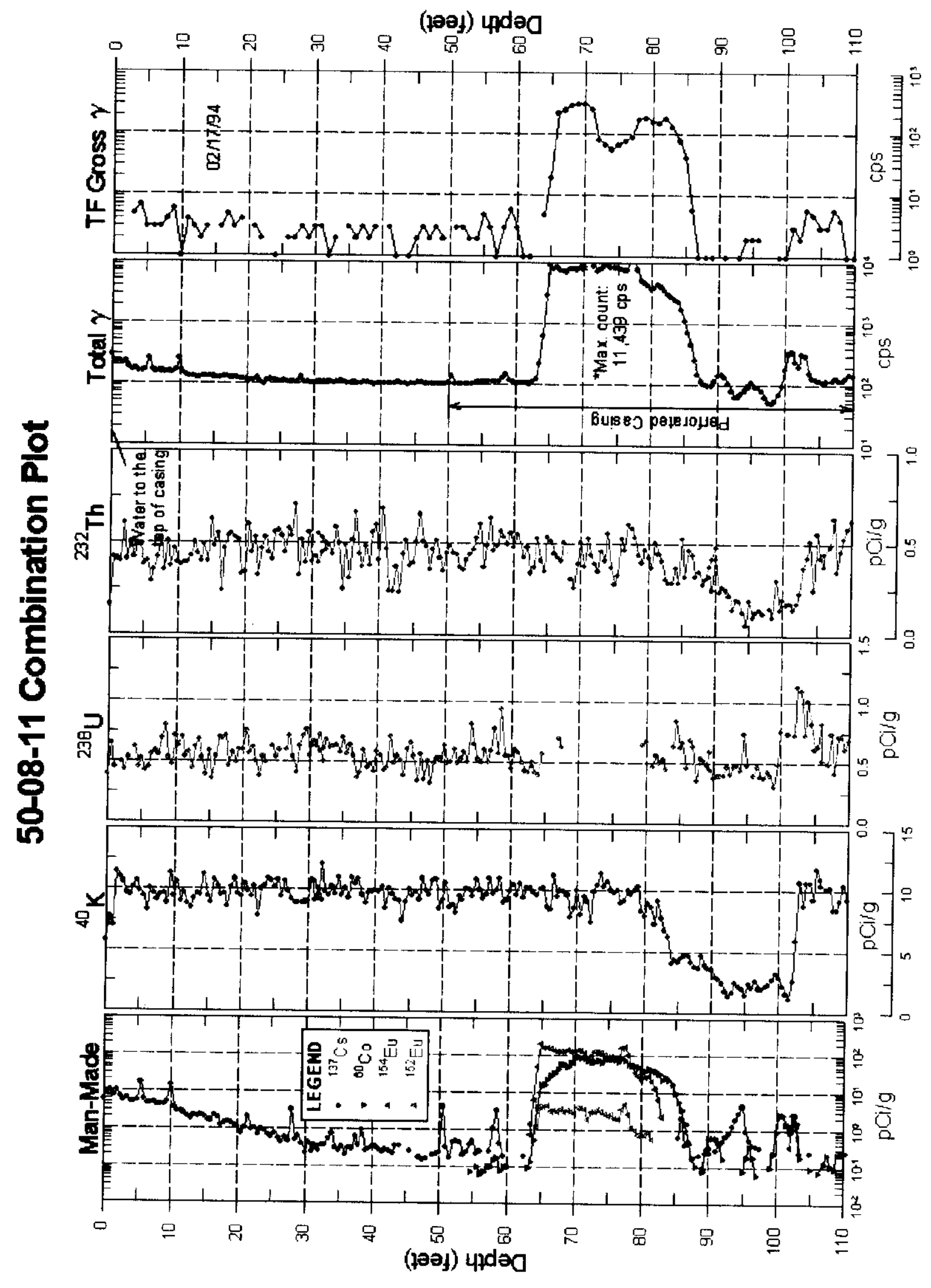




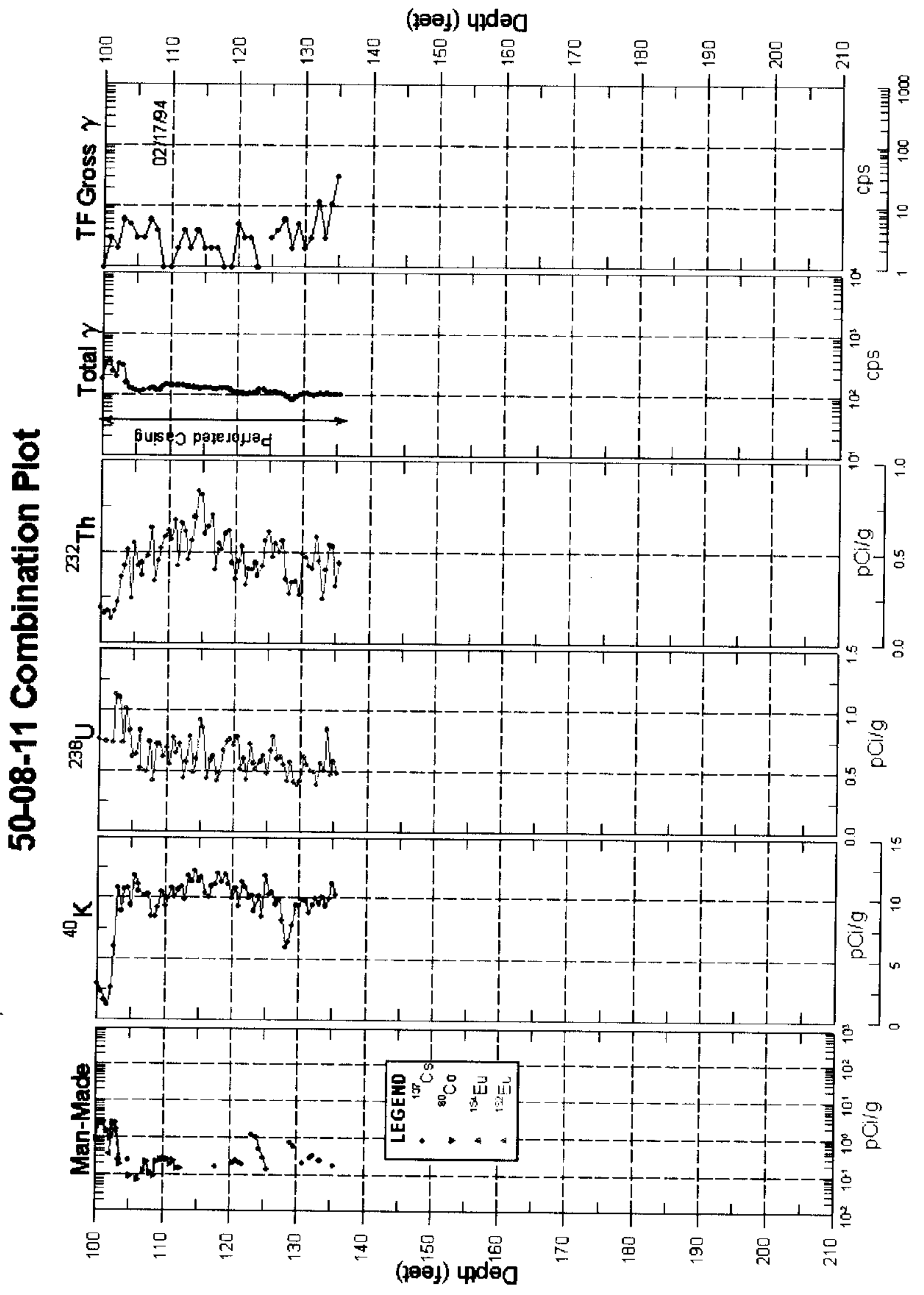


RPP-6088, Rev.0.

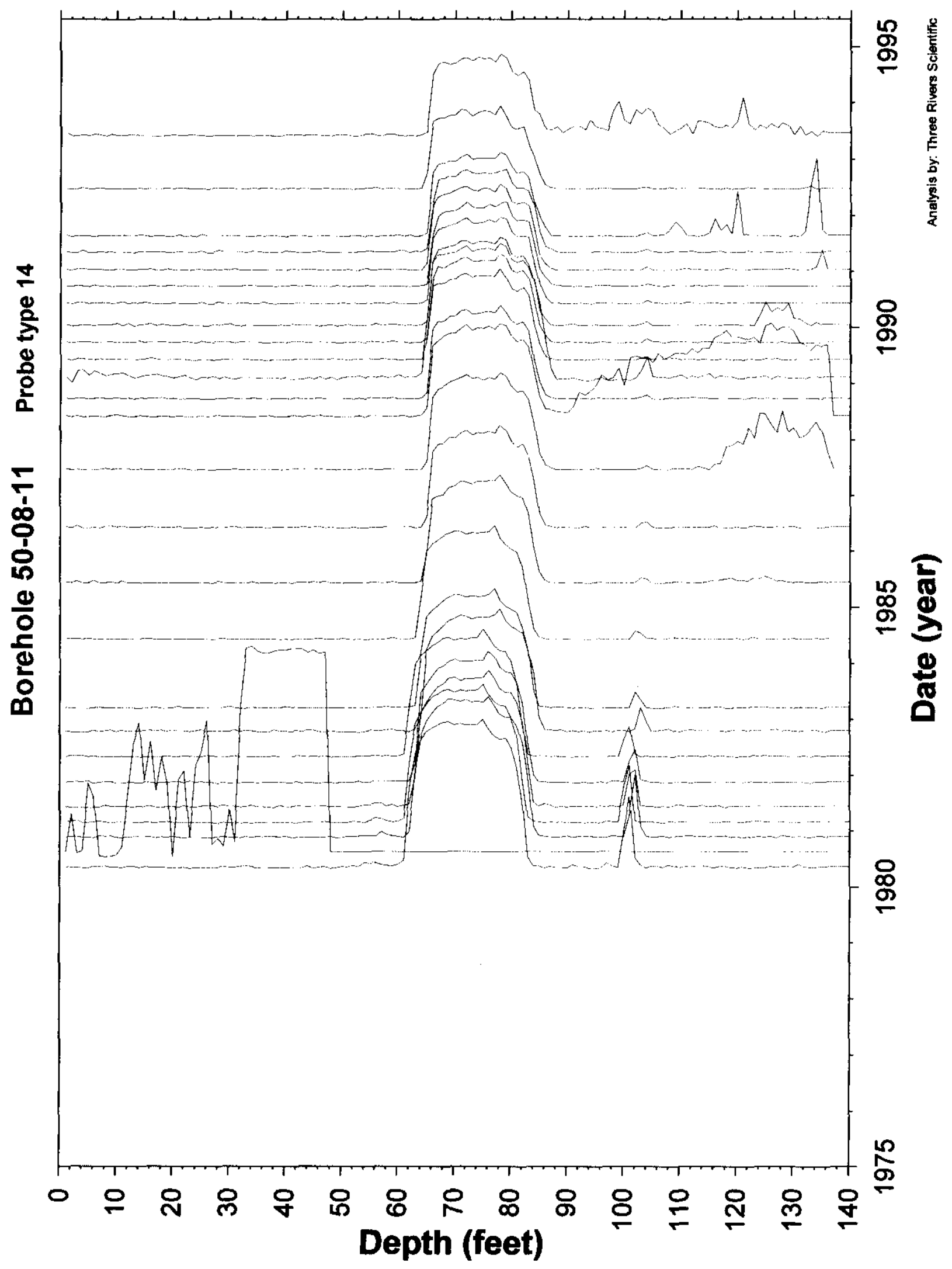

Tank T-108

Page 330 
RPP-6088, Rev.0.
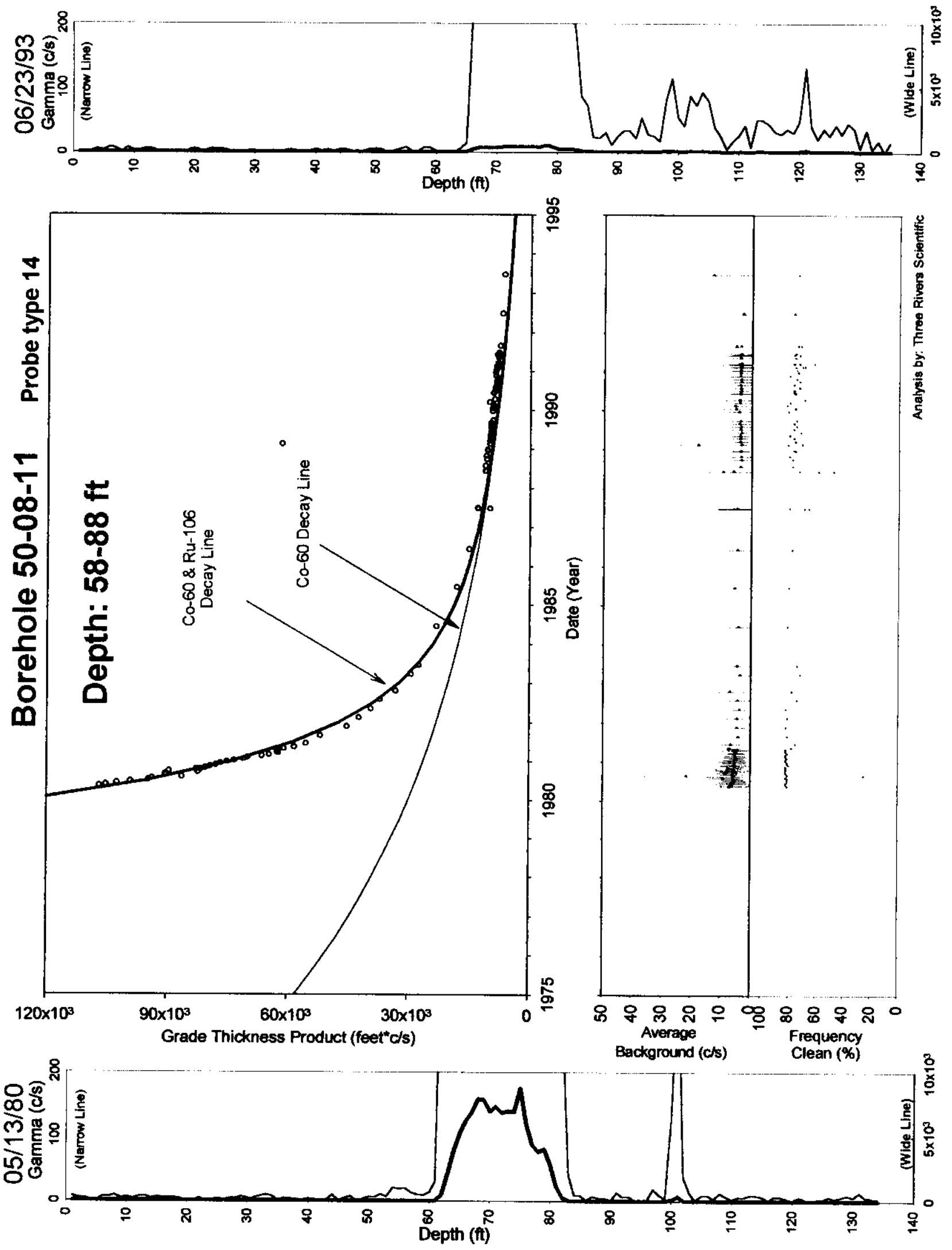
RPP-6088, Rev.0.
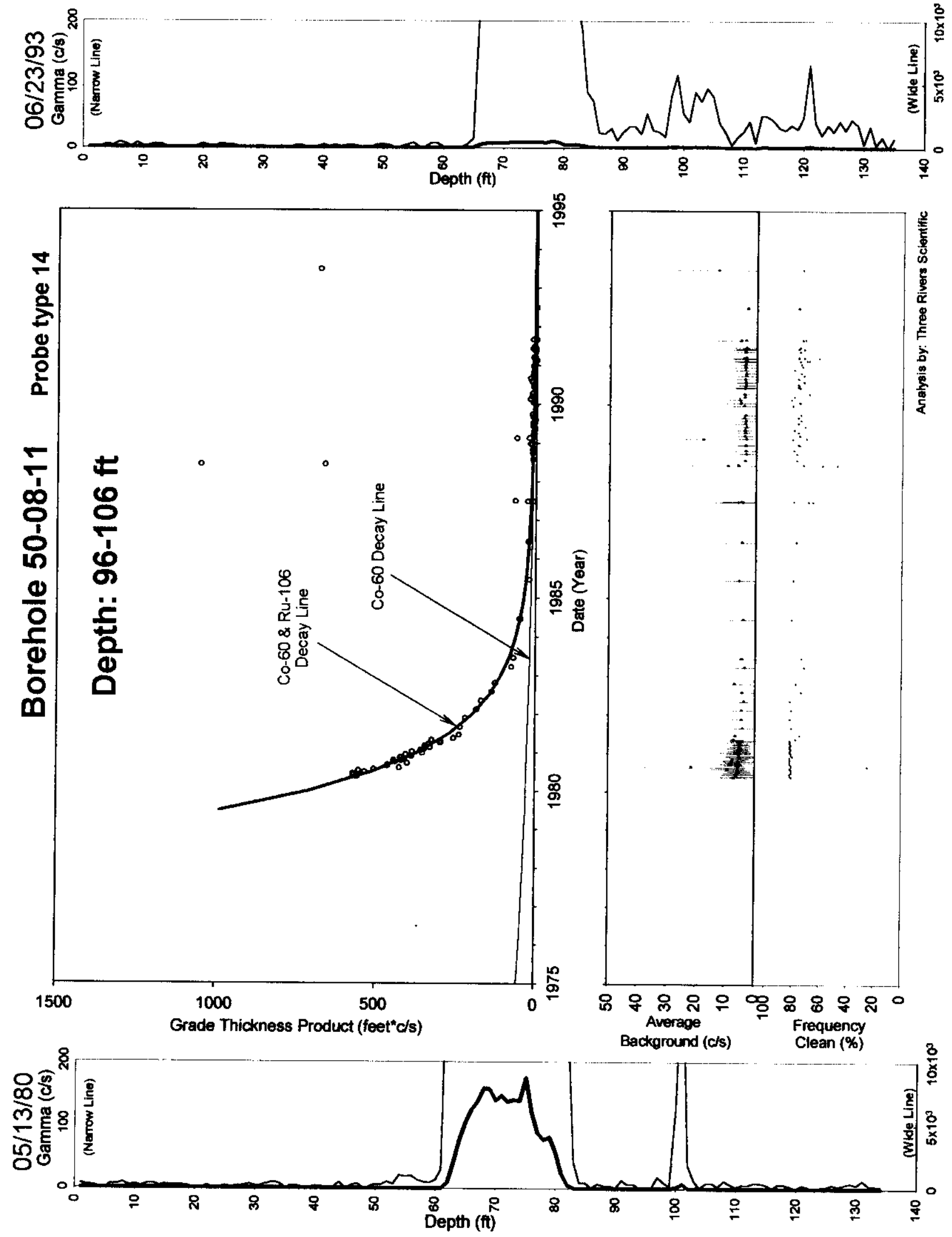


\section{Borehole 50-08-19}

\section{Contamination (Co-60 \& Ru-106) from 60 to 90 feet is Undetermined.}

Before 1982, the grade thickness product (GTP) from the gross gamma response over 60 to 90 feet is changing at a rate that does not match the decay rate of Co-60 (HPGe identified) \& Ru106 (hypothesis). Since the contamination interval extends to the bottom of the borehole and it has been demonstrated through earlier analysis that surveys before 1984 routinely exhibited depth control errors, the stability of the contamination interval can not be determined. A least square fit for $\mathrm{Co}-60$ and $\mathrm{Ru}-106$ from 1982 to 1995 is shown on the grade thickness product plot. The ratio of gross contribution from Co-60 to gross from $\mathrm{Ru}-106$ is $133: 1$ as of 2-25-1994.

Gross Gamma Survey Information

\begin{tabular}{|r|l|}
\hline Probe Type Processed : & $04:$ NaI \\
\hline Other Probe Types : & $01:$ Green GM \& 14: Shielded NaI \\
\hline Survey Depth : & $90 \mathrm{ft}$ \\
\hline First Survey Date : & $8 / 1 / 1979$ \\
\hline Last Survey Date : & $2 / 25 / 1994$ \\
\hline Number Surveys Processed : & 77 \\
\hline
\end{tabular}

Analysis Notes

\begin{tabular}{r|l} 
Method Used to Compute Background : & $30-50$ feet \\
$\begin{array}{r}\text { Depth(s) where Contamination was } \\
\text { Identified in Gross Gamma Surveys : }\end{array}$ & $60-90$ feet Undetermined \\
Analyst Name : & R. K. Price \\
\hline Company Name : & Three Rivers Scientific \\
\hline
\end{tabular}


RPP-6088, Rev.0.

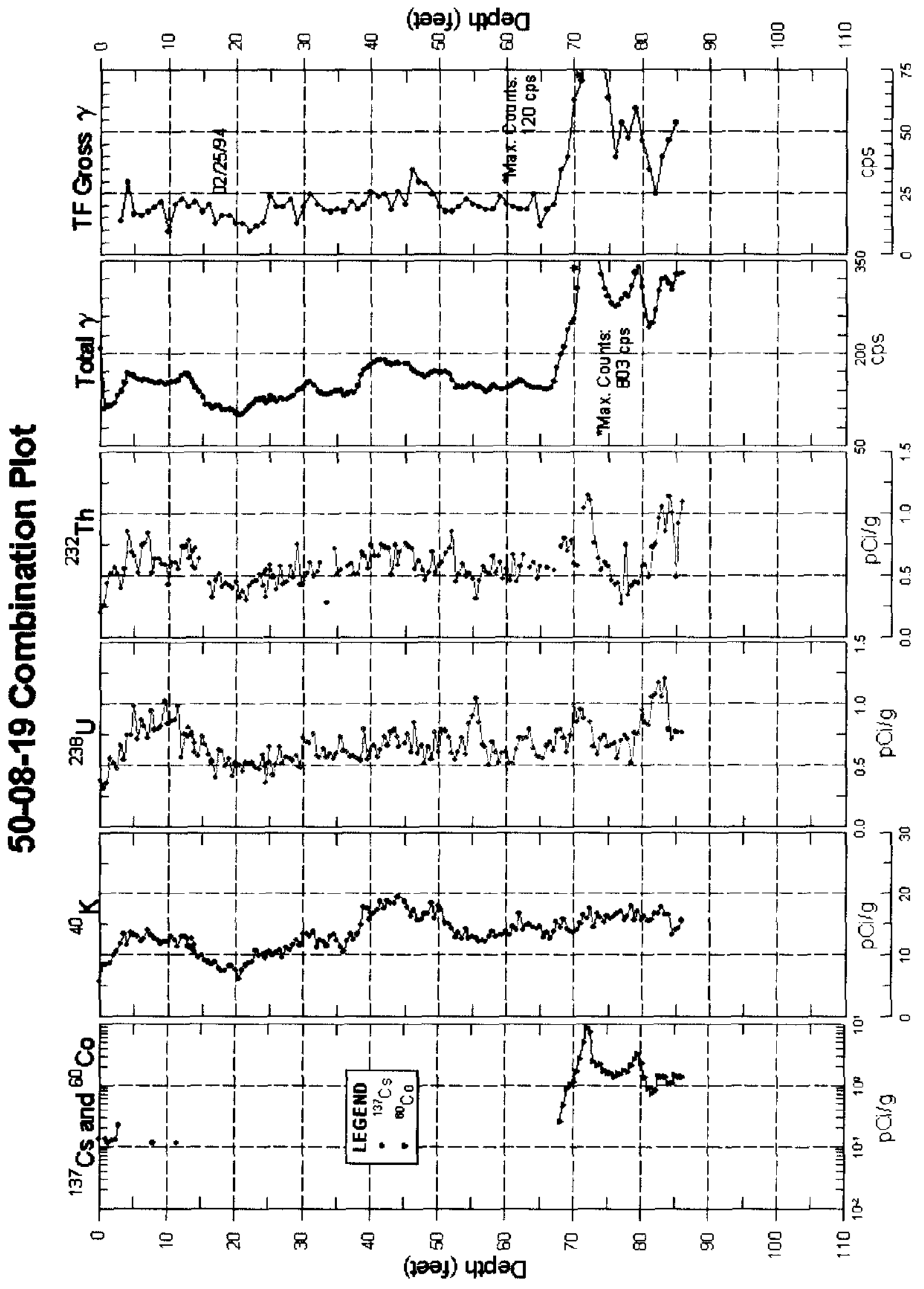


RPP-6088, Rev.0.

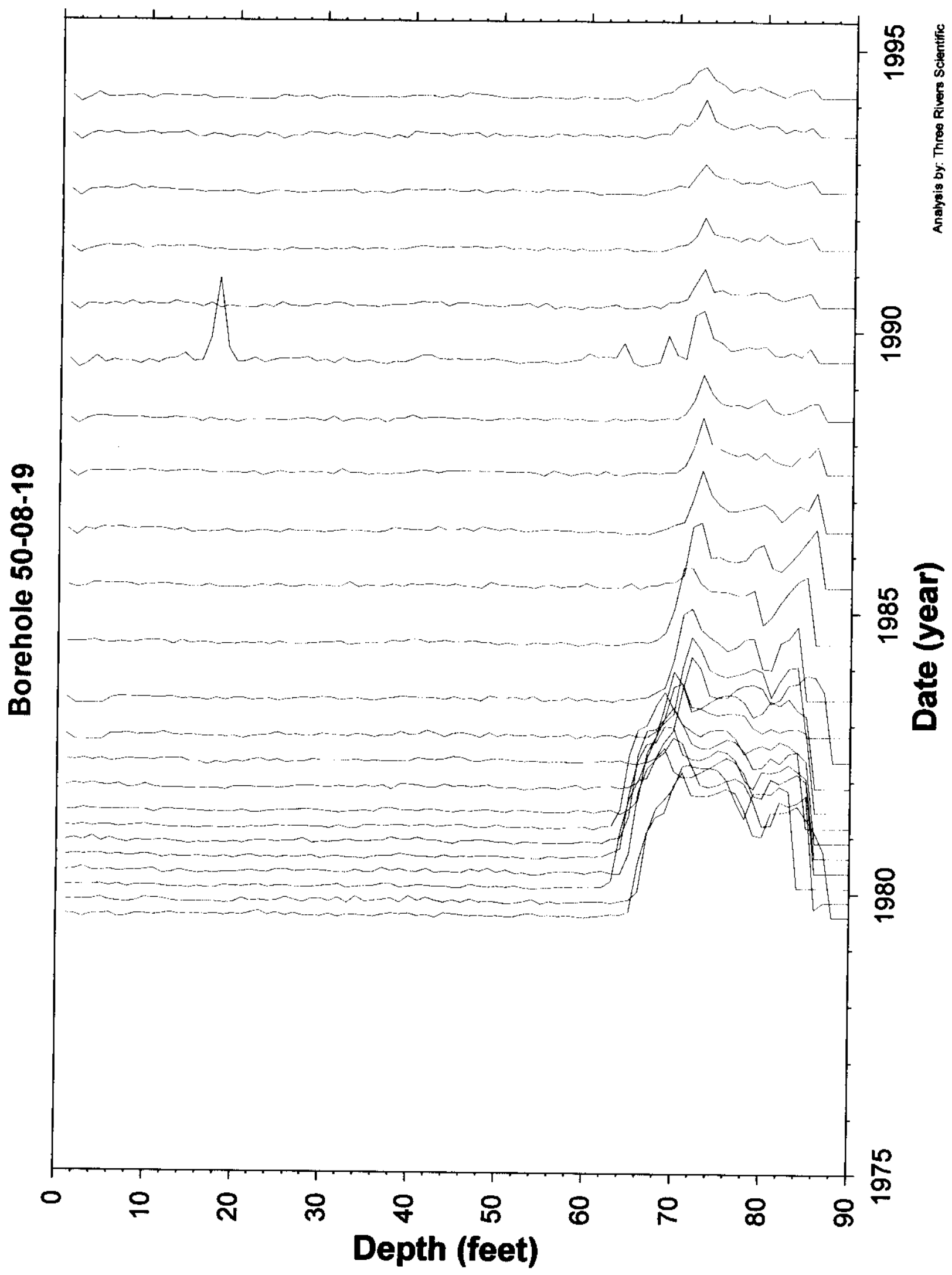

Tank T-108

Page 335 
RPP-6088, Rev.0.
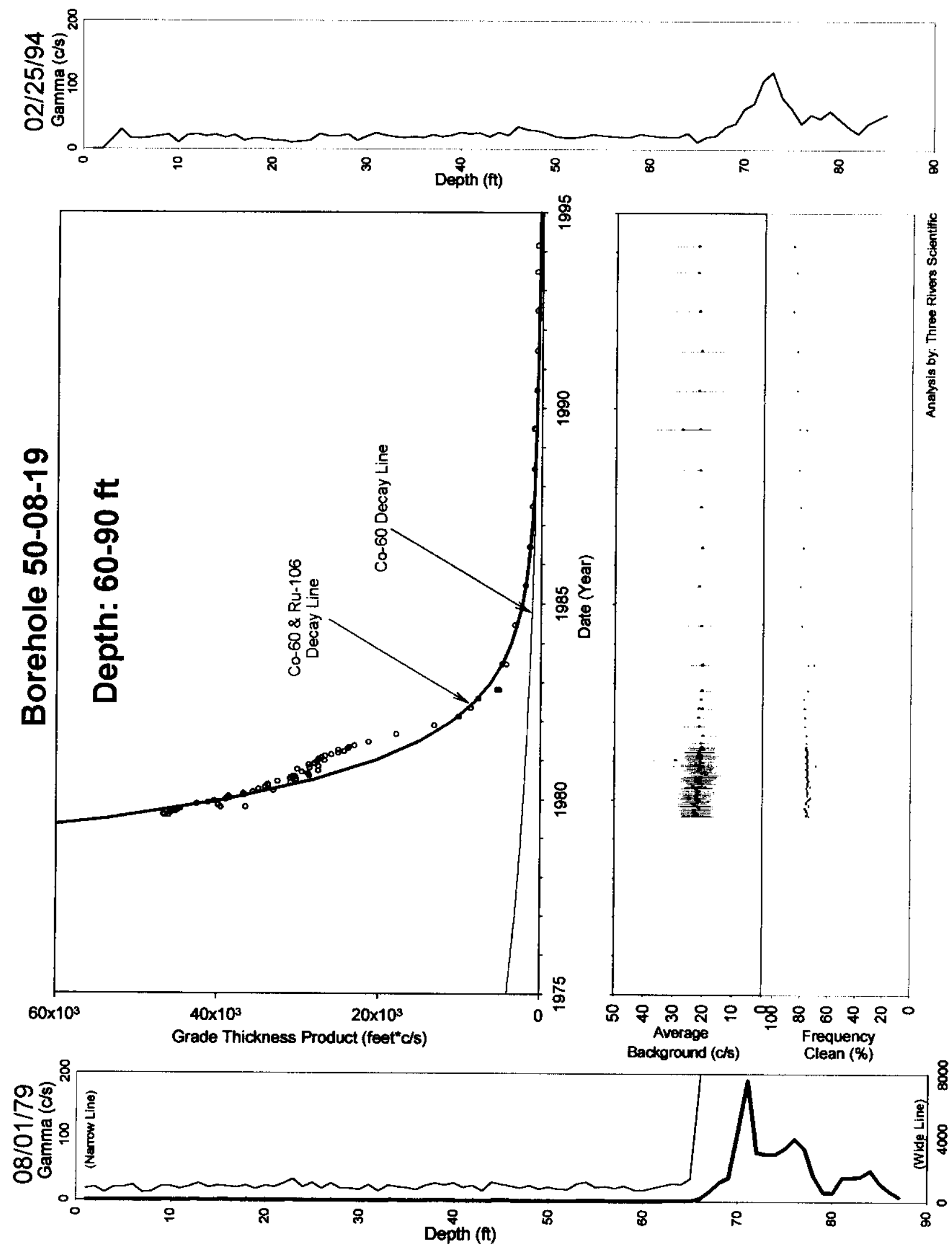

Tank T-108

Page 336 
RPP-6088, Rev.0.

\section{Tank T-109 Wells}

Table of Contents $\quad$ Page

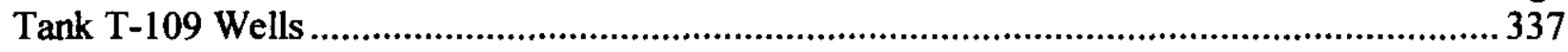

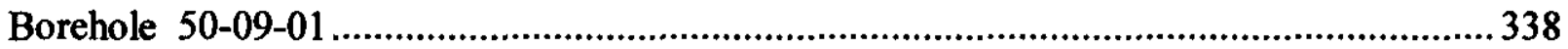

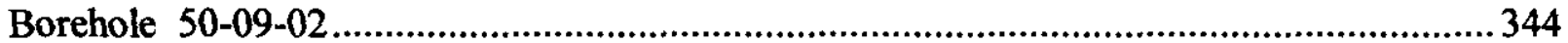

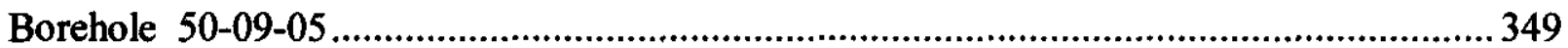

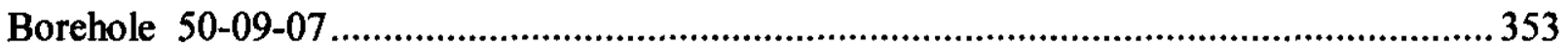

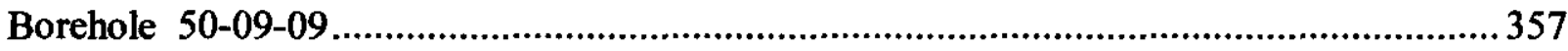

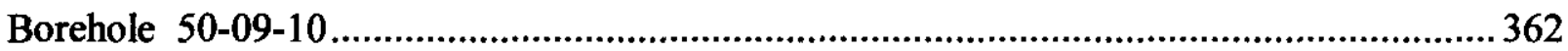

This section contains the analysis results for vadose zone boreholes (dry wells) associated with Tank 109 in the "T" Tank Farm.

Special Note: (none)

Borehole 50-09-10 has an unstable zone from 99 to 115 feet. The GTP of the zone has been increasing since 1985 
RPP-6088, Rev.0.

\section{Borehole 50-09-01}

\section{Contamination (Cs-137) from 0 to 8 feet is Stable. Contamination (Co-60 \& Ru-106) from 44 to 58 feet is Stable. Contamination (Co-60 \& Ru-106) from 58 to 86 feet is Stable.}

Grade thickness product over 0 to 8 feet is decreasing consistent with Cs-137 (HPGe identified) decay from 1984 to the last survey in 1990. The levels are at the minimum detectable with the historical gross gamma data for the Shielded NaI detector (probe type 14). The levels of Cs-137 for this interval are intermediate, with a maximum reading of $200 \mathrm{pCi} / \mathrm{g}$ (HPGe base line log) at 3 feet.

Grade thickness product over $\mathbf{4 4}$ to $\mathbf{5 8}$ feet is decreasing consistent with a least square fit for Co60 (HPGe identified) and Ru-106 (hypothesis) from the first survey in 1980 to 1990. The ratio of gross contribution from Co-60 to gross from Ru-106 is 229:1 as of 12-6-1989.

Grade thickness product over 58 to 86 feet is decreasing consistent with a least square fit for Co60 (HPGe identified) and Ru-106 (hypothesis) from the first survey in 1980 to 1990. The ratio of gross contribution from Co-60 to gross from Ru-106 is 113:1 as of 12-6-1989.

The Shielded NaI detector (probe type 14) was used for analysis of this borehole. The other gross gamma ray probe types had insufficient time span, survey frequency, and/or inappropriate sensitivity to be used in the analysis of the borehole.

Gross Gamma Survey Information

\begin{tabular}{|r|l|}
\hline Probe Type Processed: & 14: Shielded Nal \\
\hline Other Probe Types : & $\begin{array}{l}\text { 01: Green GM, 02: Red GM, } \\
\text { 03: Neutron, \& 04: NaI }\end{array}$ \\
\hline Survey Depth : & $90 \mathrm{ft}$ \\
\hline First Survey Date : & $4 / 14 / 1980$ \\
\hline Last Survey Date : & $12 / 06 / 1989$ \\
\hline Number Surveys Processed: & 78 \\
\hline
\end{tabular}

Analysis Notes

Method Used to Compute Background : $10-30$ feet

Depth(s) where Contamination was $0-8,44-58, \&$ 58-86 feet Stable Identified in Gross Gamma Surveys :

Analyst Name : R. K. Price

Company Name: Three Rivers Scientific 
RPP-6088, Rev.0.

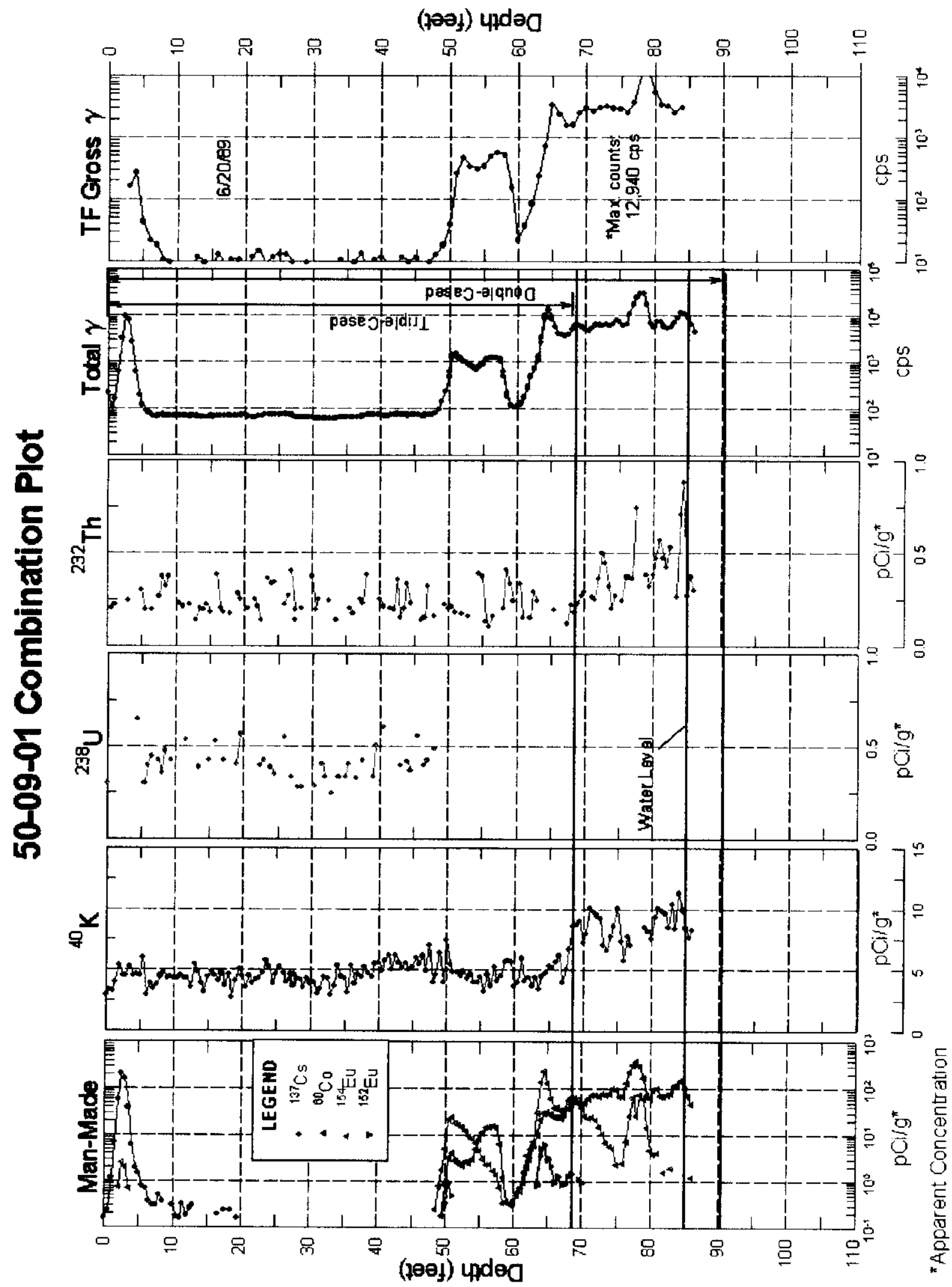

Tank T-109

Page 339 
RPP-6088, Rev.0.

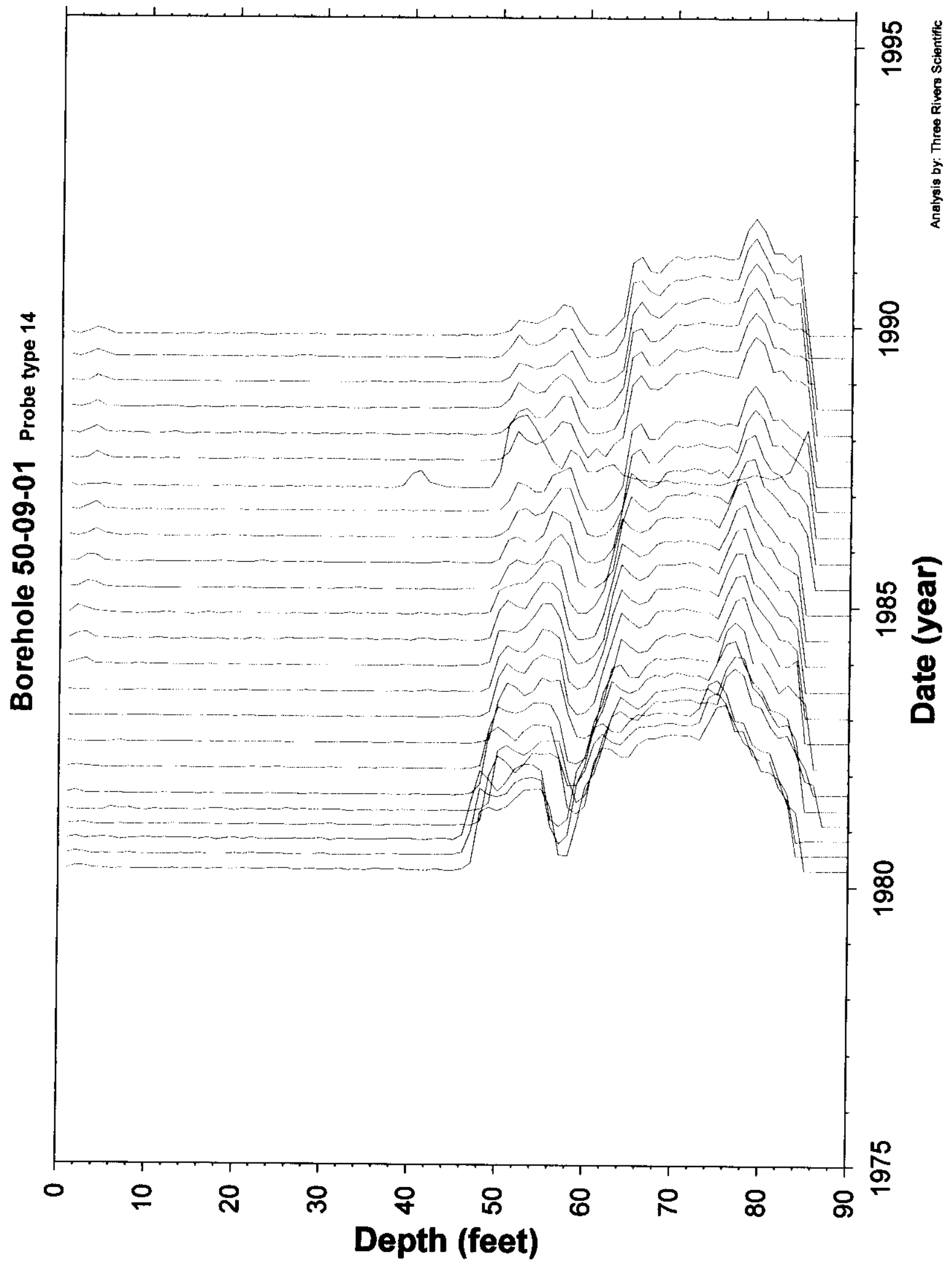

Tank T-109

Page 340 
RPP-6088, Rev.0.
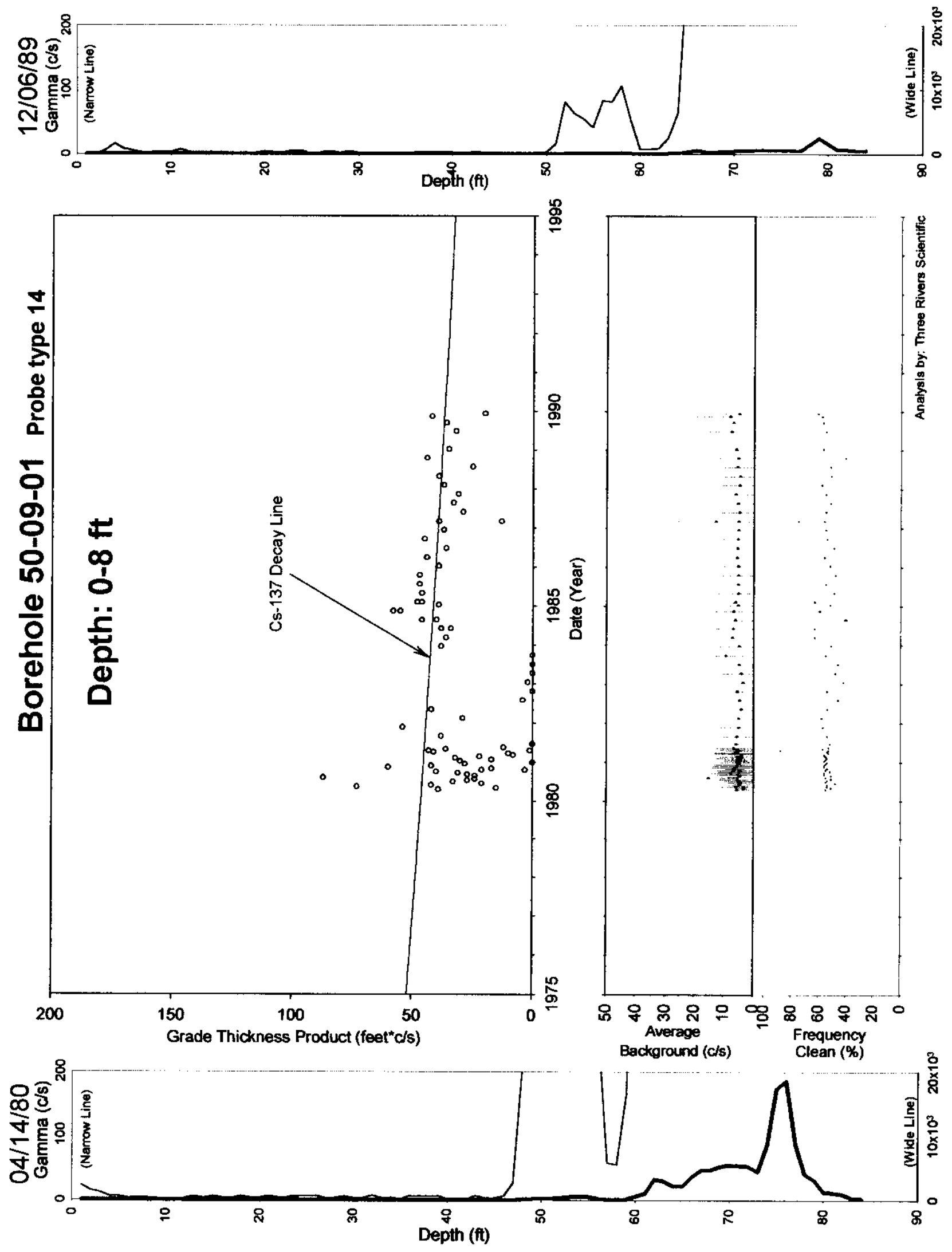

Tank T-109 
RPP-6088, Rev.0.
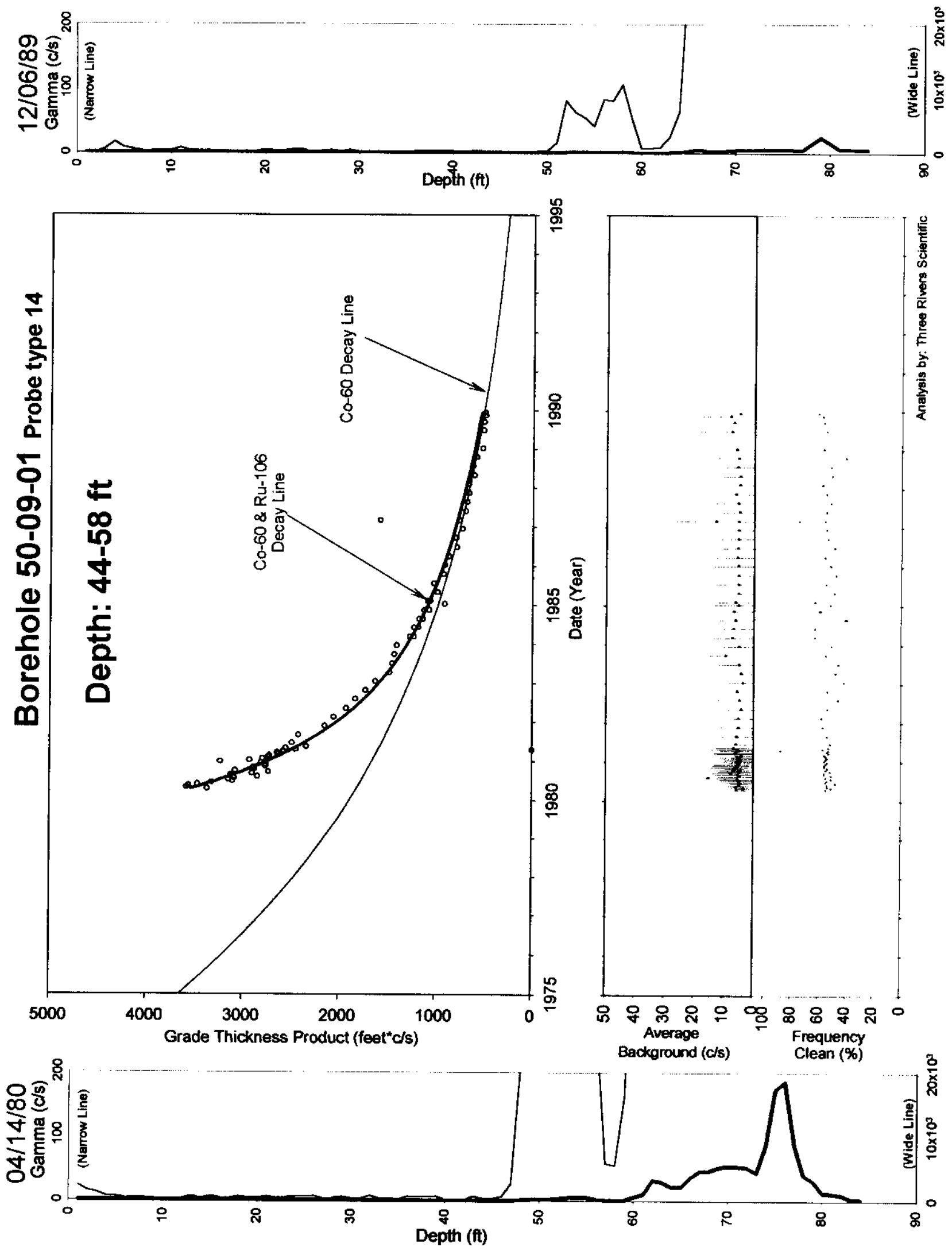

Tank T-109

Page 342 


\section{RPP-6088, Rev.0.}
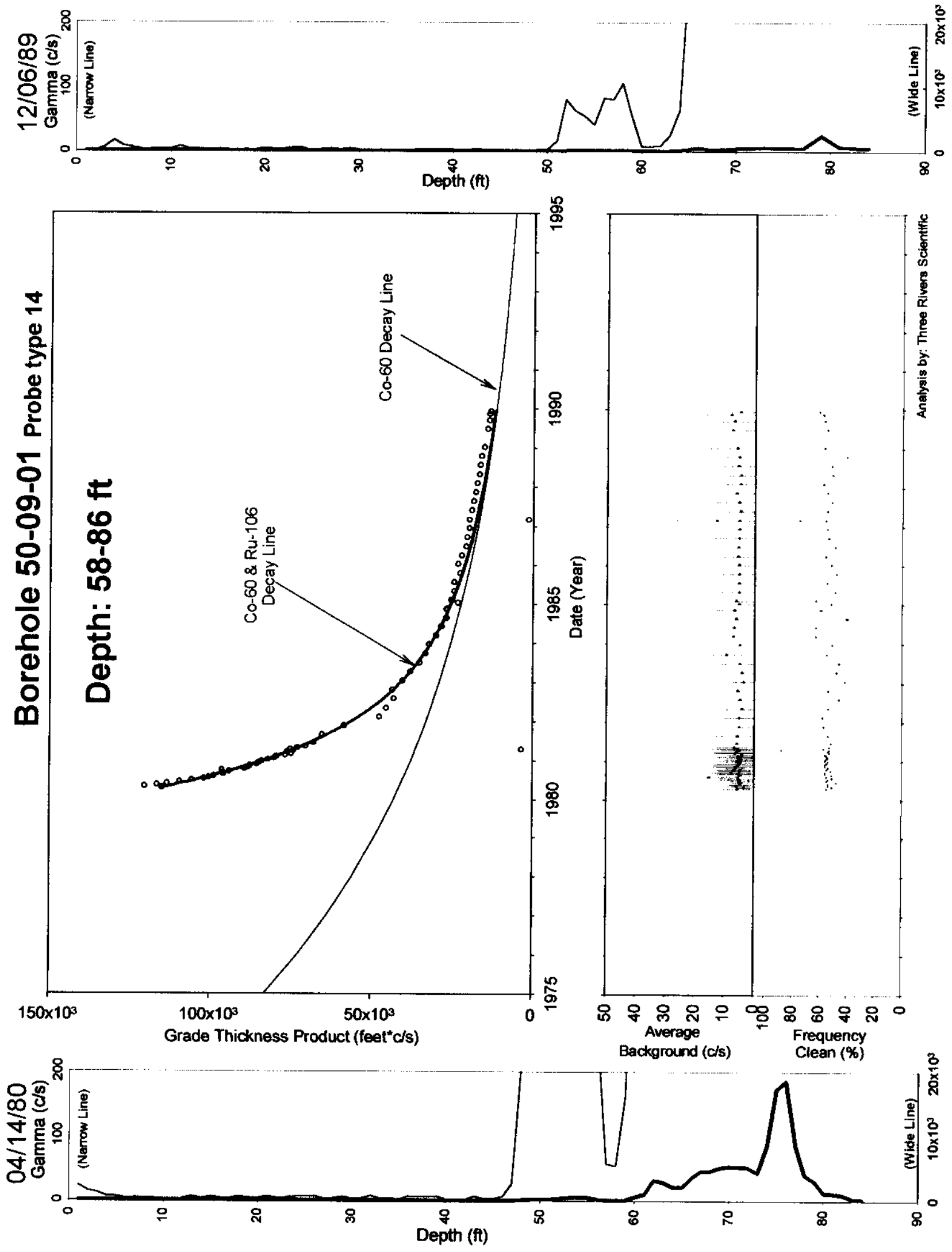
RPP-6088, Rev.0.

\section{Borehole 50-09-02}

\section{Contamination (Cs-137) from 0 to 10 feet is Undetermined. Contamination (Co-60 \& Ru-106) from 58 to 86 feet is Stable.}

Grade thickness product over 0 to 10 feet is low level activity and is characterized at undetermined. The levels are at the minimum detectable with the historical gross gamma data. The levels of Cs-137(HPGe identified) for this interval are low, with a maximum reading less than $10 \mathrm{pCi} / \mathrm{g}$ at 2 feet.

Grade thickness product over 58 to 86 feet is decreasing consistent with a least square fit for Co60 (HPGe identified) and Ru-106 (hypothesis) from the first survey in 1980 to 1990. The ratio of gross contribution from Co-60 to gross from Ru-106 is 51:1 as of 12-6-1989.

Gross Gamma Survey Information

\begin{tabular}{|r|l|}
\hline Probe Type Processed : & 04: NaI \\
\hline Other Probe Types : & $\begin{array}{l}01: \text { Green GM, 02: Red GM, } \\
\text { 03: Neutron, \& 14: Shielded NaI }\end{array}$ \\
\hline Survey Depth : & $90 \mathrm{ft}$ \\
\hline First Survey Date : & $1 / 09 / 1980$ \\
\hline Last Survey Date : & $12 / 06 / 1989$ \\
\hline Number Surveys Processed: & 76 \\
\hline
\end{tabular}

Analysis Notes

Method Used to Compute Background : $10-30$ feet

Depth(s) where Contamination was $0-10$ feet Undetermined Identified in Gross Gamma Surveys : $58-86$ feet Stable

Analyst Name : R. K. Price

Company Name : Three Rivers Scientific 
RPP-6088, Rev.0.

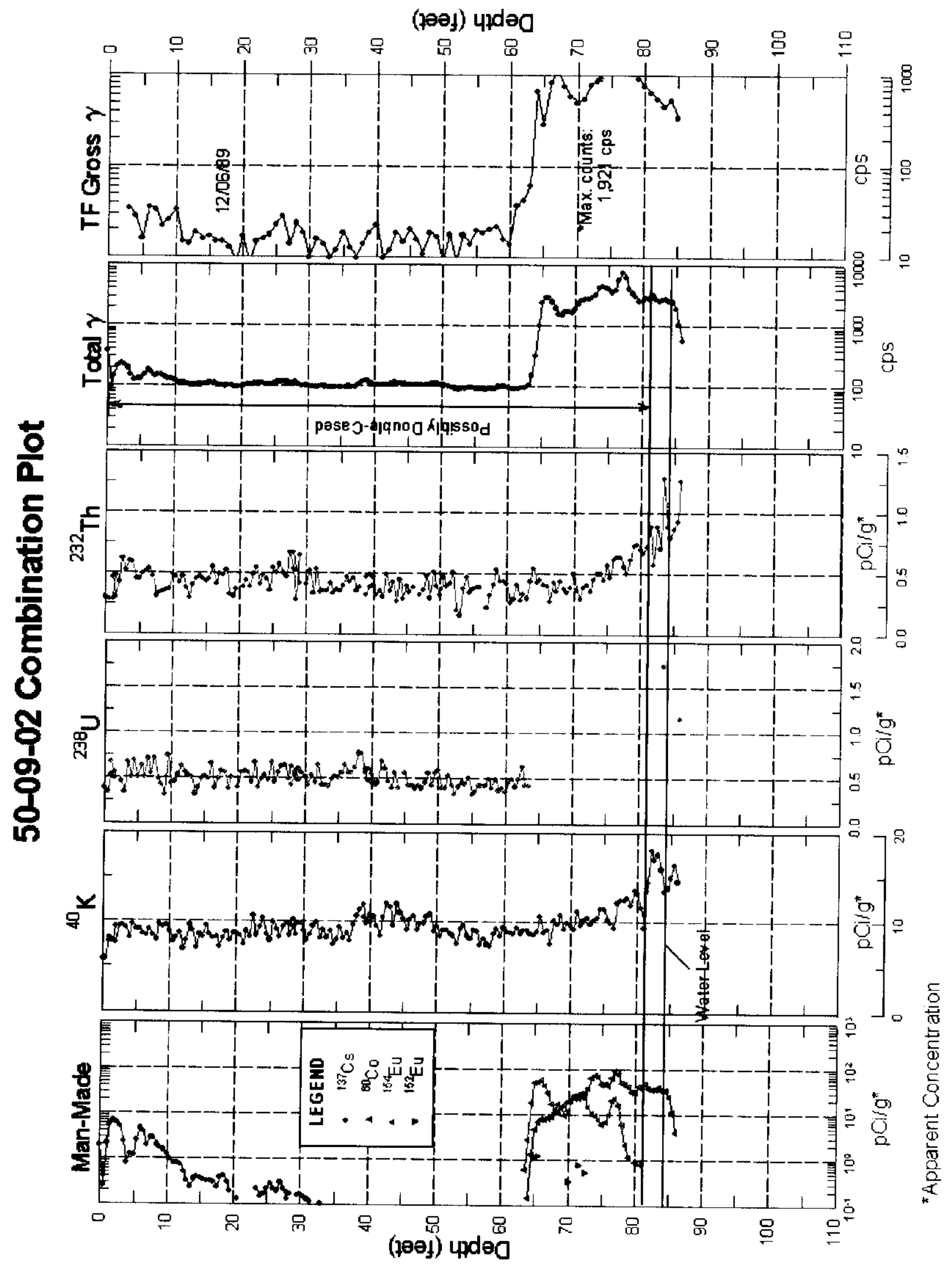

Tank T-109

Page 345 
RPP-6088, Rev.0.

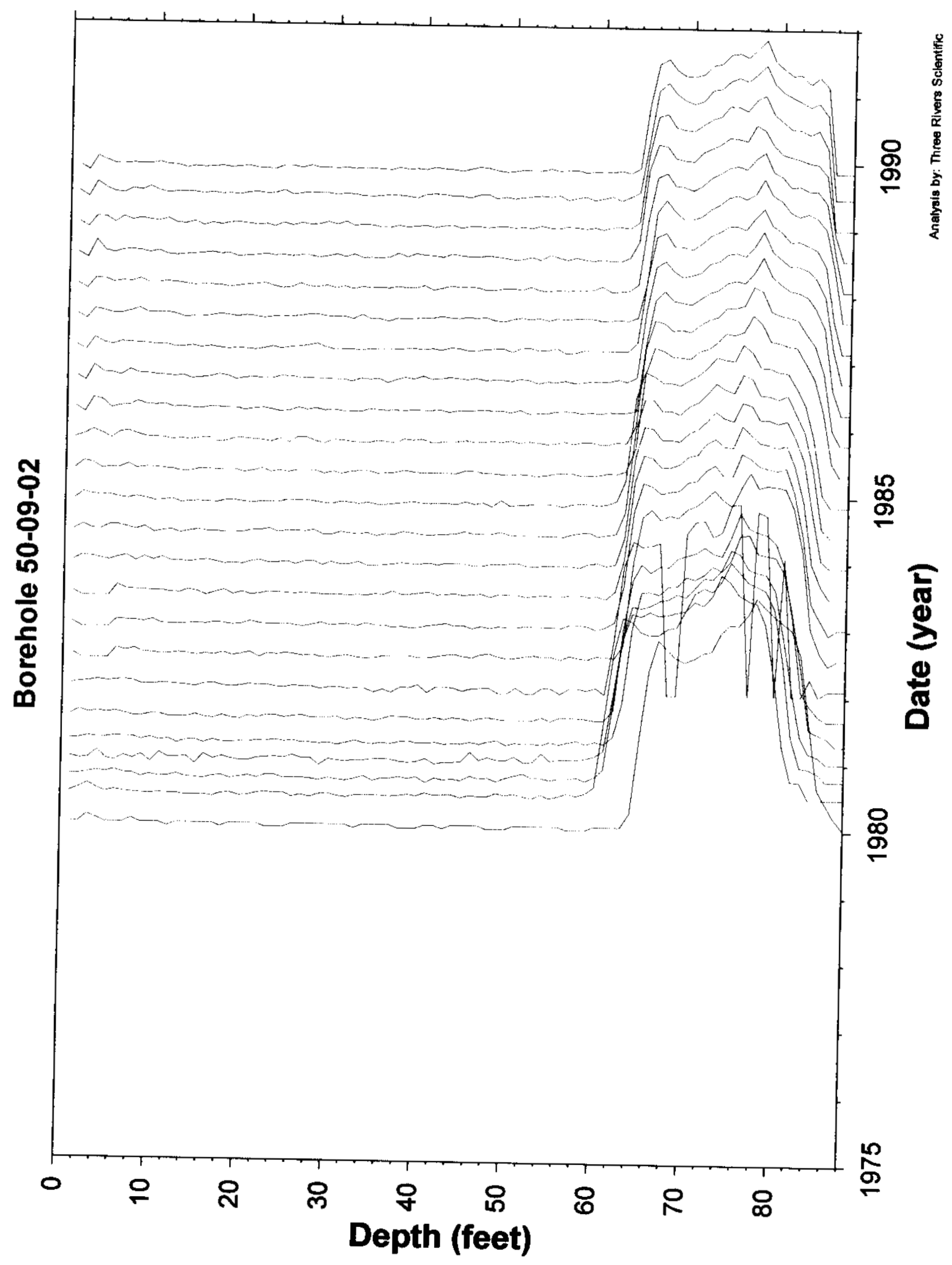

Tank T-109

Page 346 
RPP-6088, Rev.0.
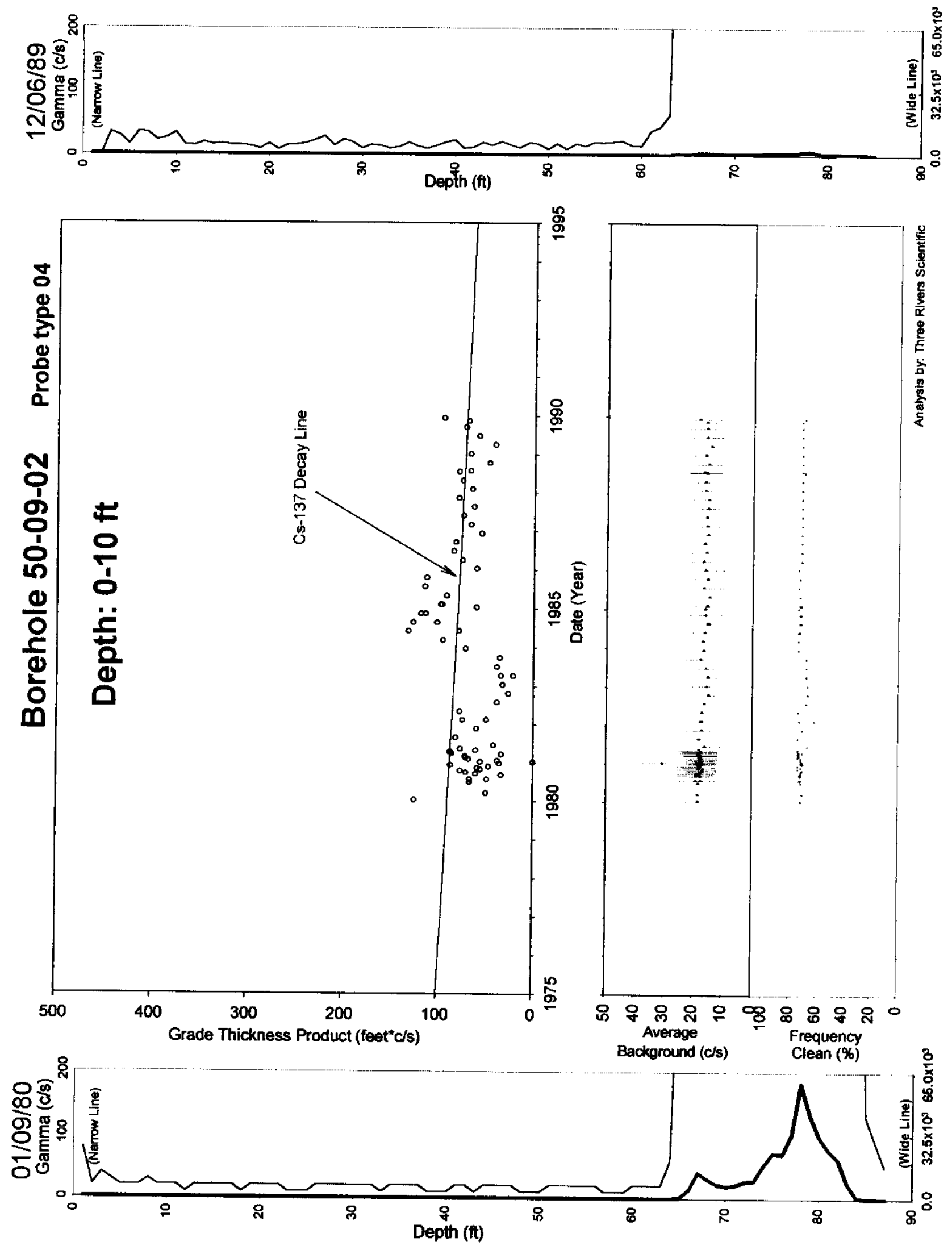

Tank T-109 
RPP-6088, Rev.0.
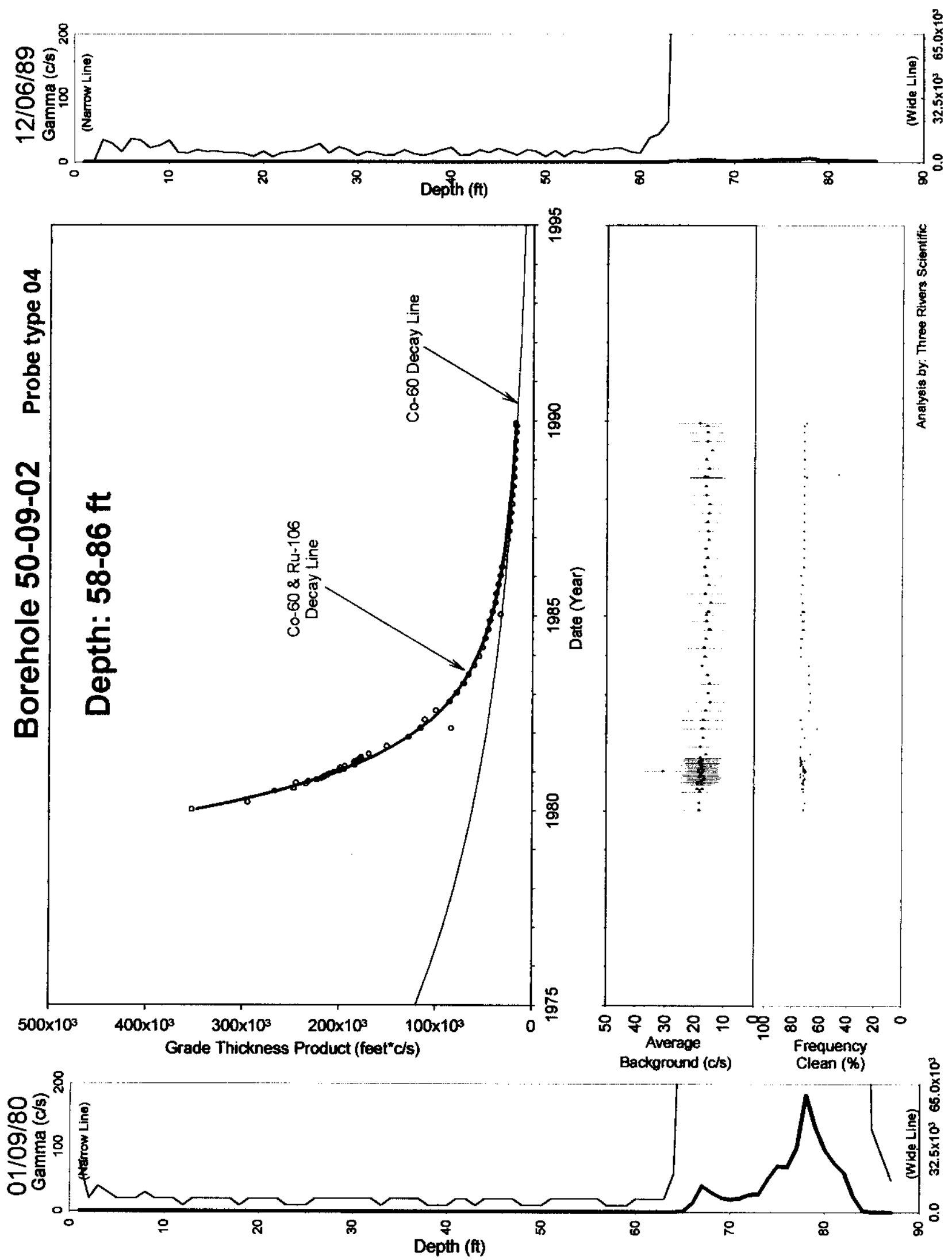

Tank T-109 
RPP-6088, Rev.0.

\section{Borehole 50-09-05}

\section{Contamination (Co-60 \& Ru-106) from 68 to 86 feet is Unstable Early.}

Grade thickness product (GTP) over 68 to 86 feet is constant from 1975 to 1981, then in early 1981 begins an unstable (increasing) condition until 1983. Finally the GTP decreases consistent with a least square fit for Co-60 (HPGe identified) and Ru-106 (hypothesis) from 1983 to 1995. The ratio of gross contribution from Co-60 to gross from Ru-106 is 1300:1 as of 6-12-1994.

The average background plot shows a step decrease after the 8/5/1980 survey.

Gross Gamma Survey Information

\begin{tabular}{|r|l|}
\hline Probe Type Processed : & $04: \mathrm{NaI}$ \\
\hline Other Probe Types : & $03:$ Neutron \\
\hline Survey Depth : & $90 \mathrm{ft}$ \\
\hline First Survey Date : & $1 / 10 / 1975$ \\
\hline Last Survey Date : & $5 / 26 / 1994$ \\
\hline Number Surveys Processed : & 333 \\
\hline
\end{tabular}

Analysis Notes

Method Used to Compute Background : $140-60$ feet

Depth(s) where Contamination was $68-86$ feet Unstable Early

Identified in Gross Gamma Surveys :

Analyst Name : R. K. Price

Company Name : Three Rivers Scientific 
RPP-6088, Rev.0.

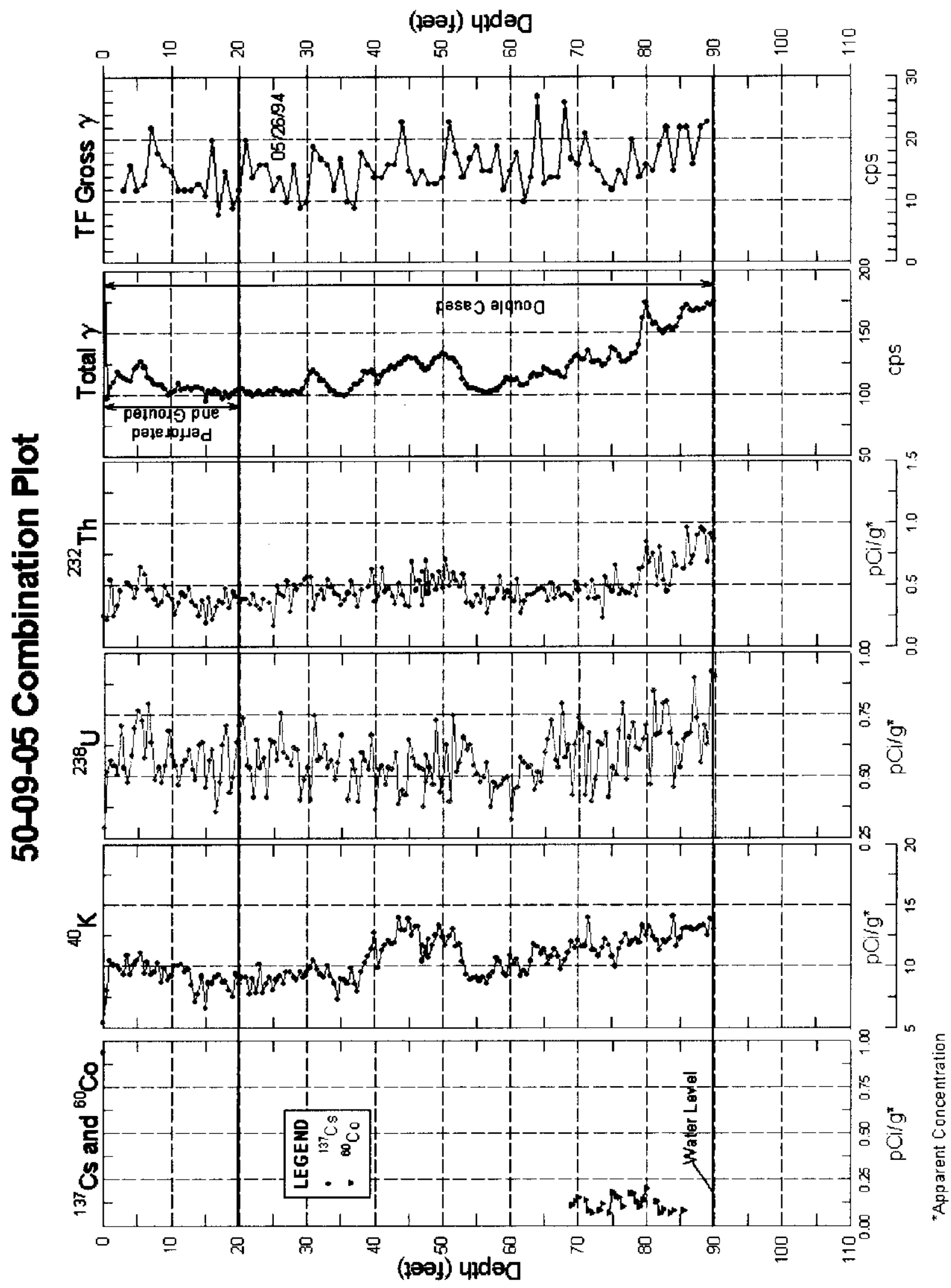

Tank T-109

Page 350 
RPP-6088, Rev.0.

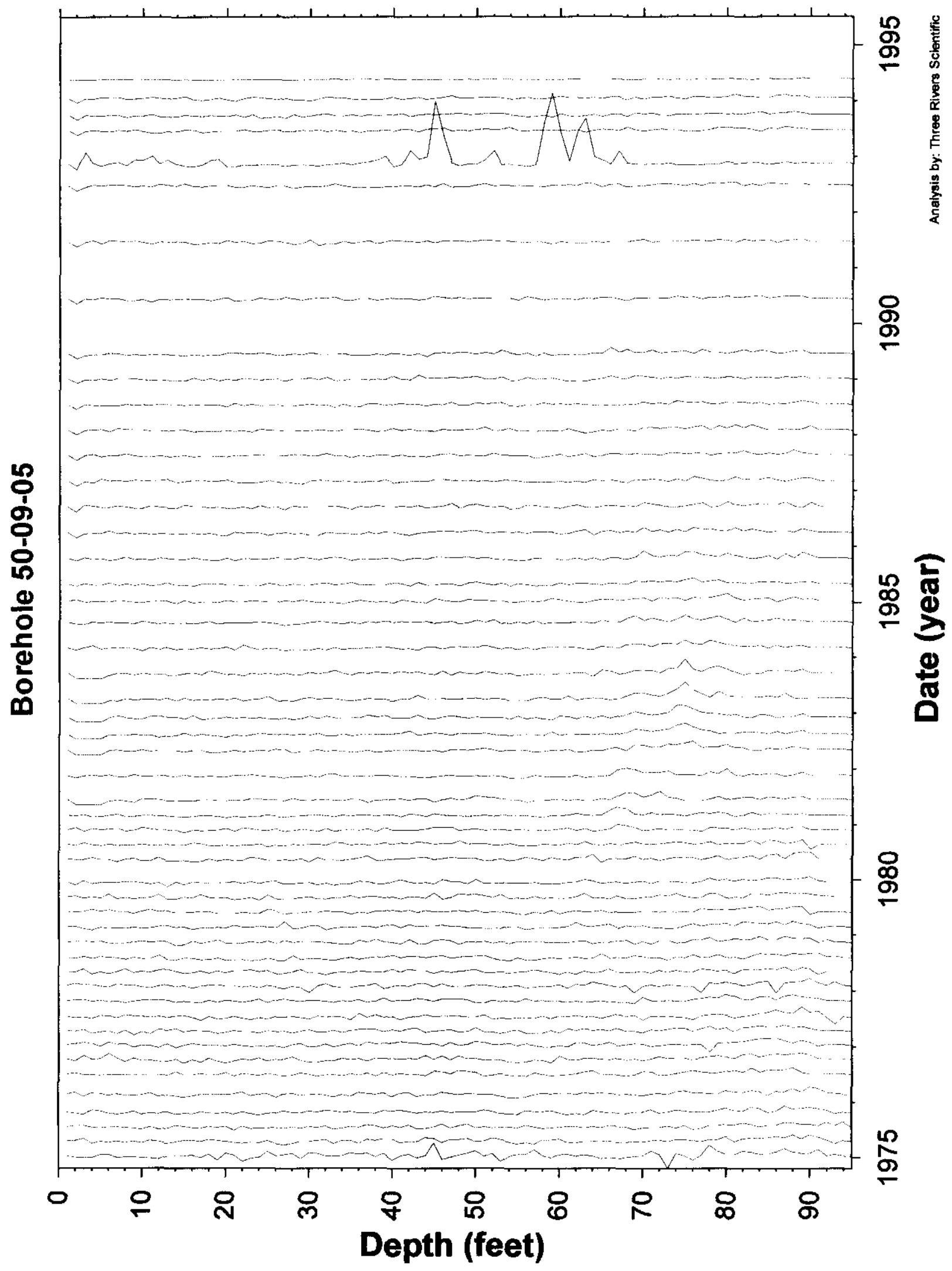

Tank T-109

Page 351 
RPP-6088, Rev.0.
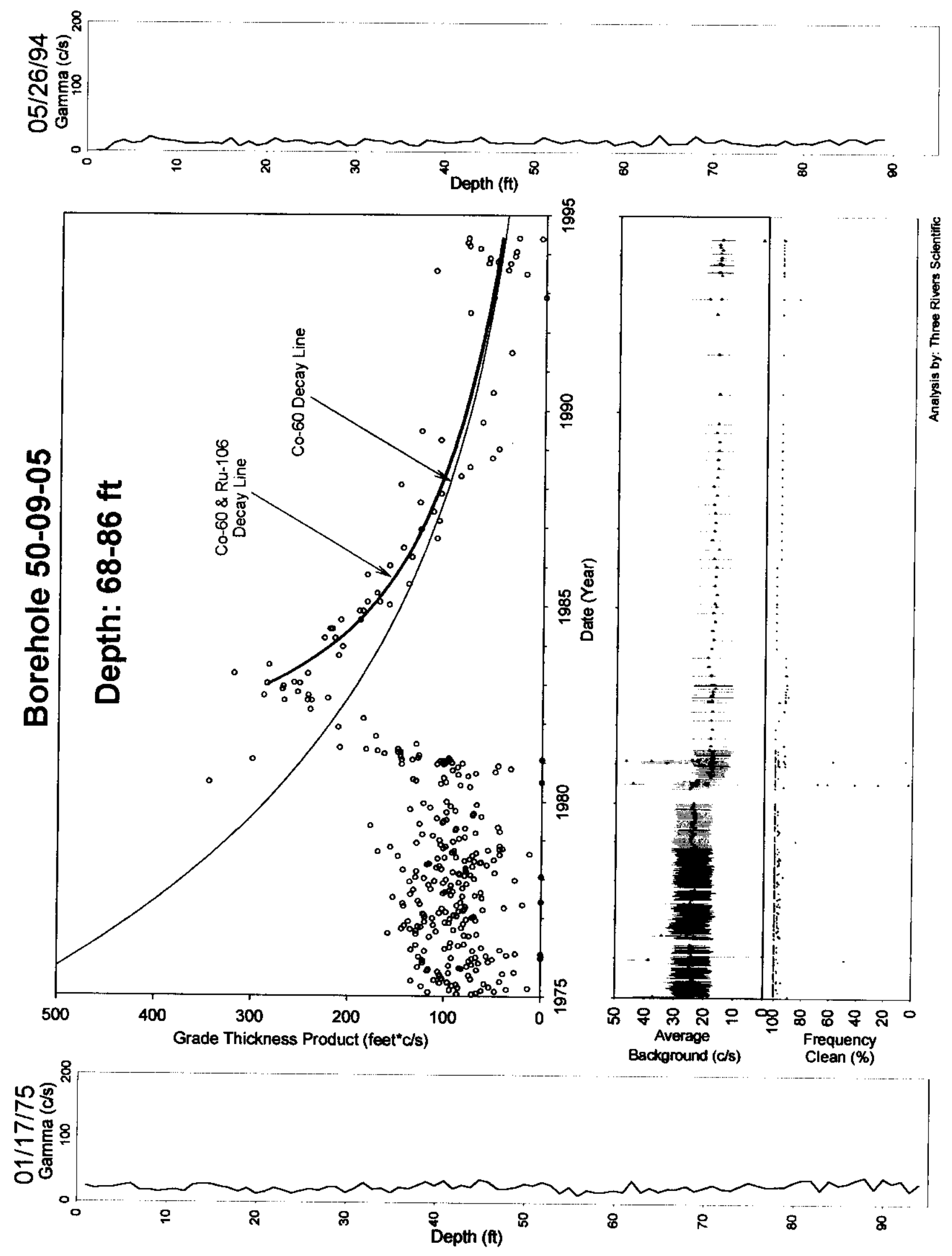

Tank T-109

Page 352 


\section{Borehole 50-09-07}

\section{No Gamma Ray Emitting Contamination Identified.}

No significant levels of gamma ray contamination are present, based upon gross gamma data, above the survey probe detection threshold between 1975 and 1994 in the vadose zone from 2 to 90 feet. The HPGe logging system detected Cs-137 at less than $0.2 \mathrm{pCi} / \mathrm{g}$ in the borehole.

The average background plot shows a step decrease after the $8 / 5 / 1980$ survey.

Gross Gamma Survey Information

Probe Type Processed : $04: \mathrm{NaI}$

Other Probe Types : $03:$ Neutron

Survey Depth : $90 \mathrm{ft}$

First Survey Date : $1 / 10 / 1975$

Last Survey Date : $5 / 26 / 1994$

Number Surveys Processed : 306

Analysis Notes

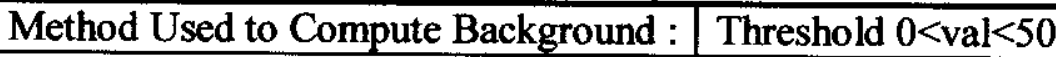

Depth(s) where Contamination was NONE

Identified in Gross Gamma Surveys :

Analyst Name: $\quad$ R. K. Price

Company Name : Three Rivers Scientific 
RPP-6088, Rev.0.

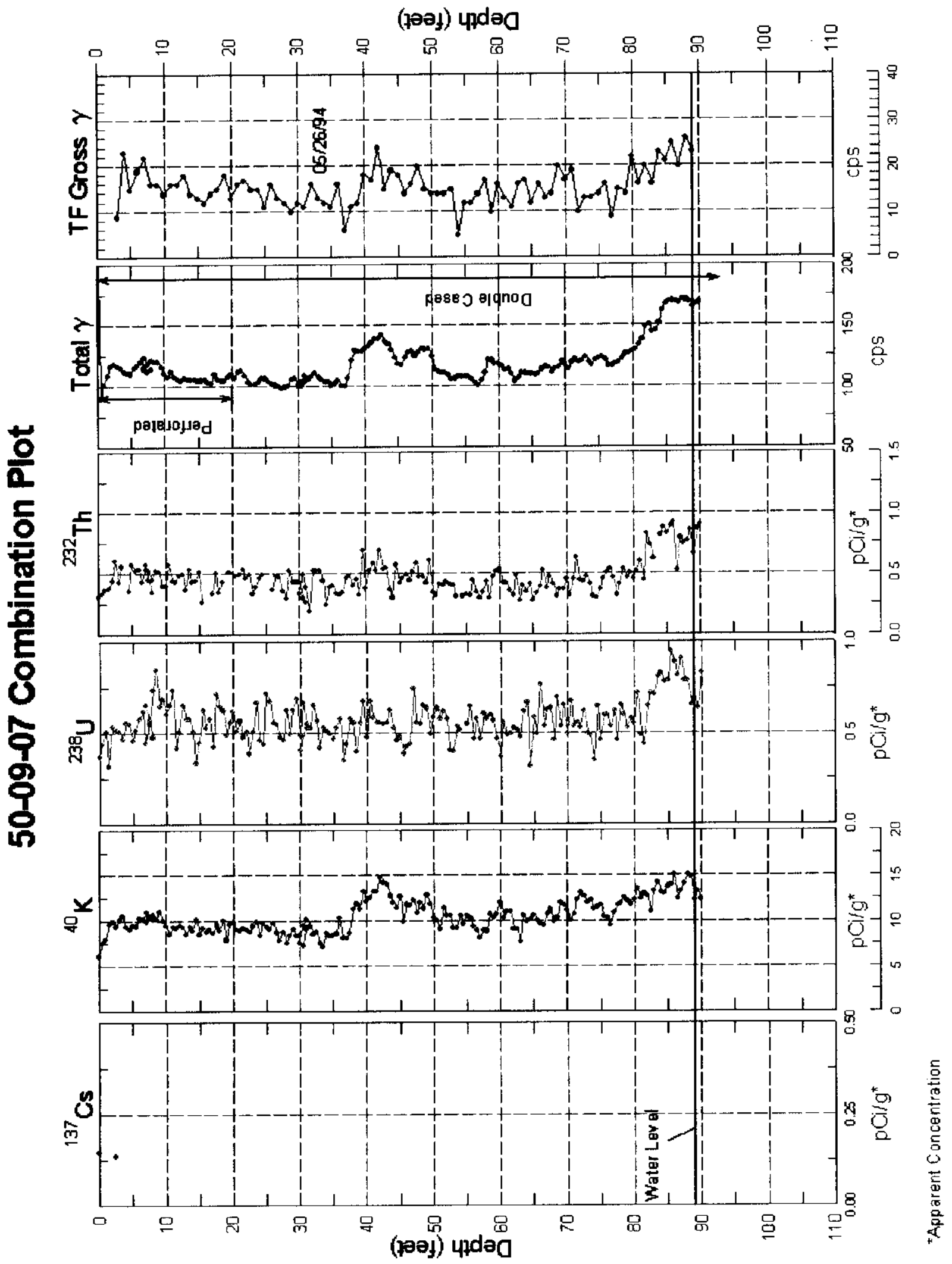


RPP-6088, Rev.0.

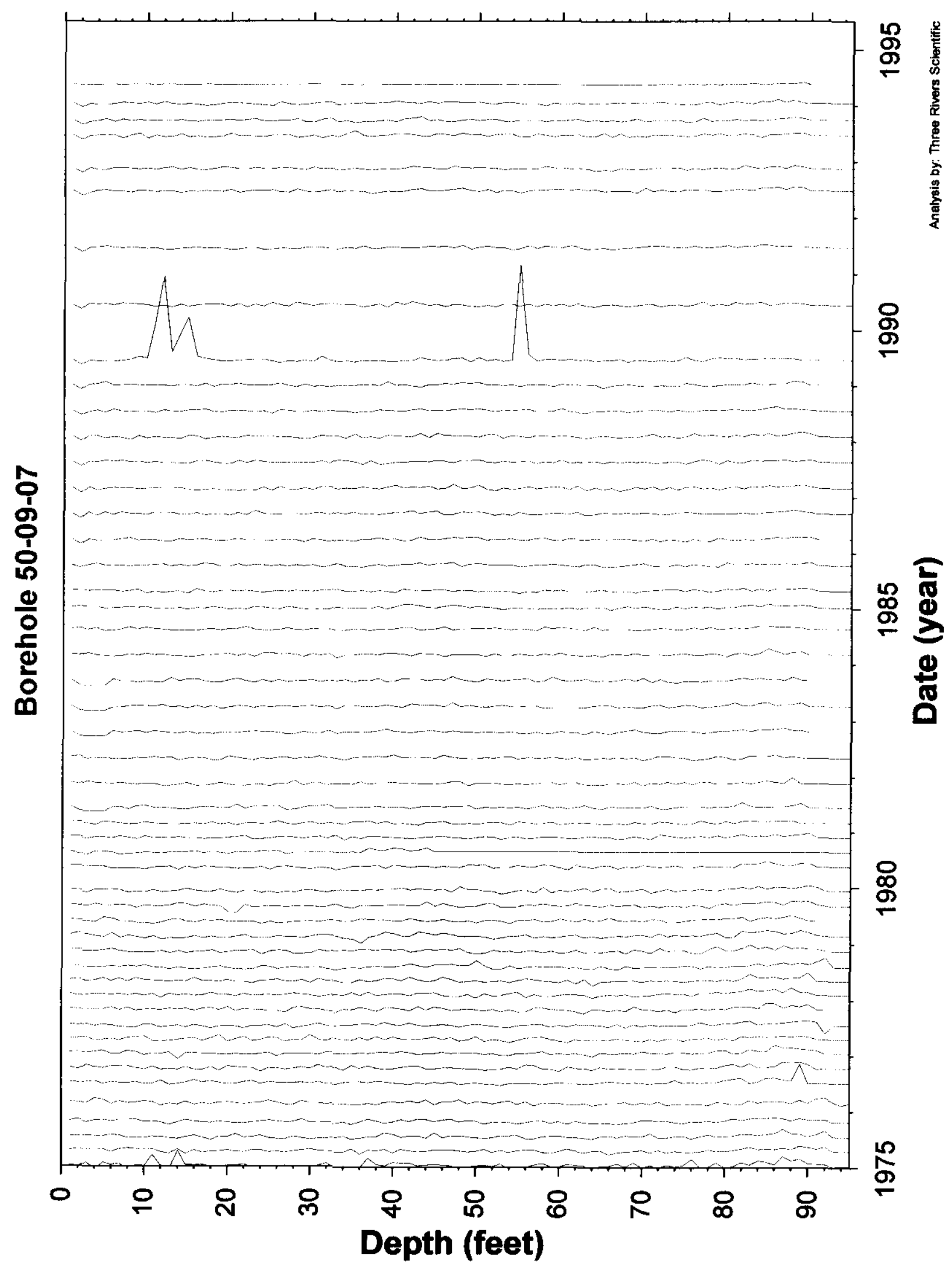

Tank T-109

Page 355 


\section{Borehole 50-09-07}

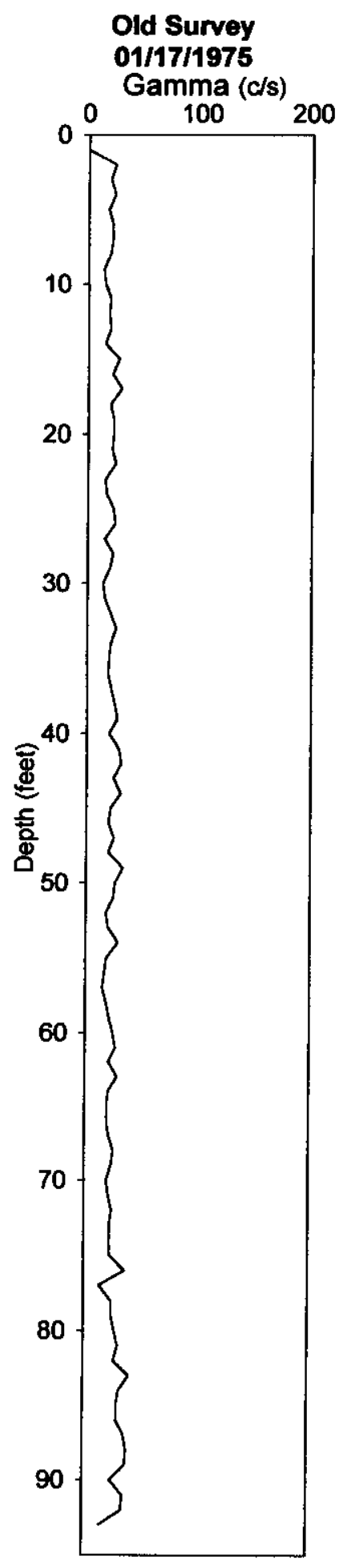
No Gamma-Ray Emitting Contamination Above Survey Detection Threshold
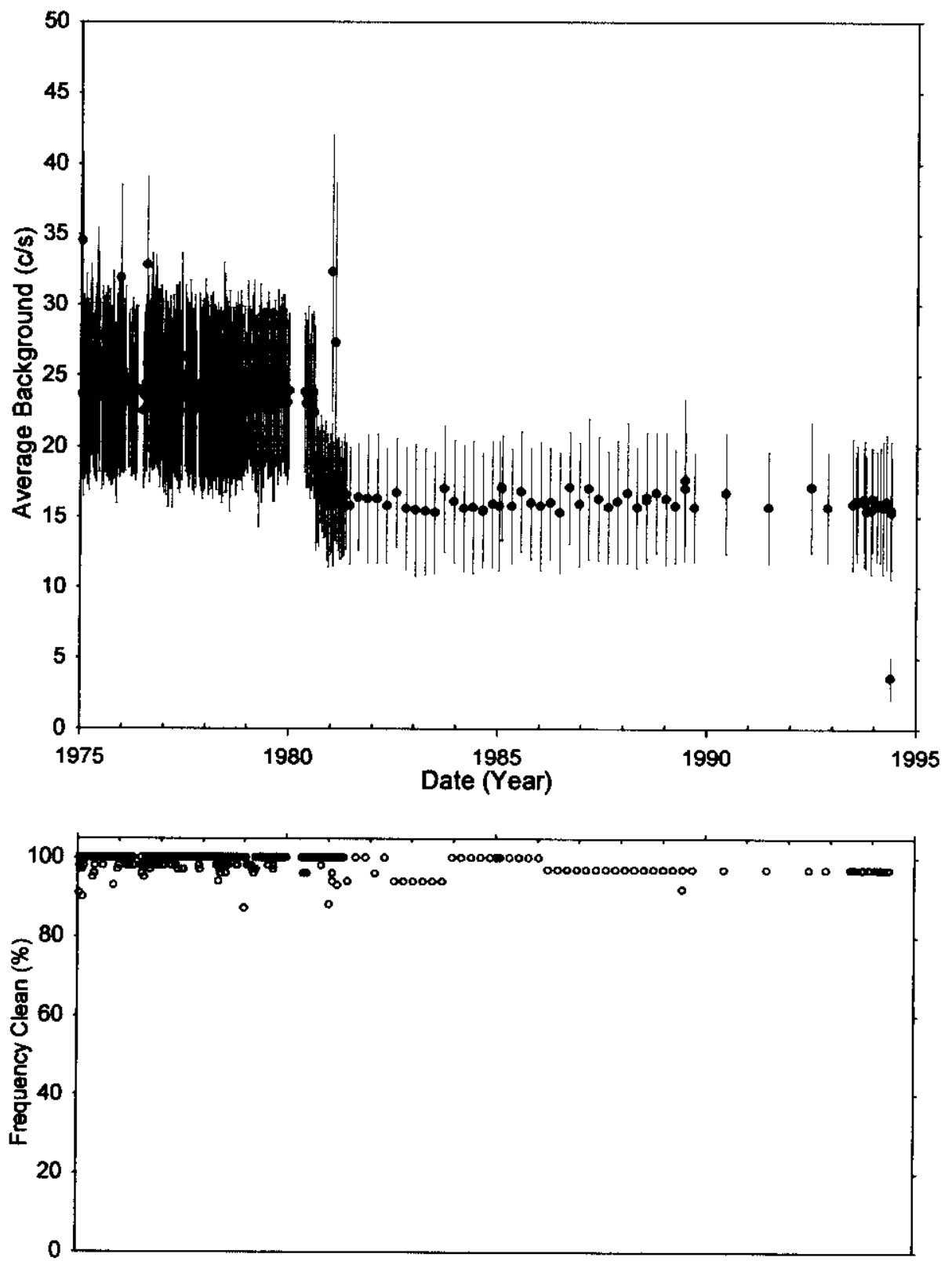

Anelysis by: Three Rivers Scientific 
RPP-6088, Rev.0.

\section{Borehole 50-09-09}

\section{Contamination (Ru-106) from 52 to 65 feet is Unstable Early.}

Grade thickness product over 52 to 65 feet shows an unstable time interval as increasing values early in 1975 then from 1977 to 1994 is decreasing consistent with the decay of Ru-106 (hypothesis). The HPGe survey identified Cs-137 from 0 to 3 feet at concentrations less than 1 $\mathrm{pCi} / \mathrm{g}$.

The average background plot shows a step decrease after the 8/18/1978 survey.

Gross Gamma Survey Information

\begin{tabular}{|r|l|}
\hline Probe Type Processed: & $04: \mathrm{NaI}$ \\
\hline Other Probe Types : & $03:$ Neutron \& 14: NaI Shielded \\
\hline Survey Depth : & $120 \mathrm{ft}$ \\
\hline First Survey Date : & $1 / 10 / 1975$ \\
\hline Last Survey Date : & $5 / 24 / 1994$ \\
\hline Number Surveys Processed: & 306 \\
\hline
\end{tabular}

Analysis Notes

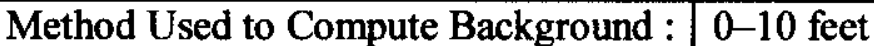

Depth(s) where Contamination was $52-65$ feet Unstable Early Identified in Gross Gamma Surveys :

Analyst Name : R. K. Price

Company Name : Three Rivers Scientific 
RPP-6088, Rev.0.

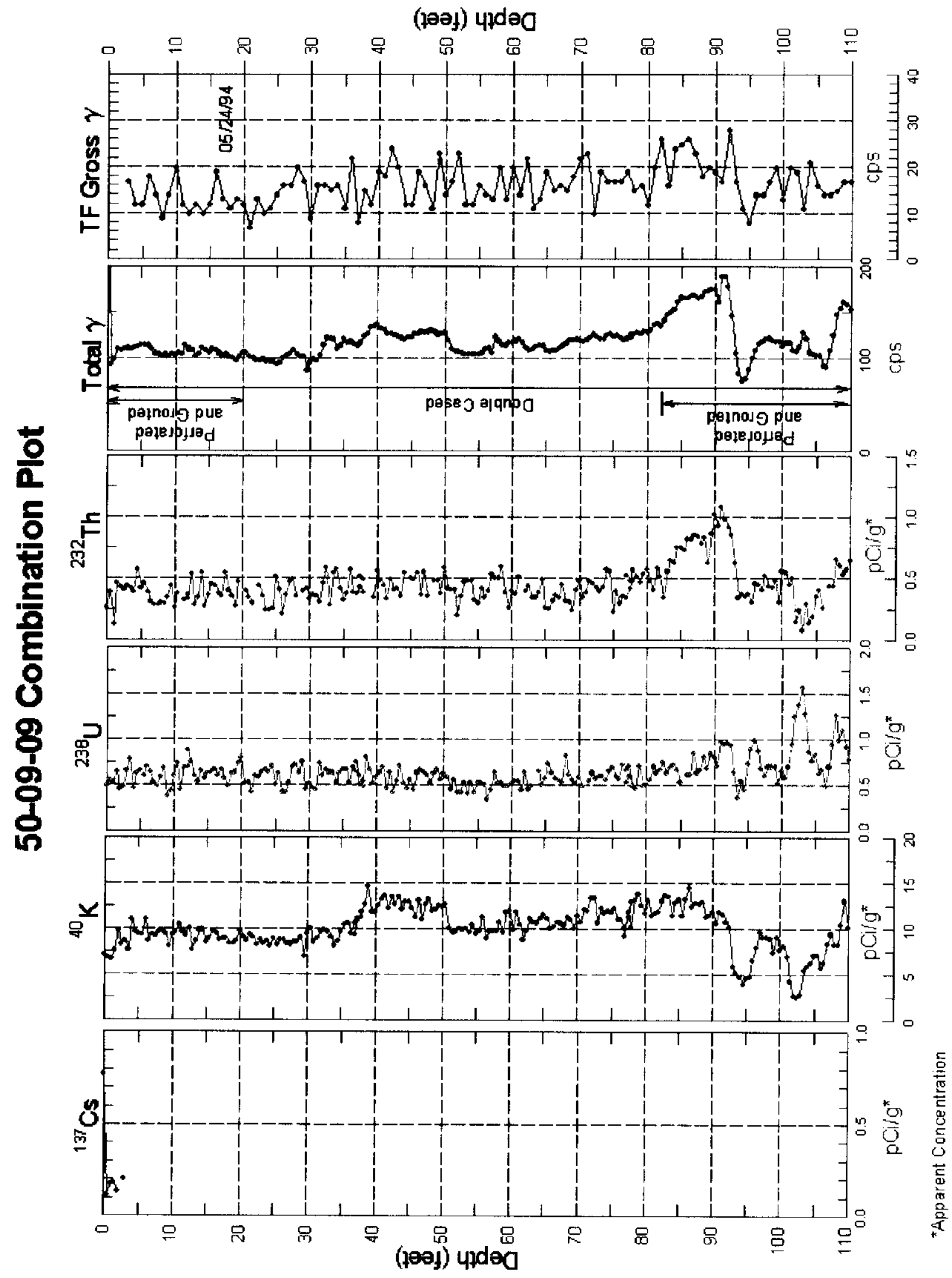

Tank T-109

Page 358 
RPP-6088, Rev.0.

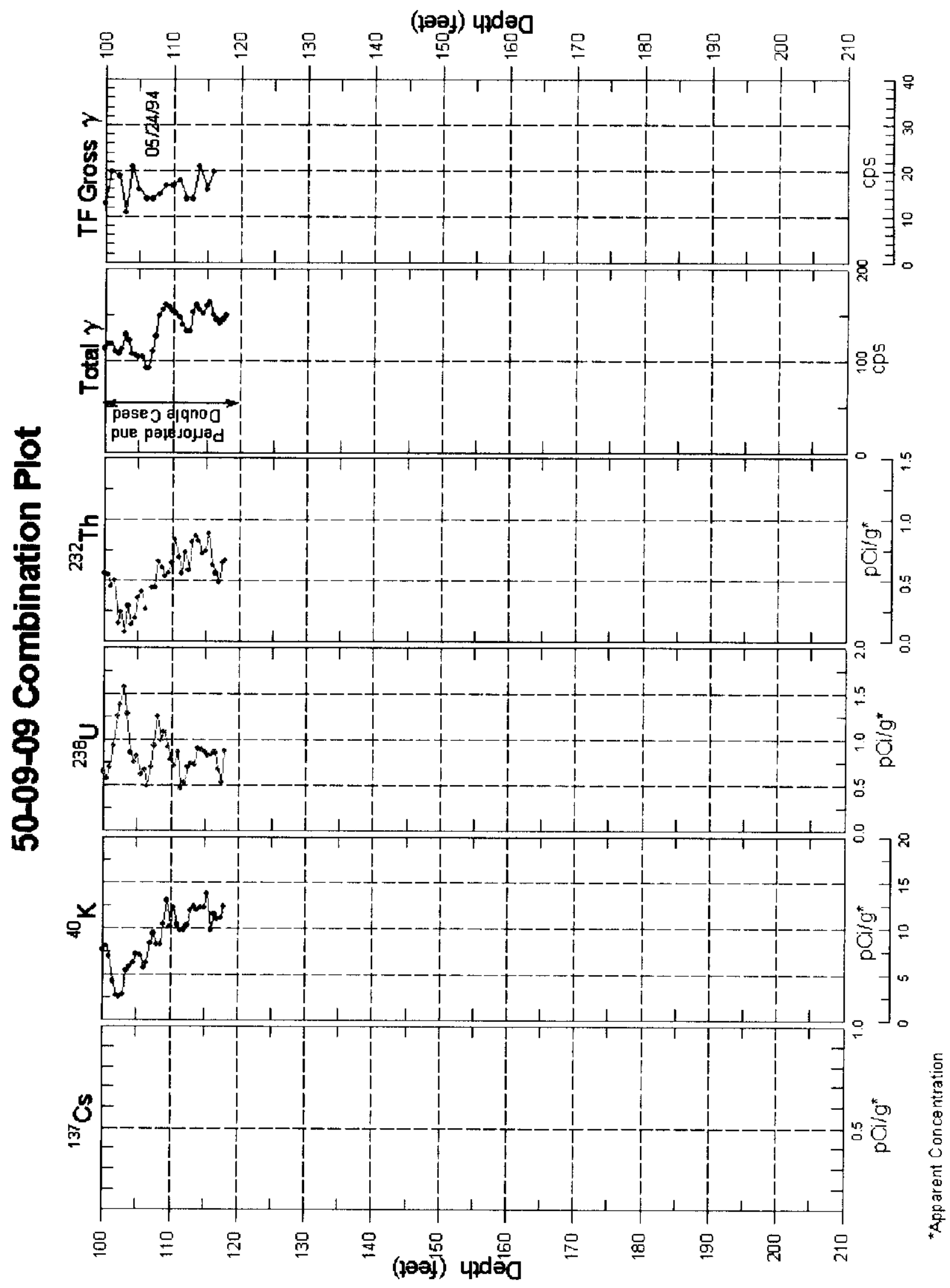

Tank T-109

Page 359 
RPP-6088, Rev.0.

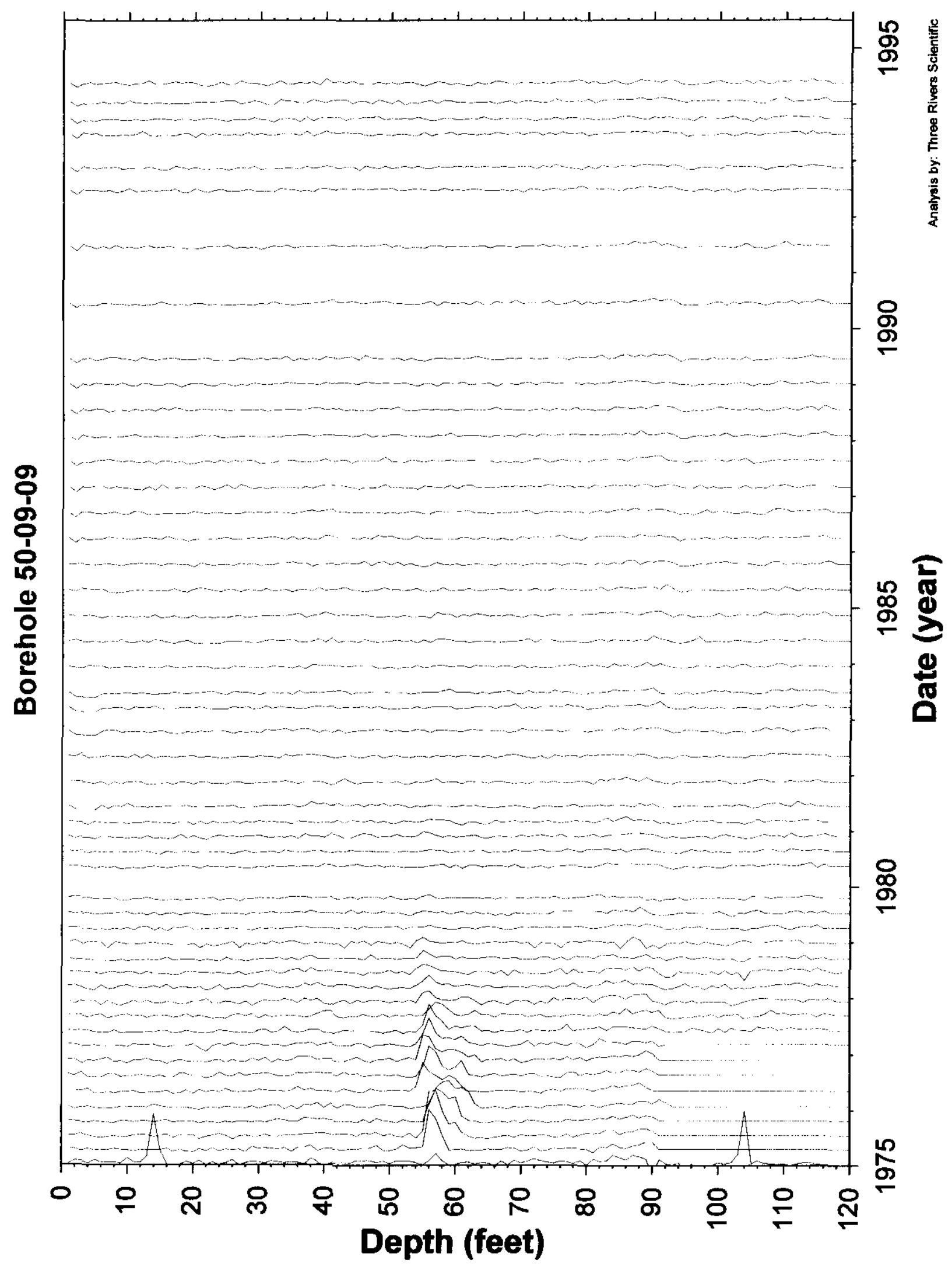

Tank T-109

Page 360 
RPP-6088, Rev.0.
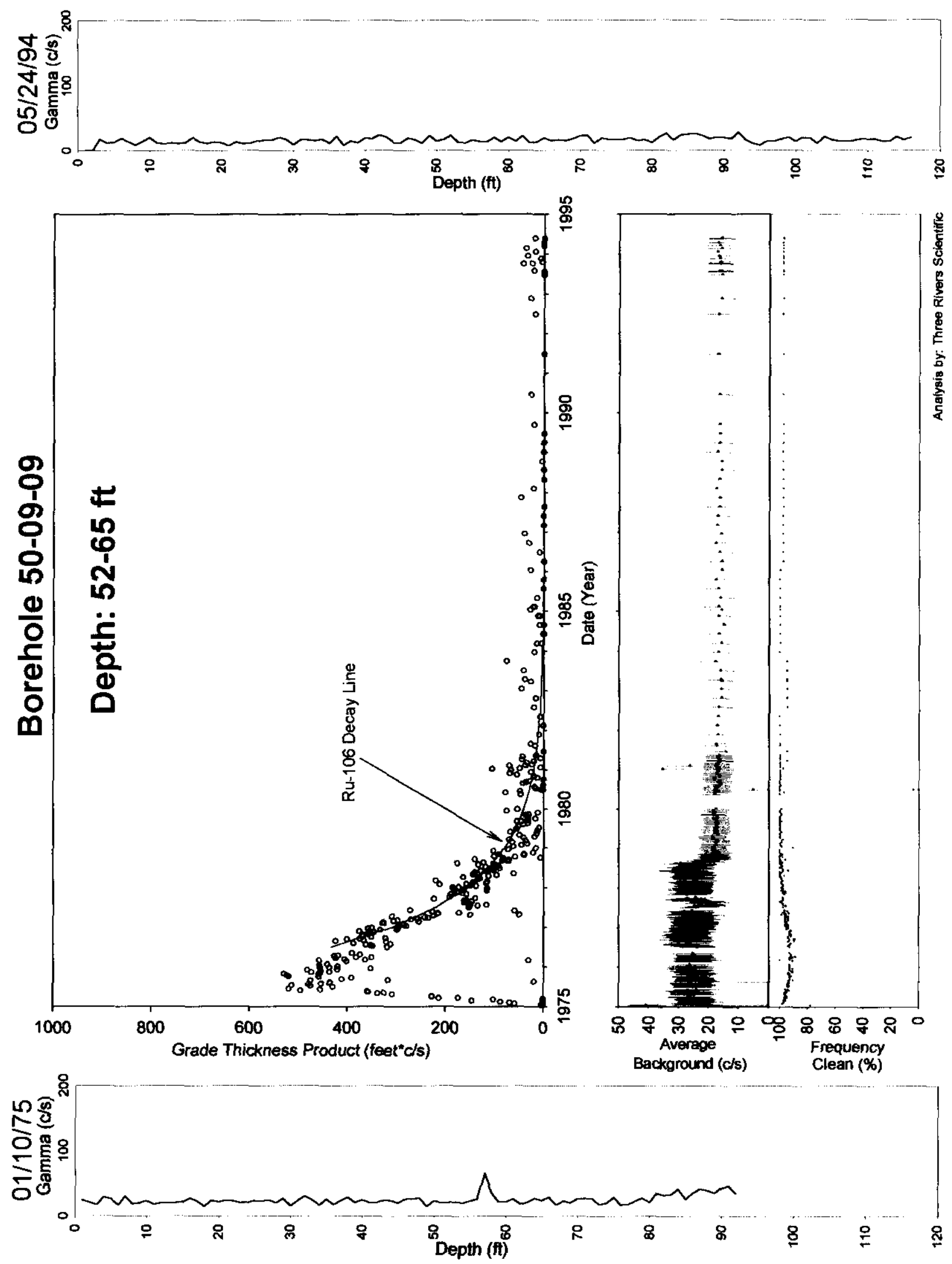

Tank T-109

Page 361 


\section{Borehole 50-09-10}

Contamination (Co-60 \& Ru-106) from 33 to 44 feet is Unstable Early. Contamination (Co-60 \& Ru-106) from 44 to 74 feet is Unstable Early. Contamination (Co-60 \& Ru-106) from 74 to 99 feet is Stable. Contamination (Co-60 \& Ru-106) from 99 to 115 feet is Unstable.

Grade thickness product (GTP) over 33 to 44 feet had an unstable time interval from the first survey in 1980 when the GTP was decreasing at a rate exceeded the decay of the HPGe identified radionuclide of $\mathrm{Co}-60$ and the hypothesized radionuclide of $\mathrm{Ru}-106$. However, from 1981 to 1995 the GTP is decreasing consistent with a least square fit for Co-60 and Ru-106. The ratio of gross contribution from Co-60 to gross from $\mathrm{Ru}-106$ is 82,000:1 as of 5-24-1994.

Grade thickness product over 44 to 74 feet shows an unstable time in 1980, then is decreasing consistent with a least square fit for Co-60 (HPGe identified) and Ru-106 (hypothesis) from 1981 to 1995 . The ratio of gross contribution $\mathrm{Co}-60$ to $\mathrm{Ru}-106$ is $996: 1$ on $5-24-1994$.

Grade thickness product over 74 to 99 feet is decreasing consistent with a least square fit for Co60 (HPGe identified) and Ru-106 (hypothesis) from 1981 to 1995 . The ratio of gross contribution from Co-60 to gross from Ru-106 is 374:1 as of 5-24-1994. The first few surveys in 1980 exhibit only a fair match with the decay line but instability can not be established, due to the high count rate $(30,000 \mathrm{c} / \mathrm{s})$.

Grade thickness product over 99 to 115 feet is decreasing consistent with a least square fit for Co-60 (HPGe identified) and Ru-106 (hypothesis) from the first survey in 1980 to 1985 then begins a consistent increase through the last survey in 1994. The ratio of gross contribution from Co-60 to gross from Ru-106 is $1.9: 1$ as of April 1994. The category of the depth interval from 99 to 115 feet is UNSTABLE and can be seen on the stack plot.

Gross Gamma Survey Information

\begin{tabular}{|r|l|}
\hline Probe Type Processed : & $04:$ NaI \\
\hline Other Probe Types : & $03:$ Neutron \& 14: Shielded NaI \\
\hline Survey Depth : & $120 \mathrm{ft}$ \\
\hline First Survey Date : & $7 / 25 / 1980$ \\
\hline Last Survey Date : & $5 / 24 / 1994$ \\
\hline Number Surveys Processed : & 86 \\
\hline
\end{tabular}

Analysis Notes

\begin{tabular}{|r|l|}
\hline Method Used to Compute Background : & $10-30$ feet \\
\hline Depth(s) where Contamination was & $33-44,44-74$ feet Unstable Early \\
Identified in Gross Gamma Surveys : & $74-99$ feet Stable \\
& $99-115$ feet UNSTABLE \\
\hline Analyst Name : & R. K. Price \\
\hline Company Name : & Three Rivers Scientific \\
\hline
\end{tabular}


RPP-6088, Rev.0.

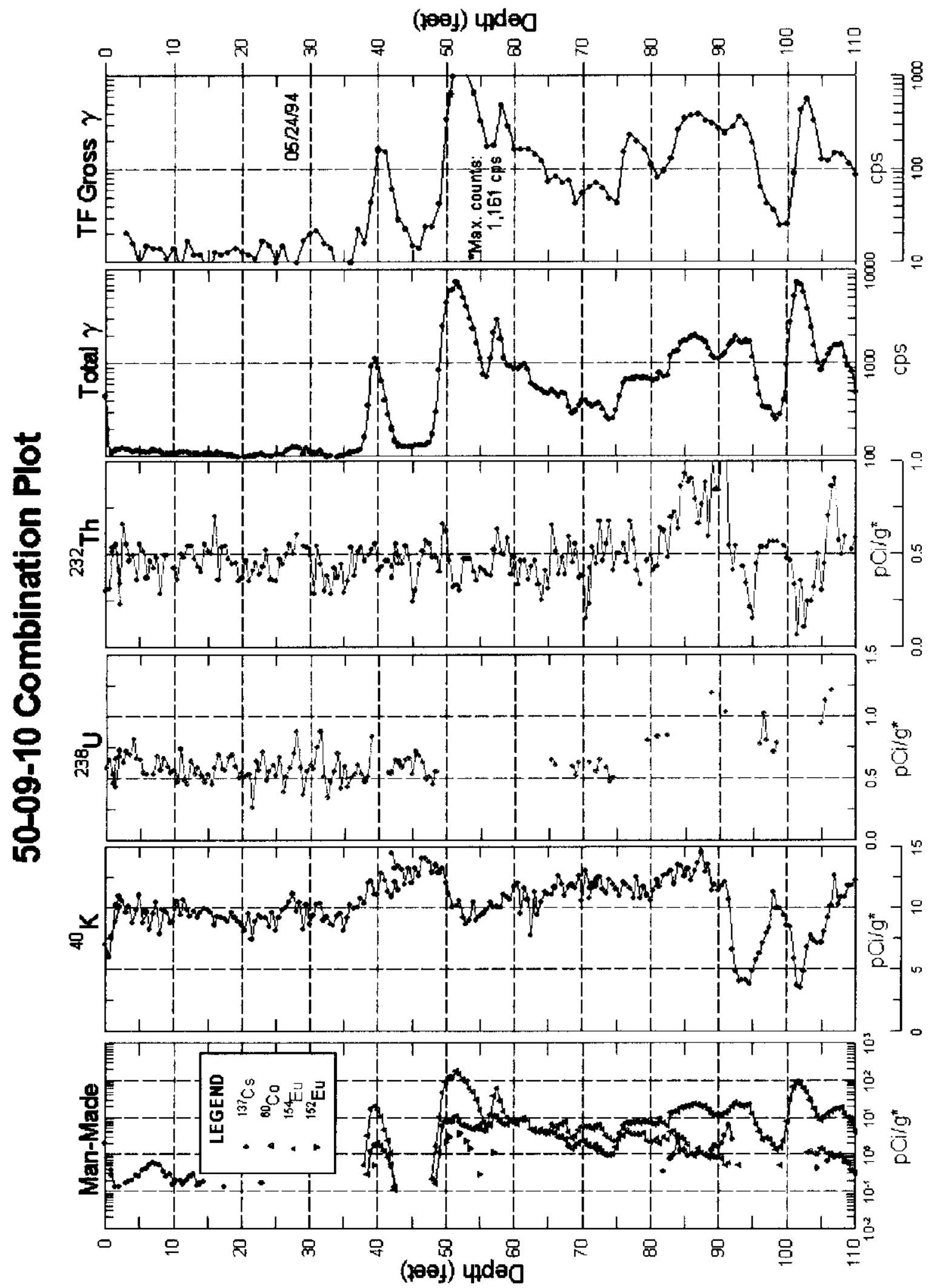

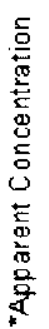


RPP-6088, Rev.0.

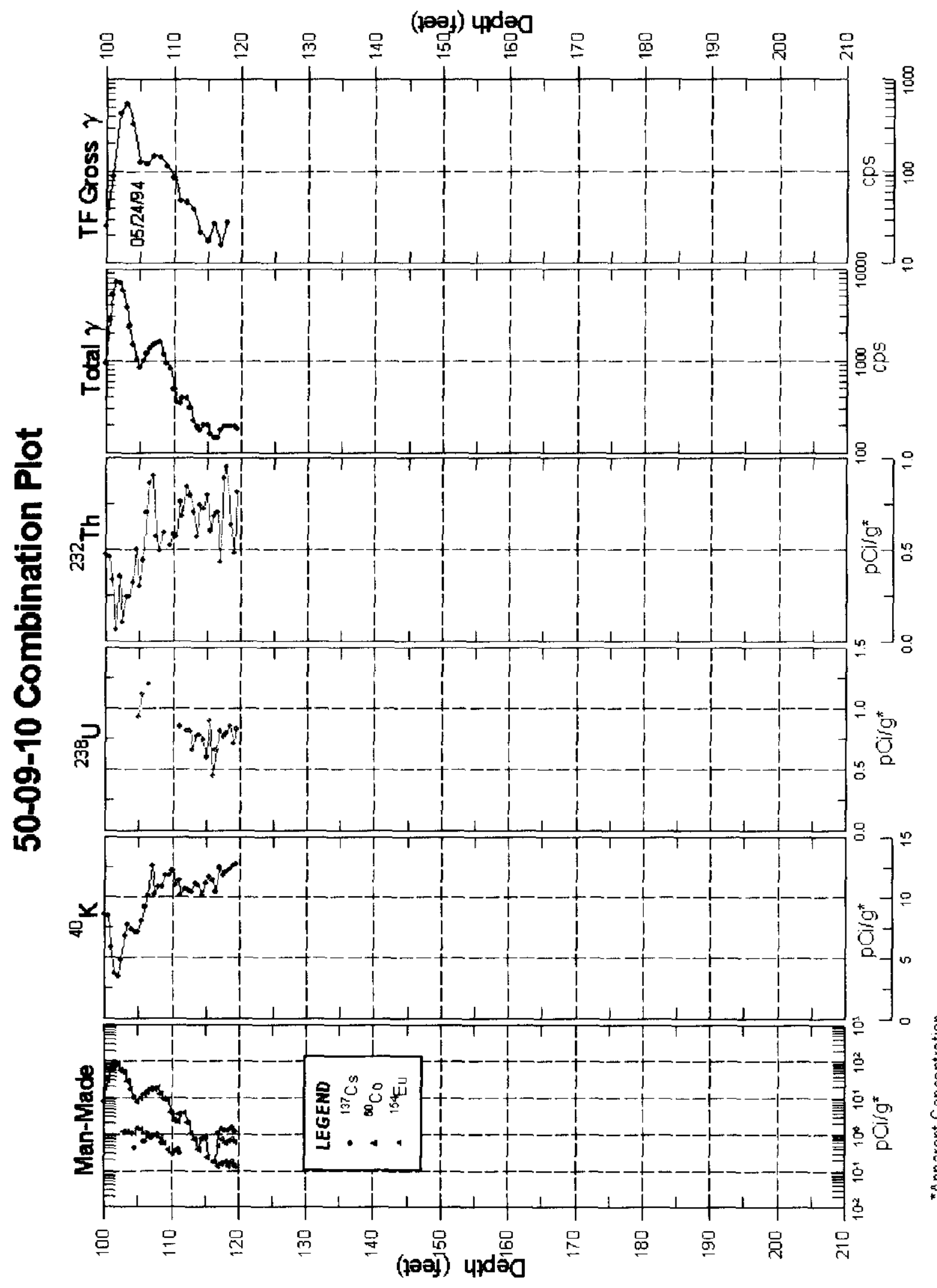

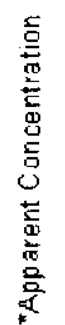

Tank T-109

Page 364 
RPP-6088, Rev.0.

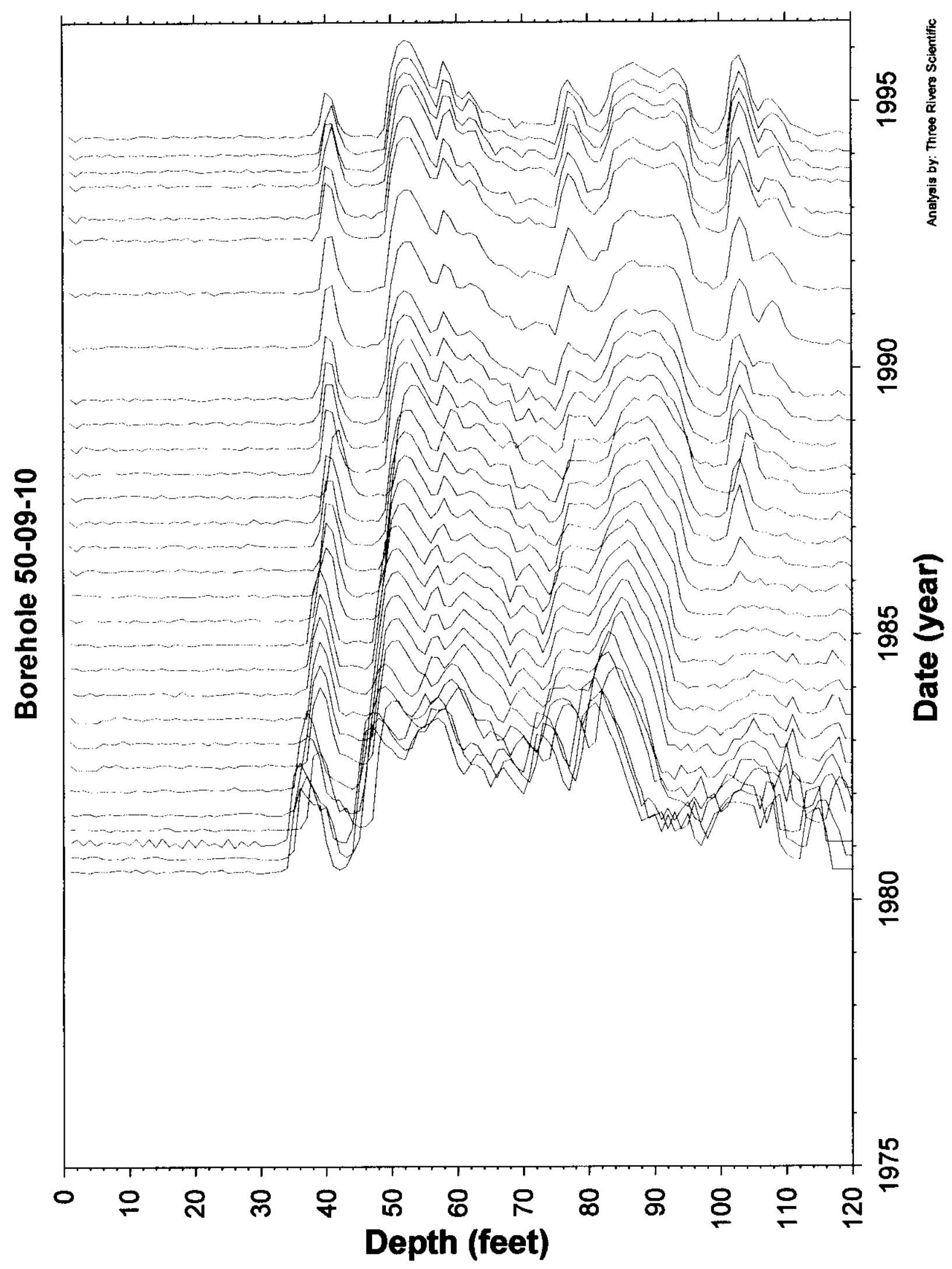

Tank T-109

Page 365 
RPP-6088, Rev.0.
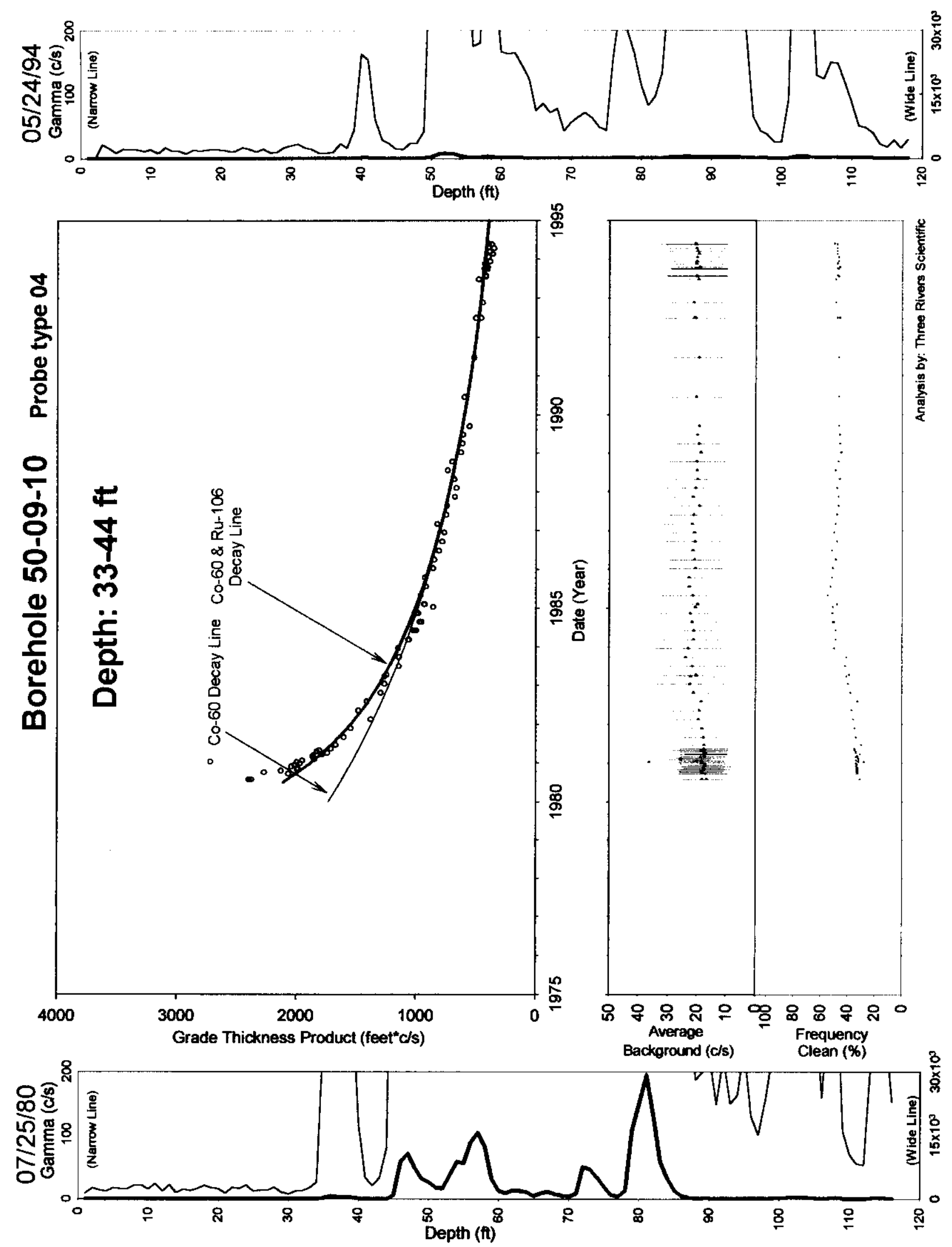

Tank T-109 
RPP-6088, Rev.0.
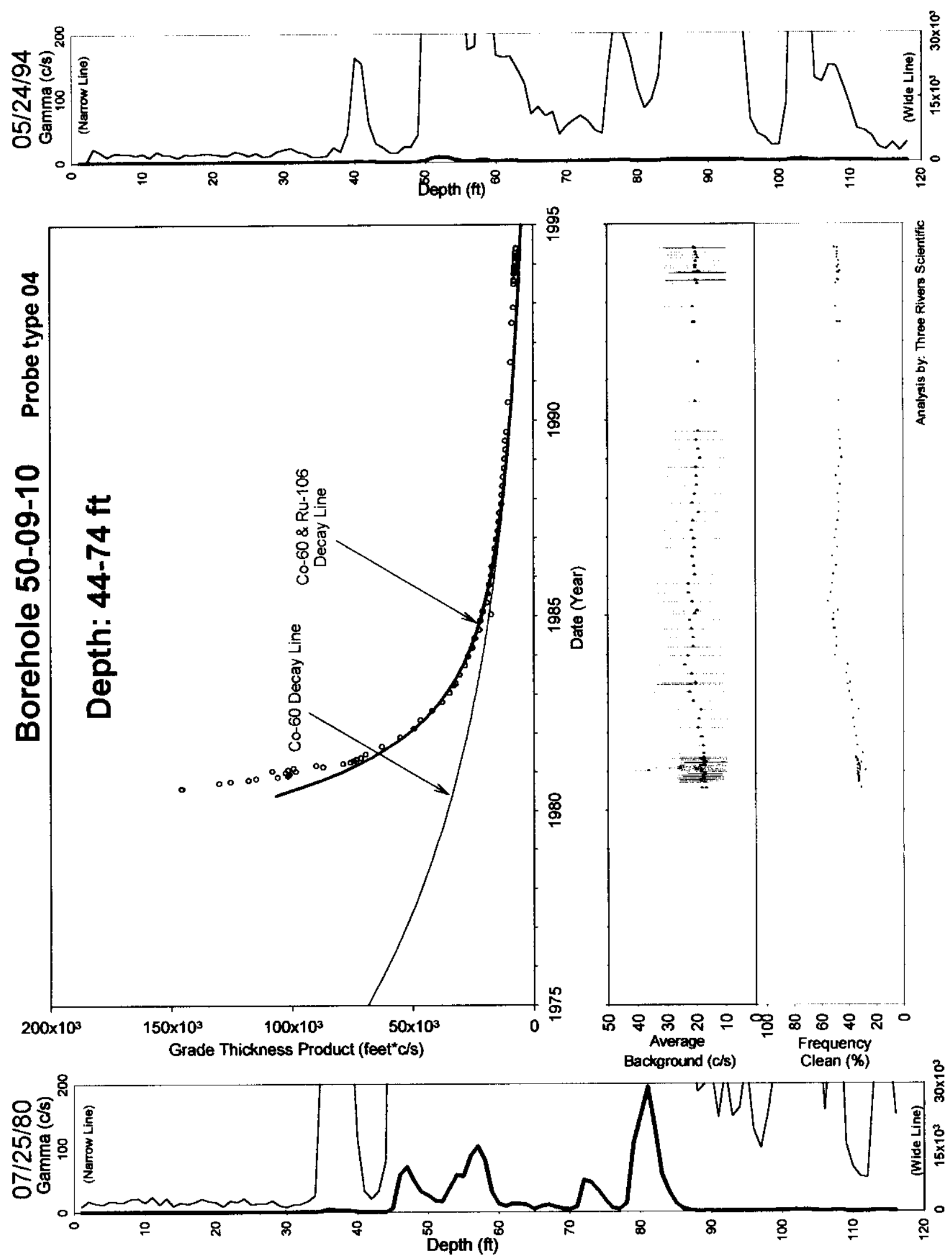

Tank T-109

Page 367 
RPP-6088, Rev.0.
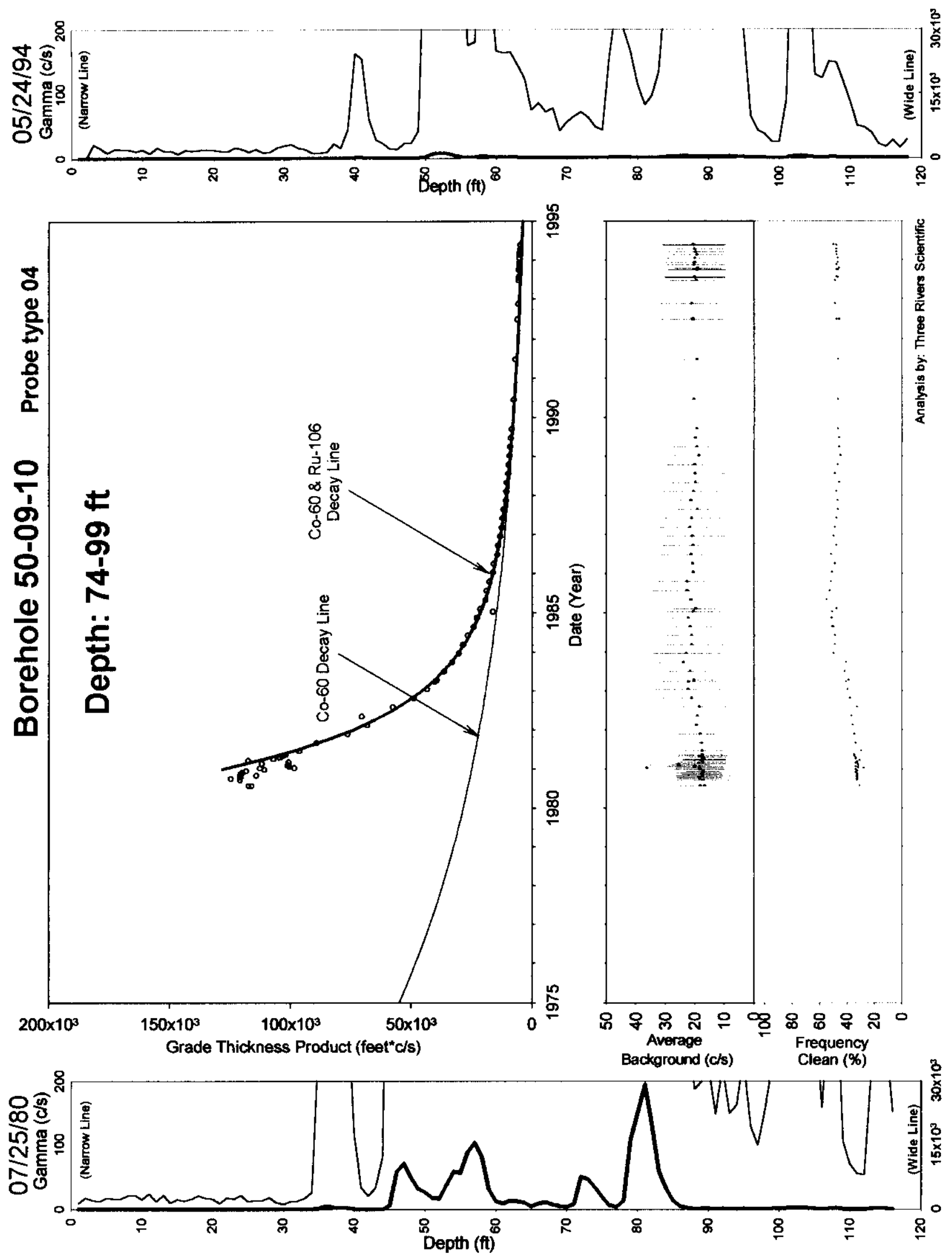

Tank T-109 
RPP-6088, Rev.0.
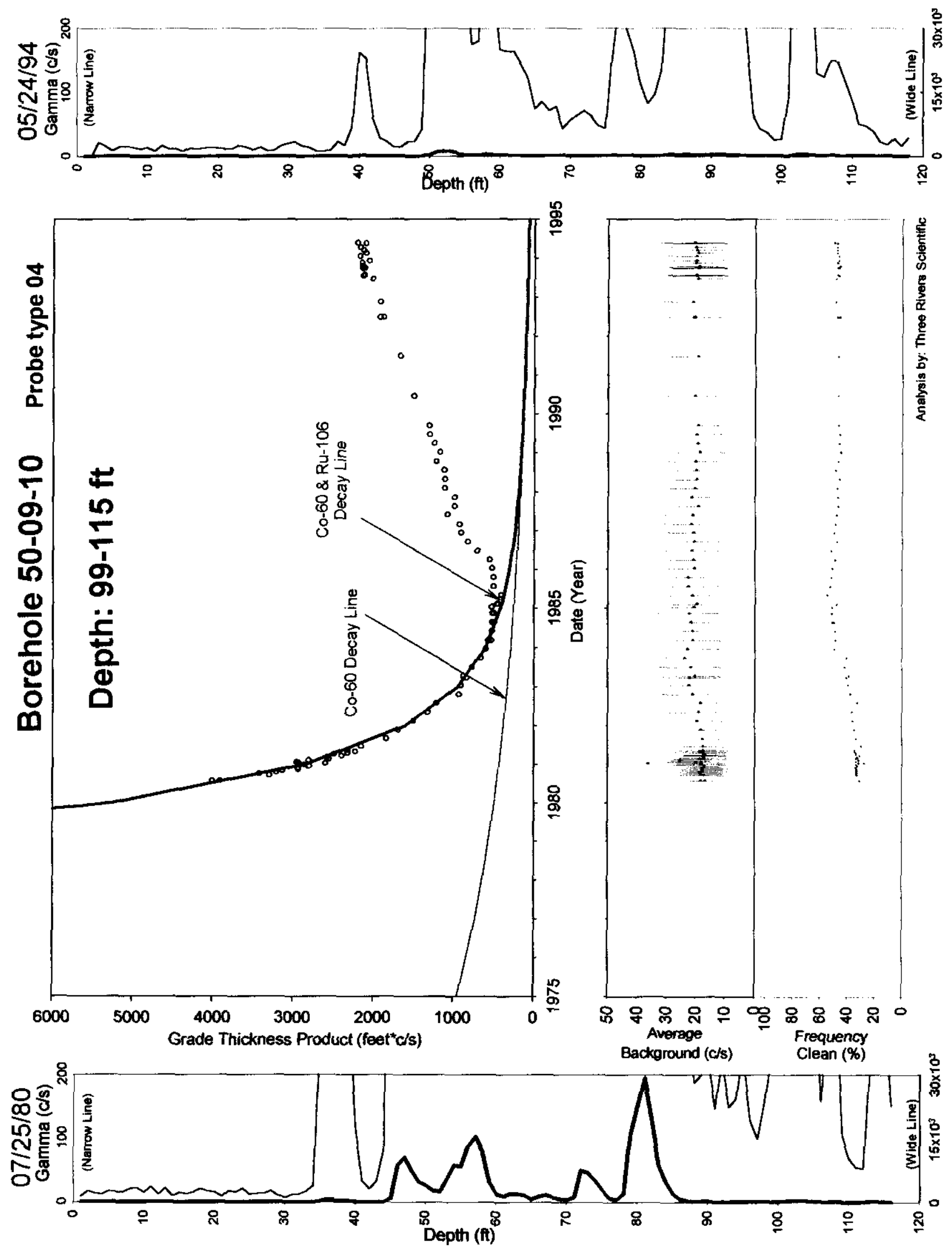

Tank T-109 
RPP-6088, Rev.0.

\section{Tank T-110 Wells}

Table of Contents $\quad$ Page

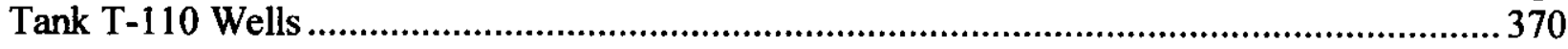

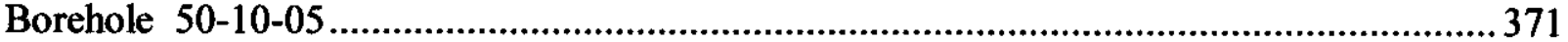

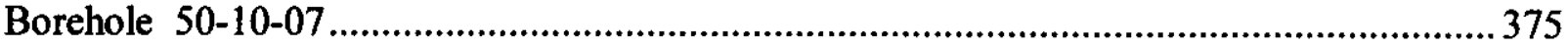

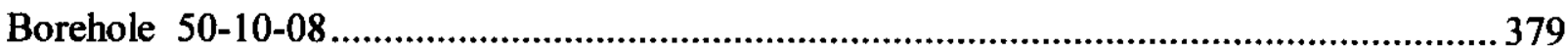

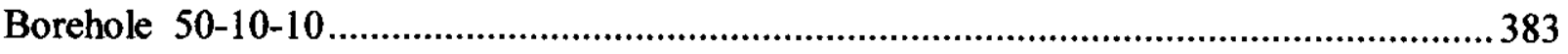

This section contains the analysis results for vadose zone boreholes (dry wells) associated with Tank 110 in the "T" Tank Farm.

Special Note: (none) 
RPP-6088, Rev.0.

\section{Borehole 50-10-05}

\section{No Gamma Ray Emitting Contamination Identified.}

No significant levels of gamma ray contamination are present, based upon gross gamma data, above the survey probe detection threshold between 1975 and 1993 in the vadose zone from 2 to 93 feet. The HPGe logging system detected Cs-137 from 0 to 29 feet with maximum concentration of $3 \mathrm{pCi} / \mathrm{g}$ at 12 feet and less than $1 \mathrm{pCi} / \mathrm{g}$ for the rest of the interval.

The average background plot shows a step decrease after the $2 / 2 / 1981$ survey.

Gross Gamma Survey Information

\begin{tabular}{|r|l|}
\hline Probe Type Processed: & $04: \mathrm{NaI}$ \\
\hline Other Probe Types : & $03:$ Neutron \\
\hline Survey Depth : & $93 \mathrm{ft}$ \\
\hline First Survey Date : & $1 / 10 / 1975$ \\
\hline Last Survey Date : & $11 / 01 / 1993$ \\
\hline Number Surveys Processed: & 886 \\
\hline
\end{tabular}

Analysis Notes

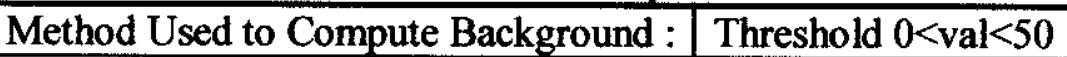

Depth(s) where Contamination was NONE

Identified in Gross Gamma Surveys :

Analyst Name : R. K. Price

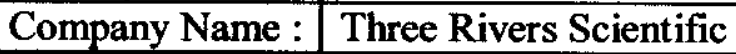


RPP-6088, Rev.0.

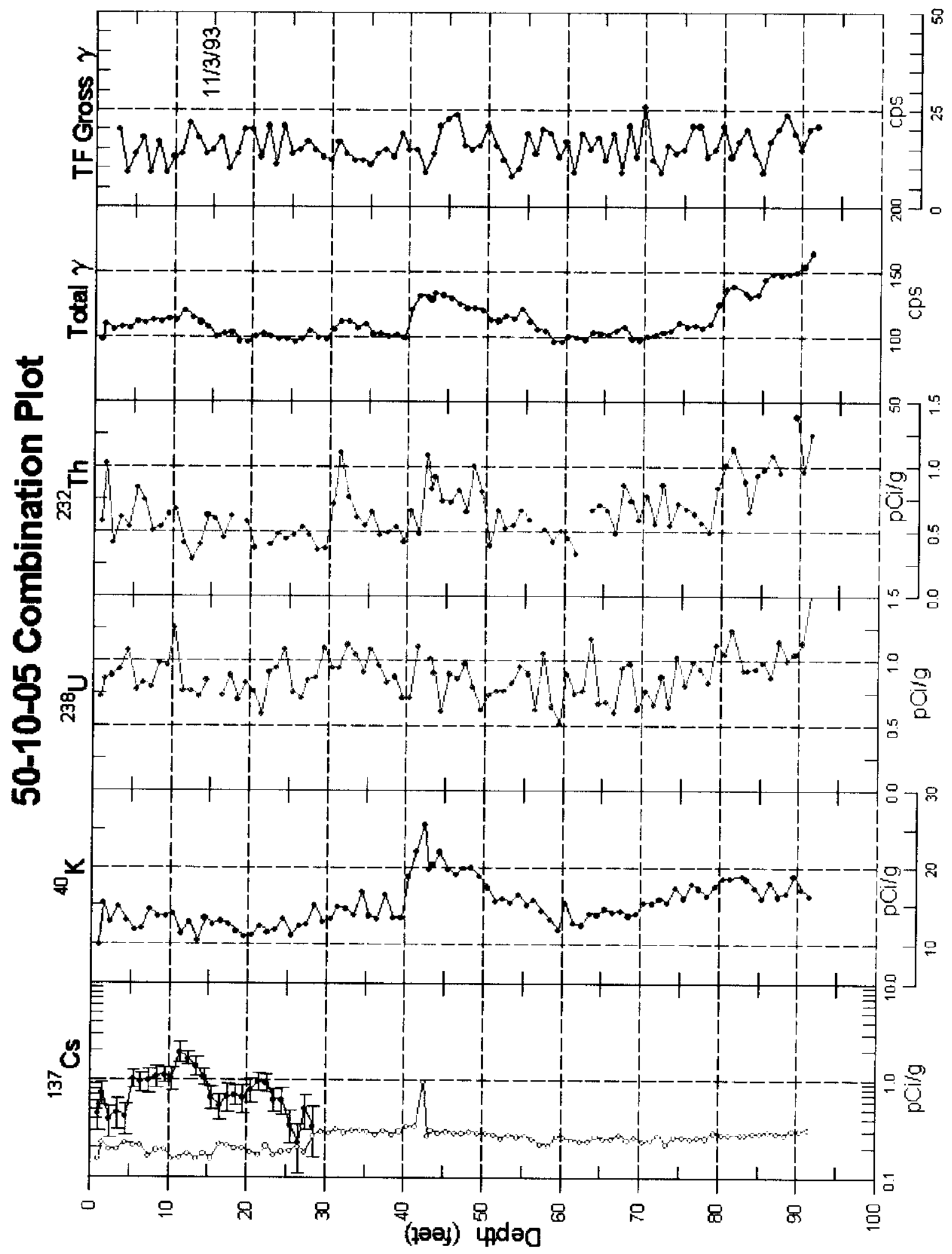


RPP-6088, Rev.0.

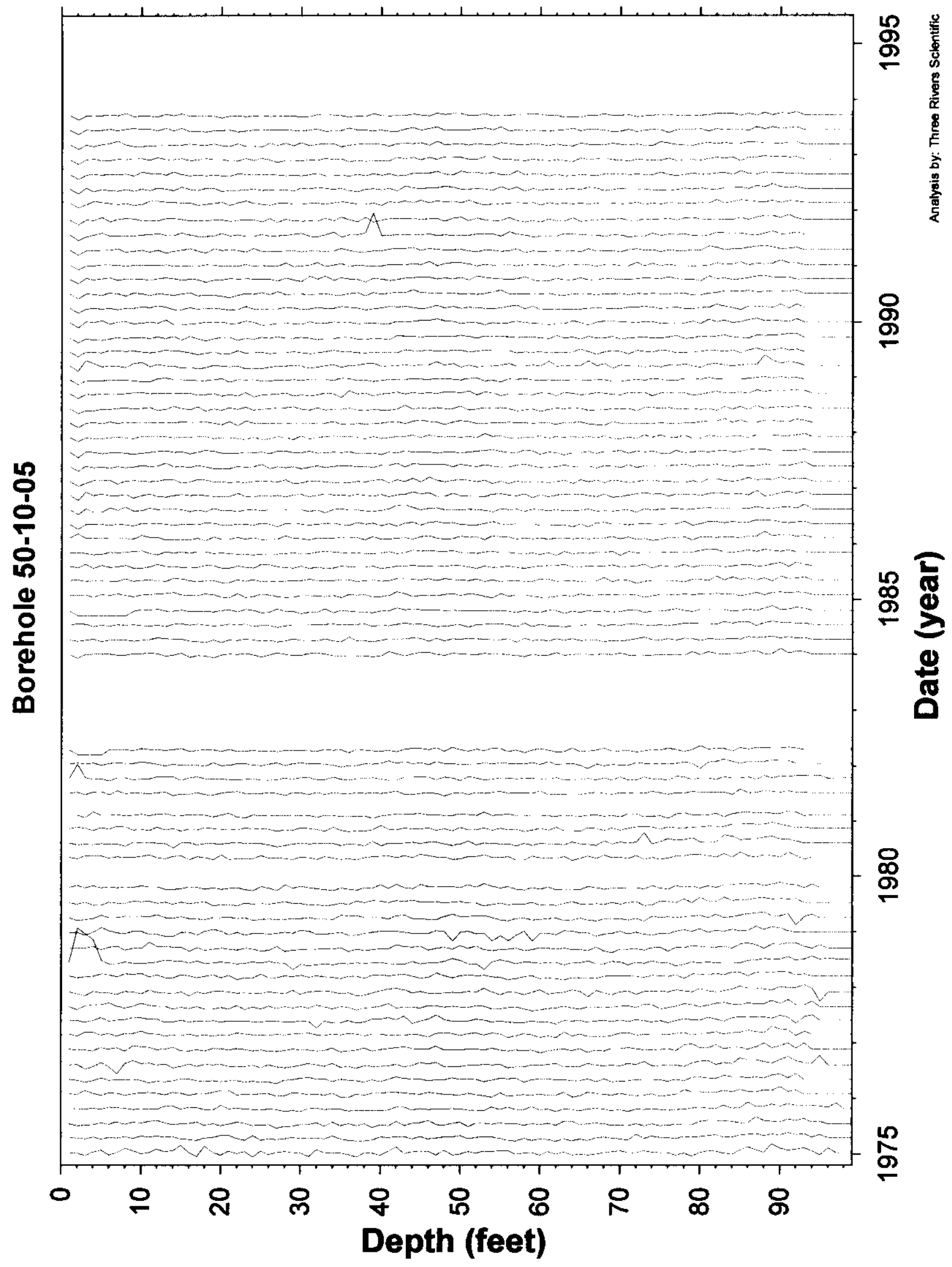

Tank T-110

Page 373 
RPP-6088, Rev.0.

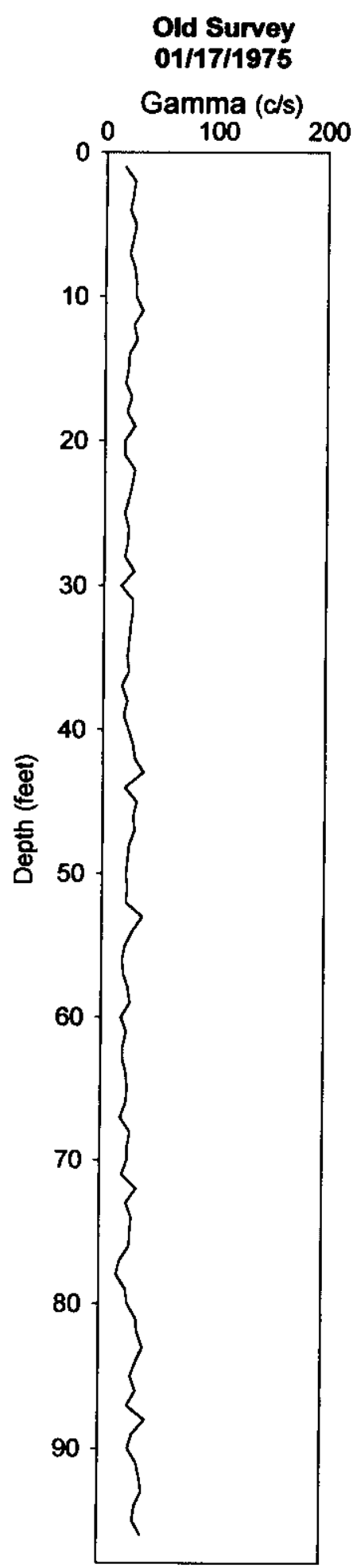

\section{Borehole 50-10-05}

\section{No Gamma-Ray Emitting Contamination \\ Above Survey Detection Threshold}
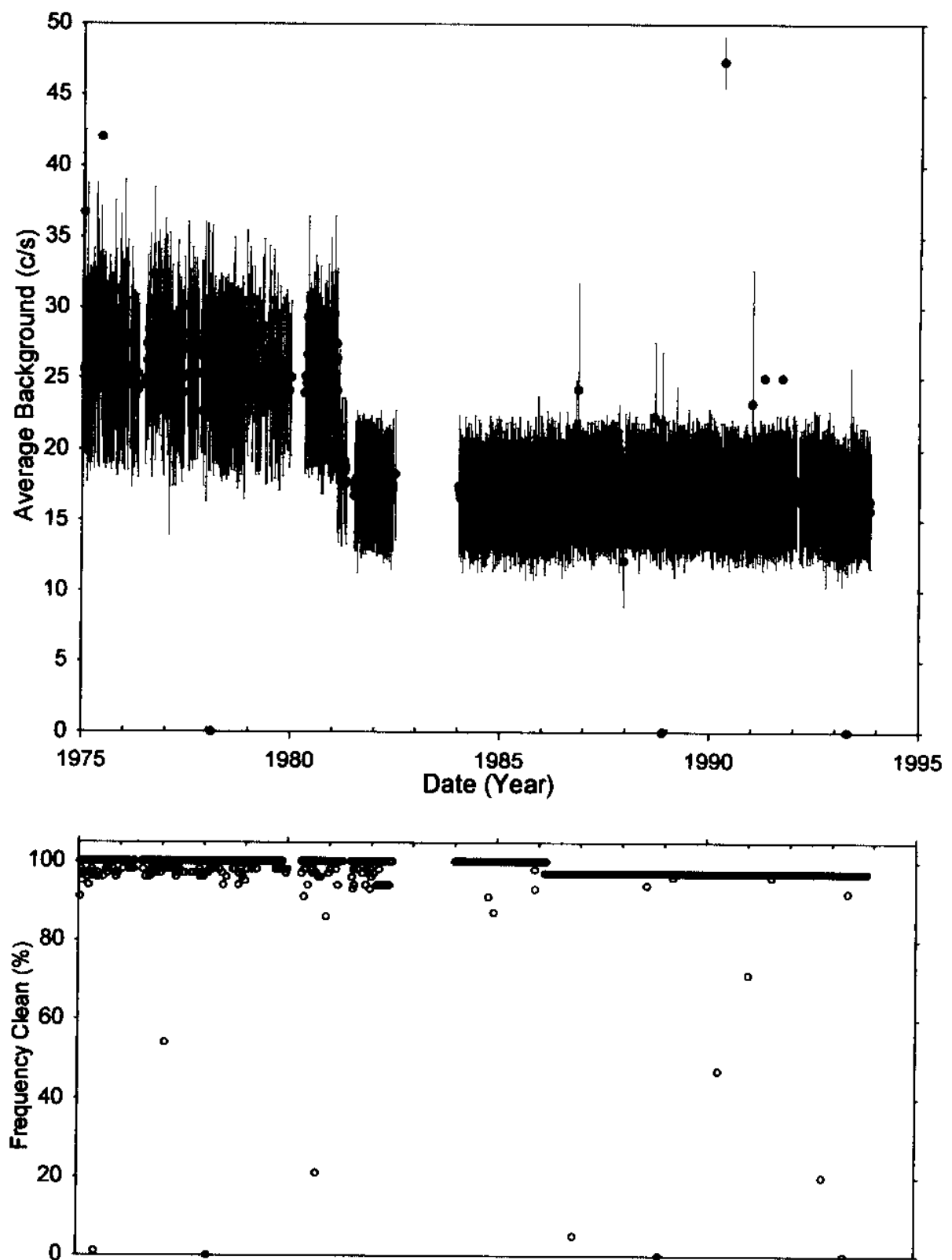

Analysis by: Three Rivers Scientific 
RPP-6088, Rev.0.

\section{Borehole 50-10-07}

\section{No Gamma Ray Emitting Contamination Identified.}

No significant levels of gamma ray contamination are present, based upon gross gamma data, above the survey probe detection threshold between 1975 and 1993 in the vadose zone from 2 to 91 feet. The HPGe logging system detected Cs-137 at less than $0.3 \mathrm{pCi} / \mathrm{g}$ in the borehole.

The average background plot shows a step decrease after the $1 / 27 / 1981$ survey.

Gross Gamma Survey Information

\begin{tabular}{|r|l|}
\hline Probe Type Processed: & $04: \mathrm{NaI}$ \\
\hline Other Probe Types : & $03:$ Neutron \\
\hline Survey Depth : & $91 \mathrm{ft}$ \\
\hline First Survey Date : & $1 / 10 / 1975$ \\
\hline Last Survey Date : & $11 / 01 / 1993$ \\
\hline Number Surveys Processed: & 875 \\
\hline
\end{tabular}

Analysis Notes

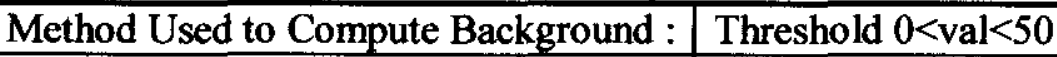

Depth(s) where Contamination was NONE

Identified in Gross Gamma Surveys :

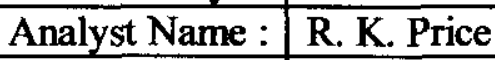

Company Name : Three Rivers Scientific 
RPP-6088, Rev.0.

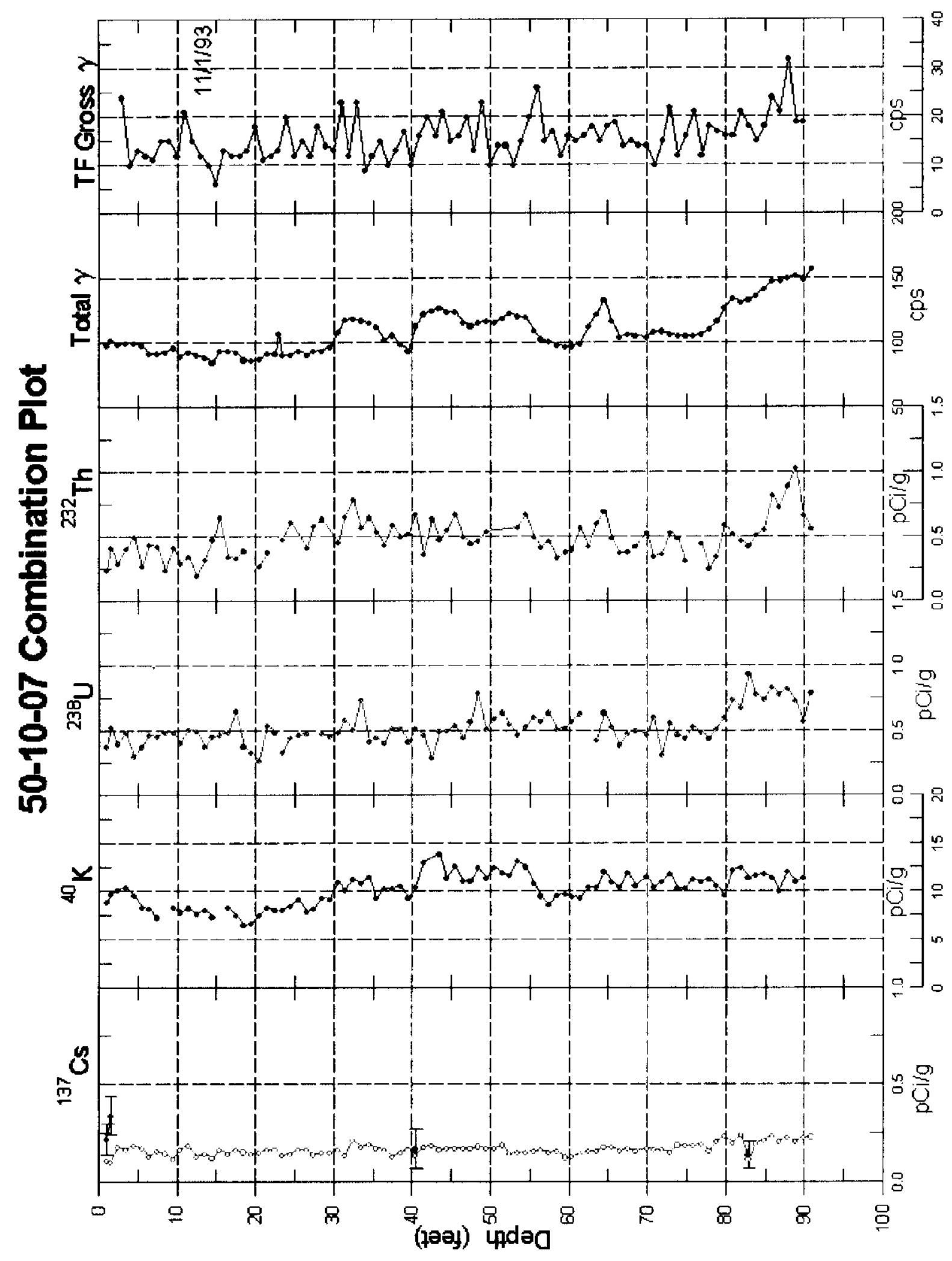

Tank T-110

Page 376 
RPP-6088, Rev.0.

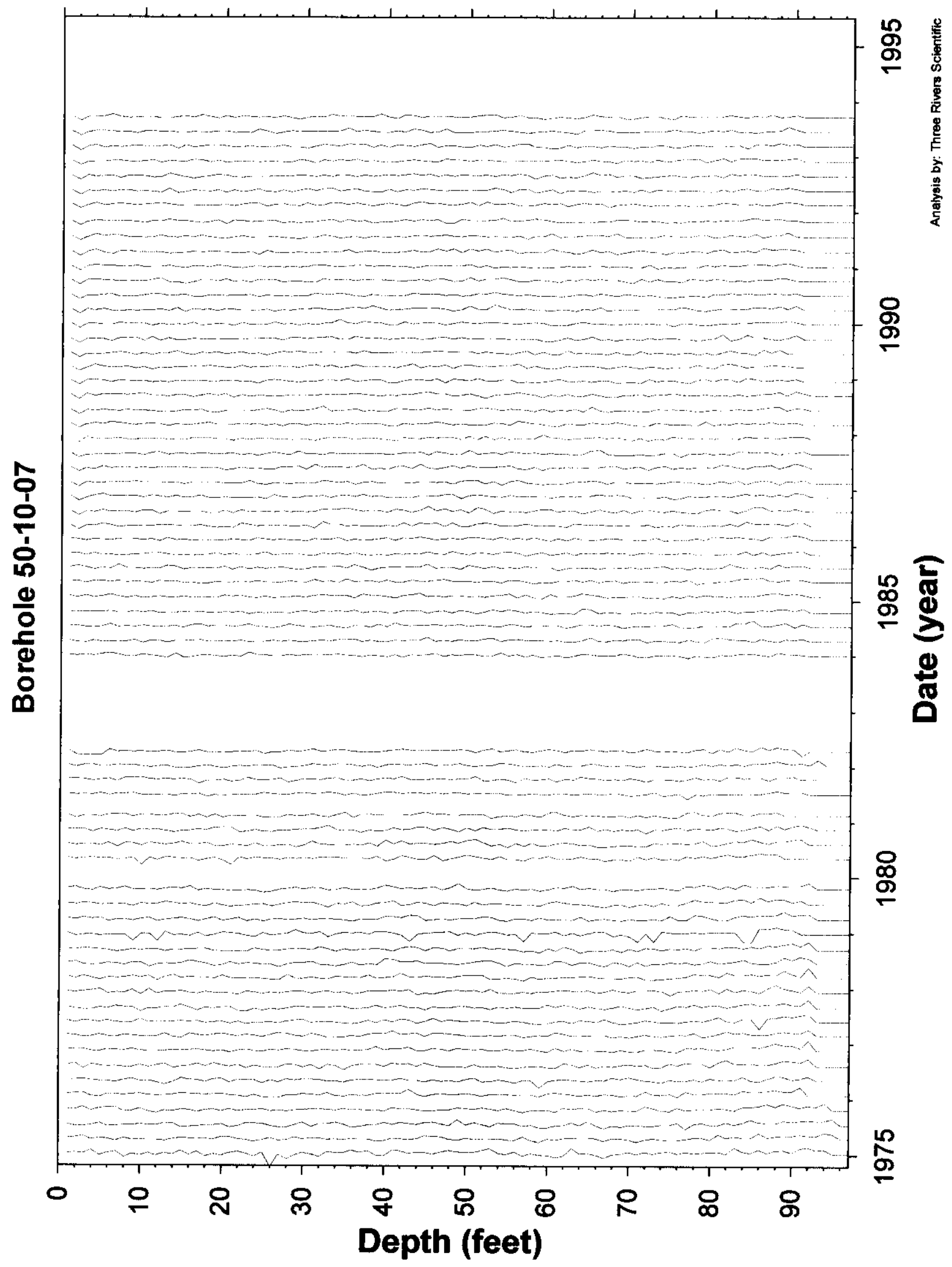

Tank T-110

Page 377 
RPP-6088, Rev.0.

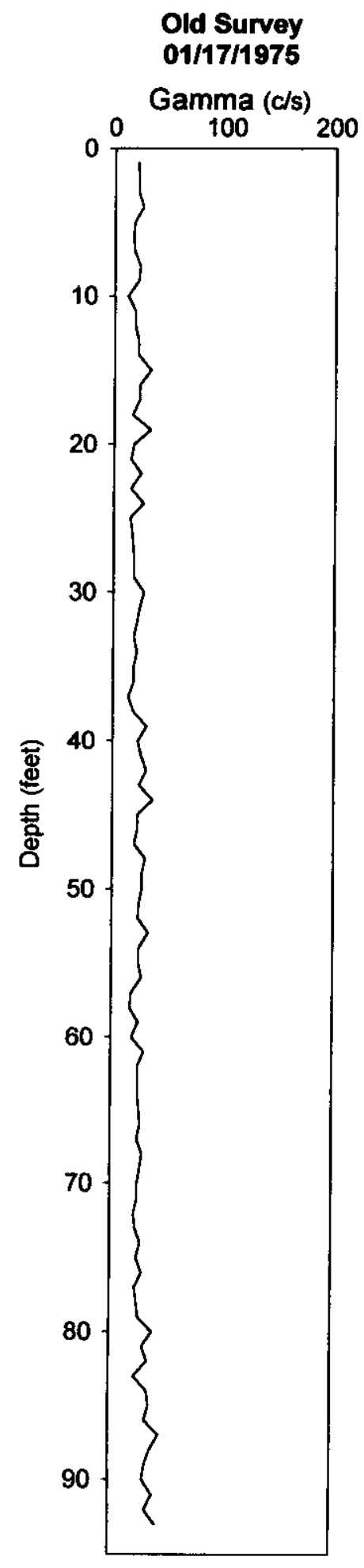

\section{Borehole 50-10-07}

No Gamma-Ray Emitting Contamination

Above Survey Detection Threshold
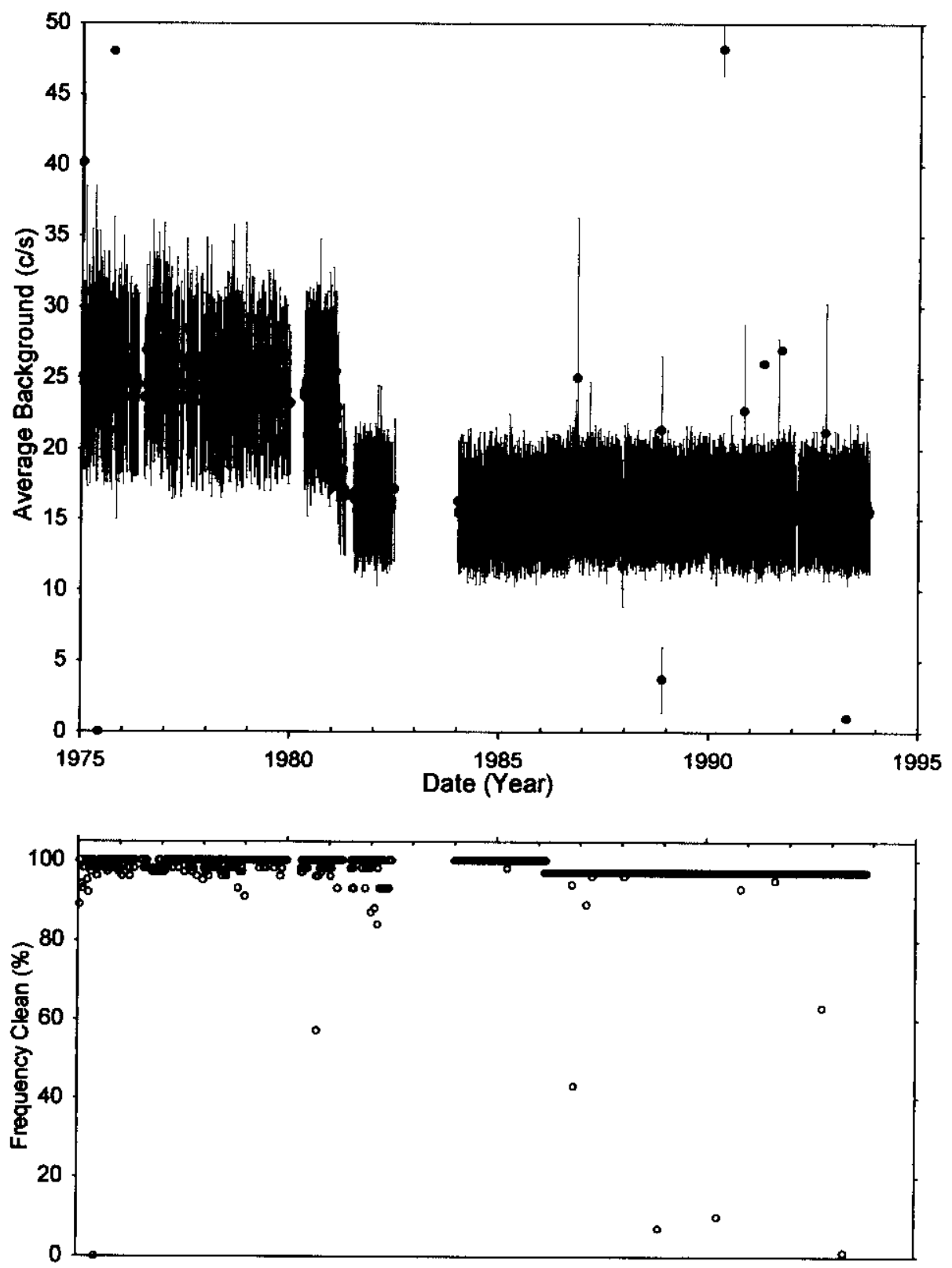

Analysis by: Three Rivers Scientific 
RPP-6088, Rev.0.

\section{Borehole 50-10-08}

\section{No Gamma Ray Emitting Contamination Identified.}

No significant levels of gamma ray contamination are present, based upon gross gamma data, above the survey probe detection threshold between 1975 and 1993 in the vadose zone from 2 to 91 feet. The HPGe logging system detected Cs-137 at less than $0.3 \mathrm{pCi} / \mathrm{g}$ in the borehole.

The average background plot shows a step decrease after the 2/17/1981 survey.

Gross Gamma Survey Information

\begin{tabular}{|r|l|}
\hline Probe Type Processed: & $04:$ NaI \\
\hline Other Probe Types : & $03:$ Neutron \\
\hline Survey Depth : & $91 \mathrm{ft}$ \\
\hline First Survey Date : & $4 / 18 / 1975$ \\
\hline Last Survey Date : & $11 / 01 / 1993$ \\
\hline Number Surveys Processed: & 676 \\
\hline
\end{tabular}

Analysis Notes

Method Used to Compute Background: $\quad$ Threshold $0<$ val $<50$

Depth(s) where Contamination was NONE

Identified in Gross Gamma Surveys :

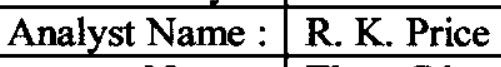

Company Name : Three Rivers Scientific 
RPP-6088, Rev.0.

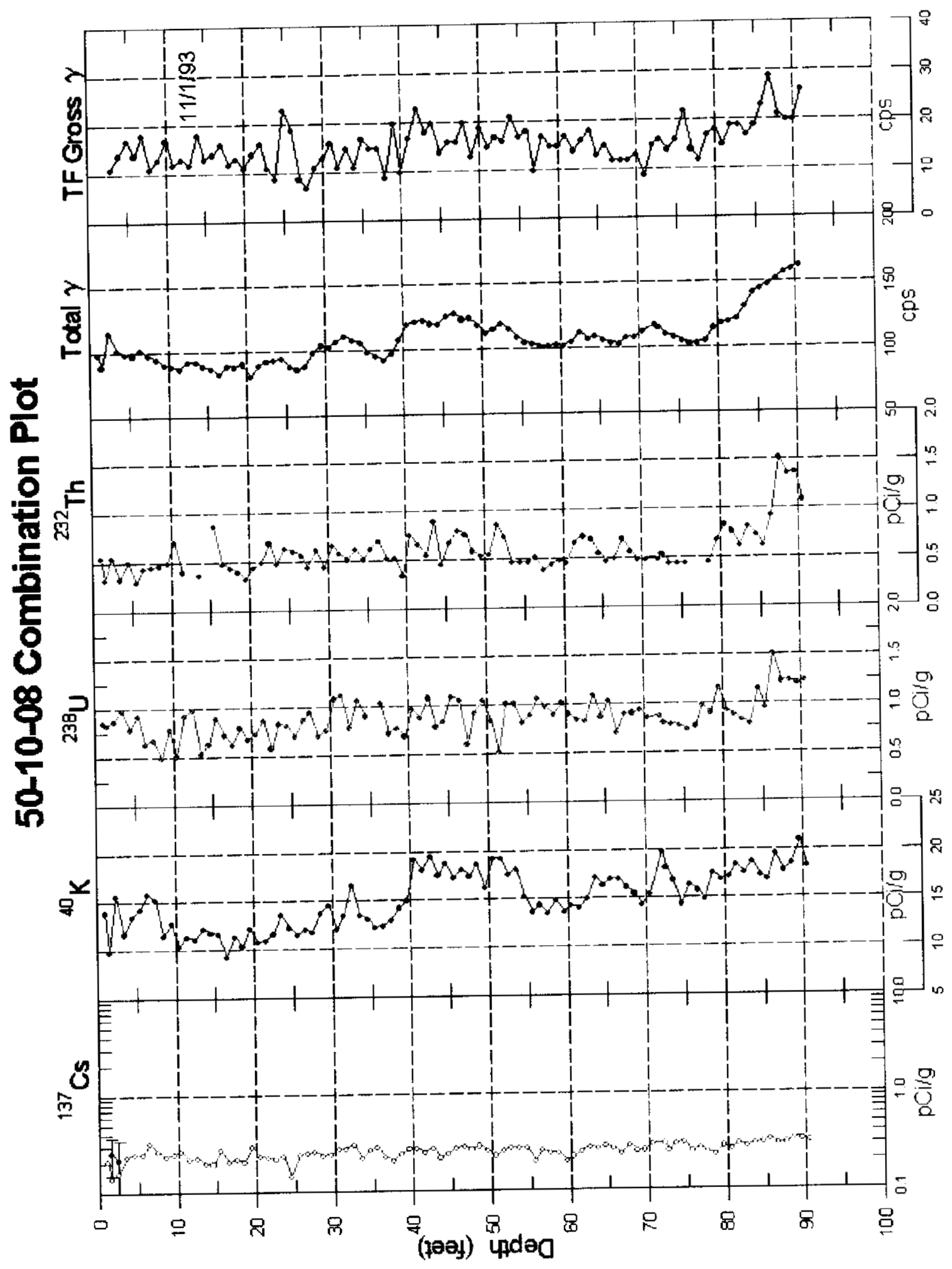

Tank T-110 
RPP-6088, Rev.0.

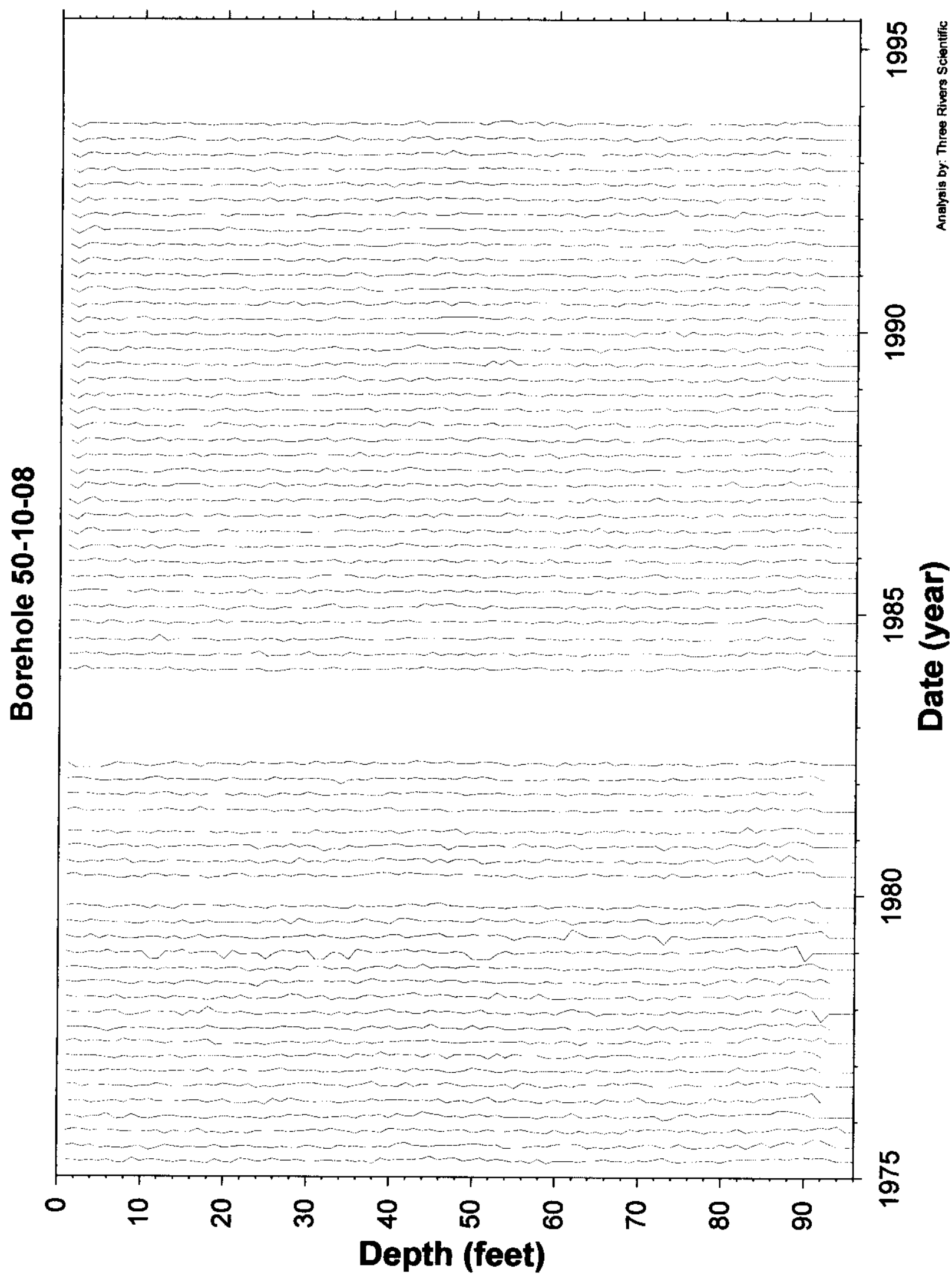

Tank T-110

Page 381 


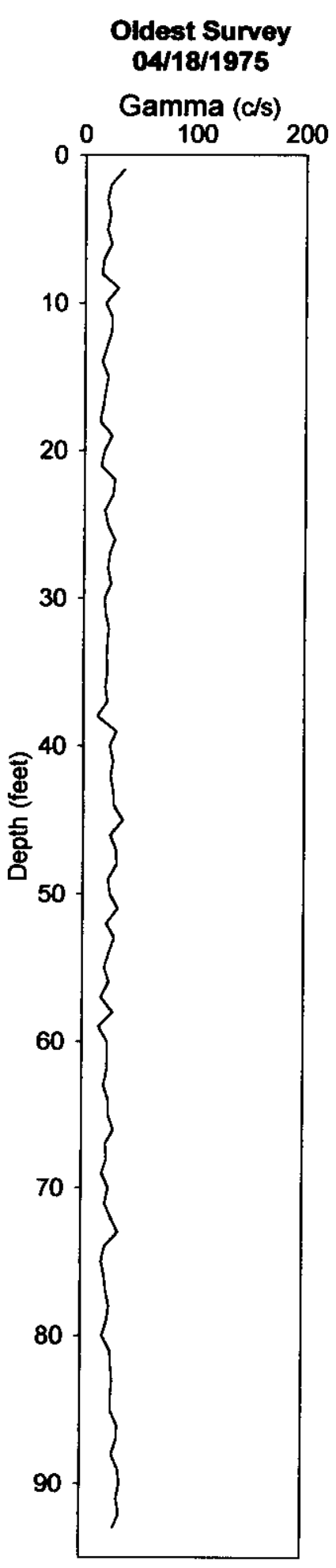

\section{Borehole 50-10-08}

No Gamma-Ray Emitting Contamination Above Survey Detection Threshold
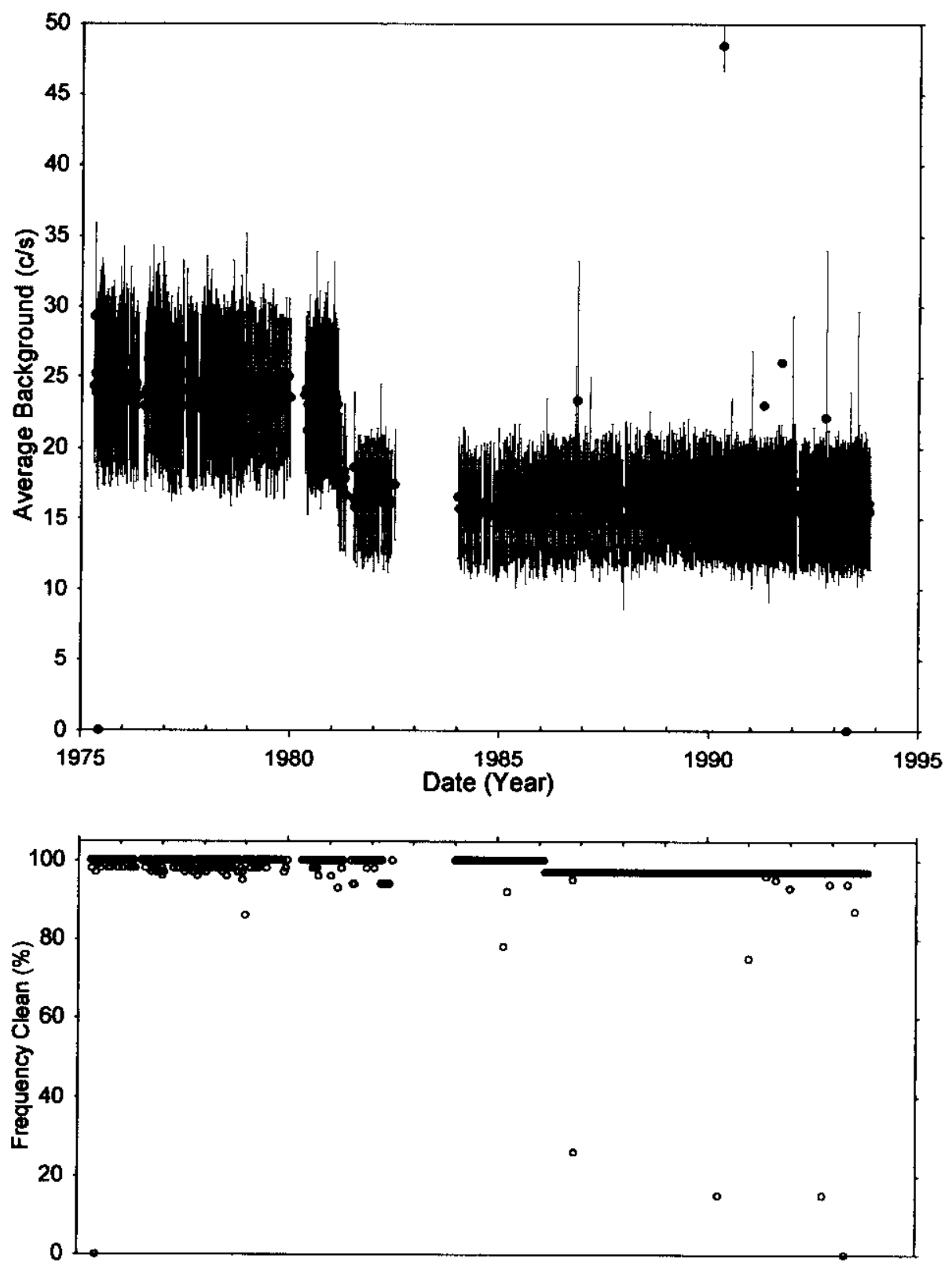

Analysis by: Three Pivers Scientific 
RPP-6088, Rev.0.

\section{Borehole 50-10-10}

\section{No Gamma Ray Emitting Contamination Identified.}

No significant levels of gamma ray contamination are present, based upon gross gamma data, above the survey probe detection threshold between 1975 and 1993 in the vadose zone from 2 to 90 feet. The HPGe logging system detected Cs-137 from 0 to 74 feet with maximum concentration of $3 \mathrm{pCi} / \mathrm{g}$ at 2 feet and less than $0.5 \mathrm{pCi} / \mathrm{g}$ for the rest of the interval.

The average background plot shows a step decrease after the $2 / 2 / 1981$ survey.

Gross Gamma Survey Information

\begin{tabular}{|r|l|}
\hline Probe Type Processed: & $04:$ NaI \\
\hline Other Probe Types : & $03:$ Neutron \\
\hline Survey Depth : & $90 \mathrm{ft}$ \\
\hline First Survey Date : & $1 / 10 / 1975$ \\
\hline Last Survey Date : & $11 / 01 / 1993$ \\
\hline Number Surveys Processed: & 693 \\
\hline
\end{tabular}

Analysis Notes

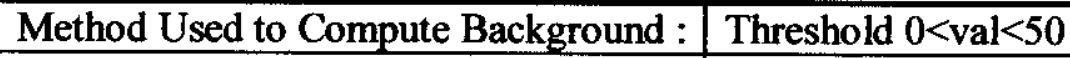

Depth(s) where Contamination was NONE

Identified in Gross Gamma Surveys :

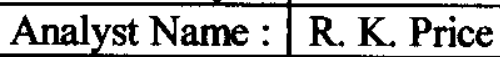

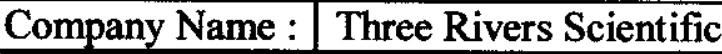


RPP-6088, Rev.0.

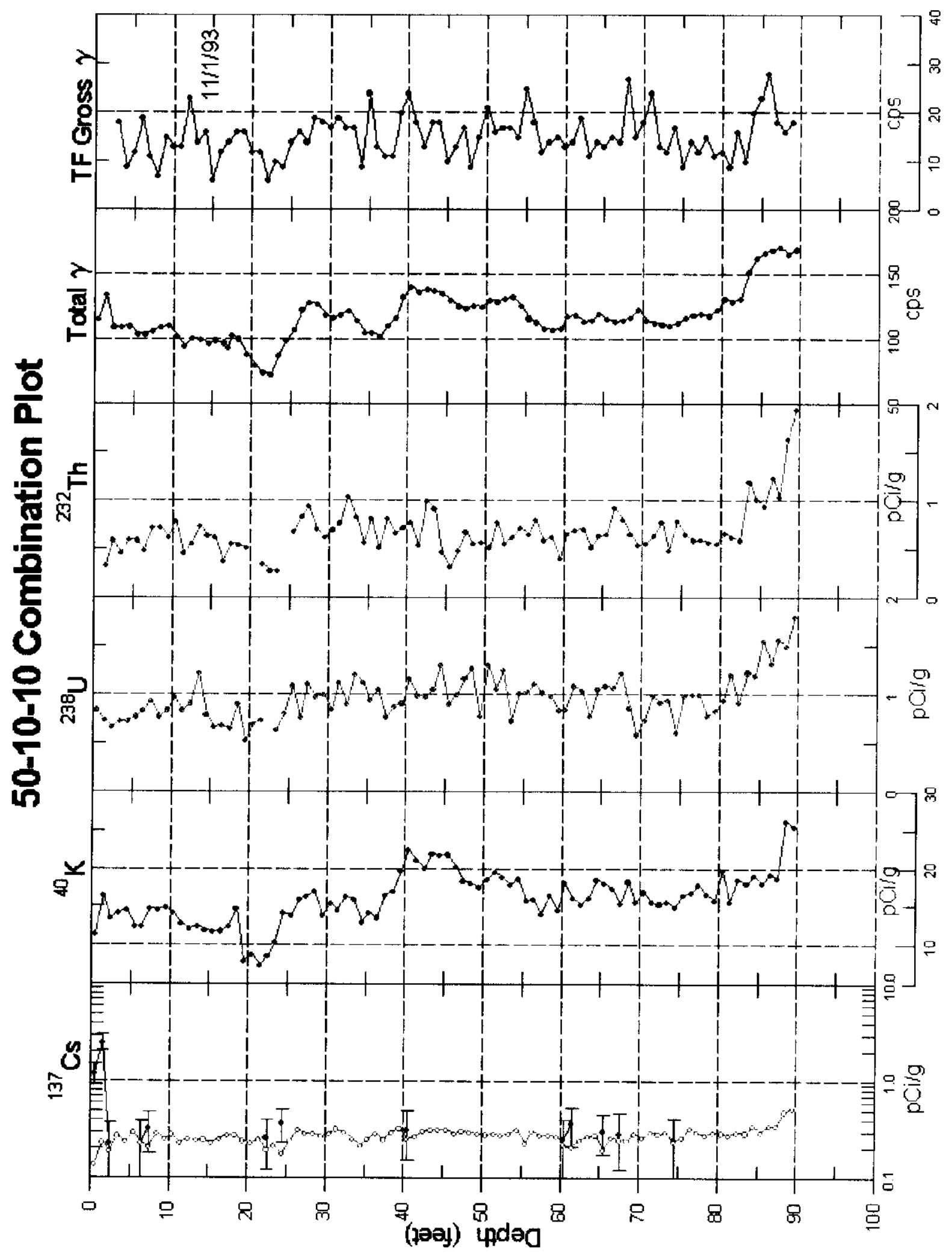


RPP-6088, Rev.0.

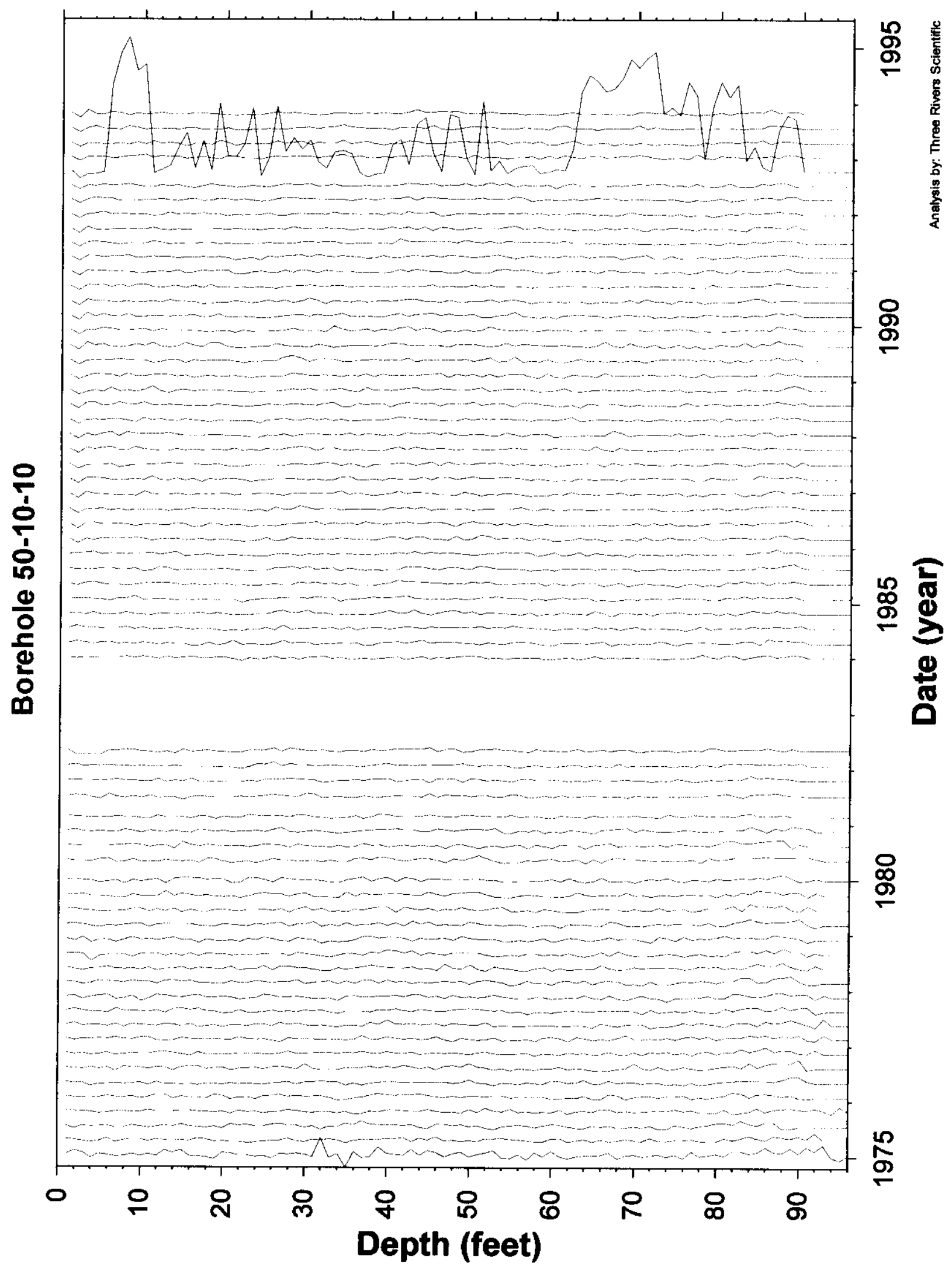

Tank T-110

Page 385 
RPP-6088, Rev.0.

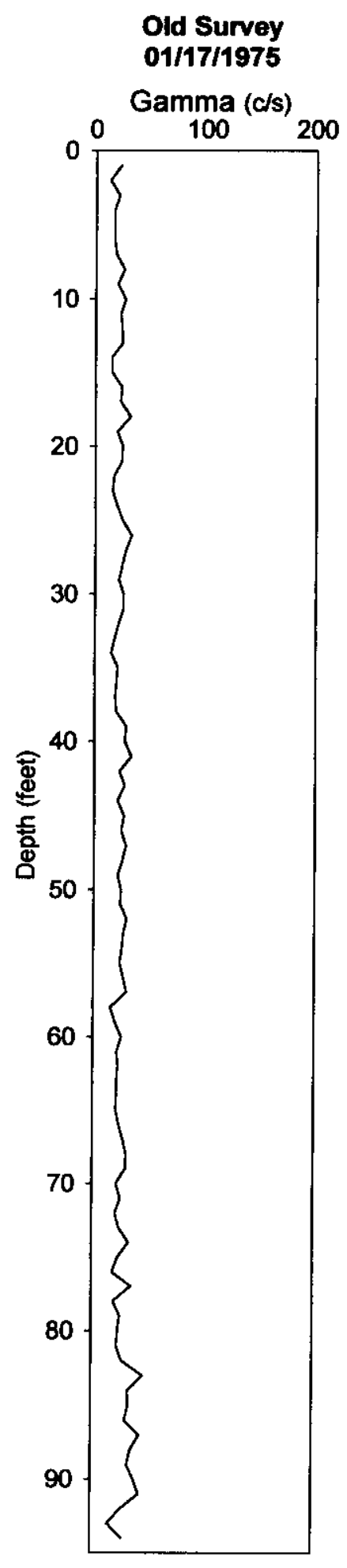

\section{Borehole 50-10-10}

No Gamma-Ray Emitting Contamination

Above Survey Detection Threshold
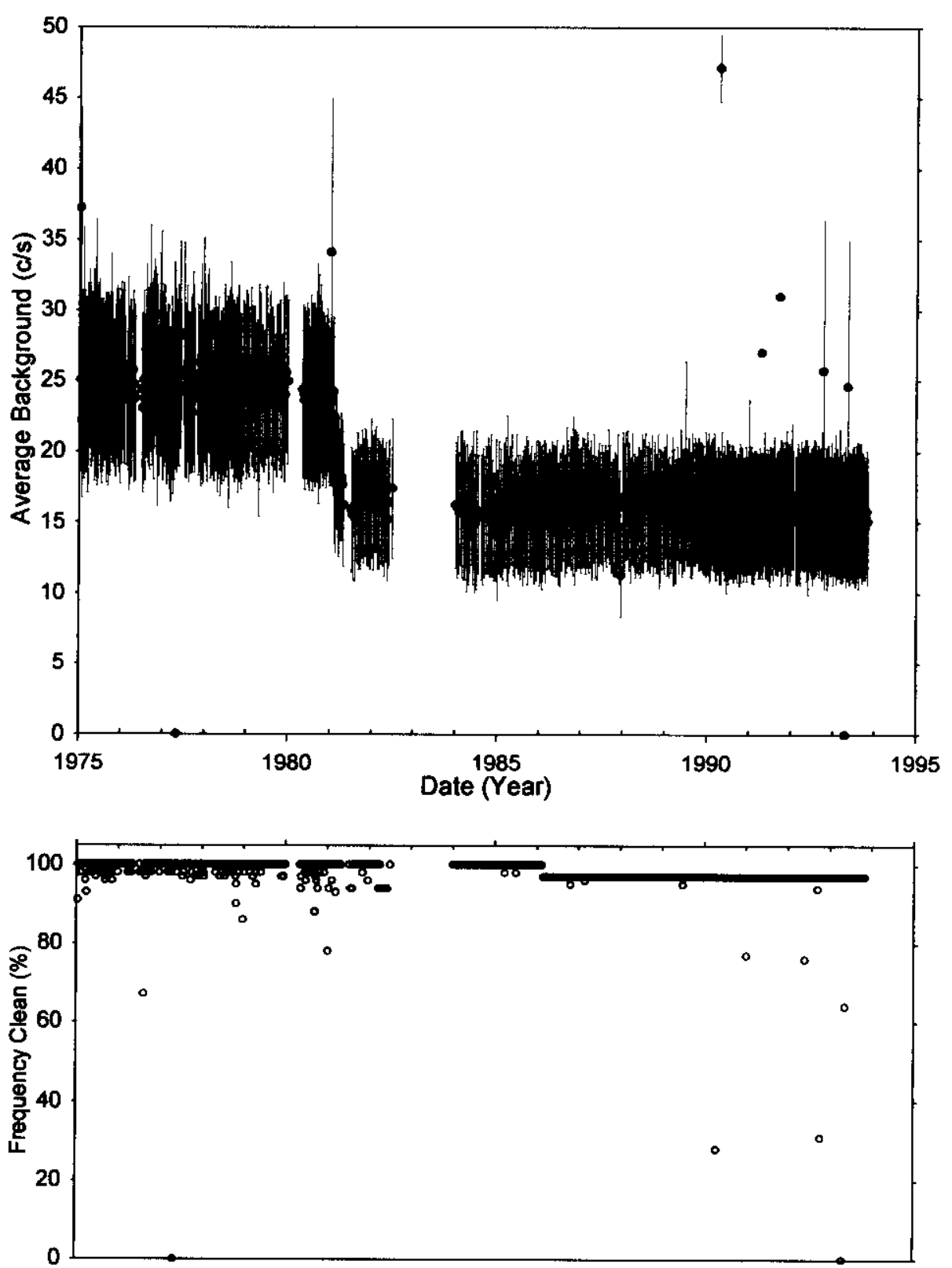

Analysis by: Three Rivers Scientific 
RPP-6088, Rev.0.

\section{Tank T-111 Wells}

Table of Contents Page

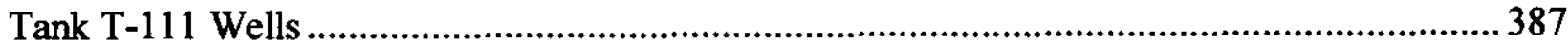

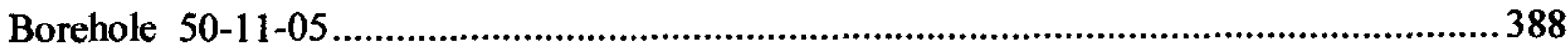

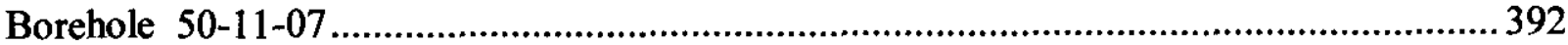

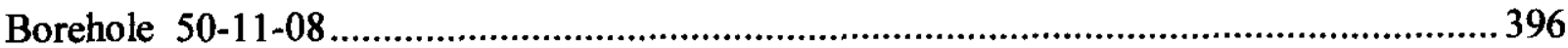

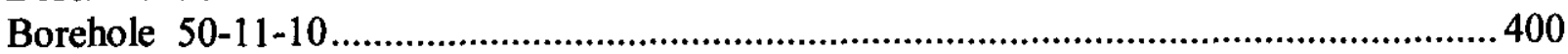

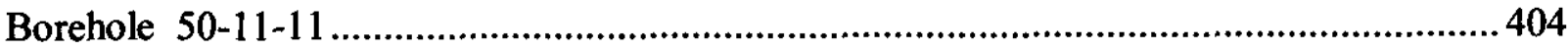

This section contains the analysis results for vadose zone boreholes (dry wells) associated with Tank 111 in the "T" Tank Farm.

Special Note: (none) 


\section{Borehole 50-11-05}

\section{No Gamma Ray Emitting Contamination Identified.}

No significant levels of gamma ray contamination are present, based upon gross gamma data, above the survey probe detection threshold between 1975 and 1994 in the vadose zone from 2 to 88 feet. The HPGe logging system detected Cs-137 at less than $0.5 \mathrm{pCi} / \mathrm{g}$ in the borehole.

The average background plot shows a step decrease after the $8 / 5 / 1980$ survey.

Gross Gamma Survey Information

\begin{tabular}{|r|l|}
\hline Probe Type Processed: & $04: \mathrm{NaI}$ \\
\hline Other Probe Types : & $03:$ Neutron \\
\hline Survey Depth : & $\mathbf{8 8 \mathrm { ft }}$ \\
\hline First Survey Date : & $1 / 17 / 1975$ \\
\hline Last Survey Date : & $2 / 17 / 1994$ \\
\hline Number Surveys Processed: & 888 \\
\hline
\end{tabular}

Analysis Notes

Method Used to Compute Background : $\quad$ Threshold $0<$ val $<50$

Depth(s) where Contamination was NONE

Identified in Gross Gamma Surveys :

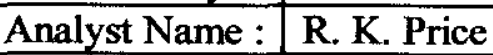

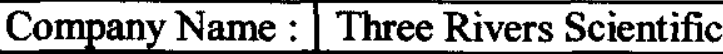


RPP-6088, Rev.0.

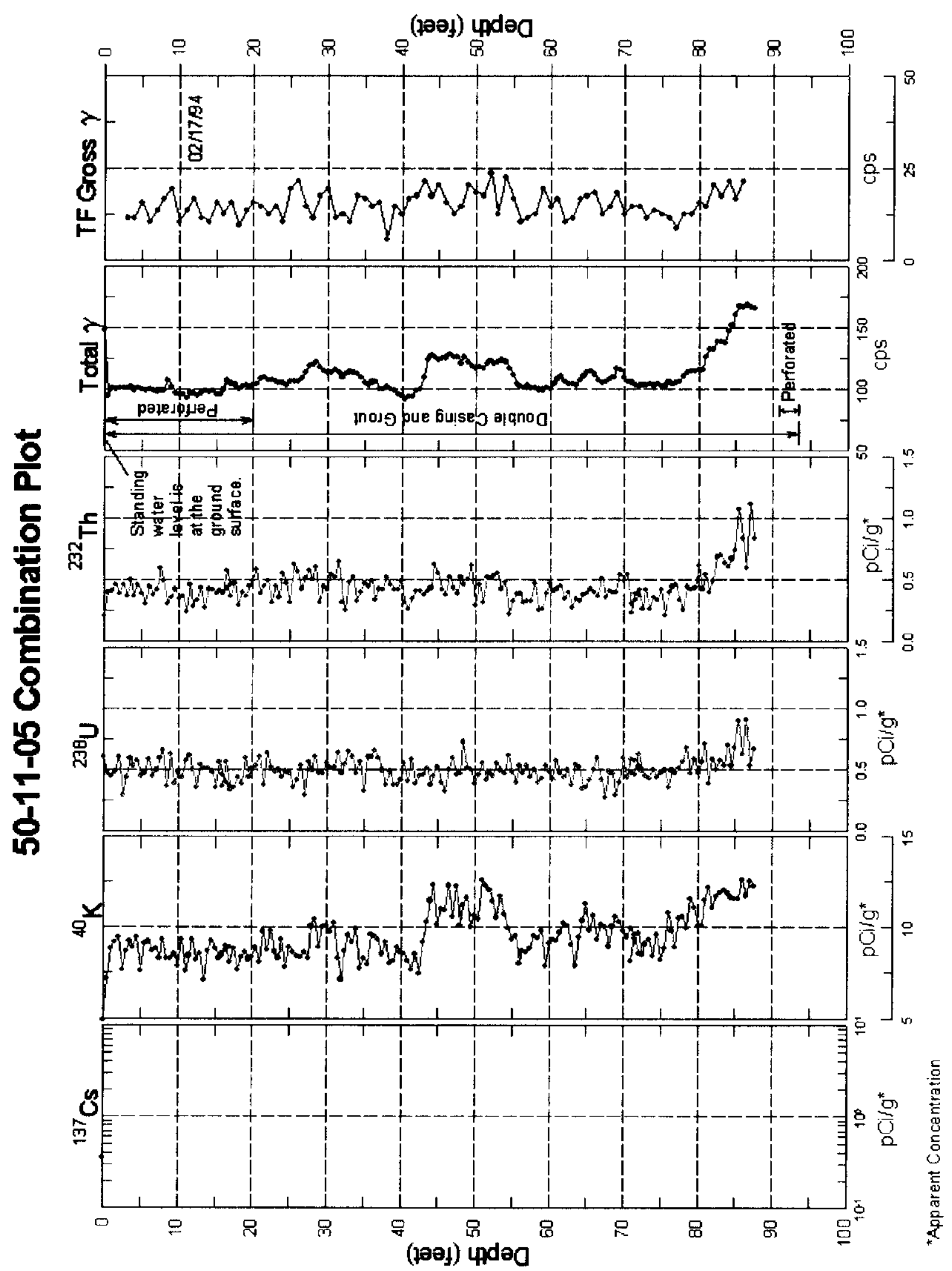


RPP-6088, Rev.0.

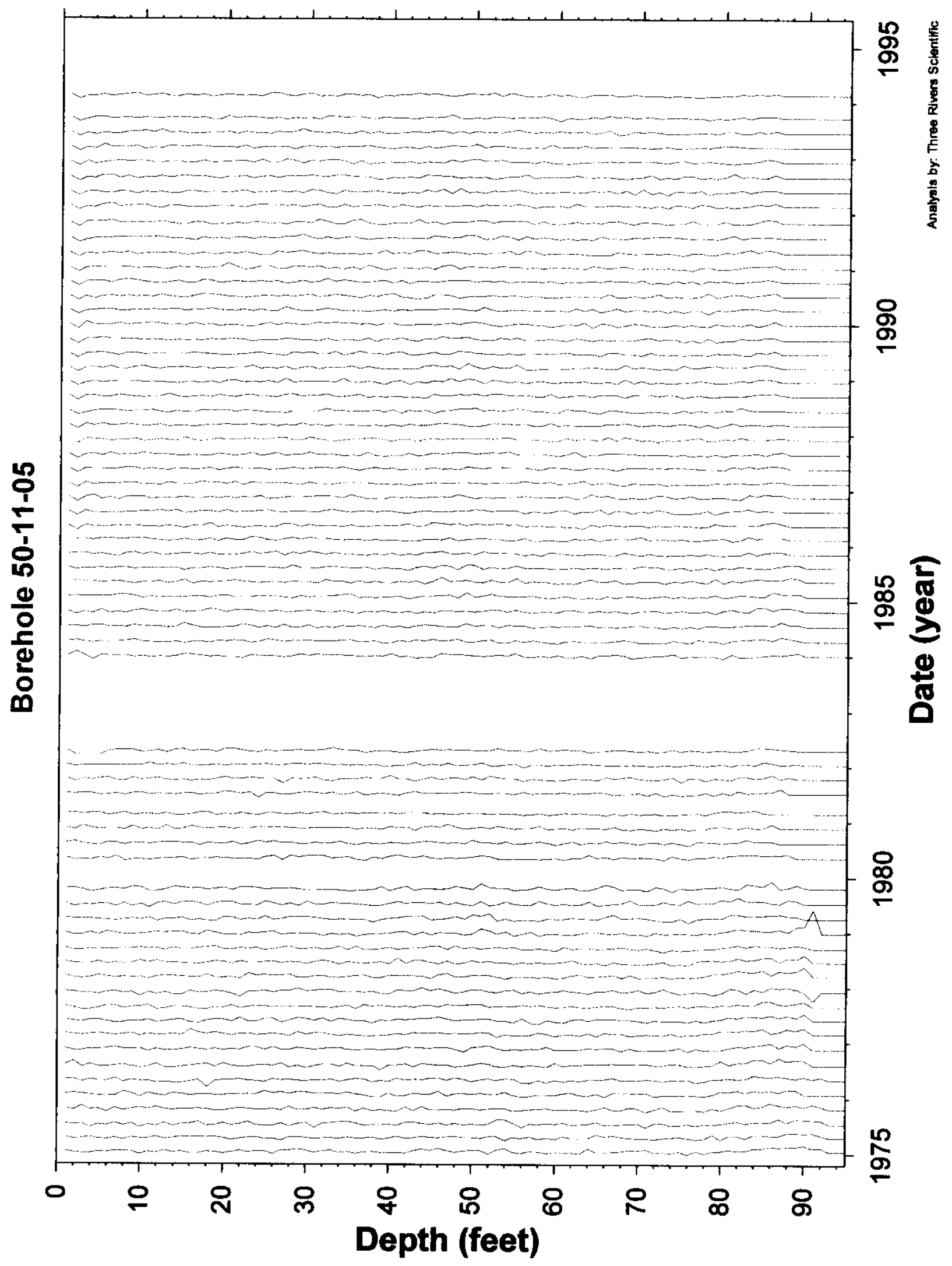

Tank T-111

Page 390 
RPP-6088, Rev.0.

\section{Borehole 50-11-05}

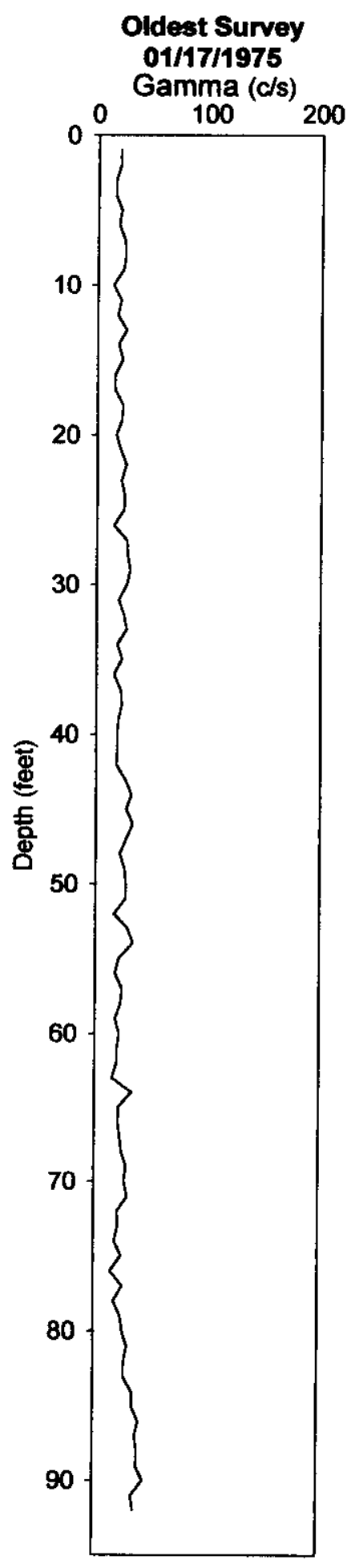

\section{No Gamma-Ray Emitting Contamination \\ Above Survey Detection Threshold}
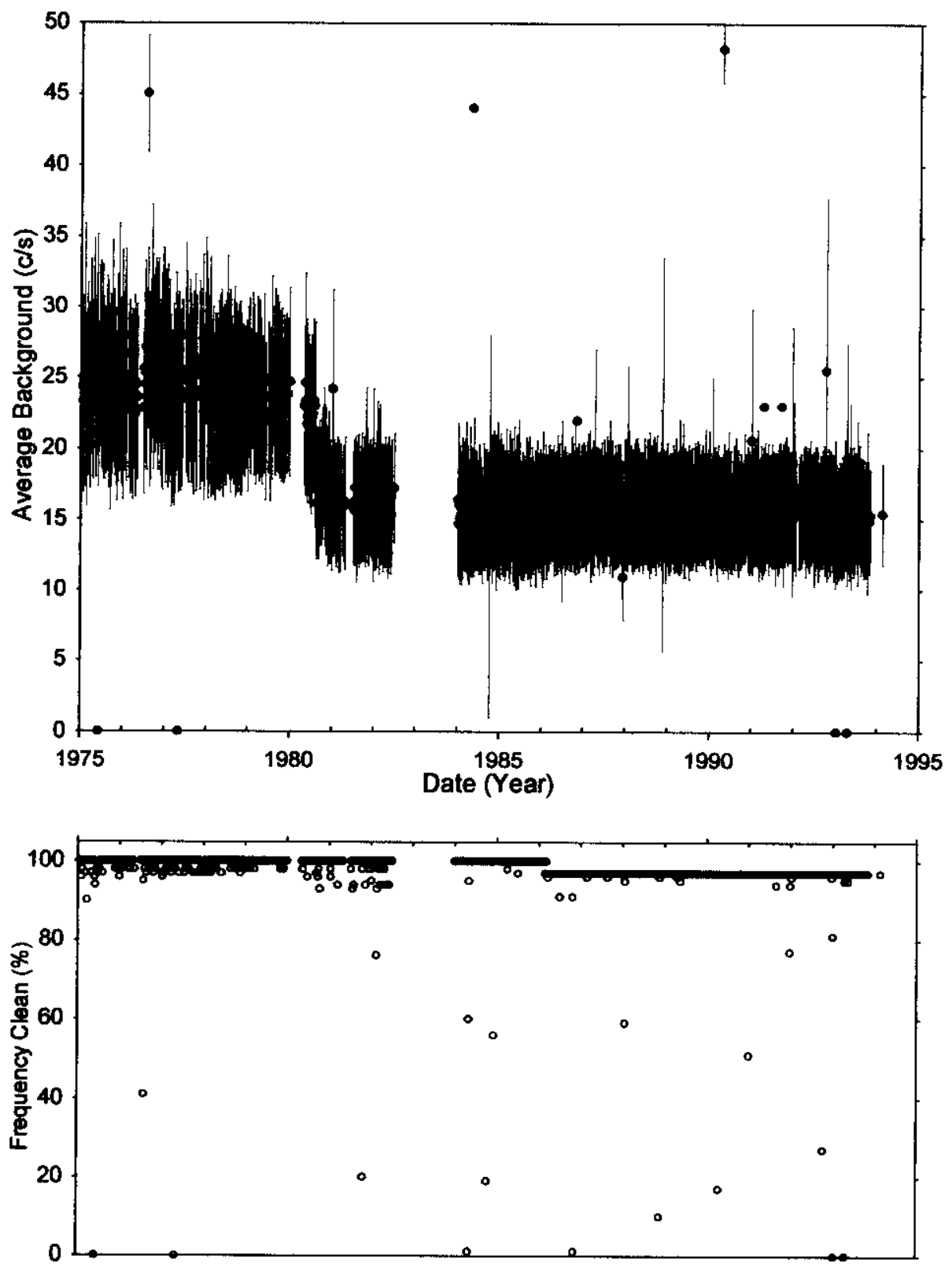

Analysis by: Three Rivers Scientific 


\section{Borehole 50-11-07}

\section{No Gamma Ray Emitting Contamination Identified.}

No significant levels of gamma ray contamination are present, based upon gross gamma data, above the survey probe detection threshold between 1975 and 1994 in the vadose zone from 2 to 91 feet. The HPGe logging system detected Cs-137 at less than $0.6 \mathrm{pCi} / \mathrm{g}$ in the borehole.

The average background plot shows a step decrease after the $8 / 5 / 1980$ survey.

Gross Gamma Survey Information

\begin{tabular}{|r|l|}
\hline Probe Type Processed: & $04: \mathrm{NaI}$ \\
\hline Other Probe Types : & $03:$ Neutron \\
\hline Survey Depth : & $91 \mathrm{ft}$ \\
\hline First Survey Date : & $5 / 02 / 1975$ \\
\hline Last Survey Date : & $2 / 17 / 1994$ \\
\hline Number Surveys Processed: & 867 \\
\hline
\end{tabular}

Analysis Notes

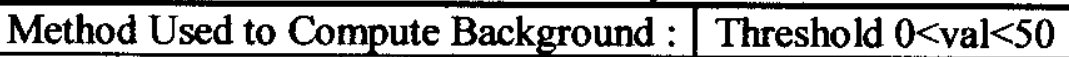

Depth(s) where Contamination was NONE

Identified in Gross Gamma Surveys :

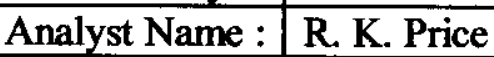

Company Name : Three Rivers Scientific 
RPP-6088, Rev.0.

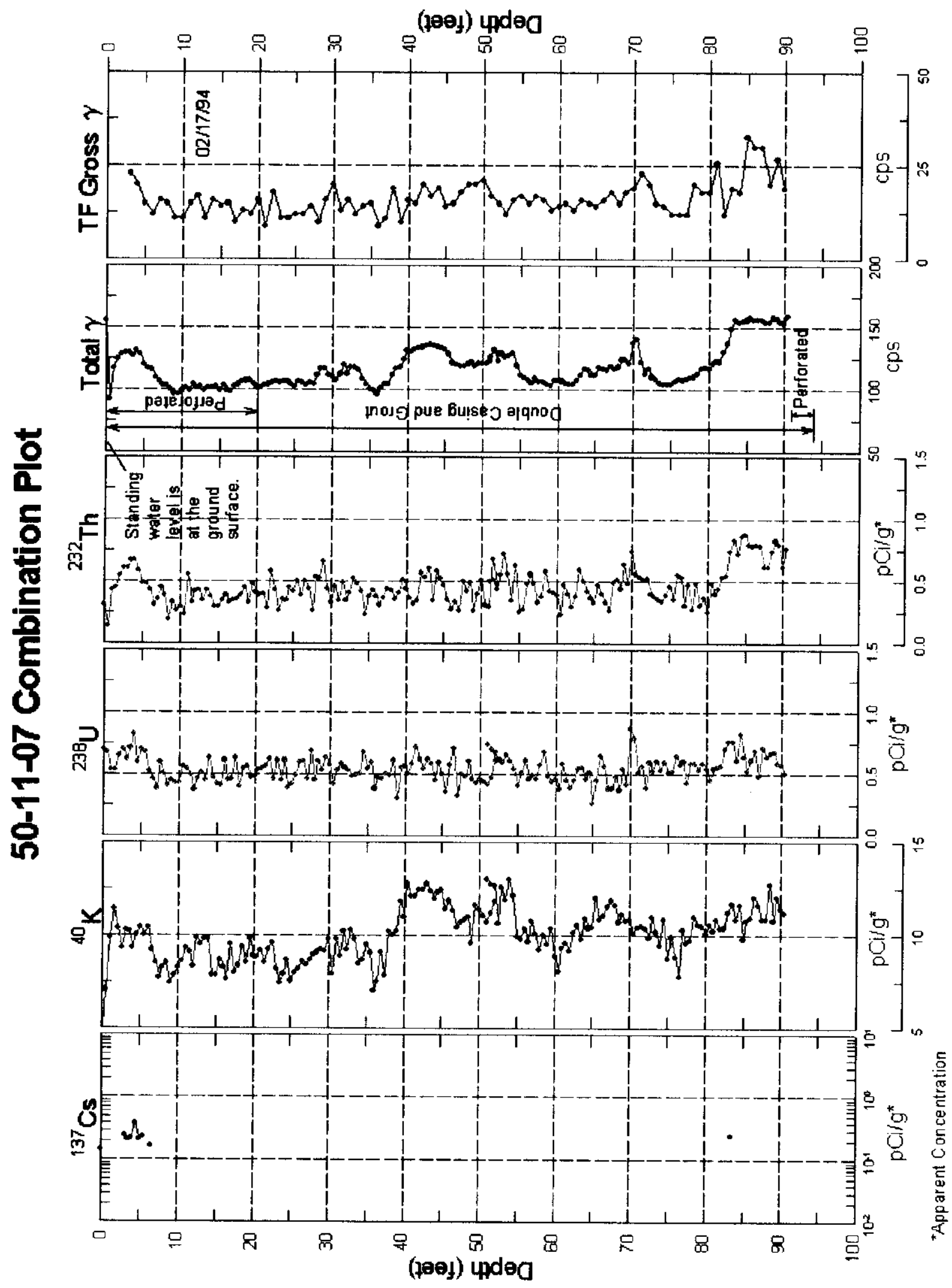

Tank T-111

Page 393 
RPP-6088, Rev.0.

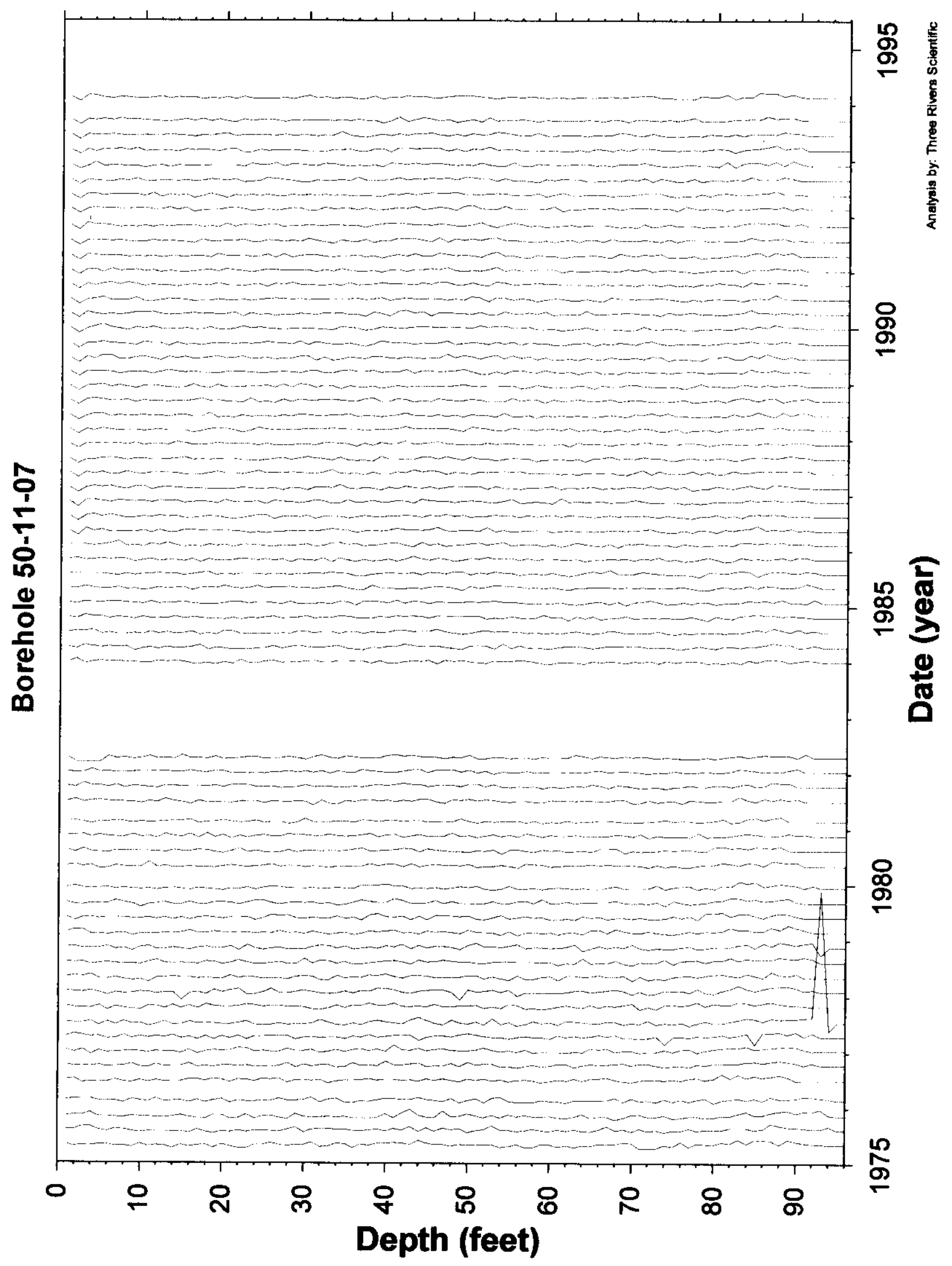

Tank T-111

Page 394 


\section{Borehole 50-11-07}

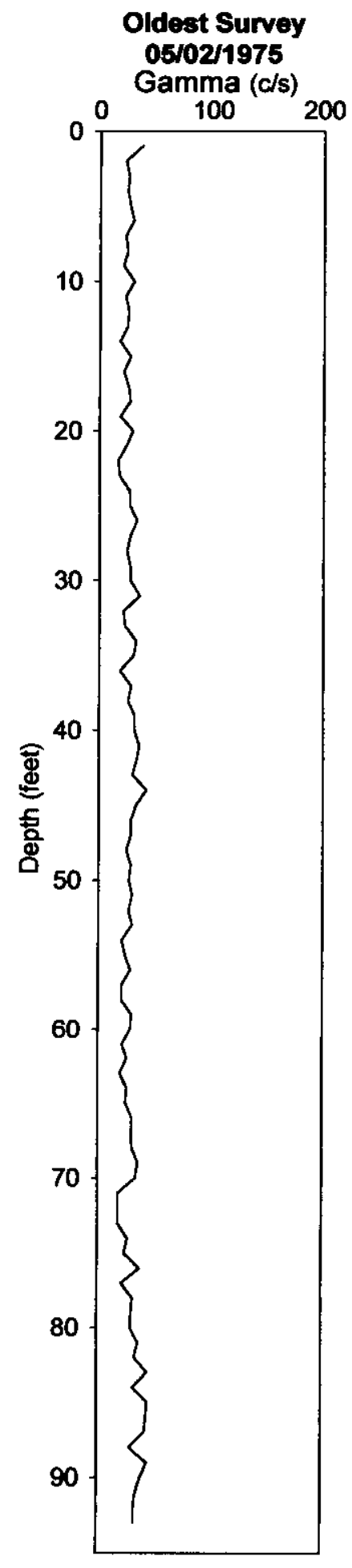
No Gamma-Ray Emitting Contamination Above Survey Detection Threshold
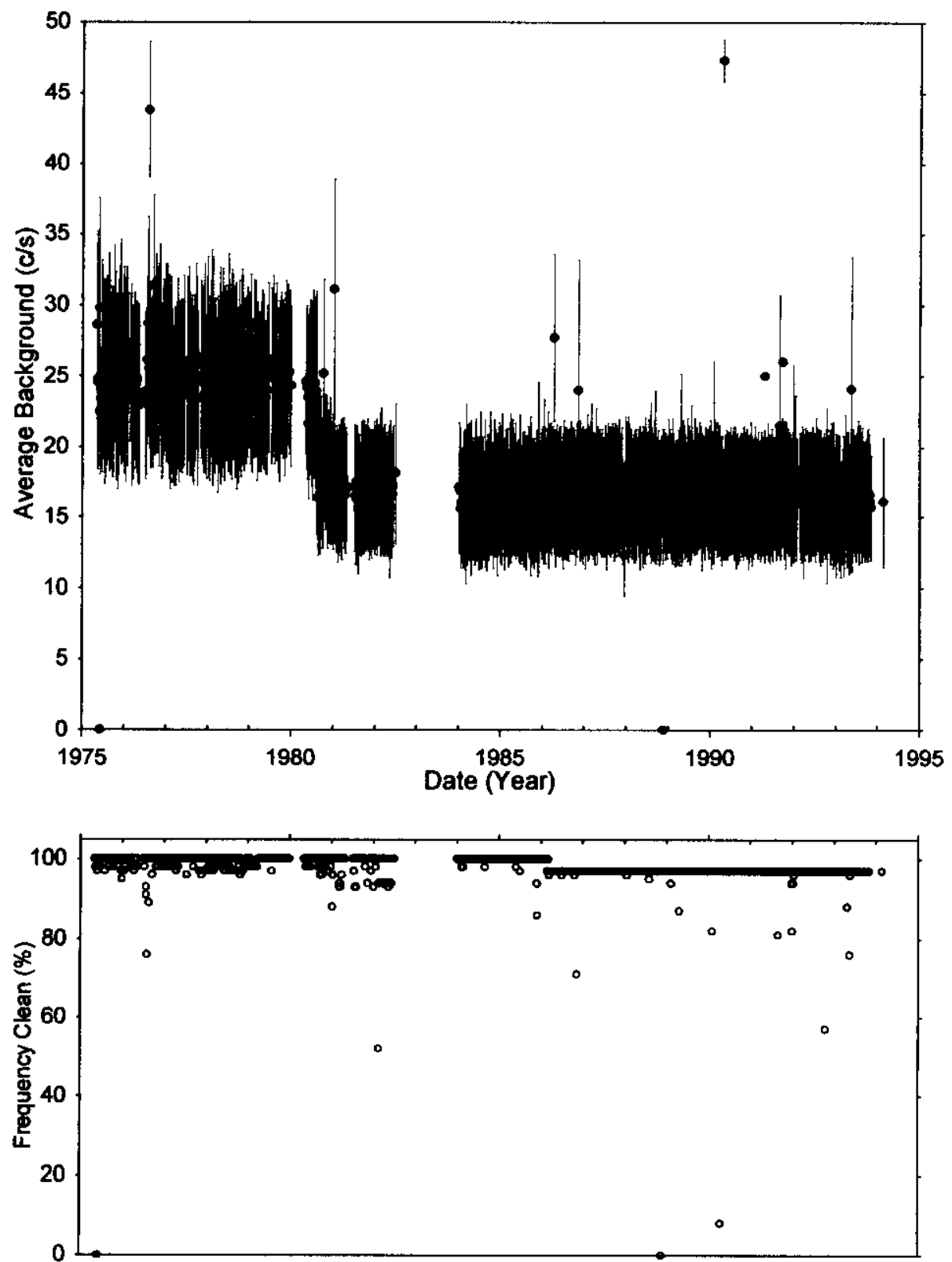

Anatysis by: Three Rivers Scientific 


\section{Borehole 50-11-08}

\section{No Gamma Ray Emitting Contamination Identified.}

No significant levels of gamma ray contamination are present, based upon gross gamma data, above the survey probe detection threshold between 1975 and 1994 in the vadose zone from 2 to 93 feet. The HPGe logging system detected Cs- 137 at less than $0.5 \mathrm{pCi} / \mathrm{g}$ in the borehole.

The average background plot shows a step decrease after the $8 / 5 / 1980$ survey.

Gross Gamma Survey Information

\begin{tabular}{|r|l|}
\hline Probe Type Processed: & $04:$ NaI \\
\hline Other Probe Types : & $03:$ Neutron \\
\hline Survey Depth : & $93 \mathrm{ft}$ \\
\hline First Survey Date : & $1 / 10 / 1975$ \\
\hline Last Survey Date : & $2 / 17 / 1994$ \\
\hline Number Surveys Processed: & 651 \\
\hline
\end{tabular}

Analysis Notes

Method Used to Compute Background : $\quad$ Threshold $0<$ val $<50$

Depth(s) where Contamination was NONE Identified in Gross Gamma Surveys :

Analyst Name : $\quad$ R. K. Price

\begin{tabular}{l|l} 
Company Name : & Three Rivers Scientific
\end{tabular} 
RPP-6088, Rev.0.

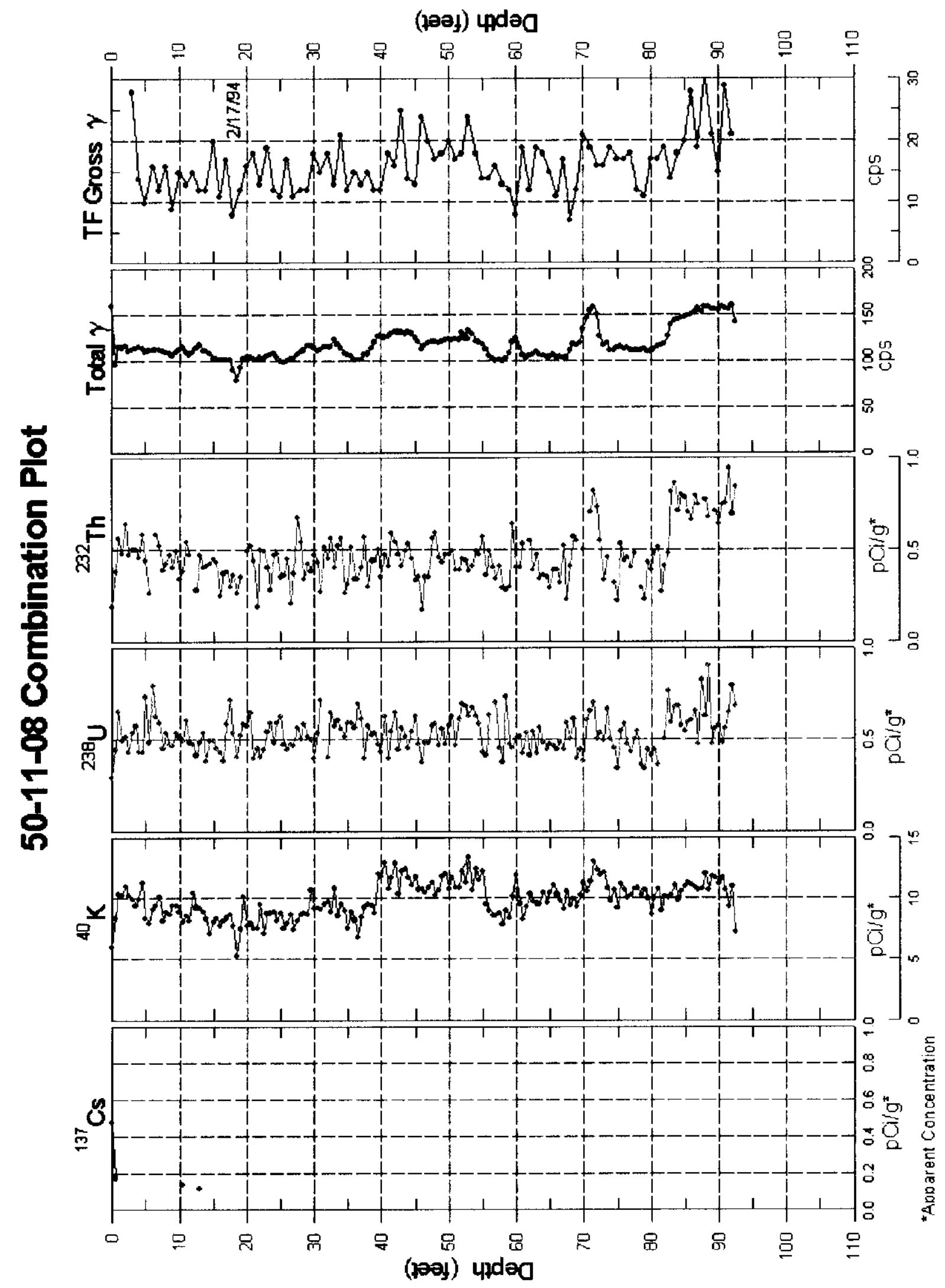

Tank T-111

Page 397 
RPP-6088, Rev.0.

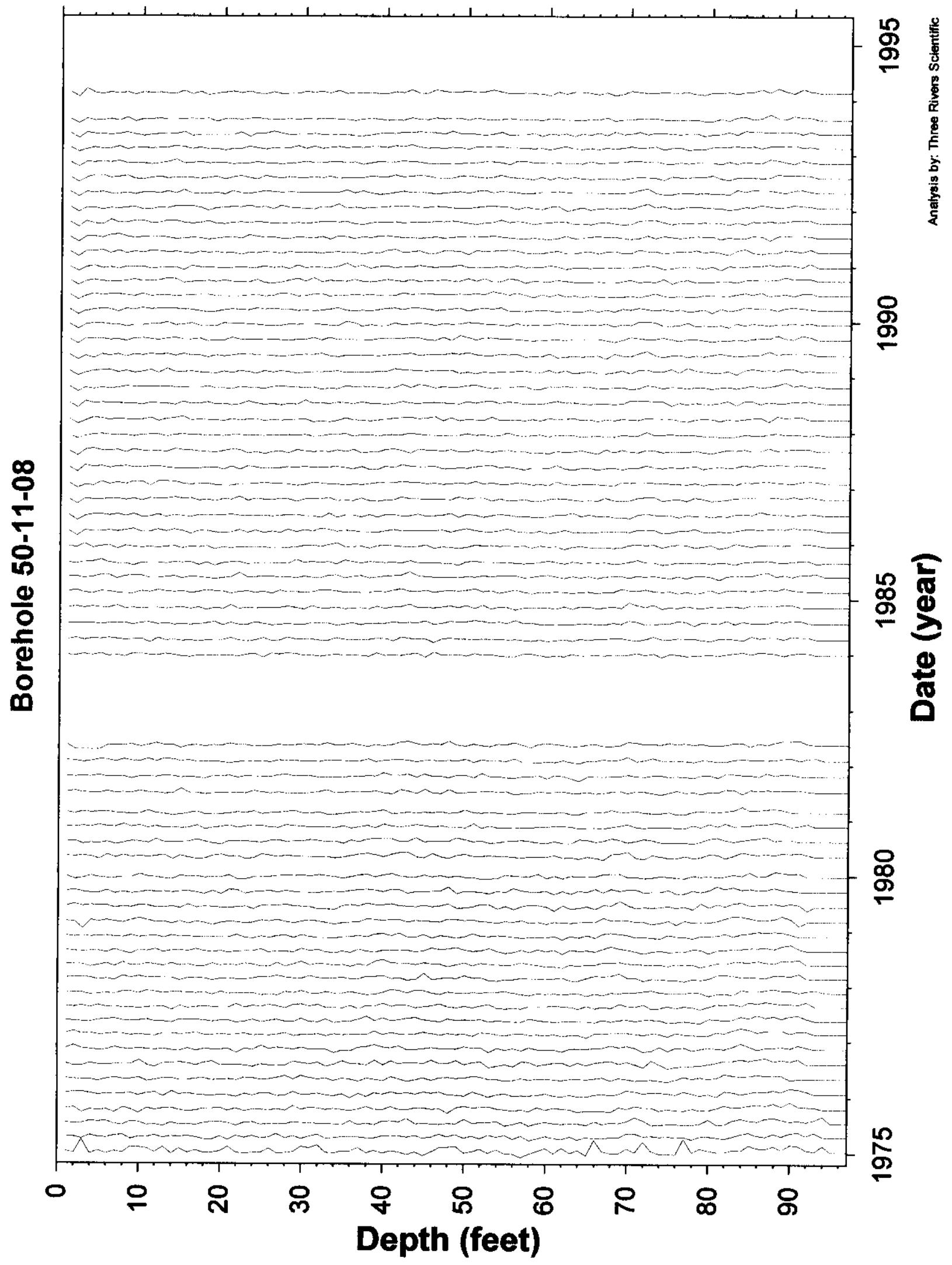

Tank T-111

Page 398 
RPP-6088, Rev.0.

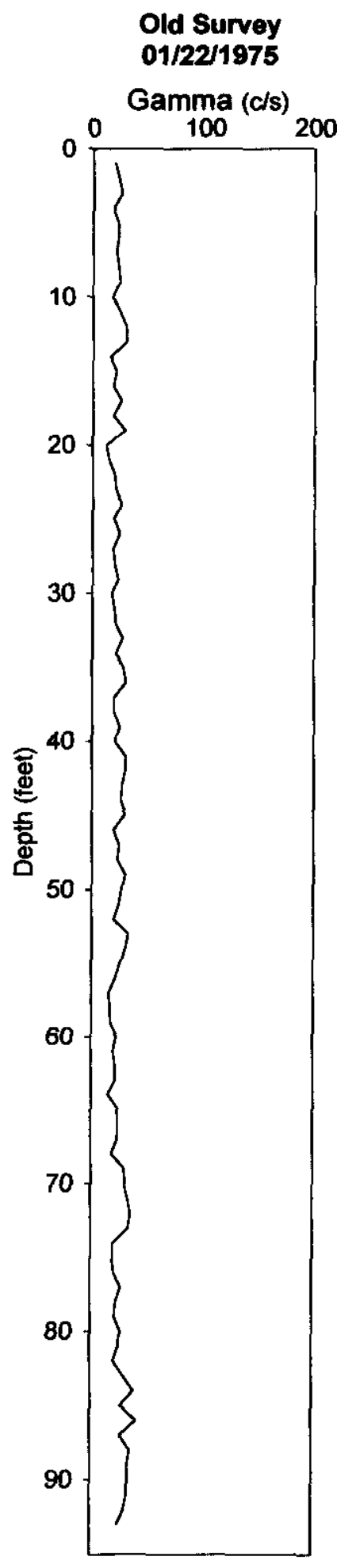

Borehole 50-11-08

\section{No Gamma-Ray Emitting Contamination \\ Above Survey Detection Threshold}
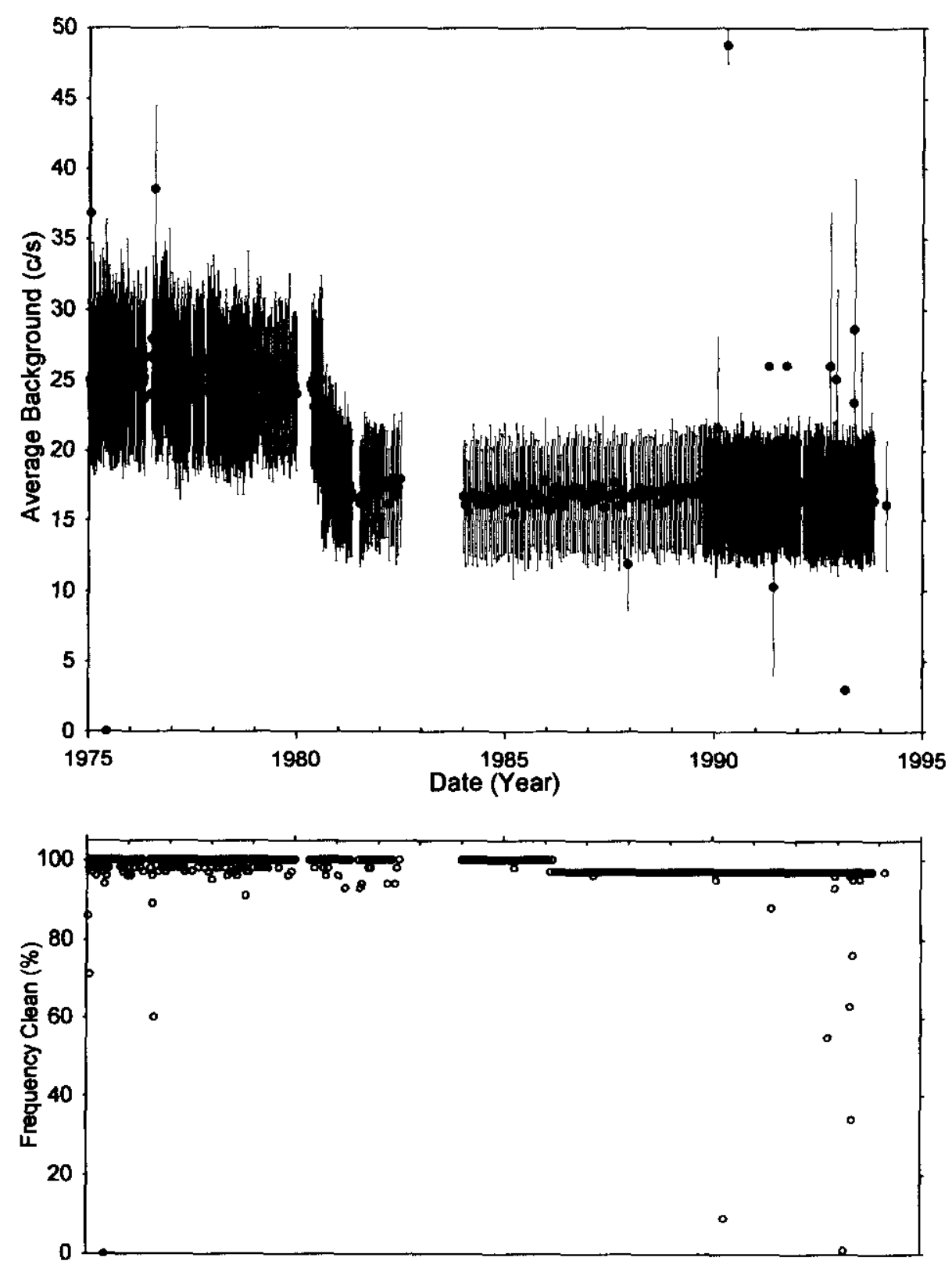

Analysis by: Three Rivers Scientific 
RPP-6088, Rev.0.

\section{Borehole 50-11-10}

\section{No Gamma Ray Emitting Contamination Identified.}

No significant levels of gamma ray contamination are present, based upon gross gamma data, above the survey probe detection threshold between 1975 and 1994 in the vadose zone from 2 to 98 feet. The HPGe logging system detected Cs- 137 at less than $0.5 \mathrm{pCi} / \mathrm{g}$ from 0 to 4 feet, and Co 60 at less than $0.1 \mathrm{pCi} / \mathrm{g}$ from 67 to 69 feet in the borehole.

The average background plot shows a step decrease after the $8 / 19 / 1980$ survey.

Gross Gamma Survey Information

\begin{tabular}{|r|l|}
\hline Probe Type Processed: & $04: \mathrm{Nal}$ \\
\hline Other Probe Types : & $03:$ Neutron \\
\hline Survey Depth : & $98 \mathrm{ft}$ \\
\hline First Survey Date : & $4 / 02 / 1975$ \\
\hline Last Survey Date : & $2 / 17 / 1994$ \\
\hline Number Surveys Processed: & 643 \\
\hline
\end{tabular}

Analysis Notes

Method Used to Compute Background : $\quad$ Threshold $0<$ val $<50$

Depth(s) where Contamination was NONE

Identified in Gross Gamma Surveys :

Analyst Name : R. K. Price

Company Name : Three Rivers Scientific 
RPP-6088, Rev.0.

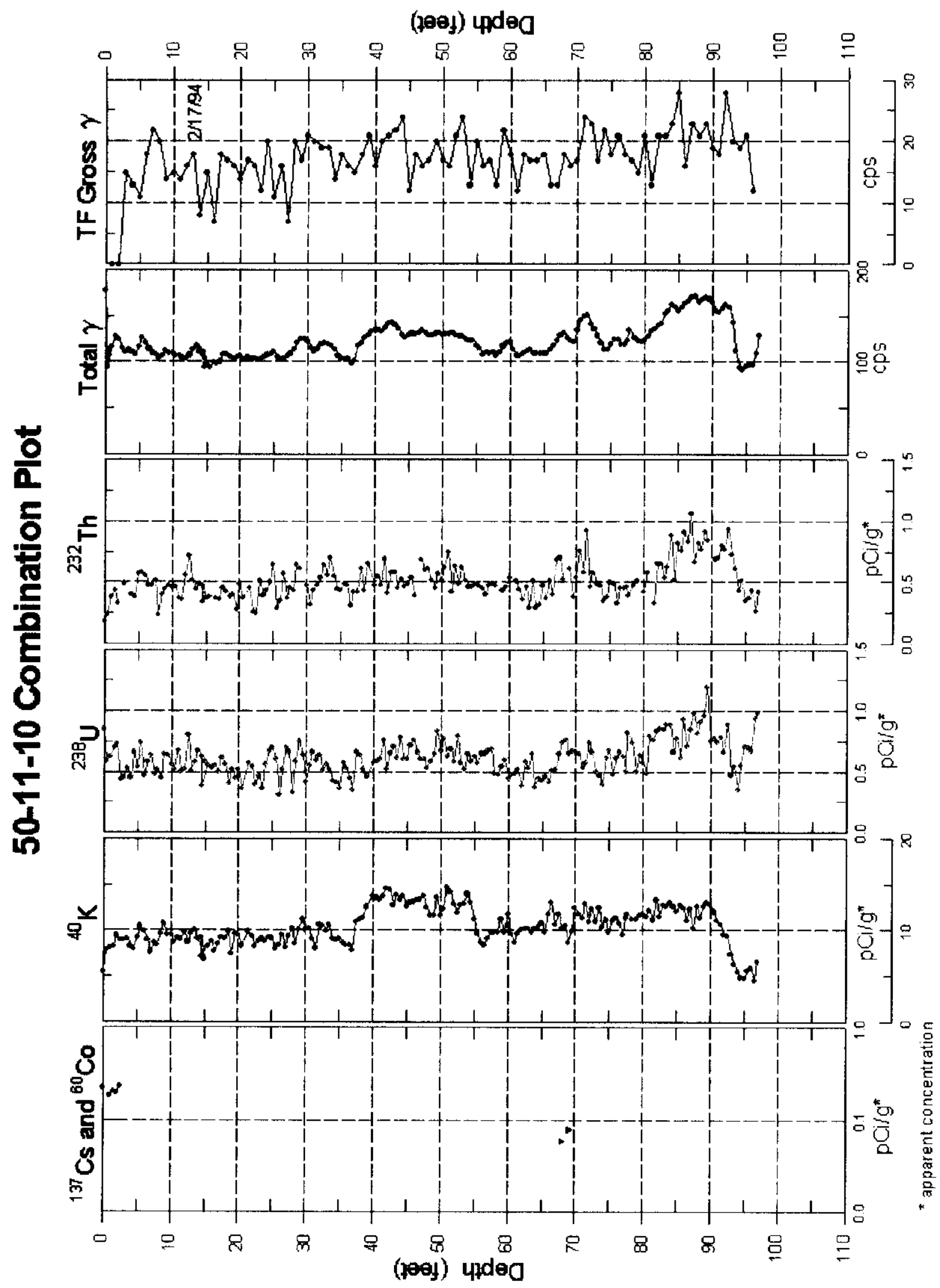


RPP-6088, Rev.0.

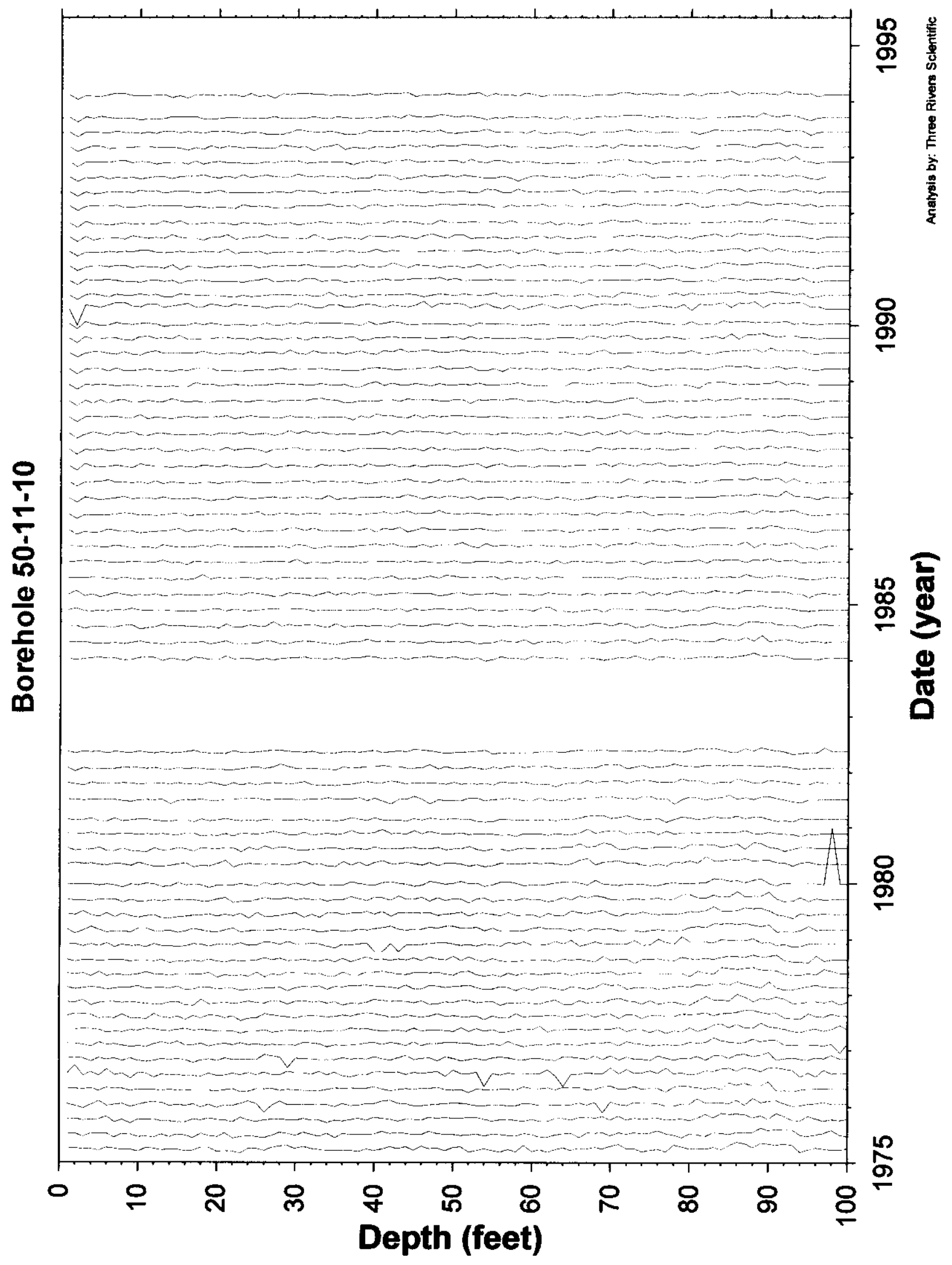

Tank T-111

Page 402 


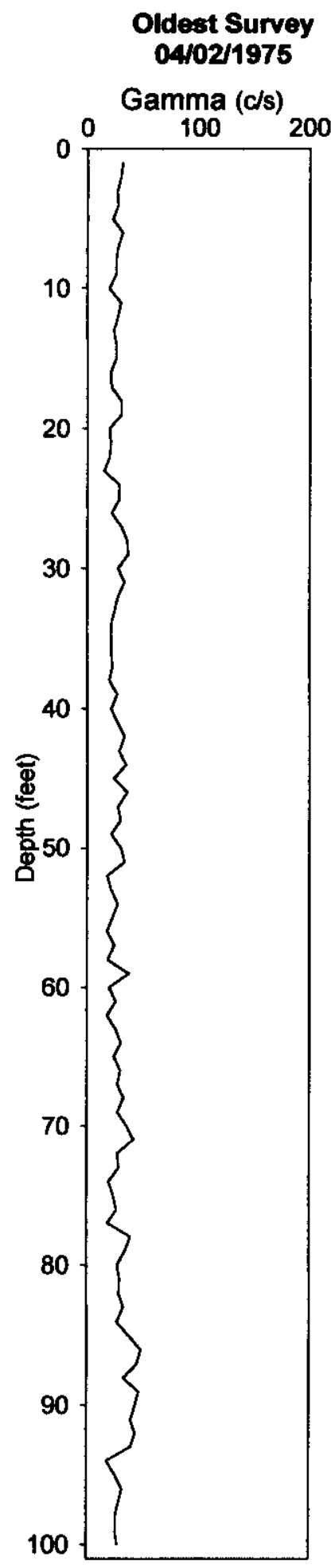

\section{Borehole 50-11-10}

\section{No Gamma-Ray Emitting Contamination \\ Above Survey Detection Threshold}
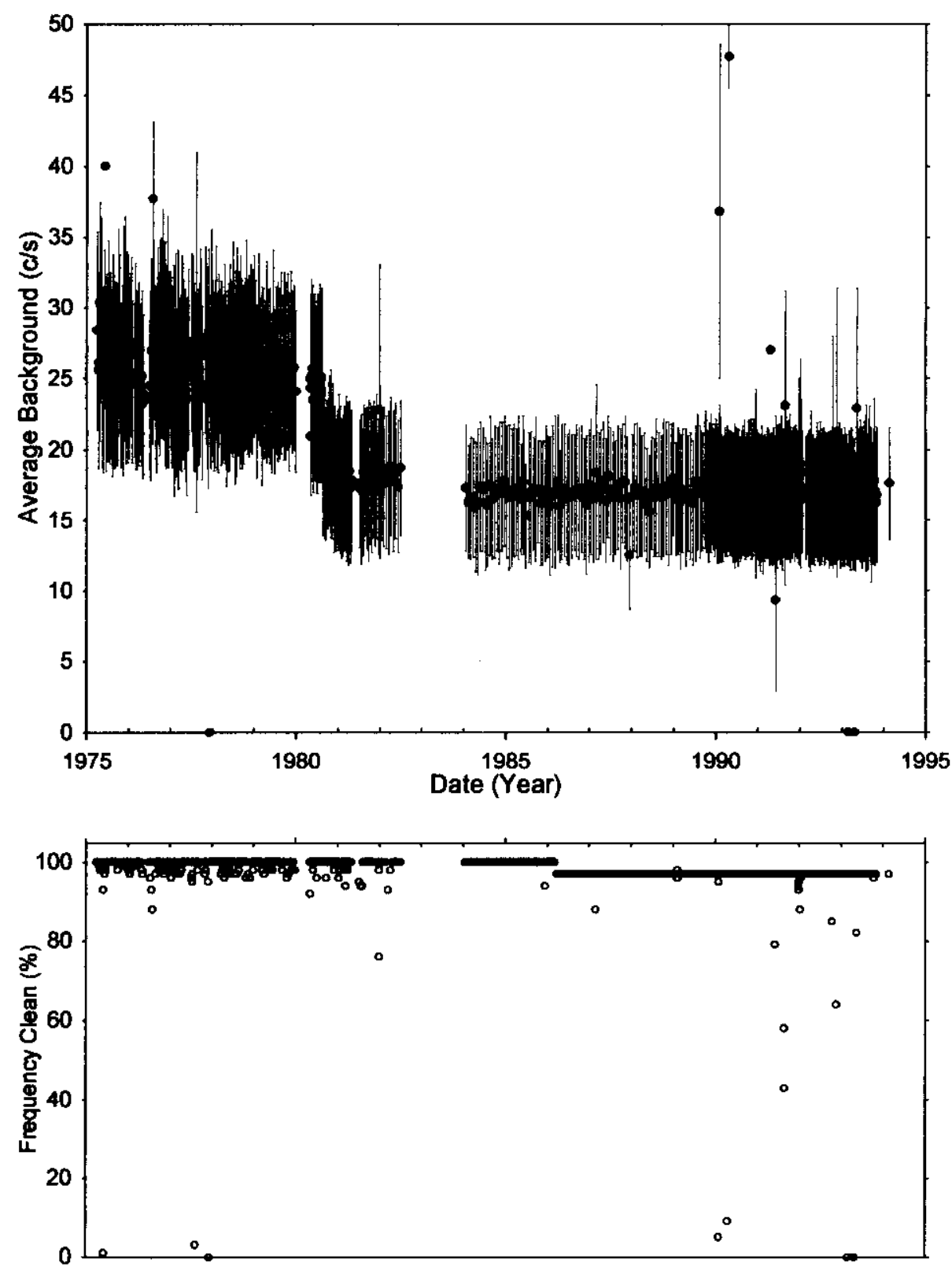

Analysis by: Throe Rivers Scientific 
RPP-6088, Rev.0.

\section{Borehole 50-11-11}

\section{Contamination (Co-60 \& Ru-106) from 64 to 74 feet is Unstable Early.}

Grade thickness product from 64 to 74 feet is increasing from the first survey in 1979 to early 1980 then decreases rapidly at a rate that does not match the HPGe identified radionuclide of Co60 or hypothesized radionuclide of Ru-106. Then, from 1984 to 1994 the GTP is at essentially background levels and is decreasing consistent with a least square fit for Co-60 (HPGe identified) and Ru-106 (hypothesis) . The ratio of gross contribution from Co-60 to gross from $\mathrm{Ru}-106$ is $111: 1$ as of $2-17-1994$.

Gross Gamma Survey Information

\begin{tabular}{|r|l|}
\hline Probe Type Processed: & $04:$ NaI \\
\hline Other Probe Types : & $03:$ Neutron \\
\hline Survey Depth : & $90 \mathrm{ft}$ \\
\hline First Survey Date : & $7 / 26 / 1979$ \\
\hline Last Survey Date : & $2 / 17 / 1994$ \\
\hline Number Surveys Processed: & 685 \\
\hline
\end{tabular}

Analysis Notes

Method Used to Compute Background : $20-50$ feet

Depth(s) where Contamination was $64-74$ feet Unstable Early

Identified in Gross Gamma Surveys :

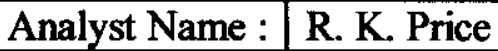

Company Name : Three Rivers Scientific 
RPP-6088, Rev.0.

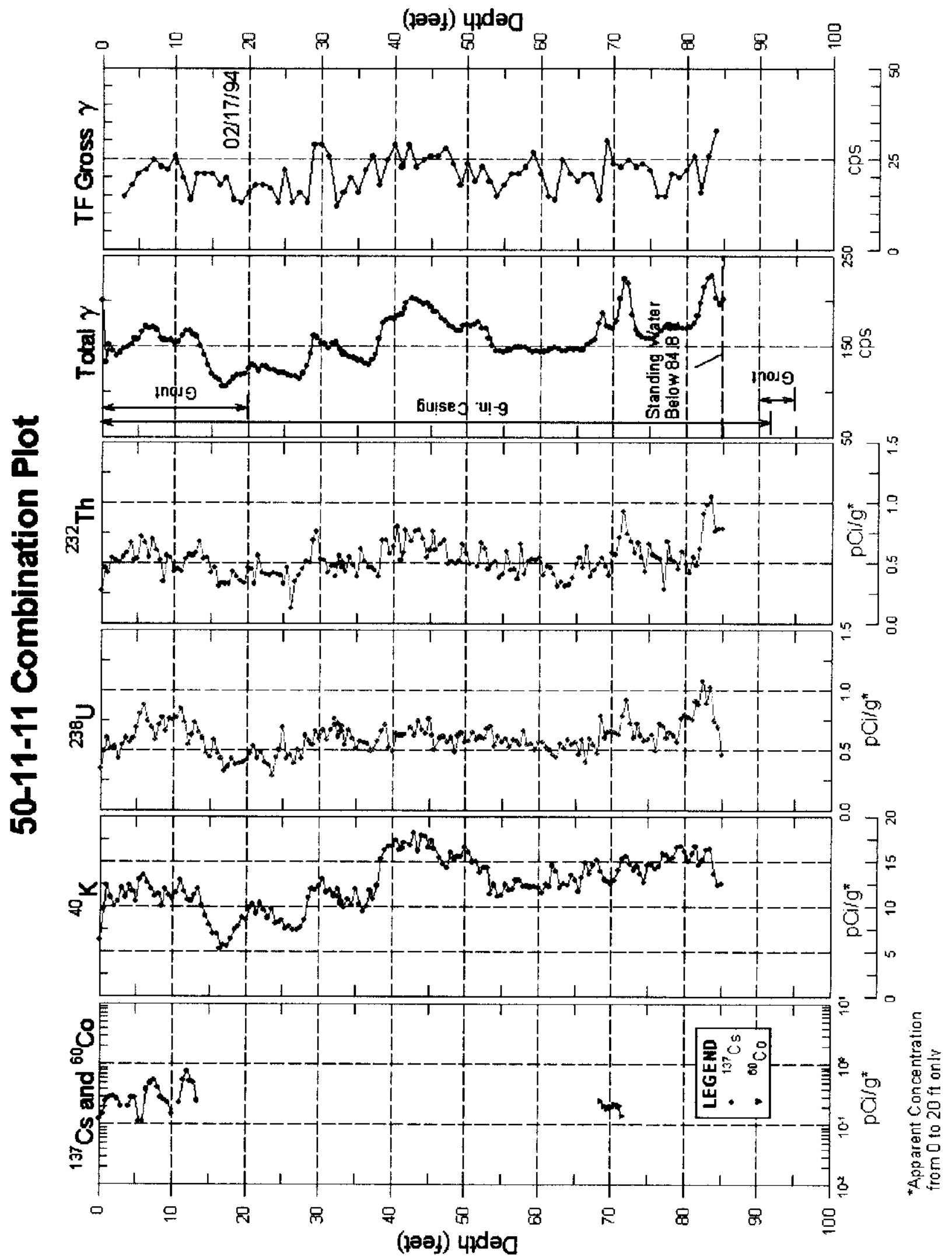


RPP-6088, Rev.0.

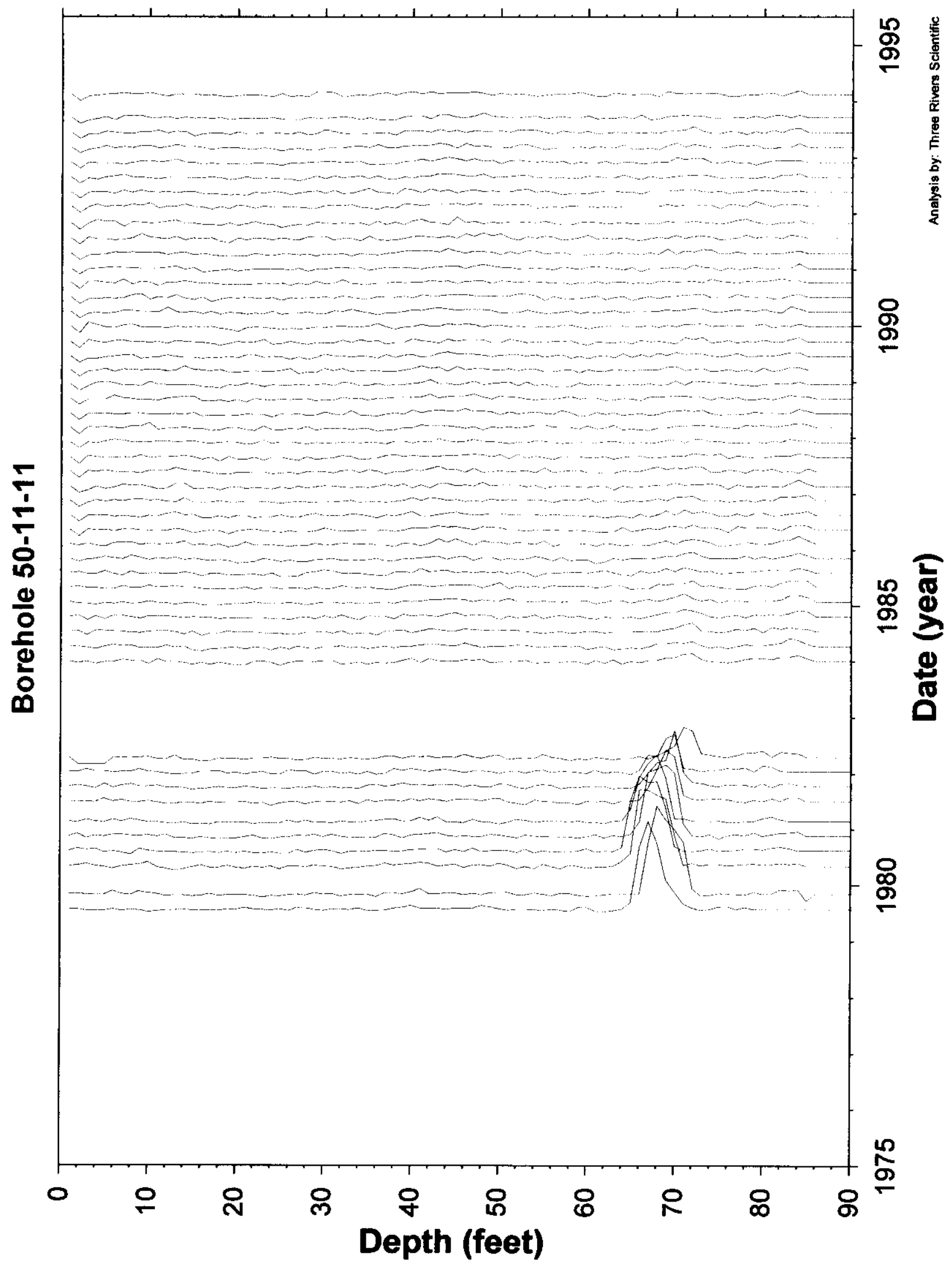

Tank T-111

Page 406 
RPP-6088, Rev.0.
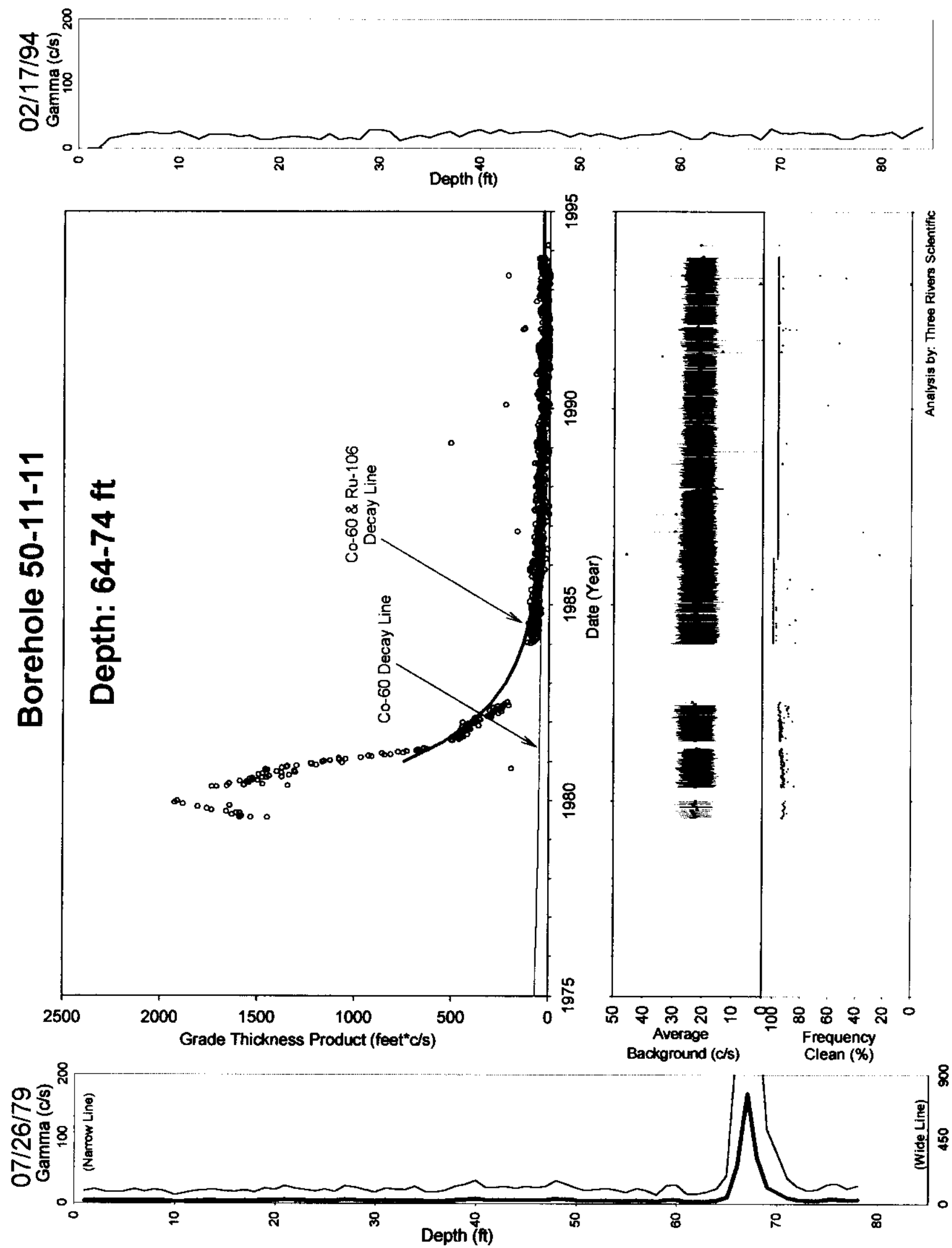

Tank T-111

Page 407 
RPP-6088, Rev.0.

\section{Tank T-112 Wells}

Table of Contents Page

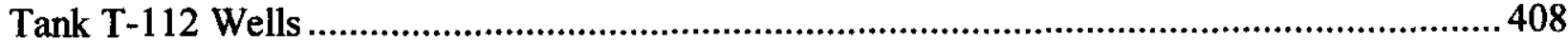

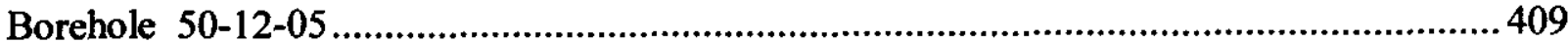

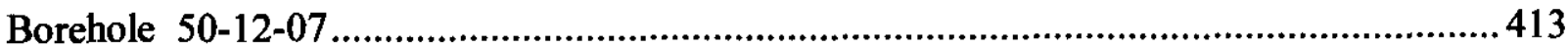

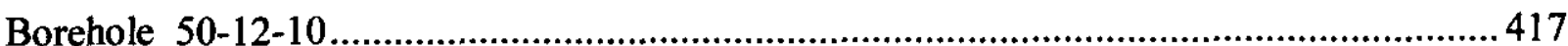

This section contains the analysis results for vadose zone boreholes (dry wells) associated with Tank 112 in the "T" Tank Farm.

Special Note: (none) 
RPP-6088, Rev.0.

\section{Borehole 50-12-05}

\section{No Gamma Ray Emitting Contamination Identified.}

No significant levels of gamma ray contamination are present, based upon gross gamma data, above the survey probe detection threshold between 1975 and 1994 in the vadose zone from 2 to 98 feet. The HPGe logging system detected Cs-137 at less than $1 \mathrm{pCi} / \mathrm{g}$ in the borehole.

The average background plot shows a step decrease after the $7 / 22 / 1980$ survey.

Gross Gamma Survey Information

Probe Type Processed: $04: \mathrm{NaI}$

Other Probe Types : $03:$ Neutron

Survey Depth : $98 \mathrm{ft}$

First Survey Date : $4 / 02 / 1975$

Last Survey Date : $2 / 17 / 1994$

Number Surveys Processed: 265

Analysis Notes

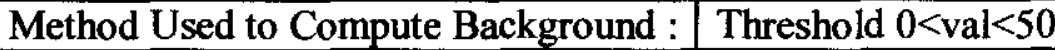

Depth(s) where Contamination was NONE

Identified in Gross Gamma Surveys :

Analyst Name : R. K. Price

Company Name : Three Rivers Scientific 
RPP-6088, Rev.0.

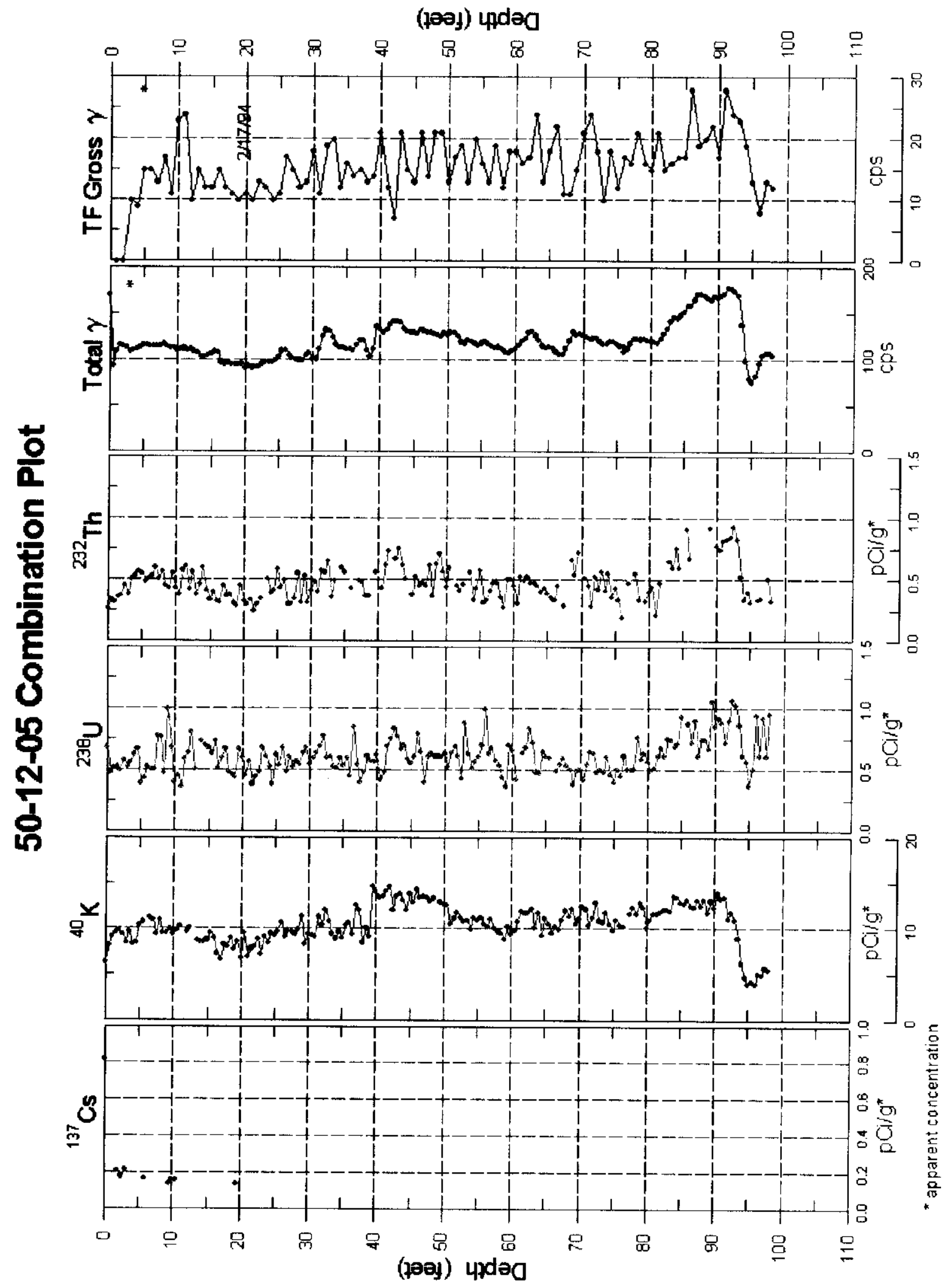

Tank T-112

Page 410 
RPP-6088, Rev.0.

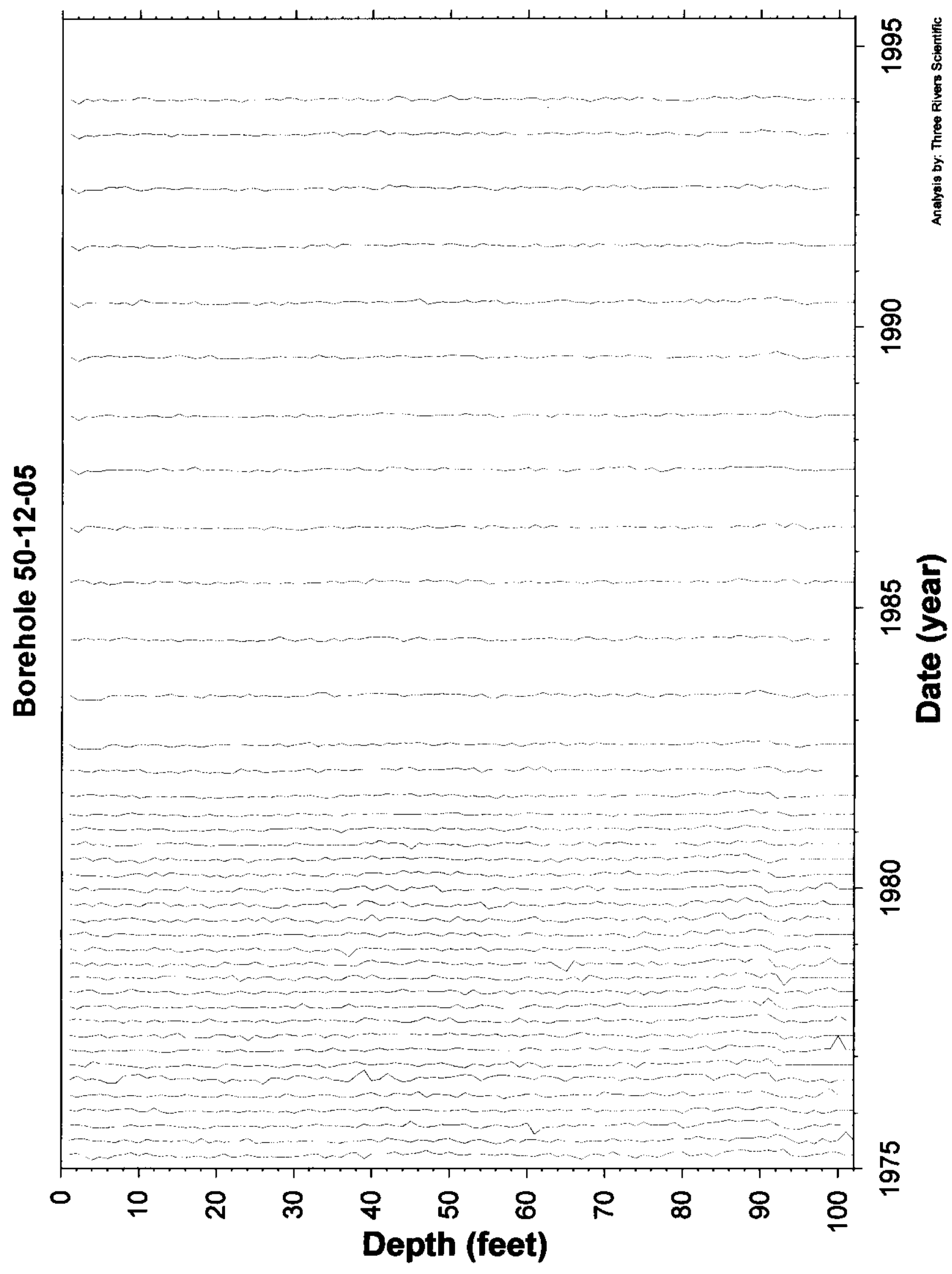

Tank T-112

Page 411 
RPP-6088, Rev.0.

\section{Borehole 50-12-05}

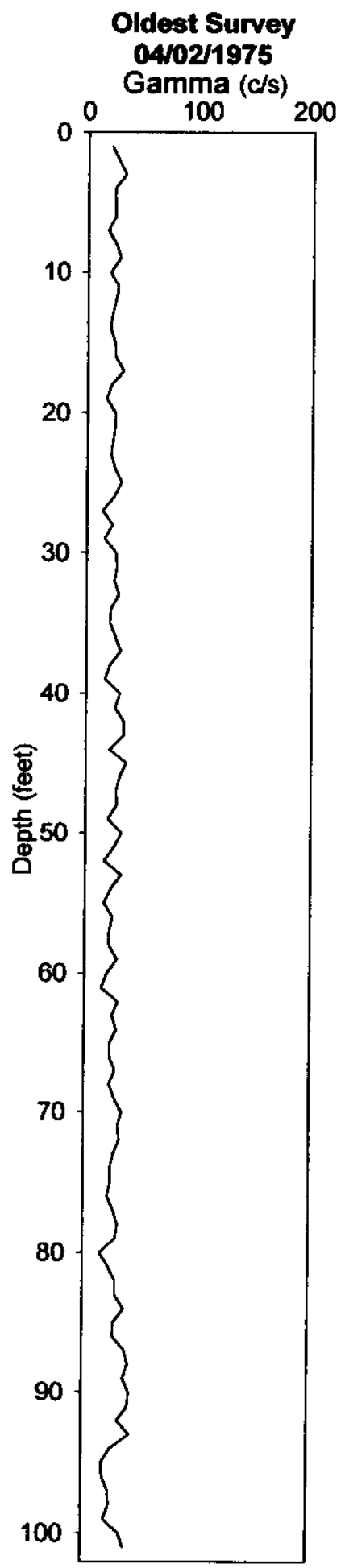

No Gamma-Ray Emitting Contamination

Above Survey Detection Threshold
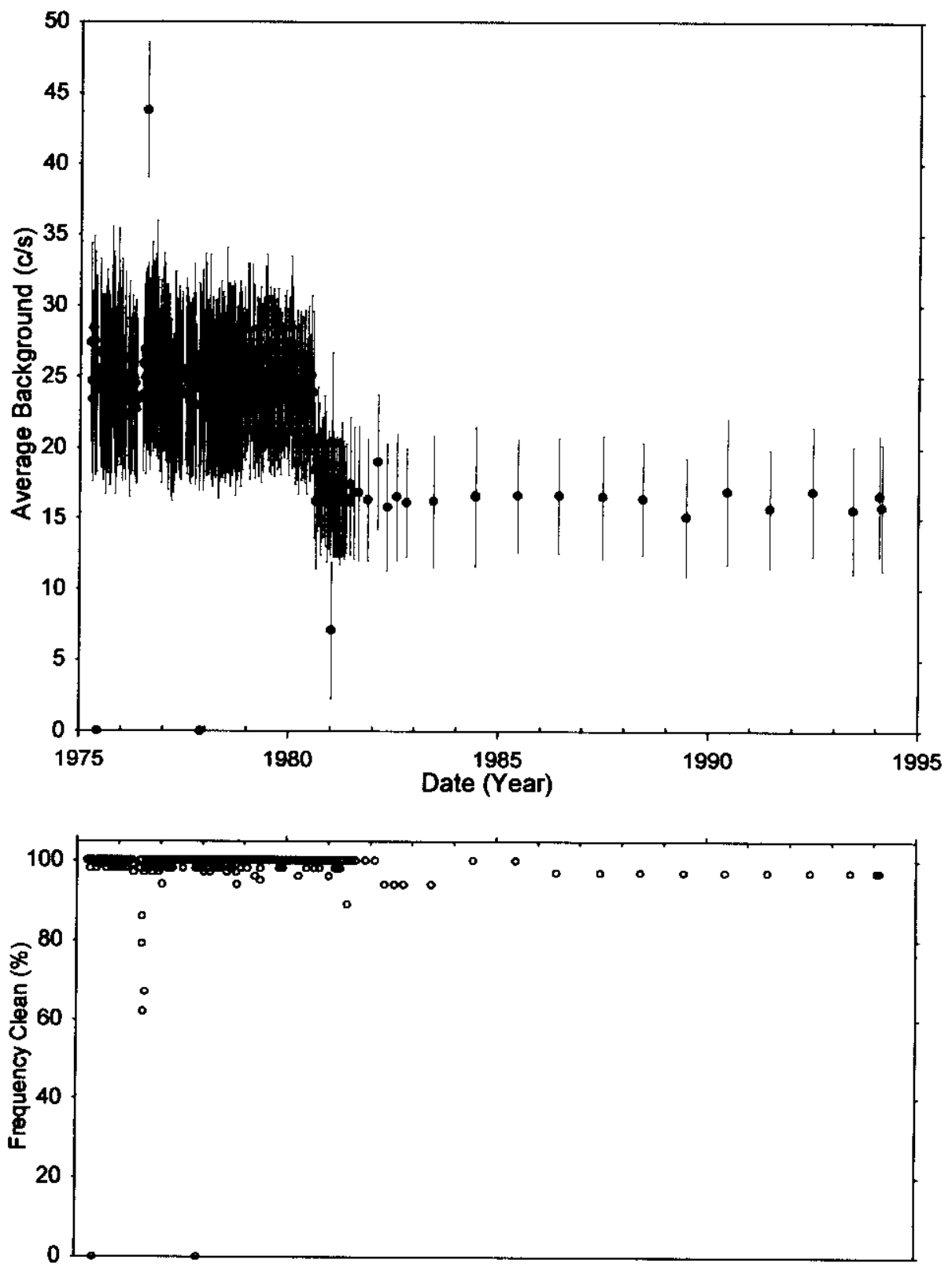

Analysis by: Three Rivers Scientific 
RPP-6088, Rev.0.

\section{Borehole 50-12-07}

\section{No Gamma Ray Emitting Contamination Identified.}

No significant levels of gamma ray contamination are present, based upon gross gamma data, above the survey probe detection threshold between 1975 and 1994 in the vadose zone from 2 to 93 feet. The HPGe logging system detected Cs-137 from 0 to 25 feet with maximum concentration of $2 \mathrm{pCi} / \mathrm{g}$ at 4 and 15 feet and less than $0.7 \mathrm{pCi} / \mathrm{g}$ for the rest of the interval.

The average background plot shows a step decrease after the 7/22/1980 survey.

Gross Gamma Survey Information

\begin{tabular}{|r|l|}
\hline Probe Type Processed: & $04: \mathrm{NaI}$ \\
\hline Other Probe Types : & $03:$ Neutron \\
\hline Survey Depth : & $93 \mathrm{ft}$ \\
\hline First Survey Date : & $1 / 22 / 1975$ \\
\hline Last Survey Date : & $2 / 17 / 1994$ \\
\hline Number Surveys Processed: & 277 \\
\hline
\end{tabular}

Analysis Notes

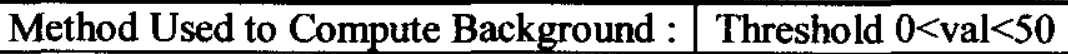

Depth(s) where Contamination was NONE

Identified in Gross Gamma Surveys :

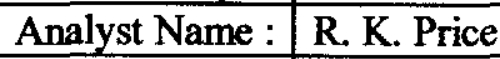

Company Name : Three Rivers Scientific 
RPP-6088, Rev.0.

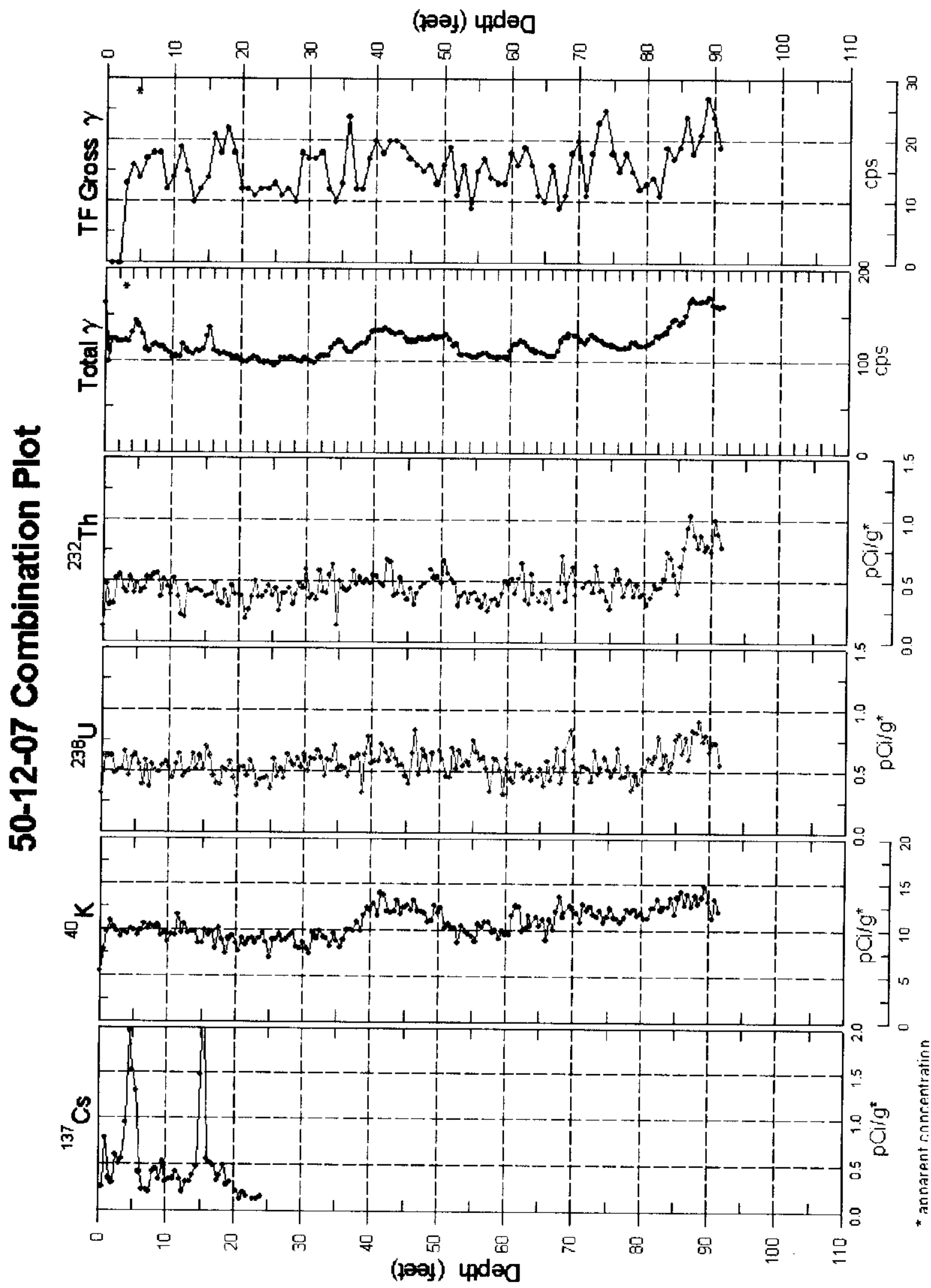

Tank T-112

Page 414 
RPP-6088, Rev.0.

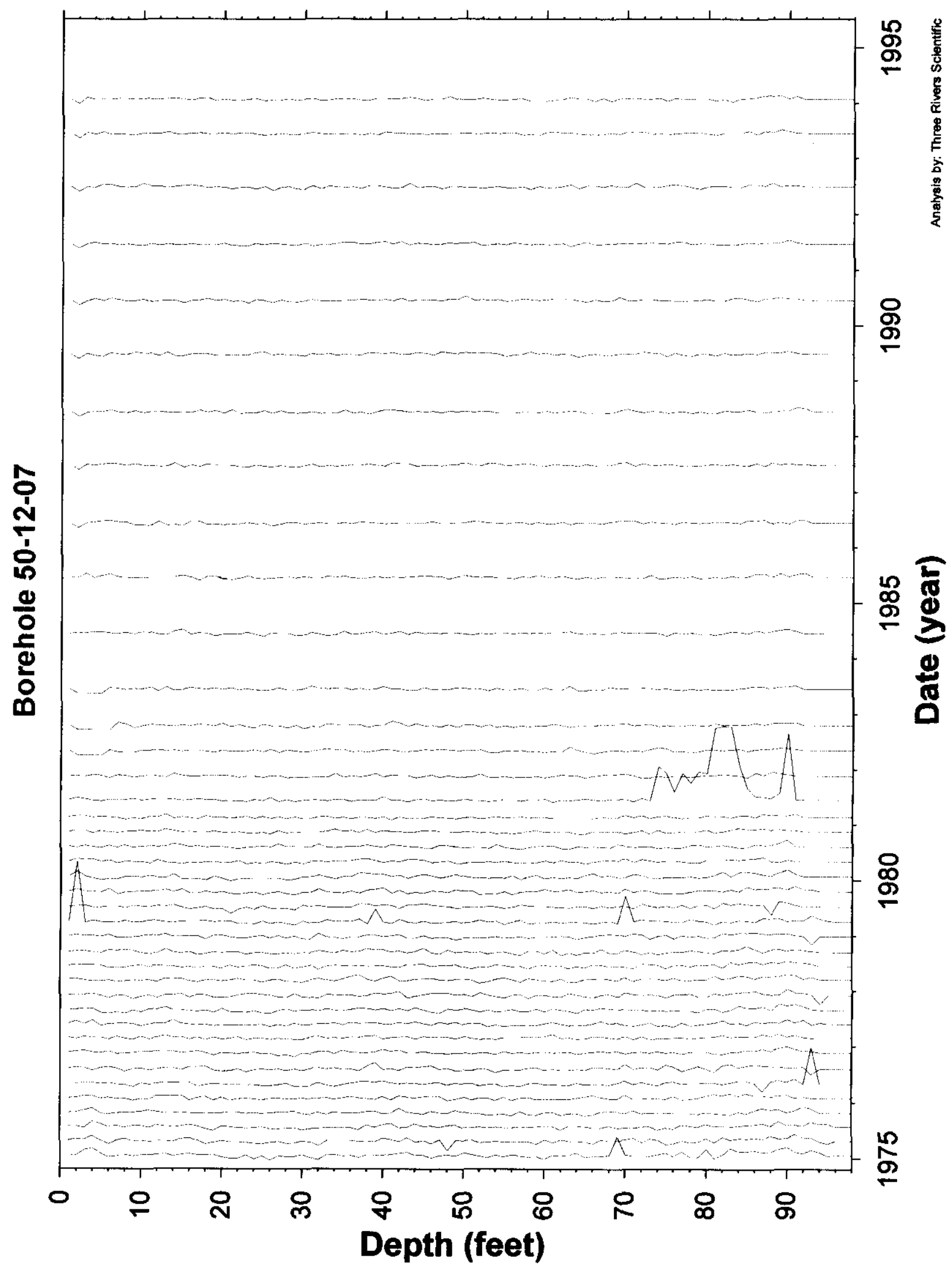

Tank T-112

Page 415 
RPP-6088, Rev.0.

\section{Borehole 50-12-07}

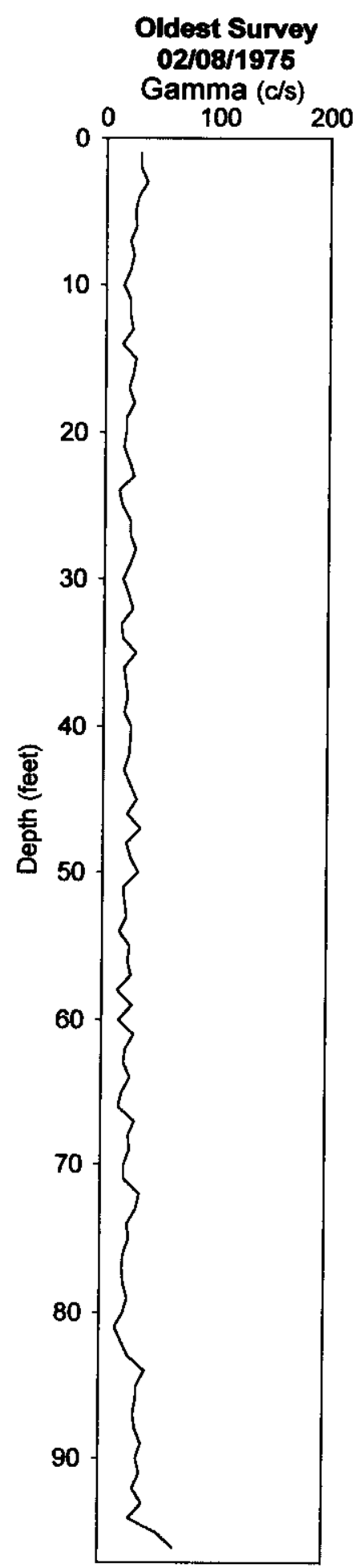

No Gamma-Ray Emitting Contamination
Above Survey Detection Threshold
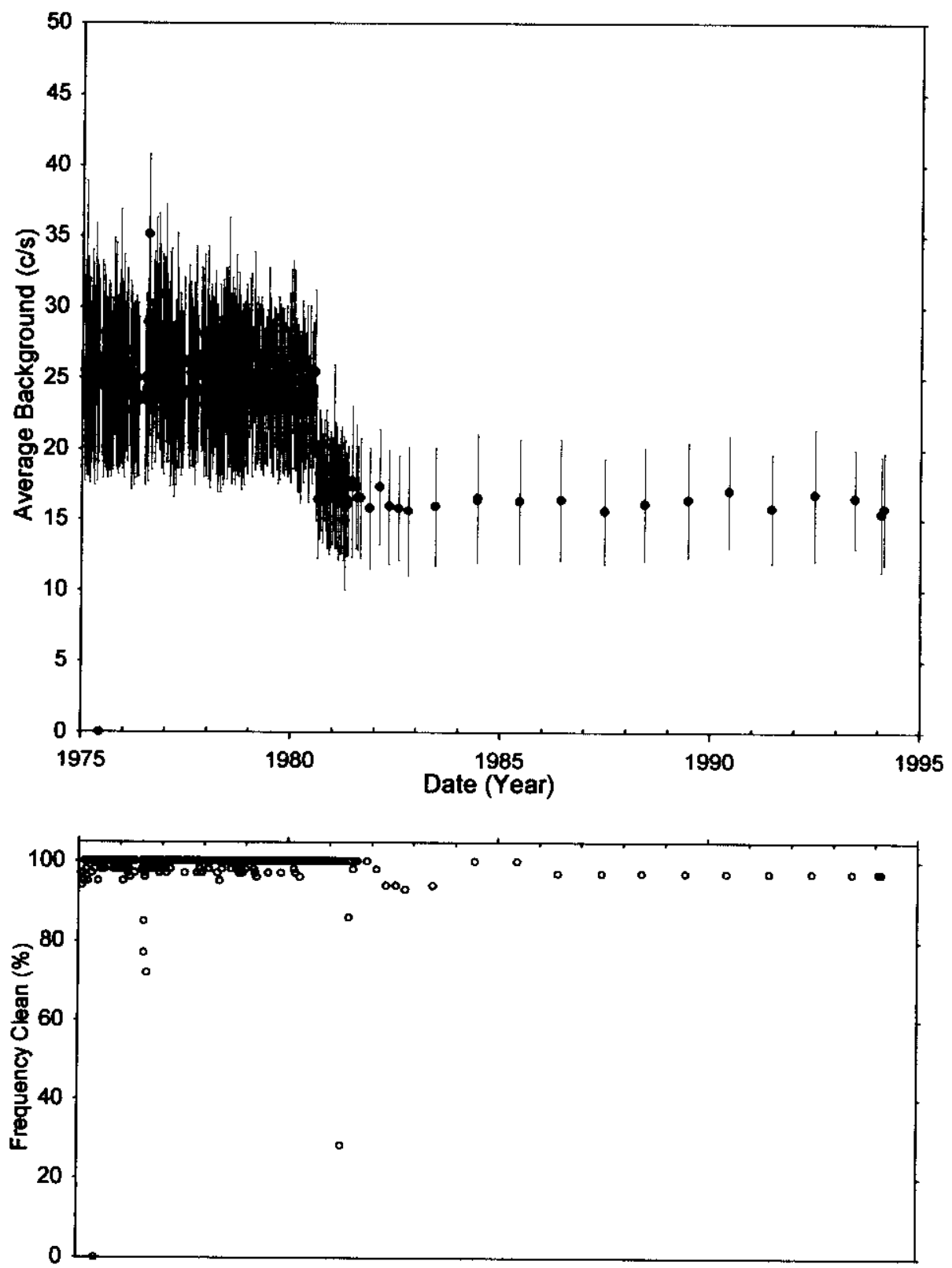

Analysis by: Three Rivers Scientific 
RPP-6088, Rev.0.

\section{Borehole 50-12-10}

\section{No Gamma Ray Emitting Contamination Identified.}

No significant levels of gamma ray contamination are present, based upon gross gamma data, above the survey probe detection threshold between 1975 and 1994 in the vadose zone from 2 to 120 feet. The HPGe logging system detected Cs-137 at less than $0.2 \mathrm{pCi} / \mathrm{g}$ in the borehole.

The stack plot shows the survey depths increased from 95 to 120 feet after the $2 / 10 / 1977$ survey. The average background plot shows a step decrease after the $9 / 8 / 1978$ survey.

Gross Gamma Survey Information

Probe Type Processed: $104: \mathrm{NaI}$

Other Probe Types : 03 : Neutron

Survey Depth : $120 \mathrm{ft}$

First Survey Date : $1 / 10 / 1975$

Last Survey Date : $2 / 17 / 1994$

Number Surveys Processed: 267

Analysis Notes

Method Used to Compute Background : $\quad$ Threshold $0<$ val $<50$

Depth(s) where Contamination was NONE

Identified in Gross Gamma Surveys :

Analyst Name : R. K. Price

Company Name : Three Rivers Scientific 
RPP-6088, Rev.0.

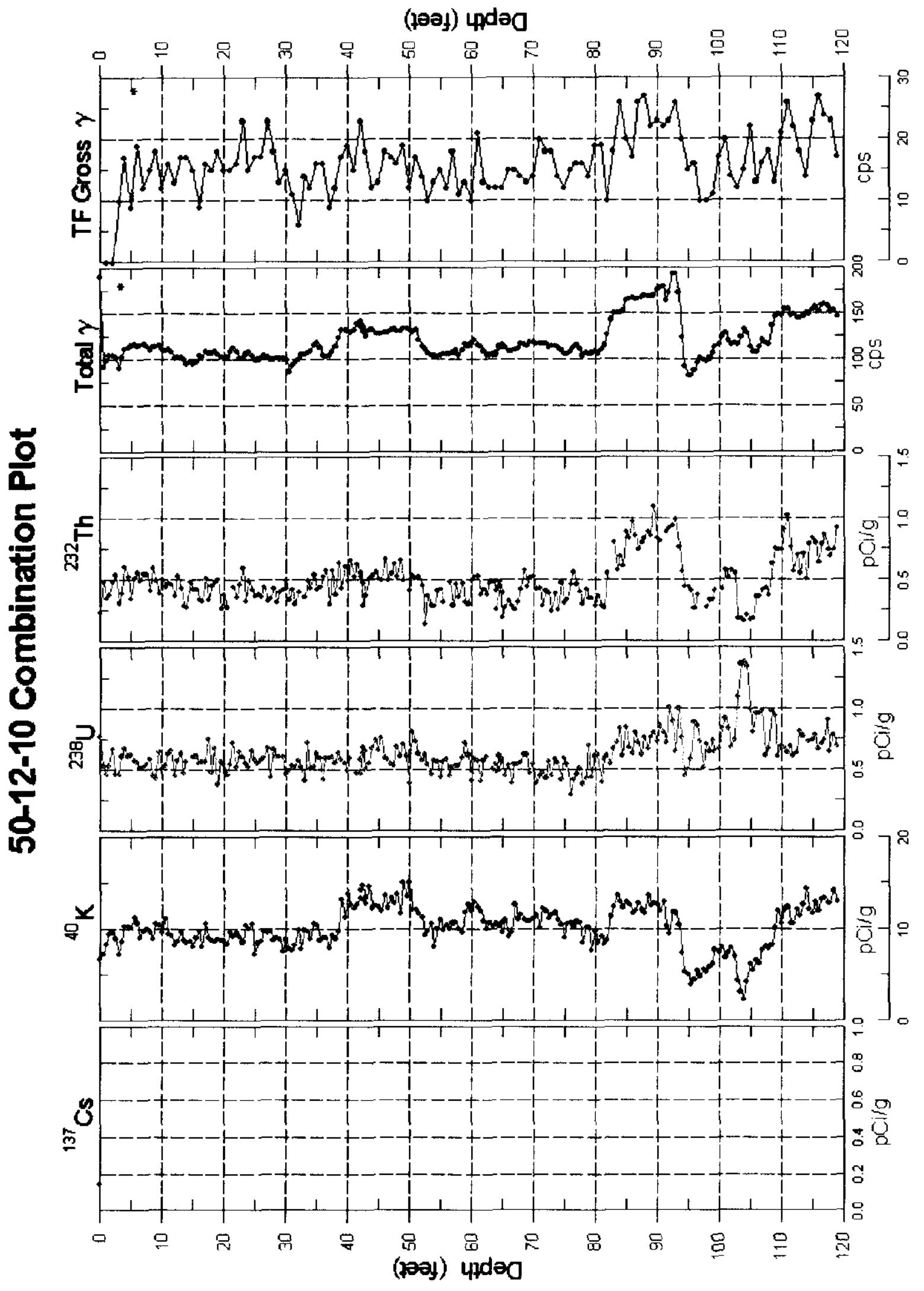

Tank T-112

Page 418 
RPP-6088, Rev.0.

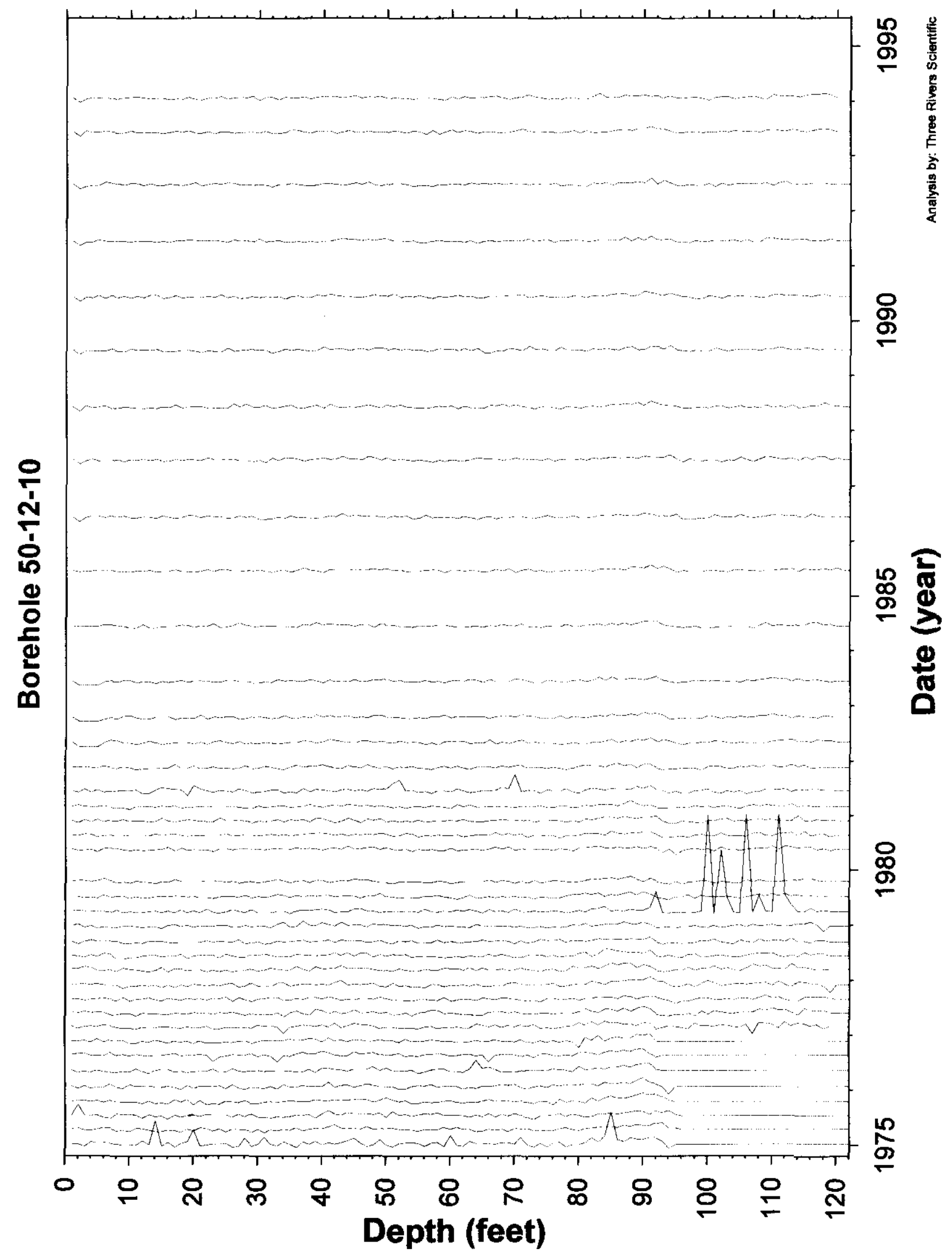

Tank T-112

Page 419 
RPP-6088, Rev.0.

\section{Borehole 50-12-10}

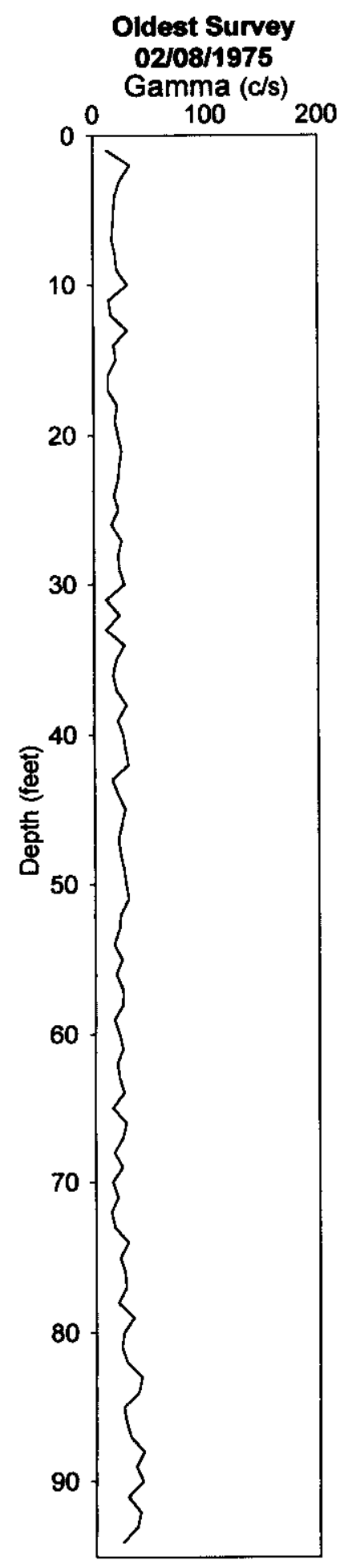
No Gamma-Ray Emitting Contamination
Above Survey Detection Threshold
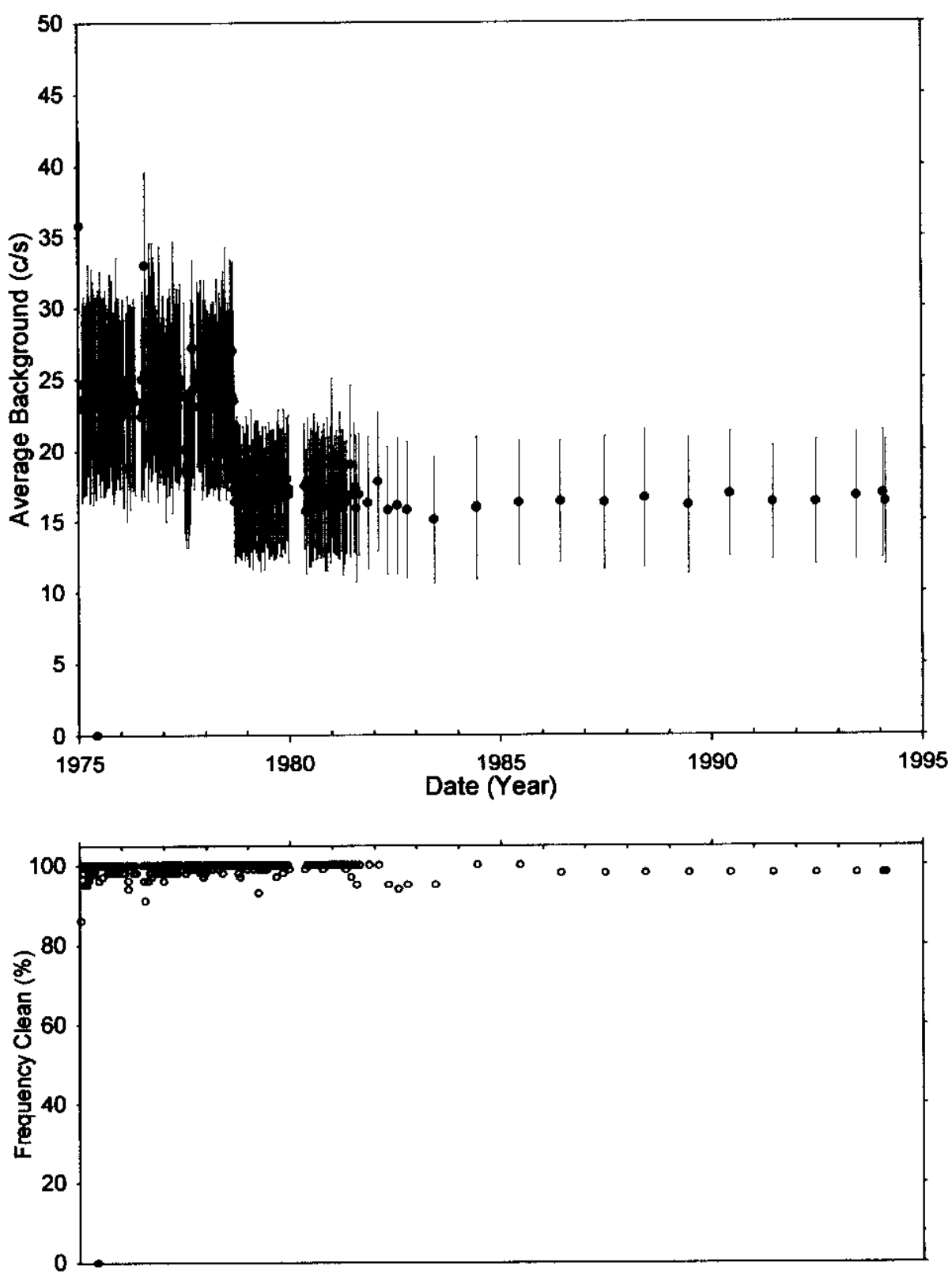

Analysis by. Three Rivers Scientific 


\section{DISTRIBUTION SHEET}

To

Distribution

Project Title/Work Order

RPP-6088, Analysis and Summary Report of Historical Dry Well Gamma Logs for the 241-T Tank Farm - 200 west

Name

CH2M Hill Hanford Group

T. E. Jones

A. J. Knepp (2)

F. M. Mann

D. A. Myers

P. M. Rogers

L. Soler

H. A. Sydnor

Fluor Daniel Hanford

M. I. Wood

Eluor Federal Sevices

R. Khaleel

Pacific Northwest National Laboratory

J. R. Serne

DOE-Office of River Protection

R. M. Yasek

Central Files (2)

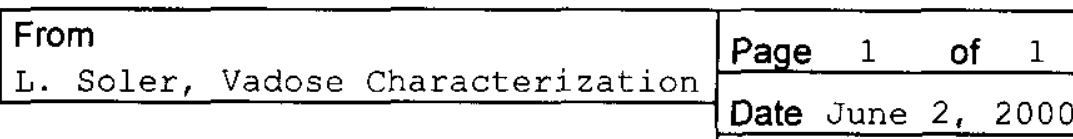

EDT No. 628613

ECN No. N/A

\begin{tabular}{|c|c|c|c|}
\hline MSIN & $\begin{array}{c}\text { Text } \\
\text { With All } \\
\text { Attach. }\end{array}$ & Text Only & $\begin{array}{c}\text { Attach./ } \\
\text { Appendix } \\
\text { Only }\end{array}$ \\
\hline
\end{tabular}

